JiSEA
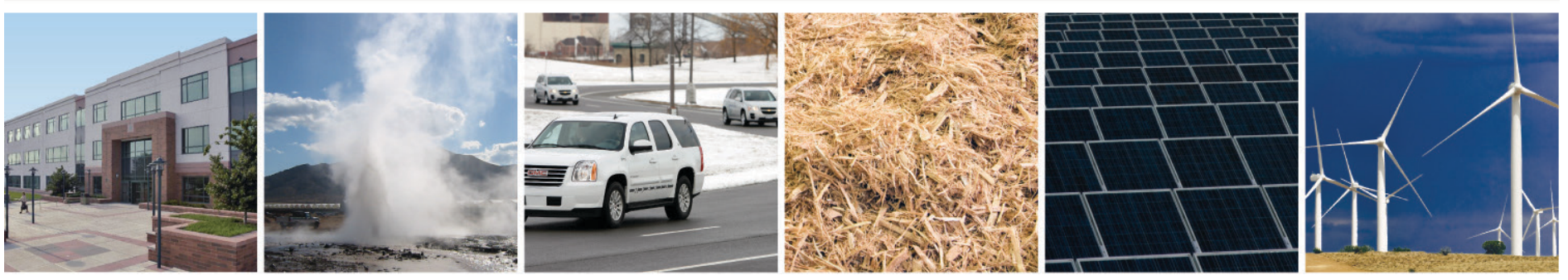

\title{
Natural Gas and the Transformation of the
} U.S. Energy Sector: Electricity

Jeffrey Logan, Garvin Heath, and Jordan Macknick National Renewable Energy Laboratory

Elizabeth Paranhos and William Boyd University of Colorado Law School

Ken Carlson Colorado State University

The Joint Institute for Strategic Energy Analysis is operated by the Alliance for Sustainable Energy, LLC, on behalf of the U.S. Department of Energy's National Renewable Energy Laboratory, the University of Colorado-Boulder, the Colorado School of Mines, the Colorado State University, the Massachusetts Institute of Technology, and Stanford University.

Technical Report

NREL/TP-6A50-55538

November 2012 


\section{Natural Gas and the}

Transformation of the

U.S. Energy Sector: Electricity

Jeffrey Logan, Garvin Heath, and Jordan

Macknick

National Renewable Energy Laboratory

Elizabeth Paranhos and William Boyd

University of Colorado Law School

Ken Carlson

Colorado State University

Prepared under Task No. WWJI.1010

The Joint Institute for

Strategic Energy Analysis

15013 Denver West Parkway

Golden, CO 80401

303-275-3000 • www.jisea.org
The Joint Institute for Strategic Energy Analysis is operated by the Alliance for Sustainable Energy, LLC, on behalf of the U.S. Department of Energy's National Renewable Energy Laboratory, the University of Colorado-Boulder, the Colorado School of Mines, the Colorado State University, the Massachusetts Institute of Technology, and Stanford University.

JISEA $^{\circledR}$ and all JISEA-based marks are trademarks or registered trademarks of the Alliance for Sustainable Energy, LLC.

Technical Report

NREL/TP-6A50-55538

November 2012

Contract No. DE-AC36-08G028308 


\section{NOTICE}

This report was prepared by the Joint Institute for Strategic Energy Analysis and funded by its corporate sponsors. The Joint Institute for Strategic Energy Analysis is operated by the Alliance for Sustainable Energy, LLC, on behalf of the U.S. Department of Energy's National Renewable Energy Laboratory, the University of Colorado-Boulder, the Colorado School of Mines, the Colorado State University, the Massachusetts Institute of Technology, and Stanford University. Neither the United States government nor any agency thereof, nor any of their employees, makes any warranty, express or implied, or assumes any legal liability or responsibility for the accuracy, completeness, or usefulness of any information, apparatus, product, or process disclosed, or represents that its use would not infringe privately owned rights. Reference herein to any specific commercial product, process, or service by trade name, trademark, manufacturer, or otherwise does not necessarily constitute or imply its endorsement, recommendation, or favoring by the United States government or any agency thereof. The views and opinions of authors expressed herein do not necessarily state or reflect those of the United States government or any agency thereof.

Available electronically at http://www.osti.gov/bridge

Available for a processing fee to U.S. Department of Energy and its contractors, in paper, from:

U.S. Department of Energy

Office of Scientific and Technical Information

P.O. Box 62

Oak Ridge, TN 37831-0062

phone: 865.576 .8401

fax: 865.576 .5728

email: mailto:reports@adonis.osti.gov

Available for sale to the public, in paper, from:

U.S. Department of Commerce

National Technical Information Service

5285 Port Royal Road

Springfield, VA 22161

phone: 800.553 .6847

fax: 703.605.6900

email: orders@ntis.fedworld.gov

online ordering: http://www.ntis.gov/help/ordermethods.aspx

Cover Photos: (left to right) PIX 12721, PIX 13995, @ GM Corp., PIX 16161, PIX 15539, PIX 16701

Printed on paper containing at least $50 \%$ wastepaper, including $10 \%$ post consumer waste. 


\section{About JISEA}

The Joint Institute for Strategic Energy Analysis (JISEA) conducts interdisciplinary researchrealized through teams drawn from the founding partners and a network of national and global affiliates - and provides objective and credible data, tools, and analysis to guide global energy investment and policy decisions. JISEA is focused on providing leading analysis; guiding decisions on energy, investment, and policy; and answering questions that enable a cost-effective transition to sustainable energy at significant speed and scale, while minimizing unintended impacts.

JISEA is operated by the Alliance for Sustainable Energy, LLC, on behalf of the U.S.

Department of Energy's National Renewable Energy Laboratory (NREL), the University of Colorado-Boulder, the Colorado School of Mines, the Colorado State University, the Massachusetts Institute of Technology, and Stanford University. Each institution brings a unique set of capabilities to the partnership.

Learn more at JISEA.org. 


\section{Foreword}

We are very pleased to present this work on natural gas and the transformation of the United States' power sector. The subject is both highly topical and divisive. Very few people saw the dramatic changes coming that are being witnessed in the U.S. natural gas sector. The critical role of unconventional gas - and specifically, shale gas - has been dramatic. The changes taking place in the U.S. natural gas sector go well beyond the boundaries of traditional energy-sector analysis. They touch on areas as diverse as foreign policy and industrial competitiveness.

This makes the topic ripe for robust analytical work, which is the role of the Joint Institute for Strategic Energy Analysis (JISEA).

To help inform both the national and international dialogue on this subject, we have focused on a few key areas critical to decision makers. These issues include greenhouse gas emissions, regulatory interventions, water management, and the portfolio of generation in the power sector.

As part of our series of studies on the U.S. energy system, this body of work continues to elucidate details related to life cycle greenhouse gas emissions of shale gas relative to other options for power generation. It also contributes new analysis related to water and regulatory frameworks that are evolving apace. Additionally, we evaluate various pathways for the evolution of the electric sector given a range of options for natural gas, other technologies, and policy.

Although the four principal areas of focus in this report are closely interrelated, each has its own specific needs in terms of analysis, investment risk, and policy design. We have presented detailed consideration of each area, with further appended supporting material, to contribute to the ongoing and increasing national and international dialogue.

We hope you enjoy the report and find the results and discussion useful for your work.

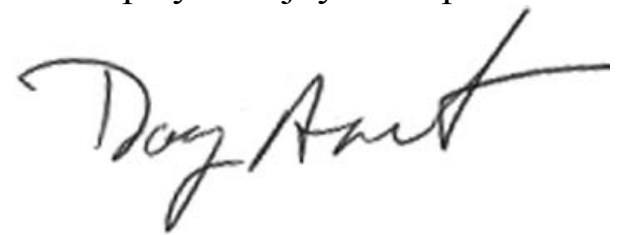

Douglas J. Arent

Executive Director, JISEA 


\section{Preface}

This report was developed with guidance from a cross-section of natural gas and electricity sector stakeholders. In 2011, JISEA convened a workshop with representatives from these organizations, some of whom also provided financial support for this work. That workshop resulted in identifying several key analytical issues for natural gas in the electric power sector that need to be addressed. Research, analysis, and writing were performed independently by the authors, with editorial oversight by JISEA. This study has been extensively peer reviewed. Findings, content, and conclusions of this study are the sole responsibility of the JISEA study team. JISEA provides objective information so that decision makers can make informed choices, but does not make its own policy recommendations.

Although the sponsoring organizations provided invaluable perspective and advice to the study group, individual members may have different views on one or more matters addressed in the report. The sponsoring organizations were not asked individually or collectively to endorse the report findings nor should any implied endorsement by the sponsoring organizations be assumed.

\section{Authors}

Jeffrey Logan, Lead Author, Introduction and Chapters 4 and 5. Mr. Logan is a Senior Research Analyst and Section Supervisor at NREL. He has two decades of experience in clean energy policy analysis and project management, including prior appointments at the International Energy Agency in Paris and the Congressional Research Service in Washington, D.C.

Garvin Heath, Ph.D., Lead Author, Chapter 1. Dr. Heath is a Senior Scientist at NREL. He has 18 years of experience evaluating environmental impacts of energy technologies, both at NREL and the U.S. Environmental Protection Agency.

Elizabeth deLone Paranhos, J.D., Lead Author, Chapter 2. Ms. Paranhos is a Senior Research Fellow, Energy Innovation Initiative, University of Colorado Law School. She is an environmental attorney specializing in clean air and energy policy with ten years of experience. For the past three years, her practice has focused primarily on natural gas activities.

William Boyd, J.D., PhD, Co-Author, Chapter 2. Mr. Boyd is an associate professor at the University of Colorado Law School, where he teaches and conducts research in the areas of energy law and regulation, environmental law, and climate change law and policy. He is a fellow of the Renewable and Sustainable Energy Institute and serves as the University of Colorado representative on the JISEA program committee.

Ken Carlson, Ph.D., Lead Author, Chapter 3. Dr. Carlson is an Associate Professor in Civil and Environmental Engineering, Colorado State University, and the Director of the Colorado Energy Water Consortium (http://cewc.colostate.edu). He has 16 years of experience in energy and water engineering issues.

Jordan Macknick, Co-Author, Chapter 3. Mr. Macknick is an Energy and Environmental Analyst at NREL. He has seven years of experience evaluating international energy and water issues. 
Contributing NREL Authors: Noah Fisher, James Meldrum, Ph.D. (Chapter 1); Courtney Lee (Chapter 3); Anthony Lopez, Trieu Mai (Chapter 4).

Study Director: Lynn Billman. Ms. Billman is a Senior Research Analyst and Section Supervisor at NREL. She has many years of experience leading major projects at NREL in all areas of renewable energy and energy efficiency.

\section{Suggested Citation}

Joint Institute for Strategic Energy Analysis (JISEA). 2012. Natural Gas and the Transformation of the U.S. Energy Sector: Electricity. Logan, J., Heath, G., Paranhos, E., Boyd, W., Carlson, K., Macknick, J. NREL/TP-6A50-55538. Golden, CO, USA: National Renewable Energy Laboratory. 


\section{Acknowledgments}

The JISEA institutional partner universities-University of Colorado-Boulder, Colorado School of Mines, Colorado State University, Massachusetts Institute of Technology, Stanford University - provided instrumental support throughout this study effort. The engagement of our partner universities made this report possible.

The authors would like to thank the following individuals for research assistance: Ashwin Dhanasekar, Shane White, and Xiaochen Yang of Colorado State University; Katie Patterson and Jamie Cavanaugh of the University of Colorado Law School; and Carolyn Davidson, Andrew Martinez, Patrick O’Donoughue, and Vanessa Pineda of the National Renewable Energy Laboratory.

We would like to thank the following organizations for their support and steering committee engagement: British Petroleum; Colorado Oil and Gas Association; ConocoPhillips; DB Climate Change Advisors; Electric Power Research Institute; GE Energy; National Grid; Southern Company; UBS Global Asset Management; and Xcel Energy.

This report has been reviewed in draft form by individuals chosen for their diverse perspectives and technical expertise. These reviews serve to make this report as technically sound as possible, and they ensure that the report meets institutional standards for objectivity, evidence, and responsiveness to the study scope.

We wish to thank the following individuals for their participation in the review of this report:

- Dan Bakal, Monika Freyman, Joe Kwasnik, and Ryan Salmon, CERES, and also for their engagement on the steering committee

- Dr. Stanley Bull, Midwest Research Institute

- Mr. Christopher Carr, J.D., C2E2 Strategies LLC

- Dr. Christa Court, Midwest Research Institute at the National Energy Technology Laboratory

- Dr. David Kline, NREL

- Dr. Joel Swisher, Stanford University and Rocky Mountain Institute

- Dr. Sue Tierney, The Analysis Group

- Dr. Azra Tutuncu, Colorado School of Mines

- Dr. Michael Webber, University of Texas

- Mr. Jeffrey Withum, Midwest Research Institute at the National Energy Technology Laboratory

- Dr. Mark Zoback, Stanford University

Additionally, the authors are grateful for review of Chapter 1 by Tim Skone of the National Energy Technology Laboratory and by Joe Marriott of Booz Allen Hamilton, who supports the National Energy Technology Laboratory. Prof. Hannah Wiseman of the Florida State University College of Law and Jon Goldstein with The Environmental Defense Fund also provided insightful review and helpful comments on the regulatory chapter. Daniel Steinberg of the National Renewable Energy Laboratory also provided key suggestions for the modeling scenarios. 


\section{Acronyms and Abbreviations}

AGR

bbl

Bcf

Bcf $/ \mathrm{d}$

BLM

Btu

CBM

CCS

CERCLA

CES

cf

$\mathrm{CH}_{4}$

$\mathrm{CO}_{2}$

$\mathrm{CO}_{2} \mathrm{e}$

COGCC

CSP

CWTs

EIA

EPA

EUR

$\mathrm{FF}$

$\mathrm{g}$

GHG

GIS

GW

hp

hr

$\mathrm{kg}$

$\mathrm{kWh}$

$\mathrm{lb}$

LCA

LNG

MJ

Mcf

MMBtu

NG-CC

NG-CCS

NG-CT

NGLs

$\mathrm{NO}_{\mathrm{x}}$

NREL

NSPS

POTWs

PW

PV acid gas removal

barrels

billion cubic feet

billion cubic feet per day

Bureau of Land Management

British thermal unit(s)

coal-bed methane

carbon capture and sequestration

Comprehensive Environmental Response, Compensation, and Liability Act

clean energy standard (also known as clean electricity standard)

cubic feet

methane, the primary component of natural gas

carbon dioxide

carbon dioxide equivalent

Colorado Oil and Gas Conservation Commission

concentrating solar power

centralized waste treatment facilities

Energy Information Administration

Environmental Protection Agency

estimated ultimate recovery

frac flowback (water)

$\operatorname{gram}(\mathrm{s})$

greenhouse gas

geographic information system

gigawatt(s)

horsepower

hour

kilogram(s)

kilowatt-hour(s)

pound(s)

life cycle assessment

liquefied natural gas

megajoules

thousand cubic feet

million British thermal unit(s)

natural gas combined-cycle

natural gas generator with carbon capture and sequestration

natural gas combustion turbine

natural gas liquids

nitrogen oxides

National Renewable Energy Laboratory

New Source Performance Standards

publicly owned treatment works

produced water

photovoltaic 


$\begin{array}{ll}\text { RE } & \text { renewable energy (also known as renewable electricity) } \\ \text { RE Futures } & \text { Renewable Electricity Futures Study } \\ \text { ReEDS } & \text { Regional Energy Deployment System } \\ \text { SCC } & \text { Source Classification Code } \\ \text { scf } & \text { standard cubic foot } \\ \text { SEAB } & \text { Secretary of Energy Advisory Board Shale Gas Production } \\ \text { SolarDS } & \text { Solar Deployment System } \\ \text { TCEQ } & \text { Texas Commission on Environmental Quality } \\ \text { Tcf } & \text { trillion cubic feet } \\ \text { Tg } & \text { teragram(s), or million metric ton(s) } \\ \text { VOC } & \text { volatile organic compound } \\ \text { yr } & \text { year }\end{array}$




\section{Table of Contents}

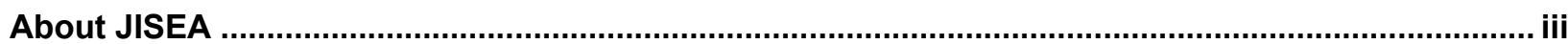

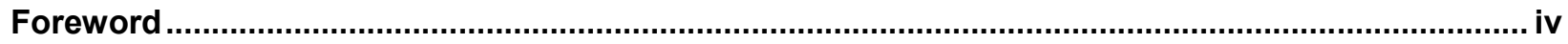

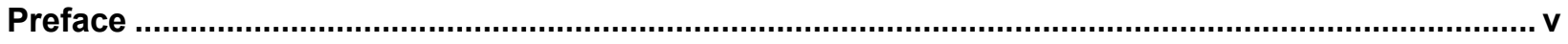

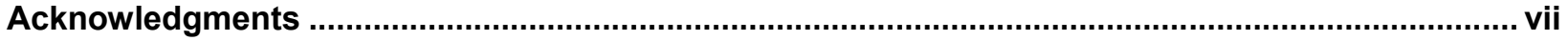

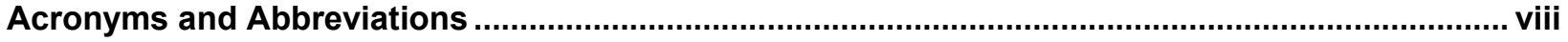

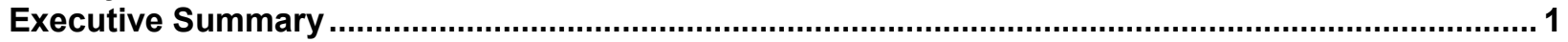

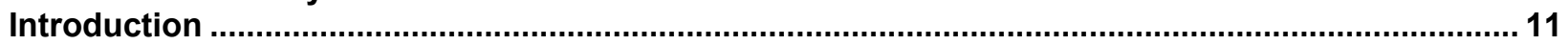

1 Life Cycle Greenhouse Gas Emissions from Barnett Shale Gas Used to Generate Electricity 16

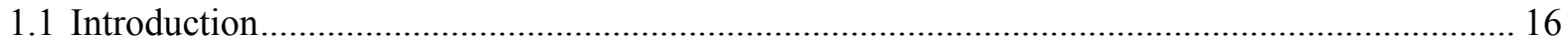

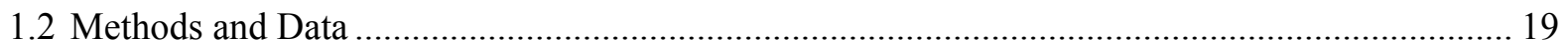

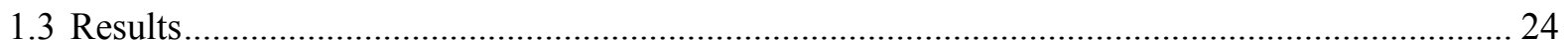

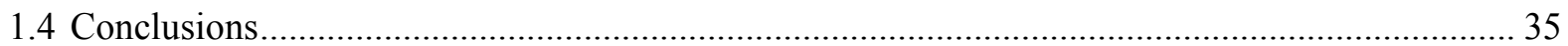

2 Regulatory Framework Governing Unconventional Gas Development.................................... 38

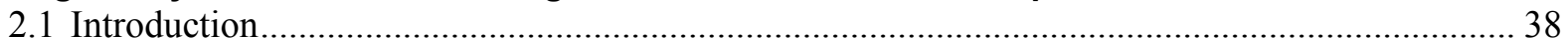

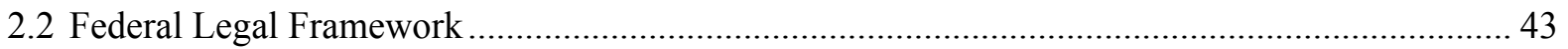

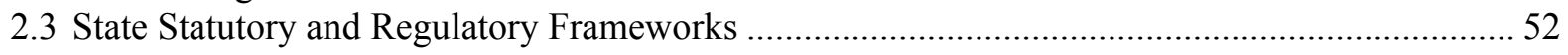

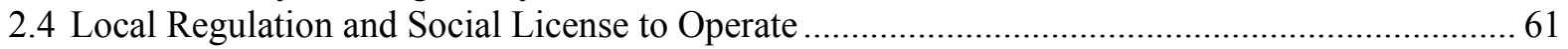

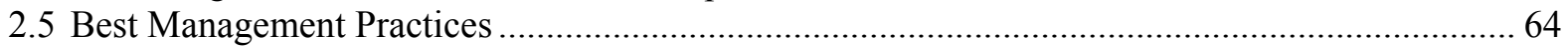

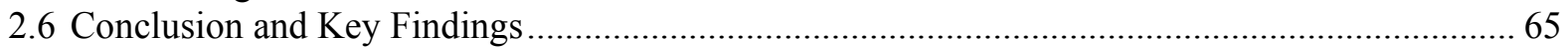

3 Key Issues, Challenges, and Best Management Practices Related to Water Availability and

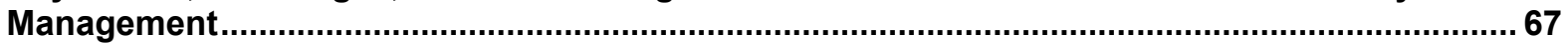

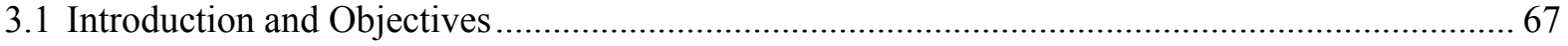

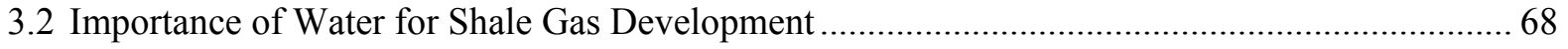

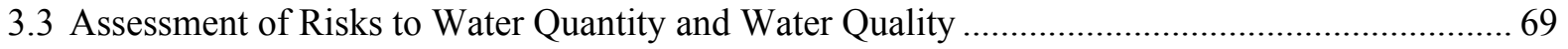

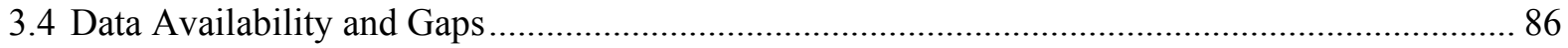

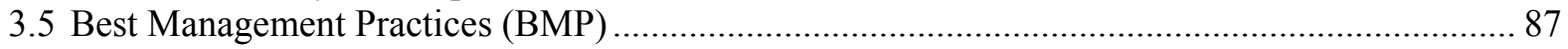

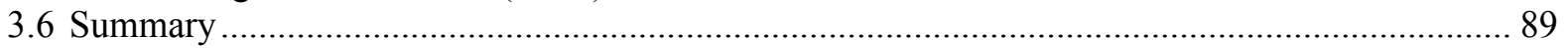

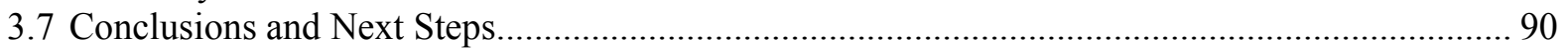

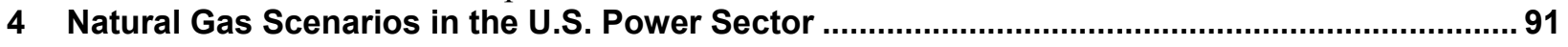

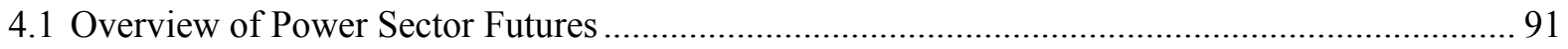

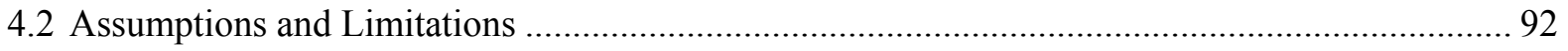

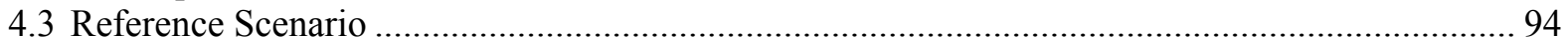

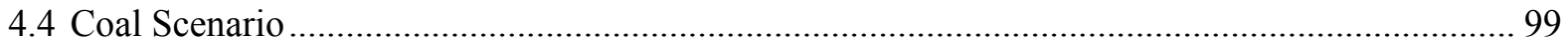

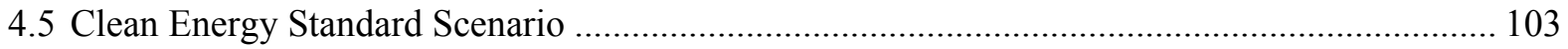

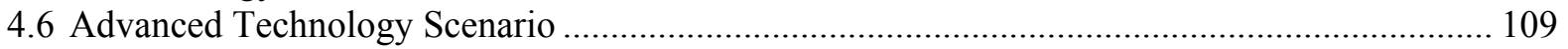

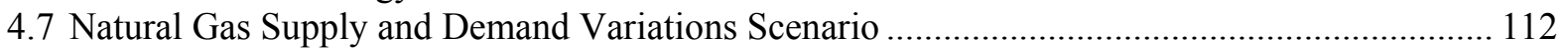

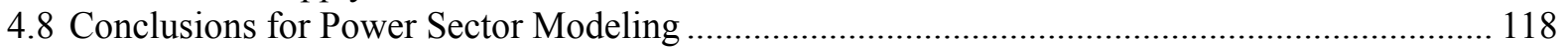

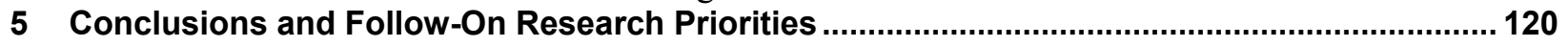

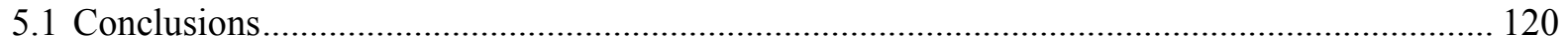

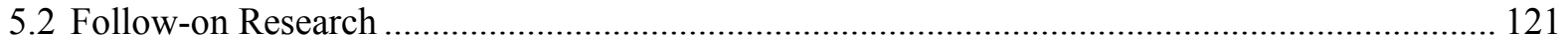

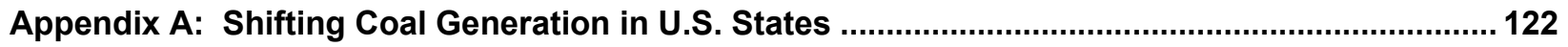

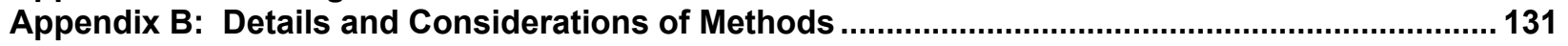

Appendix C: Requirements, Standards, and Reporting ............................................................ 167

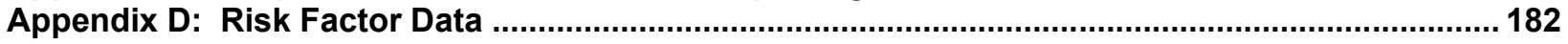

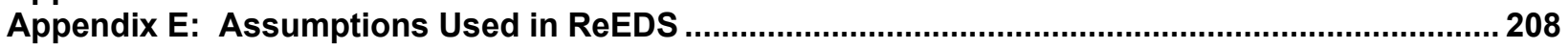

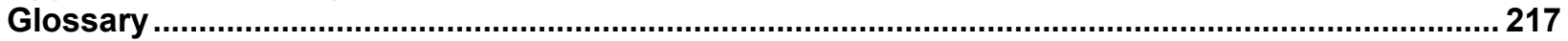

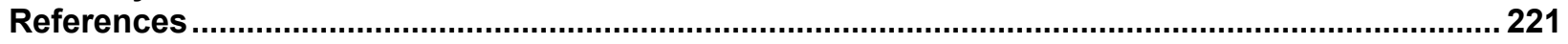




\section{List of Figures}

Figure 1. Estimate of life cycle GHG emissions from 2009 Barnett Shale gas combusted to generate electricity in a modern natural gas combined-cycle (NGCC) turbine compared to previously published estimates for unconventional (mostly shale) gas, conventional natural gas, and coal after methodological harmonization..

Figure 2. Range of electricity generated from natural gas plants in the scenario analysis.

Figure 3. Volatility in fossil fuel costs for power generators ..................................................... 12

Figure 4. Coal-fired electricity generation is declining rapidly as the use of natural gas and renewable energy expand.

Figure 5. Counties with non-zero gas production from the Barnett Shale formation in 2009, and other demarcations of the Barnett Shale area in Texas (TRRC 2012)....................................... 19

Figure 6. A life cycle assessment of electricity generated from natural gas involves estimating the

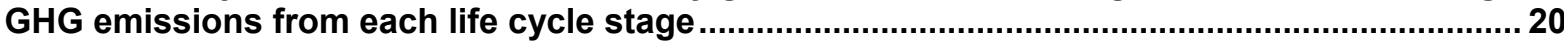

Figure 7. Greenhouse gas sources belonging to the natural gas industry in the 22-county Barnett Shale area; many are potentially controllable.

Figure 8. Combustion at the power plant contributes the majority of GHG emissions from the life cycle of electricity generated from Barnett Shale gas.

Figure 9. Estimate of life cycle GHG emissions from 2009 Barnett Shale gas combusted to generate electricity in a modern natural gas combined-cycle (NGCC) turbine compared to previously published estimates for unconventional (mostly shale) gas, conventional natural gas, and coal after methodological harmonization

Figure 10. Inventory-based analysis of production and processing fuel cycle stages showing that the majority of GHG emissions are $\mathrm{CO}_{2}$ resulting from combustion, although the $\mathrm{CO}_{2} \mathrm{e}$ from methane emissions is significant

Figure 11. EPA map of Underground Injection Control Program Primacy ..................................... 45

Figure 12. Variation in the rules for six states of rules covering natural gas fracking ......................62

Figure 13. Description of shale gas development risks and characterization metrics .....................67

Figure 14. Water quality risks by phase of natural gas production............................................. 70

Figure 15. Total number of producing wells in shale gas plays, 2009-2011 (TRRC 2012c; COGCC 2012b; LADNR 2012; PA DEP 2012a; Eagle Ford Shale 2012).

Figure 16. Average water use per well (in millions of gallons) for five regions (2011) (Fracfocus.org)

Figure 17. Water use per well for four formations, in millions of gallons. (fracfocus.org)

Figure 18. Wastewater production and total recycling at shale gas operations in Pennsylvania in 2011 (PA DEP 2012b).

Figure 19. Six shale plays considered in this study......

Figure 20. Mining water withdrawals as a percent of total water withdrawals, 2005 (Kenny 2009). 79

Figure 21. Schematic of well that includes several strings of casing and layers of cement ............ 81

Figure 22. Colorado wastewater treatment methods, 2008-2011 (COGCC 2012a) .......................... 83

Figure 23. Pennsylvania wastewater treatment methods, 2008-2011 (PA DEP 2012b).................... 84

Figure 24. Scenarios evaluated in the power sector futures ..................................................... 92

Figure 25. Projected capacity in the Reference scenario, 2010-2050, for Baseline - Mid-EUR,

Baseline - Low-EUR, and Baseline - Low-Demand cases.......................................................96

Figure 26. Projected generation in Reference scenario, 2010-2050, for Baseline - Mid-EUR, Baseline - Low-EUR, and Baseline - Low-Demand cases...................................................97

Figure 27. Selected metrics for the Reference scenario, 2010-2050..........................................98

Figure 28. Assumed distribution of retirements in the Coal scenario by percentage of total coal capacity retired in 2025 in each balancing area of ReEDS

Figure 29. Impacts of coal plant retirements and no new coal without CCS compared to the baseline for 2030 and 2050

Figure 30. Selected metrics for the Coal cases, 2010-2050

Figure 31. Projected generation in CES scenario, 2010-2050 for CES - High-EUR, CES - High-EUR, without CCS; and CES - Low-EUR cases.

Figure 32. Selected metrics for the CES scenario, 2010-2050. 107 
Figure 33. Map of new transmission required by 2050 in the CES - High-EUR case, and measures of new transmission needed in all cases, 2010-2050 ...................................................... 108

Figure 34. Generation in the Advanced Technology scenario, 2010-2050..................................111

Figure 35. Selected metrics for the Advanced Technology scenario, 2010-2050 ........................112

Figure 36. Selected metrics for the Natural Gas Supply Cost Variation case, 2010-2050 ..............115

Figure 37. EIA LNG export scenarios and their projected impacts on domestic natural gas prices,

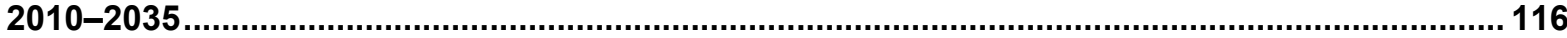

Figure 38. Power generation mix in the Dash-to-Gas case ..................................................... 117

Figure 39. Selected metrics for the Dash-to-Gas case, 2010-2050 ............................................. 118

Figure 41. Changes in coal percentage of total net generation at the state level, 2008-2012........ 122

Figure 42. Changes in generation mix in Delaware; 2005-early 2012 .......................................... 123

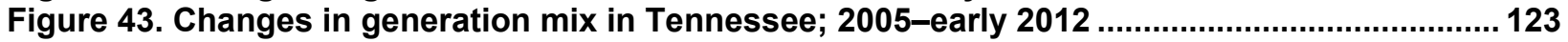

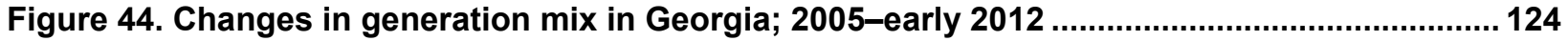

Figure 45. Changes in generation mix in Alabama; 2005-early 2012 ......................................... 124

Figure 46. Changes in generation mix in South Dakota; 2005-early 2012 ....................................125

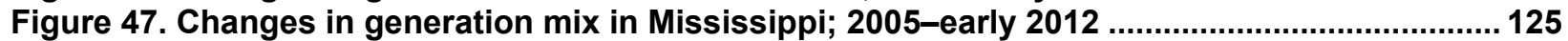

Figure 48. Changes in generation mix in Virginia; 2005-early 2012 ........................................... 126

Figure 49. Changes in generation mix in Ohio; 2005-early 2012 ............................................ 126

Figure 50. Changes in generation mix in North Carolina; 2005-early 2012 ................................ 127

Figure 51. Changes in generation mix in Wisconsin; 2005-early 2012 ......................................127

Figure 52. Changes in generation mix in Michigan; 2005-early 2012 .......................................... 128

Figure 53. Changes in generation mix in Pennsylvania; 2005-early 2012 ................................. 128

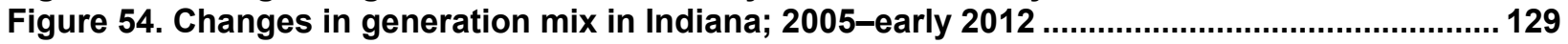

Figure 55. Changes in generation mix in Massachusetts; 2005-early 2012 ............................... 129

Figure 56. Changes in generation mix in lowa; 2005-early 2012 .............................................. 130

Figure 57. Composition of production gas by county .....................................................................139

Figure 58. Variation among gas compositions across the 22 counties of the Barnett Shale play. 140

Figure 59. Distribution of site-level emissions allocated to gas .................................................... 144

Figure 60. County-level gas production co-products by heat content............................................ 145

Figure 61. Basin-level gas processing co-products by heat content ............................................... 146

Figure 62. Proportion of GHG emissions associated with co-products ..................................... 147

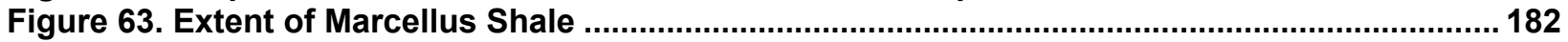

Figure 64. Marcellus Shale permits issued vs. number of wells drilled (PA DEP 2011b)...............183

Figure 66. Histogram for 100 wells of total volumes (gallons) (fracfocus.org) ............................... 184

Figure 67. Total volume of produced water, 2006-2011 (PA DEP 2012b) ..................................... 186

Figure 68. Average volume of produced water per well, 2006-2011 (PA DEP 2012b) ................... 186

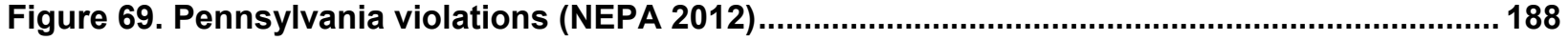

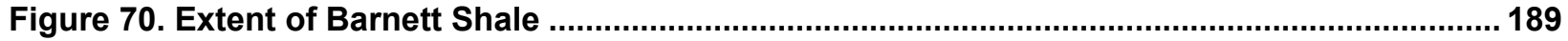

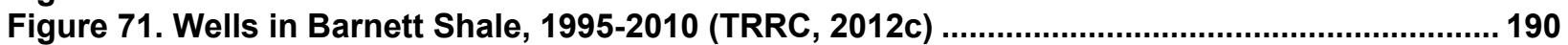

Figure 72. Gas production in the Barnett Shale (bcf), 1995-2010 (TRRC, 2012e).......................... 191

Figure 73. Histogram of 100 wells for total water volume (gallons) (fracfocus.org)....................... 192

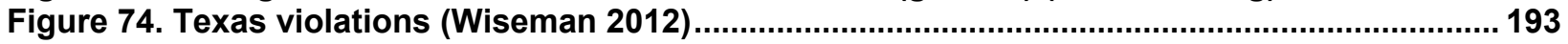

Figure 75. Extent of Eagle Ford Shale play (Eagle Ford Shale 2012) ........................................ 194

Figure 76. Number of producing oil and gas wells in Eagle Ford (Eagle Ford Shale 2012) ........... 195

Figure 77. Fresh-water use in Eagle Ford per well (fracfocus.org) .................................................. 196

Figure 78. Extent of Haynesville Shale ...................................................................................... 197

Figure 79. Monthly well count (2006-2011) (LADNR 2012b) ........................................................ 197

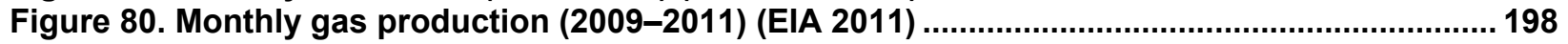

Figure 81. Fresh-water use for 100-well sample (fracfocus.org) .................................................. 199

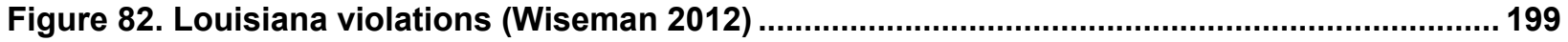

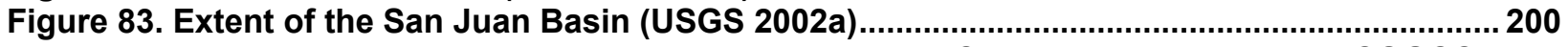

Figure 84. Water disposal volumes and methods in La Plata County (million gallons) (COGCC

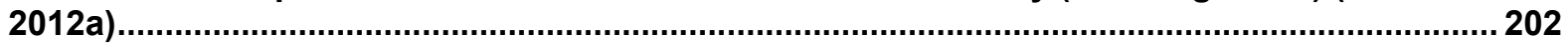

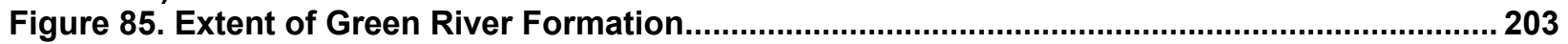

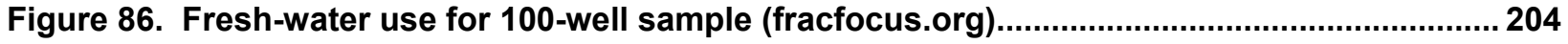

Figure 87. Volumes of hydraulic fracturing water (fracfocus.org) ................................................... 205 


\section{List of Tables}

Table 1. Loss of Produced Gas along the Fuel Cycle

Table 2. Effects of Alternative, Spatially Uniform Estimates of Gas Composition on Inventoried GHG Emissions for the Barnett Shale Play

Table 3. Effects of Alternative, Spatially Uniform Estimates of Gas Composition on Estimated Production Emissions at the County-Level.

Table 4. Description of Shale Plays and Basins Studied ............................................................41

Table 5. Compliance Monitoring and Enforcement Capabilities..................................................6 60

Table 6. Example Composition of Hydraulic Fracturing Fluids (GWPC and ALL Consulting 2009; API 2010).

Table 7. Estimates of Total Gallons of Chemicals Used per Well.

Table 8. Overview of Data Availability

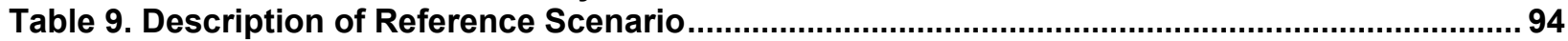

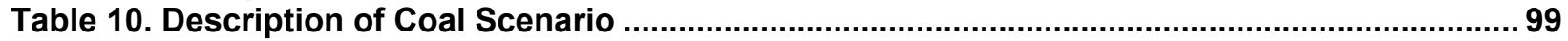

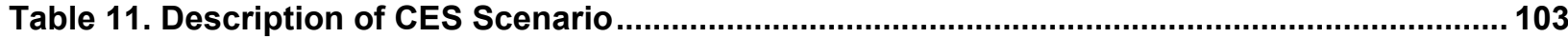

Table 12. Assumed Reductions in Capital Costs for the Advanced Technology Scenario ............ 109

Table 13. Assumed On-shore Wind Improvements in Capacity Factors for the Advanced

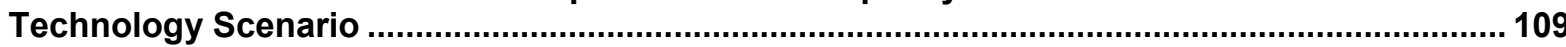

Table 14. Description of Advanced Technology Scenario.......................................................... 110

Table 15. Description of Natural Gas Supply and Demand Variations Scenario............................ 113

Table 16. Non-Power Sector Natural Gas Demand Assumptions in the Natural Gas Demand Variations Case.

Table 17. Composition of Production Gas and Produced-Water Flash Gas in Barnett Shale Counties

Table 18. 2009 Production Volumes from Barnett Shale Counties................................................. 142

Table 19. EPA's AP-42 Compilation of Air Pollutant Emission Factors .......................................... 149

Table 20. Count of Usability for each GHG Emissions Estimation Method for $\mathrm{CO}_{2}$ and Methane 150

Table 21. Life Cycle GHG Emissions Values $\left(\mathrm{g} \mathrm{CO}_{2} \mathrm{e} / \mathrm{kWh}, 100-\mathrm{yr}\right)$................................................ 166

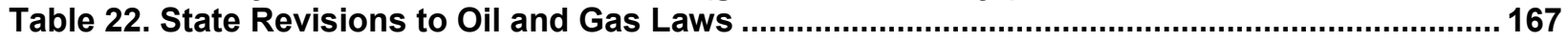

Table 23. Fracking Fluid Disclosure Requirements ..................................................................... 168

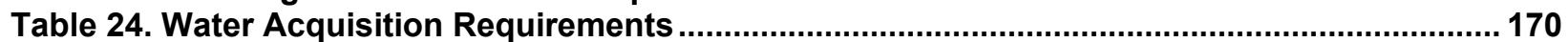

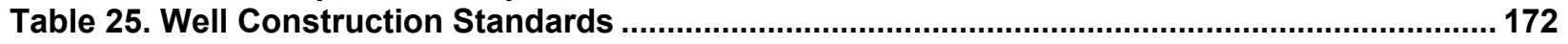

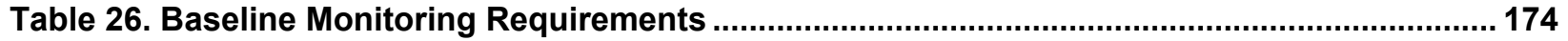

Table 27. Closed-Loop or Pitless Drilling Requirements .............................................................. 175

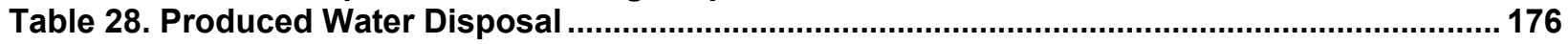

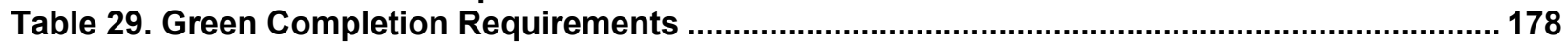

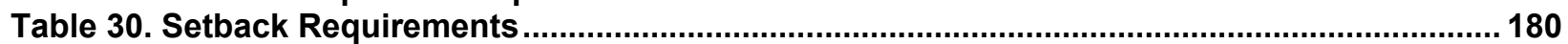

Table 31. Analysis of Water Usage per Well (gallons) for 102 Marcellus Wells (fracfocus.org) ..... 183

Table 32. Average Water Volume per Well by Well Type (gallons) (fracfocus.org)........................ 184

Table 33. Summary of Brine Produced (thousands of gallons) (PA DEP 2012b) ......................... 185

Table 34. Summary of Fracking Fluid Produced (thousands of gallons) (PA DEP 2012b) ............. 185

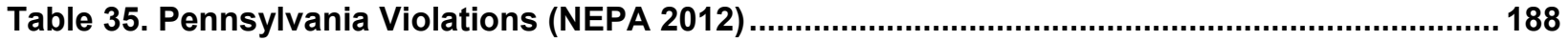

Table 36. Statistics of Water Use (Gallons) (fracfocus.org) ......................................................... 191

Table 37. Texas Violations (Wiseman 2012) .............................................................................. 193

Table 38. Fresh Water Use in Eagle Ford (in gallons) (fracfocus.org) ........................................... 195

Table 39. Analysis of Water Usage for 100 Haynesville Shale Wells (fracfocus.org) ...................... 198

Table 40. Louisiana Violations (Wiseman 2012) ..................................................................... 200

Table 41. Oil, Gas, and Water Production in La Plata County (COGCC 2012a) ............................... 201

Table 42. Produced Water and Disposal Method in La Plata County (Million Gallons)

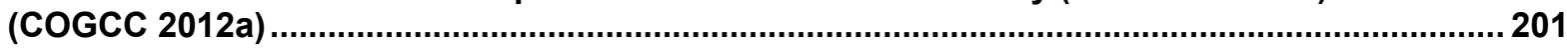

Table 43. Produced Water and Disposal Method in the State of Colorado (Million Gallons)

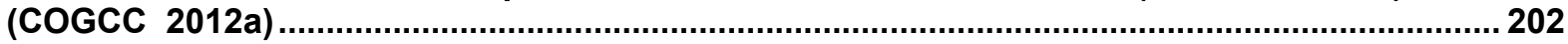

Table 44. Analysis of Water Usage for 100 Green River Formation Wells (fracfocus.org) ............. 204

Table 45. Production of Oil, Gas, and Water in Green River Basin (WOGCC 2012)....................... 205

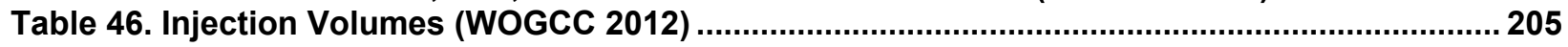


Table 47. Severity of Environmental Impact (Wiseman 2012) ....................................................207

Table 48. Technology Cost (\$2010) and Performance Assumptions Used in ReEDS .................... 212

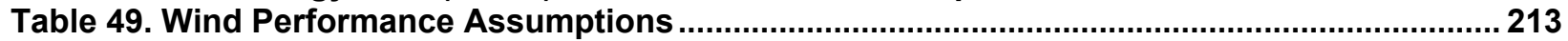

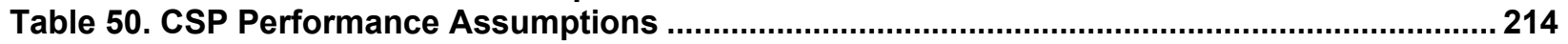

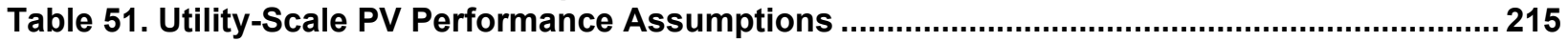




\section{Executive Summary}

Domestic natural gas production was largely stagnant from the mid-1970s until about 2005. Planning had been under way by the early 2000 s to construct about 40 liquefied natural gas import terminals along the U.S. coasts to meet anticipated rising demand. However, beginning in the late 1990s, advances linking horizontal drilling techniques with hydraulic fracturing allowed drilling to proceed in shale and other formations at much lower cost. The result was a slow, steady increase in unconventional gas production.

As the technology improved and spread, domestic shale gas output began to increase rapidly, such that by 2008 commentators began to routinely speak of a shale gas "boom." Today, shale gas accounts for about $30 \%$ of total U.S. natural gas production-up from only $4 \%$ in $2005-$ helping to make the United States the largest producer of natural gas in the world by 2009 . Within a decade, the question of how much more dependent the country would become on natural gas imports had been replaced by how much the U.S. gas supply will affect the economics and geopolitics of energy around the globe.

Although the long-term outcome of the shale gas revolution is far from decided, significant shifts are already apparent in U.S. power markets. In that context, low-price natural gas has had the greatest impact to date on generation by coal power plants. Since 2008, coal's share of annual generation has declined from $48 \%$ to $36 \%$ as of August 2012. This switch from coal to natural gas, combined with growth of renewable energy generation, has led to a reduction of carbon dioxide emissions in the U.S. power sector of about 300 million tons-equivalent to $13 \%$ of total power sector emissions in 2008 .

It remains unclear, however, whether natural gas will continue to exert such a dramatic impact on the power sector and the overall U.S. economy. If natural gas prices continue to stay at, or near, historically low levels, then a self-correction in the shale gas boom may occur. Due to price concerns, some companies have shifted away from drilling for dry gas and instead are focusing on plays that provide natural gas liquids. The ongoing debate is about what price is needed for unconventional natural gas production to be more sustainable over the medium term. As an example, analysis from Range Resources indicates that New York Mercantile Exchange prices of \$4-\$6/MMBtu are needed at the vast majority of plays to generate adequate returns on investment. ${ }^{1}$ Other factors - including "use it or lose it" lease terms, reserve filings with the Securities and Exchange Commission, and the amount of natural gas liquids that can be recovered - all play a role in continuing investment decisions. But, for now, natural gas markets are still widely acknowledged as oversupplied, and storage facilities held record high amounts of gas as of mid-2012.

Hydraulic fracturing has received negative attention in many parts of the country-especially those areas not accustomed to the oil and gas industry - due to real and perceived environmental and social concerns. Water use and contamination, air pollution, greenhouse gas (GHG) emissions, and truck traffic are among the concerns that have strained the social license to operate, and they have been the subject of multiple national and international reports and

\footnotetext{
${ }^{1}$ Specifically, a 12\% internal rate of return (IRR). The reference to this analysis appears in Ventura, J., 2012. "Uncovering Tomorrow's Energy Today," presentation at the Goldman Sachs Global Energy Conference 2012. 10 January 2012. Slide 11. Accessed 9 June 2012.
} 
continued dialogue. Field practices associated with unconventional natural gas production have evolved rapidly in some regions, either from new regulatory requirements or voluntary company practices. These field practices are still evolving, can be uneven across regions, and are sometimes controversial. At the same time, consolidation within the industry is shifting production from smaller to larger companies.

The Joint Institute for Strategic Energy Analysis (JISEA) designed this study to address four related key questions, which are a subset from the wider dialogue on natural gas:

1. What are the life cycle greenhouse gas (GHG) emissions associated with shale gas compared to conventional natural gas and other fuels used to generate electricity?

2. What are the existing legal and regulatory frameworks governing unconventional gas development at federal, state, and local levels, and how are they changing in response to the rapid industry growth and public concerns?

3. How are natural gas production companies changing their water-related practices?

4. How might demand for natural gas in the electric sector respond to a variety of policy and technology developments over the next 20 to 40 years?

\section{Major Findings}

Although the questions analyzed in this report are interlinked to a certain extent, they have specific requirements in terms of analysis methodologies and associated stakeholders. The key findings are presented very briefly as follows:

- Greenhouse gas emissions: Based on analysis of more than 16,000 sources of airpollutant emissions reported in a state inventory of upstream and midstream natural gas industry, life cycle greenhouse gas emissions associated with electricity generated from Barnett Shale gas extracted in 2009 were found to be very similar to conventional natural gas and less than half those of coal-fired electricity generation.

- Regulatory trends: The legal and regulatory frameworks governing shale gas development are changing in response to public concerns and rapid industry changes, particularly in areas that have limited experience with oil and gas development. All of the states examined in this study have updated their regulatory frameworks to address the opportunities and challenges associated with increasing unconventional natural gas production.

- Water management: Many regions evaluated in this study are making greater use of innovative water management practices to limit real and perceived risks. However, a lack of reliable, publicly available water usage and management data — such as total water withdrawals, total wells drilled, water-recycling techniques, and wastewater management practices - currently hinders efforts to develop appropriately flexible and adaptive best management practices. Recent studies have documented a number of management practices related to the chemical makeup of fracking fluids, impacts on local freshwater, and on-site wastewater management that may be appropriate in many locations. 
However, to date, no public studies have been published on cost-benefit, risk-mitigation potential, or the transferability of practices from one shale play to another.

- Electric power futures: A number of different future electric power scenarios were analyzed to evaluate both the implications of shale gas development and use, and various policy and technology changes. These scenarios include power plant retirements, advances in generation technologies, federal policies to reduce greenhouse gas emissions, and variations in natural gas supply and demand. We find that natural gas use for power generation grows strongly in most scenarios.

\section{Life Cycle Greenhouse Gas Emissions from Barnett Shale Gas Using Air-Quality Inventory Data}

A national debate over life cycle $\mathrm{GHG}_{\text {emissions }}{ }^{2}$ from shale natural gas erupted in 2011 after a study was released stating that shale gas had equivalent or even greater GHG emissions than coal. ${ }^{3}$ Since then, a number of other published, peer-reviewed studies have included contrary findings, ${ }^{4}$ although data limitations and methodological variability make conclusive statements problematic about the "real" GHG emission profile.

For Chapter 1, the study team conducted original research on life cycle GHG emissions associated with natural gas production in the Barnett Shale play in Texas. This estimate leverages high-resolution empirical data to a greater extent than previous assessments. The data sources and approach used in this study differ significantly from previous efforts, providing an estimate valuable for its complementary methodological approach to the literature.

The authors used inventories from 2009 that tracked emissions of regulated air pollutants by the natural gas industry in the Barnett Shale play. The Texas Commission on Environmental Quality (TCEQ) collected and screened these inventories. These data cover the characteristics and volatile organic compound (VOC) emissions of more than 16,000 individual sources in shale gas production and processing. Translating estimated emissions of VOCs into estimates of methane and carbon dioxide emissions was accomplished through the novel compilation of spatially heterogeneous gas composition analyses.

Major findings from this analysis of life cycle GHG emissions include:

- Electricity generated using a modern natural gas combined-cycle turbine combusting Barnett Shale gas produced and processed in 2009 has life cycle GHG emissions ranging between 420 and 510 grams carbon dioxide-equivalent emissions per kilowatt-hour ( $g$

\footnotetext{
${ }^{2}$ GHG emissions considered within a life cycle assessment (LCA) include those from the "fuel cycle" of natural gas, which includes activities from well drilling and completion, through production, processing, and transport to the power plant, as well as from the life cycle of the power plant, which includes construction and decommissioning of the power plant and combustion of the fuel. Results are normalized per unit of electricity generated $(\mathrm{kWh})$. See Figure 7 within Chapter 1 and the surrounding text for further description of the scope of this LCA.

${ }^{3}$ Howarth, R. W., R. Santoro, and A. Ingraffea. 2011. "Methane and the greenhouse gas footprint of natural gas from shale formations." Climatic Change Letters, DOI: 10.1007/s10584-011-0061-5 (http://www.springerlink.com/content/e384226wr4160653/fulltext.pdf).

${ }^{4}$ These studies include Burnham et al. 2012; Jiang et al. 2011; Skone et al. 2011; Stephenson et al. 2011; Hultman et al. 2011.
} 
$\mathrm{CO}_{2} \mathrm{e} / \mathrm{kWh}$ ) generated, depending on assumed lifetime production of a well, with a central estimate of about $440 \mathrm{~g} \mathrm{CO}_{2} \mathrm{e} / \mathrm{kWh}$ - similar to levels reported in the literature from conventional natural gas and less than half that typical for coal-fired electricity generation (Figure 1). ${ }^{5}$ Comparisons to conventional natural gas and coal are achieved through harmonization of 200 published estimates of life cycle GHG emissions for those two technologies. ${ }^{6}$ Harmonization is a meta-analytical process that makes consistent the assumptions and methods between LCAs.

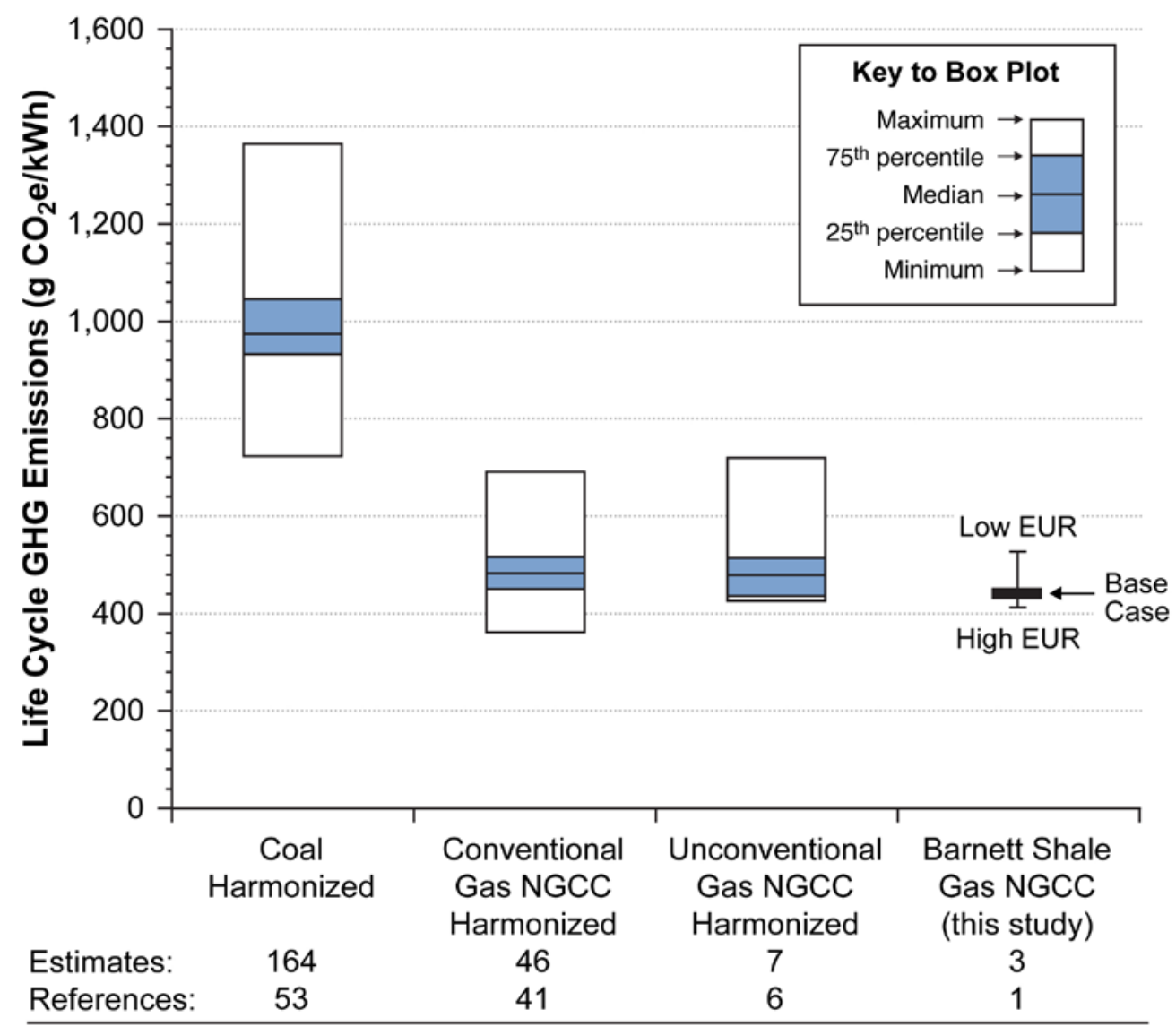

Figure 1. Estimate of life cycle GHG emissions from 2009 Barnett Shale gas combusted to generate electricity in a modern natural gas combined-cycle (NGCC) turbine compared to previously published estimates for unconventional (mostly shale) gas, conventional natural gas, and coal after methodological harmonization.

Notes: EUR = estimated ultimate recovery, or lifetime production; NGCC = natural gas combined-cycle turbine

\footnotetext{
${ }^{5}$ The results reported here do not include emissions associated with liquids unloading, a process that the natural gas industry recently reported as applicable to both conventional and unconventional wells, but without direct evidence for the Barnett Shale play. (See: Shires and Lev-On (2012).)

However, inclusion of these emissions would not qualitatively change our findings.

${ }^{6}$ See Whitaker et al. 2011 and O'Donoughue et al. 2012 for systematic review and harmonization of published estimates of life cycle GHG emissions from coal-fired and conventional natural gas-fired electricity generation, respectively.
} 
- An estimated $7 \%$ to $15 \%$ of life cycle GHG emissions from electricity generation (mean $=9 \%$ ) are from methane emissions throughout the fuel cycle of Barnett Shale gas (well pre-production activities through transmission), mostly from venting during completion and workover, and from the natural gas transmission pipeline network.

- GHG emissions result from many sources throughout the production and use of natural gas. Based on our analysis, more than half can be characterized as sources with potentially controllable leakage - for instance, from tanks or vents. Another $20 \%$ are combustion sources, which also have some emission control opportunities. Remaining sources, called fugitive emissions, are more challenging to control because of their dispersed nature.

- An estimated 1.5\% of Barnett Shale produced gas is emitted to the atmosphere before reaching the power plant, much of which is potentially preventable, with an additional $5.6 \%$ of produced gas consumed along the process chain as fuel for different types of engines. Based on the estimated methane content of this produced gas and average assumed lifetime production of a well, this equates to a central estimate of leakage rate across the life cycle of $1.3 \%$ methane volume per volume of natural gas processed.

- Chemical composition of produced gas varies considerably within the Barnett Shale area such that at the county level, estimates of GHG emissions differ significantly from those based on composition averaged at a higher spatial resolution (play or nation). Variability in gas composition has implications for the understanding of emission sources and the design of regulatory emission control strategies.

\section{A Changing Regulatory Framework for Unconventional Gas Production}

Chapter 2 examines the main federal, state, and local regulatory frameworks that govern unconventional natural gas development. Specifically, it focuses on requirements related to water withdrawals used for hydraulic fracturing, disclosure of chemicals used in hydraulic fracturing fluids, setbacks for wells, baseline water monitoring of surface water resources or water wells, well-construction standards, "green" or "reduced emission" completions, storage of waste in closed-loop systems, and the disposal of produced water. It also examines state compliance monitoring and enforcement capabilities, and the efforts by some local governments in key gasproducing states to limit - and, in some cases, ban — unconventional gas development. Major findings include the following:

- There is a trend toward more regulation at all levels of governance, but there has been a corresponding increase in regulatory fragmentation and differentiation at state and local levels. Better coordination and policy alignment among regulators can help to reduce risks to industry and the public of regulatory fragmentation-including uncertainty, delays, gaps, and redundancies across jurisdictions. Improved communication and sharing of information among regulators at all levels of government and across jurisdictions, as well as increased transparency in the form of publicly available data from industry, would help address regulatory fragmentation and inform regulatory development tailored to specific geographic and geologic characteristics.

- Compliance monitoring and enforcement varies across states, with significant implications for the efficacy of regulations, as well as public confidence. Increased public disclosure of voluntary information - as well as public disclosure of violations, 
enforcement actions, and company compliance-would increase transparency, offer opportunities to highlight the compliance records of leading companies who have demonstrated a commitment to safe natural gas production, and help address public concerns.

- There is a significant range in the environmental performance of operators in the industry, with some operators performing at a level that goes beyond existing regulations and other operators falling short. There is an evolving portfolio of recommended practices emerging from across the stakeholder community; these practices can complement and supplement regulations.

- The varied state and local approaches to regulation can provide important opportunities for learning and innovation regarding substantive rules, the role of best practices, and compliance and enforcement. Regulators might consider adopting performance-based standards, rather than freezing today's "best management practices" into prescriptive rules that could become outdated.

\section{Management Practices in Shale Gas Production: Focus on Water}

Chapter 3 addresses current water usage and water management practices at shale gas development sites and discusses risks to water availability and quality. We evaluated publicly available water usage data from six shale plays throughout the United States. When data were available, we conducted statistical analyses from a randomized sample of wells in each play to gauge current estimates of water usage per well. In addition, data were collected on current wastewater management techniques and volumes associated with managing produced water from wells along with the returned fracking fluids. Lastly, in addition to analyzing current industry practices, we evaluated how water usage, well number, and water management techniques have evolved over time, indicating that water risk and management issues in the future may differ from historical issues. Natural gas exploration and production has significant spatial variability in community and environmental issues, current practices, and regulations. Therefore, JISEA is also publishing the water-related results of this study in a web-based GIS format.

The three primary water impact risks are: regional resource depletion due to use of fresh water during hydraulic fracturing, surface water degradation, and groundwater degradation. Impact risks to water resources vary geographically based on three considerations: 1) where the water comes from, 2) what water use and management practices are followed on site for hydraulic fracturing, and 3) how and where produced water and frac flowback water are treated and/or disposed.

Major findings from this analysis of water impacts include the following:

- Risks to regional freshwater depletion depend on a variety of factors, including water use per well, total number of wells, water recycling rates, and regional water availability. Analysis of use data for four of the six regions from 2007 to 2011 indicated average water use per well ranges from 1.1 to 4.8 million gallons, with a multi-region average of 3.3 million gallons. The total magnitude of water usage depends on the number of wells drilled, which has increased in most regions from 2007 to 2011. In the Eagle Ford play, for example, gas wells increased from 67 in 2009 to 550 in 2011. Total freshwater usage depends on water recycling rates, which may vary greatly depending on location. In 
2011, the highest rates of recycling were reported in Pennsylvania, where 37\% of produced water and $55 \%$ of frac flowback water were recycled, representing nearly 200,000 gallons per well, or $4 \%$ of average water use per well in Pennsylvania. Total impacts on regional freshwater resources can be evaluated by comparing total freshwater uses with estimates of regional freshwater availability.

- Wastewater management practices vary regionally and show different trends from 2008 to 2011 . In Pennsylvania, $80 \%$ of produced water and $54 \%$ of frac flowback water was treated through surface water discharge in 2008, whereas in 2011, less than $1 \%$ of produced water and frac flowback was treated through surface water discharge. In 2011, centralized disposal facilities and recycling are the primary wastewater management methods, accounting for $80 \%$ of produced water volumes and $99 \%$ of frac flowback volumes. In Colorado, surface water discharge of both produced water and frac flowback volumes has increased from $2 \%$ in 2008 to $11 \%$ in 2011 . Management of produced water and frac flowback through onsite injection pits and evaporation ponds have remained the dominant practices from 2008 to 2011 , representing $72 \%$ and $58 \%$, respectively.

Treatment at a centralized disposal facility has increased from $26 \%$ to $31 \%$ from 2008 to 2011. The management and transport of produced water and frac flowback water is considered to be the stage at which spills and leaks are most likely.

- A lack of reliable, publicly available water usage and management data hinders comprehensive analyses of water risks. Data are not publicly available for total water withdrawals, total gas wells drilled, flowback volume per well, water recycling techniques, wastewater management, and other management practices for many regions. These data would assist in developing appropriately flexible and adaptive best management practices. Certain resources - such as the State Review of Oil and Natural Gas Environmental Regulations (STRONGER) and FracFocus - have greatly increased public access to information about risks of hydraulic fracturing; however, further efforts would be beneficial.

- A variety of best management practices are currently being employed in different regions, but there is industry uncertainty over transferability, cost-effectiveness, and risk mitigation potential. Recent studies have documented a number of water-related management practices related to the chemical makeup of fracking fluids (disclosure of additives, minimizing or switching to more benign additives, baseline water quality testing), the impacts on local freshwater (measuring and reporting of volumes, water recycling, use of non-potable or non-water sources), and onsite wastewater management techniques (use of closed-loop drilling systems, elimination of flowback and freshwater mixing in open impoundments, use of protective liners at pad sites) that may be appropriate in many locations. However, to date, there are no publicly available studies that have performed cost-benefit analyses, evaluated the risk-mitigation potential of each strategy, or analyzed practices that could be transferred from one shale play to another.

\section{Modeling U.S. Electric Power Futures Given Shale Gas Dynamics}

In Chapter 4, the study evaluates different electric power scenarios that are influenced by natural gas availability and price, as well as other key policy, regulatory, and technology factors. Many of the scenarios examine sensitivities for the estimated ultimate recovery (EUR) of gas fields. High-EUR corresponds to more abundant and inexpensive natural gas compared to Low-EUR. 
Major findings from the electric sector analysis include the following:

- Natural gas demand by the power sector would grow rapidly - more than doubling from the 2010 level by 2050 - in the Reference, or baseline, scenario. ${ }^{7}$ Figure 2 illustrates the range of natural gas power generation in all scenarios. The main Reference scenario suggests that natural gas would replace coal as the predominant fuel for electricity generation. Attributes of this baseline scenario include rising power demand, stable greenhouse gas emissions, and slowly rising electricity prices that reflect natural gas availability and prices. By 2050 , in the Reference scenario, gas could represent from $28 \%$ to $38 \%$ of power-sector generation compared to the 2010 portion of $20 \%$.

- In a coal retirement scenario, natural gas, and wind to a lesser extent, replaces coal-based generation. Our modeling results indicate no impact on power sector reliability from 80 GW of coal retirements by 2025 on an aggregate scale, although additional detailed dispatch modeling is needed to evaluate localized impacts. National average retail electricity prices in the retirement scenario increase by less than $2 \%$ in 2030 compared to the baseline.

- Under a clean energy standard (CES) scenario, U.S. power sector carbon dioxide emissions would decrease by $90 \%$ between 2010 and 2050, with a corresponding 6\%$12 \%$ increase in average retail electricity prices, including transmission build-out that ranges from 3 to 6 times more than the Reference scenario (measured in million MWmiles). Among the CES sensitivity scenarios, large quantities of variable renewable energy and flexible gas generation work synergistically to maintain system reliability requirements.

${ }^{7}$ A Reference scenario serves as a point of comparison with other alternative scenarios. The Reference assumes a fairly static view of the future, so it, and all alternative scenarios, should not be considered forecasts or predictions of the future. 


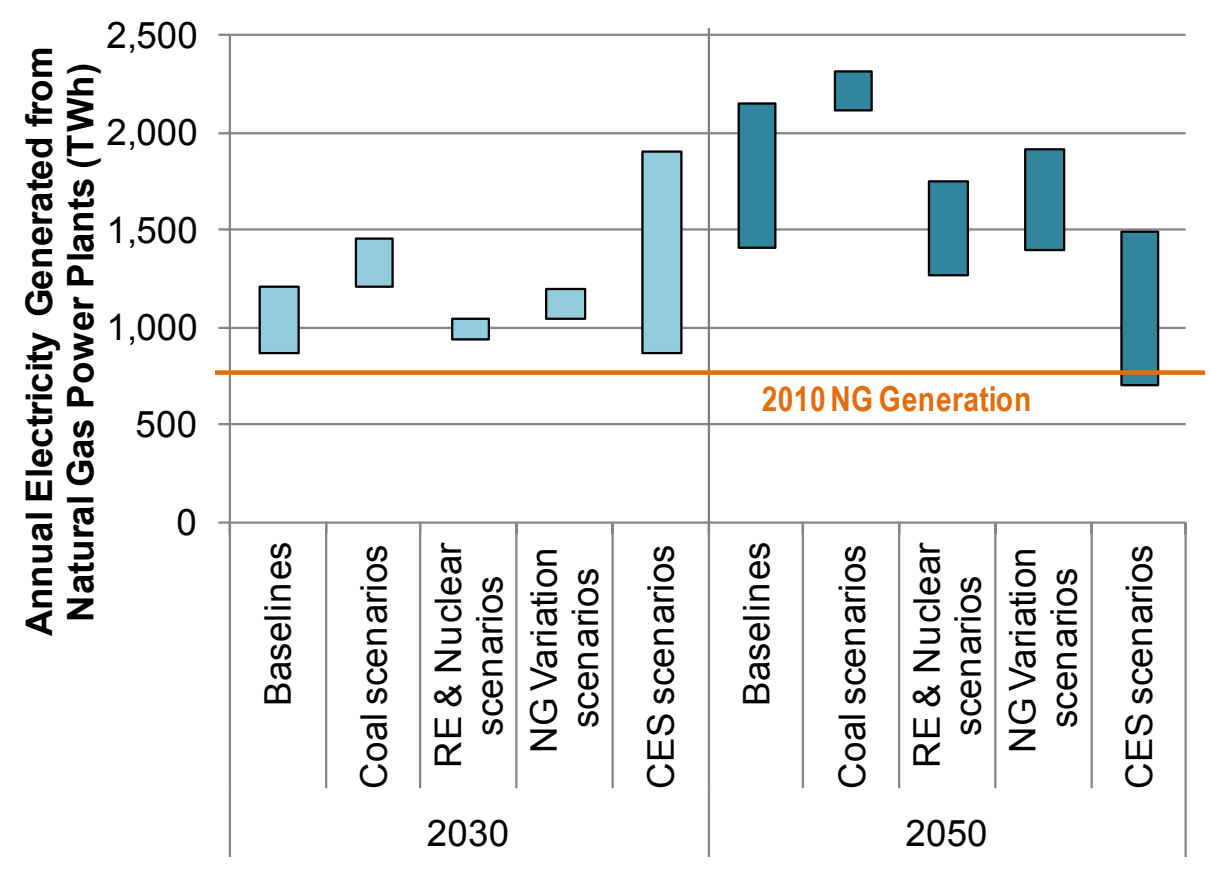

Figure 2. Range of electricity generated from natural gas plants in the scenario analysis

- Advances in generation technologies can have a significant impact on estimated carbon emissions, electricity diversity, and prices. For example, nuclear capital costs would need to decline by half, while gas prices remain relatively high (as simulated in the low-EUR assumption), for the nuclear generating option to compete economically with other options. Wind and solar electricity could more than double by 2050 compared to the Reference scenario with continued improvements in the cost and performance of these technologies. Likewise, continued improvements in production techniques for unconventional natural gas production could enable natural gas to continue to grow market share.

- We consider a range of potential incremental costs associated with operating practices that could better address some of the public concerns in the production of unconventional natural gas. Some of these options include recycling larger amounts of frac flowback water, reducing methane releases to the atmosphere, setting well locations further from potentially sensitive communities, and assuring consistent use of best practices or regulations in well drilling and completions. Sensitivities in incremental costs were evaluated from $\$ 0.50 / \mathrm{MMBtu}$ to $\$ 2 / \mathrm{MMBtu}$. For example, additional costs of $\$ 1 / \mathrm{MMBtu}$ associated with some or all of these several dozen operating practices would lead to a $17 \%$ reduction in gas use for power generation by 2050 compared to the Reference scenario; however, gas-fired generation still more than doubles from the 2010 level.

- A "dash-to-gas" scenario, where other sectors of the economy increase natural gas demand by 12 billion cubic feet per day by 2030, would likely result in higher domestic gas prices and lead to a roughly $20 \%$ reduction in power sector natural gas use by 2050 compared to the Reference scenario in that year, but still nearly twice the level used in 2010. Additional research is needed to understand how natural gas prices respond to rising demand in the new natural gas environment. 
The rapid expansion of shale gas has created dynamic opportunities and challenges in the U.S. energy sector. How long the ascendancy of natural gas in the electric sector will last will be a function of a wide variety of market and policy factors. The story of unconventional gas is evolving rapidly, and in some cases, unexpectedly. Robust and up-to-date analysis will remain critical to informing the key decisions that must be made by all types of stakeholders in the energy and environmental arenas. 


\section{Introduction}

This report addresses several aspects of the changing context of natural gas in the U.S. electric power sector. Increasingly plentiful and affordable natural gas has catalyzed major changes in U.S. power generation and has helped to boost U.S. economic recovery. Increased substitution of natural gas for coal in power generation has also cut U.S. GHG emissions. However, processes to produce natural gas - shale gas in particular - have also elevated environmental and safety concerns in certain regions of the country. The rapid rise of natural gas is also beginning to drive more thought on longer-term energy policy issues such as the appropriate level of generation diversity (given the history of volatile prices for natural gas), and trajectories of natural gas use that will still allow GHG mitigation sufficient to address the climate challenge.

This report is intended to help inform those energy policy and investment discussions. This chapter first outlines the current dynamics of natural gas in the power sector and then describes how the remainder of the report addresses selected challenges and opportunities in the use of natural gas to generate electricity.

Natural gas supply and demand are transforming the energy marketplace. Natural gas prices have been relatively volatile over the past 40 years, at least compared to coal (see Figure 3 ). Today, advances in unconventional gas production, which include a host of technologies and processes beyond horizontal drilling and hydraulic fracturing, ${ }^{8}$ have enabled a new market outlook. Shale production grew from less than 3 billion cubic feet per day (bcf/d) in 2006 to about $20 \mathrm{bcf} / \mathrm{d}$ by mid-2012. ${ }^{9}$ Without this expansion, natural gas prices might be significantly higher because most other sources of domestic natural gas production are in decline.

Given the low-price outlook, many new potential uses for natural gas outside of power generation are being considered and developed - including the export of LNG, the use of compressed natural gas in vehicles, the construction of ethylene plants and other chemical facilities that use natural gas and associated products as a feedstock, and, potentially, investment in gas-to-liquids facilities that convert natural gas into synthetic petroleum products (i.e., diesel) that can be used as a transportation fuel in existing infrastructure. Efforts to further develop the latter may become particularly strong if the price gap shown in Figure 3 remains.

\footnotetext{
${ }^{8}$ For a description of this technological progress, see Seto (2011).

${ }^{9}$ In 2011, the U.S. power sector consumed about 22 bcf/d and the entire economy consumed about 67 bcf/d (EIA 2012b).
} 


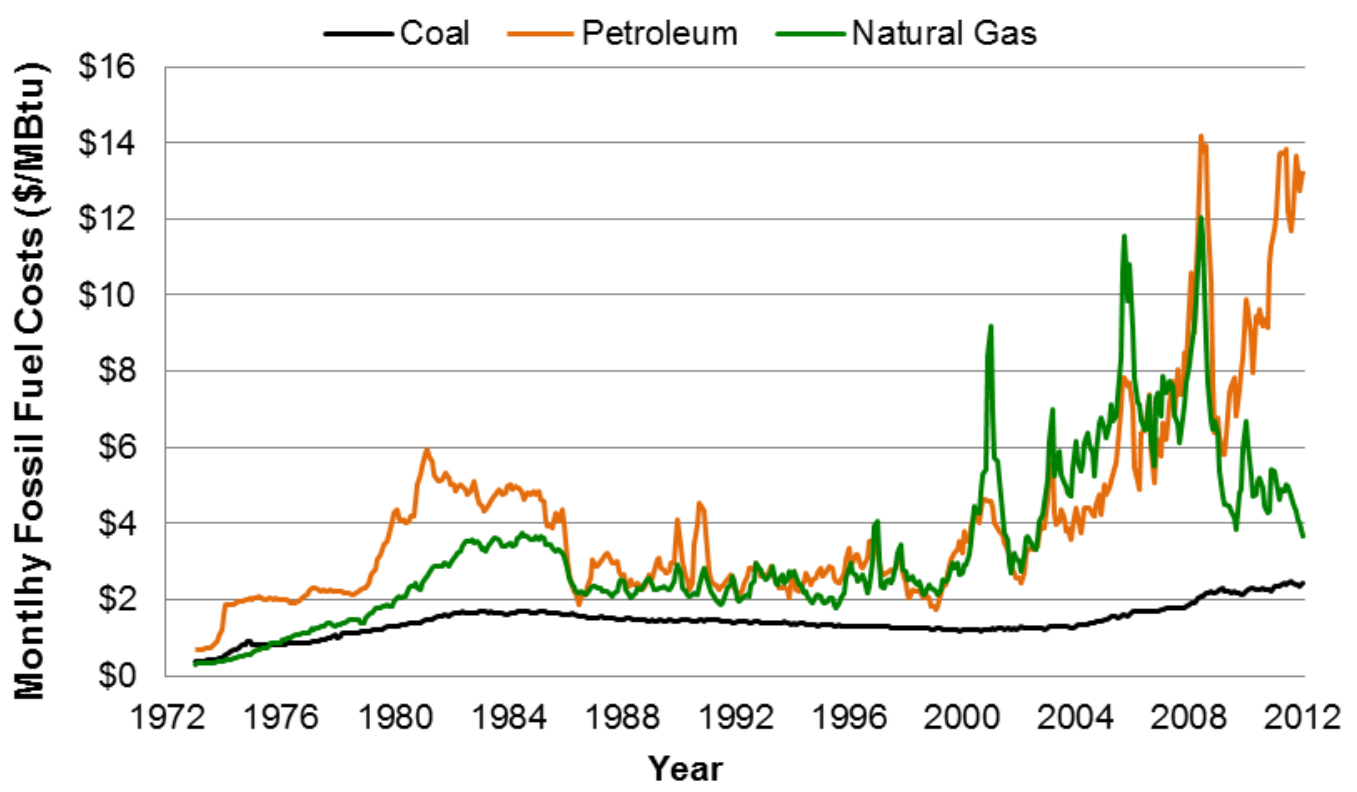

Figure 3. Volatility in fossil fuel costs for power generators

Source: EIA, “Monthly Energy Review," April 27, 2012.

However, given the current low-price environment, many producers have scaled back their plans to drill for dry natural gas, even as they accelerate drilling for wet natural gas (whose natural gas liquids are sold at prices comparable to petroleum products). These cutbacks have contributed to the recent increase in Henry Hub prices, from a low of \$1.90/MMBtu in early 2012 to more than $\$ 3.60 / \mathrm{MMBtu}$ by November 2012. On the other hand, the number of rigs actively developing natural gas has declined sharply since 2009 while production continues to expand, indicating that producers are getting more output with less input (Ebinger et al. 2012). Where prices go next will be influenced by potential new sources of demand noted above, and by supply-side issues, including continued technology improvement, efforts to better protect the environment, and regulatory requirements.

Coal-generated electricity is rapidly declining. Dramatic changes are occurring in the U.S. electric power sector. These changes include a steep reduction in the portion of electric power coming from coal combustion, and a corresponding increase in that provided by natural gas and (to a lesser extent) renewable sources, especially wind power (see Figure 4). Eastern and southern regions are generally experiencing the most rapid shift in generation mix (see Appendix A for more detail). Coal's contribution to total annual U.S. power generation has fallen more rapidly over the past four years than in any time in the history of data collection - from roughly $48 \%$ of U.S. generation in 2008 to $36 \%$ as of August 2012. Had coal generation remained at the 2008 level, the U.S. power sector would be emitting roughly 300 million tons of additional $\mathrm{CO}_{2}$ each year. ${ }^{10}$

\footnotetext{
${ }^{10}$ This is a "burner tip" analysis only and does not consider the full life cycle GHG emissions of coal or natural gas. Data for 2012 are based on a rolling 12-month sum ending in August. The carbon mitigation calculation is based on a $440 \mathrm{TWh}$ reduction in coal generation and corresponding increase in natural gas combined-cycle generation of 310 TWh. Growth in certain renewable generation sources and a reduction in power demand make up the remaining
} 


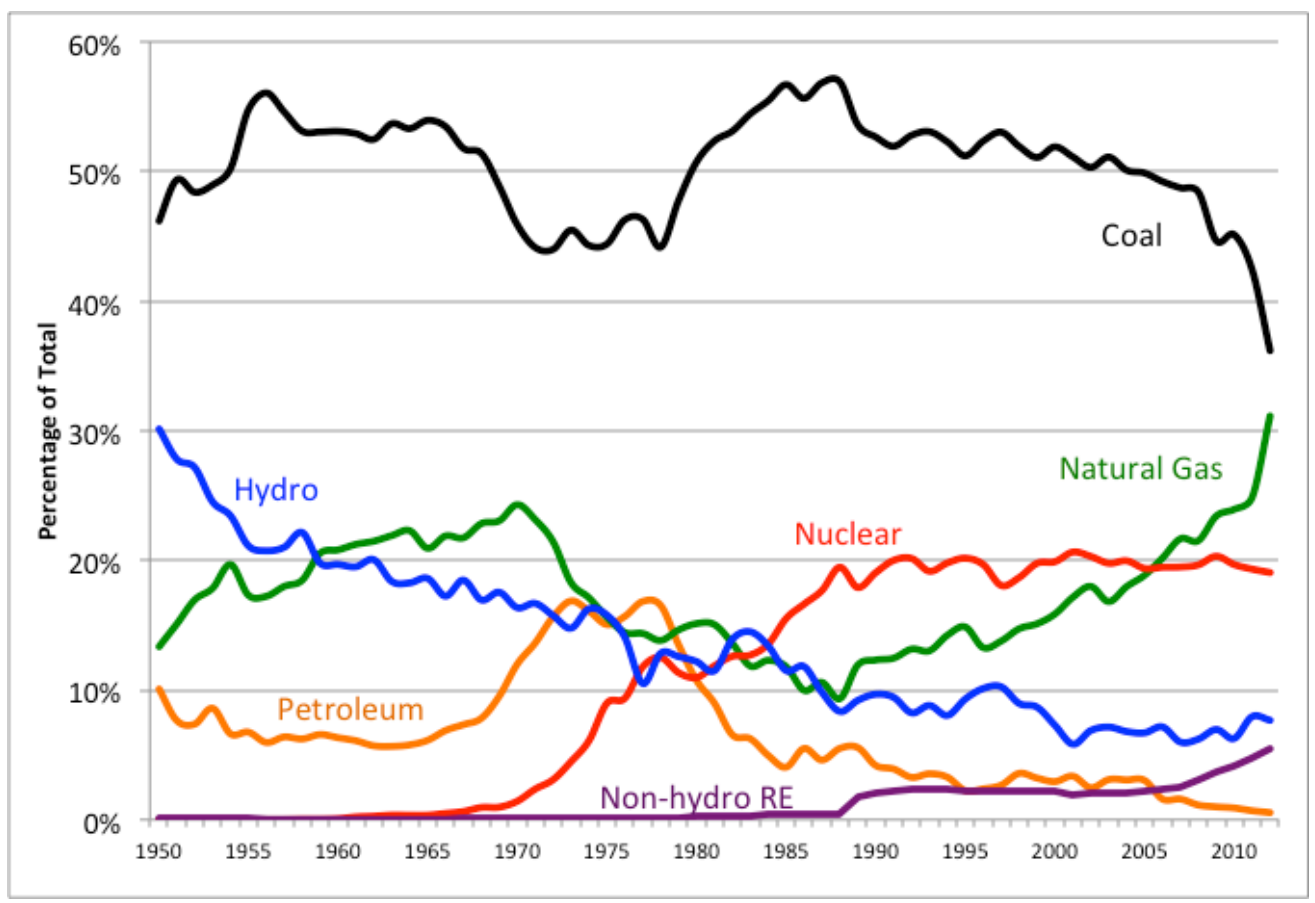

Figure 4. Coal-fired electricity generation is declining rapidly as the use of natural gas and renewable energy expand

Source: EIA, "Annual Energy Review," September 27, 2012; EIA "Electric Power Monthly," October 31, 2012. Data for 2012 includes generation through August only.

The primary drivers of these changes include low-priced natural gas resulting from rapidly growing shale gas production, an unusually warm 2011-2012 winter throughout much of the contiguous United States, ${ }^{11}$ and the expectation that EPA will issue new or revised power plant regulations to further protect the environment. ${ }^{12}$ It remains to be seen whether this trend of declining coal generation continues, stabilizes, or reverses itself. ${ }^{13}$

Hydraulic fracturing presents opportunities and challenges that are in the headlines daily. These opportunities include additional U.S. jobs, increased economic activity, potentially greater energy diversity (particularly in the transportation sector), and less reliance on imported fossil fuels. Challenges largely center on environmental and social concerns associated with shale gas

difference. See EIA Electric Power Monthly (October 2012) for more detail. Chapter 1 of this report addresses the issue of life cycle GHG emissions for various electric generating technologies.

${ }^{11}$ The U.S. Department of Energy reported that the number of heating degree days in the first quarter of 2012 were at the lowest level since record keeping began in 1895 (EIA 2012a).

12 These rules include the Cross-States Air Pollution Rule (recently vacated, but backstopped by somewhat less restrictive requirements), the Mercury and Air Toxics Standard, the Clean Water Act Section 316(b) Water Intake Structures, and the Coal Combustion Residual requirements. Numerous studies attempt to estimate the potential impacts of some or all of these rules after they take effect (see CRS 2011; CERA 2011; and Credit Suisse 2010).

${ }^{13}$ In a May 22, 2012 presentation to investors, for example, ArchCoal stated that half of the coal generation recently lost to low-cost natural gas could be recovered when gas prices rise back above \$3/MMBtu (Slone 2012). AEP also noted in an October 24, 2012 news story that it had seen some fuel switching from natural gas back to coal due to rising natural gas prices (Reuters, 2012). 
production, especially through hydraulic fracturing. ${ }^{14}$ These concerns are acute in some states and increasingly on the docket for federal regulators in several agencies. Current federal regulations to protect surface and underground water resources are less onerous for hydraulically fractured gas production than they are for conventional oil and gas drilling, although many states are passing or updating rules quickly as drilling expands (see Chapter 2, UT 2012, Zoback 2010). Companies are also making greater voluntary efforts to ensure the likelihood that air, water, land, and other resources are protected - at least compared to the early days of hydraulic fracturingalthough these efforts are still not practiced universally (see Chapters 2 and 3 ).

A more general concern for policy makers centers on the role of natural gas versus other sources of electricity in the future: low-priced natural gas could disrupt the development of advanced nuclear or renewable energy technologies, for example, and delay the date when they are cost competitive with traditional energy options. If natural gas prices rose substantially after the power sector had evolved to become more reliant on that fuel, the economy could be vulnerable to an expensive and "locked-in" power sector.

This report focuses on four topics. First, Chapter 1 addresses the full life cycle GHG emissions of shale gas compared to other power generation options. Questions about these "cradle-tograve" emissions began to appear in 2011 with several reports claiming that shale gas had life cycle GHG emissions as high as, or higher than, coal. ${ }^{15}$ Controversy remains over how much methane is released to the atmosphere during the process of producing natural gas, in general, and shale gas, in particular. Chapter 1 uses a new approach to advance the state of knowledge about the life cycle GHG emissions from shale gas based on analysis of highly resolved inventories of air pollutant emissions completely independent of the data sources used in previous research.

Second, Chapter 2 surveys the legal and regulatory trends associated with shale gas production at both the federal and state level. Although federal agencies are taking an active role in ensuring that shale gas is produced safely, Congress has imposed some limitations on what agencies can regulate. The state role in regulating unconventional natural gas production is more pronounced and varied. Chapter 2 summarizes trends in regulatory action at six major unconventional gas plays/basins: Barnett Shale play and Eagle Ford Shale play in Texas, Haynesville Shale play in Texas and Louisiana, Marcellus Shale play in New York and Pennsylvania, North San Juan basin in Colorado, and Upper Green River basin in Wyoming.

Third, Chapter 3 assesses environmental and community risks associated with unconventional natural gas production in the same six regions identified in Chapter 2. It focuses particularly on water issues and company practices that impact water. Public concern over environmental and safety issues has been severe enough in some areas to delay or halt plans to develop unconventional production.

\footnotetext{
${ }^{14}$ See, for example, SEAB (2011a and 2011b), MIT (2011), and UT (2012). There is some confusion surrounding hydraulic fracturing and the potential for environmental impact. Those in industry typically use the term in a focused way, referring to the brief period of time that a high-pressure mixture of water, sand, and additives is being injected, and later, partially removed (flowback). The general public often takes a broader view and labels the entire process of producing unconventional gas or oil as hydraulic fracturing. Significant controversy results from the difference in semantics.

${ }^{15}$ See Lustgarten (2011) and Howarth et al. (2011), for example.
} 
A GIS tool was developed to help evaluate:

- Water availability, use, and cost information

- Water flowback and produced water

- Best current practices for management.

Current practices and regulatory oversight need to be evaluated at a deeper level before the overall goal of determining the costs of acceptable practices can be achieved. Chapter 3 describes a comprehensive approach to evaluating risks and following practices so as to support greater public confidence.

In Chapter 4, we report on different U.S. electric power futures based on a variety of potential developments in technology, environmental protection, GHG mitigation, social license to operate, and gas demand outside the power sector. We use the National Renewable Energy Laboratory's (NREL's) Regional Energy Deployment System (ReEDS) to simulate the impact of these different futures, and benchmark information from Chapters 1-3 in the scenario analysis. Chapter 5 synthesizes findings and summarizes potential follow-on research. 


\section{Life Cycle Greenhouse Gas Emissions from Barnett Shale Gas Used to Generate Electricity}

\subsection{Introduction}

According to the 2010 U.S. Greenhouse Gas Emissions Inventory (EPA 2012a), the natural gas industry ${ }^{16}$ represents nearly a third of total methane emissions in the United States in 2010 - the largest single category - and is also the fourth largest category of $\mathrm{CO}_{2}$ emissions. ${ }^{17} \mathrm{EPA}$, which produces the U.S. GHG inventory, significantly increased estimates of methane emissions from the natural gas industry for the 2009 inventory year, resulting from a change in its assessment of emissions from four activities, the most important of which were: well venting from liquids unloading (attributed only to conventional ${ }^{18}$ wells by EPA); gas well venting during completions; and gas well venting during well workovers ${ }^{19}$ (EPA 2011). The sum of these changes more than doubled the estimate of methane emissions from natural gas systems from the 2009 inventory compared to the 2008 inventory. EPA acknowledges what is well understood: the estimates of GHG emissions from the natural gas sector are highly uncertain, with a critical lack of empirical data to support GHG emission assessments (EPA 2011). This is especially acute for production of unconventional gas resources. Data gathering to support re-assessment of the EPA's U.S. GHG inventory and potential regulations is under way.

An emerging literature has attempted to estimate GHG emissions from unconventional natural gas production, based on the limited available information. Measurement of GHGs in the atmosphere, if they could be reliably attributed to specific sources, would be the ideal methodological approach. However, such measurements are expensive, attribution is challenging, and only one pilot study has been published to date based on measurements in one gas field - which, since the time of measurement, has implemented new practices based on changing state regulations (Petron et al. 2012). The state of the practice employs engineeringbased modeling, based on as much empirical information as is possible to assemble.

Much of this emerging literature is guided by the methods of life cycle assessment (LCA), which in this context aims to estimate all GHG emissions attributable to natural gas used for a particular function: electricity, transportation, or primary energy content (e.g., heat). Attributable emissions are those from any activity in the process chain of producing the natural gas - from exploration and well pad preparation to drilling and completion-processing it to pipeline quality, transporting it to the location of end use, and combustion. In addition, the construction, operation and maintenance, and end-of-life decommissioning of the end-use technology are also considered.

\footnotetext{
${ }^{16}$ For purposes of the GHG Inventory, the natural gas industry includes exploration, production, processing, transmission, storage, and distribution of natural gas to the end user (EPA 2011).

${ }^{17}$ In 2010, total U.S. GHG emissions have been estimated as 6,822 $\mathrm{Tg}$ or million metric tons $\mathrm{CO}_{2} \mathrm{e}$ (EPA 2012a). Of this total, $84 \%$ were from $\mathrm{CO}_{2}$, with most of the remaining (10\%) from methane. Direct emission from the combustion of fuels, including natural gas, for electricity generation contributes $2,258 \mathrm{Tg} \mathrm{CO}_{2}$, or $33 \%$ of total GHG emissions. Natural gas systems contribute $247 \mathrm{Tg}$ of $\mathrm{CO}_{2} \mathrm{e}$, or $3.6 \%$ of total emissions, $87 \%$ from emissions of methane.

${ }^{18}$ Defined as any non-stimulated well. This report follows EPA (2011) in recognizing "that not all unconventional wells involve hydraulic fracturing, but some conventional wells are hydraulically fractured, which is assumed to balance the over-estimate."

${ }^{19}$ The frequency of which has since been reduced from $10 \%$ of wells per year to $1 \%$ of wells per year (EPA 2012b).
} 
LCAs are typically performed to compare the results from one system to another. ${ }^{20}$ The focus of this chapter is to advance understanding of GHG emissions from the production and use of shale gas in the context of the electric power sector as compared to generation of electricity from conventionally produced natural gas. Natural gas once processed for pipeline transmission to end-use customers is a homogenous product, undifferentiated by source. End-use combustion of the natural gas has, by far, the largest contribution to life cycle GHG emissions (as is true for any fossil-fueled combustion technology); but is not a point of differentiation between conventional and unconventional natural gas. Therefore, this study focuses on the activities associated with production of natural gas because they are the points of potential differentiation between unconventional and conventional natural gas.

We additionally focus on emissions from natural gas processing, given current regulatory and scientific attention to emissions from the natural gas industry and opportunity provided by the unique data sources employed in this study. Furthermore, we rely on the multitude of previously published LCAs of conventionally produced natural gas, updated for recent changes in understanding (EPA 2011; EPA 2012b) and harmonized for methodological inconsistency, as embodied in our publication (O'Donoughue et al. 2012), for comparison to the results of this study. We also compare our results to those for coal-fired electricity generation based on a systematic review and harmonization of that LCA literature, because coal has been the largest source for electricity in the United States over the last 50-plus years (Whitaker et al. 2012).

Prior research comparing life cycle GHG emissions of electricity generated from shale gas to conventional gas has been inconclusive and remains highly uncertain. Both the magnitude and direction of difference reported in these publications vary (Howarth et al. 2011; Burnham et al. 2012; Jiang et al. 2011; Skone et al. 2011; Stephenson et al. 2011; Hultman et al. 2011). This is despite their reliance on very similar data sources (mostly EPA's GHG emission inventory and supporting documentation). Uncertainty in the underlying data sources drives the uncertainty in published results. Furthermore, inconsistent approaches to data use and other assumptions thwart direct comparison of the results of these studies and the development of collective understanding.

Separately, the authors have examined this literature using a meta-analytical technique called harmonization that clarifies the collective results of this emerging literature by adjustment to more consistent methods and assumptions (Heath et al. 2012). In that publication, the authors elucidate differences between previously published estimates of life cycle GHG emissions from combustion of shale gas for power production and key sensitivities identified in this literature. Key sensitivities include EUR and lifetime (years) of wells; emissions and emissions reduction practices from well completion and workover; and emissions and emission reduction practices from well liquids unloading, all of which vary from basin to basin and from operator to operator. A key conclusion from the assessment of previous estimates of unconventional gas life cycle GHG emissions is that given current uncertainties, it is not possible to discern with a high level of confidence whether more GHGs are emitted from the life cycle of shale gas or conventional gas used for electricity generation.

\footnotetext{
${ }^{20}$ For interested readers, many texts describe LCA principles and methods, such as Horne et al. (2009) and Vigon et al. (1993).
} 
In this chapter, we present results from a new method of estimating life cycle GHG emissions from shale gas that takes advantage of unusually detailed and rarely produced empirical data specific to a shale gas play and year. Our empirical data sources and approach differ significantly from previous efforts. Broadly, we use the methods of air quality engineering, life cycle assessment, and energy analysis to estimate GHG emissions attributable to the generation of electricity from shale gas produced from the Barnett Shale play in Texas in 2009, the latest year with available data. There are several unique aspects of this research as compared to previous natural gas life cycle assessments:

- Highly resolved estimates of GHG emissions from shale gas production and processing developed at site (facility) and source (equipment and practices) levels.

- Use of industry-supplied and regulator quality-assured data regarding equipment, practices, and emissions developed with very high participation rates.

- Development of a publicly available data set of county-level, extended gas composition analyses of produced (raw) gas demonstrating wide variability of methane and VOC content within the Barnett Shale formation.

It is critical to note that the new results reported here are not necessarily applicable to other plays or years. However, they are discussed in the context of other published literature, where the broad outlines of consistency found within this literature increases confidence in the results, albeit still hampered by many areas of uncertainty remaining to be addressed through further research.

Commercial production of shale gas began in the 1980s, starting in the Barnett Shale play in Texas. The Barnett Shale play continues to be a large source of gas, estimated at more than $6 \%$ of total U.S. natural gas production (Skone and James 2010). Data on production and processing activities in this 22-county ${ }^{21}$ area (Figure 5) are some of the best available for any unconventional gas formation in the United States. For these reasons, the focus of the analysis of this chapter is shale gas produced from the Barnett Shale formation. As illustrated in Figure 5, the highest production occurred within the Dallas-Ft. Worth metropolitan area, which is in nonattainment for the National Ambient Air Quality Standard for ozone (and other pollutants).

\footnotetext{
${ }^{21}$ The Barnett Shale is sometimes referred to as consisting of 23 or 24 counties. However, this analysis focuses on the 22 counties with non-zero gas production for 2009 (TRRC 2012).
} 


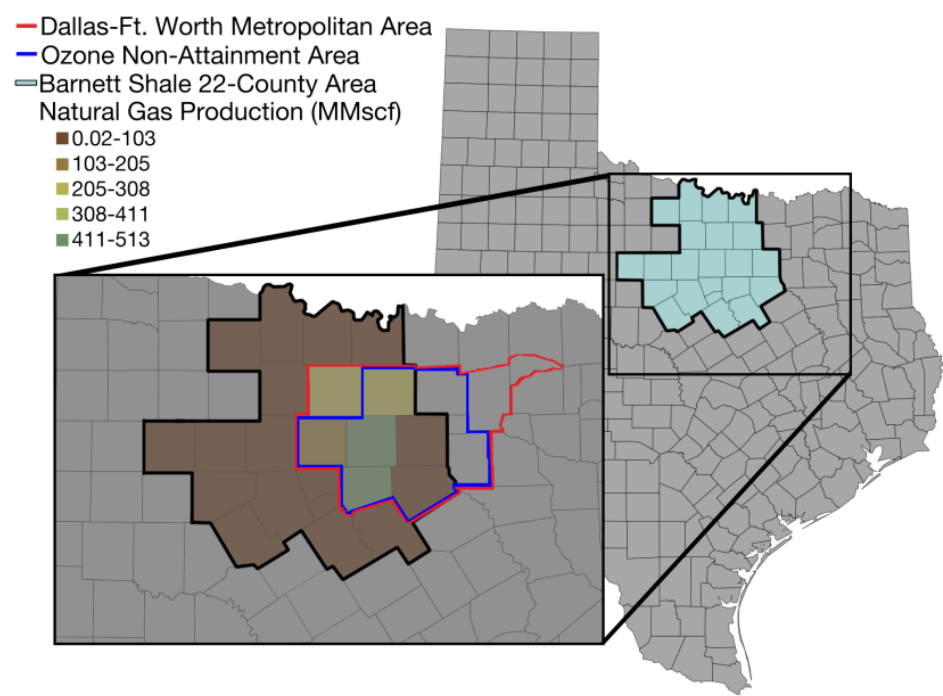

Figure 5. Counties with non-zero gas production from the Barnett Shale formation in 2009, and other demarcations of the Barnett Shale area in Texas (TRRC 2012)

\subsection{Methods and Data}

There are many different sources of GHG emissions in the natural gas industry (EPA 2011; ENVIRON 2010; API 2009), but the fundamental approach to estimating the magnitude of emission for all of them is:

$$
\text { [activity }] *[\text { emission factor }]=[\text { emission }]
$$

where the emission factor is in units of mass emission per unit activity, and "activities" for the natural gas industry range from counts of drilled wells or pieces of certain equipment to volume of natural gas produced, fuel combusted in an engine, or volume of water produced from a well (e.g., ENVIRON 2010; API 2009; EPA 1995). We call this approach activity-based emission estimates.

Different groupings of activity-based emission estimates lead to different types of results. Inventories aim to estimate emissions from a given chronological period, representing all activities occurring in that period. Inventories are developed with different foci: geographic, industrial sector, or pollutant. Few GHG emission inventories exist at higher spatial resolution than national, which aggregates industry- and pollutant-specific inventories produced at a national scale.

In contrast, LCAs aim to estimate all emissions attributable to a final product - here, a kilowatthour of electricity - scaling all the activities required over time and space to produce that unit of final product. Figure 6 depicts the scope of this LCA of electricity generated with natural gas, which covers all stages in the fuel cycle as well as the power plant's life cycle. As shown, this study combines an original inventory, for stages shown in blue, with best-available literature estimates for the remaining stages. Once co-products are separated from the produced gas, all emissions associated with their storage, processing, transport, and disposal or sale are considered outside of the system boundary for this study (as depicted with dashed lines). 


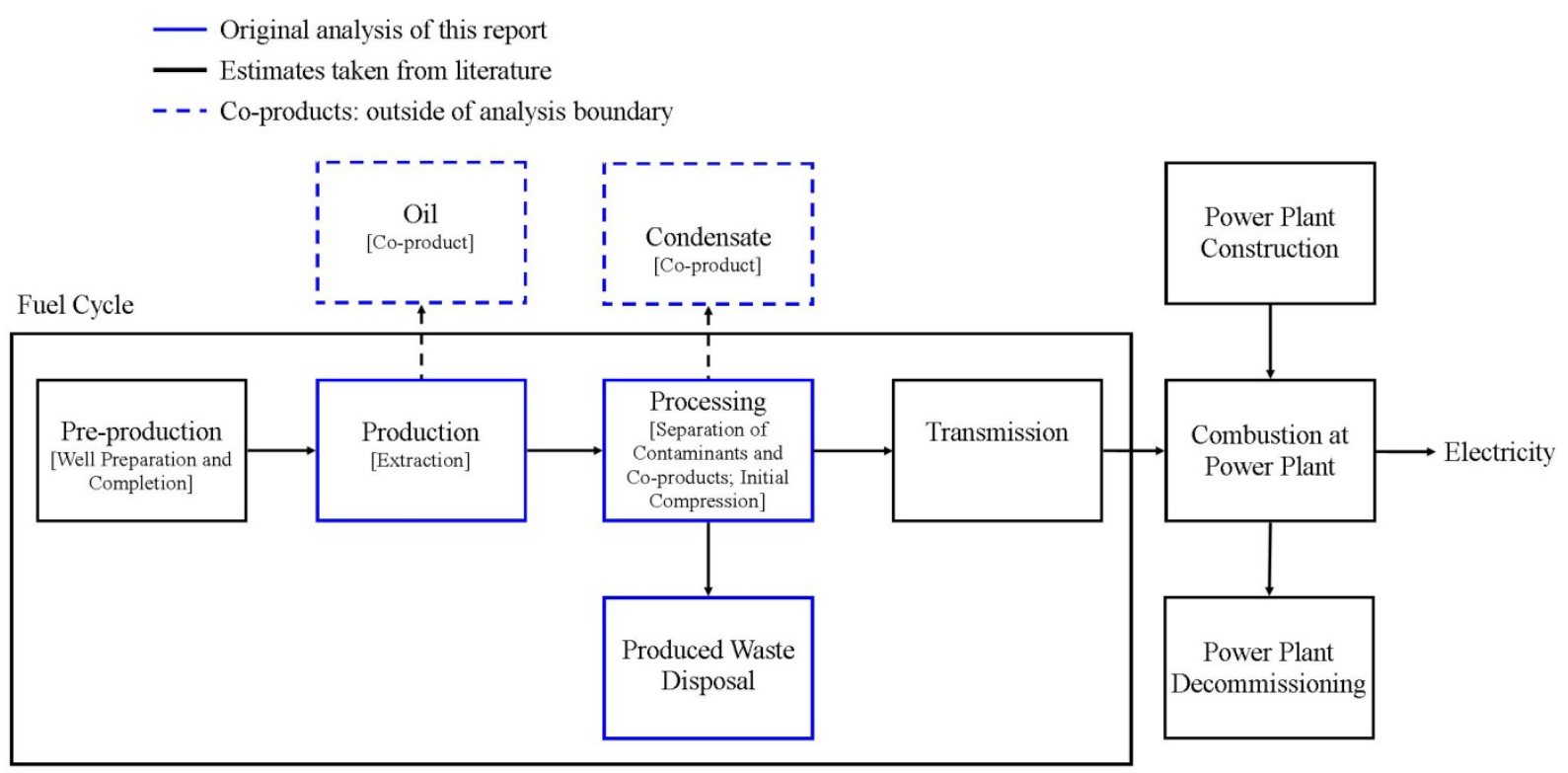

Figure 6. A life cycle assessment of electricity generated from natural gas involves estimating the GHG emissions from each life cycle stage

Because LCAs track the conceptual process chain — rather than the real supply chain - they typically model idealized activities, informed by as much empirical data on real conditions as possible. More than 30 LCAs of conventional natural gas follow this modeling philosophy (O’Donoughue et al. 2012). LCAs on shale gas that follow this approach include one employing a simplified, generic model of the industry (Stephenson et al. 2011); three assessing the U.S. national average or otherwise non-formation-specific conditions (Burnham et al. 2012; Skone et al. 2011; Howarth et al. 2011); and two assessing specific formations_-Jiang et al. (2011) on the Marcellus formation and Skone et al. (2011) on the Barnett Shale.

More recently, some LCAs have leveraged EPA's national inventory of the natural gas industry's GHG emissions from a given year to simulate the process chain (Hultman et al. 2011; Venkatesh et al. 2011). These latter assessments benefit from emission estimates meant to be more closely related to actual performance; however, their estimates carry significant uncertainty given the current state of knowledge of activities and emission factors of this industry. In addition, results will change from year to year as the level of activity changes and may not reflect the life cycle of activities for a well (e.g., completions nationally in a given year may contribute a larger fraction of total emissions than what is reflective of their contribution within the life cycle of a single well).

In contrast to such approaches, this study translates estimates of VOC emissions to GHG emissions, capitalizing on a uniquely detailed inventory of VOC emissions and activities collected by the TCEQ. This approach enables a high-resolution GHG inventory for the production and processing of natural gas in the Barnett Shale play, within which individual GHG emissions from all relevant sources are estimated. Then, this annual inventory of the natural gas industry is translated into a longitudinal life cycle assessment for electricity produced from combustion of Barnett Shale gas. A brief summary of the approach is described below, with details provided in Appendix B. 


\subsubsection{Developing a GHG Emissions Inventory}

Inventories of GHG emissions follow a long tradition of inventories for regulated air pollutants such as nitrogen oxides $\left(\mathrm{NO}_{\mathrm{x}}\right)$ and VOCs that, in combination with sunlight, are precursors of ozone. Because of their role in demonstrating compliance with the National Ambient Air Quality Standard for metropolitan areas, the unit of analysis of these inventories is the county and large, so-called point sources. Point-source inventories contain detailed information related to all sources of emissions within specific facilities and are based on activity and characteristics information supplied by those facilities. Smaller, non-mobile sources (called area sources) are too numerous for regular, facility-specific information collection efforts and instead are tracked as a class, with emission factors (often simplified) correlating emissions with readily tracked activity data. The natural gas industry has many large point sources (including processing plants, compressor stations, and some production sites); the more numerous, smaller entities (including most production sites and some processing and transmission facilities) are classified as area sources.

Motivated by changing practices in the industry, in 2009, the TCEQ initiated a special inventory to collect detailed information on the activities and characteristics of the smaller entities in the natural gas industry that are normally part of the area-source inventory, similar to what is collected routinely from large point sources (TCEQ 2011). The purpose of the special inventory is to update and improve the TCEQ's estimates of emissions of regulated air pollutants from area sources, focused on the rapidly growing shale gas industry in the Barnett Shale area surrounding the metropolitan area of Dallas-Ft. Worth. The availability of the TCEQ's special inventory, in conjunction with its standard point-source inventory (TCEQ 2010), enables estimates of GHG emissions from activities within this important play at much finer resolution-by geography and entity - than is typically possible.

This study estimates GHG emissions from more than 16,000 individual sources detailed in three different TCEQ emission inventories: ${ }^{22}$ the 2009 Point Source Inventory, 2009 Special Inventory, and 2008 Area Source Inventory (Pring et al. 2010). As shown in Figure 7, sources are characterized into profiles, which we further group into three general categories: combustion sources, potentially controllable leakage, and fugitives. ${ }^{23} \mathrm{We}$ differentiate between potentially controllable leakage and fugitives, where the former typically involves gas released from an isolatable emission point and therefore is potentially controllable, and the latter comes from more dispersed leaks that are less feasible to control. Many of the individual sources analyzed in this report are potentially controllable, as are many additional emissions in the fuel cycle, which come from completions and workovers, waste disposal, and transmission. For each profile, we estimate emissions with a tiered approach based on the availability of data. In general, primary (most accurate) methods are based on reported volumes, such as fuel combusted or gas emitted, whereas secondary methods are based on reported VOC emissions or average usage conditions. We use primary methods for $83 \%$ of sources, secondary for $15 \%$, and profile medians for the remaining $1 \%$.

\footnotetext{
${ }^{22}$ Detailed inventory data were received through personal communication (TCEQ 2012).

${ }^{23}$ Skone et al. (2011) state that $25 \%$ of compressor engines in the Barnett Shale area are electrically powered, which would require the inclusion of emissions attributed to the generation of that electricity as an additional category. However, no electrically powered compressor engines are listed in the TCEQ data provided, and personal communication with the TCEQ (TCEQ 2012) stated that few, if any, such engines exist in the area.
} 


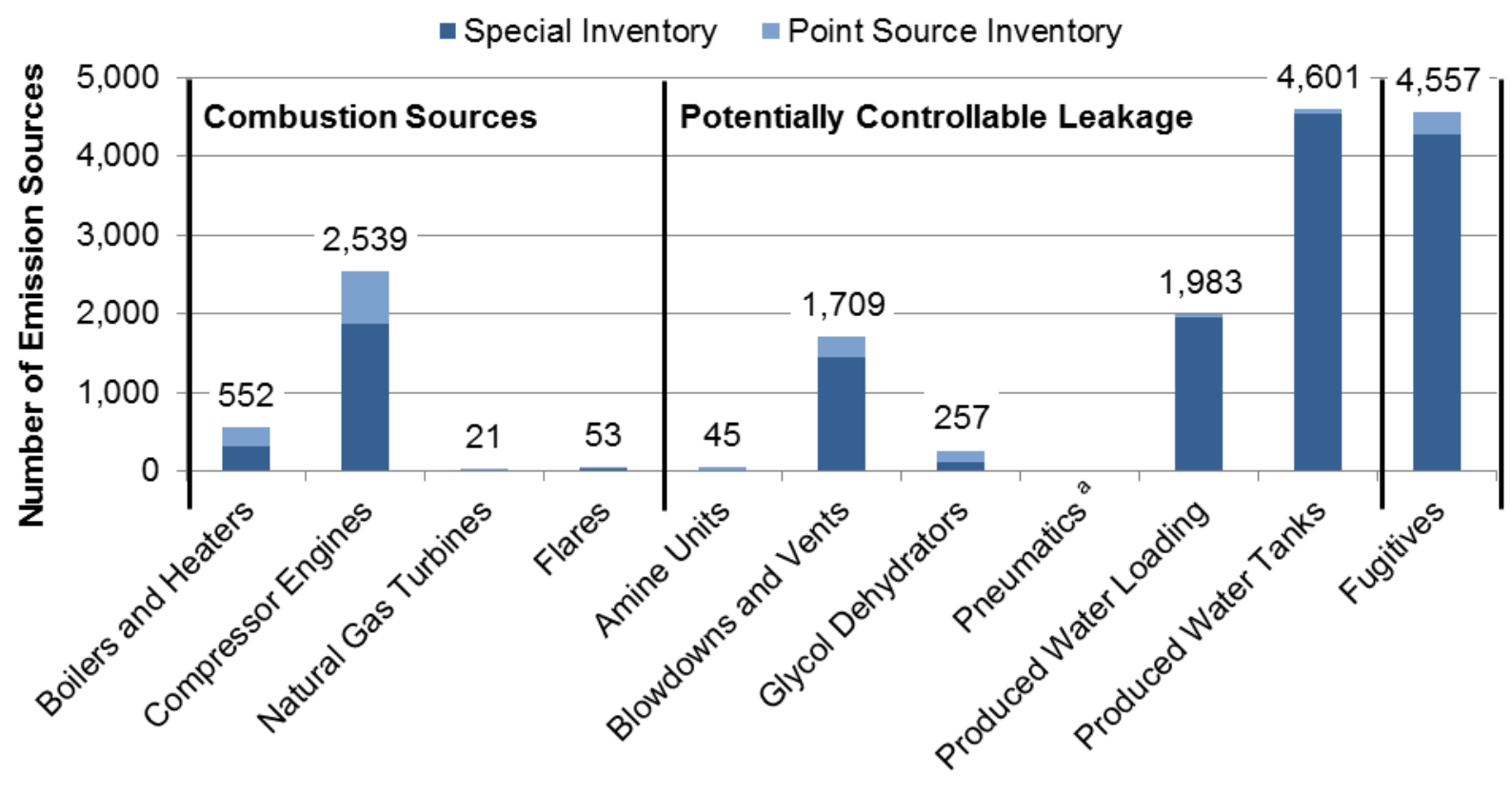

Emission Source Profiles

Figure 7. Greenhouse gas sources belonging to the natural gas industry in the 22-county Barnett Shale area; many are potentially controllable

${ }^{\text {a }}$ Pneumatics, from the area source inventory, have no count of individual sources

The central principle for translating a VOC emission inventory to one that estimates GHG emissions is the recognition that methane is a VOC, ${ }^{24}$ albeit the slowest-acting one (Seinfeld and Pandis 2006). The key to translating VOC emission estimates to methane emissions is the availability of gas composition analyses reporting the proportion of methane, VOCs, and other gases (e.g., $\mathrm{CO}_{2}$ ) within a sample. For validation purposes, the TCEQ requested many such gas composition analyses from reporting entities, which have been assembled into the largest known play-specific and publicly available set of gas-composition analyses. Organized by county, this database allows for estimation of methane and $\mathrm{CO}_{2}$ content in gas emitted through venting and fugitive sources by ratio. It is well understood by geologists, petroleum engineers, investors, and others that gas composition varies within a geologic shale gas basin (e.g., Bullin and Krouskop 2008; Bruner and Smosna 2011); however, this is the first LCA or GHG emissions inventory to explore the implications of this variability.

In addition, other valued hydrocarbon products, such as condensate and oil, are created during the production and processing of natural gas. A principle of LCA research called co-product allocation dictates that the burdens of a system should be shared among all valued products from that system (e.g., Horne et al. 2009). In this study, emissions are allocated with respect to their share of the total energy content of all products from the fuel cycle. In addition to weighting the emissions from each source according to associated condensate and oil production, this means

\footnotetext{
${ }^{24}$ The VOCs typically tracked in Texas and national (EPA) regulations are non-methane, non-ethane VOCs. Accordingly, this report follows standard convention and refers to the set of non-methane, non-ethane hydrocarbons as VOCs. However, measurements of the composition of a gas sample (a so-called "extended analysis") include methane.
} 
that the $25 \%$ of the sources in the TCEQ inventories that are associated only with the storage and handling of these co-products (e.g., condensate tanks) have been omitted. ${ }^{25}$

\subsubsection{From Inventory to LCA}

The GHG emissions inventory estimated here draws mainly from the TCEQ Special Inventory and Point Source Inventory for sources within natural gas production and processing life cycle stages (see Figure 7) (TCEQ 2010, 2011). Natural gas production relates to ongoing activities for the extraction of gas at wellheads. Natural gas processing relates to ongoing activities for the conversion of the produced gas to the required quality, composition, and pressure for pipeline transport. ${ }^{26}$ In addition, the TCEQ area-source inventory is leveraged to estimate emissions associated with some activities at produced water disposal sites (Pring et al. 2010). ${ }^{27}$

Emissions from all sources within a fuel cycle phase are summed and then divided by the energy content of gas produced in that year to estimate an emissions factor in terms of mass of GHG emissions per unit of energy content of gas. Gas production statistics come from the Texas Railroad Commission for the 22-county play (TRRC 2012). Each GHG is weighted by its Intergovernmental Panel on Climate Change (IPCC) 100-year global warming potential according to standard procedure to normalize to units of $\mathrm{CO}_{2} \mathrm{e}$ (Forster et al. 2007). ${ }^{28}$ However, these emission factors cover only a portion of the natural gas fuel cycle, which itself is a subset of the life cycle of electricity generation from natural gas (Figure 6). Therefore, although the inventory data provide an important addition to the relatively sparse information about GHG emissions from shale gas development, literature sources are relied on for data on other emissions sources and life cycle stages - including sources such as completions, workovers, and liquids unloading - where there is considerable controversy currently about activity factors, emission reduction measures, and the magnitude of emissions.

Additional fuel-cycle stages include pre-production and transmission. Pre-production consists of one-time or episodic activities related to the preparation of wells, including the drilling and construction of well pads and wells, hydraulic fracturing to stimulate production, and wellcompletion activities. Emissions factors for these one-time activities, gathered from open literature (Santoro et al. 2011; EPA 2011; EPA 2012b; Skone et al. 2011), must be amortized over the lifetime production (EUR) of a well. Transmission, also estimated from literature data (Skone et al. 2011), involves the transport of processed gas to the power plant. ${ }^{29}$

This study combines fuel cycle emission factors into a full LCA by assuming a standard efficiency of conversion to electricity and adjusting for natural gas losses throughout the fuel cycle due to both leakage to the atmosphere and the use of production gas as fuel. This study

\footnotetext{
${ }^{25}$ Sources contained within the TCEQ inventories that are considered outside of the system boundary collectively represent $60 \%$ of total reported VOC emissions but a much smaller fraction of GHG emissions.

${ }^{26}$ Processing can occur either at wellheads or at separate processing facilities.

${ }^{27}$ Emissions from produced water tanks at produced water disposal sites are tracked by TCEQ; transport of the produced water to the disposal site and operation of engines at these sites are not considered in this analysis.

${ }^{28}$ Global warming potentials (GWP) are also reported by the IPCC for a 20 year horizon and 500 year. The 100 -year GWP is used in this study to ensure consistency with the standard practice in LCA and GHG emission inventories. Results based on alternative GWPs or other metrics of climate impact could be developed based on the results reported here.

${ }^{29}$ Following Skone et al. (2011), we consider the final step of processing as initial compression to pipeline pressure.
} 
assumes combustion in a modern natural gas combined-cycle facility with thermal conversion efficiency of 51\% (higher heating value) to make the results comparable to the meta-analysis of electricity generated from combustion of conventionally produced natural gas (O'Donoughue et al. 2012). Many natural gas-fired power plants do not operate at this efficiency, and the results reported here can be easily adjusted to apply to alternative conditions. GHG emissions from power plant construction and decommissioning are also considered, amortized over the lifetime generation from the facility (O'Donoughue et al. 2012). Data on emissions from combustion at power plant, power-plant construction, and power-plant decommissioning come from open literature (Skone et al. 2011; Skone and James 2010).

The final estimate of life cycle GHG emissions is calculated as the sum of the estimated emissions from each life cycle stage, adjusted by the thermal efficiency and relevant production losses, as appropriate for each stage and detailed in the appendix. These full life cycle emissions are expressed in units of mass $\mathrm{CO}_{2} \mathrm{e}$ per kilowatt-hour generated.

\subsection{Results}

In this section, we present and discuss key findings. Because of their relevance to the current debate about GHG emissions from natural gas, the full LCA results are presented first, followed by a comparison of these results to other published estimates. Then, the primary research contribution of this chapter is detailed: a high-resolution inventory analysis of the production and processing stages of the natural gas fuel cycle for Barnett Shale gas produced in 2009. Appendix B provides further results, including county-level analysis of production gas composition, allocation of emissions to co-products, and details supporting the presented results.

\subsubsection{Life Cycle Emissions}

GHG emissions from the natural gas fuel cycle are a focus in the public sphere and of the novel analysis of this study. However, the functional unit of the fuel cycle - a unit of energy content of processed natural gas delivered to the end user-is not easily comparable to that for other fuels for end-uses other than direct heating. Use of natural gas in the electric sector is the focus of this report and is the market for about 30\% of natural gas production in 2011 (EIA 2012). Some have argued that future production of unconventional natural gas will only displace dwindling production of conventional natural gas (e.g., Howarth et al. 2012). However, others believe that natural gas could displace existing and new coal as fuel for electricity generation (e.g., Venkatesh et al. 2011; Hultman et al. 2011). Comparisons of the results to both alternatives are provided in the next section.

First, it is critical to emphasize the importance of GHG emissions from combustion at the power plant in the life cycle of natural gas electricity generation. The GHG emissions from combustion are primarily determined by the carbon content of the fuel and the efficiency of converting fuel (chemical) energy to electrical energy. Regardless of whether natural gas comes from conventional or unconventional sources, its chemical and thermal properties once processed are indistinguishable. With regard to carbon content of the fuel, coal has about $75 \%$ more carbon per unit fuel energy than gas. Regarding efficiency, when considering new power plants, most new natural gas generation assets will likely be natural gas combined-cycle, which has a characteristic higher heating value efficiency of 51\% (O'Donoughue et al. 2012). This efficiency, chosen to maintain consistency with other studies for comparison purposes, does not reflect the existing 
fleet of natural gas plants, but rather, it is characteristic of a modern, state-of-the-art facility. The existing fleet of coal power plants has an efficiency of close to 34\% (Hultman et al. 2011), whereas new plants of either supercritical or integrated gasification combined-cycle designs will reach near 40\% (MIT 2007). The efficiency improvement for natural gas combined-cycle plants over old or new coal plants is substantial, especially considering the inherent difference in carbon content of the two fuels (absent any coal decarbonization).

Assuming 51\% efficiency for natural gas combined-cycle and $50 \mathrm{~g} \mathrm{CO}_{2} / \mathrm{MJ}$ carbon intensity of natural gas yields an estimate of nearly $360 \mathrm{~g} \mathrm{CO}_{2} / \mathrm{kWh}$ from combustion at the power plant. Other stages in the life cycle of the power plant (e.g., construction and decommissioning) add very little $\left(\sim 1 \mathrm{~g} \mathrm{CO}_{2} \mathrm{e} / \mathrm{kWh}\right)$ to life cycle $\mathrm{GHG}$ emissions of electricity generation for fossil-fuel facilities because those emissions are amortized over lifetime generation.

Including the 2009 Barnett Shale fuel cycle emissions compiled in this study, total life cycle GHG emissions from natural gas combined-cycle electricity are estimated to be about $440 \mathrm{~g}$ $\mathrm{CO}_{2} \mathrm{e} / \mathrm{kWh}$ (Figure 8). Of this total, about $18 \%$ of life cycle $\mathrm{GHG}$ emissions (or $78 \mathrm{~g} \mathrm{CO}_{2} \mathrm{e} / \mathrm{kWh}$ ) are embodied in the fuel cycle of Barnett Shale gas, as defined in Figure 7. These fuel cycle emissions from unconventional gas are comparable to those estimated from the fuel cycle of conventional gas, which O'Donoughue et al. (2012) find have a median estimate of about $480 \mathrm{~g}$ $\mathrm{CO}_{2} \mathrm{e} / \mathrm{kWh}$ in the existing literature after methodological harmonization. (See the next section for further discussion and comparisons.) About $10 \%$ (or $42 \mathrm{~g} \mathrm{CO}_{2} \mathrm{e} / \mathrm{kWh}$ ) of life cycle emissions result from emissions of methane, mostly through venting during completion and workover and from the natural gas transmission pipeline network. These results are calculated assuming a basecase EUR of 1.42 bcf produced over the lifetime of a well, which is the play-average EUR used by the U.S. Energy Information Administration in their National Energy Modeling Systems (NEMS) model (INTEK 2011).

The results are fairly sensitive to alternative estimates of Barnett Shale well EUR, which other studies have found to be one of the most influential parameters on life cycle GHG emissions (Burnham et al. 2012; Stephenson et al. 2011; Skone et al. 2011; Jiang et al. 2011). Adjusting all one-time and episodic emissions by lower- and upper-bound estimates of well-level EUR (INTEK, 2011) yields estimates of life cycle GHG emissions that vary by nearly $100 \mathrm{~g}$ $\mathrm{CO}_{2} \mathrm{e} / \mathrm{kWh}$. Figure 8 displays the use of reported lower- and upper-bounds of well-level EUR for the Barnett Shale play (INTEK 2011) of 0.45 and 4.26 bcf/well, respectively. Life cycle GHG emissions then range between about 420 and $510 \mathrm{~g} \mathrm{CO}_{2} \mathrm{e} / \mathrm{kWh}$ owing to the tested variability in assumed EUR. 


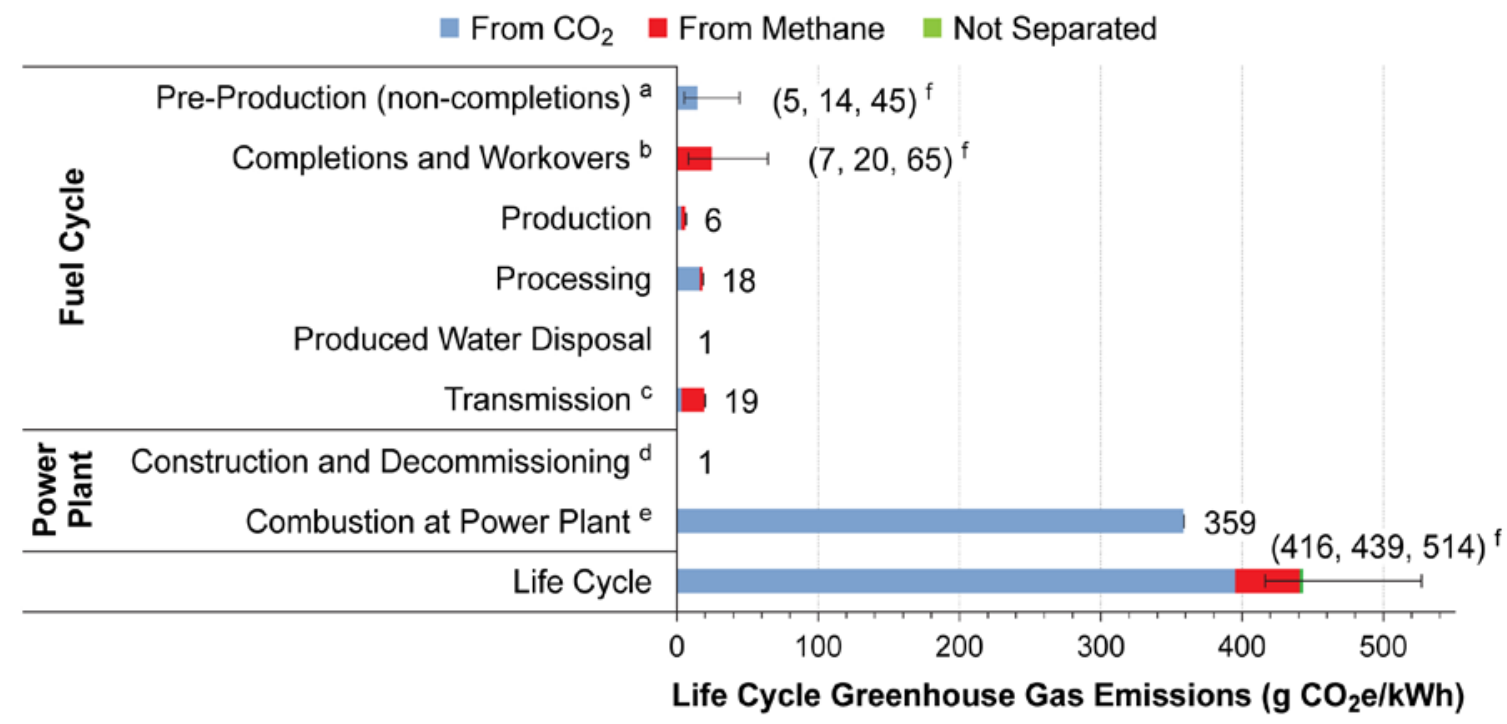

${ }^{\text {a }}$ Although lower estimates for this stage have been published, reported emissions increase as the comprehensiveness of processes considered increase. So we use the highest published estimate for this stage that provided results in a form that could be adjusted by EUR (Santoro et al. 2011).

${ }^{\mathrm{b}}$ Based on EPA (2011) estimate of 9,175 Mcf natural gas emission/completion, $1 \%$ of wells/year workover rate (EPA 2012b), 30-year assumed lifetime (Skone et al. 2011), and 22-county, Barnett Shale average natural gas molecular weight of $20.1 \mathrm{lb} / \mathrm{lb}-\mathrm{mol}$ and methane mass fraction of $66.2 \%$.

${ }^{c}$ Based on Skone et al. (2011)

a Based on Skone and James (2010)

e Based on Skone et al. (2011)

${ }^{\dagger}$ Multiple estimates, in parentheses, pertain to high EUR, base-case EUR, and low EUR, respectively. Single estimates pertain to stages without sensitivity to EUR. The error bar is plus or minus the total bar length (life cycle GHG emissions).

Figure 8. Combustion at the power plant contributes the majority of GHG emissions from the life cycle of electricity generated from Barnett Shale gas

\subsubsection{Comparisons to Other Studies}

There are three important points of comparison for the life cycle GHG emission results presented here:

1. Previous estimates for electricity generated from shale or other unconventional gas

2. Previous estimates for electricity generated from conventional gas

3. Previous estimates for electricity generated from coal.

Direct comparison of the results of LCAs is hindered by the sensitivity of results to alternative assumptions of key parameters and other methodological considerations. Harmonization, which is a meta-analytical approach to enable more direct comparison, has been demonstrated for a wide range of electricity generation technologies (e.g., Burkhardt et al. 2012; Warner and Heath 2012). For coal-fired electricity generation, Whitaker et al. (2012) harmonized 164 estimates from 53 LCAs on four coal generation technologies (i.e., subcritical, supercritical, integrated gasification combined cycle, and fluidized bed). More recently, this approach has been applied to the LCA literature on natural gas-fired electricity generation, where estimates from 42 LCAs on 
conventionally produced natural gas (O'Donoughue et al. 2012) and 6 shale gas LCAs (Heath et al. 2012) have been harmonized. Results from these studies are used for comparing results of this report to those in the literature because they ensure fair and consistent comparisons and enable insight useful for broad decision-making. ${ }^{30}$ It is important to note that the results of this study were developed using the same key assumptions and system boundaries as in the harmonization of the literature estimates for conventional and shale gas - and, more broadly, with those for coal.

Figure 9 displays the results of this chapter's analysis (base case and EUR sensitivity) — which estimates life cycle GHG emissions from Barnett Shale gas produced in 2009 and combusted to generate electricity in a modern natural gas combined-cycle turbine - compared to other estimates, which are based on a systematic review and harmonization of existing literature. Compared to other estimates for shale gas electricity generation, the base case results of this methodologically independent assessment are near the $25^{\text {th }}$ percentile of harmonized estimates, which is similar for the comparison to harmonized conventional natural gas estimates. High and low EUR scenarios are also within the range of previous estimates for shale and conventional gas life cycle GHG emissions. The results are also found to be considerably lower than those for coal—nearly half of the median estimate of $980 \mathrm{~g} \mathrm{CO}_{2} \mathrm{e} / \mathrm{kWh}$ (Whitaker et al. 2012), even under low EUR conditions.

\footnotetext{
${ }^{30}$ Estimates of life cycle GHG emissions for specific facilities can legitimately differ from those produced through harmonization. See Heath and Mann (2012) and other harmonization articles in the Special Issue on Meta-Analysis of LCA in the Journal of Industrial Ecology (http://jie.yale.edu/LCA-meta-analysis) for further discussion.
} 


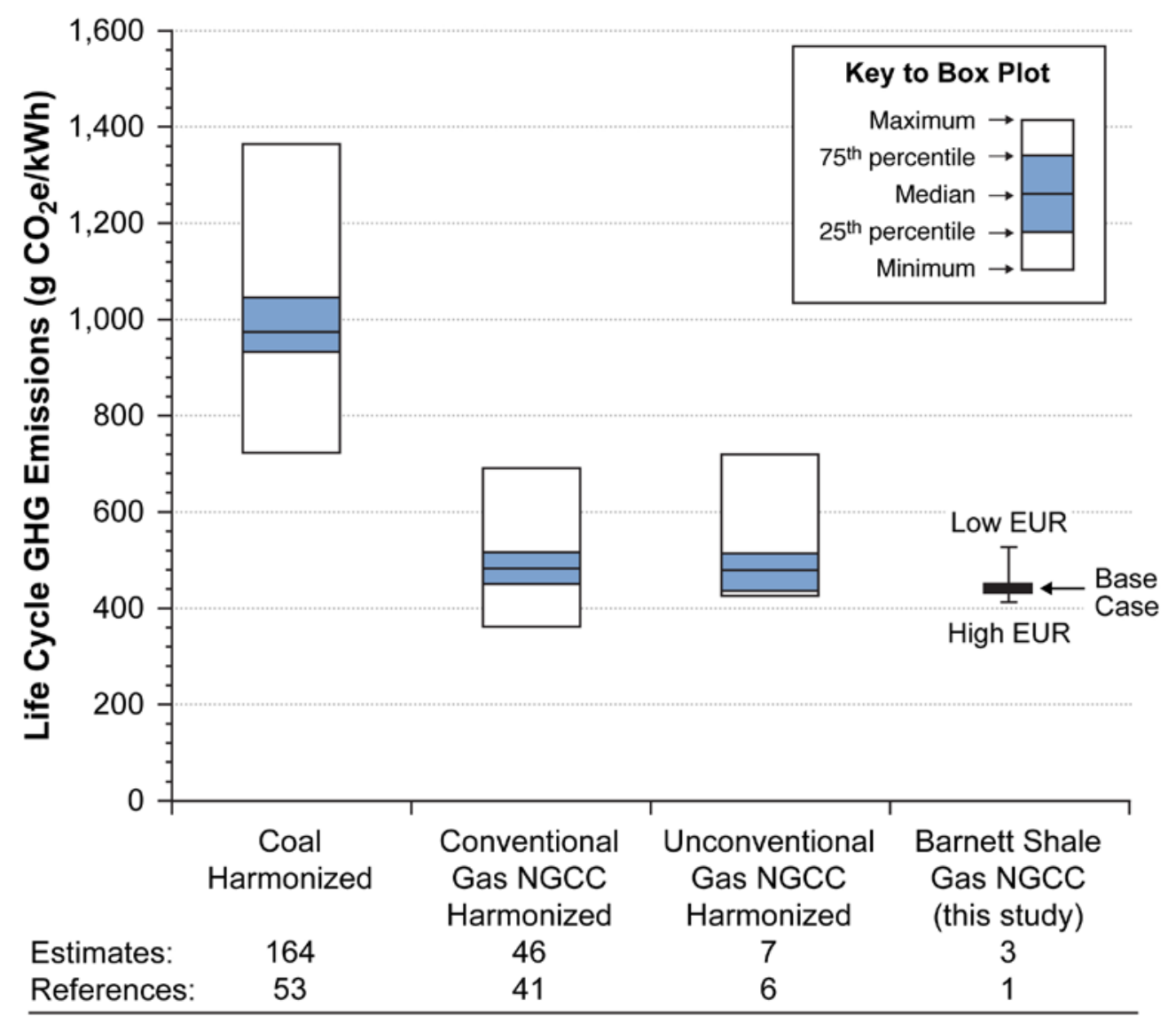

Figure 9. Estimate of life cycle GHG emissions from 2009 Barnett Shale gas combusted to generate electricity in a modern natural gas combined-cycle (NGCC) turbine compared to previously published estimates for unconventional (mostly shale) gas, conventional natural gas, and coal after methodological harmonization. ${ }^{31}$

Notes: EUR = estimated ultimate recovery, or lifetime production; NGCC = natural gas combined-cycle turbine

The rest of this section briefly reviews the key differences that could explain the relationship between the results from this study and those from other shale gas LCA literature. More detailed discussion of each of the existing shale gas life cycle GHG emission estimates can be found in Heath et al. (2012). Differentiating factors that tend to reduce estimates of life cycle GHG emissions for our study compared to some others include: equitably sharing the burdens of natural gas production with valuable co-products; not considering nitrous oxide emissions throughout the life cycle or non- $\mathrm{CO}_{2}$ emissions from power-plant combustion; not considering embodied GHG emissions of purchased fuels; and not considering transport of produced water to disposal wells. None of the following factors are considered significant points of

\footnotetext{
${ }^{31}$ See O'Donoughue et al. (2012), Heath et al. (2012) and Whitaker et al (2012) for further description of the review and harmonization of estimates of life cycle GHG emissions from electricity generated from conventional natural gas, unconventional (mostly shale) gas and coal, respectively. The studies reviewed and harmonized in Heath et al. (2012) for unconventional (mostly shale) gas are: Howarth et al. (2011); Burnham et al. (2012); Jiang et al. (2011); Skone et al. (2011); Stephenson et al. (2011); Hultman et al. (2011).
} 
underestimation: negligible impacts found in previous analyses, ${ }^{32}$ contributions only to the fuel cycle (which represents $18 \%$ of total life cycle emissions), and negligible quantities of relevant sources. ${ }^{33}$ Differentiating factors that tend to increase life cycle GHG emission estimates for particular literature estimates compared to ours include: higher natural gas leakage estimates (Howarth et al. 2011; Burnham et al. 2012; Skone et al. 2011; Hultman et al. 2011; Jiang et al. 2011); higher estimate of methane content of produced gas (Jiang et al. 2011; Burnham et al. 2012; Skone et al. 2011; Hultman et al. 2011); and inclusion of natural gas distribution for transport of gas to the power plant ${ }^{34}$ (Jiang et al. 2011; Howarth et al. 2011; Hultman et al. 2011). On the other hand, EURs considered in this chapter are considerably lower than for other studies. This is especially true for the sensitivity analyses conducted by this and other studies, where the low-bound case for all other studies is at least twice the lower-bound estimate reported by EIA for the Barnett Shale play (INTEK 2011). ${ }^{35}$

A key distinguishing feature of the practices typically assumed for conventional as compared to unconventional wells is liquids unloading (i.e., periodic removal of liquids and other debris from a well). EPA has found that this practice occurs frequently-31 times per year on average (EPA 2011) - every year in the life of a well. And emissions from this practice, even when amortized over lifetime production of a well as in LCAs, are significant (e.g., Burnham et al. 2012). A recent survey of 91,000 wells by two industry associations suggests that at least for this sample, emissions from liquids unloading are nearly 80\% lower than EPA's estimate (Shires and Lev-On 2012). Not only is the magnitude of emissions from liquids unloading controversial, but the same industry survey suggests that liquids unloading is also practiced on unconventional wells, reversing previous assumptions (Shires and Lev-On 2012). If liquids unloading were practiced on Barnett Shale wells, ${ }^{36}$ then life cycle GHG emissions under average-EUR conditions would increase between 6 and $28 \mathrm{~g} \mathrm{CO}_{2} \mathrm{e} / \mathrm{kWh}$ depending on the emission rate assumed ${ }^{37}$ and potentially as high as $100 \mathrm{~g} \mathrm{CO}_{2} \mathrm{e} / \mathrm{kWh}$ under low EUR conditions.

\subsubsection{Fuel Cycle Methane Losses}

Throughout each stage of the fuel cycle, a portion of the produced gas is used or lost: gas is used as a fuel for combustion activities, and it is lost when it leaks to the atmosphere either through potentially controllable leakage or fugitive emissions. As a potent $\mathrm{GHG}$, methane emitted to the atmosphere is especially important to understand.

\footnotetext{
${ }^{32}$ For example, Skone et al. (2011) find that nitrous oxide contributes $0.04 \%$ to the total life-cycle GHG emissions for a natural gas combined-cycle plant. They also found that nitrous oxide and methane contribute $0.001 \%$ and $0.004 \%$, respectively, to the GHG emissions from the energy-conversion facility (which primarily consist of fuel combustion emissions) for a natural gas combined-cycle plant.

${ }^{33}$ Fewer than ten engines in the inventory are identified as using purchased fuels (i.e., gasoline or diesel).

${ }^{34}$ To approximate an upper bound for such an omission, consider that even doubling the estimated emissions from transmission adds only $19 \mathrm{~g} \mathrm{CO}_{2} \mathrm{e} / \mathrm{kWh}$, or about $4 \%$, to the total life-cycle $\mathrm{GHG}$ emissions.

${ }^{35}$ Base-case EURs were 3, 3.5, 3, 2.7, and 2 bcf for Howarth et al. (2011) (average of estimates reported in Table 1), Burnham et al. (2012), Skone et al. (2011), Jiang et al. (2011) and Stephenson et al. (2011), respectively. Lower bounds tested were 1.6, 2.1, 2.7, and 1 bcf for Burnham et al. (2012), Skone et al. (2011), Jiang et al. (2011), and Stephenson et al. (2011), respectively.

${ }^{36}$ Assuming 30-year well lifetime (Skone et al. 2011), 1.42 bcf EUR (INTEK, 2011), and 12\% emission reductions (Burnham et al. 2012).

${ }^{37}$ The low estimate assumes an emission rate according to Shires and Lev-On (2012), whereas the high estimate assumes an emission rate according to EPA (2011).
} 
This section reports two related metrics, each important for different purposes. The first metric we refer to as natural gas losses, which signifies the percentage of produced natural gas either lost or consumed along the fuel cycle, expressed in units of volume natural gas lost per volume natural gas produced. ${ }^{38}$ The second metric we refer to as methane leakage, which signifies the volume of methane released to the atmosphere in relation to the amount of gas produced, expressed in units of volume methane emitted per volume natural gas produced. A leakage rate reported in these units enables rapid estimation of methane emissions based on a known amount of produced natural gas.

Based on the analysis of TCEQ inventories for natural gas production and processing emissions, as well as published estimates for other fuel cycle phases, this study estimates that $1.5 \%$ of produced gas is emitted to the atmosphere before reaching the power plant (see Table 1). Much of this is potentially preventable, with an additional $5.6 \%$ of produced gas consumed along the process chain as fuel for different types of engines. Based on the estimated methane content of this produced gas, this equates to a leakage rate across the fuel cycle of $1.3 \%$ methane volume per volume of natural gas processed, based on the assumed play-average EUR of $1.42 \mathrm{bcf} /$ well. Because of the contribution of one-time emissions to these results, they are sensitive to EUR; low EUR corresponds to an estimated 2.8\% methane leakage rate and the loss of $8.9 \%$ of produced gas across the fuel cycle, whereas high EUR corresponds to an estimated $0.8 \%$ leakage and $6.5 \%$ losses.

Table 1. Loss of Produced Gas along the Fuel Cycle

\begin{tabular}{|c|c|c|c|c|c|}
\hline & $\begin{array}{c}\text { Completions } \\
\text { and Workovers }^{\mathrm{b}}\end{array}$ & Production & Processing & Transmission $^{c}$ & Total \\
\hline Extracted from Ground & $100.0 \%$ & & & & $100.0 \%$ \\
\hline Fugitive Losses & - & $0.1 \%$ & $0.0 \%$ & $0.5 \%$ & $0.6 \%$ \\
\hline $\begin{array}{l}\text { Potentially Controllable } \\
\text { Leakage }\end{array}$ & $0.8 \%$ & $0.1 \%$ & $0.0 \%$ & $0.0 \%$ & $0.9 \%$ \\
\hline Combusted as Fuel & - & $0.9 \%$ & $3.9 \%$ & $0.8 \%$ & $5.6 \%$ \\
\hline Delivered to Power Plant & & & & & $92.9 \%$ \\
\hline
\end{tabular}

\subsubsection{Air Pollutant Emissions Inventory-Based GHG Emissions Estimates}

This study develops emissions factors for the production and processing stages of shale gas development based on original estimates of GHG emissions from TCEQ inventories and the Texas Railroad Commission's production statistics. These emission factors are shown in Figure using the functional unit of grams $\mathrm{CO}_{2} \mathrm{e}$ per mega-joule of natural gas (i.e., $\mathrm{g} \mathrm{CO}_{2} \mathrm{e} / \mathrm{MJ}$ ).

\footnotetext{
${ }^{38}$ Although the use of natural gas in production and transportation processes is for beneficial purpose, it nonetheless represents the loss of a potentially marketable product. For instance, increasing the efficiency of engines at pipeline booster stations would increase the amount of product delivered to the end user. From this perspective, we employ the simplified terminology of "loss" of natural gas to include its use prior to sale to an end user.
} 


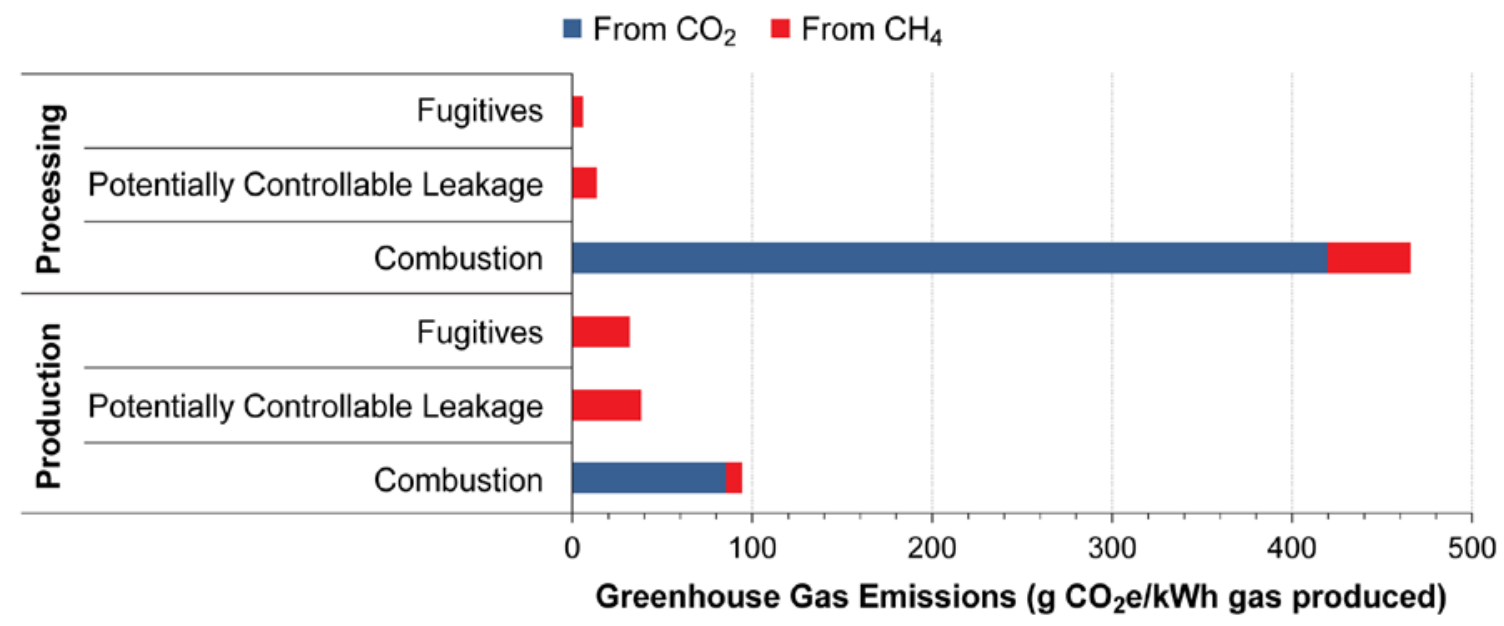

Figure 10. Inventory-based analysis of production and processing fuel cycle stages showing that the majority of GHG emissions are $\mathrm{CO}_{2}$ resulting from combustion, although the $\mathrm{CO}_{2} \mathrm{e}$ from methane emissions is significant

Most noticeably, the majority of GHG $\left(\mathrm{CO}_{2} \mathrm{e}\right)$ emissions in both of these life cycle stages comes from $\mathrm{CO}_{2}$ emissions from combustion sources. These emissions represent $53 \%$ of the total GHG emissions for the production stage and $87 \%$ for the processing stage. In the production stage, $90 \%$ of $\mathrm{CO}_{2}$ emissions come from a large number of four-cycle rich-burn engines, nearly all of which are not normally individually tracked in the point-source inventory. Of the 1,564 compressor engines contributing to $\mathrm{CO}_{2}$ emissions during natural gas production, only seven are reported to the point-source inventory, with the vast remainder of sources (and $99.9 \%$ of the $\mathrm{CO}_{2}$ emissions) being reported only in the special inventory. Although the point-source inventory is intended to cover major emissions sources, the large number of individually smaller sources that are only captured by the special inventory play an important role in the GHG emissions from natural gas production in the Barnett Shale play. In the processing stage, $49 \%$ of $\mathrm{CO}_{2}$ combustion emissions come from 405 4-cycle, lean-burn engines; 21\% from 273 4-cycle, rich burn; $20 \%$ from 552 external-combustion boilers and heaters; and the remaining $\mathrm{CO}_{2}$ emissions come from natural gas turbines, other compression engines, and equipment flares. In contrast to the production stage, $76 \%$ of these sources - representing $79 \%$ of the $\mathrm{CO}_{2}$ emissions - are covered by the point-source inventory. Direct emission of $\mathrm{CO}_{2}$ from fugitives and from processing (to achieve pipeline-quality specifications) is negligible but included for completeness.

Of the remaining GHG emissions, more methane emissions come from potentially controllable gas leakages than from fugitives. Specifically, only $41 \%$ of methane released in the production stage comes from fugitives. The $49 \%$ of methane coming from potentially controllable leakage in the production stage is dominated by emissions from pneumatic pumps and controls, which are a focus of recent EPA regulations. In the processing stage, fugitives make up an even smaller proportion (10\%) of overall methane leakage. Of the $21 \%$ of methane emissions in this life cycle stage coming from potentially controllable leakage, more than half comes from emissions from produced water tanks, and almost a third from emissions from glycol dehydrators. Despite only a small proportion of combustion emissions being methane, combustion activities still account for 
$69 \%$ of the total methane emitted in the processing stage as a result of the large numbers of engines.

\subsubsection{Sensitivity to Gas Composition Analysis}

Because it reflects a key differentiation of this study from previous analyses, this section explores the sensitivity of this study's results to assumptions about the composition of the produced gas. Specifically, this section compares the study's main results-which are based on county-specific gas composition estimates (see Appendix B)—with results based on two alternative assumptions about produced gas composition.

The first alternative calculates emissions using a play-level gas composition estimate, which reflects a production-weighted average of all county estimates with original data. The second alternative uses EPA's reported national average production gas composition (EPA 2011) as the estimated composition for all sources. The national average is used for comparison because most LCAs rely on this gas composition, even for play-specific estimates (e.g., Skone et al. 2011). Table 2 reports the difference in emission estimates for $\mathrm{CO}_{2}$, methane, and $\mathrm{CO}_{2} \mathrm{e}$ using these alternative gas composition analyses compared to this study's spatially explicit approach (main results).

Table 2. Effects of Alternative, Spatially Uniform Estimates of Gas Composition on Inventoried GHG Emissions for the Barnett Shale Play

\begin{tabular}{lccc} 
& \multicolumn{3}{c}{ Difference from Main Results } \\
\cline { 2 - 4 } & $\mathrm{CO}_{2}$ & Methane & $\mathrm{CO}_{2} \mathrm{e}$ \\
\hline \multicolumn{1}{c}{ Production and Processing Combined } \\
\hline Main Results & - & - & - \\
Barnett Shale Average & $-0.5 \%$ & $2.6 \%$ & $0.2 \%$ \\
National Average & $-3.5 \%$ & $5.7 \%$ & $-1.5 \%$ \\
\hline
\end{tabular}

The overall impact is negligible of using spatially explicit estimates versus the Barnett Shale average, which is a production-weighted average of individual estimates: the effect on the two different GHGs cancel out in terms of $\mathrm{CO}_{2} \mathrm{e}$. The impact of using national average gas composition estimates is larger, but still small. As shown by the difference in Barnett Shale average versus national average results, these impacts come not from shifting to uniform gas compositions, per se, but rather, from using gas composition estimates less reflective of the specific gas analyses obtained from locations within the Barnett Shale region.

However, estimates differ more substantially when looking at a finer scale, as shown in Table 3, which focuses on production-stage emissions estimates for the four top-producing counties in the Barnett Shale. Using Barnett Shale or national average gas composition can lead to estimates one-third lower or higher for Tarrant and Wise counties, respectively, compared to using the county-level average. This variation comes from the substantial difference in estimated gas composition across counties, also shown in the lower portion of Table 3 for the representative gas constituents of VOCs, $\mathrm{CO}_{2}$, and methane. Note that Tarrant and Wise counties both deviate substantially from the Barnett Shale average, as well as from the national average. 
Table 3. Effects of Alternative, Spatially Uniform Estimates of Gas Composition on Estimated Production Emissions at the County-Level

\begin{tabular}{|c|c|c|c|c|c|c|}
\hline & $\begin{array}{l}\text { Denton } \\
\text { County }^{\mathrm{a}}\end{array}$ & $\begin{array}{l}\text { Johnson } \\
\text { County }^{a}\end{array}$ & $\begin{array}{l}\text { Tarrant } \\
\text { County }\end{array}$ & $\begin{array}{l}\text { Wise } \\
\text { County }\end{array}$ & $\begin{array}{l}\text { 22-County } \\
\text { Total }\end{array}$ & \\
\hline $\begin{array}{l}\text { Barnett Shale average vs. main } \\
\text { results }\end{array}$ & $12 \%$ & $-5 \%$ & $-33 \%$ & $29 \%$ & $1 \%$ & \\
\hline \multirow[t]{2}{*}{ National average vs. main results } & $15 \%$ & $-11 \%$ & $-36 \%$ & $29 \%$ & $-3 \%$ & \\
\hline & $\begin{array}{l}\text { Denton } \\
\text { County }^{\mathrm{a}}\end{array}$ & $\begin{array}{l}\text { Johnson } \\
\text { County }^{\mathrm{a}}\end{array}$ & $\begin{array}{l}\text { Tarrant } \\
\text { County }^{\mathrm{a}}\end{array}$ & $\begin{array}{c}\text { Wise } \\
\text { County }^{\mathrm{a}}\end{array}$ & $\begin{array}{c}\text { Barnett } \\
\text { Shale play } \\
\text { average }^{\mathrm{b}}\end{array}$ & $\begin{array}{l}\text { National } \\
\text { average }^{\mathrm{C}}\end{array}$ \\
\hline Volatile organic compounds content $^{d}$ & $18 \%$ & $19 \%$ & $6 \%$ & $23 \%$ & $16 \%$ & $18 \%$ \\
\hline $\mathrm{CO}_{2}$ content $^{\mathrm{d}}$ & $2 \%$ & $2 \%$ & $1 \%$ & $3 \%$ & $2 \%$ & $2 \%$ \\
\hline Methane content $^{d}$ & $63 \%$ & $63 \%$ & $80 \%$ & $56 \%$ & $66 \%$ & $78 \%$ \\
\hline
\end{tabular}

These results have implications for developing more accurate GHG emission inventories at subnational levels and any regulatory system that might seek to identify high emitters within plays. Furthermore, when detailed activity data at the site or source level are developed, these data should be matched by detailed gas-composition analyses for the most accurate outcomes.

\subsubsection{Areas for Improvement in Understanding}

The estimate of life cycle GHG emissions from gas produced from Barnett Shale in 2009 reported here advances our understanding through rigorous analysis of more than 16,000 sources of emissions and accounts for the known spatial heterogeneity in gas composition within the Barnett Shale play. However, future efforts should explore the sensitivity of the estimates herein to the many contributing parameters and several other aspects because further improvement remains.

Chief among the areas for improvement are a greater number of recent measurements of emission factors and statistically representative surveys of current practices characterizing GHG emissions from the natural gas industry. For instance, there is a critical lack of measurements of emissions for completion and re-completion (workover) activities that account for different physical and operational conditions based on use of reduced-emission completion equipment, variations in gas flow during flowback and initial production, and mud degassing (EPA 2011; Shires and Lev-On 2012; CERA 2011; Burnham et al. 2012). Likewise, better and more recent measurements of fugitive emissions from well and processing equipment, as well as pipelines at all stages - gathering, transmission, and distribution lines - are warranted because the existing data are sparse and old. The prevalence of emission-reduction practices (e.g., flaring) during completion, workover, and other activities is another area of considerable lack of empirical information and variability in current assumptions (Heath et al. 2012) that would improve understanding of life cycle GHG emissions.

Furthermore, if other well-specific information - such as annual and lifetime gas, condensate, oil, and produced water production, and lifetime workovers - were available and could be 
matched to the TCEQ emissions inventories, then fuel cycle and life cycle GHG emissions could be estimated at the well level. These results could allow for consideration of well-level variability, with implications for the design of efficient strategies to control emissions. In particular, given the substantial sensitivity of results to EUR (total life cycle GHG emissions differ from base results by $-5 \%$ or $+17 \%$ for upper and lower EUR estimates, respectively), better well-specific information on EUR will improve the precision of emissions estimates. However, EUR is neither geographically nor temporally constant; rather, it relates both to physical characteristics of natural gas deposits and to the (constantly evolving) technical and economic feasibility of recovery of that natural gas. An improved and sophisticated understanding of EUR is therefore necessary. Finally, production activity is often planned for a field based on a set of wells; when initial wells decline in production, they could be restimulated and other wells could be drilled within the same area (through new laterals or new surface sites). Considerable knowledge of these dynamics is currently lacking. Yet, it is important to understanding GHG emissions in the context of deployment strategies used by many large players.

We have assembled the largest publicly available database of gas composition analyses for a shale gas play, and the counties with highest production correspond to those with the greatest number of analyses. However, given the sensitivity of the study's county-level results to the gas composition, it appears to be warranted to devote further effort toward improving the availability of production gas composition analyses specific to a region of interest. A random-sampling campaign conducted by a third party would be an ideal match for the methods used in this chapter if they are deemed useful for future analyses. A nearer-term objective could be to simply increase the pool of gas analyses from any entity willing to make such data available. Results of such further investigation could have implications for developing more accurate GHG emission inventories at sub-national levels and any regulatory system that might seek to identify high emitters within plays.

Further investigation of emissions from liquids unloading from unconventional wells is also warranted given the potentially significant GHG emissions from this activity, as described above. An emissions sampling strategy that accounts for variability across geography, gas type, well type, operator size, and operational practices, among other factors, should lead to an improved understanding of the potential for GHG emissions from liquids unloading for conventional and unconventional wells. Additional activity data regarding frequency of unloading and how this might change over the lifetime of a well, proportion of wells requiring unloading, and prevalence and effectiveness of emission-reduction activities are necessary to develop a more complete understanding of the emissions from this practice. Finally, because emissions from this episodic activity are amortized over lifetime production for use in LCAs, more certainty in the estimate of EUR would improve the accuracy of life cycle emission estimates.

Practices in the natural gas industry change over time, as do resource characteristics. Estimates of GHG emissions should be periodically repeated to reflect those changing practices and characteristics, using the most up-to-date and accurate data on emissions, emission-reduction practices, resource characteristics and activities available. Estimates could also be developed for future conditions based on expected changes in practices due to, for instance, full implementation of promulgated regulations. Such estimates could be compared to goals for GHG 
emission reduction to highlight whether additional emission reductions are necessary to reach those goals.

Analogously, industry practices and resource characteristics vary by location owing to differences in, for instance, geology, hydrology and state regulations. Estimates of GHG emissions should be developed in other locations using as much geographically specific data and information as possible. Furthermore, GHG emissions will also differ by gas type-not only by broad categories such as conventional and unconventional, but also, by different types of each, e.g., shale, tight, and coal-bed methane for unconventional, and associated, onshore, and offshore for conventional. GHG emissions for each of these types should be characterized so that a more accurate understanding of drivers of variability (if any) by type can inform discussions of opportunities to reduce emissions.

Finally, the bottom-up, engineering-based inventory of emissions should be confirmed through top-down atmospheric measurements. Literature suggests that emissions are typically underestimated through bottom-up approaches compared to concentrations of those same pollutants in the atmosphere (e.g., Townsend-Small et al. 2012; Petron et al. 2012). This effect likely results not only from issues such as non-reported sources, but also from inaccuracies that inherently arise from the use of non-specific methods that depend on average or ideal conditions. Although source attribution is still challenging and these measurements are expensive, they provide a much-needed confirmation of when inventories are accurate and when updates and improvements are necessary to support sound decision-making.

\subsection{Conclusions}

The aim of this research is to advance the state of knowledge of life cycle GHG emissions from electricity generated from shale gas extracted from a specific play-the Barnett Shale play in north Texas - using data sources independent of those used in previous LCAs of natural gas. We leveraged inventories of regulated air pollutants collected and screened by the Texas Commission on Environmental Quality for a 2009 special inventory of the Barnett Shale gas production, processing, and transportation sectors and their regular point- and area-source inventories in the 22-county Barnett Shale area. We used data supplied by the industry to TCEQ regarding the emissions and characteristics of more than 16,000 individual sources. The TCEQ inventories are used to estimate VOC emissions, a precursor of ozone. VOC emission estimates were translated to methane and $\mathrm{CO}_{2}$ emissions by using gas composition analyses that report proportions by mass of each constituent. This study compiled a large dataset of such gas composition analyses at the county level, enabling a quantitative accounting of the significant variability that exists within the play of methane, $\mathrm{CO}_{2}$, and other compounds.

Based on the analysis of TCEQ inventories and the addition of missing life cycle stages not included in those inventories, this study estimates that electricity generated using a modern natural gas combined-cycle turbine combusting Barnett Shale gas produced and processed in 2009 is associated with about $440 \mathrm{~g} \mathrm{CO}_{2} \mathrm{e} / \mathrm{kWh}$ generated, with a sensitivity range based on published high and low EURs of 420 to $510 \mathrm{~g} \mathrm{CO}_{2} \mathrm{e} / \mathrm{kWh}$. Thus, the life cycle GHG emission result is sensitive to the lifetime production of wells, where additional research would be helpful to more precisely estimate life cycle GHG emissions. Regardless of this uncertainty, however, this chapter's main conclusion is that life cycle GHG emissions from electricity produced from Barnett Shale natural gas lie within the range of previously published estimates for GHG 
emissions (after methodological harmonization) from electricity produced by either conventional or unconventional natural gas (O’Donoughue et al. 2012; Heath et al. 2012). Furthermore, this report's estimate of life cycle GHG emissions is less than half of the median of published estimates for coal-fired electricity generation (after methodological harmonization) (Whitaker et al. 2012). It should be noted that the estimate of life cycle GHG emissions developed here is not strictly applicable to other locations or years, and that several important aspects of uncertainty in the methods of this research should be improved through additional research. However, the broad agreement between the estimate developed here and those published independently for both unconventional and conventional gas increases confidence in our understanding of life cycle GHG emissions of natural gas used for electricity generation.

This study found that about $19 \%$ of base case life cycle GHG emissions results from the fuel cycle of Barnett Shale gas (pre-production through transmission). About $10 \%$ of base case life cycle GHG emissions are methane, mostly vented during completion and workover and released from the natural gas transmission pipeline network. Only $11 \%$ of life cycle GHG emissions depend on characteristics of shale gas (e.g., extraction techniques, composition); the vast majority of life cycle emissions are not affected by the type or origin of the gas because they occur after processing that has the function of creating a homogenous product.

With regard to the fuel cycle GHG emissions, which were the focus of the analytical effort of this chapter, the vast majority comes from $\mathrm{CO}_{2}-80 \%$ or more of which is emitted from combustion sources (mostly engines and turbines) in the production and processing stages. The majority of emissions coming from natural gas production activities is from sources not routinely tracked individually (because they do not meet regulatory thresholds) in a classic example of how important the more numerous small sources can be to total emissions and how challenging quantifying and reducing emissions from the natural gas industry will be for regulators. Only through special inventories, such as the one conducted in 2009 for the Barnett Shale area, is it possible to have the kinds of detailed information necessary to estimate source-specific emissions for the vast majority of production sources within this industry. By contrast, processing sources are typically larger, meeting the threshold for annual emissions reporting under the regular point-source inventory.

We find that methane leakage, though playing a smaller role in life cycle GHG emissions from this analysis of 2009 Barnett Shale gas as compared to others, comes mostly from what we have classified as potentially controllable sources, rather than from fugitives - with implications for the potential for GHG emission reductions in the natural gas industry. In gas production, $40 \%$ of methane released comes from fugitive sources; methane emitted from potentially controllable leakage in the production stage comes mostly from pneumatic pumps and controls, which are specifically addressed in recent EPA regulations. In the processing stage, fugitives make up an even smaller proportion (10\%) of overall methane emissions. As for potentially controllable leakage in processing, half comes from emissions from produced water tanks and a third from glycol dehydrators.

Our method represents an improvement in accuracy by accounting for spatial differences in gas composition as compared to previous LCAs. For instance, methane content of raw gas from the top four producing counties ranges from $56 \%$ to $80 \%$, with implications for how much methane is released in venting or fugitive emissions. Previous research has either used play-level average 
gas composition (e.g., Jiang et al. [2011] for the Marcellus) or the national average. For Barnett Shale total emissions, the difference in results between using county-level gas composition compared to a play-wide average composition is relatively small; however, the improvement is more significant compared to using national average composition.

The overall results for the Barnett Shale play are only marginally sensitive to the variability in gas composition across the play because of offsetting differences. But the variability observed in gas composition has implications for accurate estimation of GHG emissions at finer spatial resolution, monitoring programs, and regulatory strategies. This study found differences in GHG emission estimates at the county level compared to estimates using national average figures; furthermore, inventories of the level of detail of the special inventory provide an important piece of the overall story of emissions. Therefore, accurate usage of such detailed information needs to be matched by more detailed input information, notably gas composition analyses. The database assembled for this study is a first step toward developing more robust databases in the Barnett and other natural gas basins around the country.

Improvements can be made to the estimate produced here of life cycle GHG emissions for 2009 Barnett Shale gas used in a modern combined cycle electricity generator. But this study's methodologically independent estimate confirms previous research on shale gas electricity generation. In addition, it is similar to previous estimates for generation using conventionally produced natural gas, and it is less than half of that estimated in other studies for coal. Liquids unloading, which is typically assumed to occur only for conventional wells, accounts for most of the difference between this study's estimate and that developed based on meta-analysis and updating of more than 40 references reporting life cycle GHG emissions for electricity generated from conventionally produced natural gas. However, evidence has emerged suggesting that liquids unloading is also a practice applicable to unconventional wells. If confirmed for Barnett Shale wells in particular, then it means that the estimate reported here should be updated accordingly. The high carbon content and significantly lower thermal efficiencies of coal-fired power plants account for their substantially higher life cycle GHG emissions. 


\section{Regulatory Framework Governing Unconventional Gas Development}

\subsection{Introduction}

Rapid development of unconventional natural gas in the United States in recent years has raised a number of important environmental concerns, including ground and surface water contamination; disposal practices for frac flowback, produced water, and other associated drilling wastes; impacts on local and regional air quality; methane leakage and venting rates; and increased traffic, noise, and other community impacts. It is clear that regulations have increased at virtually all levels of governance in response to the unconventional gas boom. Various commissions, advocacy groups, and research organizations have weighed in on the pros and cons of additional regulation, including two reports issued by the Secretary of Energy Advisory Board Shale Gas Production Subcommittee ("SEAB Subcommittee"). ${ }^{39}$ But questions persist regarding the sufficiency of these regulations across differing jurisdictions and the adequacy of compliance monitoring and enforcement in the face of rapid growth.

Because of the "distributed" nature of unconventional gas development and the substantial increase in wells in key basins, ${ }^{40}$ local land-use conflicts have erupted in certain areas of the country that have led to restrictions and moratoria on drilling by state, county, and municipal governments, raising questions about the industry's continued social license to operate in specific jurisdictions ${ }^{41}$ (Dryden 2012; Middlefield 2012). In response, some states - notably Pennsylvania - have recently enacted legislation to restrict the ability of local governments to

\footnotetext{
${ }^{39}$ See e.g., U.S. DOE, Secretary of Energy Advisory Board Shale Gas Production Subcommittee, Ninety-Day Report, (Aug. 11, 2011) and Second Ninety-Day Report (Nov. 18, 2011), http://www.shalegas.energy.gov/resources/081111_90_day_report.pdf; National Petroleum Council, Prudent Development Realizing the Potential of North America's Abundant Natural Gas and Oil Resources (2011), http://www.npc.org/NARD-ExecSummVol.pdf; Cardi Reports, The Economic Consequences of Marcellus Shale Gas Extraction: Key Issues, prepared on behalf of Cornell University (Sept. 2011), http://www.greenchoices.cornell.edu/downloads/development/marcellus/Marcellus CaRDI.pdf; Thomas Kurth, et al., "American Law and Jurisprudence on Fracing," Haynes and Boone, LLP (2010), http://www.haynesboone.com/files/Publication/3477accb-8147-4dfc-b0b4380441178123/Presentation/PublicationAttachment/195a3398-5f02-4905-b76d3858a6959343/American_Law Jurisprudence Fracing.pdf ; Bipartisan Policy Center, Energy Project, Shale Gas: New Opportunities, New Challenges (Jan. 2012), http://www.scribd.com/doc/95194795/Shale-Gas-NewOpportunities-New-Challenges; Charles G. Groat and Thomas W. Grimshaw, Fact-Based Regulation for Environmental Protection in Shale Gas, report prepared for the Energy Institute, University of Texas at Austin (Feb. 2012), http://energy.utexas.edu/images/ei shale_gas_regulation120215.pdf; Rebecca Hammer, et al, In Fracking's Wake: New Rules are Needed to Protect $\bar{O}$ ur Health and Environment from Contaminated Wastewater, Natural Resources Defense Council (May 2012) http://www.nrdc.org/energy/files/Fracking-Wastewater-FullReport.pdf; International Energy Agency, Golden Rules for a Golden Age of Gas, 9-10 (May 29, 2012), http:/www.worldenergyoutlook.org/media/weowebsite/2012/goldenrules/WEO2012_GoldenRulesReport.pdf (discussing the importance of public acceptance for continued expansion of unconventional gas development in the U.S. and abroad).

${ }^{40}$ For a graphic depiction of the rapid increase in shale gas wells in Pennsylvania, see U.S. Energy Information Administration, "Horizontal drilling boosts Pennsylvania's natural gas production," available at http://www.eia.gov/todayinenergy/detail.cfm?id=6390.

${ }^{41}$ Some national governments, including France and Bulgaria, have also banned hydraulic fracturing (BBC News 2012). For a list of current moratoria and bans, see Sierra Club, FRAC Tracker, http://www.sierraclub.org/naturalgas/rulemaking/.
} 
regulate unconventional gas development. ${ }^{42}$ Other states, such as Colorado, have engaged in multi-stakeholder processes to strengthen and continue to revise new rules for oil and gas development that have been embraced by multiple constituencies and paved the way for innovative legislation that is re-shaping the electric power sector in the state (COGCC 2008; Xcel 2012). See Textbox 1 for more on Colorado's recent experience. But even in those states, such as Colorado, where oil and gas development has been a feature of the landscape for decades, a number of communities have expressed concerns about the proximity and pace of unconventional gas development and are seeking to impose new restrictions on development. ${ }^{43}$

\section{Text Box 1: Colorado's Clean Air-Clean Jobs Act}

In 2010, then Governor of Colorado Bill Ritter introduced landmark legislation that fundamentally altered the energy make-up of the state's electric power sector. The legislation, HB 1365, also known as the "Clean Air-Clean Jobs Act," required regulated utilities to reduce emissions of nitrogen oxides by $70 \%$ to $80 \%$ or greater from 900 megawatts of coal-fired generation by 2018 and meet certain "reasonably foreseeable" environmental requirements, such as lower ozone standards. To meet these targets, the state's regulated utilities proposed a plan that included retiring aging coal-fired power units, retrofitting others with state-of-the-art clean technology, and expanding capacity for units powered by natural gas and renewable energy sources. The Act had broad support from a number of constituencies including local Front Range governments, local and national non-governmental organizations, Xcel Energy and the natural gas industry (CCC 2010; Xcel 2012). Importantly, much of this support can be tied to the state's decision to first put in place strong rules for the development of its oil and gas resources before introducing legislation that would very likely lead to increased production. Many believe there is still work to be done to ensure that production is done properly statewide, especially in the Front Range, where new production is taking hold that did not exist to the same extent in 2008. However, many point to the Colorado model as an example of collaboration, innovation, and leadership that can be replicated elsewhere.

In short, the regulatory landscape affecting unconventional gas development is complex, dynamic, and multi-layered. Going forward, there is a risk of increased regulatory fragmentation within and among gas-producing basins, as well as a lack of coordination among the different government entities responsible for regulating and ensuring compliance with various aspects of unconventional gas development, leading to additional uncertainty, gaps, redundancies, potential delay for producers, and under-enforcement. ${ }^{44}$ At the same time, leading companies continue to

\footnotetext{
${ }^{42} 58$ Pa. Cons. Stat. § 3218; see also CO SB 088, introduced unsuccessfully Feb. 16, 2012.

${ }^{43}$ For example, Boulder County, Resolution No. 2012-16 (Feb. 2, 2012); Colorado Springs, Steve Bach, Mayer of Colorado Springs, "Memorandum on Administration of the Use of Regulations Set Forth in Chapter 7, City Code," (Nov. 28, 2011); the City of Erie, Ord. No. 09-2012 (Mar. 7, 2012); and the city of Longmont, Ord. No. O-2012-18 (Dec. 20, 2011) - all enacted temporary moratoria on applications for oil and gas development.

${ }^{44}$ For a recent report that surveys state shale gas regulation and similarly finds significant variations among them, see Resources for the Future, "A Review of Shale Gas Regulations by State," http://www.rff.org/centers/energy_economics_and_policy/Pages/Shale_Maps.aspx.
} 
develop and elaborate best practices ${ }^{45}$ to control and/or mitigate some of the environmental impacts associated with unconventional gas development. Some of these corporate practices go beyond existing regulation and some have served as the basis for new regulations. ${ }^{46}$ Although it is impossible to predict the precise mix of future regulation, it is likely that additional regulations will be adopted and implemented as unconventional gas development proceeds. These could affect the costs of producing unconventional gas, but without basin- and company-specific data, it is not possible to determine the amount of additional compliance costs associated with any particular regulatory scenario. This is an important area for future research.

This chapter examines the main federal, state, and local regulatory frameworks that govern unconventional natural gas development. ${ }^{47}$ Specifically, this chapter focuses on requirements related to water withdrawals used for hydraulic fracturing, disclosure of chemicals used in hydraulic fracturing fluids, setbacks for wells, baseline water monitoring of surface water resources or water wells, well construction standards, "green" or "reduced emission" completions, storage of waste in closed-loop systems, and the disposal of produced water. It also examines state compliance monitoring and enforcement capabilities. The goal of the research was to identify changes and trends in the governing legal frameworks across the different basins, as well as key challenges going forward. Specific attention is given to regulatory uncertainty, fragmentation, gaps, and redundancies associated with the proliferation of new rules and regulations at multiple levels, as well as the implications of shifting public perception and support for gas development across various jurisdictions.

Due to time constraints, it was not possible to examine all impacts associated with gas development and corresponding regulatory responses. Key areas for future research include, for example, regulations aimed at reducing the risk of surface spills of acids and chemicals used in hydraulic fracturing, storm-water controls, open-pit requirements, and mitigation measures for truck traffic. Beyond the scope of this report is a complete discussion of the environmental and public health risks posed by unconventional gas development and an analysis of the extent to which the current regulatory and statutory regimes reduce such risks, or the extent to which voluntary implementation of best practices fill any gaps remaining.

The chapter focuses on six unconventional U.S. basins: Barnett Shale play and Eagle Ford Shale play in Texas, Haynesville Shale play in Texas and Louisiana, Marcellus Shale play in New York and Pennsylvania, North San Juan basin in Colorado, and Upper Green River basin in Wyoming. As Table 4 illustrates, each of these basins is marked by distinct resource, geologic, and hydro-geologic characteristics, and each has had different historical and contemporary

\footnotetext{
${ }^{45}$ The term best practices used here has the same meaning as that used by the SEAB in that it refers to "improvements in techniques and methods that rely on measurement and field experience" (SEAB 2011a). Best practices are not static, but rather, continuously evolving, as evidenced by the rapid changes in technologies related to stimulation techniques, methane capture, and water recycling.

${ }^{46} \mathrm{See}$, for example, green completions, voluntary disclosure of chemicals used in hydraulic fracturing fluids, and reuse of produced and flowback waters. EPA specifically cited industry's voluntary use of green completions in promulgating recent federal standards to limit air pollution from new and modified stationary sources in the Crude Oil and Natural Gas Production Category (EPA 2012c).

${ }^{47}$ Statutes applying uniquely to federal lands or actions, such as the Federal Lands Policy and Management Act, National Environmental Protection Act, and Endangered Species Act, are not discussed. For a more complete description of the federal framework that applies to unconventional gas development, see EPA 2000 and Kurth 2010.
} 
experiences with oil and gas development. Accordingly, unconventional gas development in each of these basins and jurisdictions poses a distinct set of environmental issues, and it is the subject of a different mix of state and local regulation.

Table 4. Description of Shale Plays and Basins Studied

\begin{tabular}{|c|c|c|c|c|}
\hline Primary Designation & $\begin{array}{l}\text { Secondary } \\
\text { Designation }\end{array}$ & $\begin{array}{l}\text { Hydrocarbon } \\
\text { Resources }\end{array}$ & Interest for Study & $\begin{array}{c}\text { Production } \\
\text { Characteristics }\end{array}$ \\
\hline Barnett Shale Play & $\begin{array}{c}\text { District 5, North } \\
\text { Texas }\end{array}$ & $\begin{array}{l}\text { Mostly dry gas, } \\
\text { shale }\end{array}$ & $\begin{array}{c}\text { Original shale gas } \\
\text { basin, history, water } \\
\text { stressed, near urban } \\
\text { areas }\end{array}$ & $6,000-8,500$ feet deep \\
\hline Eagle Ford Shale Play & $\begin{array}{c}\text { Oil Producing } \\
\text { Counties, South } \\
\text { Texas }\end{array}$ & $\begin{array}{c}\text { Oil, NGLs and gas, } \\
\text { shale }\end{array}$ & $\begin{array}{l}\text { High activity, } \\
\text { resource diversity, } \\
\text { water stressed }\end{array}$ & $\begin{array}{c}\text { Oil 4,000-8,000 feet, } \\
\text { NGLs/gas 8,000-12,000 } \\
\text { feet deep, average } \\
\text { thickness } 450 \text { feet }\end{array}$ \\
\hline Haynesville Shale Play & $\begin{array}{l}\text { DeSoto Parish, } \\
\text { Louisiana }\end{array}$ & $\begin{array}{l}\text { Mostly dry gas, } \\
\text { shale }\end{array}$ & $\begin{array}{l}\text { Second-largest shale } \\
\text { gas reserves in U.S., } \\
\text { active production }\end{array}$ & $\begin{array}{c}10,500-13,000 \text { feet } \\
\text { deep, high temperature } \\
\text { and pressure }\end{array}$ \\
\hline Marcellus Shale Play & $\begin{array}{l}\text { Susquehanna River } \\
\text { Basin, Ohio River } \\
\text { Basin, Pennsylvania }\end{array}$ & $\begin{array}{l}\text { Mostly dry gas, } \\
\text { shale }\end{array}$ & $\begin{array}{l}\text { Rapidly growing, } \\
\text { diverse, area of } \\
\text { significant public } \\
\text { attention }\end{array}$ & $\begin{array}{l}5,000-7,000 \text { feet deep, } \\
100-500 \text { feet thick, } \\
\text { largest shale gas } \\
\text { reserves in U.S. }\end{array}$ \\
\hline North San Juan Basin & $\begin{array}{l}\text { La Plata County, } \\
\text { Colorado }\end{array}$ & Coal-bed methane & $\begin{array}{l}\text { Colorado regulations, } \\
\text { distinct risks due to } \\
\text { CBM production }\end{array}$ & $\begin{array}{l}\text { Fruitland formation, } \\
550-4,000 \text { feet deep }\end{array}$ \\
\hline $\begin{array}{c}\text { Upper Green River } \\
\text { Basin }\end{array}$ & $\begin{array}{c}\text { Jonah Field, } \\
\text { Pinedale Anticline } \\
\text { Wyoming }\end{array}$ & $\begin{array}{l}\text { Mostly dry gas, tight } \\
\text { sands }\end{array}$ & $\begin{array}{c}\text { Active production, } \\
\text { ozone nonattainment }\end{array}$ & $\begin{array}{c}\text { Vertical wells, } \\
8,000-11,000 \text { feet } \\
\text { deep in tight sands }\end{array}$ \\
\hline
\end{tabular}

This chapter also examines recent actions by local governments to ban, delay, or regulate hydraulic fracturing or gas development; responses to such actions by state courts and legislatures; and the implications of these developments for the industry's social license to operate in specific parts of the country.

Lastly, this chapter identifies several important examples where companies have adopted measures that go beyond compliance - namely, "green" completions, voluntary disclosure of chemicals used in hydraulic fracturing fluids, and reuse of produced and flowback waters. In some cases, these best practices have become the basis for new regulations (e.g., "green" completions). In others, they continue as voluntary actions that fill gaps or go beyond existing regulatory frameworks (e.g., reuse of produced and flowback waters). 
The major conclusions that emerge from this analysis are as follows:

- Although there is a trend toward more regulation at all levels of governance, there has been a corresponding increase in regulatory fragmentation and differentiation at state and local levels. Better coordination and policy alignment among regulators can help to reduce risks of regulatory fragmentation including uncertainty, delays, gaps, and redundancies across jurisdictions. Improved communication and sharing of information between regulators at all levels of government and across jurisdictions - as well as increased transparency in the form of publicly reported and publicly available data from industry-will help ensure that regulations are coordinated and tailored to specific geographic and geologic characteristics. Appropriately designed regulations that reflect local conditions such as gas composition and geology reduce environmental risks and ensure more efficient resource recovery.

- Compliance monitoring and enforcement actions vary significantly across states, with significant implications for the efficacy of regulations, as well as public confidence in the ability of state regulators to ensure that development proceeds safely. Public disclosure of violations, enforcement actions, and company compliance would bring greater transparency and accountability to an industry that, by its nature, poses unique compliance and enforcement challenges due to the disparate and often remote location of facilities and its rapid development in recent years. It would also provide an opportunity to highlight the compliance records of leading companies that have demonstrated a commitment to safe natural gas production.

- There is a significant range in the environmental performance of operators in the industry, with some operators performing at a level that goes beyond existing regulations and other operators falling short. Ongoing consolidation in the industry could lead to more widespread adoption of best practices across the industry. However, additional implementation of beyond-compliance measures is unlikely to lead to less regulation given limited public acceptance of the concept of self-regulation in the industry. In some instances, the implementation of best practices may serve as the foundation for future regulation (Efstathiou 2012), which, in turn, could serve to level the playing field among producers and may help restore public trust in areas of the country where unconventional gas development has been controversial.

- There is a need for basin- and company-specific data to analyze the extent to which implementing beyond-compliance measures or additional regulation will affect the cost of producing natural gas and, by extension, the supply of gas to the electric power sector. $^{48}$ This study was not able to collect such data (see Chapter 4), but this will be a focus of a potential follow-up study.

- Notwithstanding the challenges of regulatory fragmentation, different state and local approaches to regulating unconventional natural gas development provide important opportunities for learning and innovation regarding substantive rules, the role of best practices, and process. Colorado, for example, recently implemented landmark legislation

\footnotetext{
${ }^{48}$ A recent report estimates that the application of 22 "Golden Rules" for shale gas development could add about 7\% to the overall drilling and completion costs on a per well basis (IEA 2012). Assuming today's costs and prices are roughly equivalent, $7 \%$ added costs in the U.S. would amount to roughly an additional $\$ 0.25 / \mathrm{MMBtu}$ produced.
} 
with the support of multiple constituencies, including the natural gas industry and environmental groups, that resulted in a dramatic shift in the state's electric power sector away from coal toward greater use of natural gas and renewable energy (see Chapter 1 for a discussion of the potential climate benefits associated with using natural gas as opposed to coal as a feedstock for electricity generation). This could not have happened absent an initial effort to revise the state's oil and gas laws. New York's decision to undertake a detailed and extensive study of the impacts associated with high-volume hydraulic fracturing has led to development of some of the most comprehensive rules in the country. It remains to be seen whether, if adopted, they alleviate public concerns regarding the risks associated with unconventional gas development .

\subsection{Federal Legal Framework}

The major federal environmental laws provide the overarching framework for regulating many of the environmental impacts associated with unconventional natural gas development. Some of these laws, however, contain explicit exemptions or definitional exclusions for natural gas development, resulting in a significant role for state regulation in key areas such as waste management, disclosure of chemicals used in hydraulic fracturing and releases, and well construction standards other than for underground-injection disposal wells. This section analyzes the federal regulatory framework governing air, water, and waste issues associated with unconventional gas development. It focuses on the scope of federal regulation, the extent to which state law fills any gaps left open by the federal regulatory scheme, recent legislative proposals and rule-makings, key trends, and the implications of a changing federal regulatory framework for future development.

\subsubsection{Overview and Key Trends}

Federal laws governing the air, water, and waste impacts associated with the production of unconventional natural gas vary in terms of scope. EPA has broad authority to regulate emissions of air pollutants, including GHGs, direct and indirect discharges of wastewater from point sources, and the injection of produced water into underground injection wells for disposal. ${ }^{49}$ The federal government, primarily through the U.S. Department of the Interior, also has authority over the development of natural gas on federal and tribal lands. Federal oversight over the management of hazardous and solid wastes, reporting and disclosure requirements of toxic or hazardous releases, and the process of hydraulic fracturing itself is much more limited - and, in some cases, it is entirely absent given specific exemptions and definitional exclusions under certain federal laws such as the Resource Recovery and Conservation Act; the Comprehensive Environmental Response, Compensation and Liability Act; and the Safe Drinking Water Act.

Some federal exemptions have been the focus of proposed legislation in past and current Congresses, ${ }^{50}$ and efforts to repeal or narrow these exemptions are likely to continue. Congress also recently requested that EPA conduct a study evaluating the potential impacts of hydraulic fracturing on drinking water (EPA 2011e). Depending on the results of this study, the first of

\footnotetext{
${ }^{49}$ An exception to this is section 112(n)(4) of the Clean Air Act, which contains prohibitions on the aggregation of hazardous air pollutant emissions from certain gas wells and other equipment that constrain regulation of such sources (42 U.S.C. § 7412(n)(4)).

${ }^{50}$ See, for example, The Fracturing Responsibility and Awareness Act of 2011, H.R. 1084.
} 
which are due out sometime in 2012 with additional results in 2014, EPA may assume a more active role in regulating hydraulic fracturing - including reconsidering its determination that certain natural gas wastes are not hazardous, and recommending changes to the statutory framework that applies to the process of hydraulic fracturing. In the meantime, the states continue to play an important role in regulating various aspects of hydraulic fracturing. The extent to which states have filled gaps left open by federal regulation is discussed in Section 2.3.

The trend at the federal level is toward more regulation. As discussed in more detail below, a number of federal rules related to gas development have been finalized, proposed, or announced recently in response to increased development, and there have been repeated calls for new legislation. Taken together, these efforts indicate a growing interest in hydraulic fracturing and unconventional gas development at the federal level and the likelihood of additional federal regulation, and possibly legislation regarding the removal of certain exemptions in existing statutes, as has been proposed in the past.

\subsubsection{Hydraulic Fracturing}

The process of hydraulic fracturing, other than when diesel fuel is used, is expressly excluded from federal regulation under the Safe Drinking Water Act's Underground Injection Control program. ${ }^{51}$ Were hydraulic fracturing not specifically excluded from the definition of underground injection, the natural gas industry would be required to comply with certain federal well construction, operation, and closure requirements, as well as disclosure requirements. This has been, and likely will continue to be, a source of controversy because numerous bills were introduced in 2009, 2010, and 2011 to bring the process of hydraulic fracturing within EPA's control (Martin et al. 2010). ${ }^{52}$ Although prior attempts have all been unsuccessful, it is likely that similar legislation will be introduced in the future (Hammer and VanBriesen 2012). Additional pressure for greater federal regulation could also come as a result of EPA's hydraulic fracturing study if it concludes that the process of injecting fluids underground during hydraulic fracturing increases the risk of groundwater contamination. ${ }^{53}$

EPA recently published draft guidance governing the use of diesel in hydraulic fracturing fluids that includes requirements for diesel fuels used for hydraulic fracturing wells, technical recommendations for permitting, and a description of diesel fuels for EPA underground injection control permitting (EPA 2012b). As proposed, this guidance only applies where the EPA is the permitting authority. States with primacy over the Underground Injection Control program, which include Texas, Louisiana, and Wyoming, are not required to follow the guidance (Figure $11)$.

\footnotetext{
${ }^{51} 42$ U.S.C. $\S 300 \mathrm{~h}(\mathrm{~d})(1)(\mathrm{B})(\mathrm{ii})$ (2005).

${ }^{52}$ The most recent efforts being The Fracturing Responsibility and Awareness Act of 2011, H.R. 1084.

53 An area of ongoing controversy and debate is whether or not the process of hydraulic fracturing poses a greater risk of subsurface water contamination than other aspects of development that are common to all types of oil and gas production such as surface spills, impoundment failures, and faulty well construction (Groat and Grimshaw 2012; Hammer and VanBriesen 2012; Jones 2011).
} 


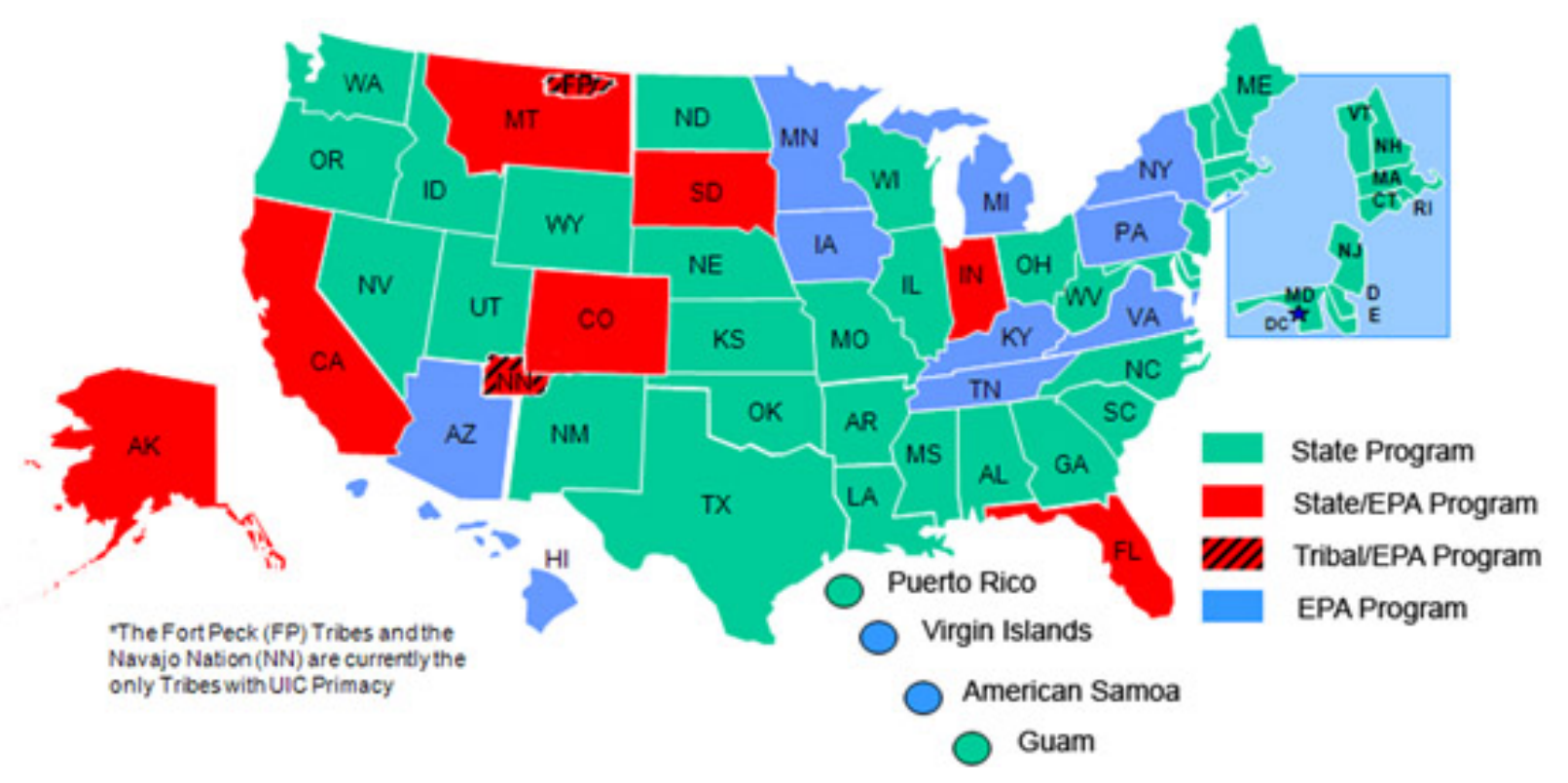

Figure 11. EPA map of Underground Injection Control Program Primacy ${ }^{54}$

Given the limited federal role in this area, states are the primary regulators of well construction standards that apply to the process of hydraulic fracturing (see Section 2.3.3 below) ${ }^{55}$ However, with respect to natural gas development on federal lands, the Bureau of Land Management (BLM) recently proposed a rule that would require the use of cement bond logs on surface casing and mechanical integrity testing prior to hydraulic fracturing to improve well integrity (BLM 2012). Both EPA's proposed diesel fuel guidance and BLM's proposed well construction standards help to provide greater regulatory certainty to the production of natural gas. However, state regulations remain central given the limited applicability of the EPA guidance and BLM standards.

\subsubsection{Water Quality}

As reported in various news media, for the public, some of the most prominent environmental concerns associated with unconventional gas development that have emerged are adverse impacts to groundwater and surface water resources. The major federal statutes protecting water quality - the Clean Water Act and the Safe Drinking Water Act - apply to various aspects of unconventional gas development, with different approaches and experiences in different parts of the country.

The Clean Water Act prohibits the unauthorized discharge of wastewater into the surface waters of the United States from point sources. Discharges may be authorized by permits issued under the National Pollutant Discharge Elimination System, whose permits require industry-specific, technology-based limits and water-quality-based effluent limitations. The latter vary depending

\footnotetext{
${ }^{54}$ EPA, “UIC Program Primacy,” http://water.epa.gov/type/groundwater/uic/Primacy.cfm.

${ }^{55}$ Well integrity is essential not only to reduce risks associated with hydraulic fracturing, but also, with the entire universe of down-hole activities (i.e., wells that are not hydraulically fractured also pose a risk to surface and subsurface water sources if not properly cased, cemented, and monitored).
} 
on local conditions because they are tailored to protect specific designated uses of surface waters.

EPA has established two national effluent limitation guidelines that apply to unconventional gas wells. The first completely prohibits the discharge into navigable waters of natural gas wastewater pollutants, such as produced water, drilling muds, or drill cuttings from any source associated with oil and gas production, field exploration, drilling, well completion, or well treatment, located east of the $98^{\text {th }}$ meridian. ${ }^{56}$ The second guideline applies to operators west of the $98^{\text {th }}$ meridian and allows the discharge of produced water only if it may be used beneficially for agricultural or wildlife propagation. ${ }^{57}$

Indirect discharges to publicly owned treatment works (POTWs) and discharges from centralized waste treatment facilities (CWTs) are also subject to the Clean Water Act framework. However, EPA has not promulgated pretreatment standards that apply to the discharge of shale and coalbed methane (CBM) wastewater to POTWs, leaving a gap in the federal framework that has been the source of considerable controversy. Discharges from CWTs are subject to federal technology-based standards, although these standards do not contain limits for all of the pollutants contained in natural gas wastewater - in particular, bromide or total dissolved solids. ${ }^{58}$

EPA's decision under the CWA to prohibit direct discharges of drilling wastewater to surface waters in states east of the $98^{\text {th }}$ meridian, combined with limited injection well capacity in that part of the country (see Chapter 4, discussing the fact that Pennsylvania has only eight Class II underground disposal wells), has resulted in increased use of indirect discharges to POTWs and CWTs. Many POTWs, however, are not designed or permitted to handle the volumes and types of wastewater produced from the booming shale gas industry (Urbina 2011). In Pennsylvania, insufficient treatment capacity for shale gas wastewater resulted in contamination of state waters - in particular, elevated levels of total dissolved solids, organic chemicals, and metals (EPA 2011c) - prompting the state to request operators to voluntarily cease sending shale gas wastewater to older POTWs and also resulting in new state limits for total dissolved solids and chlorides $^{59}$ (EPA 2011b).

EPA has announced its intent to develop pretreatment standards for discharges of CBM and shale wastewater in 2013 and 2014, respectively (EPA 2011a). These standards should bring certainty to this area, reduce the likelihood that treated wastewater discharges from POTWs will contaminate surface waters, and improve public confidence in the ability of natural gas development to be done safely. Depending on how these standards are set, they may also drive the development of technologies to recycle and reuse wastewater. If, for example, EPA adopted a "no discharge" or otherwise stringent limit, operators would need to rely more heavily on other

\footnotetext{
${ }^{56}$ Onshore Subcategory Guidelines, 40 C.F.R. $§ 435.30$ (2012). The $98^{\text {th }}$ meridian runs through North Dakota, South Dakota, Nebraska, Kansas, Oklahoma, and Texas. Direct discharges of produced water west of the $98^{\text {th }}$ meridian are permitted provided the water does not exceed specified parameters for oil or grease and can be used for agricultural or wildlife propagation. $I d$. $\S 435.50$.

${ }^{57} I d$. $\S 435.50$. Produced water has an effluent limitation of $35 \mathrm{mg} / \mathrm{L}$ of oil and grease. Id. $\S 435.52$.

${ }^{58}$ See 33 U.S.C. $§ 1317$ (2012); EPA, "National Recommended Water Quality Criteria," available at http://water.epa.gov/scitech/swguidance/standards/criteria/current/index.cfm.

${ }_{59} 25 \mathrm{~Pa}$. Code $\S 95.10(\mathrm{~b})(3)(\mathrm{iv})$-(vi).
} 
forms of wastewater disposal such as underground injection or recycling. In parts of the country, such as Pennsylvania, where underground injection wells are limited, a "no discharge" standard could result in significantly more recycling and reuse-especially if doing so is less costly than transporting wastewater out of state for injection.

As noted above, in addition to complying with national effluent limitation guidelines, POTWs and CWTs discharging wastewater must comply with numeric limits on certain pollutants designed to ensure that discharges do not impair the designated uses of surface water bodies. Although EPA has established guidance for water-quality criteria for some natural gas wastewater, it does not cover all pollutants contained in wastewater (Hammer and VanBriesen 2012). ${ }^{60}$ Additional guidance from EPA would provide a certain degree of certainty and more uniform protection because states rely on EPA guidance when adopting water-quality criteria, and EPA retains authority to promulgate its own criteria if it determines a state has failed to adopt adequate standards of its own. Notably, EPA recently signaled its intent to update waterquality criteria for chloride, which is arguably outdated because it was established well before the recent shale gas boom (EPA 2011b).

\subsubsection{Hazardous and Solid Wastes}

\subsubsection{Management of Waste}

Subtitle C of the Resource Conservation and Recovery Act imposes stringent "cradle-to-grave" requirements that apply to the generation, transportation, treatment, storage, and disposal of hazardous waste. ${ }^{61}$ Most of the wastes associated with natural gas drilling, however, are exempt from the Resource Conservation and Recovery Act's program for hazardous wastes. Specifically, drilling fluids, produced water, and other wastes "intrinsically related" to the production and development of natural gas are exempt from Subtitle $\mathrm{C}$ hazardous waste requirements. ${ }^{62}$ As a result, management of these wastes is primarily a matter of state law. Non-exempt wastes, such as unused fracturing fluids, waste solvents, and used hydraulic fluids, are subject to the Resource Conservation and Recovery Act and may be covered under Subtitle $\mathrm{C}$ if they exhibit hazardous characteristics or are specifically listed as hazardous wastes. Exempt wastes not regulated as hazardous are subject to state rules because EPA has not promulgated regulations governing the management of oil and gas solid waste (NRLC 2012). Although this allows for regulation to be tailored to local geologic or hydrologic conditions, it also creates greater horizontal fragmentation, uncertainty, and the potential for inadequate state rules. See the discussion in Section 2.3.5.2 and Table 28 in Appendix C comparing state rules for produced water.

\footnotetext{
${ }^{60}$ The current guideline only applies to certain pollutants such as chloride, oil and grease, suspended solids, turbidity, and nitrates. See EPA, "National Recommended Water Quality Criteria," available at http://water.epa.gov/scitech/swguidance/standards/criteria/current/index.cfm.

${ }^{61} 40$ C.F.R. pt. 260 et seq. Specifically, generators must ensure and fully document that their hazardous waste is properly identified, managed, and treated prior to recycling and disposal. They must comply with requirements for training and emergency arrangements (including having an emergency coordinator and testing and maintaining emergency equipment) and must track the shipment and receipt of their waste. Additionally, a hazardous waste generator is limited in the amount of waste it can accumulate. A large-quantity hazardous waste generator (one that generates $1,000 \mathrm{~kg}$ or more of hazardous waste per month) must move all the waste it generates off site within 90 days; a small-quantity generator must move all its waste off site within 180 days. See EPA, Regulations Governing Hazardous Waste Generators, at III-41-47, http://www.epa.gov/osw/inforesources/pubs/orientat/rom33.pdf.

${ }^{62}$ In addition, EPA has determined that produced water injected for enhanced recovery is not waste subject to the Resource Conservation and Recovery Act and is therefore exempt from regulation under the statute. However, produced water stored in above-ground impoundments is subject to state law (EPA 2000).
} 
Some observers have called for the federal regulation of natural gas waste as hazardous under Subtitle $\mathrm{C}$ of the Resource Conservation and Recovery Act (Hammer and VanBriesen 2012). EPA has not signaled its intent to reverse its decision regarding the management of natural gas waste; however, it remains a possibility, and may turn, in part, on the outcome of EPA's study on hydraulic fracturing.

\subsubsection{Liability for Releases of Hazardous Substances}

The Comprehensive Environmental Response, Compensation, and Liability Act (CERCLA), also known as "Superfund," imposes strict liability for releases of hazardous substances on owners and operators of "facilities" (which include natural gas production sites), as well as arrangers and transporters of hazardous substances. The definition of hazardous substance under CERCLA, however, is limited in its application to crude oil, petroleum, and natural gas. ${ }^{63}$ Specifically, petroleum and crude oil- as well as hazardous substances that are normally mixed with or added to crude oil or crude oil fractions during the refining process - are not considered hazardous substances under the so-called "petroleum exclusion." 64 Also excluded from the definition of hazardous substances are natural gas, natural gas liquids, liquefied natural gas, and synthetic gas usable for fuel. ${ }^{65}$ Releases of other hazardous substances from natural gas drilling operations, such as hydraulic fracturing fluids containing hazardous chemicals, are subject to standard CERCLA liability. Thus, federal law provides for some potential CERCLA liability for natural gas operators, but the scope of such liability is narrow. Moreover, even though some states, such as Colorado, Texas, and Pennsylvania, have adopted their own environmental cleanup

legislation, these states have all retained the federal definition of hazardous substances. ${ }^{66}$

\subsubsection{Reporting of Hazardous or Toxic Chemical Releases}

Federal law imposes few reporting requirements on operators of natural gas production facilities for the release of hazardous or toxic chemicals. Under CERCLA, operators must report releases of hazardous substances above reportable quantities, although the same definition of hazardous

\footnotetext{
${ }^{63} 42$ U.S.C. $\S 9601(14)$.

${ }^{64} I d$. Discharges of oil from certain production facilities may be subject to the Clean Water Act's Oil Pollution Prevention Program, which requires covered facilities to prepare and implement Spill Prevention Control and Countermeasures to prevent oil discharges (EPA 2000).

${ }^{65} \mathrm{Id}$. at $\S 9601(14)$.

${ }^{66}$ New York has a state law mirroring CERCLA, including a state Superfund to pay for site cleanup when no responsible party can be identified or the responsible party has inadequate funds for the cleanup. The state requires reporting and cleanup of petroleum spills within the state through its spill response program and its Brownfield and Superfund laws. New York's Brownfield regulations still exclude "natural gas, natural gas liquids, liquefied natural gas, synthetic gas usable for fuel, or mixtures of natural gas and such synthetic gas" from the definition of "hazardous waste" and "contaminant," thereby removing natural gas from the law's application. New York Department of Environmental Conservation, Chemical and Petroleum Spills, http://www.dec.ny.gov/chemical/8428.html; see also New York General Remedial Program Requirements, N .Y. Comp. Codes R. \& Regs. title 6, § 375-1.2(w)(1). Pennsylvania operates within the CERCLA framework, but also has separate state legislation to fill in gaps in CERCLA. Pennsylvania Department of Environmental Protection, Superfund, http://www.portal.state.pa.us/portal/server.pt?open=514\&objID=589587\&mode=2. This state legislation retains the exclusion for natural gas and petroleum from the definition of "hazardous substance" and "hazardous waste." Pennsylvania Hazardous Sites Cleanup Act, 756 Act 1988-108, sec. 103 (definitions of "hazardous substance" and "hazardous waste"). Colorado has a statute on hazardous waste cleanup that essentially authorizes the State to cooperate with the federal government in the implementation of CERCLA. Colorado Hazardous Waste Cleanup Act, C.R.S. § 25-16-101. The Colorado statute adopts the CERCLA definition of hazardous substance, thereby excluding petroleum and natural gas. Id.
} 
substance applies here as it does to the statute's liability scheme. ${ }^{67}$ Oil and gas operators are not required to report annual releases of toxic chemicals under rules promulgated pursuant to the Emergency Planning and Community Right-to-Know Act's Toxics Release Inventory or to disclose the chemicals used in hydraulic fracturing to members of the public or regulators due to the exemption of hydraulic fracturing under the Safe Drinking Water Act. ${ }^{68}$

Natural gas operators are subject to requirements to report or disclose chemicals stored on-site, although these are limited. Owners and operators of storage facilities holding in excess of 10,000 pounds of any hazardous chemical must submit chemical inventory information to state and local emergency response and fire officials. ${ }^{69}$ In addition, under the Emergency Planning and Community Right-to-Know Act and regulations promulgated pursuant to the Occupational Safety and Health Act, natural gas operators using products containing hazardous chemicals must maintain material safety data sheets on site, and must make them available to state and local emergency response and fire officials, subject to trade secret protection. ${ }^{70}$

States are increasingly filling the gap related to public disclosure of the chemicals used in hydraulic fracturing fluids. As discussed in more detail below, there is a clear trend toward public disclosure of all chemicals, not just those listed on material safety data sheets (Table 23 in Appendix C). This trend is evident at the state level and in the recently proposed BLM rule, which would require disclosure for production on federal and tribal lands (BLM 2012).

In terms of other reporting requirements, EPA has announced an intention to gather data on the aggregate amounts of exploration and production chemical substances and mixtures used in hydraulic fracturing. It is unclear to what extent these regulations will fill any of the gaps that remain in federal reporting requirements. But EPA has signaled an intent to avoid vertical fragmentation by framing its proposal as one that "would not duplicate, but instead complement, the well-by-well disclosure programs of states"(EPA 2011d). ${ }^{71}$ In addition, states may adopt their own reporting requirements for releases. ${ }^{72}$

\subsubsection{Disposal of Produced Water}

As noted above, states primarily regulate waste disposal. One exception is the disposal of produced water into Class II underground injection wells, which is regulated by EPA's Underground Injection Control program, although states with primacy issue the actual permits. ${ }^{73}$ Some states have recently raised concerns regarding the disposal of produced water into Class II wells, in response to evidence linking such disposal to earthquakes (Niquette 2011; Hammer and VanBriesen 2012). For example, nine earthquakes were recorded recently in Youngstown, Ohio,

\footnotetext{
${ }^{67} 42$ U.S.C. $\$ 11004$ (2012). EPA also requires operators to disclose "the source and analysis of the physical and chemical characteristics" of chemicals used in underground well stimulation permit applications (EPA 2008b).

${ }^{68} 42$ U.S.C. $\$ 11023$ (b) (2012) (EPA 2000; Wiseman 2010).

${ }^{69} 42$ U.S.C. $\$ 11022(2012)$.

${ }^{70} I d$.; 29 C.F.R. $\$ 1960.34$ (b)(6) (2012). Disclosure to the public of material safety data sheets is available upon written request.

${ }^{71}$ Letter from Stephen A. Owens, Assistant Administrator to Ms. Deborah Goldberg, Earthjustice re: TSCA Section 21 Petition Concerning Chemical Substances and Mixtures Used in Oil and Gas Exploration or Production, (Nov. 23, 2011), http://www.epa.gov/oppt/chemtest/pubs/EPA_Letter_to_Earthjustice_on_TSCA Petition.pdf.

${ }^{72}$ See, for example, COGCC R. 906(b)(3) (requiring oil and gas producers to report spills that threaten to impact waters of the state).

${ }^{73} 40$ C.F.R. § 144.6 (2010).
} 
all of which were located within a half mile of an injection well, and all of which occurred within the first 11 months of injection of produced water into the well (Niquette 2011). Although scientists have yet to determine the cause of recent earthquakes, there have been instances in the past where injection wells used by other industries have been linked to earthquakes. (Holland 2011). This indicates that any causal relationship between underground injection of waste and seismic activity is not an impact unique to the natural gas industry. However, the volume of produced water associated with the significant increase in unconventional gas development across the country may place an increased strain on underground injection well capacity, especially in those areas where other disposal methods are less available. In addition to potentially causing earthquakes, underground injection of large amounts of produced water can increase the risk of subsurface contamination due to leaky wells. ${ }^{74}$ Some suggest EPA should require the disposal of produced water into Class I, rather than Class II, wells because the former are subject to more rigorous standards on well construction, operation, and closure (Hammer and VanBriesen 2012). This will likely be an area of continuing public scrutiny and could be subject to additional state or federal regulation in the future. ${ }^{75}$

\subsubsection{Air Quality}

EPA has broad authority under the Clean Air Act to promulgate rules to reduce air pollution from natural gas sources. The most prominent air-quality issues associated with unconventional gas development include emissions of ozone precursors, VOCs and oxides of nitrogen, various hazardous air pollutants, and methane, all of which are subject to the basic Clean Air Act framework. Concentrated natural gas development has led to elevated ozone levels in rural parts of Wyoming and Utah where little other industrial activity occurs (Fruedenthal 2009; Streater 2010), and has also contributed to ozone pollution in more urban and industrial areas such as the Dallas Fort-Worth metropolitan area (Armendariz 2009). In 2012, the EPA responded to exceedances of the national health-based ambient air quality standards (i.e., National Ambient Air Quality Standards) for ozone in the Upper Green River basin by classifying the basin-for the first time - as in nonattainment with the 2008 8-hour National Ambient Air Quality Standard for ozone. ${ }^{76}$ This listing could result in the state adopting more stringent rules to reduce emissions of VOCs and/or $\mathrm{NO}_{\mathrm{x}}$ from natural gas sources in the basin to meet its Clean Air Act obligations.

Until recently, EPA has exercised its Clean Air Act authority with respect to natural gas production by focusing on a select number of natural gas production sources such as new and modified gas-processing plants, glycol dehydrators, crude oil and condensate storage vessels, and select engines used in the natural gas supply chain (e.g., engines used to power compressors). Most of these rules were implemented long before the unconventional natural gas boom occurred.

\footnotetext{
${ }^{74}$ Personal conversation with Mark Williams, Professor of Geography and Fellow, INSTAAR, University of Colorado-Boulder, April 25, 2012.

${ }^{75}$ Notably, the Ohio Dept. of Natural Resources has enhanced Class II well permitting requirements, requiring seismic tests prior to construction of the well and ongoing monitoring, among other protections. Ohio Dept. of Natural Resources, Class II Disposal Well Reforms/Youngstown Seismic Activity Questions and Answers, http://ohiodnr.com/downloads/northstar/YoungstownFAQ.pdf.

${ }^{76}$ See EPA State Final Designations, April 2012 and May 2012, http://www.epa.gov/ozonedesignations/2008standards/state.htm.
} 
In April 2012, however, EPA issued revised New Source Performance Standards (NSPS) and National Emission Standards for Hazardous Air Pollutants (NESHAPS) (EPA 2012c) ${ }^{77}$ that update existing standards and apply new requirements to previously unregulated sources. Specifically, EPA's new rules add requirements limiting VOCs and hazardous air pollutants emitted from completions and recompletions of hydraulically fractured natural gas wells (known as the "reduced emission completion" or "green completion" requirement), pneumatic devices, storage vessels, compressors, and "small" glycol dehydrators located at major sources of hazardous air pollution (EPA 2012c). Certain of these requirements result in the co-benefit of reducing methane because, in many cases, controlling VOCs also results in methane reductions (EPA 2012c). In addition, EPA updated standards and limits that apply to gas processing plants and large glycol dehydrators located at major sources of air pollution (EPA 2012c).

The revised NSPS and NESHAPS regulations provide a national floor that addresses unevenness in state air requirements. For example, EPA's new green completion requirements impose a level of uniformity across states with respect to control of ozone precursors and methane from unconventional natural gas development, as illustrated in Table 29, Appendix C, which compares green completion requirements. These new requirements implement one of the key recommendations of the SEAB, that EPA "adopt rigorous standards for new and existing sources of methane, air toxics, ozone precursors and other air pollutants from shale gas operations[.]" (SEAB 2011a, 2011b). Prior to EPA's adoption of the reduced emission completion requirement, many operators voluntarily used green completion practices to maximize resource recovery, illustrating how certain best management practices can serve as the foundation for future regulation (Efstathiou 2012, EPA 2012c).

In August 2012, EPA released a rule that requires capture or high-efficiency combustion of associated gas produced from crude oil wells in the Fort Berthold Indian Reservation in North Dakota. $^{78}$ The rule applies during well completions and re-completions, the separation phase of oil production, and during production. Specifically, the rule requires that operators control emissions of VOCs by $90 \%$ during well completions or re-completions or perform a reducedemission completion, route all produced gas and gas emissions to a control device capable of at least a $90 \%$ control efficiency upon production, and, within 90 days of production, capture all associated gas or route it to a control device capable of $98 \%$ control efficiency.

In September 2012, natural gas producers will also begin reporting GHG emissions from facilities subject to EPA's Mandatory Greenhouse Gas Reporting rule. As required by that rule, natural gas facilities that emit 25,000 metric tons of $\mathrm{CO}_{2} \mathrm{e}$ or more of GHGs will be required to report GHG emissions (EPA 2010). Operators have been granted a grace period to use less rigorous measurement practices initially, but the data collected will provide much greater certainty regarding actual methane leakage rates. Precise information regarding methane emissions from natural gas systems is essential to resolving discrepancies among life cycle assessments, such as those discussed in Chapter 1.

\footnotetext{
${ }^{77}$ U.S. E.P.A, Final Rule, “Oil and Natural Gas Sector: New Source Performance Standards and National Emission Standards for Hazardous Air Pollutants Reviews," http://www.epa.gov/airquality/oilandgas/pdfs/20120417finalrule.pdf.

${ }^{78}$ EPA, "Approval and Promulgation of Federal Implementation Plan for Oil and Natural Gas Well Production Facilities; Fort Berthold Indian Reservation (Mandan, Hidatsa, and Arikara Nations), ND” 77 Federal Register 48878 (August 15, 2012).
} 
Despite EPA's broad authority to implement clean air measures, states retain significant room to regulate. States with delegated programs may implement standards more stringent than federal law, unless prohibited by state law from doing so. States retain authority to regulate sources and air pollutants not covered by existing federal rules, and states may also impose more stringent rules than federal to meet National Ambient Air Quality Standards for criteria pollutants.

\subsection{State Statutory and Regulatory Frameworks}

Against this backdrop of federal environmental regulation, state and local governments have adopted numerous laws and regulations governing unconventional gas development, with considerable variation across different states, especially regarding the handling of waste and wastewater, construction of wells other than underground injection disposal wells, and baseline water-monitoring requirements. States also have exclusive jurisdiction over water withdrawals, other than those occurring on federal lands, ${ }^{79}$ and over various land-use controls such as setback requirements and zoning, some of which have been delegated to local governments. As discussed above, although a number of federal rules apply to protecting water and air resources, states also retain authority to develop more stringent standards and to regulate impacts or sources not covered by federal law. Prior to EPA's recent revisions of the NSPS and NESHAPS, some states - notably Colorado and Wyoming - adopted air regulations that went beyond then-existing federal standards ${ }^{80}$ (WY DEQ 2010), whereas New York has proposed a number of regulations to protect water sources and ensure safer waste management that go beyond federal and other state rules. Some states have increased inspection capacity to respond to the rapid increase in unconventional gas development; however, there is considerable variation in state inspection capacities and enforcement approaches.

This section analyzes the state regulatory frameworks governing air, water, waste, and compliance and enforcement issues associated with unconventional gas development in Colorado, Wyoming, New York, Texas, Louisiana, and Pennsylvania. It focuses on the extent to which state law fills any gaps left open by the federal regulatory scheme, as well as on key trends, differences in the regulatory frameworks across the different basins, compliance monitoring, and enforcement capabilities and actions.

\subsubsection{Overview and Key Trends}

The wide variation in state approaches to the regulation of unconventional natural gas development reflects differences in resource characteristics (e.g., dry versus wet gas, deep shale versus shallow CBM), geology, and hydrology, as well as different experiences with oil and gas development and different approaches to and preferences for environmental protection. Across the country, states have responded to hydraulic fracturing in very different ways. Vermont, for example, recently enacted legislation banning hydraulic fracturing in the state. ${ }^{81}$ New York, as noted, has imposed a temporary moratorium on drilling as it develops regulations. ${ }^{82}$ Recently, the Cuomo administration announced that it will undertake a public health study of the potential impacts of hydraulic fracturing and re-start the rule-making process prior to issuing any new

\footnotetext{
${ }^{79}$ See, for example, the proposed BLM rule, which requires operators to identify the source of water to be used in fracturing in order for the BLM to determine impacts and mitigation measures, if needed (BLM 2012).

${ }^{80}$ COGCC R. 805(b).

${ }^{81}$ H 464 (enacted May 16, 2012).

829 N.Y. Comp. Codes R. \& Regs. tit. 9, § 7.41.
} 
regulations. ${ }^{83}$ A number of states (specifically Colorado, Wyoming, and Pennsylvania) have revised their oil and gas rules extensively - at least once, and in some cases, continue to do soto respond to the uptick in unconventional resource development; Louisiana and Texas have engaged in much more limited revisions. New York, as noted above, is in the process of revising its regulations. Louisiana, Pennsylvania, and Colorado have all recently submitted their hydraulic fracturing rules to the State Review of Oil and Natural Gas Environmental Regulations for review, whereas Wyoming and Texas have not (and New York has not yet finalized its highvolume hydraulic fracturing regulations) (STRONGER, 2010; STRONGER 2011a; STRONGER 2011b). Pennsylvania and Louisiana significantly increased the number of oil and gas inspectors in response to increased development, whereas resources in other states appear quite limited. Data are limited and more research is needed, but there appears to be very little consistency in the ways that states record, respond to, and enforce against violations - including substantial ranges in penalties and the number of violations that result in enforcement actions. Areas highlighted as meriting additional attention from state regulators are improved transparency regarding compliance monitoring, company compliance histories, and enforcement actions.

Different regulatory approaches by states can lead to uncertainty, gaps, and/or redundancies in mitigating some of the more significant environmental risks associated with unconventional gas development and ensuring overall compliance. But they can also provide a source of policy innovation because different jurisdictions experiment with new approaches to regulating various aspects of shale gas development. An example is New York's proposal to require operators to document that, compared to available alternatives, chemical additives used in hydraulic fracturing fluids exhibit reduced aquatic toxicity and pose a lower potential risk to water resources and the environment. ${ }^{84}$ For this reason, it is important that state regulators and policy makers share information and lessons learned with other states. National standards provide a baseline or floor in some areas, such as national effluent limitation guidelines for wastewater discharges and EPA's recent NSPS and National Emission Standards for Hazardous Air Pollutants. However, a permanent feature of the regulatory landscape appears to be the uneven and varied nature of state and local regulation and enforcement regarding most other aspects of shale gas development.

Despite the variety in specific state and local regulations and enforcement, some important trends are evident. All states reviewed here recently revised their oil and gas rules and/or laws to respond specifically to the increase in unconventional resource development. Colorado, New York, Wyoming, and Pennsylvania recently undertook extensive reviews and revisions of their laws and regulations that, in some cases, resulted in considerably more comprehensive - and in many instances, protective - rules than those in Louisiana and Texas. For example, Colorado and Wyoming have been leaders in rules to reduce emissions of ozone precursors, and New York and Pennsylvania are leaders in laws regarding measurement and public disclosure of water sources and waste. See Table 22, Appendix C, for a general description of revisions to state oil and gas laws.

\footnotetext{
${ }^{83}$ Danny Hakim, "Shift by Cuomo on Gas Drilling Prompts Both Anger and Praise," New York Times, Sept. 30, 2012.

${ }^{84}$ N.Y. Comp. Codes R. \& Regs. tit. 6, §560. 3.
} 
There is a clear trend in all of the states studied toward greater transparency - such as mandatory public disclosure of chemicals used in hydraulic fracturing and the composition of wastewater, reporting of the amounts and sources of water used in hydraulic fracturing, and more rigorous well-construction standards, including notifications of hydraulic fracturing and well completions. A key recommendation of the SEAB Subcommittee (SEAB 2011a) was greater transparency, in the form of public disclosure of the chemicals, amounts, and sources of water used or produced during hydraulic fracturing, baseline water monitoring measurements, and reduction and measurement of air emissions. These activities have the potential to lead to better public understanding and acceptance of natural gas development.

All states covered in this study have added requirements that providers of fluids used in hydraulic fracturing and/or operators disclose the contents of most chemicals to the public. These requirements are in addition to, and go beyond, federal requirements that require operators to maintain material safety data sheets for certain hazardous chemicals stored on-site in threshold quantities, and to report releases of hazardous chemicals in threshold quantities. ${ }^{85}$ In addition, all of the states covered in this study require operators to report the amount and, in most cases, the source of water used in hydraulic fracturing either to the public or state regulators.

Other areas of state regulation or interest include: baseline water-monitoring requirements; use of closed-loop drilling systems to contain waste, rather than open, earthen pits; reporting or reduction of emissions of air pollutants; standards to ensure well integrity; and more active involvement on the parts of local government over drilling activities.

State compliance monitoring and enforcement capacity varies considerably, although significant data limitations across the different states mean that any comparisons should be considered provisional. Based on available data, some states - notably Pennsylvania and Louisianarecently increased state inspection capabilities to respond to increased development, whereas resources in other states appear quite limited. The methods that states use to track and report violations and enforcement actions also differ substantially — with some states, notably Pennsylvania, making violations and enforcement actions publicly available via online databases; other states, notably Colorado and Wyoming, have been criticized for a lack of transparency and limited public access to such information. ${ }^{86}$

Variation across states in substantive regulations, as well as compliance monitoring and enforcement capacity, can be explained by a number of factors. Some are legal, such as federal effluent limitation guidelines that differ across regions and state statutes limiting the amount of penalties that can be assessed for violations. Others reflect differences in local environmental conditions (e.g., elevated ozone levels in the Upper Green River basin and Denver metropolitan area, respectively, led Wyoming and Colorado to adopt air rules that went beyond then-existing federal requirements, forming the basis for some of EPA's new NSPS rules); geologic and hydro-geologic conditions (e.g., developing shallow CBM resources poses unique risks that deep shale does not $)^{87}$; proximity of drilling to densely populated areas or sensitive environmental

\footnotetext{
${ }^{85} 42$ U.S.C. $\S 11021-11022$ (2006); 55 Fed. Reg. 30,632 (July 26, 1990).

${ }^{86}$ See, for example, Earthworks (2012b) and Soraghan (2011).

${ }^{87} \mathrm{See}$, for example, COGCC R. 608(b)(4).
} 
areas (e.g., setback requirements and buffer zones) ${ }^{88}$; historical and contemporary experiences with oil and gas development; and preferences for environmental protection.

\subsubsection{Water Acquisition}

The regulation of water withdrawals is primarily a matter of state and local, rather than federal, law. The legal framework governing water rights differs from state to state, although there is some consistency along regional lines. ${ }^{89}$ There is a clear trend toward requiring operators to identify the sources of water used, report the amount of water used in hydraulic fracturing, and provide for incentives to promote reuse of water used in hydraulic fracturing such as by recycling flowback waters or production fluids. All states require operators to report on the amount of water used for hydraulic fracturing, as does BLM's new proposed rule. ${ }^{90}$ In addition, both New York and Pennsylvania require operators to provide for the reuse and recycling of flowback water or production fluids in water management plans or wastewater source reduction strategies. States also have begun to require minimum in-stream flow below points of water withdrawal and other measures to ensure that aquatic wildlife, water quality, and other water users will not be adversely affected. ${ }^{91}$

A handful of local governments also regulate some aspects of water acquisition. For example, Archuleta County, Colorado, requires operators in the North San Juan basin to submit a water management plan that includes a plan for disposal or reuse, projected water use, identification of the water source, and water availability (Archuleta 2010). The City of Fort Worth, Texas, requires operators to describe the water source proposed to be used for drilling in application for permits to drill. ${ }^{92}$ As unconventional gas development expands in various parts of the country, it seems likely that more local governments will seek to get involved in regulating aspects of water acquisition.

For more information related to state and local regulation of water withdrawals, see Table 24, Appendix C, Water Acquisition Requirements.

\subsubsection{Hydraulic Fracturing and Well Construction Standards}

State well-construction standards vary considerably, which to a certain extent can be explained by differences in local geology. However, certain safeguards do not depend on differences in local conditions. Standards that have been recommended to increase well integrity include the use of state-of-the-art cement bond logs, pressure testing of casing, monitoring and recording bradenhead annulus pressure, and assurances that surface casing is run below all known underground aquifers to reduce the risk of drinking water contamination from fluid or gas

\footnotetext{
${ }^{88}$ See, for example, setback requirements in the Barnett Shale and New York's proposed buffer zones to protect sources of drinking water, Appendix C.

${ }^{89}$ The two most common doctrines governing water rights are the prior appropriation and riparian doctrines. The prior appropriation doctrine provides rights to continued use of water to those who first put water to beneficial use and is the predominant regime in most of the West (CDWR 2012; Groat and Grimshaw 2012). In a riparian water rights system, water rights are tied to the ownership of land adjacent to water resources.

${ }^{90}$ DOI, Bureau of Land Management, Proposed Rule "Oil and Gas; Well Stimulation, Including Hydraulic Fracturing, on Federal and Indian Lands", May 4, 2012, http:/www.doi.gov/news/pressreleases/loader.cfm?csModule=security/getfile\&amp;pageid=293916.

${ }^{91}$ See, e.g., 58 Penn. Stat. $\S 3211(\mathrm{~m})(2)$.

${ }^{92}$ Fort Worth, Tex., Ord. No. 18449-02-2009.
} 
migration (SEAB 2011b). Of the states reviewed, only Colorado and Louisiana require the use of cement bond logs. ${ }^{93}$ New York has proposed to require the use of cement bond logs. All states except Wyoming require some kind of pressure testing of casing, although the specifics vary regarding the testing and circumstances requiring testing. Colorado is the only state that requires monitoring of annulus pressure with bradenhead (Texas requires all wells to be equipped with bradenhead, but only requires a pressure test in certain instances). All states require surface casing to be set below known aquifers, although the specific requirements vary. For specific requirements, see Table 25 in Appendix C.

\subsubsection{Baseline Water-Quality Monitoring}

Requiring operators to conduct baseline monitoring of wells or water resources near gas operations is an important objective for all stakeholders because it results in science-based measurement data that can be used to identify whether or not well activities cause contamination. For example, in Pennsylvania, operators who conduct pre- and post-baseline water monitoring of nearby water sources can overcome a rebuttable presumption that a well operator is responsible for pollution of nearby water resources if the monitoring demonstrates that constituents found in the sampled water sources did not come from the well operator's activities. ${ }^{94}$ In Colorado, the Colorado Oil and Gas Association instituted a voluntary baseline monitoring program, with results being submitted to the Colorado Oil and Gas Conservation Commission (COGCC), provided landowner consent. ${ }^{95}$ Colorado requires baseline water testing in the North San Juan basin (as well as other parts of the state), in limited circumstances to protect sources of drinking water, resources located near CBM wells, and in the Greater Wattenberg Area. ${ }^{96}$ New York has proposed to require operators to make reasonable attempts to sample and test all residential water wells within 1,000 feet of a well pad prior to commencing drilling. If no well is located within 1,000 feet, or the surface owner denies permission, then the operator must sample all wells within a 2,000-foot radius. Monitoring continues at specified intervals as determined by the U.S. Department of Environmental Conservation. ${ }^{97}$ For more information related to state baseline monitoring requirements, see Table 26, Appendix C, Baseline Monitoring Requirements.

\subsubsection{Storage and Management of Wastes}

\subsubsection{Waste Storage}

As noted above, waste storage is largely a matter of state and local law. The onsite storage of waste - such as produced and flowback water, drill cuttings, and fluids - is usually restricted to either storage tanks or open lined or unlined pits. Open pits pose a number of risks, including

\footnotetext{
${ }^{93}$ We do not include where state regulations refer to logs generally, as opposed to using the specific terminology "cement bond logs."

${ }^{94} 58 \mathrm{~Pa}$. Cons. Stat. § 3218. In those instances where an operator is deemed responsible for contaminating or diminishing a private or public water source, he or she must restore or replace the water with an alternate source.

${ }^{95}$ Colorado Oil \& Gas Association, "Colorado Oil \& Gas Association Voluntary Baseline Groundwater Quality Sampling Program," http://www.coga.org/index.php/BaselineWaterSampling.

${ }^{96}$ Colorado requires baseline sampling of surface waters located downstream of drilling operations conducted near surface waters intended for drinking water and baseline sampling of water wells located near CBM wells. COGCC R. 317.b (2012). The state also recently added a statewide requirement that operators provide notice to surface and adjacent landowners, which must include instructions for the collection baseline water samples. COGCC R.

305.e.1.A (2012). Operators drilling in the Greater Wattenberg Area must also conduct limited baseline water sampling prior to drilling. COGCC R. 318A.

${ }^{97}$ Proposed N.Y. Comp. Codes R. \& Regs. tit 6, § 560.5(d).
} 
threats of drowning to migratory birds and wildlife, air pollution caused by the volatilization of hazardous or organic compounds, and soil and water contamination posed by overflowing pits or liner failures (Earthworks 2012, NM OCD 2008). According to the Ground Water Protection Council, "The containment of fluids within a pit is the most critical element in the prevention of shallow ground water contamination" (GWPC 2009). This study did not perform a comprehensive analysis of state pit requirements; however, a preliminary review revealed significant variation among state pit rules in terms of liner, monitoring, fencing, and other construction and operation requirements, which is complicated somewhat by the use of inconsistent nomenclature for pit types.

An alternative to the use of pits is the use of closed-loop or "pitless" drilling systems that require the storage of fluids in tanks, preferably closed tanks, rather than open pits. Closed-loop drilling reduces many of the risks associated with open pits (Earthworks 2012). Closed-loop drilling also "allows for enhanced monitoring of fluid levels and characteristics which allows for more efficient use of drilling fluids, reduces waste, encourages recycling, and reduces potential liability associated with waste management and reduces site closure costs" $" 98$ (TRRC 2012). New York has proposed to require closed-loop drilling for drilling fluids and cuttings associated with high-volume hydraulic fracturing operations. Colorado, Pennsylvania, Wyoming, and Fort Worth (Texas), require the practice in certain situations, such as where drilling occurs in sensitive areas where there is a heightened risk of water contamination from pit failure or the implications of contamination are more severe if contamination does occur. A recent bill introduced in Colorado would have required enhanced use of this practice statewide. ${ }^{99}$ BLM's proposed rule for development on public and tribal lands provides for the use of either closed-loop systems or pits (BLM 2012). For a comparison of state and local closed-loop drilling requirements, see Table 27, Appendix C, Closed-Loop or Pitless Drilling Requirements.

\subsubsection{Produced Water Disposal}

State requirements regarding the disposal of produced water also vary considerably. Some of this variation can be explained by local conditions, such as the scarcity of underground injection wells in Pennsylvania, as noted above. However, disparate regulatory requirements also contribute to state-by-state variation.

In general, natural gas operators have a variety of options for disposing of wastewater. These include discharging wastewater directly to surface waters, sending the waste to treatment facilities such as POTWs or CWTs authorized to discharge, disposal via underground injection well, reuse for further hydraulic fracturing, disposal into evaporation ponds or impoundments, or disposal via land application. However, legal and practical constraints can limit some of these options.

Of the states reviewed, Colorado, Wyoming, and Texas allow for direct discharges only in specified circumstances (e.g., if produced water meets national effluent limitation guidelines for agricultural or wildlife propagation). State requirements vary considerably with respect to indirect discharges to POTWs or CWT facilities. All of the states studied except New York allow for disposal or storage of produced water in evaporation or open pits, subject to specific

\footnotetext{
${ }^{98}$ NY SGEIS, § 7.1.7.4.

${ }^{99}$ SB 12-107 (introduced January 31, 2012).
} 
circumstances where closed-loop systems are required. Similarly, all states except New York and Texas allow for produced water to be disposed of via land application, such as road-spreading or land farming, but the specific requirements and limits for doing so vary considerably. New York has proposed to require operators to demonstrate that all flowback water and production brine will be treated, recycled, or otherwise properly disposed of over the projected life of the well, ${ }^{100}$ and also, that operators prepare a waste tracking form for flowback and production brine similar to what is required for medical waste. ${ }^{101}$ Operators in Pennsylvania must prepare a wastewater source reduction strategy identifying the methods and procedures operators will use to maximize recycling and reuse of flowback or production fluids, and most states are increasingly encouraging reuse and recycling. Additional requirements to incent or require recycling and reuse of produced and flowback are likely given the heightened interest in reducing the risk of contamination posed by other disposal methods, and reducing impacts to freshwater resources associated with withdrawals. See Table 28, Appendix C, Produced Water Disposal, for specific state disposal requirements for produced water.

\subsubsection{Air Quality}

As discussed above, EPA and the states exercise joint authority over standards to limit or report amounts of air pollution from unconventional gas activities.

State regulation of air contaminants varies significantly, with Colorado and Wyoming containing some of the most comprehensive and rigorous requirements to reduce emissions statewide and in areas home to significant drilling activity. Some of Colorado's and Wyoming's air rules have been driven by exceedances of the national ambient air-quality standards for ozone. For example, Wyoming adopted more stringent requirements to reduce VOCs from natural gas operations in the Upper Green River basin in response to elevated levels of ozone in the winter, as did Colorado in response to violations of national ambient air-quality standards for ozone in parts of the Denver-Julesburg Basin in the Denver Metropolitan Area. Attainment of national ambient air-quality standards (i.e., National Ambient Air Quality Standards) is determined at regional and local levels (so-called "air quality management regions"); also, states have flexibility under the Clean Air Act in developing state implementation plans under the National Ambient Air Quality Standards program. Therefore, state air pollution requirements and controls vary considerably.

In addition to meeting baseline federal requirements, areas that fail to meet—or are at risk of failing to meet - national ambient air-quality standards may adopt additional measures beyond those that apply statewide in order to improve air quality. Indeed, many of the standards recently adopted by EPA in its recent NSPS - such as those that apply to completions and re-completions of hydraulically fractured wells, storage vessels, and pneumatic devices - are similar to those already required in the Upper Green River basin in Wyoming and in Colorado (WY DEQ 2010, CDPHE 2012, COGCC 2008). ${ }^{102}$ A different situation exists for the Barnett Shale, also in an area that fails to meet national ambient air-quality standards for ozone, where the state imposes few limits on the emissions of VOCs and hazardous air pollutants; here, EPA's new rules will add a number of requirements. See Table 29, Appendix C, for a comparison of how EPA's new

\footnotetext{
${ }^{100}$ Proposed N.Y. Comp. Codes R. \& Regs. tit 6, § 750-3.12.

${ }^{101}$ NY SGEIS, $\S$ 7.1.7.1.

${ }^{102}$ See also COGCC R. 805.
} 
reduced-emission completion requirement (or "green completion") compares with existing requirements in the basins reviewed. ${ }^{103}$

Despite EPA's enhanced role in regulating air pollution, states retain substantial discretion to regulate uncovered sources or pollutants, or, where permitted under state law, adopt more stringent rules and/or require additional reporting. For example, Pennsylvania recently added a requirement that natural gas operators report annually amounts of air pollutants. ${ }^{104}$ New York has also proposed additional clean-air measures, including a requirement that natural gas operators submit plans to reduce $\mathrm{GHG}$ emissions. ${ }^{105}$ State requirements vary considerably related to the amount of associated natural gas that operators may flare or vent during production. As production increasingly shifts toward liquids and oil-rich formations, this issue is likely to be an area of continuing policy focus because EPA's reduced-emission completion requirement does not apply to associated gas emitted during the production phase of oil wells. ${ }^{106}$ EPA's recent Fort Berthold Indian Reservation rule provides one example of how regulators, going forward, may address the problem of associated gas emissions.

A number of recent air studies and reports have raised questions related to the sufficiency of current air regulations to protect the health of local communities from hazardous air pollutants and reduce fugitive and vented methane emissions (McKenzie et al. 2012; Petron 2012). As the industry expands, especially into more densely populated areas, concerns regarding air quality and GHG emissions will likely persist and receive ongoing regulatory attention.

\subsubsection{Compliance Monitoring and Enforcement}

Compliance is essential if regulations are to serve their purpose of mitigating environmental risks. Significant challenges for compliance monitoring occur due to the unique nature of the unconventional natural gas industry, characterized by dispersed and often remotely located facilities controlled by numerous operators whose practices can vary significantly. On top of this, regulators face a rapidly changing industry as development, technologies, and practices continue to expand in scale and scope.

A number of reports that have addressed the adequacy of state compliance monitoring and enforcement capabilities conclude that state inspection and enforcement capacity varies significantly, as do state processes for recording and disseminating compliance histories to the public (Groat and Grimshaw 2012; Earthworks 2012b; Soraghan 2011). For example, as Table 5 illustrates, Colorado and Wyoming have 15 and 12 inspectors, respectively, dedicated to oil and gas facilities (Earthworks 2012b; Groat and Grimshaw 2012). Pennsylvania, by comparison, quadrupled its enforcement staff in 2010, resulting in 193 enforcement personnel, 65 of whom are inspectors (Earthworks 2012b). Similarly, Texas has 125 inspectors while Louisiana has 38 (Groat and Grimshaw 2012, LDNR 2011). Data for New York were not identified.

\footnotetext{
${ }^{103}$ Texas air rules are not comparable to EPA's recent rules in overall scope or rigor, with the exception of Fort Worth's "green completion" requirement. See Appendix C for green completion requirements.

${ }^{104}$ Act 13.

${ }^{105}$ NY SGEIS, $§ 7.6 .8$.

${ }^{106}$ For a discussion of this issue, see Clifford Kraus, New York Times, "In North Dakota, Flames of Wasted Gas Light the Prairie" (September 28, 2011).
} 
As illustrated in Table 5, the number of inspections performed in each state varied considerably as well, although the data demonstrate a correlation between the number of inspectors and number of onsite inspections. Adequate inspection capability is critical to carry out the SEAB recommendation that "regulation of shale gas development should include inspections at safetycritical stages of well construction and hydraulic fracturing” (SEAB 2011a).

Table 5. Compliance Monitoring and Enforcement Capabilities ${ }^{107}$

\begin{tabular}{cccccc}
\hline State & $\begin{array}{c}\text { Inspectors } \\
(\mathbf{2 0 1 0 - 2 0 1 1 )}\end{array}$ & $\begin{array}{c}\text { Field } \\
\text { Inspections } \\
(\mathbf{2 0 1 0 - 2 0 1 1 )}\end{array}$ & $\begin{array}{c}\text { Total } \\
\text { Violations } \\
(\mathbf{2 0 0 9 - 2 0 1 1 )})\end{array}$ & $\begin{array}{c}\text { Percent of } \\
\text { total } \\
\text { Violations that } \\
\text { are Procedural }\end{array}$ & $\begin{array}{c}\text { Percent of Violations } \\
\text { that Result in } \\
\text { Enforcement }\end{array}$ \\
\hline CO & $15^{109}$ & $16,228^{110}$ & N/A & N/A & N/A \\
\hline LA & $38^{111}$ & 363 & 158 & 60 & 70 \\
\hline PA & $65^{112}$ & 298 & 2,280 & 22.4 & N/A \\
\hline TX & 125 & N/A & $35^{113}$ & $72^{114}$ & 20 \\
\hline WY & 12 & 2 & N/A & N/A & N/A \\
\hline
\end{tabular}

Research conducted by the University of Texas identified significant variation among states in terms of the types of violations found (e.g., pit and tank construction and maintenance are the most common violations in Louisiana, whereas permitting violations are most common in Texas). Despite the variation in violations, it appears that most violations identified are minor or procedural violations. Note, however, that this does not necessarily mean that most environmental impacts associated with gas development are minor, nor that companies comply with more "serious" requirements at higher rates. A number of factors affect the types of violations that inspectors identify, such as the visibility of violations (e.g., special equipment is needed to detect and measure natural gas leaks from equipment), state inspector capacity to respond to complaints or conduct investigations, and types of complaints reported (Groat and Grimshaw 2012).

Enforcement varies considerably among states, as well. Table 5 illustrates that the percent of violations leading to enforcement actions differed significantly among states where data are available (e.g., 70\% of violations noted resulted in enforcement actions in Louisiana compared to only $20 \%$ in Texas) (Groat and Grimshaw 2012; Soraghan 2011). Penalties also vary significantly across jurisdictions, due in part to statutory constraints limiting the amount of penalties a state may assess for a given violation (e.g., the maximum fine for a violation in Colorado is $\$ 1,000$ per day, whereas enforcement authorities in Pennsylvania and Texas can issue fines of $\$ 5,000$ and $\$ 10,000$ per day, respectively) (Earthworks 2012b). Some have questioned whether monetary penalties are sufficient to deter non-compliance given the

\footnotetext{
${ }^{107}$ Data taken from Groat and Grimshaw (2012), unless otherwise noted.

108 Soraghan 2011.

${ }^{109}$ Earthworks 2012 b.

${ }^{110} \mathrm{Id}$.

111 LDNR 2011.

112 Earthworks, 2012b.

${ }^{113}$ See Chapter 4.

114 These are for 2008-2011, rather than 2009-2011.
} 
resources of some companies (Earthworks 2012; Soraghan 2011). Others posit that orders to cease production may be more likely to lead to compliance (Soraghan 2011).

Lastly, public dissemination regarding violations, enforcement actions, and company compliance histories also varies across states. Of the states reviewed, only Pennsylvania maintains a publicly searchable database of violations and enforcement actions. More complete and publicly available data on the compliance histories of companies are needed to understand the effectiveness of compliance and rules, as is more transparency and consistency in the ways that states record and report violations and impose penalties (SEAB 2011a). As with regulations themselves, unevenness in state compliance monitoring and enforcement capacity can lead to additional uncertainty and gaps as well as delay, because public mistrust of industry and regulators can undermine the industry's social license to operate, resulting in bans or moratoria on drilling.

\subsubsection{Summary of State Statutory and Regulatory Framework}

States are the primary regulators, inspectors, and enforcers of most impacts associated with unconventional natural gas development. Regulatory requirements, compliance monitoring, and enforcement capabilities vary across states. Some of this variation is reduced by the recent trend toward consistency in requirements related to the public disclosure of fluids and the amount and sources of water used in hydraulic fracturing. Additional regulation is likely in the area of well integrity standards - specifically, greater adoption of requirements to ensure adequate casing and cement jobs such as cement bond logs and pressure testing of casing. In addition, in light of continued public concern regarding adverse air, water, and waste impacts associated with unconventional gas development, states are likely to adopt regulations requiring baseline watermonitoring requirements, air-quality rules, and provisions that encourage or require greater reuse of produced and flowback waters. Some states may need to increase their inspection and enforcement resources to ensure that rules are being followed. Processes that provide greater transparency regarding state methods for identifying violations and bringing enforcement actions would help to improve public understanding of the extent to which additional resources are needed. Additional accountability and public trust are likely to result from self-reporting mechanisms that are publicly available, such as a joint industry non-governmental organization database on company compliance records (see SEAB 2011a).

\subsection{Local Regulation and Social License to Operate}

Across the country, communities have responded to the increased development of unconventional natural gas with mixed reactions. In half of the states reviewed for this study (Colorado, New York, and Pennsylvania), legislation has recently been proposed or enacted to limit the power of local governments to regulate unconventional gas development, or to make such local authority explicit (see Figure 12). In these states, 30 local governments have banned hydraulic fracturing or oil and gas development altogether, and an additional 73 have issued temporary moratoria pending review and potential revision of local land-use or other ordinances. ${ }^{115}$ This section examines three different approaches to the issue of local authority,

\footnotetext{
${ }^{115}$ A handful of states have also banned or issued moratoria. In addition to New York, New Jersey (see A 3653 (introduced Jan. 6, 2011, http://www.njleg.state.nj.us/2010/Bills/A4000/3653 R1.HTM), and Maryland (see The Marcellus Shale Safe Drilling Act of 2011 H.B. 852 (effective June 1, 2011, http://mlis.state.md.us/2011rs/fnotes/bil_0002/hb0852.pdf) instituted temporary moratoriums on hydraulic fracturing; Vermont recently banned the practice (see H. 464 [enacted May 16, 2012]).
} 
and provides an example of one set of requirements - setback requirements - intended to protect local communities and sensitive resources from adverse drilling impacts to illustrate differing approaches across and among states.

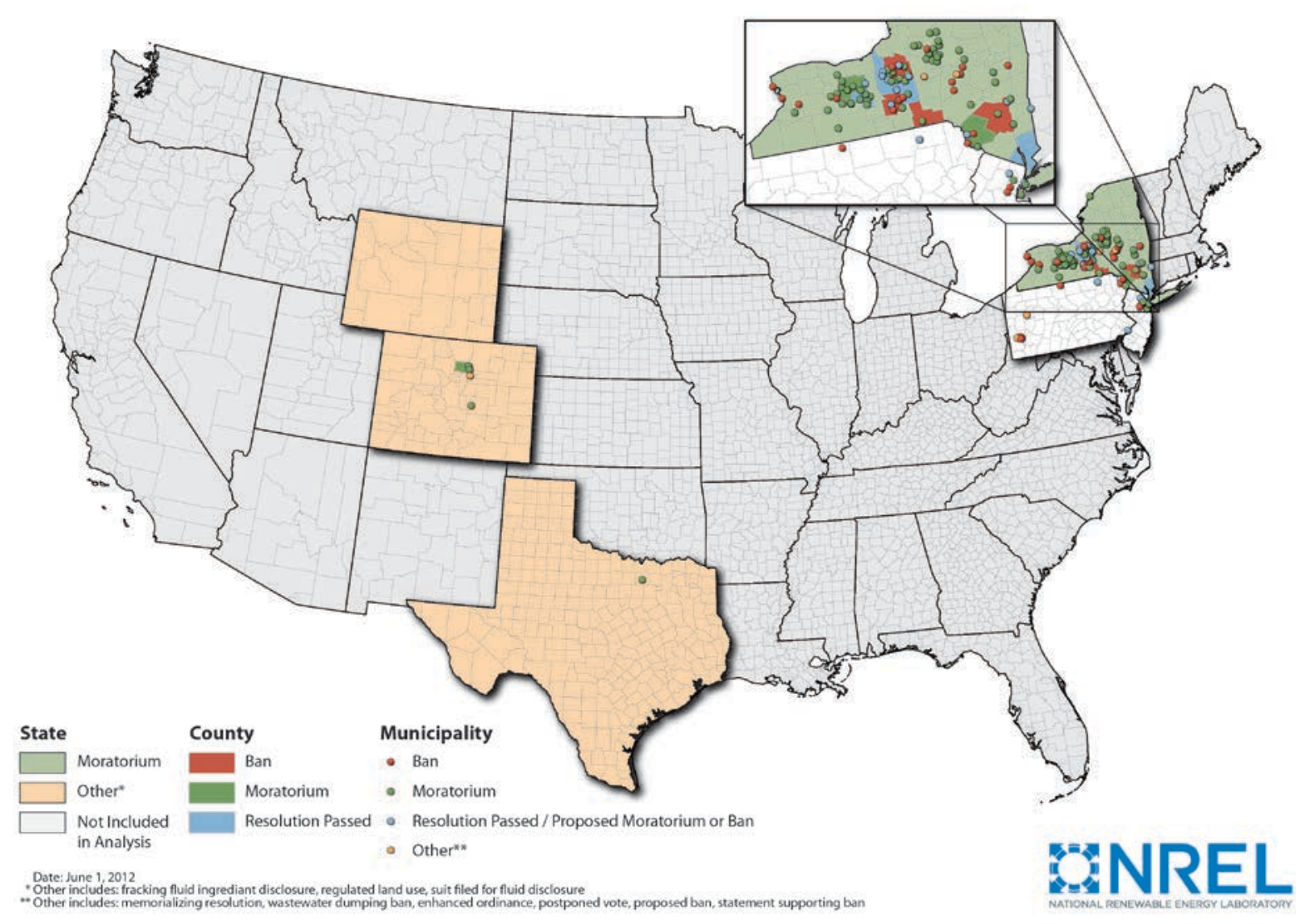

Figure 12. Variation in the rules for six states of rules covering natural gas fracking

States grappling with the issue of local control have adopted very different postures. At one end of the spectrum, Pennsylvania recently enacted legislation that places virtually all control over natural gas development in the hands of the state government. ${ }^{116}$ This law, which went into effect April 16, 2012, elicited significant public opposition (Robinson 2012a; Robinson 2012b). A state court judge recently overturned those portions of the law restricting local governments from regulating oil and gas development on the basis that they unconstitutionally violate the substantive due process rights of local governments to enact zoning ordinances that protect the interests of neighboring property owners and neighborhood characteristics (Pellegrini 2012).

\footnotetext{
${ }^{116}$ Act 13 supersedes all local ordinances purporting to regulate oil and gas operations, other than those adopted pursuant to the Pennsylvania municipalities and planning code and Flood Plain Management Act and provides that "all local ordinances regulating oil and gas operations shall allow for the reasonable development of oil and gas resources." Municipalities must allow "oil and gas operations, other than activities at impoundment areas, compressor stations and processing plants as a permitted use in all zoning districts." The Act allows for the location of well pads within 300 feet of existing buildings, unless the wellhead is less than 500 feet from any existing building. Under the Act, counties may require oil and gas operators to pay impact fees ranging from $\$ 40,000$ to $\$ 60,000$ for the first year of production adjusted based on natural gas prices and inflation thereafter. $58 \mathrm{~Pa}$. Cons. Stat. $\S 3218$.
} 
The Corbett Administration filed an appeal of that decision which is set to be heard by the Supreme Court of Pennsylvania on October 17, 2012. ${ }^{117}$

New York's approach to local control represents the other end of the spectrum. In that state, 26 localities have banned natural gas development or hydraulic fracturing altogether, two of which have been upheld as valid exercises of local zoning authority (Dryden 2012; Middlefield 2012). In addition, two bills have been proposed in New York that would allow local governments to enact or enforce laws and ordinances relating to oil, gas, and solution mining. ${ }^{118}$

In Colorado, the issue of local control over oil and gas drilling has become an increasingly prominent subject of discussion. Earlier this year, the Governor formed a multi-stakeholder task force to address the issue. The task force ultimately recommended "coordinated regulation through a collaborative approach..." (CDNR 2012), but what this means in practice remains to be seen. Five bills related to the topic of local control were introduced in the most recent legislative session. ${ }^{119}$ In addition, four localities in the Front Range have moved to delay drilling pending a review of their oil and gas, land use, and public health laws; a fifth locality is currently considering a moratorium. ${ }^{120}$ To date, the result of these reviews has been one set of final regulations issued by the City of Longmont, draft regulations issued by Boulder County, ${ }^{121}$ and one set of operator agreements. ${ }^{122}$ The City of Longmont finalized its ordinance in July 2012. The ordinance includes riparian and residential setbacks, disclosure requirements, water testing, wildlife protections, and a ban on drilling in residential areas. ${ }^{123}$ Boulder County's draft revisions also contain residential and riparian setbacks, water-testing requirements, emergency response, and other measures intended to protect public health such as air-pollution controls. ${ }^{124}$ Shortly after Longmont issued its ordinance, the Colorado Oil and Gas Conservation Commission filed a lawsuit against the City of Longmont alleging that state law preempts a

\footnotetext{
${ }^{117}$ Scott Detrow, StateImpact, "Corbett Administration Filed Act 13 Appeal with State Supreme Court” (July 27, 2012), http://stateimpact.npr.org/pennsylvania/2012/07/27/corbett-administration-files-act-13-appeal-with-statesupreme-court/.

${ }^{118}$ A8557 (Aug. 24, 2011) (authorizes local governments to address natural gas drilling in their zoning or planning ordinances); A3245 (Jan. 24, 2011) (would allow local governments to enact and enforce local laws/ordinances of general applicability).

${ }_{119}$ SB 088, introduced Feb. 16, 2012 (would have granted COGCC exclusive jurisdiction to regulate oil and gas operations); HB 1173, introduced Feb. 6, 2012 (would have required closed-loop systems for hydraulic fracturing fluid storage/containment); HB 1176, introduced Feb. 6, 2012 (would have mandated setbacks of at least 1000 feet from any school or residence in urban areas); HB 1277, introduced Feb. 20, 2012 (would have stated that oil and gas operators would be subject to the same local government control as for other types of mineral extraction, i.e., a shared state and local approach); SB 107, introduced May 5, 2012 (contained specific requirements, such as closedloop drilling, water reporting requirements, and the prohibition of the use of carcinogens in hydraulic fracturing fluids).

${ }^{120}$ As noted above, these include Boulder County, Erie, Longmont, and Colorado Springs. At the time this chapter went to publication, the town of Lafayette, Colorado, was considering a temporary ban on oil and natural gas drilling. NGI's Shale Daily, "Another Colorado City Considering Drilling Restrictions" (September 6, 2012).

${ }^{121}$ At the time this Chapter went to publication, the Boulder County Planning Commission was considering proposed Land Use Code amendments to address drilling in the County. The City of Longmont finalized its oil and gas revisions to its Municipal Code, Ordinance O-2012-25, on July 17, 2012.

${ }_{122}$ Copies of the agreements are available on the Town of Erie's website, http://www.erieco.gov/CivicAlerts.aspx?AID=487 (last visited September 25, 2012).

${ }_{123}$ City of Longmont Ordinance O-2012-25 (July 17, 2012).

${ }^{124}$ Boulder County, Docket DC-12-0003: Amendments to Oil and Gas Development Regulations, http://www.bouldercounty.org/find/library/build/dc120003stafrecregs20120924.pdf.
} 
number of the purported protections including the riparian and wildlife setbacks, residential wellsite ban, disclosure rule, water-testing requirements, a requirement that operators use multi-well sites, and visual mitigation measures. ${ }^{125}$ The Oil and Gas Conservation Commission has yet to take an official position on Boulder County's regulations. Nevertheless, the Commission's suit against Longmont may indicate that the approach recommended by the Governor's Task force earlier this year will tilt in favor of state rather than local regulation, with the amount of control retained by the local governments unclear.

Local governments across all states covered in this study are also seeking to impose additional setback requirements, but the governing state law on these requirements varies by jurisdiction. Local setback requirements that are more stringent than state law exist in the Barnett Shale play, Eagle Ford play, Marcellus Shale play in Pennsylvania, and North San Juan basin. There is considerable variety in setback requirements, as well as increasing public interest in this issue. Lack of consensus regarding the appropriate distance required to protect against adverse air, noise, visual, or water pollution may, in part, explain the continuing controversy over setback requirements (CU 2012). For a comparison of specific state and local requirements, see Table 30, Appendix C, Setback Requirements.

\subsection{Best Management Practices}

Various commissions and reports have stressed the need for continuous improvement in industry practices, as well as industry-led organizations dedicated to developing and disseminating information on best practices (SEAB 2011b; NPC 2011; IEA 2012). Technological innovation in the effort to control and mitigate some of the resource and environmental impacts of unconventional gas development can improve efficiency, reduce environmental risk, and bolster public confidence. As in many industries, leading operators in unconventional gas development have often performed at a level over and above existing regulatory requirements, providing important sources of innovation for new practices and regulations. Notably, a handful of important regulatory developments started as best management practices adopted by leading operators.

For example, as noted above, prior to EPA's adoption of its recent NSPS for the oil and gas sector, leading companies implemented reduced-emission completions ("green completions") to increase profits by maximizing sales of natural gas from the recovery of natural gas otherwise lost to the atmosphere; others voluntarily report chemicals used in hydraulic fracturing fluids to the Groundwater Protection Council's public FracFocus website. ${ }^{126}$ Today, a number of companies are developing methods to recycle and reuse flowback and produced waters that reduce operator costs, as well as the risks associated with other forms of disposal. ${ }^{127}$ As discussed in the following chapter, documenting such beyond-compliance best practices is an area that merits further study.

\footnotetext{
${ }^{125}$ Colorado Oil and Gas Conservation Commission v. City of Longmont (filed August 30, 2012 in the Boulder County District Court).

${ }^{126}$ See Ground Water Protection Council Chemical Disclosure Registry, http://fracfocus.org/.

127 See GIS Mapping Tool in Chapter 4 of this report.
} 


\subsection{Conclusion and Key Findings}

The combination of hydraulic fracturing and horizontal drilling has been hailed by some as the most important energy innovation of the last century, with dramatic implications for the economics and politics of energy in the United States and throughout the world. This "disruptive" technology has fueled a boom in unconventional gas development in various parts of the United States over the last 10 years. Law and regulation (at multiple levels) have struggled to keep up with the rapid growth of the industry. And the contemporary legal and regulatory landscape that applies to unconventional natural gas development is complex, dynamic, and multi-layered.

The federal government has demonstrated a keen and growing interest in this area, as evident by the prominent role natural gas plays in the current Administration's energy policy (White House 2011), the formation of the SEAB Subcommittee, and the announcement or promulgation of a number of new rules related to air and water quality, data collection regarding the aggregate amounts of chemicals used in fracturing fluids, and development on public lands discussed above. Additional federal regulations and new legislation are also possible. The results of EPA's study on the effects of hydraulic fracturing on drinking water could play a key part in directing any such changes.

States will continue to serve as the major source of regulation, with primary responsibility for well-construction standards, disclosure requirements for hydraulic fracturing fluid chemicals and water used during well stimulation, baseline water-monitoring requirements, waste management, and overall compliance monitoring and enforcement. State and local requirements - other than disclosure requirements regarding chemicals and water usage - vary considerably, and this is likely to continue as more states revise their rules to respond to new development. Greater coordination between regulators at all levels of government could help to reduce uncertainty and fragmentation, ${ }^{128}$ as would greater reliance on the expertise contained in organizations such as the State Review of Oil and Natural Gas Environmental Regulation and the Ground Water Protection Council (SEAB 2011a; SEAB 2011b).

State compliance monitoring and enforcement capabilities vary widely. The limited data that have been assembled indicate most violations are minor, but that "enforcement actions are sparse compared to violations noted" (Groat and Grimshaw 2012). Substantially more data and research are needed to understand the extent to which companies are complying with state, local, and federal requirements.

This information gap could begin to be filled by greater reporting, via self-certification requirements that are publicly available, as well as by state databases, searchable by the public, that contain compliance and enforcement records. These activities would also bring greater certainty to this issue.

A number of commissions and industry associations have expressed support for continued development and implementation of beyond-compliance measures (SEAB 2011b; NPC 2011; IEA 2012), and the need for such measures to avoid controversy, delay, and continued

\footnotetext{
${ }^{128}$ For example, BLM's recent proposed rule notes the importance of consistency in federal and state disclosure requirements and the intent to provide consistency by lining up its requirements with those adopted in leading states.
} 
opposition in certain parts of the country. As discussed in the following chapter, more work is needed to identify and evaluate such measures. Given the rapid pace of unconventional gas development in various parts of the country, best practices will have to complement regulationand, in some cases, be folded into it. But as the regulatory landscape evolves, it will be important to establish a framework, where possible, that incentivizes the ongoing development and adoption of new state-of-the-art practices and technologies to minimize the risks associated with developing natural gas resources. 


\section{Key Issues, Challenges, and Best Management Practices Related to Water Availability and Management}

\subsection{Introduction and Objectives}

Shale gas development has several categories of potential risks including air, water, land, and community (Figure 13). Examples of air risks include emissions of GHGs (largely methane) and hazardous air pollutants (e.g., benzene). Land impact risks include ecosystem degradation and land disturbance. Related to water, the risks are either quantity related (regional water depletion) or concerns of quality (surface or groundwater contamination). Community risks include excessive truck traffic and the noise, road damage, and other associated impacts. Induced seismicity is also considered a community issue and the broadest community risk from it could be the loss of the social license to operate (e.g., Energy Institute 2012; Robinson 2012; Zoback et al. 2010.)

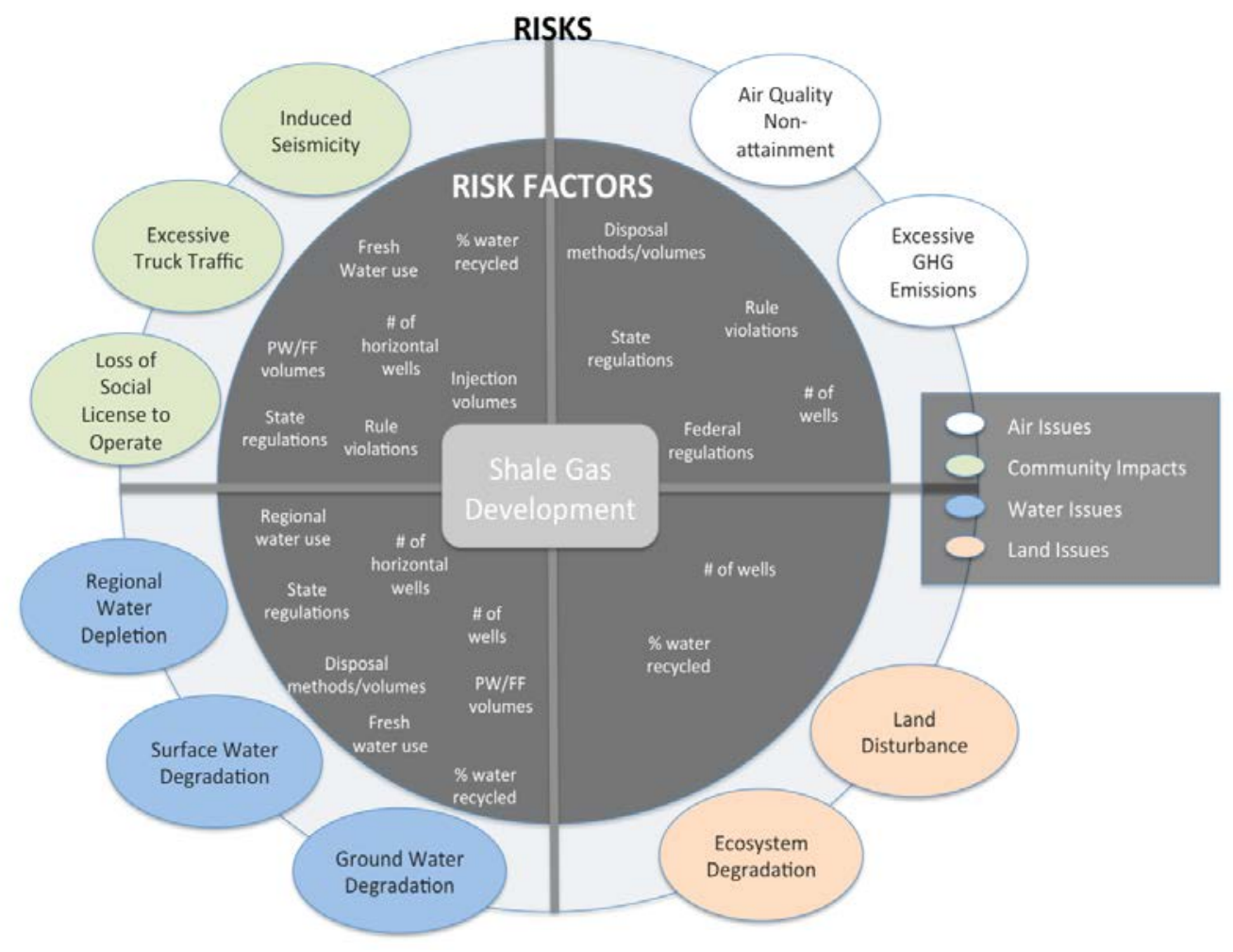

Figure 13. Description of shale gas development risks and characterization metrics

This chapter focuses on the risks and impacts of shale gas development on water resources. Ongoing improvement of the quality and quantity of water resource-related data will inform decisions related to shale gas development. Data collected in this chapter mark the beginning of the risk characterization needed to adequately define best management practices. Specifically, unconventional shale gas development might impact water resources through four major causal routes - one related to water quantity and three related to water quality. 
- Water Quantity:

- Regional water depletion due to large volumes of freshwater use for hydraulic fracturing

- Water Quality:

- Surface and groundwater degradation resulting from inadequate construction practices and well integrity

- Surface and groundwater degradation resulting from inadequate onsite management of chemicals used in hydraulic fracturing

- Surface and groundwater degradation resulting from inadequate wastewater management practices

To better understand the risks to water resources from shale gas production, the variety of risk factors related to water need to be further defined and a thorough spatial and temporal characterization should be completed. The science regarding risks and impacts of the shale gas industry is relatively new and still in a state of flux (EDF 2012; IEA 2012). For this project, we approached the topic by using available literature studies, public databases, and industry interactions.

We established the following objectives to assess the risks to water resources:

- Understand the quantities of water currently being used in six shale plays in the United States as they relate to current estimates of water availability and existing water uses

- Understand the quantities of flowback and produced water for each shale play and the wastewater management techniques employed

- Identify Best Management Practices, including quantity and quality impacts and costs

To accomplish these objectives, we studied six unique natural gas producing regions of the country (as identified in Chapter 2) to capture the spatial variability of water use, water availability, and wastewater management (see Table 8). The six regions include a coalbed methane (CBM) basin (North San Juan); a vertically fractured tight sand basin (Upper Green River); three primarily dry gas shale formations (Barnett, Haynesville, and Marcellus); and one shale formation that is producing condensates and oil along with natural gas (Eagle Ford).

\subsection{Importance of Water for Shale Gas Development}

The recent expansion of shale gas development is, in part, due to advances in horizontal drilling and hydraulic fracturing. As shale gas development continues to grow rapidly across the U.S., the demand for water used during site operations is also expected to increase (COGCC 2012b). Drilling and fracking operations involved in shale gas development require millions of gallons of water per well that must be acquired and transported to sites to fracture the shale formations (EPA 2011). Hydraulic fracturing is essential for tight formations such as shale because the 
geological structure does not have the necessary permeability to allow natural gas to flow freely through the formation and into a wellbore (Arthur 2011). The current development of unconventional shale gas would not be economically viable without hydraulic fracturing, making it important to have an adequate, dependable supply of water to support fracking operations. Equally important is preventing fracking operations from negatively affecting a region's water resources, both in terms of quantity and quality.

Water used in hydraulic fracturing comes from several sources including surface water, groundwater, municipal potable water supplies, or reused water from other water sources (Veil 2010). To date, freshwater has been used for most hydraulic fracturing operations in most regions (Nicot 2012). Surface water, such as streams, rivers, creeks, and lakes, are the largest source of fresh water for operators in the Eastern United States. Groundwater can be a feasible source of water, but only when sufficient amounts are available. In Texas, groundwater is more commonly used than surface water. Public water supply might be an alternative in some regions, because permits for surface and groundwater can take more time to secure.

The impact of water usage will depend on the availability of local water resources, which can vary regionally depending on the geographic location of the shale play, ground and/or surface water sources, and competing demands for water from other users. In locations vulnerable to droughts, operational water needs could adversely impact the viability of gas production from tight formations (Vail 2010). Droughts, particularly in water-stressed regions (such as the arid Southwest), can limit the amount of available water, increasing the competition for water between potable water supplies, water for agriculture, and water for fuel.

\subsection{Assessment of Risks to Water Quantity and Water Quality}

Shale gas development may incur risks to both regional water quantity and quality. Quantityrelated risks depend on the number of wells drilled, water use per well, amount of recycling or non-potable water use that occurs to offset freshwater demands, and local water availability. Quality-related risks depend on onsite construction techniques, onsite chemical management practices, and wastewater management practices. Risks may vary for any given shale gas development site. In many cases, risks to water resources extend beyond the location of the well being drilled, depending on the source location of the water and where wastewater is treated. Figure 14 shows the various risks to water resources that can result from hydraulic fracturing operations. 


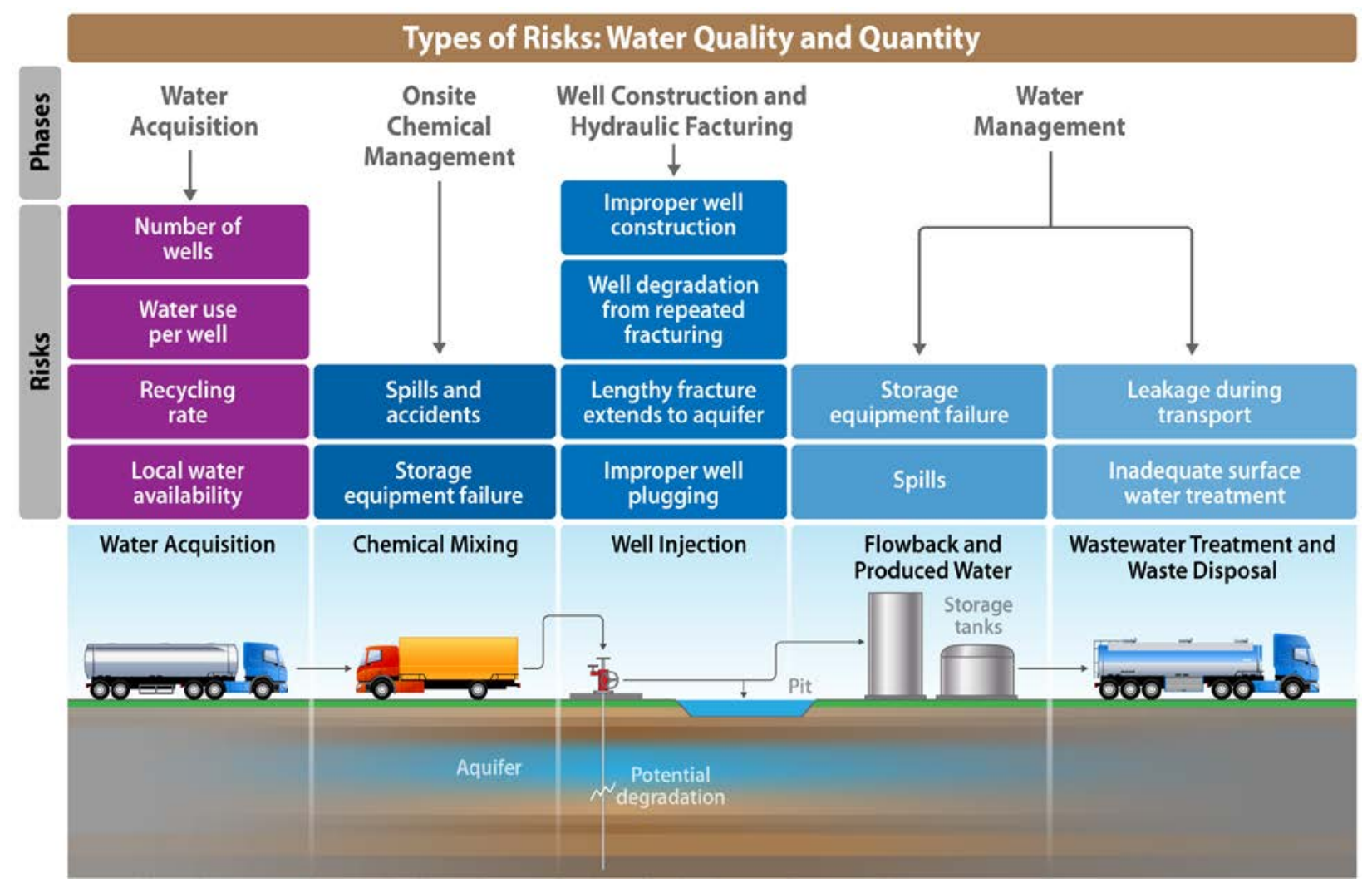

Figure 14. Water quality risks by phase of natural gas production. ${ }^{129}$

\subsubsection{Risks to Water Quantity}

\subsubsection{Current Industry Activities Affecting Water Use}

A crucial component of hydraulic fracturing is securing a sufficient amount of water for operations. Water may not always be available on the lease site; therefore, developers may have to obtain access to water from a different location and transport water to the site. In such cases, the risks to water resource quantities are assessed with respect to the water's source location, not to where it is eventually used. Where operators source their water depends on several factors, such as location, availability, timing, and cost. The closer a water source is to a well, the lower are the operational costs, whether it be pumping or transporting the water by truck. ${ }^{130}$ In many cases, the total amount of water required for multiple operating wells (and the permits required) will be greater than local daily flows. For example, in Pennsylvania, the Susquehanna River Basin Committee (SRBC), which oversees all water source permits in the basin, has approved permits totaling 108 MGD (million gallons per day) at 151 locations (as of September 1, 2011), whereas the estimated peak daily withdrawal of those locations is only around $30 \mathrm{MGD}$. This means that freshwater impoundments might need to be constructed to collect and store water over a period of time to eventually be used to supply water for drilling and developing multiple wells (SRBC 2012).

\footnotetext{
${ }^{129}$ Graphic adapted from (EPA, 2011).

${ }^{130}$ Trucks can often have an impact on rural roads, both in terms of increased traffic and increased wear on roads. Analysis of these impacts is beyond the scope of this paper.
} 
Total water use at a shale gas development site depends on the number of wells drilled, water use per well, and amount of recycling that occurs. The term water "use" is used in this chapter, which, in part, reflects the ambiguity of whether the water usage reported in publicly available sources represents freshwater withdrawals, use of freshwater along with recycled water, water consumption, or a combination of these categories. Future research could clarify the definitions of water usage reported by industry.

\section{Number of wells}

In the areas for which data are available, the number of producing wells drilled each year has been increasing since 2009 (Figure 15).

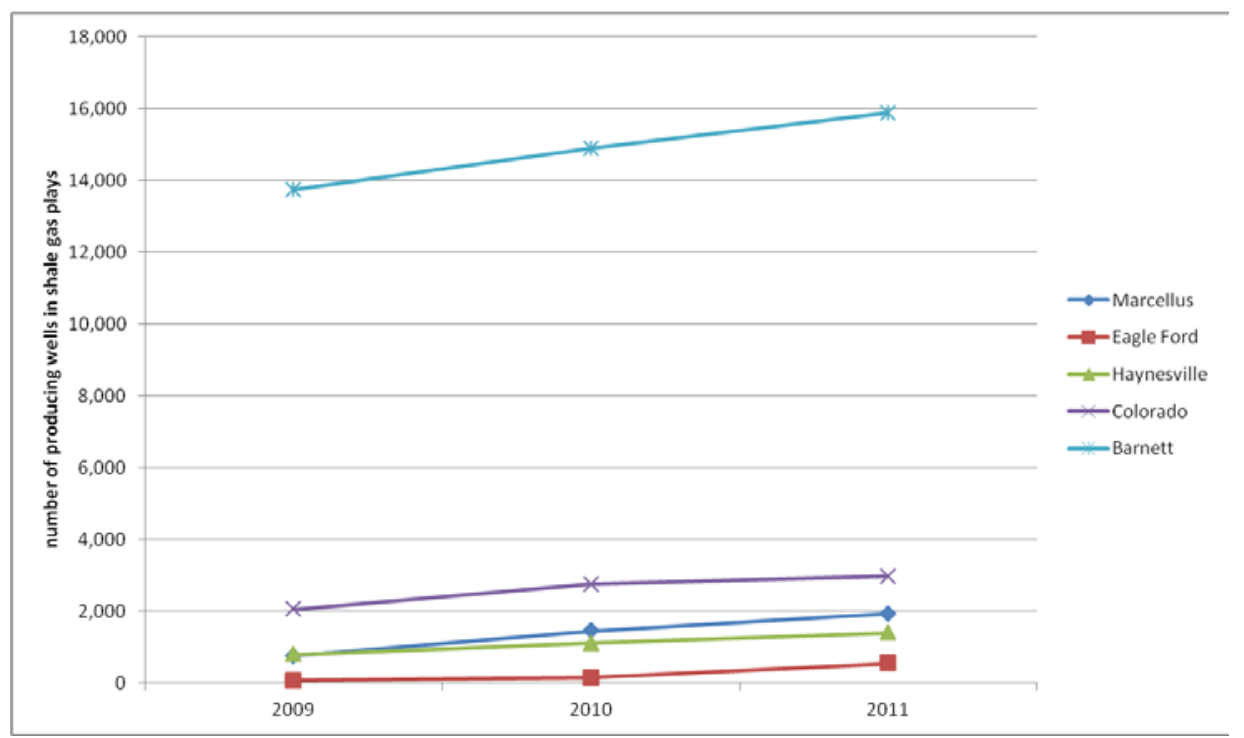

Figure 15. Total number of producing wells in shale gas plays, 2009-2011 (TRRC 2012c; COGCC 2012b; LADNR 2012; PA DEP 2012a; Eagle Ford Shale 2012).

The greatest number of wells is in the Barnett Shale formation, increasing 16\% from 2009 to 2011, with nearly 16,000 producing wells (TRRC 2012c). In the other formations considered in this study, the total numbers of wells are smaller, but have been increasing faster. From 2009 to 2011, the total number of wells increased by $45 \%$ in Colorado (COGCC 2012b), 76\% in the Haynesville formation (LADNR 2012), 154\% in the Marcellus formation (PA DEP, 2012a), and $721 \%$ in the Eagle Ford formation (Eagle Ford Shale 2012). In all of these formations, well drilling applications have continued to increase each year, indicating a continued trend for the near future.

\section{Water use per well}

Data on the water usage per well were available for five of the six regions considered here. Data from about 100 nominal wells were randomly collected for four regions (Marcellus, Barnett, Eagle Ford, and Haynesville) from www.fracfocus.org, a voluntary online chemical disclosure registry of the water used for fracturing. FracFocus provides statewide and county-wide data. Well data are classified according to their API number, county, fracture date, operator name, well name, well type (Oil/Gas), latitude, longitude, datum, and total water use (including fresh water, produced water, and/or recycled water). Water use statistics are compiled and are displayed in Appendix D. 
Average water use from the 100-well study in the five regions ranges from 1.1 to 4.8 million gallons per well, with a multi-region average of 3.3 million gallons per well (Figure 16).

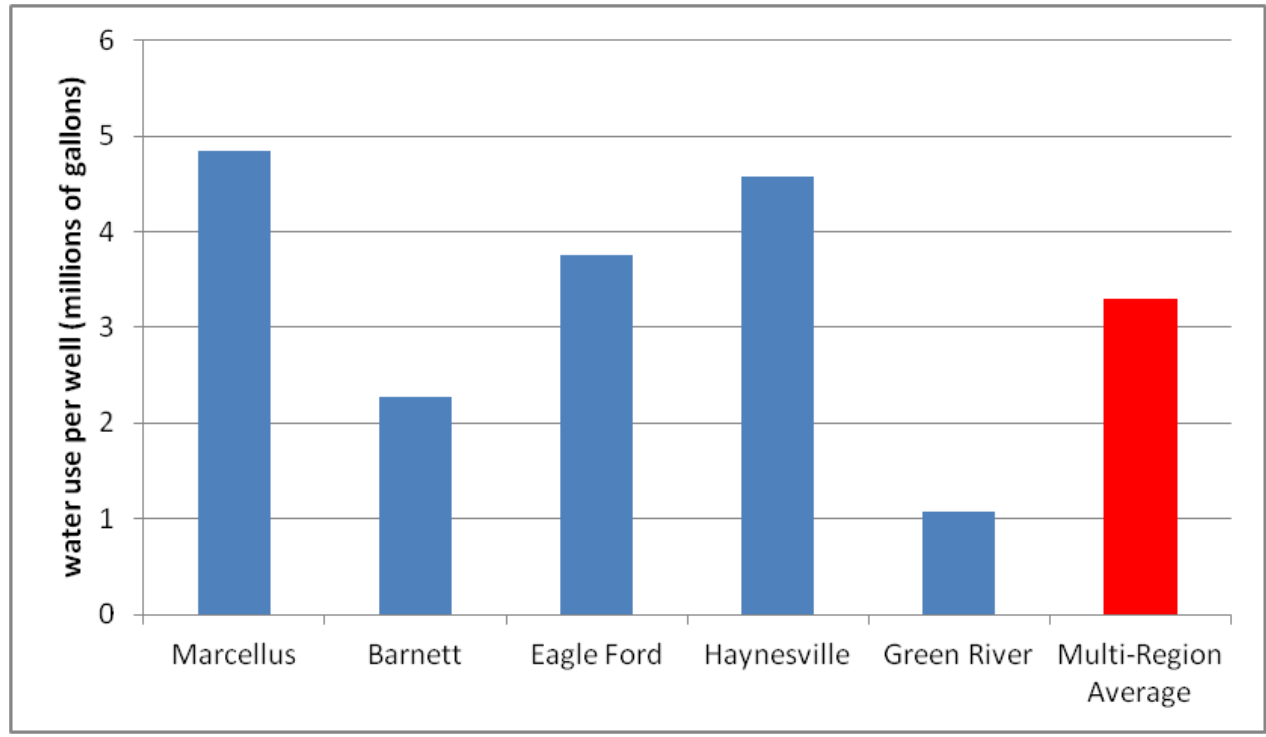

Figure 16. Average water use per well (in millions of gallons) for five regions (2011) (Fracfocus.org).

The Barnett, Eagle Ford, and Green River formations had average water uses of less than 4 million gallons per well, and the Marcellus formation had the highest average water use of 4.8 million gallons per well. Furthermore, considerable variation in water use per well within each formation is shown in Figure 17.

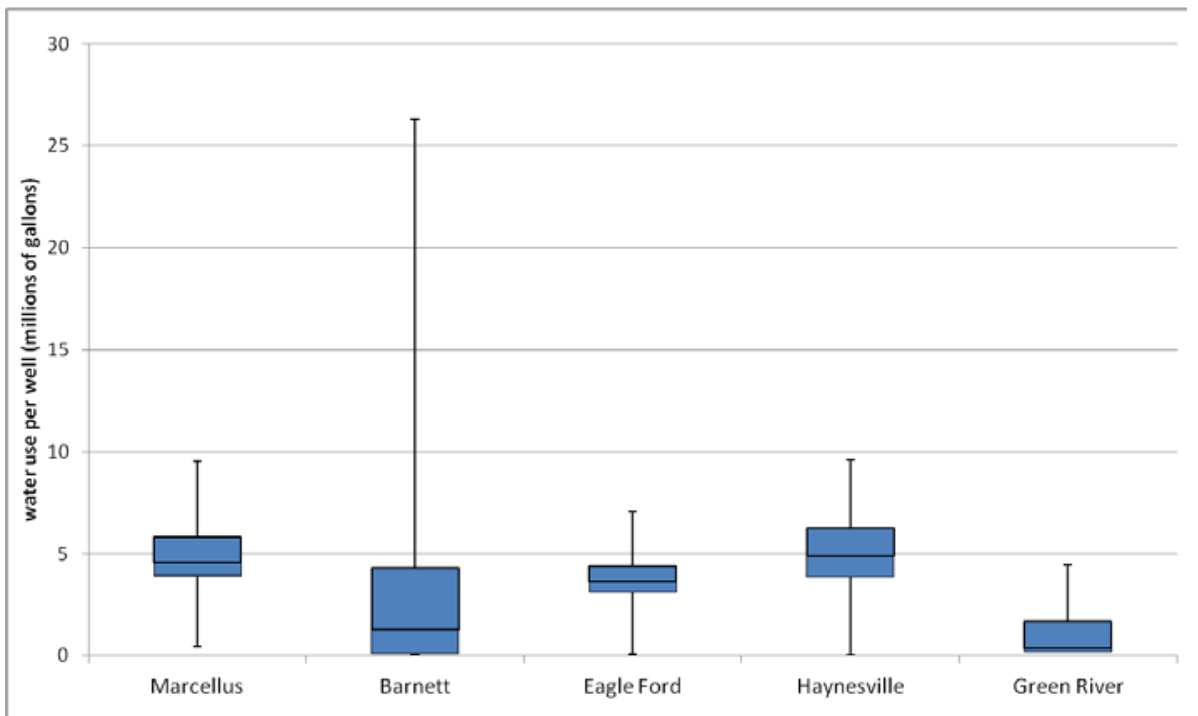

Figure 17. Water use per well for four formations, in millions of gallons. (fracfocus.org)

Note: Low and high error bars represent minimum and maximum reported water usage per wells, respectively. Upper and lower ends of boxes represent $75^{\text {th }}$ and $25^{\text {th }}$ percentile, respectively. Horizontal lines in boxes represent medians. 
Results of the 100 well analyses indicate that water usage per well can vary by up to three orders of magnitude (29,000 gallons to 26 million gallons per well in the Barnett formation) depending on geology, type of well and drilling techniques, and industry practices. Median estimates of water usage per well are around five million gallons for the Marcellus, Eagle Ford, and Haynesville formations, yet individual wells can vary greatly. The Barnett formation has the second lowest median value of 2.3 million gallons per well, yet also the highest individual well value of 26 million gallons per well. These statistics do not indicate whether a portion of the water utilized for hydraulic fracturing includes recycled water.

\section{Recycling rates}

The impacts on local freshwater resources can be reduced by recycling produced water and frac flowback water. To use wastewater, a series of steps are commonly employed (Mantell, 2011). The water must often be stored in onsite holding tanks before treatment and is filtered or transported to another storage tank to test its remaining constituents. The water is then pumped or otherwise transported to another well location for reuse. Currently, only Pennsylvania tracks the amount of produced water and frac flowback water being recycled for reuse for drilling and hydraulic fracturing operations. Other states considered in this analysis do not have recycling or reuse as a category in their annual reporting forms, yet recycling may be occurring. In Pennsylvania, recycling of produced water has increased from 9\% in 2008 to 37\% in 2011 (PA DEP 2012b). In general, recycling of frac flowback water has increased from $2 \%$ in 2008 to $55 \%$ in 2011. In 2011, based on data reported, this recycling led to the reuse of about 65,000 gallons of produced water per well and 120,000 gallons of frac flowback water per well (Figure 18).

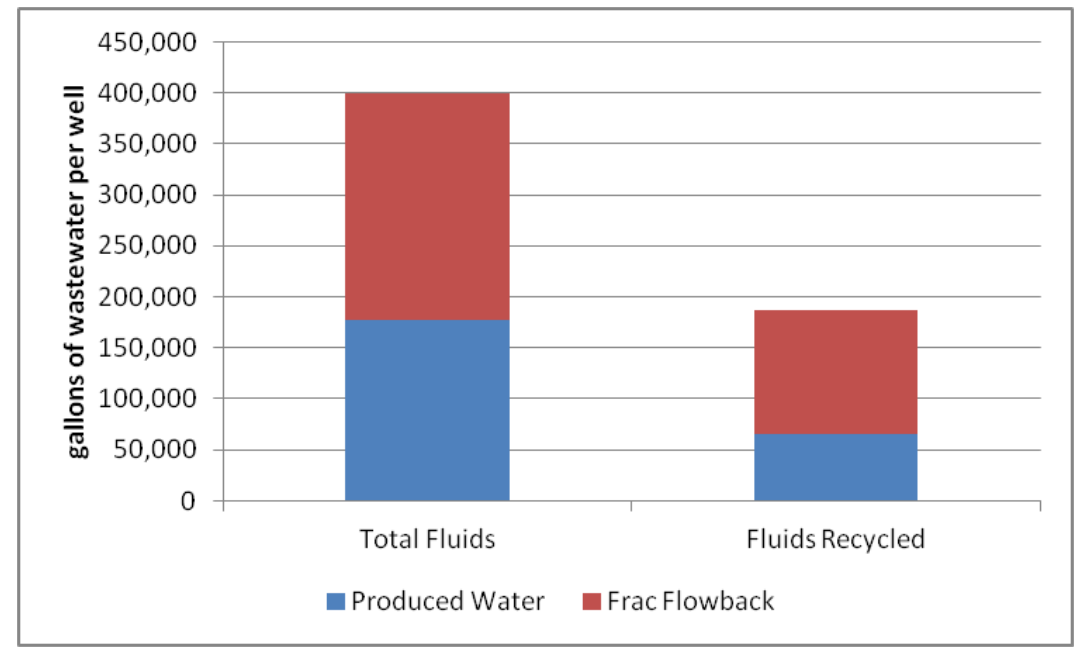

Figure 18. Wastewater production and total recycling at shale gas operations in Pennsylvania in 2011 (PA DEP 2012b)

Although data are not available for recycling rates in other formations, certain state organizations actively encourage recycling practices. The Railroad Commission (RRC) of Texas has provided authorization for seven recycling projects in the Barnett formation, five of which are still active (TRRC 2012d). No recycling authorizations have been given for the Eagle Ford or Haynesville formations to date. The Colorado Oil and Gas Conservation Commission (COGCC) actively 
encourages reuse and recycling of water used in well construction as well as produced water. Although there are no data of quantities, the COGCC notes that several operators in the Piceance Basin have constructed infrastructure for reusing water for drilling and completing new wells (COGCC, 2012b).

The feasibility of recycling and reusing produced water and frac flowback depends, in part, on how much and how quickly water returns to the surface. In the Marcellus and Barnett shale formations, Chesapeake Energy reports that about 500,000 to 600,000 gallons per well will return to the surface in the first 10 days, compared to about 250,000 gallons per well in the Haynesville formation (Mantell, 2011). How much of the produced water can be recycled depends on the chemical composition of the water, including its total dissolved solids (TDS), total suspended solids (TSS), and its concentration of chlorides, calcium, and magnesium. High TDS can increase unwanted friction in the fracking process. High TSS can plug wells and decrease the effectiveness of biocides. High concentrations of other elements can lead to high risks associated with scaling.

Recycling produced water and frac flowback can partially reduce the demand for freshwater sources for new hydraulic fracturing operations. The reduction in freshwater demand is limited by the amount of water that is returned to the surface. In general, the amount of water returned to the surface - and thus, the amount of water that could be recycled — is on the order of $10 \%$ of the freshwater requirements for developing a well with hydraulic fracturing. The volumes of produced water may vary widely from well to well, making it difficult to predict how much water is produced and how much recycling potential there is for each well.

\section{Water availability}

Local water availability conditions in the six study regions can vary greatly. Further information of each shale region can be found in Appendix D. An overview of the six regions is shown in Figure 19. 


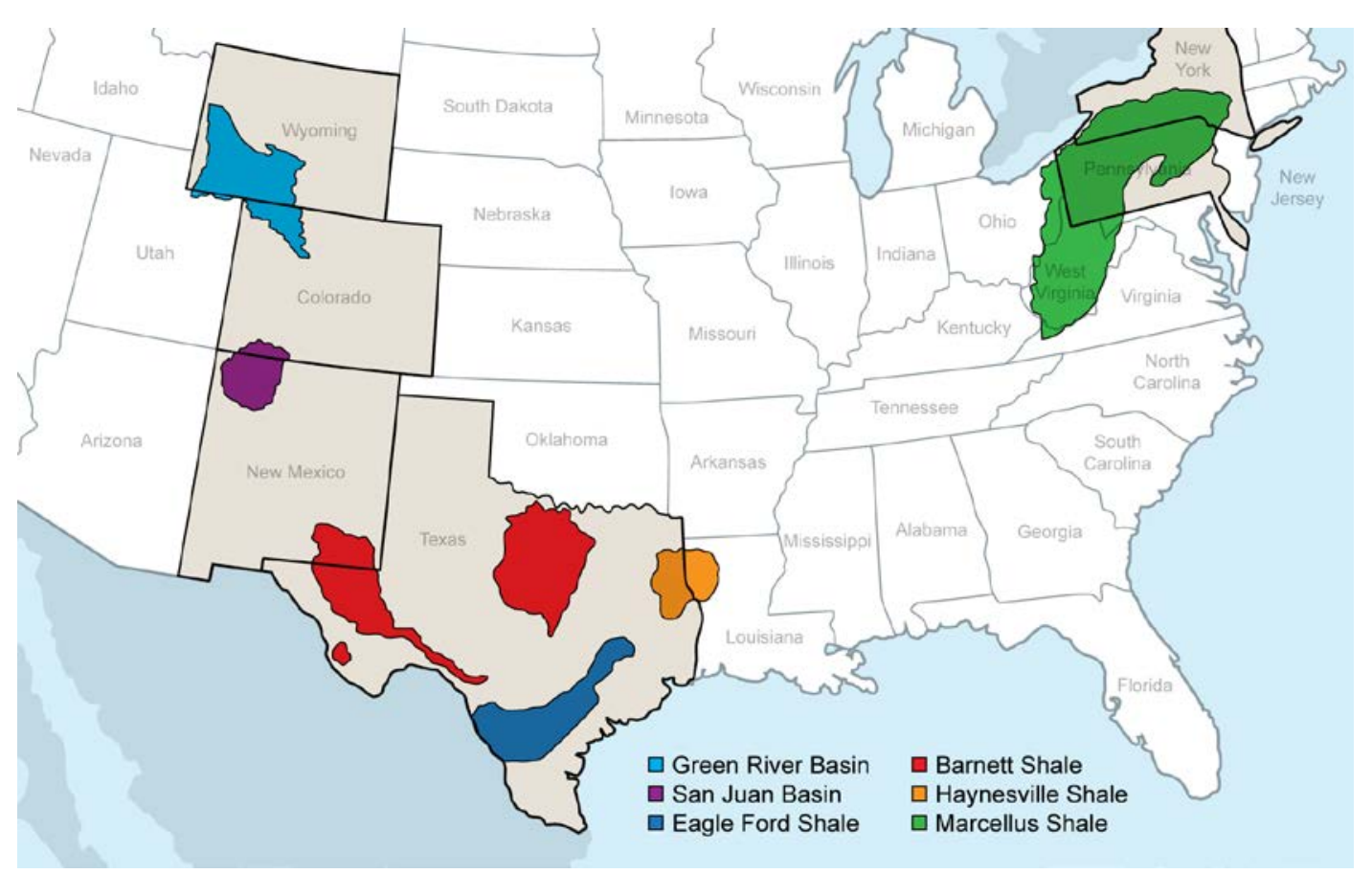

Figure 19. Six shale plays considered in this study.

\section{Marcellus Shale, $P A$}

The Marcellus Shale is located within or nearby highly populated areas of the northeast U.S. occupying the states of New York, Pennsylvania, Maryland, West Virginia, and Ohio. Competition for water might be challenging for shale gas development. However, the area overlying the Marcellus Shale formation has abundant precipitation, making water readily available (Arthur 2010). Three major watershed basins overlie the formation: the Susquehanna, Delaware, and Ohio River Basins are the main suppliers of water for shale gas development.

The Marcellus Shale is overlain by about $72 \%$ of the Susquehanna River Basin (SRB), 36\% of the Delaware River Basin, and about 10\% of the Ohio River Basin (Arthur 2010). The SRB drains 27,510 square miles, covering about half the land area of Pennsylvania and portions of Maryland and New York (Arthur 2010). Major streams and rivers in the SRB are potential surface water withdrawals for shale gas development.

\section{Texas water}

Texas has dominated shale gas production in the U.S. over the past decade. The Barnett Shale was the sole producer in the early 2000 s and accounted for about $66 \%$ of the U.S. shale gas production from 2007 to 2009 (Nicot 2012). Texas is subject to drought and wet period cycles that might become extreme with climate change and impact the water available. Water requirements are reported to the RRC of Texas. Surface water is owned and managed by the State and requires a water-right permit for diversions. Groundwater is owned mostly by landowners, but is generally managed by legislatively authorized groundwater conservation districts (Nicot 2012). Groundwater is generally available in each of the shale gas plays, and unlike surface water, groundwater is located close to production wells. 


\section{Barnett Shale, TX}

The Barnett Shale is located in central Texas around the Dallas-Ft. Worth area. Precipitation is variable across the state of Texas. The mean annual precipitation in the Barnett area is about 790 $\mathrm{mm}$ per year (Nicot 2012). About $60 \%$ of the water used in hydraulic fracturing operations in the Barnett Shale play comes from groundwater sources, specifically the Trinity and Woodbine aquifers in North Central Texas (Andrew et al. 2009). The Trinity Aquifer extends from southcentral Texas to southeastern Oklahoma, and groundwater use varies across the Barnett Shale development area. For example, groundwater provides about $85 \%$ of total water supply in Cooke County, but only 1\% for Dallas County (Andrew et al. 2009). Extensive development of the Trinity Aquifer in the Dallas-Ft Worth metropolitan area had caused groundwater levels to drop more than 500 feet in some areas (Andrew et al. 2009). For many rural areas, groundwater from the Trinity Aquifer remains the sole water source. Water use can vary widely from county to county depending on the pace of shale gas development. Municipal water use is dominant (greater than 85\%) in the footprint of the Barnett Shale play in Denton and Tarrant counties; elsewhere, water use is mixed with some irrigation and manufacturing (Nicot 2012). Surface water is available in the Barnett Shale area, including major rivers and reservoirs; however, population growth is expected to increase demand for water resources and cause increasing competition. It is predicted that the net water use for shale gas production in the Barnet Shale play will increase from $1 \%-40 \%$ at the county level for selected counties (Nicot 2012).

\section{Eagle Ford Shale, TX}

The Eagle Ford Shale play is located in South Texas. The mean annual precipitation in the Eagle Ford Shale is about $740 \mathrm{~mm}$ per year (Nicot 2012). Surface water in the Eagle Ford Shale region is not as readily available and abundant as the northeast sections of Texas. A small portion of the Rio Grande River at the Mexican border is used, and several streams are ephemeral and recharge underlying aquifers. However, even when surface water is available, it is often not located adjacent to sites; therefore, trucking and piping of water is often required. Operators rely mostly on groundwater from the Carrizo Aquifer, though groundwater has already been partially depleted for irrigation in the Winter Garden region of South Texas (Nicot 2012). Over-extraction of groundwater for irrigation in the past limits water availability for current and future shale gas production (Nicot 2012). Water used in south Texas is variable; municipal water use is dominant (greater than 85\%) in the footprint of the Eagle Ford in Web County (Nicot 2012). It is predicted that during the peak years of production, the net water use for shale gas production in the Eagle Ford Shale region will increase from 5\% to $89 \%$ at the county level for selected counties (Nicot 2012).

\section{Haynesville Shale, LA}

The Haynesville Shale is located in East Texas and western Louisiana. The eastern part of Texas has high precipitation, with a mean annual precipitation of $1,320 \mathrm{~mm}$ per year, resulting in a widespread and abundant supply of surface water (Nicot 2012). The region also hosts large aquifers, specifically, the Carrizo Wilcox and Queen City/Sparta Aquifers. Shale gas production in Louisiana relies heavily on local groundwater from the Carrizo Aquifer and currently derives about $75 \%$ of the water from surface water or lesser-quality shallow groundwater (Nicot 2012). The groundwater is more readily available in East Texas, with the only competition for water use being industrial and municipal demands (Nicot 2012). Furthermore, it is predicted that during the 
peak years of production, the net water use for shale gas production in the Haynesville Shale region will increase from $7 \%$ to $136 \%$ at the county level for selected counties (Nicot 2012).

\section{San Juan Basin, CO}

The San Juan Basin is located in the arid Southwest U.S., occupying the Four Corners area of Colorado, New Mexico, Arizona, and Utah. The basin is characterized by a wide range of topographic settings that include valleys, canyons, badlands, uplands, mesas, and buttes (Haerer 2009). Precipitation in the San Juan Basin varies regionally. Annual precipitation in the high mountain areas in Colorado can receive as much as $1,020 \mathrm{~mm}$ per year, whereas annual precipitation in lower altitudes of the central basin in New Mexico can receive less than $200 \mathrm{~mm}$ per year (Levings 1996). Runoff water from snow and precipitation, which flows into rivers such as the San Juan River, makes up a large portion of the surface water. However, because of high evaporation rates and the hot and dry climate of the Southwest, surface water in the basin is limited and has already been fully appropriated.

Thus, groundwater resources tend to be the only source of water in most of the basin, and they are used mainly for municipal, industrial, domestic, and stock purposes (Levings 1996). The San Juan structural basin is a major oil and gas producing area, and groundwater is produced as a byproduct of these operations (Levings 1996). Several major aquifers exist in the basin; most are unconfined and located within the Tertiary formations (Haerer 2009). The amount of available water varies, depending on the underlying geological rock formations. For example, the Fruitland Formation and Pictured Cliffs Sandstone are aquifers that are sources of drinking water along the northern margin of the basin and act as a single hydrologic unit. The Ojo Alamo Sandstone is the primary aquifer for the southern margins and is a possible source of groundwater (EPA 2004). Groundwater levels in the Fruitland Formation have declined significantly due to the development of energy resources in the San Juan Basin (Levings 1996).

\section{Green River Basin, $W Y$}

The Green River Basin is located in the southwest corner of Wyoming, northwest Colorado, and northeast Utah. The basin drains to the Green River, a major tributary to the Colorado River. On

average, the basin receives about $250-400 \mathrm{~mm}$ of precipitation annually and less than $13 \%$ of the basin receives more than $500 \mathrm{~mm}$ (WWDC 2010). Precipitation is highest during the months of April and May and the least in December and February. There are four regional aquifer systems in the Wyoming side of the Green River Basin. The Cenozoic, Mesozoic, Paleozoic, and Precambrian aquifer systems range from the youngest and most heavily used to the oldest and least used, respectively (WWDC 2010). There has been relatively little development of groundwater resources in the Green River Basin, and the recent increase in shale oil and gas development has relied on groundwater resources as the primary supply to the industry. In Wyoming, irrigated agriculture is the largest water consumer. However, the energy and mineral sectors have historically added volatility in water use and allocation, requiring large amounts of water (WWDC 2010). Groundwater in the basin is used for domestic and pubic supplies, and industrial uses including mining and irrigation. Oil and gas development has increased substantially in the Green River Basin and accounts for a large part of the increase in groundwater use (WWDC 2010). 


\subsubsection{Current Water Quantity Risks Resulting from Industry Activities}

Risks to water quantity resulting from industry practices in shale gas development include reductions in both available surface water and groundwater. These risks occur in the areas from which water resources are sourced, not necessarily the hydraulic fracturing site. In areas where the levels of the groundwater table are already affected by multiple sectors' uses (e.g., agriculture, municipal water supply), large increases in use by any sector might affect water availability or the cost of pumping for all other users.

The water quantity risk to any given water basin depends on how much water is used and on the local water availability. Water usage in shale gas development, as described above, depends on the total number of wells, water use per well, and recycling rate. Water availability depends on local geologic and climatic conditions and on competing users of water. In the study regions, the total number of producing wells has been increasing steadily since 2008. With the exception of Pennsylvania, there are no data indicating a substantial increase in the recycling rate of wastewaters, and the total quantities of freshwater used for hydraulic fracturing have been increasing. The impact of recycling on reducing freshwater demands is limited by the amount of flowback and brine produced from each well. The use of non-freshwater sources, such as shallow brackish waters, could alleviate demands on freshwater; but there are no readily available data on availability or current usage of these water sources for shale gas operations.

Values of total water available physically and legally can be difficult to quantify, but our report analyzes the water usage of oil, gas, and mining activities as a percentage of all other existing water uses. On a state level, the amount of water currently withdrawn for hydraulic fracturing is a relatively minor fraction of total water withdrawals. In Colorado for example, total water diversions for hydraulic fracturing represent only $0.1 \%$ of all water diversions in the state (COGCC 2012b). In Texas, mining activities, which include hydraulic development, accounted for just $2 \%$ of total water withdrawals in 2011 (TDWB 2012).In Texas and Colorado, irrigation accounts for more than $55 \%$ and $85 \%$, respectively, of total water withdrawals (COGCC 2012b; TDWB 2012).

Greater insights into risks to water resources can be gained by analysis on a geospatial scale smaller than the states, such as the county level. In many counties where shale gas development sites are located, mining activities already account for a substantial percentage of existing water usage (Figure 20) (Kenny et al. 2009). 


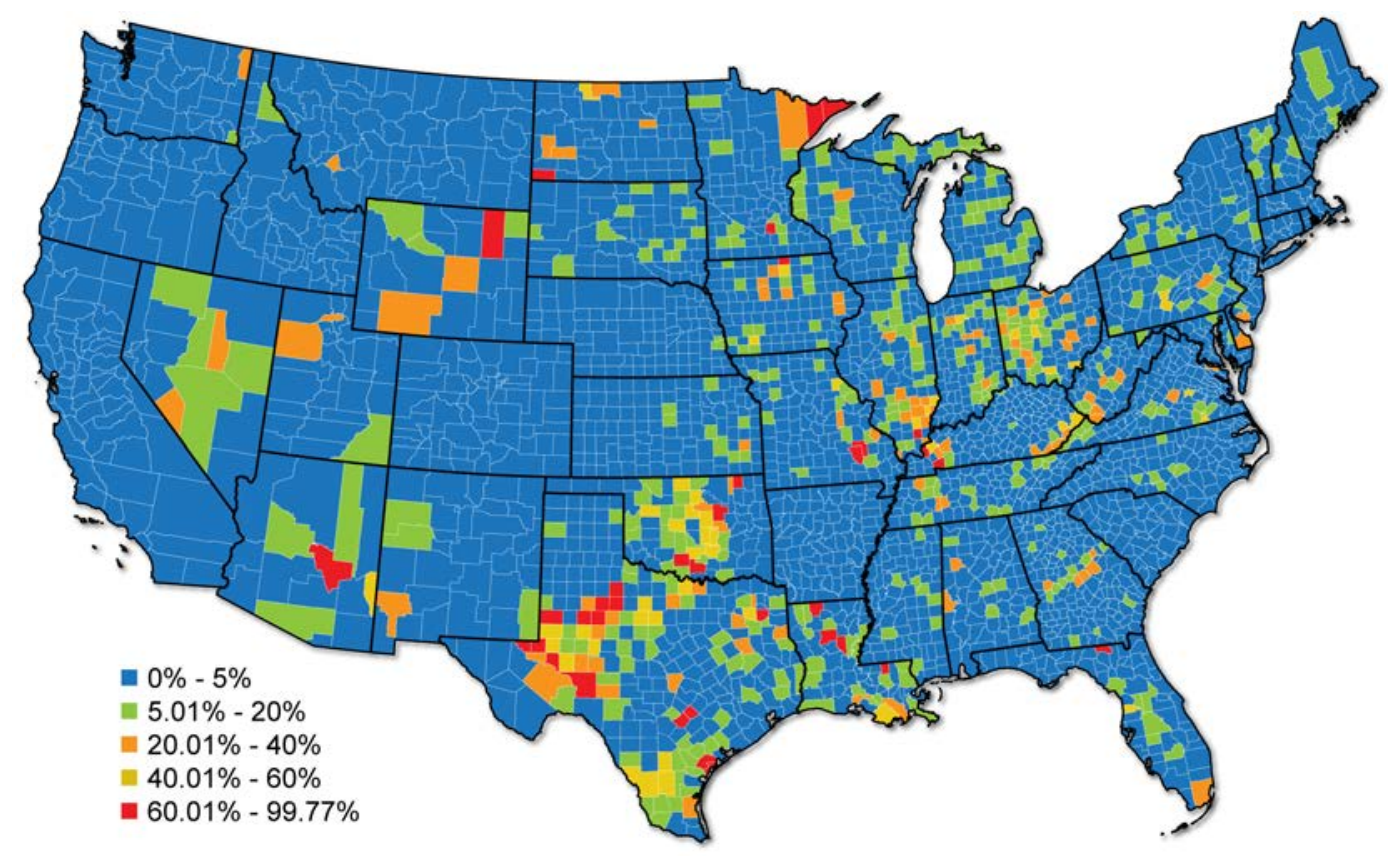

Figure 20. Mining water withdrawals as a percent of total water withdrawals, 2005 (Kenny 2009).

In 2005, mining activities in Texas counties that overlapped with the Barnett, Eagle Ford, and Haynesville formations accounted for a large percentage of total water withdrawals. Similarly, counties in Louisiana overlapping with the Haynesville formation, counties in New Mexico overlapping with the Barnett and San Juan formations, and counties in Wyoming overlapping with the Green River formation show that mining activities account for water withdrawals representing $5 \%$ to over $60 \%$ of total withdrawals in that county. Thus, water use for mining activities already represents a substantial portion of total water usage in the regions where shale gas development is occurring. Rapid expansion of water required for hydraulic fracturing could impact local water availability, depending on water resources in each region. Further research is needed to evaluate the impact that the current and projected water use for mining activities, including hydraulic fracturing, could have on the water resources and other water demands in these regions.

\subsubsection{Risks to Water Quality}

\subsubsection{Current Industry Activities Affecting Water Quality}

Risks to water resources depend on well and drilling construction practices, handling of chemicals on site, and wastewater management. Risks to water quality can occur at both the location of hydraulic fracturing and where water is stored or treated.

\section{Onsite well-construction and hydraulic fracturing practices}

In terms of risk to water resources, well design and construction phase is a crucial component of the hydraulic fracturing process. Proper well construction can separate the production operations from drinking water resources. Well construction involves drilling, casing, and cementing - all of which are repeated multiple times until a well is completed. Drilling is conducted with a drill bit, drill collars, drill pipe, and drilling fluid such as compressed air or a water- or oil-based liquid (EPA 2011). Water-based liquids typically contain a mixture of water, barite, clay, and 
chemical additives (OilGasGlossary.com 2010). Once removed from the well, drilling liquids and cuttings must be treated, recycled, and/or disposed of.

Casing is steel pipe that separates the geologic formation from the materials and equipment in the well, and that also provides structural support. The casing is designed to withstand the external and internal pressures during the installation, cementing, fracturing, and operation of the well. Some operators might forego casing, in what is called an open-hole completion, if the geologic formation is considered strong enough structurally to not collapse upon itself. Casing standards vary regionally and are set by state regulations. Once the casing is in place, a cement slurry is pumped down the inside of the casing and forced between the formation and the casing exterior. The cement serves as a barrier to migration of fluids up the wellbore behind the casing, as well as a structural support for the casing. The cement sheath around the casing and the effectiveness of the cement in preventing fluid movement are the major factors in establishing and maintaining the mechanical integrity of the well; however, even a properly constructed well can fail over time due to stresses and corrosion (Bellabarba et al. 2008). For a given well, there may be multiple levels of drilling, casing, and cementing to prevent contamination of local water resources (Figure 21).

Once the well is constructed, the formation is hydraulically fractured. The hydraulic fracturing occurs over selected intervals where the well is designed to permit fluids to enter the formation. Hydraulic fracturing fluids, by volume, are mostly water and propping agents such as sand, designed to facilitate the fracturing and keep the new fractures open.

The chemicals present in hydraulic fracturing fluids can react with naturally occurring substances in the subsurface, causing these substances to be liberated from the formation (Falk et al. 2006; Long and Angino 1982). These naturally occurring substances include formation fluids (brine), gases (natural gas, carbon dioxide, hydrogen sulfide, nitrogen, helium), trace elements (mercury, lead, arsenic), radioactive materials (radium, thorium, uranium), and organic materials (organic acids, hydrocarbons, volatile organic compounds). 


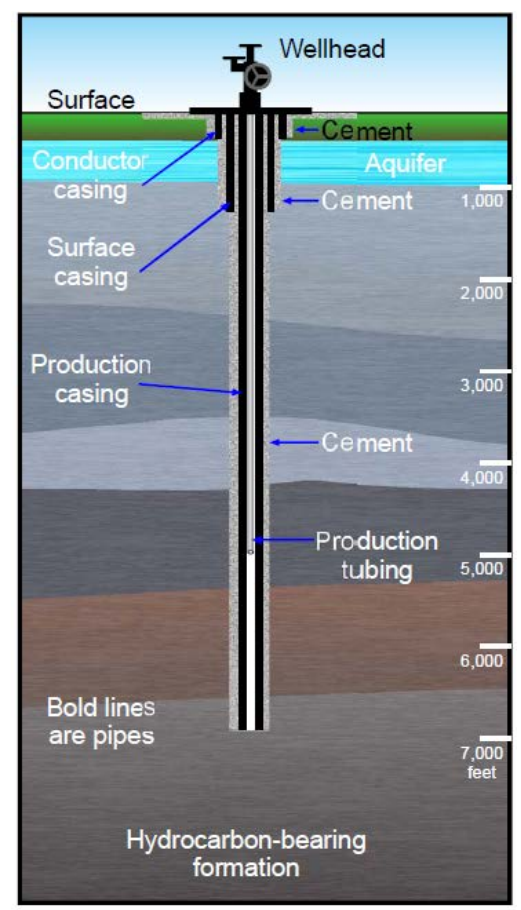

Figure 21. Schematic of well that includes several strings of casing and layers of cement (EPA 2011)

Once a well is no longer producing gas economically, it can either be re-fractured or plugged, to prevent possible fluid migration that could contaminate soils or waters (API 2009). A surface plug is used to prevent surface water from seeping into the wellbore and migrating into groundwater resources.

\section{Onsite handling of chemicals}

The chemicals used in fracking fluids are often mixed together on site with the propping agent (usually sand) and water. The types of chemicals and their volumes might vary from site to site and from developer to developer, depending on formation properties and developer common practices. Chemicals are stored on site in tanks before mixing and hydraulic fracturing operations begin. In general, $0.5 \%$ to $2 \%$ of the total volume of fracking fluid is made up of chemicals (GWPC and ALL Consulting 2009). The composition and relative amounts of chemicals might change from site to site. Table 6 provides an example of the variety and amounts of chemicals that comprise fracking fluid, where chemicals contribute $0.5 \%$ of the volume.

Table 6. Example Composition of Hydraulic Fracturing Fluids (GWPC and ALL Consulting 2009; API 2010)

\begin{tabular}{|l|l|l|l|r|}
\hline Component & $\begin{array}{l}\text { Example } \\
\text { Compounds }\end{array}$ & Purpose & $\begin{array}{l}\text { Percent } \\
\text { Composition } \\
\text { (by Volume) }\end{array}$ & $\begin{array}{l}\text { Volume of } \\
\text { Component } \\
\text { (Gallons) }\end{array}$ \\
\hline Water & & Deliver proppant & 90 & $2,970,000$ \\
\hline Proppant & $\begin{array}{l}\text { Silica, quartz } \\
\text { sand }\end{array}$ & $\begin{array}{l}\text { Keep fractures open to } \\
\text { allow gas flow out }\end{array}$ & 9.51 & 313,830 \\
\hline
\end{tabular}

${ }^{131}$ Based on the average water use per well identified in this study, 3.3 million gallons 


\begin{tabular}{|c|c|c|c|c|}
\hline Component & $\begin{array}{l}\text { Example } \\
\text { Compounds }\end{array}$ & Purpose & $\begin{array}{l}\begin{array}{l}\text { Percent } \\
\text { Composition } \\
\text { (by Volume) }\end{array} \\
\end{array}$ & $\begin{array}{l}\text { Volume of } \\
\text { Component } \\
\text { (Gallons) }^{131} \\
\end{array}$ \\
\hline Acid & Hydrochloric acid & $\begin{array}{l}\text { Dissolve minerals, } \\
\text { initiate cracks in rock }\end{array}$ & 0.123 & 4,059 \\
\hline Friction Reducer & $\begin{array}{l}\text { Polyacrylamide, } \\
\text { mineral oil }\end{array}$ & $\begin{array}{l}\text { Minimize friction } \\
\text { between fluid and pipe }\end{array}$ & 0.088 & 2,904 \\
\hline Surfactant & Isopropanol & $\begin{array}{l}\text { Increase viscosity of } \\
\text { fluid }\end{array}$ & 0.085 & 2,805 \\
\hline $\begin{array}{l}\text { Potassium } \\
\text { Chloride }\end{array}$ & & $\begin{array}{l}\text { Create a brine carrier } \\
\text { fluid }\end{array}$ & 0.06 & 1,980 \\
\hline Gelling Agent & $\begin{array}{l}\text { Guar gum, } \\
\text { hydroxyethyl } \\
\text { cellulose }\end{array}$ & $\begin{array}{l}\text { Thicken fluid to } \\
\text { suspend proppant }\end{array}$ & 0.056 & 1,848 \\
\hline Scale Inhibitor & Ethylene glycol & $\begin{array}{l}\text { Prevent scale deposits } \\
\text { in pipe }\end{array}$ & 0.043 & 1,419 \\
\hline $\begin{array}{l}\text { pH Adjusting } \\
\text { Agent }\end{array}$ & $\begin{array}{l}\text { Sodium } \\
\text { carbonate, } \\
\text { potassium } \\
\text { carbonate }\end{array}$ & $\begin{array}{l}\text { Maintain effectiveness } \\
\text { of other components }\end{array}$ & 0.011 & 363 \\
\hline Breaker & $\begin{array}{l}\text { Ammonium } \\
\text { persulfate }\end{array}$ & $\begin{array}{l}\text { Allow delayed } \\
\text { breakdown of gel }\end{array}$ & 0.01 & 330 \\
\hline Crosslinker & Borate salts & $\begin{array}{l}\text { Maintain fluid viscosity } \\
\text { as temperature } \\
\text { increases }\end{array}$ & 0.007 & 231 \\
\hline Iron Control & Citric acid & $\begin{array}{l}\text { Prevent precipitation of } \\
\text { metal oxides }\end{array}$ & 0.004 & 132 \\
\hline Corrosion Inhibitor & $\begin{array}{l}\mathrm{N}, \mathrm{N} \text {-dimethyl } \\
\text { formamide }\end{array}$ & Prevent pipe corrosion & 0.002 & 66 \\
\hline Biocide & Glutaraldehyde & Eliminate bacteria & 0.001 & 33 \\
\hline
\end{tabular}

In this example, we consider the average water use per well as identified in this study to be 3.3 million gallons. Therefore, the total volume of chemicals used- $0.5 \%$ of the fracking fluid volume - is about 16,500 gallons per well. The total average volume of chemicals used in hydraulic fracturing fluids ranges from 5,500 to 96,000 gallons per well, given the wide range of water use per well, in addition to the chemical composition (Table 7).

Table 7. Estimates of Total Gallons of Chemicals Used per Well

\begin{tabular}{|l|c|c|c|}
\hline & $\begin{array}{c}4.6 \text { million } \\
\text { gallons per well } \\
\text { (average estimate) }\end{array}$ & $\begin{array}{c}\text { 2.3 million } \\
\text { gallons per well } \\
\text { (low estimate) }\end{array}$ & $\begin{array}{c}7.3 \text { million } \\
\text { gallons per well } \\
\text { (high estimate) }\end{array}$ \\
\hline $\begin{array}{l}\text { Lower bound of } \\
\text { chemical } \\
\text { composition (0.5\% } \\
\text { of volume) }\end{array}$ & 16,500 gallons & 5,500 gallons & 24,000 gallons \\
\hline $\begin{array}{l}\text { Upper bound of } \\
\text { chemical } \\
\text { composition }(2.0 \% \\
\text { of volume) }\end{array}$ & 66,000 gallons & 22,000 gallons & 96,000 gallons \\
\hline
\end{tabular}




\section{Wastewater management practices}

After hydraulic fracturing operations, pressure decreases and fluids return to the surface before the well begins formal gas production. Although there are no standardized definitions, the used fracking fluids (frac flowback) and naturally occurring water resources (produced water) both return to the surface. In general, the frac flowback returns first at high rates (e.g., 100,000 gallons per day) for a few days; then produced water surfaces at lower rates for the remainder of the well's lifetime (e.g., 50 gallons per day). The rates of production and total volumes of frac flowback and produced water vary greatly within and between shale plays - ranging from 10\% of original fracking fluid volume to as high as 75\% (EPA 2011). Frac flowback and produced water both contain naturally occurring substances, including oil, gas, radionuclides, volatile organic compounds, and other compounds that could contaminate local water resources.

Frac flowback and produced water are stored on site in storage tanks or impoundment pits prior to treatment, recycling, and/or disposal (GWPC 2009).Onsite impoundments can be designed for short-term use (for storage purposes) or for long-term use (evaporation pits), and impoundment regulations and requirements can vary greatly by location.

Operators have a variety of options for managing wastewaters, including recycling and reusing, onsite evaporation in impoundments, onsite injection into wells, disposal at a centralized facility through evaporation or underground injection, and treatment through surface water treatment plants. Overall, national disposal methods are dominated by underground injection (EPA 2011). Current industry practices might vary from state to state, and have shown different trends from 2008 to 2011. For example, Colorado (Figure 22) and Pennsylvania (Figure 23) show stark differences and trends.

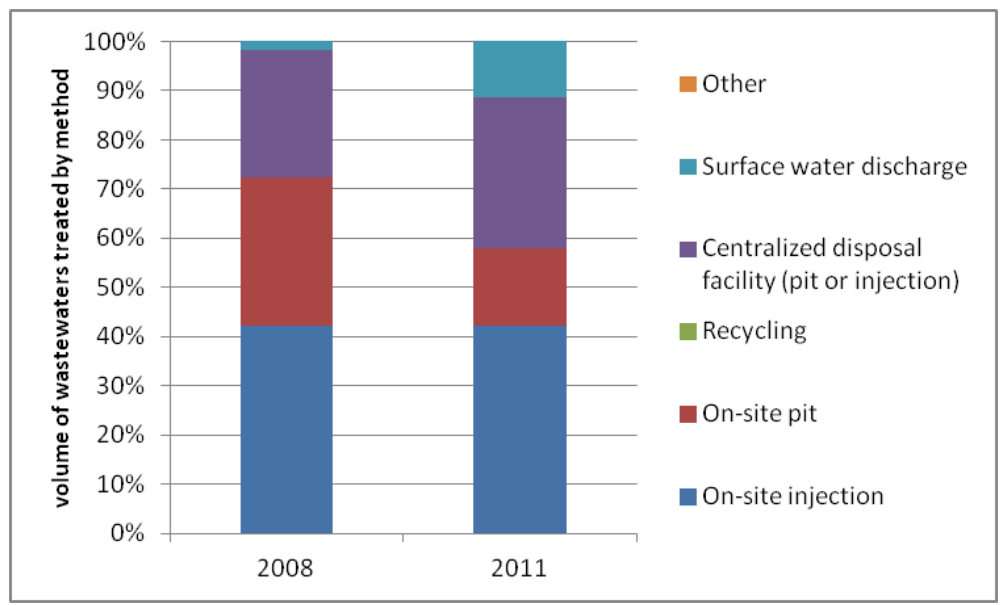

Figure 22. Colorado wastewater treatment methods, 2008-2011 (COGCC 2012a) 


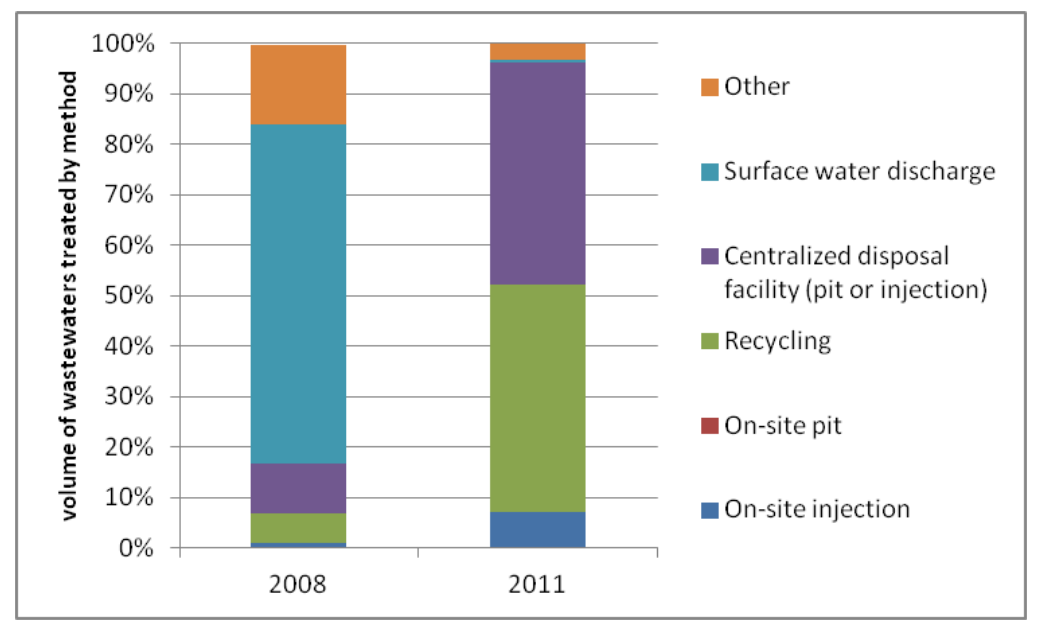

Figure 23. Pennsylvania wastewater treatment methods, 2008-2011 (PA DEP 2012b)

In Pennsylvania, surface water treatment decreased from $67 \%$ of total wastewater volumes in 2008 to less than 1\% in 2011 (PA DEP 2012b). In contrast, in Colorado, surface water treatment increased from $2 \%$ of total wastewater volumes in 2008 to $11 \%$ in 2011 (COGCC 2012a). In Pennsylvania, recycling increased from $6 \%$ of total wastewater volumes in 2008 to $45 \%$ in 2011 , whereas there are no data indicating any recycling occurring in Colorado. The dominant disposal method in Colorado remains injecting or evaporating wastewater fluids on site. Onsite disposal methods decreased in Colorado, managing $72 \%$ of total wastewater volumes in 2008 to $58 \%$ in 2011. In Pennsylvania, onsite well injection increased from $1 \%$ of total wastewater volumes in 2008 to $7 \%$ in 2011. Both states increased their use of centralized industrial disposal facilities between 2008 and 2011. In Pennsylvania, the use of centralized disposal facilities increased from $10 \%$ of total wastewater volumes in 2008 to $44 \%$ in 2011 . In Colorado, the use of centralized disposal facilities increased from $26 \%$ of total wastewater volumes in 2008 to $31 \%$ in 2011 .

Water disposal methods can change from year to year due to evolving regulations and industry experience. Data from 2008 showed a high percentage of surface water discharge for wastewaters in Pennsylvania; after 2008, there was a sharp decline. This is due to the changes to the Pennsylvania Department of Environmental Protection's (DEP) 25 Pa Code Chapter 95 Wastewater Treatment Requirements. These requirements were changed on April 11, 2009, after total dissolved solids levels were measured far above environmentally healthy levels in 2008 and 2009 (STRONGER, 2010). The high TDS was above drinking water standards in the Monongahela River. The TDS also promoted golden algae growth, resulting in higher toxicity levels in Drunkard Creek, killing over 30 different species of aquatic life. The new regulations required a maximum TDS discharge of $500 \mathrm{mg} / \mathrm{L}$ (STRONGER, 2010). This new regulation makes it uneconomical to use municipal water treatment in Pennsylvania because wastewaters can reach up to $360,000 \mathrm{mg} / \mathrm{L}$ TDS (USGS 2002b). In addition, injection has remained relatively unfavorable in Pennsylvania because the state has only eight Class II underground injection wells, three of which are commercially owned. The other injection wells are privately owned and only service the companies that own them (Phillips 2011).

Recycling operations can be more expensive than other waste management options. Recycling and reuse of water involves energy for treatment, and costs associated with storing water, transport of water, and transport and disposal of the solid wastes removed from the treated water. 
In contrast, injecting wastewater into wells only involves the transport of water to an injection well and fees for the disposal. Recycling options can also be limited by high concentrations of materials that make recycling uneconomic.

\subsubsection{Current Water-Quality Risks Resulting from Industry Activities}

Risks to public water quality resulting from industry practices include risks to both surface water and groundwater sources, and they are not limited to the location of the hydraulic fracturing operation. Risks to surface and groundwater resources exist at each stage of development-well construction and hydraulic fracturing operations, chemical handling, and wastewater management.

Improper well construction or improperly plugged wells are one source of risk by which groundwater contamination can occur (PA DEP 2010b; McMahon et al. 2011). In addition to risks associated with construction integrity, risks are also associated with well durability for wells that are repeatedly hydraulically fractured. The potential exists for fracking fluids, as well as other naturally occurring substances, to reach groundwater sources if well construction or plugging operations are inadequate. The degree of risk will be dependent upon local geology, the composition of the chemicals and naturally occurring substances, and the mobility of the substances within the formation.

Another source of risk during the hydraulic fracturing operation in coalbed methane (CBM) reservoirs is the potential for the fractures to extend into aquifers or into pre-existing faults or fractures (natural or man-made) that might directly extend into aquifers. Currently, it is difficult to predict and control fracture location and lengths, and the overall risk will depend on the local geology and fracking practices used. In shale gas formations, decreasing pressure gradients and natural barriers in the rock strata serve as seals for the gas in the formation and also block the vertical migration of frack fluids (GWPC and ALL Consulting 2009). In contrast, CBM reservoirs, such as the North San Juan considered here, are mostly shallow and may also be colocated with drinking water resources. In CBM areas, hydraulic fracturing operations near a drinking water source might raise the risk of contamination of shallow water resources from hydraulic fracturing fluids (Pashin 2007; EPA 2011).

Another risk to water quality is the handling and mixing of chemicals on site. Risks include spills or leaks that might result from equipment failure, operational error, or accidents. Leaked chemicals could be released into bodies of surface water or could infiltrate groundwater resources. There have been reports of surface spills of hydraulic fracturing fluids; however, little is known about the frequency, severity, and causes of these spills (Lustgarten 2009; Lee 2011; Williams 2011). The risks to local water resources will depend on the proximity to water bodies, the local geology, quantity and toxicity of the chemicals, and how quickly and effectively cleanup operations occur.

Wastewater management practices have risks to water quality that potentially affect water resources both on and off site of the location of the shale gas development operations.

Considering risks on site, spills of frac flowback or produced water could contaminate local surface and/or groundwater resources. In addition, there could be equipment failures (e.g., poorly constructed impoundments) during onsite wastewater storage prior to treatment. Potential offsite risks include spills or leakage that might occur during the transport of wastewaters to the location 
where they will be treated. If surface water treatment is used, there is a risk of the surface water treatment plant not having the capabilities to fully treat the wastewater before it is released back into the hydrologic cycle (Puko 2010; Ward Jr. 2010; Hopey 2011).

From 2009 to 2011, Pennsylvania had 337 reported violations that were classified as "minor effect" or "substantial effect" (NEPA 2012). Violations of these types include the release of wastes or produced water on site in amounts less than 10 barrels (420 gallons). From 2009 to 2011, Texas had 14 reported "minor effect" or "substantial effect" violations, and one reported "major effect" violation. "Major effect" violations include large spills or improperly disposed of wastes greater than 10 barrels (420 gallons), small to large spills that were moved off site and impacted a resource such as a drainage ditch or wetland, and any spill of fracturing fluid greater than 1 barrel (42 gallons). For Colorado, the only publicly accessible statistics related to violations are Notices of Alleged Violations (NOAVs). The number of NOAVs does not represent the number of violations because violations do not necessarily lead to the issuance of NOAVs. Also, when NOAVs are issued, they may cite violations of more than one rule, order, or permit condition. Colorado violations could not be acquired, and data for violations in other states were not available. More detailed information about violations in states where data are available is listed in Appendix D. Further research is needed to fully determine the severity and cause of the reported violations.

\subsection{Data Availability and Gaps}

Substantial gaps in data availability prevent a full assessment of risks to water resources resulting from shale gas operations. Only certain statistics are publicly available for each region, and in some regions that cross state boundaries, information is only available for the part of a play that is in one state (Table 8.) 
Table 8. Overview of Data Availability

\begin{tabular}{|c|c|c|c|c|c|c|c|c|c|}
\hline & & $\mathrm{CO}$ & NM & PA & NY & $T X$ & $T X$ & LA & WY \\
\hline & $\begin{array}{l}\text { Risk Factor or } \\
\text { Analysis Metric }\end{array}$ & $\begin{array}{l}\text { North } \\
\text { San } \\
\text { Juan }\end{array}$ & $\begin{array}{c}\text { North } \\
\text { San } \\
\text { Juan }\end{array}$ & Marcellus & Marcellus & Barnett & $\begin{array}{l}\text { Eagle } \\
\text { Ford }\end{array}$ & Haynesville & $\begin{array}{l}\text { Upper } \\
\text { Green } \\
\text { River }\end{array}$ \\
\hline 1 & $\begin{array}{l}\text { Disposal } \\
\text { methods/volumes }\end{array}$ & $\diamond$ & & $\diamond$ & $\diamond$ & & & & $\wedge$ \\
\hline $1 a$ & $\begin{array}{l}\text { Fraction of water } \\
\text { recycled }\end{array}$ & $\diamond$ & & $\diamond$ & & & & & \\
\hline 2 & Fresh water use & $\wedge$ & $\wedge$ & $\diamond$ & & $\wedge$ & $\wedge$ & $\diamond$ & $\wedge$ \\
\hline $2 a$ & Fracturing water & $\diamond$ & & $\diamond$ & & 0 & $\diamond$ & $\Delta$ & $\diamond$ \\
\hline $2 \mathrm{~b}$ & Source permitting & $\wedge$ & & $\diamond$ & & $\wedge$ & $\wedge$ & $\wedge$ & $\wedge$ \\
\hline 3 & PW/FF volumes & $\diamond$ & & $\diamond$ & & $\wedge$ & $\wedge$ & $\wedge$ & \\
\hline $3 a$ & Injected volumes & $\diamond$ & & & & $\wedge$ & $\wedge$ & $\diamond$ & $\diamond$ \\
\hline 4 & State regulations & & & & & $\diamond$ & & & \\
\hline $4 a$ & Rule violations & & & $\diamond$ & & & & & \\
\hline 5 & Regional water use & & & $\diamond$ & & & & & \\
\hline 6 & Total wells & & & $\diamond$ & & $\wedge$ & $\diamond$ & & \\
\hline $6 a$ & $\%$ Horizontal & & & $\diamond$ & & & $\diamond$ & & \\
\hline \multicolumn{10}{|l|}{ Key } \\
\hline$\diamond$ & Data available & & & & & & & & \\
\hline$\Lambda$ & Partial data available & & & & & & & & \\
\hline
\end{tabular}

Comprehensive analyses of water risks are hindered by a lack of reliable, publicly available water usage and management data. Data are not publicly available for many regions for total water withdrawals, total wells drilled, water recycling techniques, wastewater management, and other management practices. These data would assist in developing appropriately flexible and adaptive best management practices. Certain resources - such as the State Review of Oil and Natural Gas Environmental Regulations (STRONGER) and FracFocus - have greatly increased public access to information about risks of hydraulic fracturing; but further efforts are desired. Data collection and availability could improve with further collaboration and interaction with industry stakeholders, as well as other stakeholders.

\subsection{Best Management Practices (BMP)}

Various attempts have been made to define best practices for water management (e.g., IEA 2012; Energy Institute 2012; ASRPG 2012; Chief O\&G 2012; SEAB 2011; API 2010). Based on these reports, the following are best practices that are generally accepted to be important for understanding and minimizing risks related to water quantity and quality:

\subsubsection{Monitoring and Reporting}

- Measure and publicly report the composition of water stocks and flow throughout the fracturing and cleanup process. There is little information on the management of fracturing water from acquisition to disposal or recycle, both in terms of quality and quantity. 
- Adopt requirements for baseline water-quality testing. Background testing is recognized for its value, but is often not standardized. Better guidance is needed for statistically defensible testing.

- Fully disclose hydraulic fracturing fluid additives. Disclosure of fracturing fluid chemicals on fracfocus.org is now in place in Colorado, Wyoming, and Texas and is being considered in several other states.

\subsubsection{Water Quantity}

- Recycle wastewaters. Freshwater demand can be minimized by treatment and reuse of produced water and frac flowback. Flowback water produced in the hydraulic fracturing process is returned at relatively high flows and might contain more chemicals of concern than produced water. Optimized handling of this fluid is important for mitigating risks to water quality and quantity because it can lessen the need for transport and wastewater disposal.

\subsubsection{Water Quality}

- Use a closed-loop drilling system. In closed-loop drilling processes, contaminated water is not exposed to air or pits where it could leak, thus eliminating the storage of discarded drilling fluids in open pits at the drilling site.

- Eliminate flowback water mixing with fresh water in open impoundments. Disposing of untreated flowback water in reservoirs containing fresh water to be used for hydraulic fracturing increases the risk of harmful spills or leaks.

- Use protective liners at pad sites. The use of liners or other protective devices at pad sites can contain minor spills and prevent environmental contamination. Proper collection and disposal equipment is also important to have on site.

- Minimize use of chemical additives and promote the development and use of more environmentally benign alternatives. "Green" hydraulic fracturing fluid has been developed - based on fluid mixtures from the food industry - that do not impair groundwater quality in the case of an inadvertent leak or spill.

A next step in developing BMPs for reducing risks to water resources in shale gas development is to evaluate the efficacy of each of the above BMPs (Kemp 2012; Energy Collective 2012). Currently, little or no data exist that analyze the effectiveness or cost-benefit tradeoffs of these BMPs. Further examination of BMPs could assist developers in evaluating important water management questions - such as whether installing protective liners at pad sites or reducing use of chemical additives would have a greater impact on reducing risks to water resources in their regions. A first step in this direction would be to develop a methodology for quantifying and comparing current water-management practices with potential risks.

In many cases, BMPs might be more appropriate or cost-effective for certain geological conditions than others. A further area of needed research is to evaluate the extent to which certain BMPs are applicable or effective across multiple types of formations. To better address this question, researchers could engage a variety of stakeholders - including industry, regulators, researchers, environmental groups, and the public - to understand what practices are currently in use, how effective they are at reducing the risk of water impacts, and where improvements are needed. 
A major challenge facing some of these BMPs is that there are no national or state-level disclosure initiatives to track or evaluate the success of their implementation. For example, it is difficult to determine how many operators are currently employing (and with what success) the widely discussed BMP to use closed-loop drilling practices because operators are not required to report this information. Absent such reporting, data collection efforts would likely require close collaboration with multiple industry partners operating in a variety of locations, and this could be time-intensive.

\subsection{Summary}

We used publicly available datasets to provide an initial evaluation of water risks associated with hydraulic fracturing in six natural gas plays in the United States. Data were limited in every region; continued efforts to catalogue and publish water data will improve future analyses.

Hydraulic fracturing operations have the potential to impact water resources. One of the impact risks associated with water is regional resource depletion due to the use of fresh water during hydraulic fracturing. Water-use data were collected for five of the six regions with average use per well ranging from 1.1 to 5.8 million gallons, with a multi-region average of 3.3 million gallons per well. Total water usage can be estimated by determining the average water use per well, number of wells, and recycling rate; this total freshwater demand value can be compared with estimates of local water availability. Hydraulic fracturing demands are a small fraction of total state water demands, but they can be a substantial portion of water demands in the counties in which the hydraulic fracturing operations are active. If water must be transported from off site to a hydraulic fracturing site, water quantity risks might extend to counties where hydraulic fracturing is not occurring. In all regions considered, the number of wells drilled for hydraulic fracturing has increased each year since 2009. Recycling rates have increased significantly in Pennsylvania since 2009, when the state issued new regulations regarding the treatment of wastewaters.

A second impact risk associated with water is degradation of surface and groundwater quality. Water-quality impacts are a risk during the well construction, hydraulic fracturing, mixing of chemicals, and the wastewater management of shale gas development. As noted above, hundreds of substantial or major violations have been reported that have resulted in spills of produced water, frack fluids, or chemicals. However, it is not clear if water resources have been contaminated — and if so, to what extent — or by which pathway the spills occurred.

A better understanding of the potential contamination pathways (listed here) and their impacts to water resources could assist in identifying and evaluating the phases of operation that have the highest risk of impacting water quality. Potential contamination pathways during well construction and hydraulic fracturing are improper well construction, well degradation from repeated use, lengthy fractures, and improper well plugging. Potential contamination pathways during the mixing of chemicals phase are spills, accidents, and storage equipment failures. Potential contamination pathways at the hydraulic fracturing site during the management of wastewaters are onsite storage equipment failures and spills. Additional contamination pathways and risks occur during the transport of wastewaters to disposal facilities and the potential stress put on surface water treatment plants that might not be capable of treating the types of wastes produced from hydraulic fracturing operations. 
Currently, a variety of BMPs are being employed in different regions to minimize risks to water resources. However, there is uncertainty in the industry concerning BMP transferability, costeffectiveness, and risk mitigation potential. In addition, it is unclear to what extent these BMPs are being employed by different operators. Recycling of frac flowback and produced water is an accepted recommended practice, but limited information exists regarding prevalence, methods, and costs. Except for Pennsylvania, recycling data are not available from public databases, so it is difficult to estimate how much water is being reused in these regions.

\subsection{Conclusions and Next Steps}

Prior efforts, in addition to with this study, have identified the variety of water-related risks and potential contamination pathways resulting from shale gas development. However, existing publicly available data are not sufficient to perform a full risk assessment on a national or regional scale. A comprehensive and actionable risk assessment would require additional analyses, including the following:

- Quantitatively assess the magnitude of the impacts of the contamination pathways discussed in this report.

- Quantitatively assess the probability that the risks discussed will occur, based on existing industry practices.

- Identify the contamination pathways and risks that, at present, are adequately or inadequately addressed by current industry practices.

- Evaluate BMPs in terms of risk mitigation potential, cost-effectiveness, regional transferability, and industry prevalence.

- Evaluate in detail the wastewater recycling practices, including estimates of current recycling rates, estimates of total potential freshwater savings resulting from recycling, and a life cycle assessment (in terms of energy inputs, emissions, and costs) to identify thresholds for deciding whether to dispose of or recycle wastewaters.

The application of systematically developed BMPs could increase the transparency and consistency by which shale gas development occurs, providing benefits to industry and interested stakeholders. Effective BMPs follow from a defined prioritization of risks in the context of other risks. Risk prioritization would be facilitated by greater availability of industry data and current practices. Further collaboration and interaction with industry, and other stakeholders could improve data collection efforts and are a first step in achieving the analysis objectives above. Lastly, water resources are just one category of risk resulting from shale gas development. Future efforts could evaluate water-related risks and BMPs alongside other risks to air, land, and community. 


\section{Natural Gas Scenarios in the U.S. Power Sector 4.1 Overview of Power Sector Futures}

This chapter summarizes results from modeling different U.S. power sector futures. These futures assess key questions affecting today's natural gas and electric power markets, including the impacts of:

- Forthcoming EPA rules on power plants

- Decarbonization options such as a clean energy standard (CES)

- Potential improvements in key generation technologies

- Higher costs for natural gas production assumed to arise from more robust environmental and safety practices in the field

- Expanded use of natural gas outside of the power generation sector.

The simulations were done using NREL's ReEDS model, incorporating findings from Chapters 1,2 , and 3, as applicable, and looking out to the year 2050.

ReEDS is a capacity expansion model that determines the least-cost combination of generation options that fulfill a variety of user-defined constraints such as projected load, capacity reserve margins, emissions limitations, and operating lifetimes. The model has a relatively rich representation of geographic and temporal detail so that it more accurately captures the unique nature of many generation options, as well as overall transmission and grid requirements. It is a power-sector-only model, so special steps were taken to consider the feedback effects of natural gas demand in other sectors of the economy. These steps, along with additional details about the model, are more fully described in Appendix E of this report. ${ }^{132}$

The scenario analysis presented here is not a prediction of how the U.S. electricity sector will evolve in the future - rather, it is an exercise to compare the relative impacts of different scenarios. Three Reference scenario cases are used as points of comparison for other scenarios based on policy, business, or technology change:

1. Baseline - Mid-EUR

2. Baseline - Low-EUR, and

3. Baseline - Low-Demand.

The modeling team explored four potential policy scenarios in addition to the Reference scenario:

1. A Coal scenario, driven by a combination of forthcoming EPA rules, low-cost natural gas, and the age of existing coal generators. Specifically, this scenario addresses the

\footnotetext{
${ }^{132} \mathrm{~A}$ full description of the model is also available at: http://www.nrel.gov/analysis/reeds/pdfs/reeds_documentation.pdf.
} 
question of what new capacity will need to be built if and when coal plants retire, and what impacts would result from proposed NSPS.

4. A CES scenario with carbon mitigation sufficient for the U.S. power sector to contribute its share in lowering emissions to a level that many scientists report is necessary to address the climate challenge (IPCC 2007; C2ES 2011). This simulates a CES similar to that proposed by Senator Jeff Bingaman, but analyzes impacts through 2050 (EIA 2012a).

5. An Advanced Technology scenario where several different generation options - nuclear, solar, and wind - achieve cheaper and thus more widespread deployment; and

6. A Natural Gas Supply-Demand Variation scenario for natural gas, aimed to simulate the impact of (1) steps taken to incrementally address environmental and safety concerns associated with unconventional gas production, and (2) significant growth in natural gas demand outside the power sector (Dash-to-Gas). In both cases, the incremental cost of securing natural gas for power generation results in different power sector futures over the long term.

The family of scenarios is summarized in Figure 24.

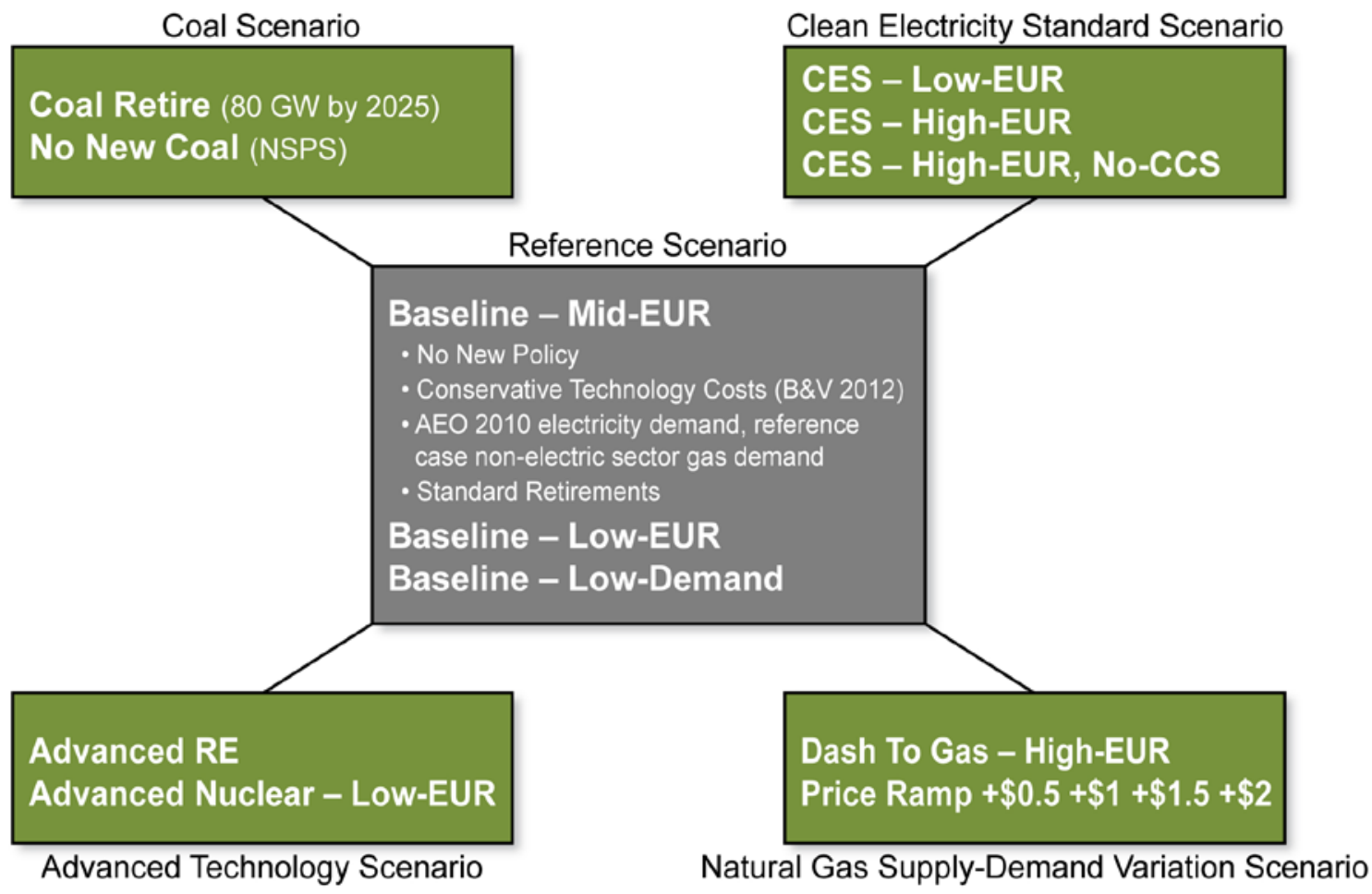

Figure 24. Scenarios evaluated in the power sector futures

\subsection{Assumptions and Limitations}

Technology cost and performance metrics used in ReEDS are presented in Appendix E. All costs in this study are listed in 2010 dollars unless otherwise noted. 
Supply curves were developed to represent natural gas cost to the power sector and the response of this cost to increased power sector demand. The supply curves were developed based on linear regression analyses from multiple scenarios developed by the Energy Information

Administration in the Annual Energy Outlook 2011 (EIA 2011). ${ }^{133}$ The supply curves represent the price of fossil fuel to the power generators as a function of overall electric sector consumption of the fuel. In particular, as electric sector consumption increases, the marginal fossil fuel price to power generators (and all consumers of the fossil fuel) would increase. Within each year of the ReEDS optimization, the model sees this price response to demand through the linear supply curves. Three sets of supply curves were developed, representing different levels EUR $^{134}$ of natural gas. Additional detail on these supply curves is also outlined in Appendix E.

Current renewable tax incentives and state renewable portfolio standards are represented in the ReEDS model. Tax incentives include the modified accelerated cost recovery system for tax depreciation, the production tax credit for utility-scale wind technologies, and the investment tax credit for solar and geothermal technologies. ${ }^{135}$ The tax credits are assumed to expire at their legislative end date and not be renewed. In particular, the wind production tax credit expires at the end of 2012, and the solar ITC declines from 30\% to 10\% in 2016. Although the solar and geothermal investment tax credits have no legislative end date, they are assumed to expire in 2030 as to not influence the long-term expansion decision of the model.

All scenarios evaluated here assume that $30 \mathrm{GW}$ of coal-fired capacity will retire by 2025 . The Coal scenario in Section 4.4 considers a higher level of coal retirement and has more detail on the assumed distribution of coal retirements.

ReEDS determines when new high-voltage electricity transmission infrastructure is required and tracks the costs associated with its deployment. It does not track the need to build new natural gas pipeline infrastructure, so those costs are not included in this analysis.

ReEDS is not designed to account for distributed generation; therefore, the penetration of distributed (residential and commercial) rooftop PV capacity was input exogenously into ReEDS from NREL's Solar Deployment Systems (SolarDS) model (Denholm et al. 2009). SolarDS is a market penetration model for commercial and residential rooftop PV, which takes as inputs rooftop PV technology costs, regional retail electricity rates, regional solar resource quality, and rooftop availability. In all cases, except in the Advanced Technology scenario, $85 \mathrm{GW}$ of rooftop PV was assumed to come on line by 2050. This assumption was based on some of the Renewable Electricity Futures (RE Futures) Report 80\%-by-2050 renewable electricity scenarios (NREL 2012).

\footnotetext{
133 (EIA 2011). Annual Energy Outlook 2011 scenarios are projections out to the year 2035, and these results are extrapolated to 2050 for use in the ReEDS model. A separate supply curve was developed for each year to represent changes in projected supply and demand interactions as estimated in the multiple Annual Energy Outlook 2011 scenarios. The modeling team had already commenced work by the time the 2012 edition of the Annual Energy Outlook was released, so it could not take advantage of those newer data.

${ }^{134}$ EUR is the amount of natural gas (or petroleum) that analysts expect to be economically recovered from a reservoir over its full lifetime. Three potential measures of EUR are used throughout this study (High, Mid, and Low) to reflect the ranges of optimism and uncertainty over unconventional natural gas availability and price.

${ }^{135}$ Detailed information on these tax incentives can be found on the Database of State Incentives for Renewables and Efficiency at: http://www.dsireusa.org/.
} 


\subsection{Reference Scenario}

Three different baseline cases were evaluated in the Reference scenario:

- Baseline - Mid-Estimated Ultimate Recovery (Mid-EUR) case, with average power demand growth and a moderate outlook for natural gas prices

- Baseline - Low-EUR case reflecting the potential for more limited - and hence, more expensive - natural gas

- Baseline - Low-Demand case with Mid-EUR expectations. Low demand for electricity could be the result of continued economic stagnation (low gross domestic product [GDP] growth) or successful efforts to curb energy demand through energy efficiency, demand response, smart grid, and other programs to reduce the need for new electricity supply.

A Baseline - High-EUR case was not considered in this family in order to keep the number of results manageable. As noted previously, the Reference scenario is not a prediction of the future U.S. electricity mix per se, but instead, it serves as a point of comparison for the other scenarios. Each baseline case in the Reference scenario is summarized in Table 9.

Table 9. Description of Reference Scenario

\begin{tabular}{ccc}
\hline Case Name & $\begin{array}{c}\text { Assumption for Future Electricity } \\
\text { Demand }\end{array}$ & $\begin{array}{c}\text { Assumption for Estimated Ultimate } \\
\text { Recovery (EUR) }\end{array}$ \\
\hline Baseline - Low-EUR & $\begin{array}{c}\text { Standard Growth } \\
\text { (EIA 2010) }\end{array}$ & Low-level \\
\hline Baseline - Mid-EUR & $\begin{array}{c}\text { Standard Growth } \\
\text { (EIA 2010) }\end{array}$ & Mid-level \\
\hline Baseline - Low-Demand & Low Growth (NREL 2012) & Mid-level \\
\hline
\end{tabular}

Figure 25 and Figure 26 present the projected growth of electric generating capacity and generation for each of the three baseline cases. In the Baseline - Mid-EUR case, total capacity grows from roughly $1,000 \mathrm{GW}$ in 2010 to just over 1,400 GW in 2050. While nuclear and coal capacity decrease as a result of net aged-based retirements, natural gas combined-cycle and natural gas combustion-turbine capacities nearly double, with especially strong growth expected after 2030 when nuclear and coal retirements accelerate. On-shore wind capacity grows steadily from roughly $40 \mathrm{GW}$ in 2010 to nearly $160 \mathrm{GW}$ in 2050 , representing about $3 \mathrm{GW}$ of new additions each year on average over the period - a significant reduction from deployment in recent years. In all three baseline cases, oil and gas steam-turbine capacity is fully retired by roughly 2035 due to their low efficiency. Nuclear capacity also declines in all three baseline cases beginning around 2030 as plants reach the end of their operational lifetime and licensing arrangements, and no new plants are built due to uncompetitive economics. As noted above, rooftop PV is not endogenously calculated by ReEDS, but was exogenously assumed for each of the scenarios and baseline cases. Under the technology cost assumptions used, utility-scale PV showed more limited growth compared to natural gas and wind, reaching roughly $10 \mathrm{GW}$ by 2030 and $20 \mathrm{GW}$ by 2050 .

The Baseline - Low-EUR case considers a future in which natural gas is less abundant, and thus more expensive, than the Baseline - Mid-EUR case. The primary impact in such a future is less 
natural gas capacity and more coal and wind. For example, in this baseline case, the cumulative installed wind capacity reaches about $200 \mathrm{GW}$ by 2050.

In the final Baseline - Low-Demand case, growth in natural gas capacity is affected the most, although wind and coal also see little to no growth.

Considering the associated generation futures in these three baseline cases may be more instructive because capacity alone does not indicate how power plants are operated. Generation from natural gas combined-cycle plants doubles over the 40-year period, growing especially rapidly starting around 2030 because it is used to make up for the retired nuclear and coal generation (see Figure 26). Generation from natural gas combustion-turbine is almost too small to see in these charts, but plays an important role in meeting peak load needs. In the Baseline Low-EUR case, new coal capacity is added and its generation plays a growing role in meeting power demand after 2030. This new coal is not needed in a low-demand future, and little new wind or other renewable energy generation is needed either.

Figure 27 presents four key metrics for the baseline family of cases. First, natural gas consumption rises 2.5-fold from 2010 to 2050 in the Baseline - Mid-EUR case, but still nearly doubles in the other two cases. Second, average real natural gas prices that generators pay are expected to nearly double by 2050 in the Baseline - Mid-EUR case, ${ }^{136}$ while the Baseline Low-EUR case would see higher prices throughout the period. A Baseline - Low-Demand future will put far less pressure on natural gas prices because they peak at just over \$8/MMBtu in 2050 . Third, $\mathrm{CO}_{2}$ emissions from the power sector are expected to remain relatively flat throughout the period. In the Baseline - Low-Demand case, emissions decline significantly as existing coal is replaced with natural gas. Finally, average real prices paid for retail electricity grow steadily through 2050 to roughly \$130/MWh in the Baseline - Mid-EUR and Baseline - Low-EUR cases, but are about $\$ 15 / \mathrm{MWh}$ cheaper in the Baseline - Low-Demand case.

${ }^{136}$ Prices to power generators are higher than well head prices by approximately \$1/MMBtu, but vary by region. 

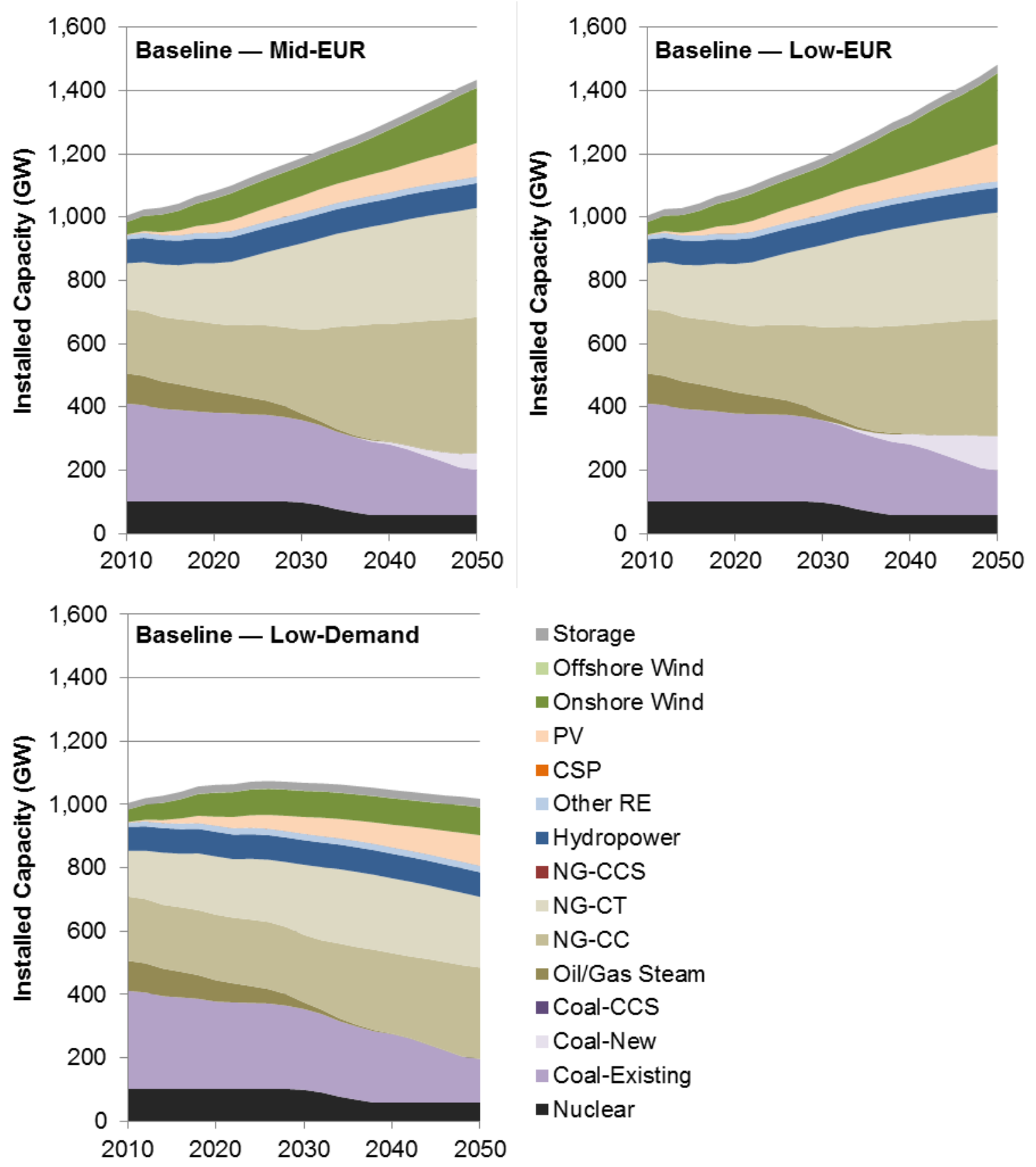

- Storage

Offshore Wind

- Onshore Wind

PV

CSP

Other RE

- Hydropower

-NG-CCS

NG-CT

-NG-CC

- Oil/Gas Steam

- Coal-CCS

Coal-New

Coal-Existing

- Nuclear

Figure 25. Projected capacity in the Reference scenario, 2010-2050, for Baseline - Mid-EUR, Baseline - Low-EUR, and Baseline - Low-Demand cases 

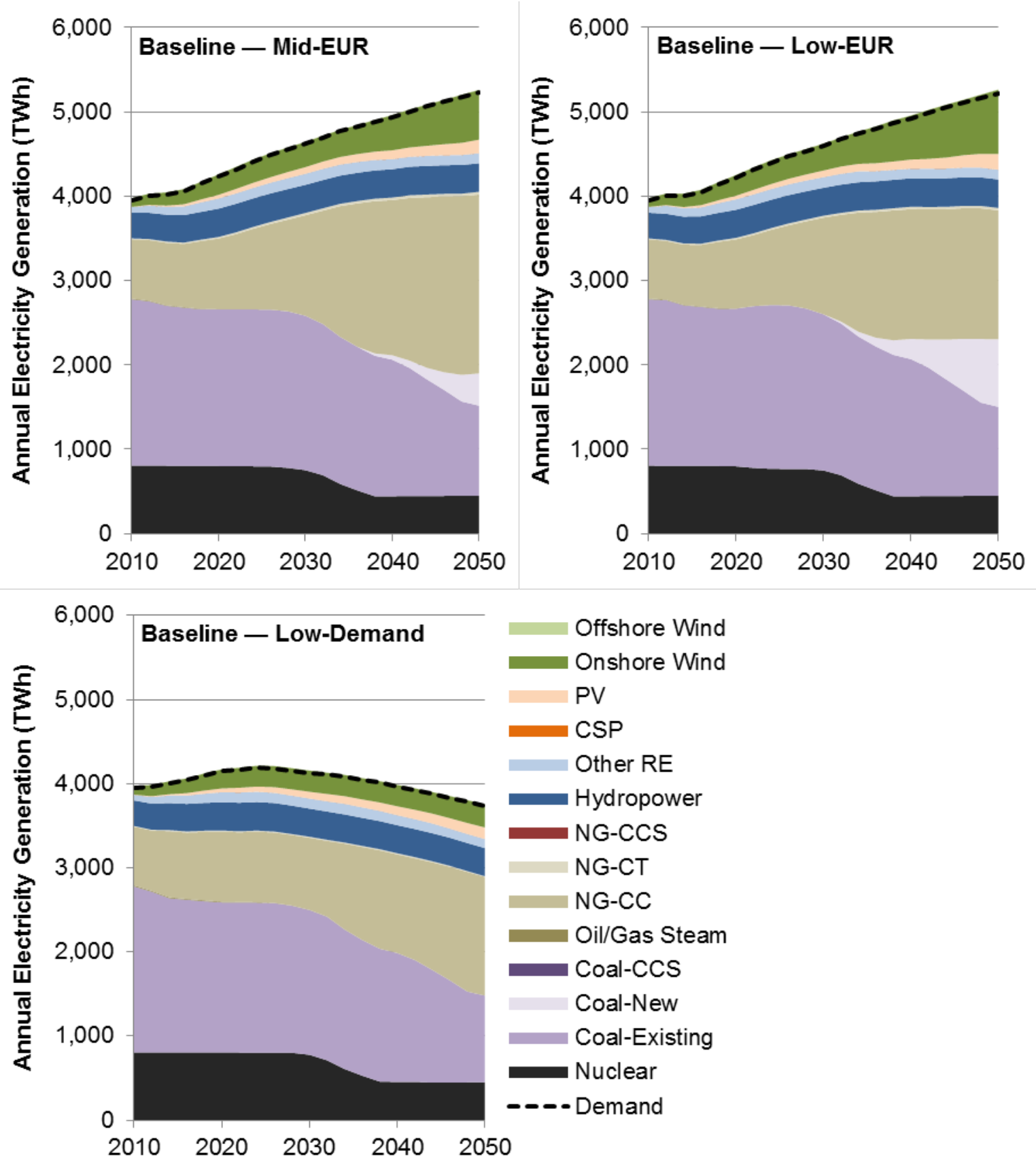

Figure 26. Projected generation in Reference scenario, 2010-2050, for Baseline - Mid-EUR, Baseline - Low-EUR, and Baseline - Low-Demand cases 
(a) Power Sector Natural Gas Consumption

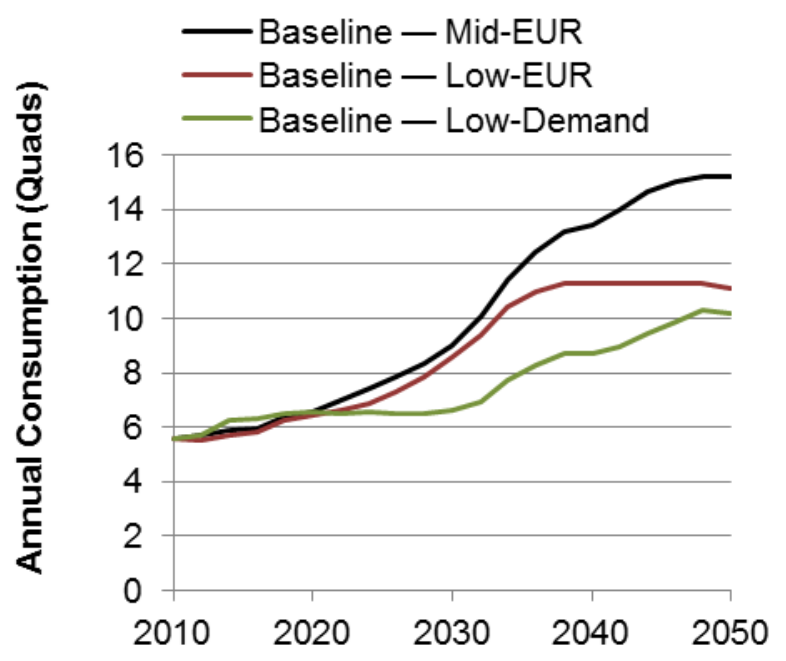

(c) Power Sector $\mathrm{CO}_{2}$ Emissions

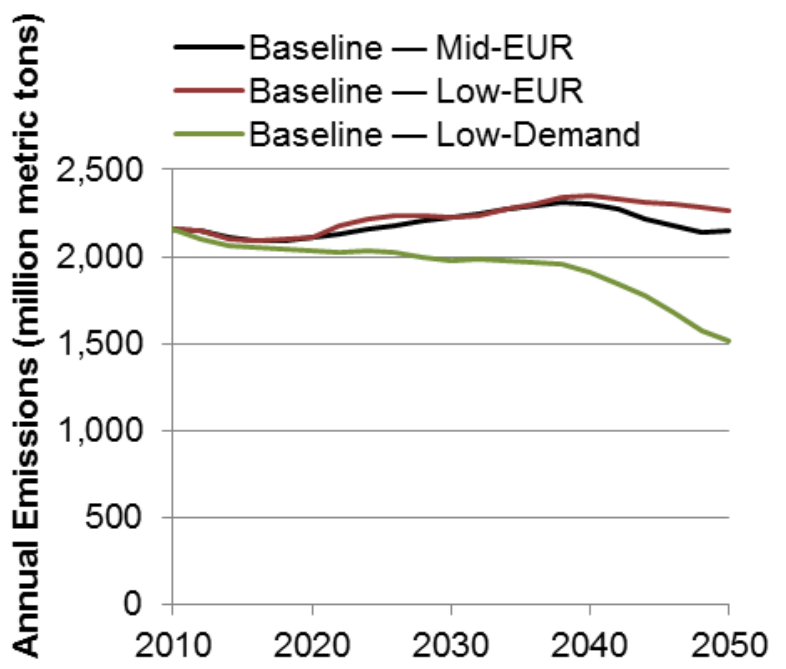

(b) Power Sector Natural Gas Price

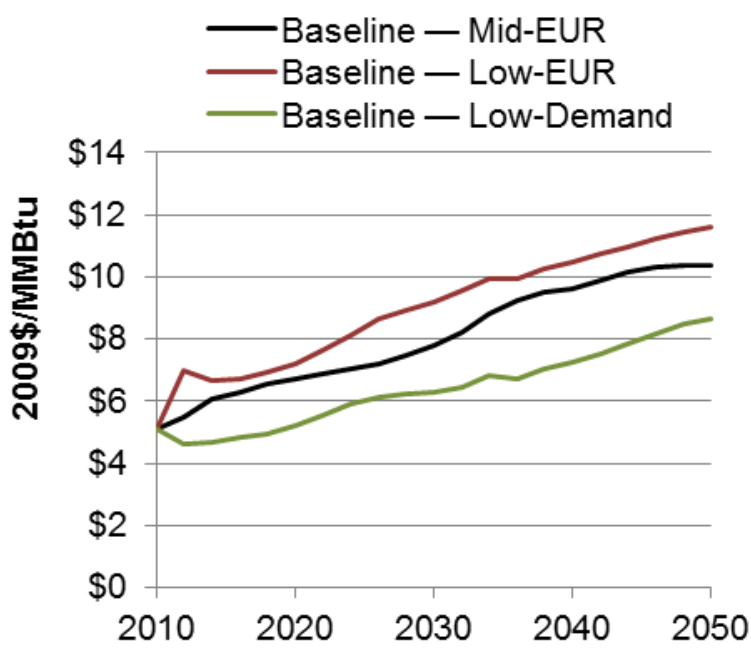

(d) National Average Retail Electricity Price

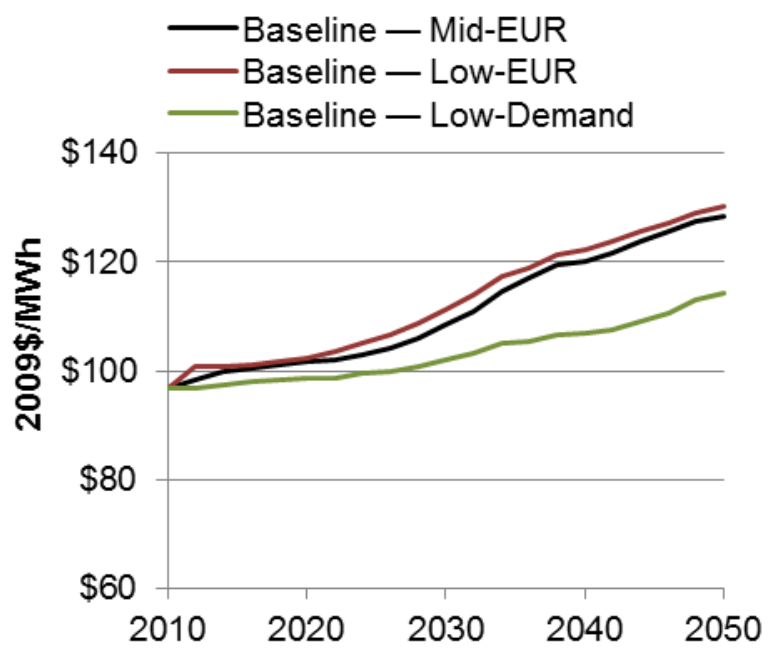

Figure 27. Selected metrics for the Reference scenario, 2010-2050

\subsubsection{Implications of Reference Scenario}

An electric power future as envisioned in the Baseline - Mid-EUR case would include rapid growth in natural gas generation and less reliance on coal and nuclear power. In effect, natural gas and coal swap positions compared to their historical levels. One concern in such a future is that if volatility returns to natural gas prices after additional new capacity is built—and coal plants are already retired - the economy will be more directly exposed to fluctuating electricity prices. Careful consideration of the benefits and costs of such a shift in generation diversity is warranted.

Although $\mathrm{CO}_{2}$ emissions do not grow signficantly in such a future, they also do not begin to transition to a trajectory that many scientists believe is necessary to avoid dangerous impacts from climate change. GHG emission reductions of up to $80 \%$ by 2050 (compared to 2000 levels) 
are considered necessary by most climate scientists to stabilize atmospheric concentrations of GHG and prevent the most serious impacts from a changing climate (IPCC 2007). The Reference scenario results do not put the U.S. power sector on a trajectory to meet this target.

A low power demand future, consistent with recently observed trends, ${ }^{137}$ may provide greater generator diversity and prevent a potential over-reliance on natural gas. This Baseline - LowDemand case also has lower emissions and price impacts, although growth in low-carbon energy deployment slows significantly.

\subsection{Coal Scenario}

This scenario considers two cases:

- Coal Plant Retirements case: The impact of retiring an aggregate $80 \mathrm{GW}$ of coal-fired generation by 2025

- No New Coal without CCS case: The impact of not allowing any new coal-fired generating capacity to be built unless it is equipped with CCS technology, which is similar to the proposed EPA New Source Performance Standard rule ${ }^{138}$

As noted previously, the baseline in all scenarios assumes that $30 \mathrm{GW}$ of coal will retire by 2025 due to endogenous age-based rules, plus additional retirements of other aging non-coal-fired plants. Many studies have been published that estimate the potential impact of the forthcoming EPA rules - and increasingly, low-priced natural gas - that are assumed to drive the decision to retire existing plants (Macedonia et al. 2011). A more fundamental reason for retirement may be that about two-thirds of the U.S. coal fleet was built in the 1970s or before (SNL 2011). The two cases evaluated in the Coal scenario are summarized in Table 10. Text Box 2 provides additional information on the EPA rules.

Table 10. Description of Coal Scenario

\begin{tabular}{ccc}
\hline Case Name & $\begin{array}{c}\text { Coal Capacity Retired by } \\
\mathbf{2 0 2 5}(\mathbf{G W})\end{array}$ & $\begin{array}{c}\text { Assumption for natural gas Estimated } \\
\text { Ultimate Recovery (EUR) }\end{array}$ \\
\hline Coal Plant Retirements & 80 & Mid-level \\
\hline No New Coal without CCS & 30 (same as Reference) & Mid-level \\
\hline
\end{tabular}

As noted previously, there are two forthcoming EPA rules that are likely to cause many older coal-fired plants to consider either costly retrofits to control pollution or retirement as a more economic solution: the Cross-States Air Pollution Rule and the Mercury and Air Toxics Standard. Two other EPA rules are under development that would attempt to address concerns about (1) water intake structures for cooling purposes at most power plants (the 316(b) rule) and (2) disposal of coal combustion residuals, also known as the coal ash rule.

\footnotetext{
${ }^{137}$ Total net power generation in the U.S. peaked in 2007, according to EIA statistics, and has not yet returned to pre-recession levels (EIA 2012c).

${ }^{138}$ For additional background on the proposed NSPS ruling, see http://epa.gov/carbonpollutionstandard/.
} 


\section{Text Box 2: Coal Plant Retirements, EPA Rules, and Low-Price Natural Gas}

Over the past few years, power sector analysts have debated the impact of new and forthcoming EPA rules on coal plant retirements. These rules include, but are not limited to, the following:

- Cross-States Air Pollution Rule

- Mercury and Air Toxics Standard

- Clean Water Act Section 316(b) cooling water intake structure ruling

- Coal Combustion Residual Rule.

Selected highlights of the rules include:

Cross-States Air Pollution Rule: Limits fine particulate emissions and ozone transport in many eastern state power plants by reducing $\mathrm{SO}_{\mathrm{x}}$ and $\mathrm{NO}_{\mathrm{x}}$ emissions. Compliance options include the installation of low- $\mathrm{NO}_{\mathrm{x}}$ burners, catalytic reduction, and scrubbers. The U.S. Court of Appeals struck down this rule in August 2012, and an earlier version known as the Clean Air Interstate Rule will be enforced in its place until EPA redesigns it.

Mercury and Air Toxics Standard: Reduces mercury, acid gases, trace metals and organics emissions at power plants by requiring maximum achievable control technology. Compliance options include scrubbers, filters, and activated carbon injection. Final rule released, and a 3-year compliance period is under way, although legal challenges are also mounting.

316(b): Protects fish and aquatic life from entrapment or entrainment in cooling-water intake structures at power plants. Compliance options include screens, barriers, nets, or cooling towers. The date for issuing the final rule was recently pushed back from July 2012 to June 2013.

Coal Combustion Residual Rule: Establishes standards to manage risk of post-combustion coal waste from power plants. There are two regulatory options under consideration by EPA with different ramifications on power generation cost and impact.

Dozens of studies have been conducted to estimate the impact of these rules on power generators, although most were conducted before the rules were finalized and natural gas prices plummeted in early 2012 .

Relatively straight-forward financial analysis can be used to determine if it is better to retrofit a power plant so that it can comply with the new rule or retire it. However, real-world decision-making depends on a host of other factors - including future market outlook and plans, portfolio risk management, potential carbon regulations, and reliability assessments.

Some studies anticipated relatively minor impacts from plant retirements (5-20 GW by 2020) (EIA 2011; BPC 2011), whereas others forecast major potential impact and reliability concerns (30-75 GW by 2020) (EEI 2011; CERA 2011; NERA 2011). As of early 2012, about $35 \mathrm{GW}$ of coal-fired generators had already announced that they would retire before 2020. At the same time, as natural gas prices plummeted through 2011 and 2012, generators ramped up operation of natural gas combined-cycle units and scaled back on use of coal generation.

The fuel switching that has already occurred primarily due to low gas prices is equivalent to about $60 \mathrm{GW}$ of coal-fired capacity, although this calculation assumes the coal plants are operated infrequently (32\% capacity factor). Most of the oldest coal generators in the U.S. fleet are operated infrequently and have fewer pollution controls. Although fuel switching is a voluntary decision by power generators - and hence, optimized to maximize profits in most cases - the impact of the forthcoming EPA rules will apply different decisionmaking criteria on top of the inexpensive natural gas driver. Thus, many of the studies conducted to assess the impact of coal plant retirements may need to be redone to account for both drivers of changing generation. 
Although most existing studies have anticipated anywhere from 20 to $70 \mathrm{GW}$ of coal retirements by 2020 due to these rules, natural gas price forecasts have fallen below levels that many of the studies used to evaluate the retrofit-retirement decision. The level chosen for this study, $80 \mathrm{GW}$, is based on these lower natural gas prices and a longer time horizon (2025). Where the retirements occur is another important assumption because it will impact whether or not new plants or transmission lines need to be built to replace the lost generation, or if existing natural gas combined-cycle plants can be operated more frequently to meet the load. The retirement distribution chosen was based mainly on the age of existing coal plants and the degree to which they had already installed pollution control devices such as activated-carbon injection and fluegas desulfurization. Figure 28 displays where existing coal plants were retired, and shows the percentage of coal capacity that is assumed to shut down in each balancing area.

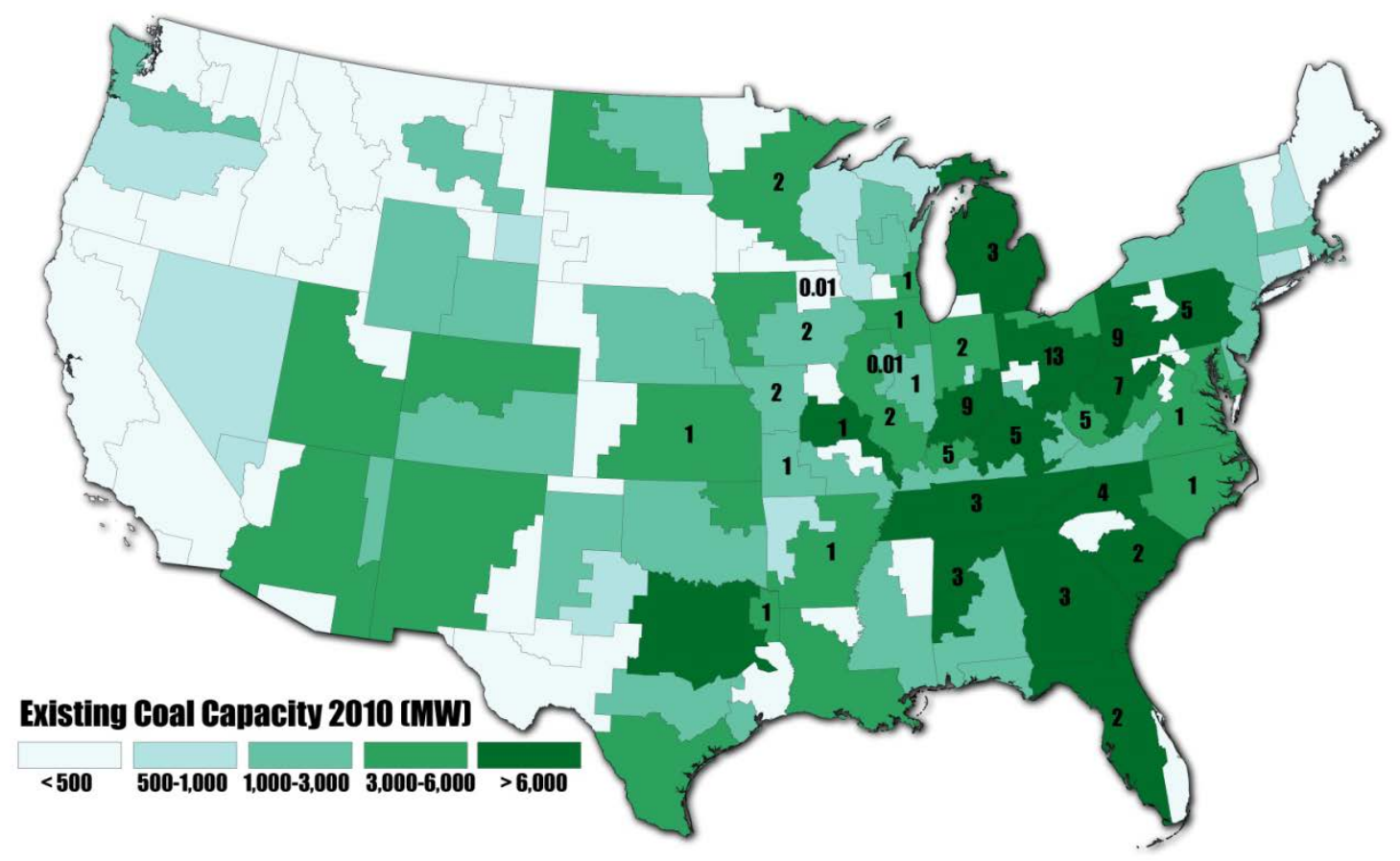

Figure 28. Assumed distribution of retirements in the Coal scenario by percentage of total coal capacity retired in 2025 in each balancing area of ReEDS

The impacts of the two coal cases are summarized in Figure 29 for the years 2030 and 2050. In the Coal Plant Retirements case (where a net $50 \mathrm{GW}$ of additional retirements are seen, compared to the baseline in 2025), most of the retired coal in 2030 is replaced with natural gas combined-cycle, although some additional new wind generation is also added. In the No New Coal without CCS case, there is no difference from the Baseline - Mid-EUR through 2030 because no new coal plants were built by then in the baseline. Cumulative $\mathrm{CO}_{2}$ emission savings are significant in the Coal Plant Retirements case: 3,300 million tons of $\mathrm{CO}_{2}$ between 2011 and 2050, even if annual reductions are more modest (see Figure 30). The impact of retirements on average real electricity prices is also modest. 

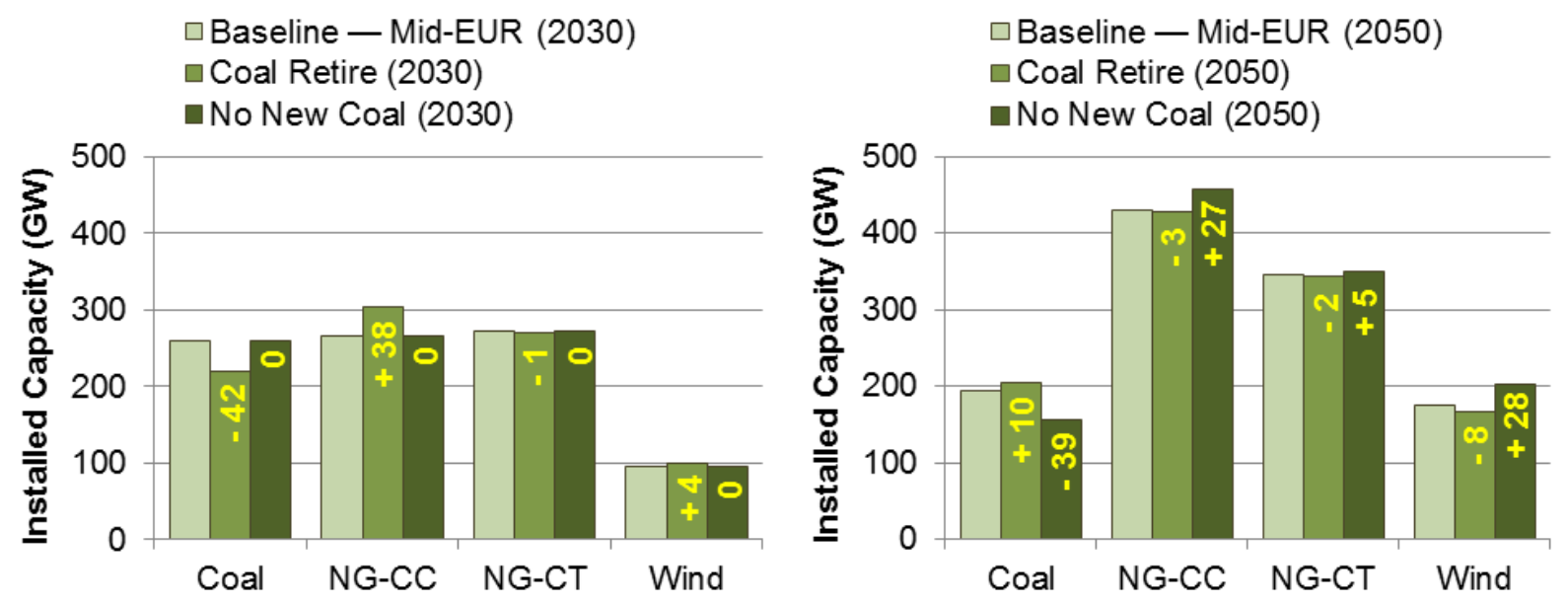

Figure 29. Impacts of coal plant retirements and no new coal without CCS compared to the baseline for 2030 and 2050

(a) Power Sector $\mathrm{CO}_{2}$ Emissions

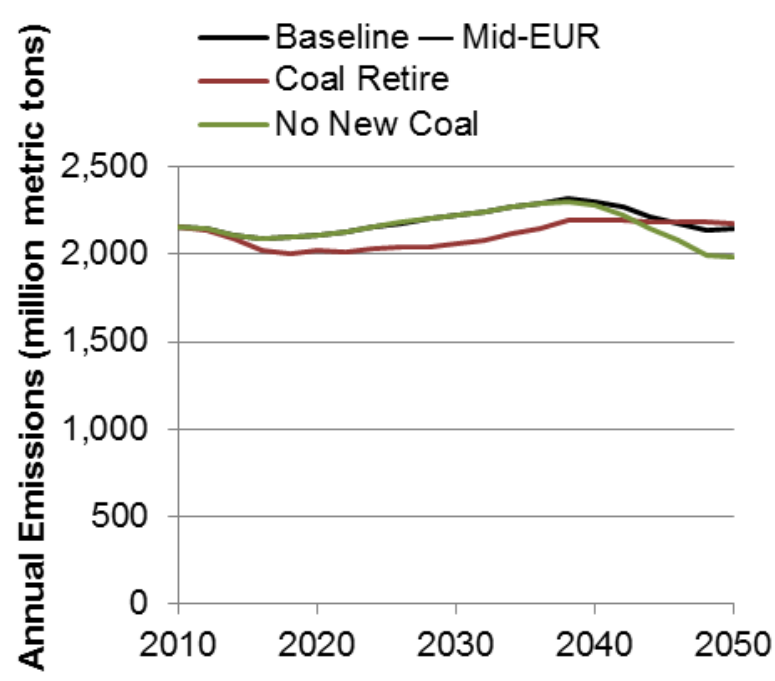

(b) National Average Retail Electricity Price

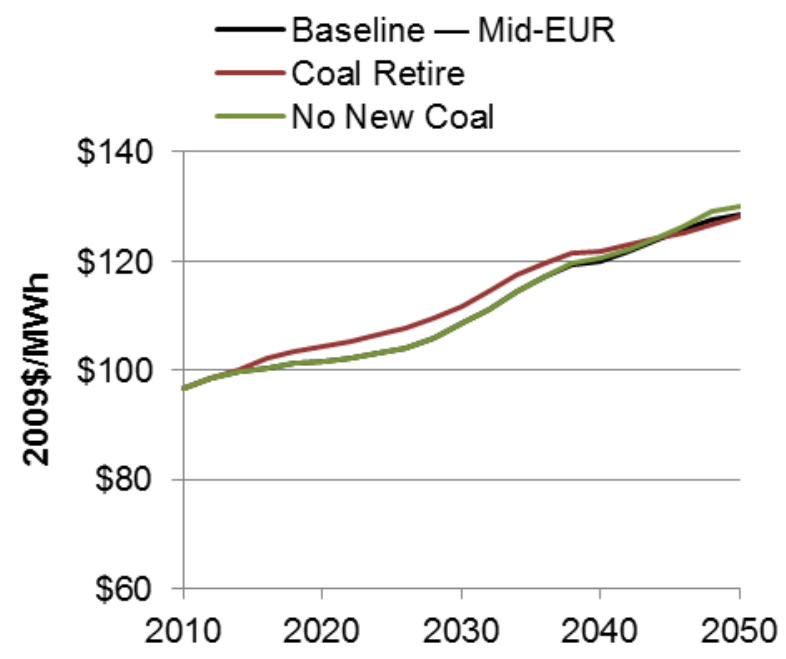

Figure 30. Selected metrics for the Coal cases, 2010-2050

\subsubsection{Implications of Coal Scenario Findings}

Coal retirements are replaced on a nearly one-to-one basis with natural gas, although wind plays a small role in the early years. In later years, more new coal is built, compared to the baseline, and less wind. In aggregate, however, coal retirements lead to a notable reduction in cumulative $\mathrm{CO}_{2}$ emissions at relatively modest cost. Initial statistically based analysis does not indicate any difficulty in maintaining adequate reserve margins needed for reliability purposes, although this evaluation is done at a relatively coarse level. A more detailed dispatch model would be required for realistic evaluation of grid reliability issues in such a coal retirement case.

The No New Coal without CCS case, intended to simulate the NSPS, has little impact in early years, but does prevent the construction of new coal after 2030. Compared to the Reference scenario, where new coal does come on line after 2030, the No New Coal without CCS case does 
not have any new coal coming on line through 2050 because CCS is not an economic option. In this case, natural gas combined-cycle and wind contribute equally to replace what coal would have been built in the baseline.

\subsection{Clean Energy Standard Scenario}

After cap-and-trade legislation failed to pass the U.S. Senate in 2010, CES became the preferred vehicle for those decision makers seeking to mitigate GHG emissions in the U.S. power sector. ${ }^{139}$ A CES sets targets for the sale of qualifying clean energy generation over time, similar to a renewable portfolio standard, ${ }^{140}$ but awards credits roughly based on the relative carbon weighting of emissions compared to standard coal-fired generation (EIA 2012a). In this analysis, new nuclear and renewable generators receive $100 \%$ crediting because they have no burner-tip emissions; natural gas combined-cycle generation receives $50 \%$ crediting when used without CCS and 95\% crediting with CCS; and coal receives 90\% crediting, but only with CCS. This analysis follows the current CES legislation under discussion in Congress ${ }^{141}$ calling for an $80 \%$ clean energy target in 2035, but extends the target to reach $95 \%$ by 2050 .

Full life cycle GHG emission values could be used in the CES crediting, rather than the current burner-tip estimates, to provide a more representative picture of climate impacts. As discussed in Chapter 1, the current understanding of the full life cycle emissions of unconventional gas is not significantly different from the values noted above; therefore, this analysis does not attempt to use them. As additional information becomes available, however, follow-on research could evaluate the impacts of different crediting values on the long-run evolution of the U.S. power sector.

Three separate CES cases are considered here:

- $\quad$ EES - High-EUR case

- $\mathrm{CES}$ - High-EUR case where CCS is not available, either for technical, economic, or social reasons

- $\quad$ CES - Low-EUR case.

Table 11 summarizes the three cases evaluated in the CES scenario.

Table 11. Description of CES Scenario

\begin{tabular}{|c|c|c|}
\hline Case Name & $\begin{array}{l}\text { Is Carbon Capture and } \\
\text { Sequestration Available/Economic? }\end{array}$ & $\begin{array}{c}\text { Assumption for Estimated Ultimate } \\
\text { Recovery (EUR) }\end{array}$ \\
\hline CES - High-EUR & Yes & High-level \\
\hline $\begin{array}{l}\text { CES - High-EUR, } \\
\text { without CCS }\end{array}$ & No & Mid-level \\
\hline CES - Low-EUR & Yes & Mid-level \\
\hline \multicolumn{3}{|c|}{$\begin{array}{l}139 \text { Three Senate leaders have put forth CES legislation since then: Senator Lindsay Graham (SC), Senator Dick } \\
\text { Lugar (IN), and Senator Jeff Bingaman (NM). } \\
140 \text { For more background on renewable portfolio standards and clean energy standards, see (C2ES 2012). } \\
141 \text { On March 1, 2012, Senator Jeff Bingaman introduced the Clean Energy Standard Act of 2012. More information } \\
\text { on the bill is available at: http://www.energy.senate.gov/public/index.cfm/democratic-news?ID=67e21415-e501- } \\
42 \mathrm{c} 3 \text {-a1fb-c0768242a2aa. }\end{array}$} \\
\hline
\end{tabular}


Figure 31 presents the impacts of the three CES cases on generation through 2050. In the early years before 2030, natural gas replacing coal is the primary contributor to meeting the rising CES targets. Beginning around 2030, however, natural gas is no longer able to contribute to meeting the target without CCS because it receives only $50 \%$ crediting toward the target. Instead, coal with CCS, wind, and natural gas with CCS are the next-cheapest options in the CES - High-EUR case. If CCS is not available (CES - without CCS), wind generation is the next-cheapest alternative to take its place. In such a case, renewable energy sources contribute about $80 \%$ of total generation by $2050 .^{142}$

A CES power future with more costly natural gas (CES - Low-EUR) would result in less natural gas generation, more solar and wind, and reliance on coal CCS rather than gas CCS compared to the CES - High-EUR case.

\footnotetext{
${ }^{142}$ NREL recently published the RE Futures study that evaluates many of the technical issues and challenges of operating the grid with such high percentages of renewable energy. See NREL (2012) for more detail.
} 

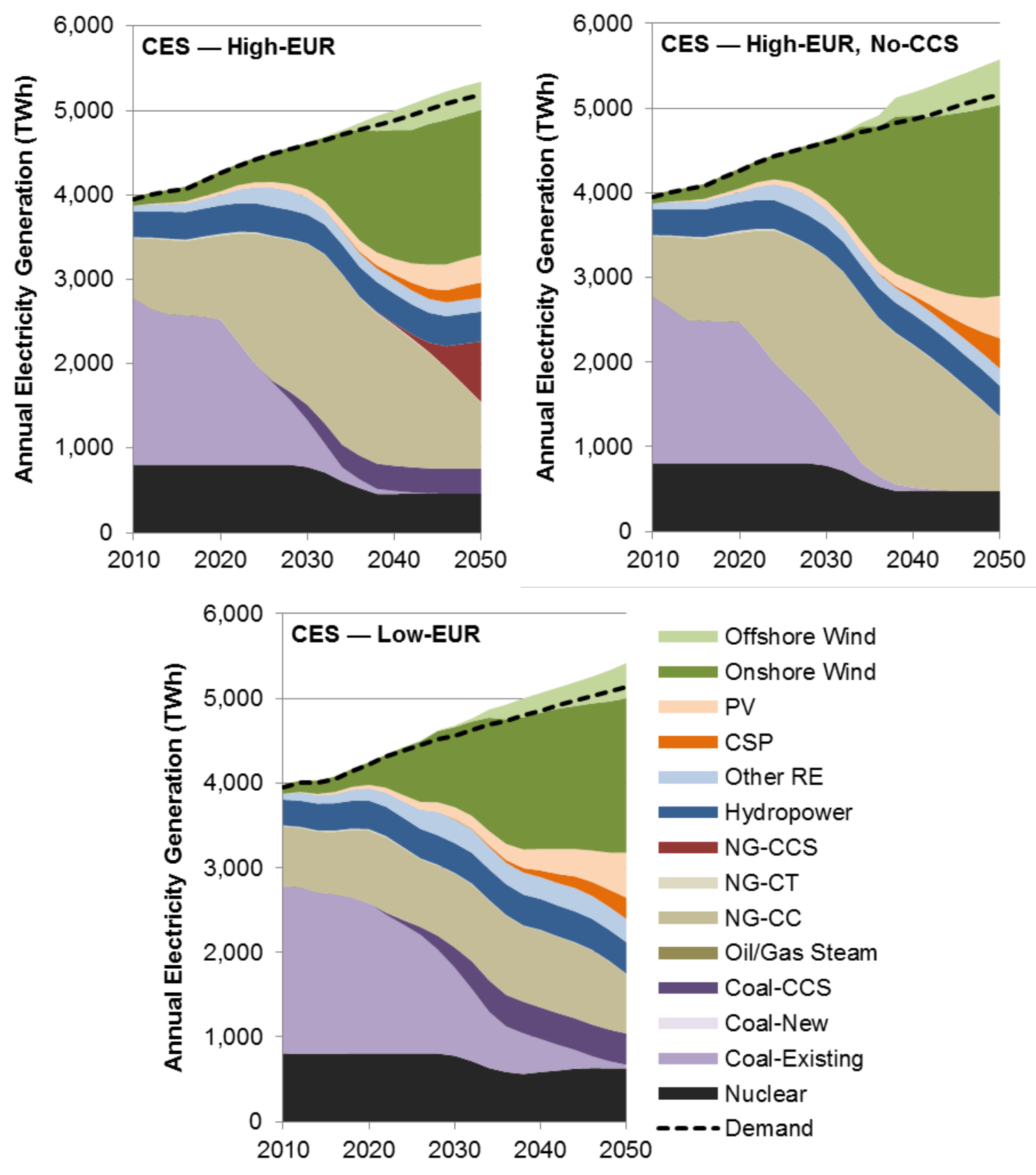

Figure 31. Projected generation in CES scenario, 2010-2050 for CES - High-EUR, CES - High-EUR, without CCS; and CES - Low-EUR cases 
The amount of natural gas used in the CES scenario varies significantly by case, as shown in Figure 32. In all cases, however, it peaks around 2030, and prices remain lower than the Baseline - Mid-EUR case through 2050. Power sector gas demand temporarily falls after 2030 in the CES - High-EUR case, but begins to climb again around 2040 as natural gas CCS becomes an economic contributor to the CES target. When CCS is not available, natural gas consumption continues to decline and is back at 2010 levels by 2050. In the CES - Low-EUR case, natural gas usage remains muted throughout the scenario lifetime as other options meet the target more economically. Average real electricity prices would increase compared to the Baseline - MidEUR case beginning in roughly 2020 and settle at levels between 6\% and 12\% higher by 2050 .

By 2050, $\mathrm{CO}_{2}$ emissions from the U.S. power sector decline by more than $80 \%$ in all CES cases compared to the baseline. Coal generation without CCS has disappeared by that time in all cases. The power sector would be on a trajectory in all CES cases to achieve that sector's contribution to carbon mitigation commensurate with levels the Intergovernmental Panel on Climate Change deems necessary to stabilize atmospheric concentrations of greenhouse gases (IPCC 2007) at a level that could avoid the most dangerous aspects of climate change.

Because the CES cases project a very large build-out of wind power, ReEDS tracks the amount of new transmission lines needed to deliver power from where it is generated to where it is used. The estimated costs of building this new transmission infrastructure are included in the capacity analysis. Figure 33 presents a geospatial map of where new transmission lines would be required through 2050. The vast majority of this new wind generation would be constructed in the Midwestern states for use throughout the Eastern Interconnect. Smaller quantities would be built in the Western and Electric Reliability Council of Texas (ERCOT) Interconnects. The greatest amount of transmission is needed when CCS is not available, and wind must play an even larger role. In this case, more than twice the amount of transmission, as measured in million megawattmiles of capacity, would be needed compared to the CES - High-EUR case in 2050 (or six-times the amount as the Baseline - Mid-EUR case).

\subsubsection{Implications of CES Scenario}

The CES options analyzed here indicate that the U.S. power sector could achieve significant decarbonization by 2050 at relatively modest economic costs, although barriers to building sufficient transmission may be formidable (NREL 2012). About six times more transmission is needed in the CES - without CCS case than in the Baseline - Mid-EUR case by 2050, and three times as much in the CES - High-EUR case. A greater diversity of power generation is achieved when CCS is available and economic for use on coal or gas plants. Heavy reliance on the need for transmission is also lessened when CCS is available. Additional research should be considered to evaluate potential natural gas infrastructure barriers in such a scenario of high variable renewable energy generation.

In all CES cases, large quantities of variable renewable energy are supported and firmed by flexible natural gas generators. Natural gas generators help enable a power generation mix that relies heavily on variable renewable technologies such as wind and solar. 
(a) Power Sector Natural Gas Consumption

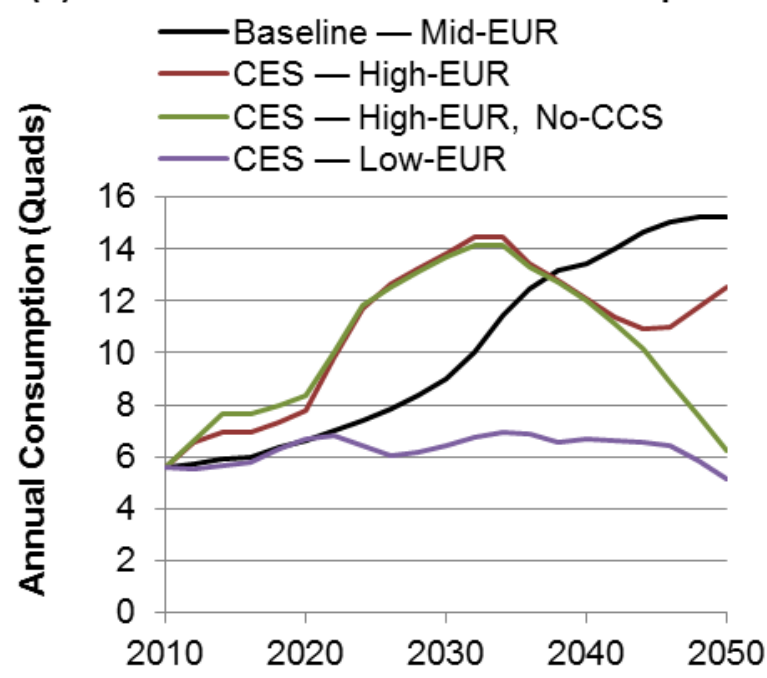

(c) Power Sector $\mathrm{CO}_{2}$ Emissions

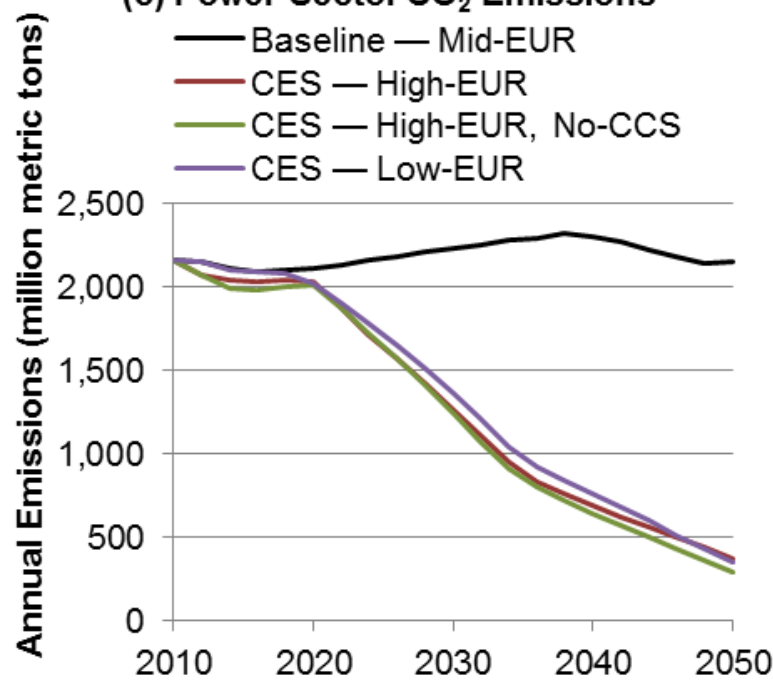

(b) Power Sector Natural Gas Price

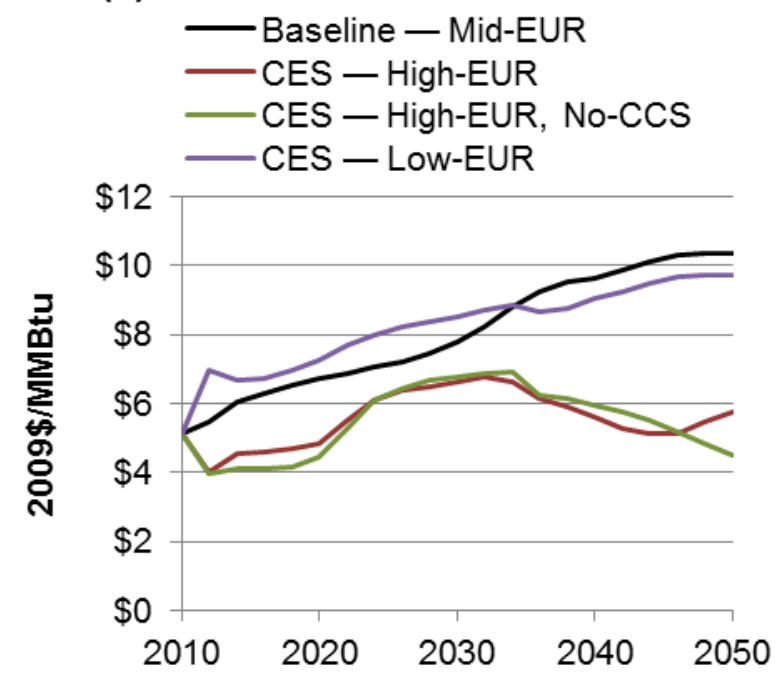

(d) National Average Retail Electricity Price

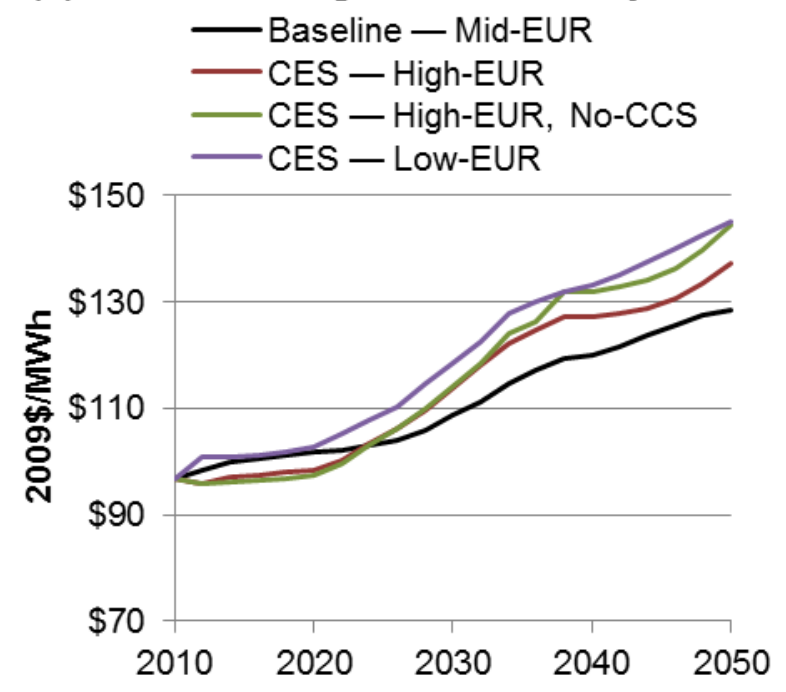

Figure 32. Selected metrics for the CES scenario, 2010-2050 

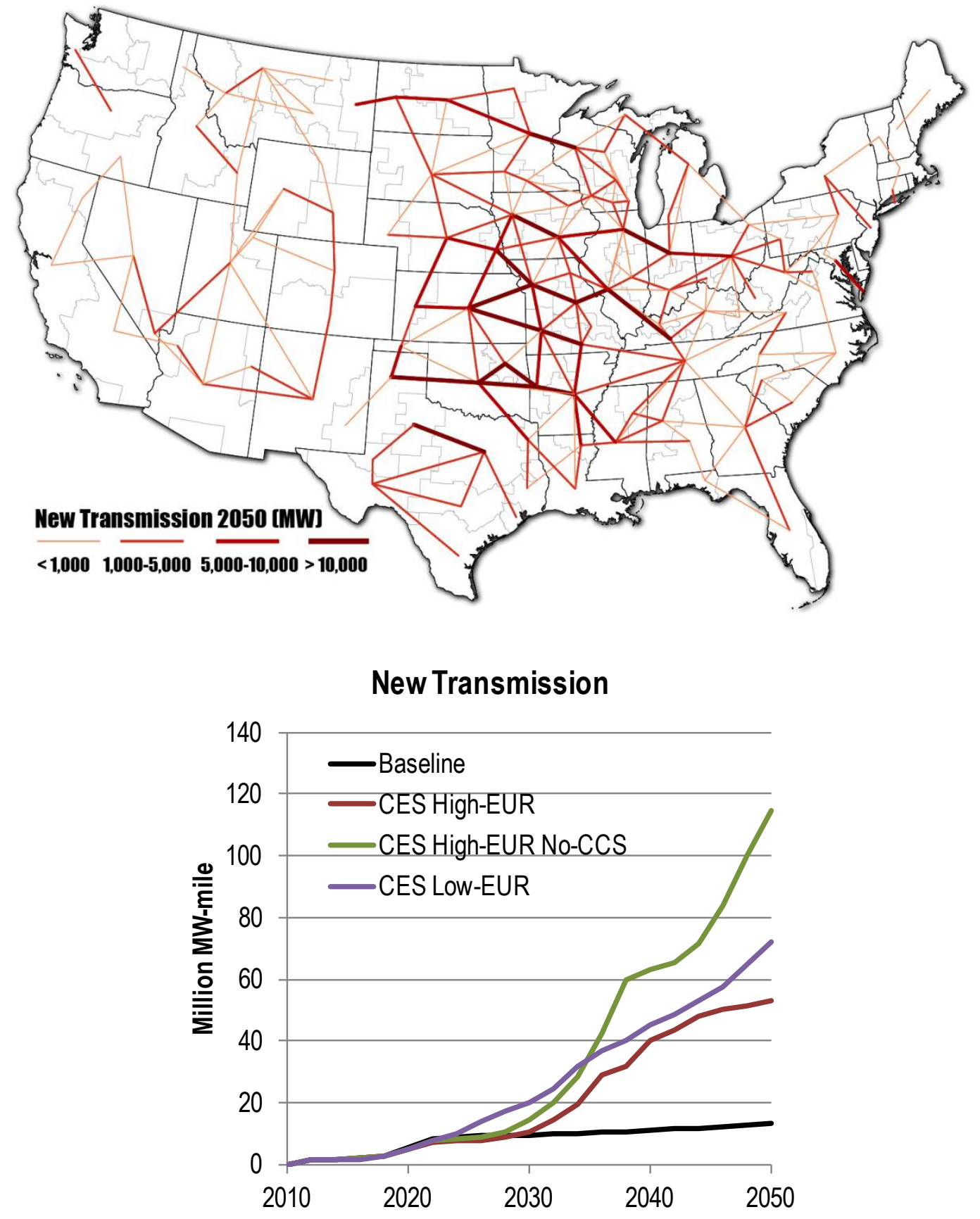

Figure 33. Map of new transmission required by 2050 in the CES - High-EUR case, and measures of new transmission needed in all cases, 2010-2050 


\subsection{Advanced Technology Scenario}

The Advanced Technology scenario considers additional progress in the evolution of cost and performance metrics of certain generation options compared to the Baseline - Mid-EUR case. Two cases are considered here:

- Advanced Nuclear: A 50\% reduction in the capital costs of nuclear generation by 2020 . This scenario also uses a Low-EUR assumption for natural gas.

- Advanced Renewable Electricity (RE): ${ }^{143}$ Capital costs for utility-scale solar PV, concentrating solar power (CSP) with thermal storage, and wind are assumed to decline, as shown in Table 12. In addition, improvements in performance of advanced RE technologies are assumed to be more significant, as shown in Table 13 (e.g., in 2050, Class 5 wind is assumed to have an annual capacity factor of $46 \%$ compared with $43 \%$ in the baseline). CSP is assumed to have the same performance as in the baseline, but with towers available at an earlier time (2015 instead of 2025), resulting in higher performance earlier. Furthermore, distributed PV was exogenously input and assumed to reach 240 GW of capacity by $2050,{ }^{144}$ compared to $85 \mathrm{GW}$ in the baseline. This case uses a MidEUR natural gas assumption.

Table 12. Assumed Reductions in Capital Costs for the Advanced Technology Scenario

\begin{tabular}{lll}
\hline & $\mathbf{2 0 2 0}(\mathbf{\$} / \mathbf{k W})$ & $\mathbf{2 0 5 0}(\mathbf{\$} / \mathbf{k W})$ \\
\hline Advanced Nuclear & $6,200 \rightarrow 3,100$ & $6,200 \rightarrow 3,100$ \\
\hline Advanced On-shore Wind & $2,012 \rightarrow 1,964$ & $2,012 \rightarrow 1,805$ \\
\hline Advanced PV & $2,550 \rightarrow 2,213$ & $2,058 \rightarrow 1,854$ \\
\hline Advanced CSP & $6,638 \rightarrow 4,077$ & $4,778 \rightarrow 2,982$ \\
\hline
\end{tabular}

Table 13. Assumed On-shore Wind Improvements in Capacity Factors for the Advanced Technology Scenario

\begin{tabular}{cccccc}
\hline & Class 3 & Class 4 & Class 5 & Class 6 & Class 7 \\
\hline $\mathbf{2 0 2 0}$ & $0.33 \rightarrow 0.38$ & $0.37 \rightarrow 0.42$ & $0.42 \rightarrow 0.45$ & $0.44 \rightarrow 0.48$ & $0.46 \rightarrow 0.52$ \\
\hline $\mathbf{2 0 5 0}$ & $0.35 \rightarrow 0.38$ & $0.38 \rightarrow 0.43$ & $0.43 \rightarrow 0.46$ & $0.45 \rightarrow 0.49$ & $0.46 \rightarrow 0.53$ \\
\hline
\end{tabular}

Table 14 summarizes the major assumptions used in the Advanced Technology scenario.

\footnotetext{
${ }^{143}$ Advanced RE capital costs and performance improvements were taken from the RE Futures report (NREL 2012), evolutionary technology improvement (RE-ITI) cost projection.

${ }^{144}$ This projection is based on the SunShot Vision Report (DOE 2012).
} 
Table 14. Description of Advanced Technology Scenario

\begin{tabular}{cll}
\hline Case Name & \multicolumn{1}{c}{ Cost Assumption } & $\begin{array}{c}\text { Assumption for Estimated } \\
\text { Ultimate Recovery (EUR) }\end{array}$ \\
\hline Advanced Nuclear & $\begin{array}{l}\text { Nuclear capital costs decline by } 50 \% \text { in } 2020 \\
\text { compared to the baseline scenario. }\end{array}$ & Low-level \\
\hline Advanced RE & $\begin{array}{l}\text { Wind, PV, and CSP capital costs decline as shown } \\
\text { in Table 12. Performance improvements as } \\
\text { described above and shown in Appendix E. }\end{array}$ & Mid-level \\
\hline
\end{tabular}

The impact of potential improvements in these two categories of technology is shown in Figure 34. The primary impact in the Advanced Nuclear case is that enough new nuclear generation is built to offset the decline in age-based retirements by the end of the modeling period. ${ }^{145}$ Additionally, because this case assumes a Low-EUR for natural gas (and thus, higher prices), some new coal plants are also built beginning in 2030 to meet load. The new coal plants largely offset the carbon abatement that otherwise would have occurred due to the new nuclear generation. Retail prices are also higher during most of the reporting period because the LowEUR assumption was made (see Figure 35).

In the Advanced RE case, wind and solar generation expands considerably compared to the Reference scenario. In the case of wind, this illustrates the sensitivity of potential expansion because the assumed cost reductions and performance improvements were relatively modest. Growth in utility-scale PV capacity is substantial in this case, while actual generation increases more modestly due to the relatively low capacity factor that solar achieves. By $2050, \mathrm{CO}_{2}$ emissions decline by a little more than one-quarter compared to the baseline, while retail electricity prices are also slightly lower due to the assumed reduction in cost for RE technologies (Figure 35).

\subsubsection{Implications of the Advanced Technology Scenario Findings}

Under the assumptions used in this analysis, nuclear generation does not become cost competitive with other options until capital costs decline by roughly one-half from today's level and natural gas prices are assumed to be relatively high (Low-EUR). Even under the cost assumptions used in the Advanced Nuclear case, new coal was still competitive with the cheaper nuclear, offsetting some of the carbon advantages of nuclear. Despite these apparently high hurdles, breakthroughs in advanced nuclear designs are possible (OECD 2011; Martin 2012) and could contribute meaningfully to a more diverse and energy-secure power future in the United States.

Even modest reductions in capital costs for renewable energy technologies can have significant impact on their competitiveness compared to baseline assumptions. Wind power appears particularly sensitive to assumed reductions in capital cost and performance improvements, expanding nearly $100 \%$ compared to the baseline with capital cost reductions of about $10 \%$. Similar reductions in utility PV capital costs lead to near-identical impacts in the deployment of that technology, whereas a greater reduction in CSP capital costs would be needed to see a large expansion in the role of that technology.

\footnotetext{
${ }^{145}$ This case was also evaluated under High-EUR and Mid-EUR gas futures, but nuclear was not competitive in that environment, so only the Low-EUR results are shown here.
} 

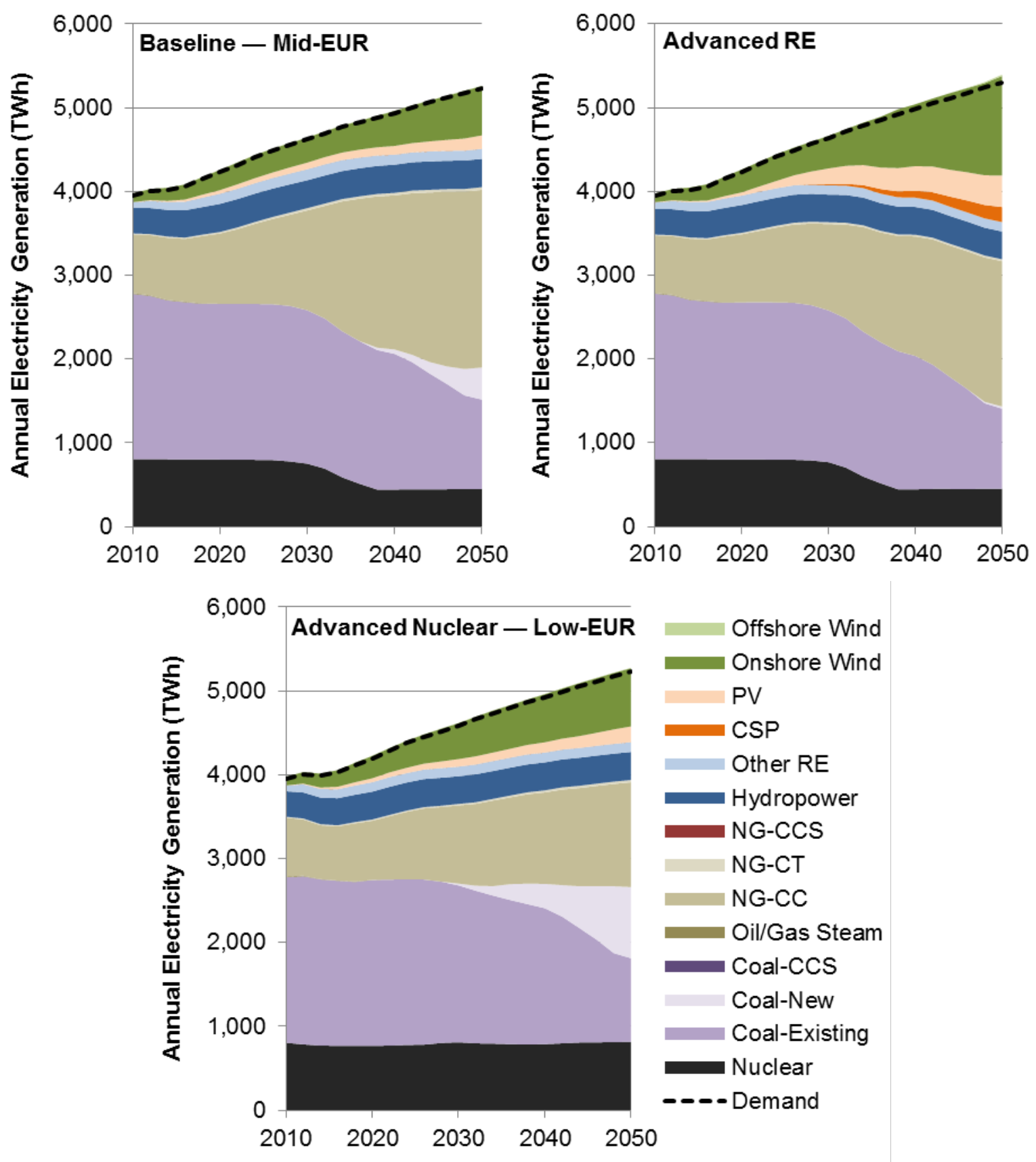

Figure 34. Generation in the Advanced Technology scenario, 2010-2050 
(a) Power Sector $\mathrm{CO}_{2}$ Emissions

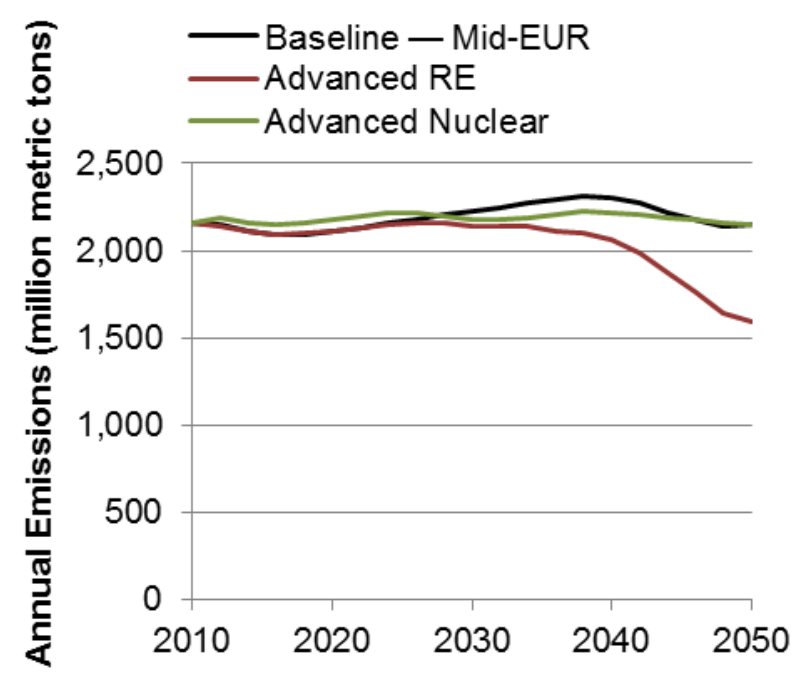

(b) National Average Retail Electricity Price

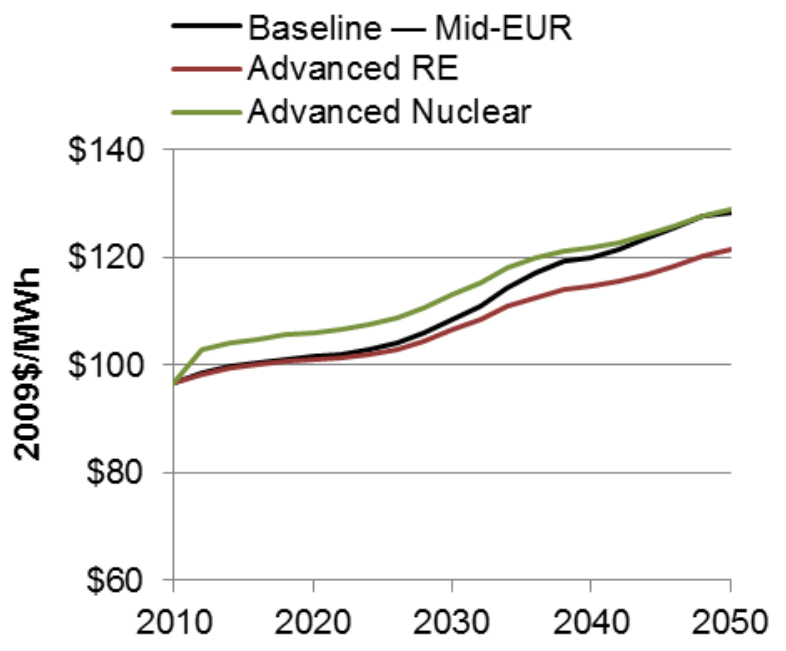

Figure 35. Selected metrics for the Advanced Technology scenario, 2010-2050

\subsection{Natural Gas Supply and Demand Variations Scenario}

Two separate cases are considered here:

- Natural Gas Supply Cost Variations: Variations in natural gas supply costs that could result either from additional state or federal regulations, or from more costly field practices that suppliers follow to better protect the environment. The impact of these incremental natural gas costs on the power sector over the longer-term are simulated using ReEDS. This analysis covers a broad range of potential incremental costs associated with producing natural gas in a way that commands stronger public support yet is still feasible for producers and consumers. Chapters 2 and 3 of this study discuss practices that could result in this more secure outcome on the supply side, but does not arrive at actual estimates of incremental cost impacts in \$/MMBtu terms. The values used here could still be helpful to those who know what their incremental costs are, or to a broader audience in the future when cost estimates are available.

- Natural Gas Demand Variations: Variations in demand for natural gas outside the power sector that could result from a "dash-to-gas" across the larger economy. This dash-to-gas could occur in the export of LNG, greater use of natural gas in vehicles (either as compressed natural gas throughout the fleet, or as LNG in heavy-duty vehicles). Under a dash-to-gas case, natural gas prices rise due to the greater demand and make it more expensive for power generators to use natural gas generation.

Table 15 summarizes key assumptions used in the Supply and Demand Variations scenario. 
Table 15. Description of Natural Gas Supply and Demand Variations Scenario

\begin{tabular}{clc}
\hline Case Name & \multicolumn{1}{c}{ Focus } & $\begin{array}{c}\text { Assumption for Estimated } \\
\text { Ultimate Recovery }\end{array}$ \\
\hline $\begin{array}{c}\text { Natural Gas Supply Cost } \\
\text { Variations }\end{array}$ & $\begin{array}{l}\text { Evaluate impact to power sector as } \\
\text { incremental natural gas production costs } \\
\text { increase from \$0.50/MMBtu to \$2/MMBtu }\end{array}$ & Mid-level \\
\hline Natural Gas Demand & $\begin{array}{l}\text { Evaluate impact to power sector as natural } \\
\text { gas demand in other sectors increases by } \\
\text { Variations (Dash-to-Gas) }\end{array}$ & High-level \\
\hline
\end{tabular}

\subsubsection{Natural Gas Supply Cost Variations}

Figure 36 illustrates adjustments to the natural gas supply curves that could result when additional measures are taken to protect the environment when producing natural gas. These measures could be the result of new regulations or different practices in the field. Examples of these added costs might include the following:

- Activities such as recycling or treating a greater quantity of water supply used in hydraulic fracturing

- Minimizing the amount of methane that is released to the atmosphere before, during, and after fracturing a well

- Casing wells in a more robust and consistent way

- Practicing more robust techniques of cement bond logging

- Substituting more environmentally benign options for traditional hydraulic fracturing additives

- Engaging local stakeholders in dialogues in advance of drilling to ensure their concerns are heard and addressed

- Enforcing larger setbacks from potentially sensitive communities

- Disposing of or treating flowback water in improved ways.

Few publicly available studies estimate what these specific costs might be and how they vary by region. The International Energy Agency (IEA) recently published Golden Rules for a Golden Age of Natural Gas (IEA 2012), a very general statement of 22 steps that should be considered when producing natural gas. The IEA report stated that, "We estimate that applying the Golden Rules could increase the overall financial cost of development a typical shale-gas well by an estimated 7\%." [sic] (IEA 2012). Therefore, if it normally costs $\$ 3.00 /$ MMBtu to develop shale gas, the Golden Rules cost would be \$0.21/MMBtu higher at a typical play. This is nominally consistent with, although lower than, recent estimates of the costs of complying with pending federal rules - including the new EPA air regulations for oil and gas producers, which might cost between $\$ 0.32$ and \$0.78/MMBtu, according to one analyst (Book 2012). Informal consultations associated with this study suggest that maximizing water recycling might result in $\$ 0.25 / \mathrm{MMBtu}$ in added costs. The additional costs that could result from enhanced environmental and safety practices in the field, noted in Chapters 2 and 3, were unable to be quantified. However, it is clear that these costs will vary by region and that many additional safeguards could be practiced at less than an incremental cost of \$1/MMBtu. A 2009 study funded by the American Petroleum 
Institute anticipated much higher costs if new federal regulations were imposed on natural gas producers (IHS 2009).

To assess the potential impacts of these incremental supply costs, this study considers a range of additional costs - starting from $\$ 0.50 / \mathrm{MMBtu}$ and going up to $\$ 2 / \mathrm{MMBtu}$ in increments of $\$ 0.50 / \mathrm{MMBtu}$ - and evaluates the impacts on the long-range evolution of the power sector when these costs are applied. Figure 36 shows the reduction in natural gas use in the power sector as incremental costs are increasingly applied. At the upper limit, natural gas consumption for power generation declines from roughly 15 quads ${ }^{146}$ in the Baseline - Mid-EUR case to 10 quads (incremental $\$ 2 / \mathrm{MMBtu}$ added) by 2050 . With a $\$ 0.50 / \mathrm{MMBtu}$ added cost of gas production, the long-term impacts are far more modest - resulting in a reduction of gas use for power generation in 2050 of less than 2 quads. Coal — and wind, to a lesser extent — replaces the generation lost by the more expensive gas. Other impacts associated with these assumed incremental costs appear relatively modest.

${ }^{146}$ To roughly convert from quads to bcf/d, multiply by 2.6 . Thus, 15 quads per year equal about $38.5 \mathrm{bcf} / \mathrm{d}$. 
(a) Power Sector Natural Gas Consumption

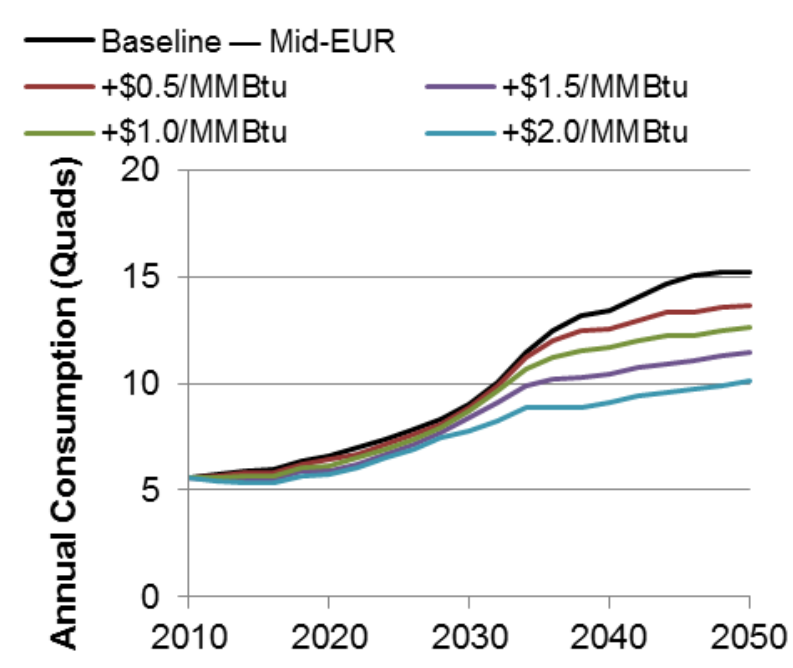

(c) New Coal Capacity

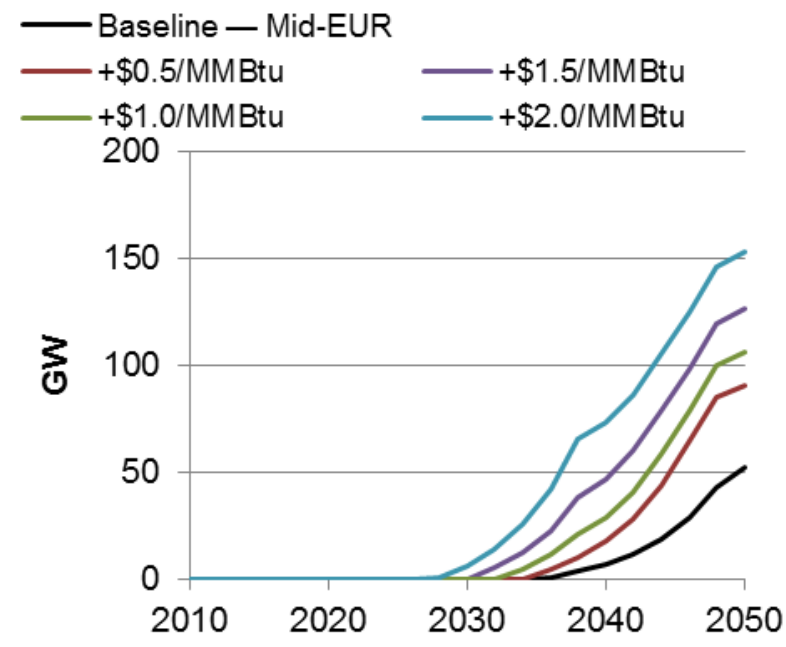

(b) Natural Gas Supply Curve (2020)

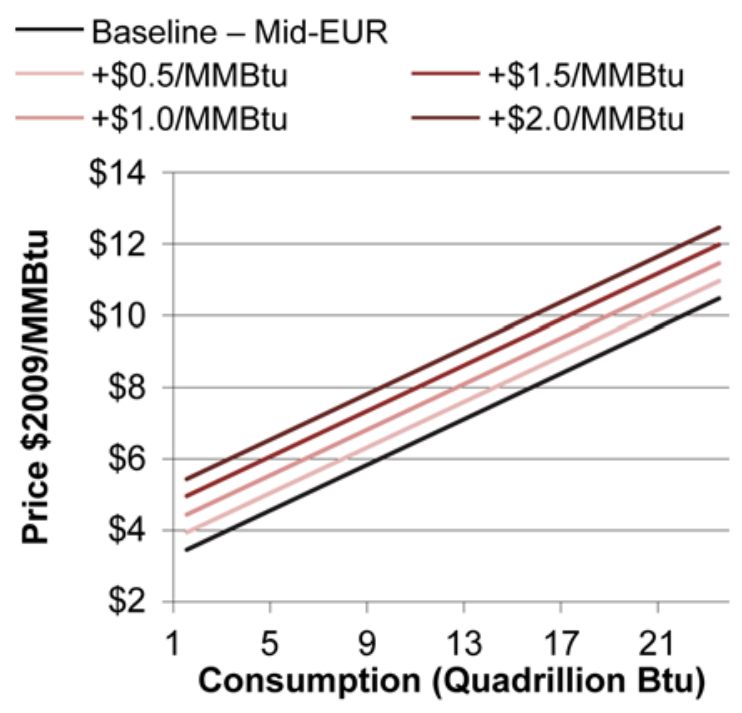

(d) Wind Capacity

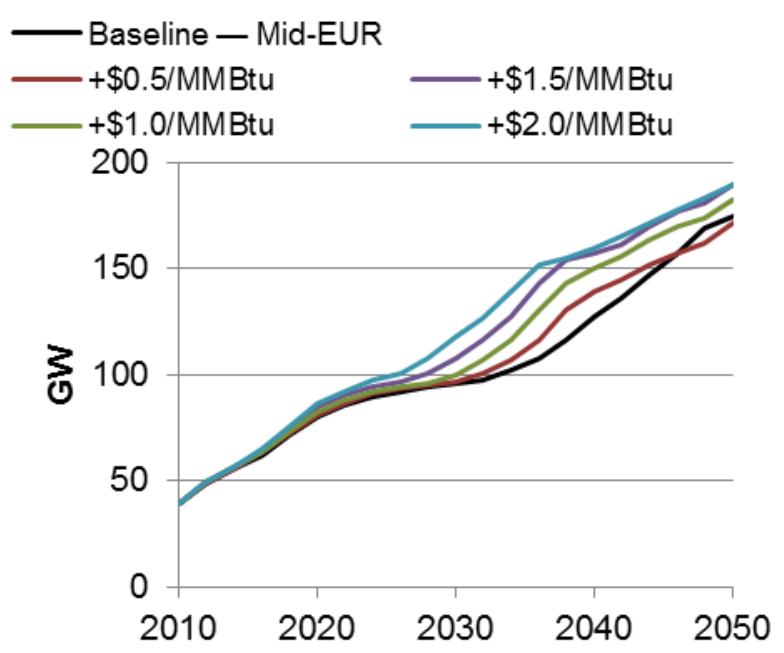

Figure 36. Selected metrics for the Natural Gas Supply Cost Variation case, 2010-2050

\subsubsection{Natural Gas Demand Variations (Dash-to-Gas)}

The Natural Gas Demand Variations case considers the impact to potential expansion of natural gas generation if a significant shift to natural gas occurs in other sectors of the economy. Specifically, it looks at the combined potential of new LNG exports, natural gas vehicle deployment (both compressed natural gas and LNG in heavy-duty trucking), and use in industrial and chemical applications and any other sector that in aggregate reaches $12 \mathrm{bcf} / \mathrm{d}$ by 2026 .

A growing number of studies analyze the impact of LNG exports on domestic natural gas prices (EIA 2012b; Pickering 2010; Deloitte 2011; Ebinger et al. 2012). Estimates vary considerably depending on methodology used, location, and assumptions about overall gas availability. The case examined here uses the methodology in the EIA LNG exports scenario as a basis for the full 
economy "dash-to-gas." 147 Thus, it takes the "high and slow" EIA-derived price impact of exporting $12 \mathrm{bcf} / \mathrm{d}$ of LNG by 2026 and uses it to represent the impact of a combined $12 \mathrm{bcf} / \mathrm{d}$ in the total economy, distributed among LNG exports, vehicle use, industrial use, and any other applications (see Figure 37 and Table 16).

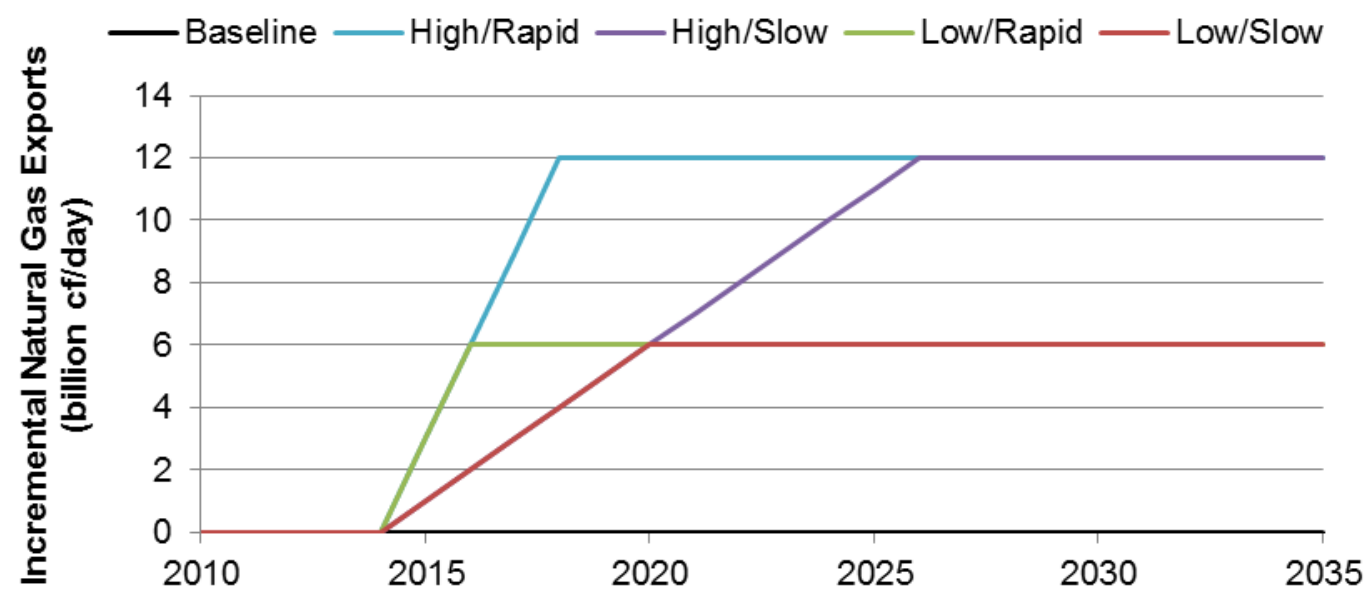

Source: U.S. EIA based on DOE Office of Fossil Energy request letter

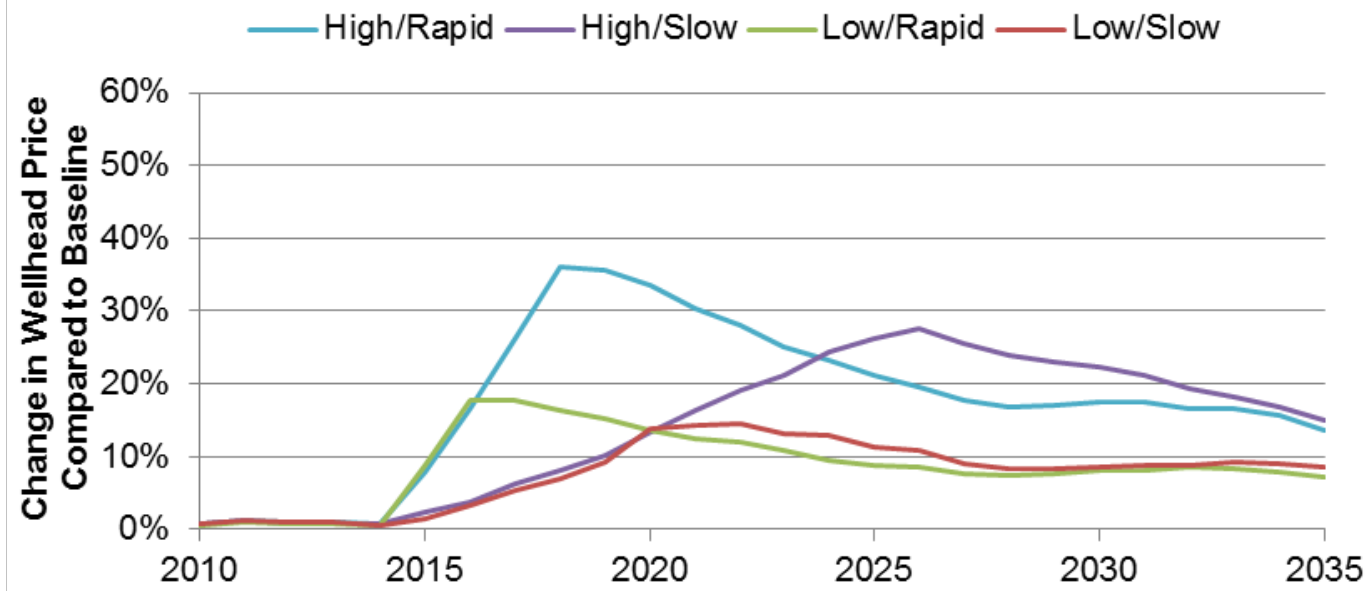

Source: U.S. EIA, National Energy Modeling System

Figure 37. EIA LNG export scenarios and their projected impacts on domestic natural gas prices, 2010-2035

\footnotetext{
${ }^{147}$ The upper limits (i.e., high/rapid scenario) of the EIA study have been criticized by some (Ebinger et al. 2012) as too extreme and not representative of how LNG exports might really occur. Although the study in this report uses the second-most extreme (high/slow) LNG export scenario considered by the EIA, the scenario is constructed to capture a wider range of potential natural gas end-uses than just LNG exports.
} 
Table 16. Non-Power Sector Natural Gas Demand Assumptions in the Natural Gas Demand Variations Case

\begin{tabular}{lccccc}
\hline & $\mathbf{2 0 1 0}$ & $\mathbf{2 0 2 0}$ & $\mathbf{2 0 3 0}$ & $\mathbf{2 0 4 0}$ & $\mathbf{2 0 5 0}$ \\
\hline LNG Exports & 0 & (billions of cubic feet per day) & \\
\hline Vehicles & & 5.0 & 7.3 & 5.0 & 0 \\
\hline Industry/Other & 0 & 1.5 & 2.7 & 3.0 & 0 \\
\hline Subtotal & 0 & 1.5 & 2.0 & 1.5 & 0 \\
\hline
\end{tabular}

In the Natural Gas Demand Variations (dash-to-gas) case, gas prices rise by a maximum of 29\% above the Reference scenario value in 2026 before re-equilibrating. The power sector mix is similar to the Baseline - Low-EUR case (compare Figure 38 with Figure 26), although still slightly more reliant on natural gas generation. A dash-to-gas future, then, would restrict gas generation to less than doubling by 2050 compared to the 2010 level. The larger macroeconomic impacts associated with this future were not evaluated; however, overall gas demand declines by about 3 quads by 2050 (Figure 39) compared to the baseline. The price of natural gas for power generators rises by a maximum of $\$ 2 / \mathrm{MMBtu}$ above the baseline value in the early 2020 s before returning to the baseline level in 2050, when the other sectors are assumed to terminate their extra reliance on natural gas (see Figure 39).

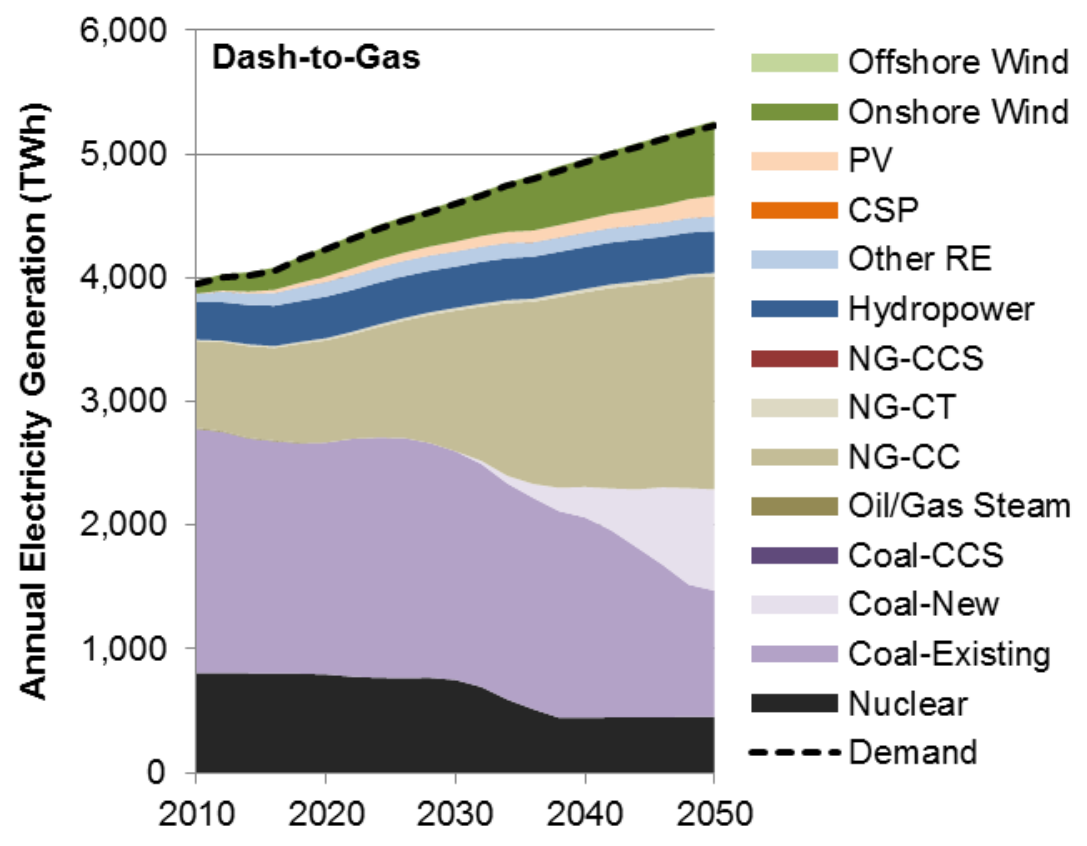

Figure 38. Power generation mix in the Dash-to-Gas case

\footnotetext{
${ }^{148}$ These estimates for compressed natural gas use in vehicles are proposed by Wellkamp and Weiss (2010).
} 
(a) Power Sector Natural Gas Consumption

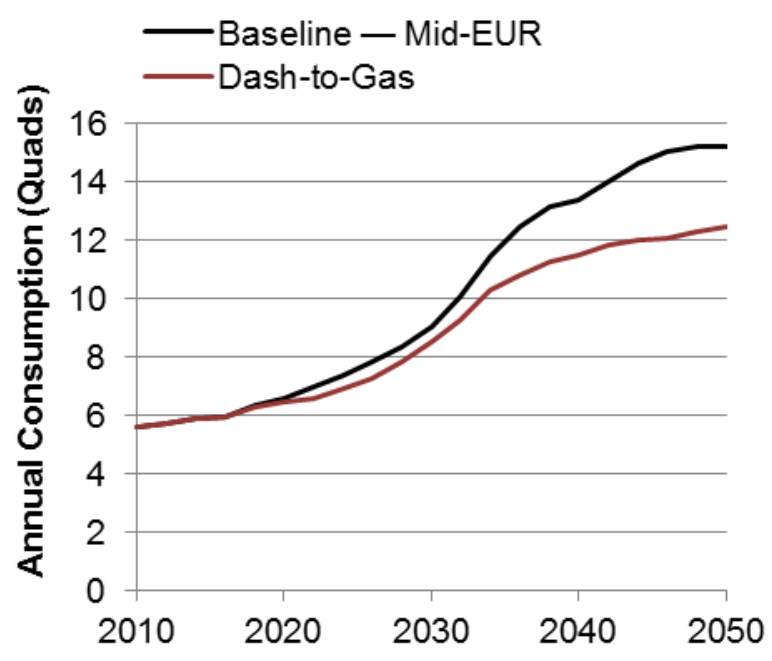

(b) Power Sector Natural Gas Price

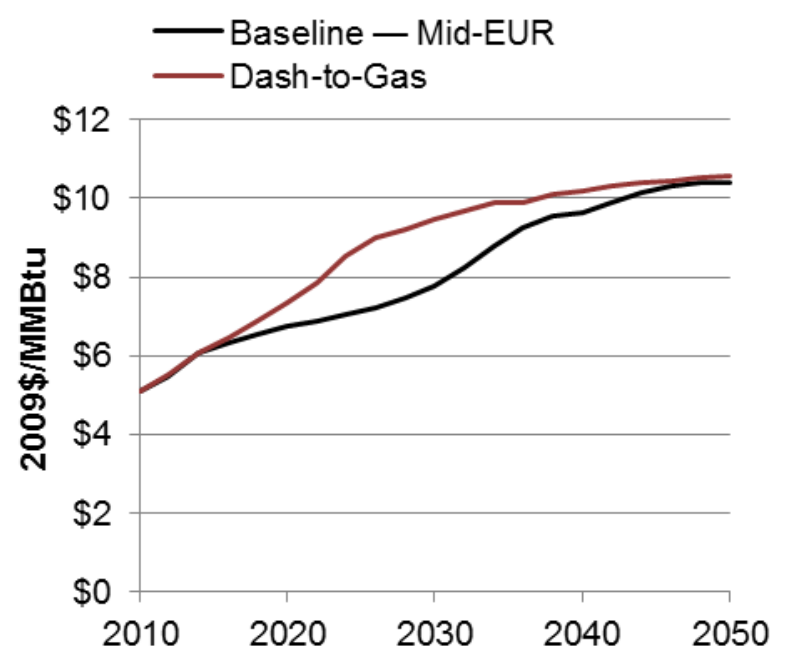

Figure 39. Selected metrics for the Dash-to-Gas case, 2010-2050

\subsubsection{Implications of the Natural Gas Supply and Demand Variations Findings}

Many additional measures could be taken by producers to address the real and perceived risks associated with unconventional natural gas production at a modest impact to the evolution of the power sector. If total costs from a long list of potential practices reached \$1.00/MMBtu, natural gas usage in the 2050 power sector might be expected to decline from 2.5 times the 2010 level in the Baseline to 2 times in the Supply Variation case. Costs associated with ensuring stronger public support of unconventional gas and oil production would vary by region and producer. Technologies associated with unconventional natural gas production are under rapid development, so the cost impacts will be changing dynamically. Follow-on research should attempt to gather additional data from producers to better estimate what the real cost would be of addressing issues of social license to operate on a basin-by-basin level. The question for industry might then be: Are these added costs worth absorbing — and an acceptable price to pay - to ensure both greater public and utility-sector confidence in the production practice over the longer term?

Understanding the price impacts of a Dash-to-Gas case is still poorly characterized due to the newness of the recent change in natural gas supply outlook. Based on currently available estimates, a fairly strong dash-to-gas in other sectors of the economy would have a visible, although still marginal, impact on the evolution of the electric power sector-with natural gas use declining somewhat due to the higher prices and other forms of generation increasing to take its place. As additional experience and estimates of this elasticity become available, follow-on research should re-examine the impacts.

\subsection{Conclusions for Power Sector Modeling}

The role of natural gas in the U.S. power sector is sensitive to assumptions about EUR. More research is needed to better understand how much gas will ultimately be recovered from unconventional plays. 
Coal retirements and fuel switching are already occurring ahead of the rollout of EPA rules. The modeling results indicate that any new plants needed to replace retiring coal would mostly be fired by natural gas and that on an aggregate level, reliability standards are maintained without an unusual level of new construction. This analysis did not attempt to evaluate location-specific reliability impacts associated with coal-plant retirements; more granular dispatch models would be needed to investigate those questions with more certainty.

The CES modeling results indicate that substantial reductions in $\mathrm{CO}_{2}$ emissions are achievable at modest cost, although transmission barriers could stand in the way. When CCS is not available under a CES, generation options decline, the need for new transmission expands significantly, and the power mix becomes less diverse. Therefore, CCS is an important option for a low-carbon power sector, but may not be essential.

Continued focus on technology research, development, and deployment is needed to bring down costs and ensure a diverse power mix in the future. Even modest reductions in renewable energy capital costs and improvements in performance may have a meaningful impact on their continued deployment in the future. Continued advancements in technologies used to find and produce unconventional gas could also have a strong impact on improving the social license to operate at an acceptable price, and thus, should be pursued at all levels.

Finally, increased costs associated with potential changes in field practices of natural gas producers were evaluated over a fairly broad range. If these costs turn out to be less than an incremental \$1/MMBtu, then the long-term impact on natural gas in the power sector is not significantly different from the baseline conclusions: gas demand for power generation declines by about $17 \%$ while $\mathrm{CO}_{2}$ emissions increase marginally. An important outcome of this studyand a potential question for follow-on research and discussion-would be whether these additional costs associated with protecting the environment, improving safety, and commanding public confidence are worthwhile to society and gas producers.

Natural gas appears plentiful and at historically low price levels for the foreseeable future, but going forward, decision makers may want to pay special attention to generation diversity. An undesirable outcome would result if a major shift to natural gas generation occurred before a substantial rise in natural gas prices - due, for example, to mischaracterizations of EUR, a failure to earn the social license to operate, or some other reason that may currently be considered "unlikely." Continuing research, development, and deployment over a wide variety of generation and gas production options can help prevent such an outcome. It would also provide greater flexibility in addressing the threat of climate change. 


\section{Conclusions and Follow-On Research Priorities}

\subsection{Conclusions}

Major, high-level findings derived from the research conducted in this study include:

- Life cycle greenhouse gas emissions associated with electricity generated from the Barnett Shale play gas in 2009 were found to be very similar to conventional natural gas and less than half of those associated with coal-fired power generation.

- Low-priced natural gas has led to more than 300 terawatt-hours of fuel switching from coal to gas in the U.S. power sector between 2008 and 2012. This switching, in combination with rapid growth in certain renewable energy generation sources, has led to a reduction in power-sector carbon dioxide emissions of about 300 million tons-about $13 \%$ of the sector's total. This fuel switching may stop or reverse itself if natural gas prices rise relative to coal. Natural gas can play an important role in greenhouse gas mitigation over the short- to mid-term, but if policymakers pursue an $80 \%$ mitigation target by 2050 , carbon capture and sequestration may need to be commercially viable by 2030 for natural gas power generation to continue growing.

- The legal and regulatory frameworks governing shale gas development are changing in response to public concerns, particularly in regions that have less experience with oil and gas development. All of the states examined in this study have updated their regulatory frameworks to address the opportunities and challenges associated with greater unconventional natural gas production. Better coordination and information sharing among regulators may help ensure efficient and safe production, while greater availability of transparent and objective data may help address some of the public's concerns.

- States and natural gas producers are developing additional, often voluntary, field practices to ensure that shale gas can be produced with high standards of environmental protection - although these standards are not always uniformly followed. Continued advances in technologies and practices could help address public concern over unconventional gas production. Some data, such as the amount of water used per well in hydraulic fracturing, are readily available and can be analyzed on a regional basis. However, a lack of publicly available information on industry practices limits a full-scale assessment of water risks associated with shale gas operations. Further collaboration and interaction with industry partners could help improve data collection efforts.

- A suite of different future electric power scenarios was evaluated to test the implications of different policy and technology changes. These scenarios include power plant retirements, advances in generation technologies, federal policies to reduce greenhouse gases, and variations in natural gas supply and demand. The study found that natural gas use grows robustly in nearly all scenarios over the next two decades. Over the longer term, natural gas demand for electricity generation faces greater uncertainty, leading to larger ranges of change in gas demand - including the case where demand in 2050 is roughly the same as that in 2010 in the event a clean energy standard is pursued and carbon capture and sequestration is not commercially available (see Figure 32).

Readers should consult corresponding chapters to view more comprehensive findings and ensure that the appropriate context is conveyed with each finding. 


\subsection{Follow-on Research}

Because of time and budget constraints, the research team could not investigate some issues as fully as warranted. Each chapter identifies areas where additional research would likely lead to improved understanding on certain issues. Selected follow-on research taken from this larger list is presented below. Please refer to the main chapters for a more comprehensive discussion on these follow-on research topics.

- More field-measurement-based research on methane leakage and mitigation options at unconventional gas production facilities (outside of the Barnett Shale play) considering geographic and operational variability at well, play, and national scales.

- More industry- and basin-specific research to estimate the incremental costs associated with various regulatory scenarios, including more robust environmental standards in unconventional gas production. Additional social research to understand how improved standards might impact public perception of gas production and the social license to operate. Additional economic research to understand how higher costs would impact producers, and the degree to which they might be able to pass costs on directly to consumers.

- More comprehensive evaluation of risks in shale gas production and how they can be best addressed using new technologies and field practices. Increased quantitative understanding of the magnitude and probability of risks to water resources that result from current industry practices and proposed best management practices. More comprehensive evaluation of the regional diversity of risks, costs, and effective industry practices inherent in shale gas development.

- Greater understanding of the impact of additional natural gas demand, especially liquefied natural gas exports, on domestic and international prices. In general, greater certainty and understanding of natural gas price volatility and estimated ultimate recovery in the relatively new abundant natural gas environment would also be beneficial.

- Finally, this study did not use a modeling tool that simulated operation and expansion of natural gas pipelines. Follow-on work that included such capabilities might identify additional opportunities and barriers to growth in electric power natural gas use. 


\section{Appendix A: Shifting Coal Generation in U.S. States}

This appendix summarizes recent data on changes in coal-fired electricity generation published by the Energy Information Administration (EIA) of the U.S. Department of Energy. Many of these changes are due to some combination of low-priced natural gas, aging coal generators, and impending regulations from EPA. However, some changes - especially in small states - could be unrelated. Using data at the state level—rather than the larger boundaries of regional transmission organizations or independent system operators - is somewhat artificial when showing changes in electricity generation. Nevertheless, state-level data are convenient, and important trends can be seen in the grouping of some states.

Figure 41 presents a snapshot of the change in coal-fired generation percentage between 2008 and the first 2 months of 2012 for most states. The charts that follow provide additional information on how changes in generation mix have occurred in the first 15 states shown in Figure 41.

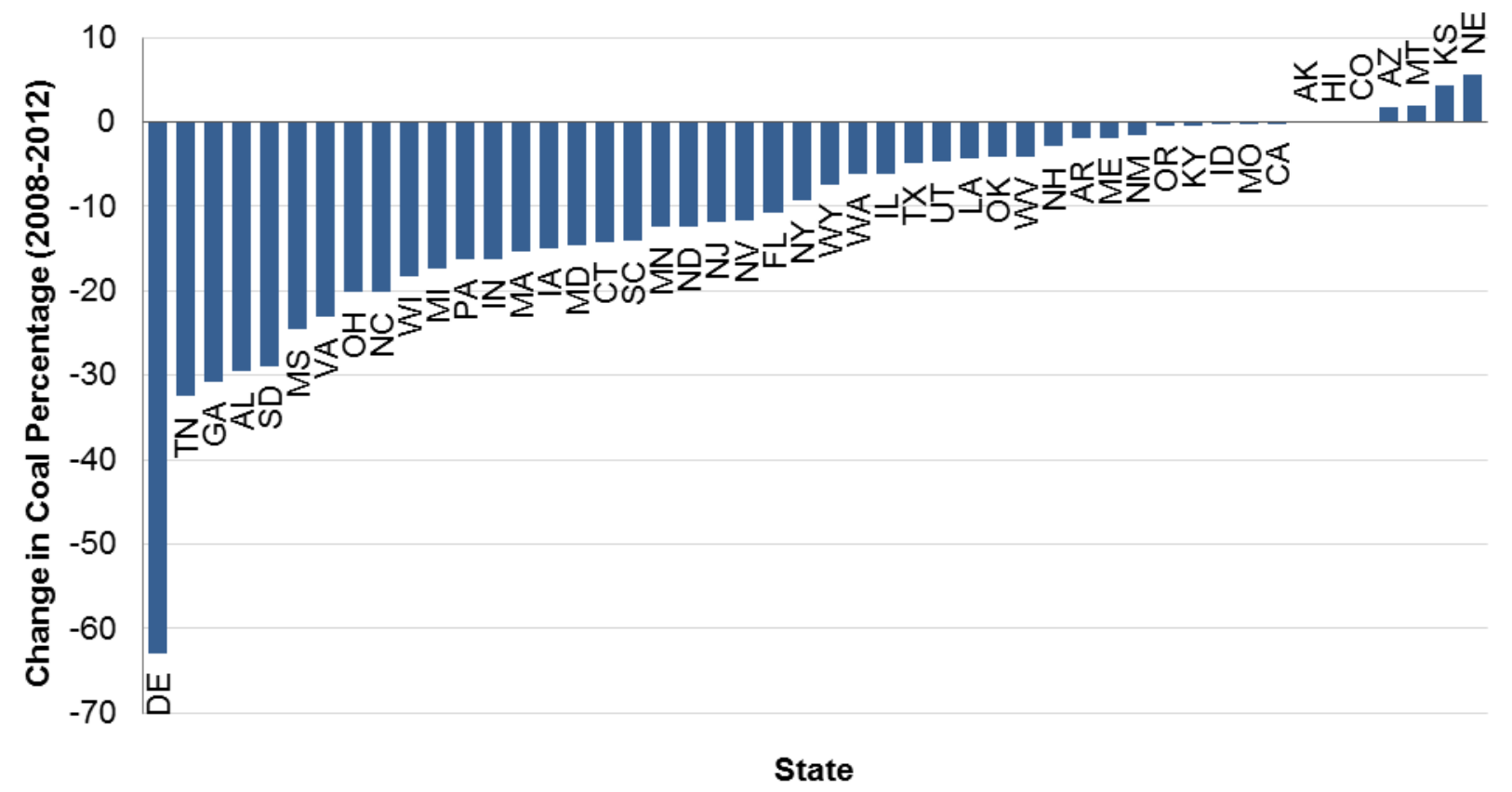

Data: U.S. Energy Information Administration, Electric Power Monthly, data through February 2012. Note: DC, RI, and VT are not included.

Figure 41. Changes in coal percentage of total net generation at the state level, 2008-2012 
Figure 42 through Figure 56 show how generation mix has changed between 2005 and early 2012 for the 15 states with the largest drop in coal percentage as a percent of total net generation. The data for all of these figures come from the U.S. Energy Information Administration, "Electric Power Monthly." The data are through February 2012, and the 2012 data include only January and February net generation. Some seasonal effect is reflected in the 2012 year-to-date data points.
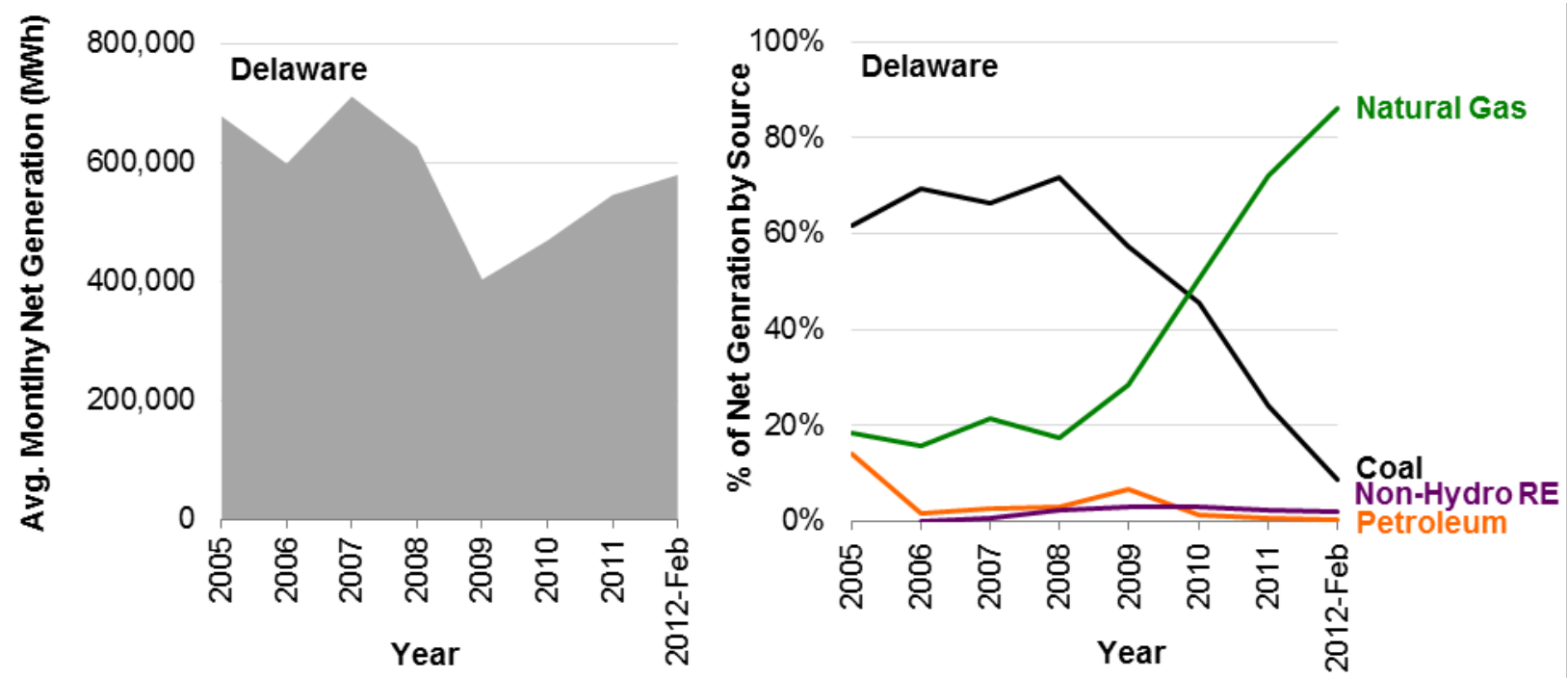

Figure 42. Changes in generation mix in Delaware; 2005-early 2012
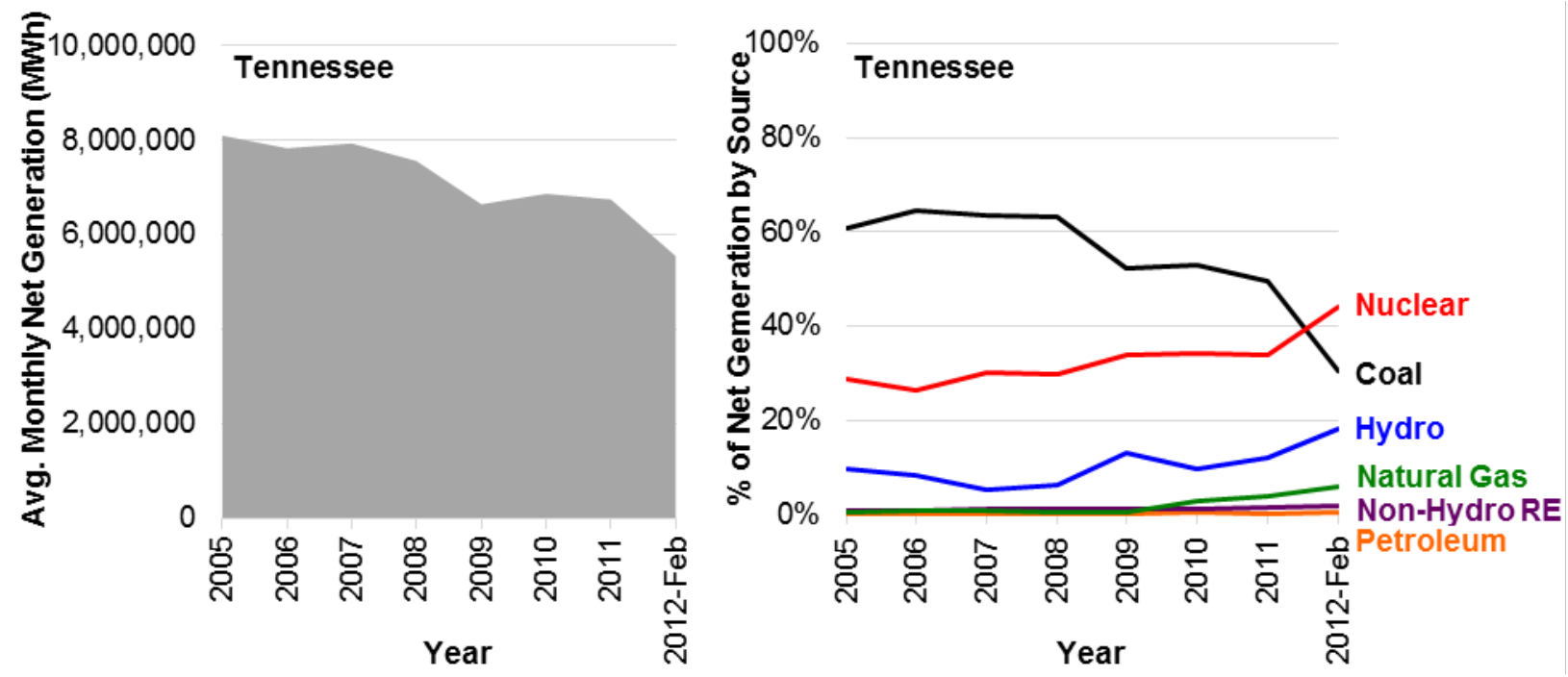

Figure 43. Changes in generation mix in Tennessee; 2005-early 2012 

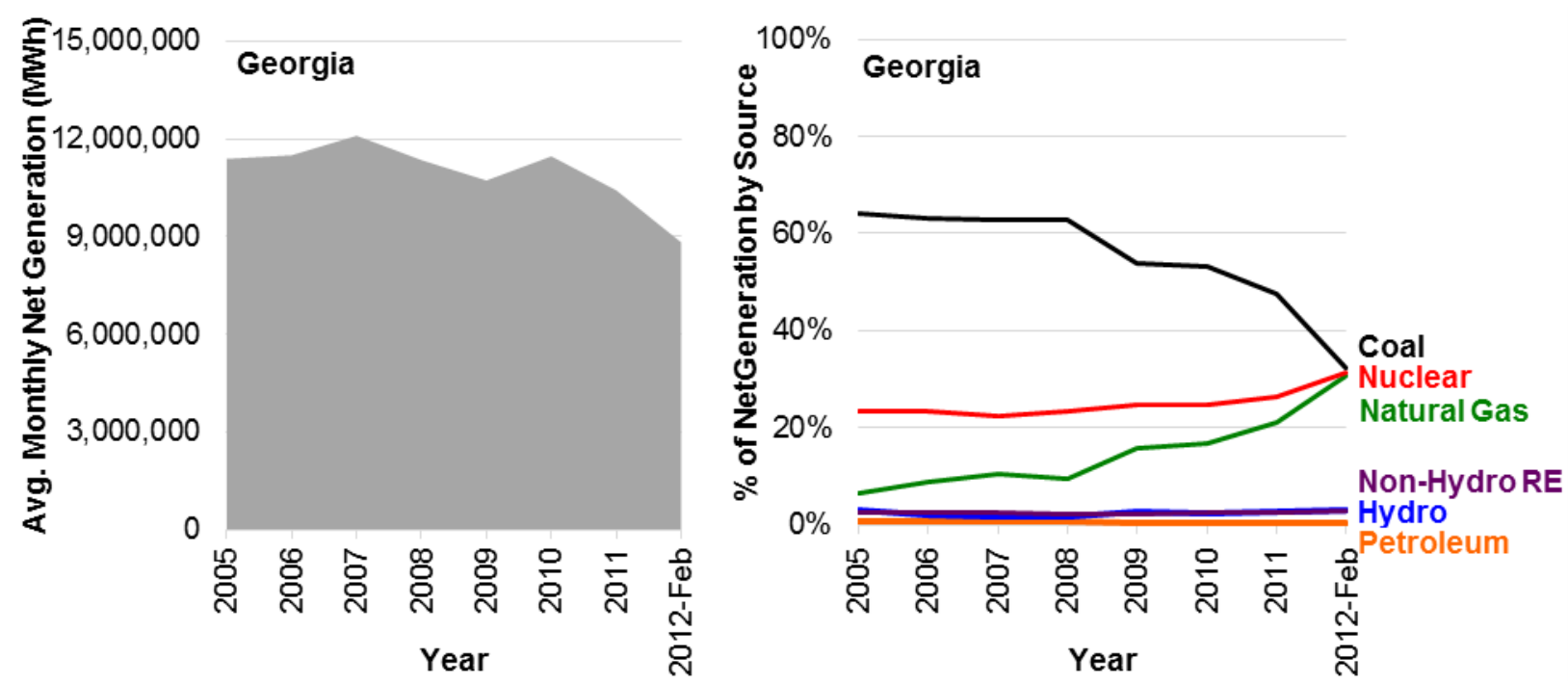

Figure 44. Changes in generation mix in Georgia; 2005-early 2012
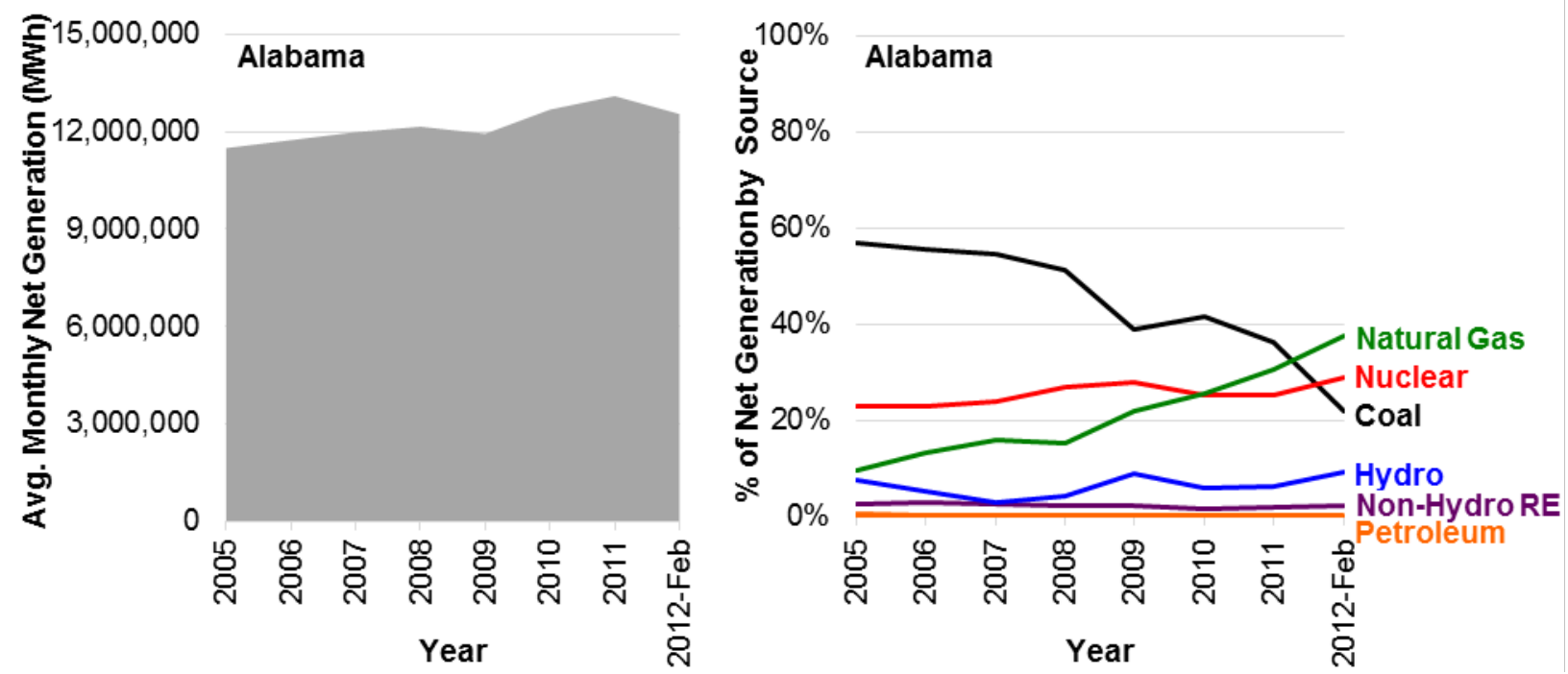

Figure 45. Changes in generation mix in Alabama; 2005-early 2012 


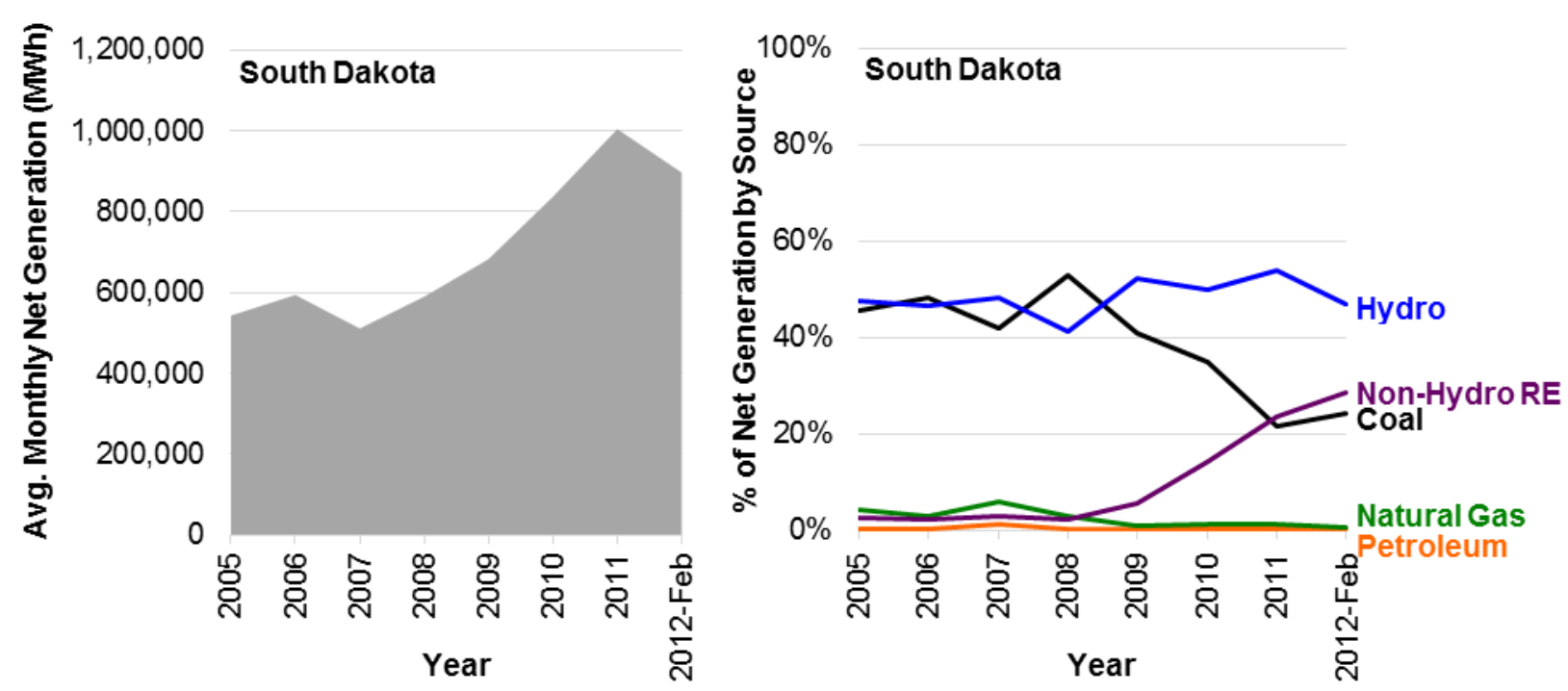

Figure 46. Changes in generation mix in South Dakota; 2005-early 2012
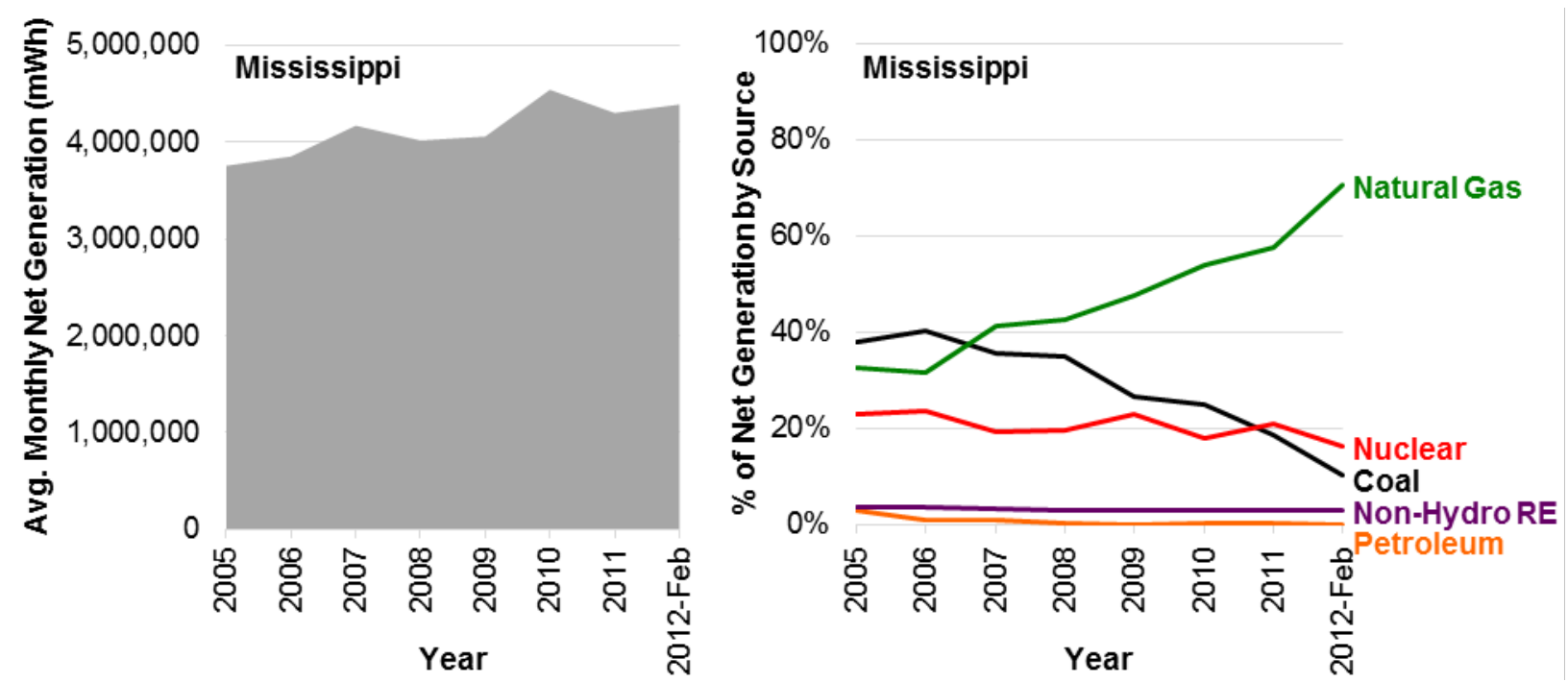

Figure 47. Changes in generation mix in Mississippi; 2005-early 2012 

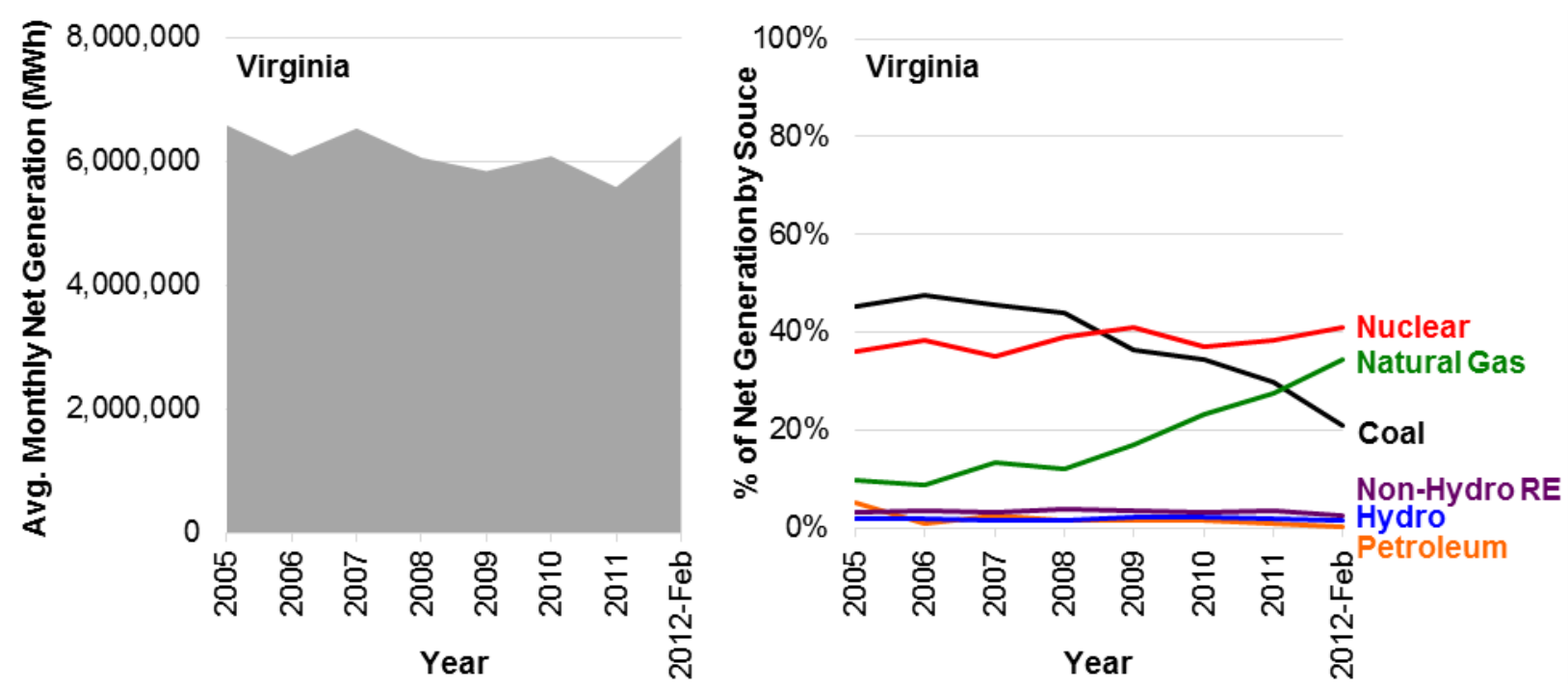

Figure 48. Changes in generation mix in Virginia; 2005-early 2012
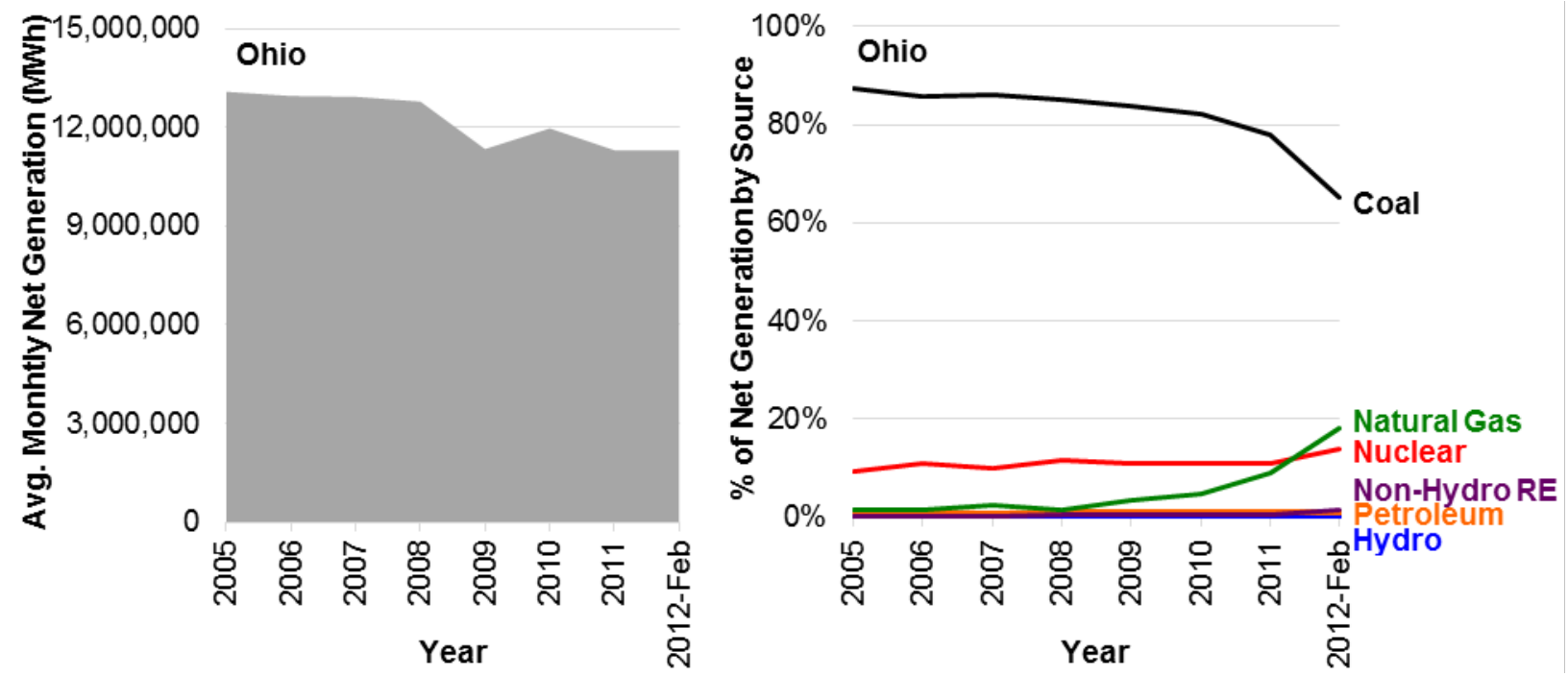

Figure 49. Changes in generation mix in Ohio; 2005-early 2012 

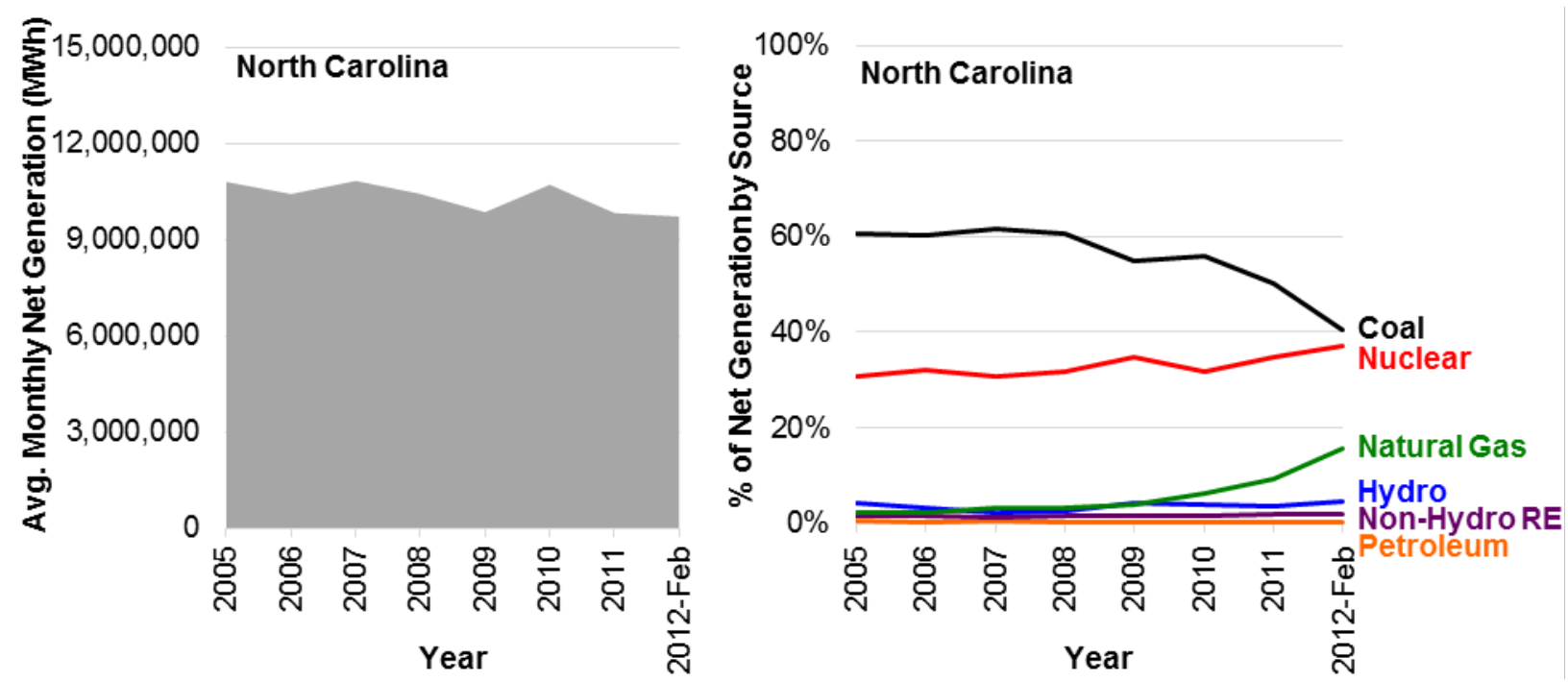

Figure 50. Changes in generation mix in North Carolina; 2005-early 2012
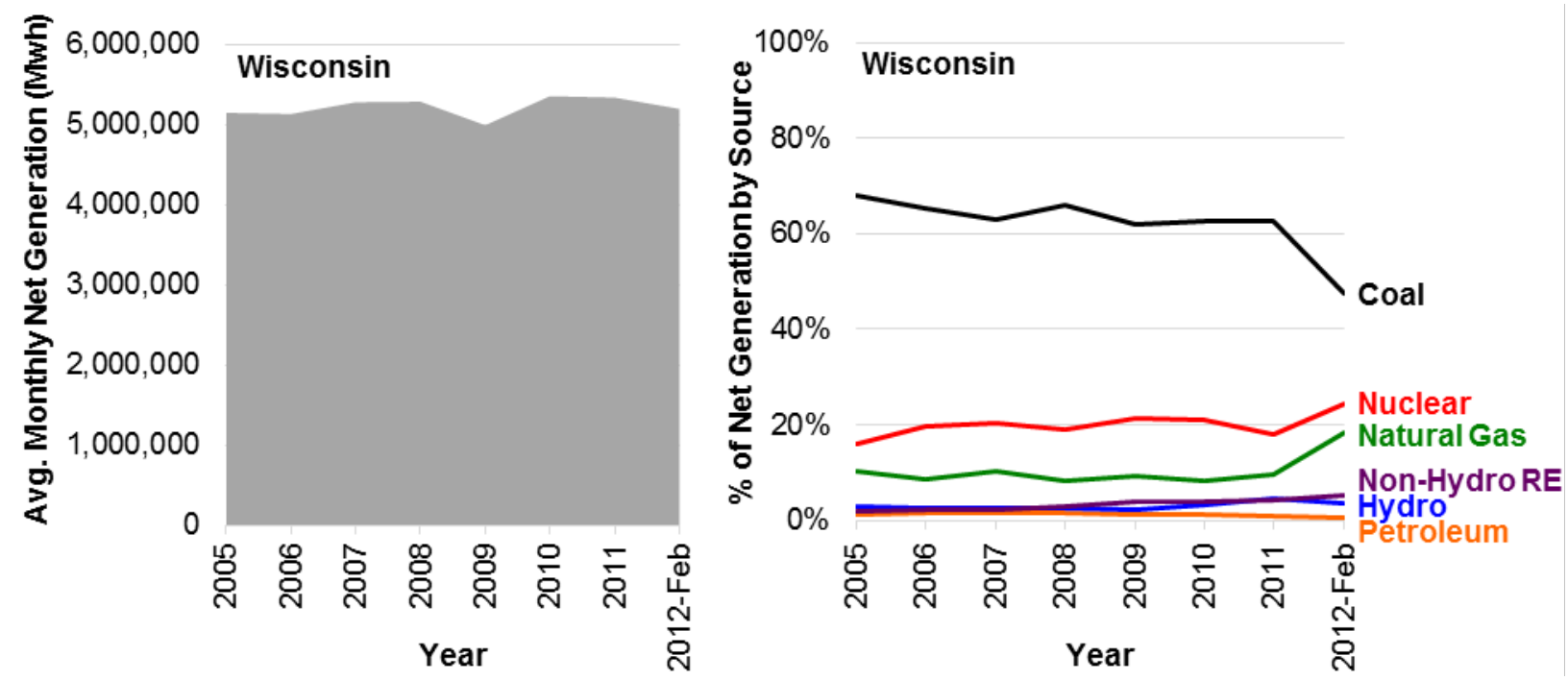

Figure 51. Changes in generation mix in Wisconsin; 2005-early 2012 


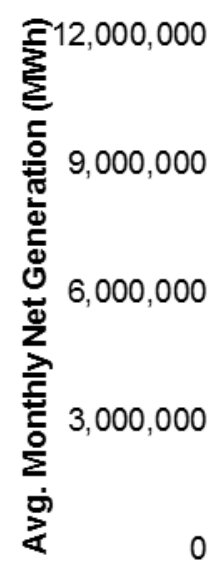

Michigan

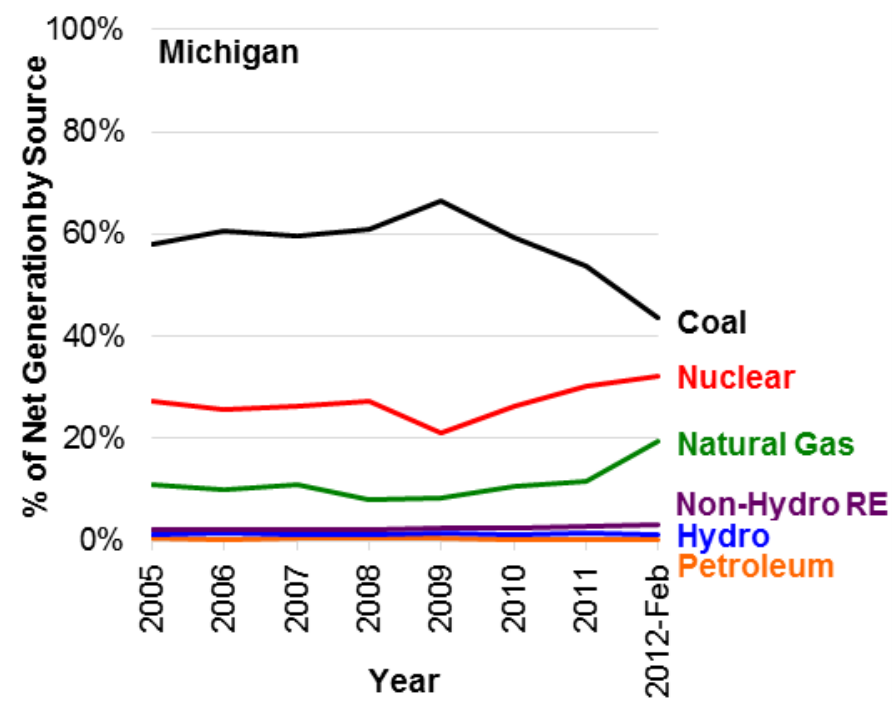

Figure 52. Changes in generation mix in Michigan; 2005-early 2012
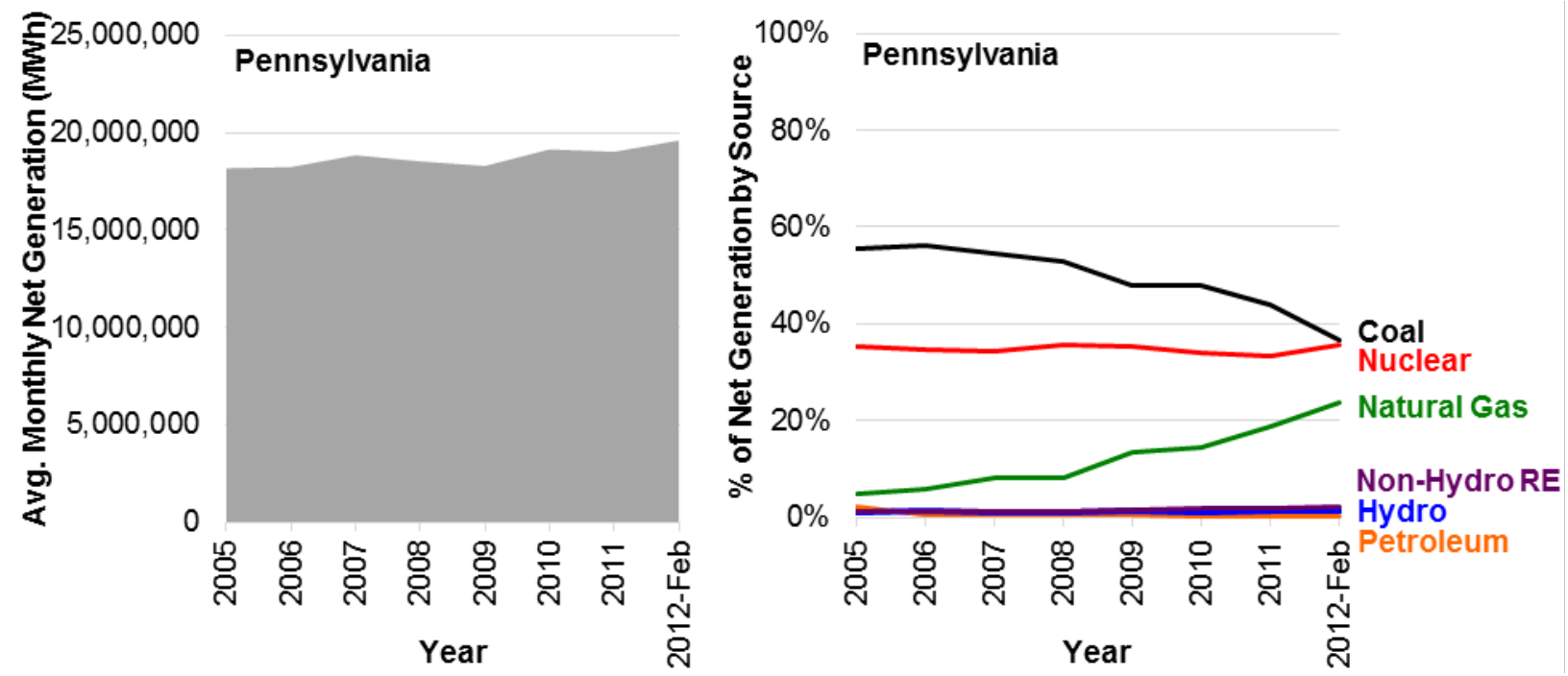

Figure 53. Changes in generation mix in Pennsylvania; 2005-early 2012 

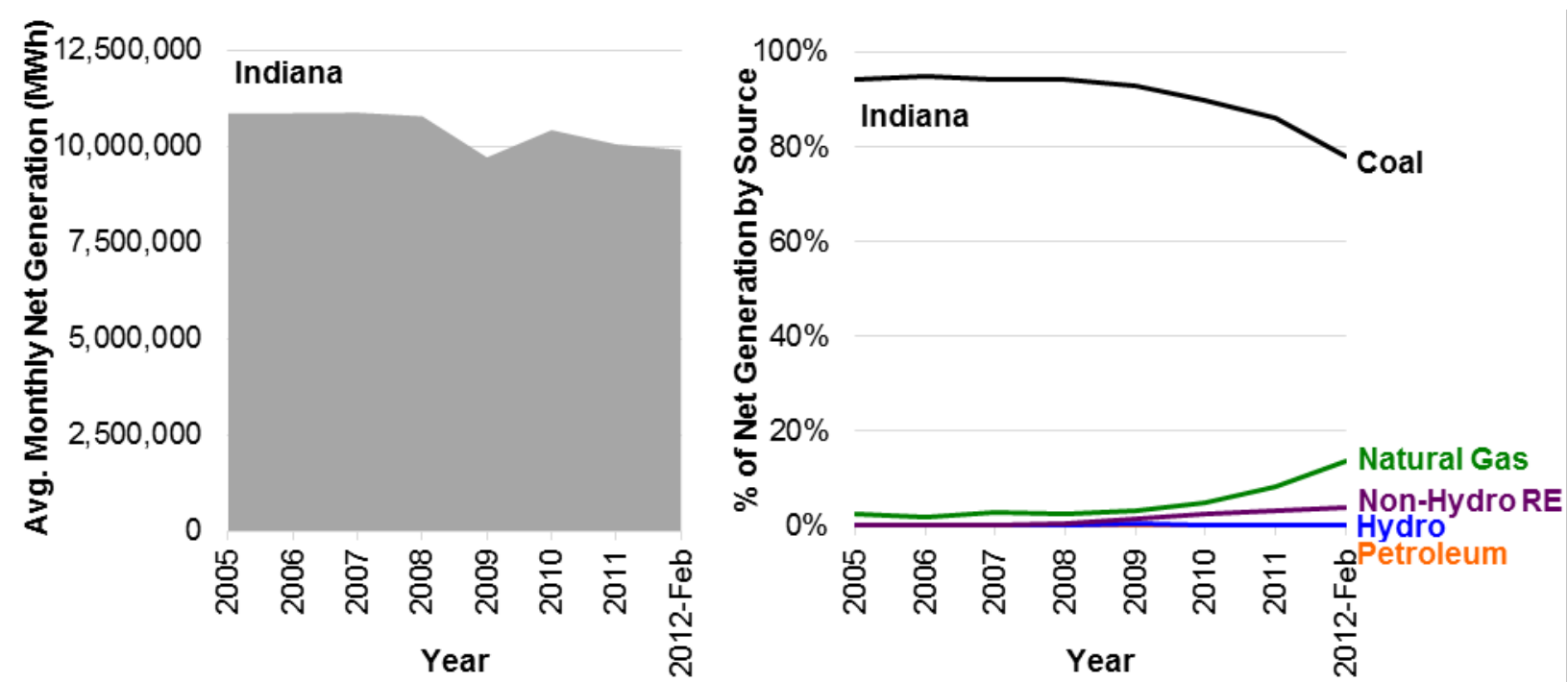

Figure 54. Changes in generation mix in Indiana; 2005-early 2012
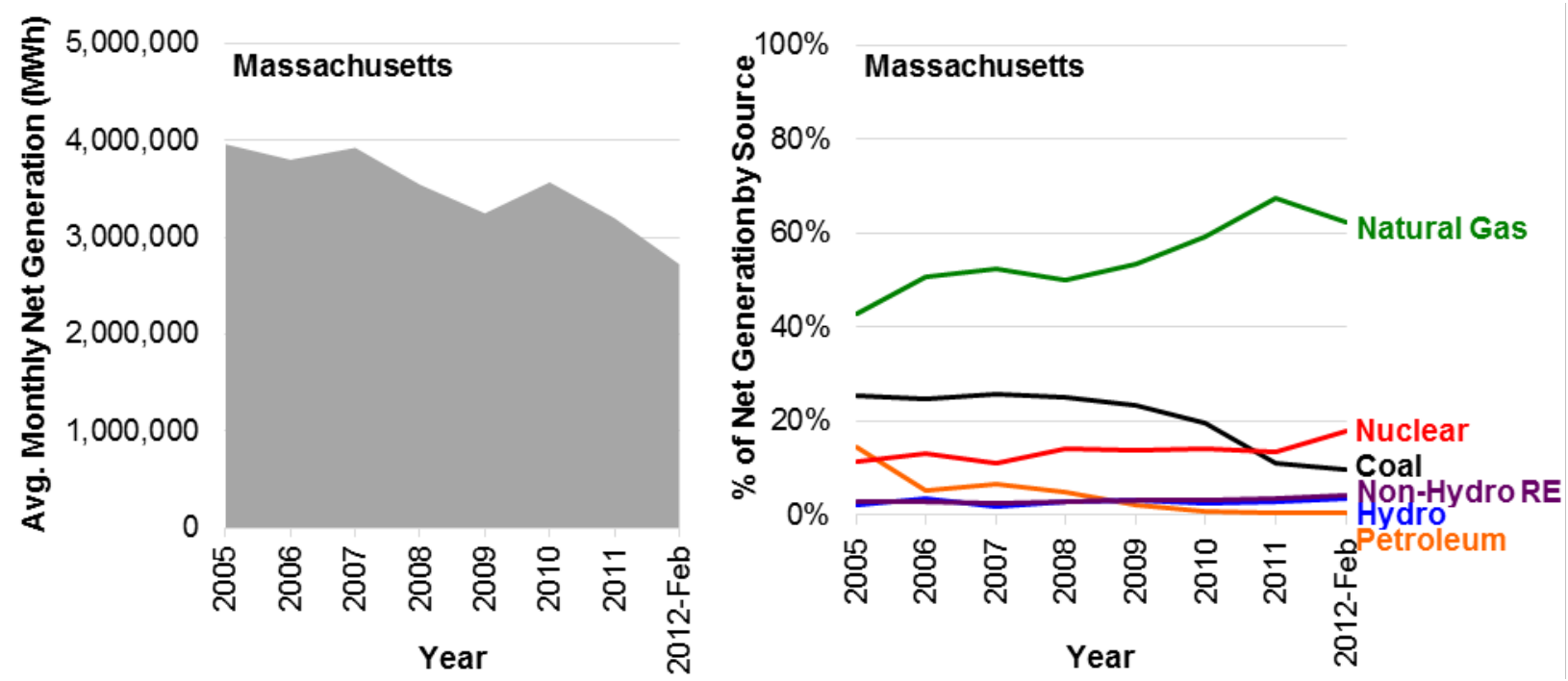

Figure 55. Changes in generation mix in Massachusetts; 2005-early 2012 

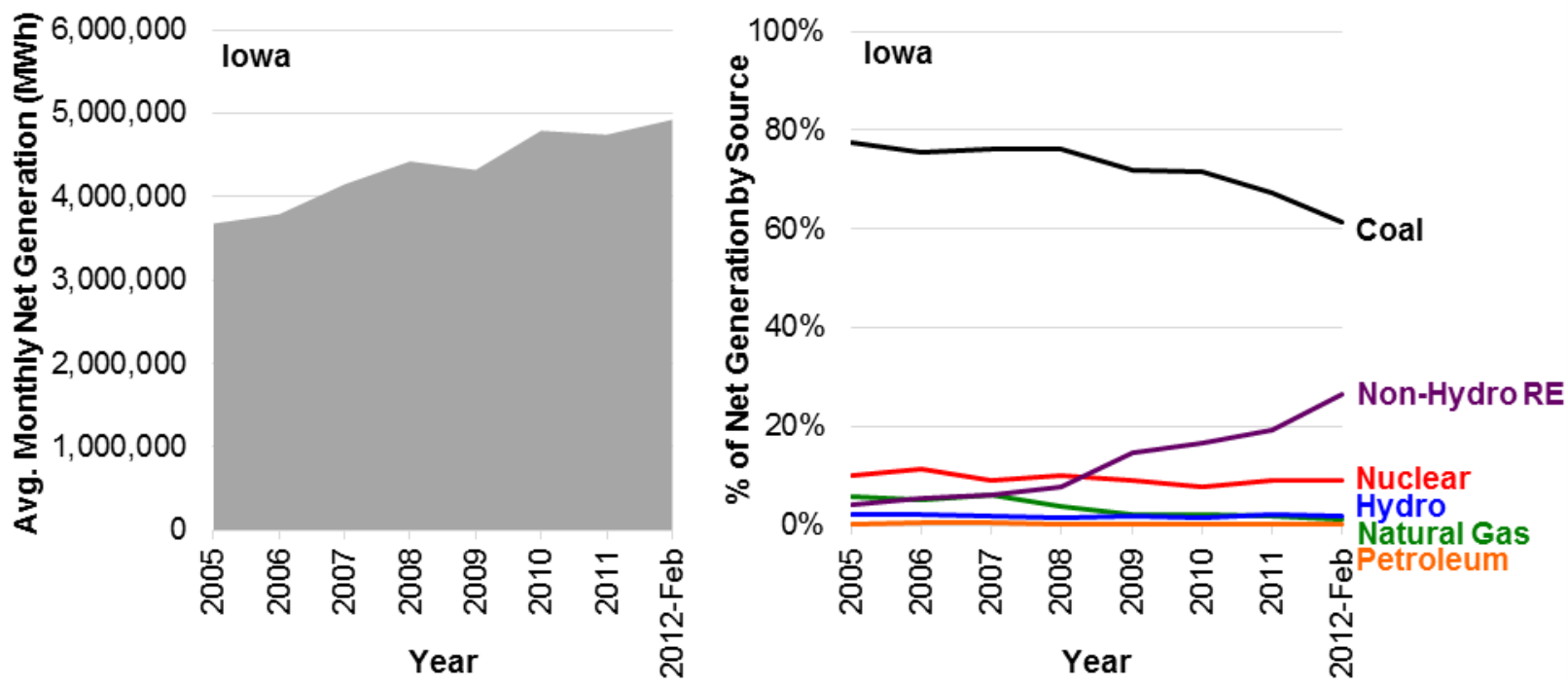

Figure 56. Changes in generation mix in lowa; 2005-early 2012 


\section{Appendix B: Details and Considerations of Methods}

This appendix offers details of data, methods, and results for Chapter 1. First, we define several terms relevant to estimating GHG emission factors from the TCEQ inventories.

The basin refers to 22 counties under which the Barnett Shale is being developed. Therefore, production in the basin includes production from the Barnett Shale as well as a small amount of additional production from other geological formations contained within the 22 counties.

As defined by the TCEQ (2010: p.23), "any source capable of generating emissions (for example, an engine or a sandblasting area) is called a facility. Thus, facility and emissions source, or 'source' for short, are synonymous." To avoid confusion, we use the term source to refer to any individual such facility.

Sources can be characterized into common types called profiles. Common examples of profiles include engines, turbines, fugitives, and tanks. Profiles are designated such that the emissions from sources with the same profile can all be estimated with a common method.

The term site refers to a physical location for which data are reported to the inventories, where each site consists of multiple different emissions sources. Each site is associated with a unique TCEQ account number and site name. Common examples of types of sites include wells, compressor stations, and gas processing plants. In the Special Inventory, sites are referred to as leases.

Production gas refers to the raw, unprocessed gas captured through development activities, and pipeline gas refers to the saleable final natural gas product. Emissions refer to tons of the specified pollutant(s) emitted per year, whereas emission factors refer to the amount of emissions associated with a unit of gas production. This report follows the EPA and TCEQ convention of referring to the set of non-methane, non-ethane hydrocarbons as VOCs.

\section{TCEQ Inventory Data}

The TCEQ collects an annual, statewide emissions inventory for sources classified as point sources per 30 Texas Administrative Code $\$ 101.10$. For this study, data were obtained for any sources within this inventory with Standard Industrial Classification (SIC) codes pertaining to the production and processing of natural gas. From the point-source inventory data, GHG emissions are estimated from amine units, boilers, compressor engines, flares, fugitives, glycol dehydrators, heaters, produced-water loadings, produced-water tanks, natural gas turbines, and vents.

To complement the point-source inventory, the TCEQ performs an Area Source Inventory every three years. Data were obtained from the 2008 Area Source Inventory on VOC emissions from pneumatics and produced-water disposal activities, which were not available in the other inventories. These data are reported only at the county level. To combine emissions estimated from pneumatics with those estimated from other inventories, these profile's emissions are adjusted by a factor equal to the change in gas production between 2008 and 2009, at the county level, as shown: 


$$
\text { Adjustment }=\frac{Q_{G W g a s, 2009}}{Q_{G W g a s, 2008}}
$$

where:

Adjustment $=$ the county-level adjustment from 2008 to 2009 emissions estimates (unitless)

$Q_{G W g a s, 2008}=$ volume of gas-well gas produced in 2008 (Mcf)

$Q_{G W g a s, b, 2009}=$ volume of gas-well gas produced in 2009 (Mcf).

In 2009, the TCEQ performed a Special Inventory, for which it requested detailed equipment and production information for stationary emissions sources associated with Barnett Shale oil and gas production, transmission, processing, and related activities. The Special Inventory data cover only stationary emissions sources on site for more than 6 months that were not reported to the 2009 Point Source Inventory. These sources are used in this study to estimate GHG emissions from amine units, boilers, heaters, compressor engines, flares, fugitives, glycol dehydrators, produced-water loadings, produced-water tanks, and vents.

Some emissions sources are not reported to the Special Inventory that nonetheless contribute to the reported site-level total in that inventory. These sources are likely omitted because their emissions are below thresholds for reporting requirements for that inventory. However, although they may be individually negligible, their collective impact is significant - with the sum of the VOC emissions reported for all individual sources equaling only $93 \%$ of the sum of all site-level totals reported, across the entire inventory. To account for this underreporting, emissions estimated from Special Inventory data are scaled at the site-level by the inverse of the percentage of site VOCs accounted for by the individual sources reported at each site, as follows:

$$
\text { Correction }_{\text {site }}=\frac{1}{\left[\frac{\sum_{k \in K_{n}} V O C_{k}}{V O C_{n}}\right]}=\frac{V O C_{n}}{\sum_{k \in K_{n}} V O C_{k}} \geq 1
$$

where:

Correction $_{\text {site }}=$ the site-level correction for non-reported sources (unitless)

$V O C_{k}=$ the mass of VOCs emitted from source $k$ annually, where $k \in K_{n}$ is the set of reported sources at site $n$ (tonne/year)

$V O C_{n}=$ the reported total mass of VOCs emitted from site $n$ annually (tonne/year).

In addition, to account for a stated $98 \%$ level of completion for the Special Inventory, all emissions estimated from the inventory's data by the inverse of that completion rate are also adjusted by the inverse of this estimate, as follows:

$$
\text { Correction }_{\text {inventory }}=\frac{1}{98 \%}=1.0204
$$

\section{Stages of the Natural Gas Life Cycle}

Emissions factors are compiled from the profiles associated with each life cycle stage. 


\section{Pre-Production Stage}

The pre-production process stage consists of episodic activities related to the preparation of wells. Activities in this stage include the drilling and construction of wells, hydraulic fracturing of shale to stimulate production, and various well-completion activities, which specifically involve the following:

- Drilling rigs are used for drilling an oil or gas well. For the purpose of estimating emissions, rigs consist of a collection of diesel-powered engines, which are associated with combustion-generated GHG emissions.

- Hydraulic fracturing involves complex liquids, pumps, and trucks for transporting equipment and fluids, which are associated both with combustion-generated GHG emissions and with emissions from off-gassing and fugitives.

- Well-construction activities are associated with combustion-generated GHG emissions due to the use of heavy construction equipment.

- Well-completion activities involve the release of natural gas from a well before and during the installation of the equipment necessary for recovery of that gas.

\section{Natural Gas Production Stage}

The production process stage consists of ongoing activities related to the extraction of natural gas at a gas well. Emissions sources include the following:

- Compressor engines are used to maintain well pressure and for other processes at the wellhead. These engines, which typically burn the production gas being extracted, are associated with combustion-generated GHG emissions.

- Fugitives occur from the unintentional release of production gas through leaks from equipment and connections throughout the natural gas process chain; therefore, they are identified with a process stage by the type of site at which they are found.

- Vents and blowdowns refer to the intentional release of gas from equipment throughout the natural gas process chain; therefore, they are identified with a process stage by the type of site at which they are found.

- Pneumatics devices are used to open and close valves and other control systems during natural gas extraction. These sources are associated with gas release emissions, which depend on the composition of their identified contents.

- Miscellaneous material loading and tanks refer to sources at production sites that are associated with any materials not expected to be co-products of natural gas processing, such as gasoline, diesel, or lubricating oil. These sources are associated with gas release emissions, which depend on the composition of their identified contents.

- Condensate and crude-oil-related sources, including loading areas and storage tanks, are associated with substantial VOCs but occur in the process chain only after the coproducts have been separated from the natural gas process chain. Therefore, although these emissions sources sometimes are reported in natural gas emission inventories, they are outside the boundary of this analysis. 


\section{Natural Gas Processing Stage}

The processing process stage consists of ongoing activities related to converting the extraction production gas to the required quality, composition, and compression of pipeline gas. Activities in this stage include separating the condensate co-product from the gas, removing naturally occurring acid gases such as $\mathrm{CO}_{2}$, lowering the moisture content of the gas, and pressurizing and heating the gas. These activities can occur at either the wellhead or at separate processing facilities, and they are associated with the following emissions sources:

- Compressor engines and natural gas turbines are used to pressurize the gas and power other processing activities. These engines, which typically burn the production gas being processed, are associated with combustion-generated GHG emissions.

- Boilers and heaters, which typically burn the production gas being processed, are used for processing activities, including the separation of condensate from natural gas and the reduction of ice crystals in the gas stream. Boilers and heaters are associated with combustion-generated GHG emissions.

- Amine units, also known as acid gas removal (AGR) units, remove acid gases, such as $\mathrm{CO}_{2}$, from the production gas to help bring the gas composition to that required for pipeline gas. Amine units are associated with the release of GHGs through venting.

- Glycol dehydrators remove water from the production gas to help bring the gas composition to that required for pipeline gas. Dehydrators are associated with the release of GHGs through venting.

- Fugitives occur from the unintentional release of production gas through leaks from equipment and connections throughout the natural gas process chain; therefore, they are identified with a process stage by the type of site at which they are found. Because the precise composition of the fugitive gas cannot be identified, it is assumed that all fugitives consist of production gas.

- Vents and blowdowns refer to the intentional release of gas from equipment throughout the natural gas process chain; therefore, they are identified with a process stage by the type of site at which they are found. Because the precise composition of the vented gas cannot be identified, it is assumed that assume all vents and blowdowns consist of production gas.

- Produced water handling, including loading areas and storage tanks, is associated with gas release emissions, which are assumed identical in composition to water flash gas.

- Flares are combustion-based emission control devices used to convert methane from gasrelease emissions into $\mathrm{CO}_{2}$ from combustion emissions. Flares are used as controls on a variety of gas-release emission sources, including produced-water tanks, condensate tanks, and glycol dehydrators.

- Miscellaneous material loading and tanks refer to sources at processing sites that are associated with any materials not expected to be co-products of natural gas processing, such as gasoline, diesel, or lubricating oil. These sources are associated with gas-release emissions, which depend on the composition of their identified contents. 
- Separators are used for processing oil and natural gas; however, only separators at oil sites vent to the atmosphere. Therefore, separators at sites producing only natural gas and not oil should be associated with no VOC emissions. Although these emissions sources sometimes are reported in natural gas emission inventories, they are outside the boundary of this analysis.

- $\quad$ Thermal oxidizers are used for processing natural gas, but only a negligible number are reported in the inventories used because of prohibitive capital costs. Therefore, although these emissions sources sometimes are reported in natural gas emission inventories, they are outside the boundary of this analysis.

\section{Waste Disposal Stage}

Natural gas production and processing generates the byproduct of produced water, which must be disposed of because of its high level of contaminants, including salt, hydrocarbons, and various pollutants. Although these activities are associated with stationary and mobile emissions sources, the only tracked emission source for this category is that pertaining to tanks that store the produced water at disposal sites.

\section{Identification of Source Profiles and Attribution to Process Stages}

This study identifies the process stage (e.g., production, processing, or transport) to which each source belongs using the provided site names in both inventories. To attribute sources to process stages, the profile associated with each source must first be identified. In the Special Inventory, each source is explicitly identified with the profile under which it was reported to the TCEQ. For the sources in the Point Source Inventory, however, the profile of each source is identified using additional provided information.

The primary source of information for this profile identification is the Source Classification Code (SCC). As described by the TCEQ (2010: p. 90), "A facility's SCC is an eight-digit EPAdeveloped code that associates emissions determinations with identifiable industrial processes. The TCEQ uses a facility's SCC for modeling, rulemaking, and SIP-related activities; therefore, a facility's SCC must be as accurate as possible. The EPA maintains a current list of SCCs under the 'EIS Code Tables (including SIC)' link at www.epa.gov/ttn/chief/eiinformation.html."

Despite the regulatory importance of the SCC classification, the SCCs provided in the Point Source Inventory do not identify the associated source's profile to the detail necessary for 254 (or $12 \%$ ) of the 2,177 sources within the 22 counties of the basin. The remaining sources rely on the additional information within characteristics files provided by the TCEQ for specific profiles, such as tanks and engines, and by consistent coding schemes within the Facility Identification Number, which is self-designated by the respondents to the emissions inventory surveys. The study identifies 43 (or $2 \%$ ) of the sources by characteristics files and 211 (or $10 \%$ ) by the Facility Identification Number, which represent $1.4 \%$ and $2.0 \%$, respectively, of the total VOCs reported for all reported sources within the 22 counties of the basin.

For those source categories that can exist at multiple types of process stages, the default assumption is that a location is a production facility (i.e., a well site), unless the site name ("Lease Name" in the Special Inventory and "Site Name" in the Point Source Inventory) is identifiable as belonging to a facility type associated with the processing stage, such as a 
processing plant or a compressor station, or with the disposal stage, such as salt-water disposal sites. In addition, four sites identified as disposal by this method are reassigned to production due to non-zero gas-well gas production statistics, which means all sources at those four sites are assigned to production, although some presumably relate to water-disposal activities instead. To the extent that this allocation method introduces an error, that error is not the omissions of emissions from the overall estimates, but rather, the incorrect allocation of total emissions across different process stages.

TCEQ inventory data are available for some pre-production processes, but such data cannot be used for original analysis because it incompletely covers the life cycle stage. Also, literature estimates available for supplementing the original analysis do not segregate between different processes as would be necessary for incorporation with the original analysis.

This study uses site-level allocation to select sources into the processing stage. The same site name in both the Point Source Inventory and the Special Inventory is used to positively identify processing sites, with the default stage for the remaining sites being production. Of the processing sites, following the recommendation of the TCEQ, ${ }^{149}$ those that do not have any processing-related sources are designated as transmission sites, and accordingly, are considered outside the boundary of this analysis.

After site-level identification, processing-type sources at production sites are associated with the processing life cycle stage. Such equipment includes heaters, boilers, amine units, and dehydrators. In addition, following Stephenson et al. (2011), this study assumes that all tanksand therefore, also all loading (which occurs after tanks in the process chain) - belong to the processing stage and not the production stage, regardless of where the tanks are physically located.

To avoid double counting with third-party emission factors for transmission, transmission sites (identified as non-well facilities without any processing equipment) are omitted from the analysis of TCEQ inventory data. Specifically, 833 sources are omitted from the special inventory and point-source inventory analyses as pertaining to transmission. This represents $5 \%$ of the total sources from these inventories, or about $10 \%$ of the $\mathrm{CO}_{2}$ and the $\mathrm{CH}_{4}$ emissions from these inventories.

\section{Spatially Explicit Estimation of Production Gas Composition}

An important differentiation of this study's estimation approach from similar studies is that this study attempts to estimate the composition of production gas in a specific area. The methods used in this study improve upon the use of a general gas composition developed from nationallevel averages by 1) developing a novel gas composition estimate that is specific to a region of interest, but also by (2) further recognizing the spatial heterogeneity of this composition within the 22-county basin. Specifically, this method collects data on speciation of production gas and the flash gas from produced water to calculate the $\mathrm{CO}_{2}$ and $\mathrm{CH}_{4}$ emissions from numerous sources in the TCEQ Special Inventory using spatially explicit estimates of gas composition. The following factors come from this speciation:

${ }^{149}$ Personal communication (TCEQ 2012). 
$f_{C}==$ the fraction of carbon in the production gas by mass (unitless)

$f_{\mathrm{CO}_{2}}=$ the fraction of $\mathrm{CO}_{2}$ in the production gas by mass (unitless)

$f_{\mathrm{CH}_{4}}=$ the fraction of $\mathrm{CH}_{4}$ in the production gas by mass (unitless)

$f_{V O C}=$ the fraction of VOCs in the production gas by mass (unitless)

$M W_{\text {gas }}=$ the molecular weight of the production gas (lb/lb-mole)

$H H V=$ the higher heating value of the production gas (Btu/scf).

These data are collected from supplementary files from the TCEQ's Barnett Shale Phase Two Special Inventory. As part of the quality assurance procedures of this Special Inventory, the TCEQ requested supplementary files from respondents. These files consist of a record of the written correspondence between the respondent and TCEQ, which varies considerably in content and form across different respondents. To estimate gas composition across the Barnett Shale region, this analysis focuses on included reports from independent laboratory analyses of the gas compositions, identifiable as pertaining to relevant samples of either production gas or of leaked gas in the form of vents or gaseous fugitives. Due to the nature and the origin of these files, the inclusion and reporting of such gas content analyses are not consistent across different files. Detailed supporting information - such as the specific origin of the sample tested, both with respect to process and geographic location - is not consistently available; therefore, it cannot be confirmed in many cases.

Given the disparate nature of these files and the inconsistent reporting of identifying information, these analyses therefore omit many reported composition analyses due to a lack of clarity regarding the geographical or process-source of the analyzed sample. Instead, those analyses are retained that can be assigned a location and content type with a reasonable level of confidence. The creation of these supplementary files and selection of a subset of them for obtaining gas composition analyses is neither random nor intended to be representative; therefore, such elimination does not introduce selection bias created by such omissions. The randomness of the errors will lead to attenuation bias of the analytical results, which is typical in cases of measurement error where there is no reasonably expected consistent bias to the error. In this context, measurement error should reduce the impact of calculating the spatial variation in gas content versus using the central estimate of gas content across the entire region.

In a related limitation of this method, we identified a substantial number of duplicate analyses in these records associated with different lease locations and even across different counties, based on identifying identical laboratory-assigned sample numbers and identical compositions to the reported level of precision provided by the same company. We attempted to identify and remove duplicate analyses; but misspecification in the dataset is possible because it is unclear in some cases which analysis is the original source.

From these data, county-level estimates of gas composition are developed separately for production gas, condensate flash, oil flash, and produced-water flash. Counties with one or more available composition analyses are assigned the composition analysis with the median level percentage-by-weight of methane in the reported composition analyses. In addition to providing a central estimate of gas composition for each county, this estimation of central tendency buffers the results against the impact of misspecifications of location described above. 
We used a production-weighted average of the median adjacent counties' estimates with reported composition analyses for counties with no reported composition analyses. A productionweighted average of all reported composition analyses across the Barnett Shale region is used for the few counties with no reported composition analyses either for that county or for all adjacent counties.

In addition to attempting to err on the side of caution in including gas composition analyses, we estimated the sensitivity of the analysis to the gas composition by comparing results of this study's method-which uses the county-level gas composition estimates as described above for emissions estimates - to results using the same emissions estimation calculations with two different sets of alternative gas compositions: one reflecting the production-weighted average of this study's gas analyses from the TCEQ Special Inventory supplementary files and another reflecting standard assumptions of gas composition identified in the literature. Given the imperfect source of information and the assumptions on which this study's analysis depends, substantial variation between these different methods makes a compelling case for the importance of using geographically appropriate gas compositions that are accurate to a reasonably fine scale when estimating GHG emissions from natural gas extraction and production. This study's approach provides the best-available approximation, using the bestavailable data, of a spatially explicit definition of gas compositions relevant to estimating GHG emissions. To improve on this analysis, future data collection efforts should emphasize the measurement and reporting of spatially explicit gas compositions.

\section{Estimated Composition of Production Gas}

The top panel of the Figure 57 presents the estimates of the main components of production gas from each of the 22 counties of the Barnett Shale play, as well as the Barnett Shale productionweighted average and the national average commonly used in the literature. Key parameters and production statistics for each county are also presented in Table 17 and Table 18. Components, which are shown in their mass percentage within the production gas, include methane, VOCs (as defined above to include all non-methane and non-ethane hydrocarbons), $\mathrm{CO}_{2}$, and other gases. Primary gas species represented in the "other" category are nitrogen and ethane. The lower panel of Figure 57 depicts, for reference, the production volume for each county. Shown after each county's name is the number of unique analyses collected for that county - with counties estimated by a weighted average of adjacent county's compositions designated with an "A," rather than a number. 


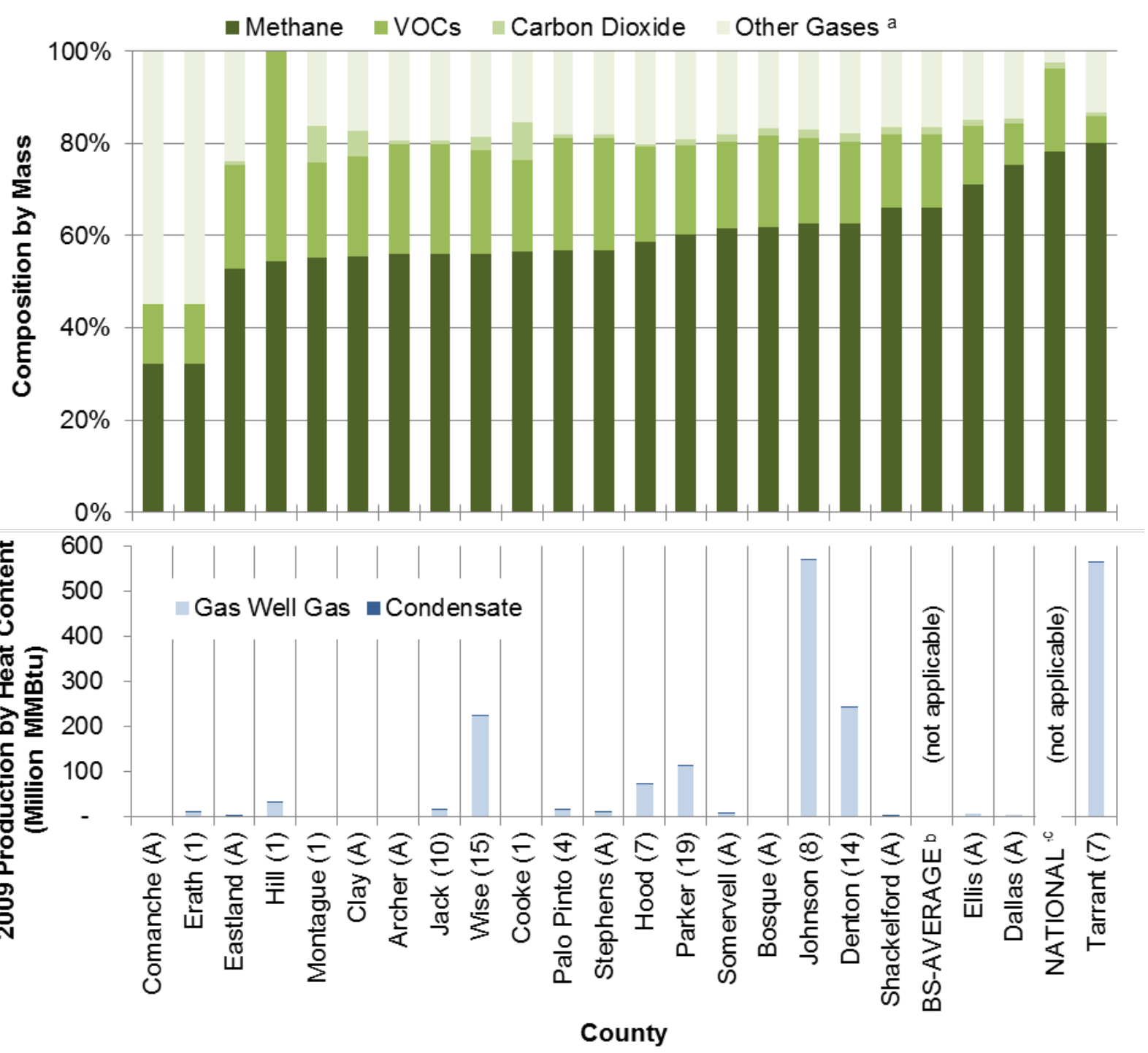

a "Other" gas include nitrogen, ethane, and any other non-methane, -VOC, or -carbon dioxide gases reported ${ }^{b}$ BS-AVERAGE refers to the production-weighted average gas composition in the 22-county Barnett Shale basin c NATIONAL refers to the national average composition commonly used in the literature (EPA 2011)

Figure 57. Composition of production gas by county

NOTE: number of gas composition samples is reported in parentheses following each county name, where "A" denotes counties with no samples such that samples from adjacent counties were substituted.

The gas composition estimates for the six counties that represent the vast majority of production volumes are supported by high numbers of estimates. However, reflecting this study's nonrandom, targeted strategy for seeking these estimates, many of the estimates for the remaining counties come from either a small number of estimates or the weighted average of adjacent counties. Specifically, no usable estimates were found for 10 of the 22 counties.

The uncertainty inherent to this approach for obtaining gas analyses is highlighted by the difference in gas composition in Comanche County and Erath County versus the majority of the 
counties. These compositions, which are both estimated by a single analysis from Erath County, show an abnormally large presence of nitrogen - and thus, are suspect of contamination with ambient air. However, the available information offers no verifiable support of such suspicion. The presence of such uncertainty emphasizes the need for better documentation of gas composition if this factor is to be used in further analysis or other factors, such as implementing regulations. However, it is important to note that the very low production volumes associated with these two counties means that their analyses have a nearly negligible impact on the overall results.

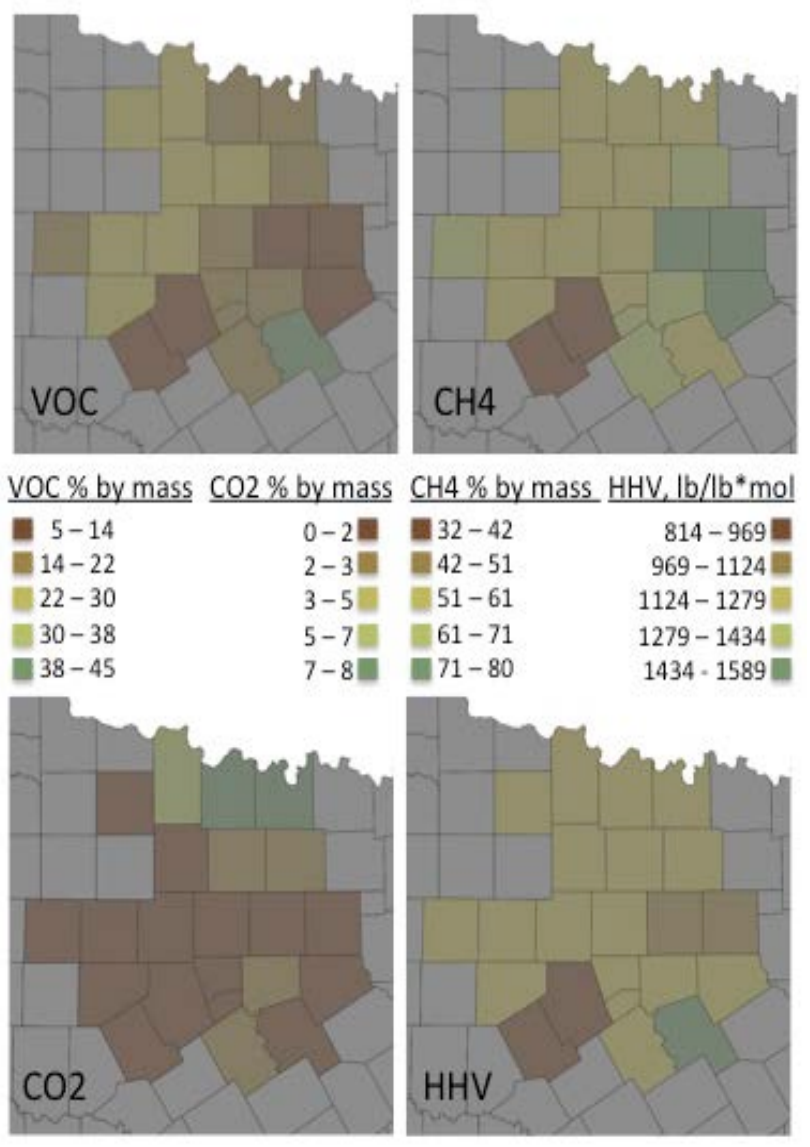

Figure 58. Variation among gas compositions across the 22 counties of the Barnett Shale play

The variation among gas compositions is demonstrated as being patterned across the 22 counties of the Barnett Shale play differently for different key parameters, as shown Figure 58. Such patterned distribution is to be expected if the observed variation reflects geological heterogeneity rather than simply uncertainty in the sampling methodology. The counties represented by weighted averages are located primarily on the western and eastern periphery of the region; therefore, the central north-south corridor represents both the majority of production and the estimates supported by larger samples. Along this corridor, parameters can be observed to vary relatively smoothly, although the differentiation between different parameters demonstrates the complexity of the variation in gas composition. In other words, this map demonstrates that gas composition varies across space, but also, it suggests that the complexity of this variation might extend to finer scales than the county level. 
Table 17. Composition of Production Gas and Produced-Water Flash Gas in Barnett Shale Counties

\begin{tabular}{|c|c|c|c|c|c|c|c|c|c|}
\hline \multirow[b]{2}{*}{ County } & \multicolumn{6}{|c|}{ Production Gas } & \multicolumn{3}{|c|}{ Produced-Water Flash Gas } \\
\hline & $\begin{array}{l}\text { Molecular } \\
\text { Weight } \\
\text { (lb/lb-mole) }\end{array}$ & $\begin{array}{l}\text { Higher } \\
\text { Heating } \\
\text { Value } \\
\text { (Btu/scf) }\end{array}$ & $\begin{array}{c}\text { Carbon } \\
\text { Content } \\
\text { (\% by mass) }\end{array}$ & $\begin{array}{c}\text { Methane } \\
\text { (\% by mass) }\end{array}$ & $\begin{array}{l}\text { VOCs } \\
\text { (\% by } \\
\text { mass) }\end{array}$ & $\begin{array}{c}\text { Carbon } \\
\text { Dioxide } \\
\text { (\% by mass) }\end{array}$ & $\begin{array}{c}\text { Methane } \\
\text { (\% by mass) }\end{array}$ & $\begin{array}{c}\text { VOCs } \\
\text { (\% by mass) }\end{array}$ & $\begin{array}{c}\mathrm{CO}_{2} \\
\text { (\% by mass) }\end{array}$ \\
\hline Comanche & 23.86 & 813.78 & 43.6 & 32.2 & 12.9 & 0.2 & 33.5 & 24.8 & 31.1 \\
\hline Erath & 23.86 & 813.78 & 43.6 & 32.2 & 12.9 & 0.2 & 43.1 & 34.8 & 7.8 \\
\hline Eastland & 22.07 & $1,188.04$ & 69.3 & 52.8 & 22.4 & 0.7 & 27.7 & 52.0 & 6.4 \\
\hline Hill & 26.92 & $1,589.66$ & 79.2 & 54.5 & 45.6 & 0.0 & 38.3 & 5.8 & 54.8 \\
\hline Montague & 21.99 & $1,216.13$ & 72.6 & 55.1 & 20.7 & 8.1 & 53.3 & 17.4 & 13.0 \\
\hline Clay & 21.86 & $1,229.52$ & 73.2 & 55.4 & 21.8 & 5.5 & 26.7 & 6.2 & 61.1 \\
\hline Archer & 21.63 & $1,253.47$ & 74.2 & 55.9 & 23.8 & 1.0 & 26.7 & 6.2 & 61.1 \\
\hline Jack & 21.63 & $1,253.47$ & 74.2 & 55.9 & 23.8 & 1.0 & 26.7 & 6.2 & 61.1 \\
\hline Wise & 21.79 & $1,274.01$ & 75.5 & 56.0 & 22.6 & 2.9 & 59.5 & 19.9 & 1.9 \\
\hline Cooke & 21.76 & $1,199.75$ & 72.2 & 56.5 & 20.0 & 8.1 & 46.8 & 17.2 & 18.0 \\
\hline Palo Pinto & 21.72 & $1,261.53$ & 74.3 & 56.9 & 24.3 & 0.8 & 27.7 & 52.0 & 6.4 \\
\hline Stephens & 21.72 & $1,261.53$ & 74.3 & 56.9 & 24.3 & 0.8 & 27.7 & 52.0 & 6.4 \\
\hline Hood & 21.19 & $1,248.33$ & 75.2 & 58.5 & 20.8 & 0.6 & 48.2 & 29.1 & 8.2 \\
\hline Parker & 20.85 & $1,242.78$ & 75.9 & 60.3 & 19.3 & 1.2 & 16.3 & 52.4 & 1.1 \\
\hline Somervell & 20.71 & $1,224.89$ & 75.3 & 61.5 & 19.0 & 1.6 & 40.1 & 10.0 & 46.4 \\
\hline Bosque & 20.89 & $1,236.59$ & 75.5 & 61.7 & 19.8 & 1.7 & 38.3 & 5.8 & 54.8 \\
\hline Johnson & 20.57 & $1,226.04$ & 75.8 & 62.5 & 18.7 & 1.8 & 38.3 & 5.8 & 54.8 \\
\hline Denton & 20.54 & $1,218.65$ & 75.4 & 62.5 & 17.9 & 1.9 & 34.8 & 14.5 & 33.3 \\
\hline Shackelford & 20.12 & $1,191.89$ & 74.8 & 66.2 & 15.9 & 1.6 & 33.5 & 24.8 & 31.1 \\
\hline Ellis & 19.41 & $1,159.09$ & 74.6 & 71.0 & 12.9 & 1.3 & 32.5 & 19.4 & 43.2 \\
\hline Dallas & 18.63 & $1,112.74$ & 73.9 & 75.4 & 9.0 & 1.1 & 23.9 & 39.5 & 23.1 \\
\hline Tarrant & 17.92 & $1,072.83$ & 73.3 & 80.2 & 5.6 & 0.9 & 20.7 & 46.7 & 20.1 \\
\hline Barnett Shale Average $^{a}$ & 20.12 & $1,191.89$ & 74.8 & 66.2 & 15.9 & 1.6 & 33.5 & 24.8 & 31.1 \\
\hline National Average ${ }^{b}$ & 17.40 & $1,027.00$ & 75.0 & 78.3 & 17.8 & 1.5 & & & \\
\hline
\end{tabular}

141 - Appendix B 
Table 18. 2009 Production Volumes from Barnett Shale Counties

Heat Content (MMBtu)

\begin{tabular}{|c|c|c|c|c|c|c|}
\hline County & Oil & Condensate & $\begin{array}{c}\text { Casinghead } \\
\text { Gas }\end{array}$ & $\begin{array}{c}\text { Gas-Well } \\
\text { Gas }\end{array}$ & $\begin{array}{c}\text { Combined } \\
\text { Gas }\end{array}$ & County Total \\
\hline Archer & $6,018,590$ & 737 & 458,853 & 21,351 & 480,205 & $6,499,532$ \\
\hline Bosque & 0 & 98 & 0 & 354,480 & 354,480 & 354,578 \\
\hline Clay & $3,514,046$ & 37,503 & 494,346 & 351,615 & 845,961 & $4,397,511$ \\
\hline Comanche & 31,946 & 8,046 & 54,996 & 513,967 & 568,963 & 608,955 \\
\hline Cooke & $11,740,372$ & 43,729 & $4,394,033$ & 485,521 & $4,879,554$ & $16,663,655$ \\
\hline Dallas & 0 & 0 & 0 & $4,923,785$ & $4,923,785$ & $4,923,785$ \\
\hline Denton & 486,574 & $2,516,461$ & $1,023,276$ & $241,825,407$ & $242,848,683$ & $245,851,717$ \\
\hline Eastland & $1,491,957$ & 314,574 & 834,641 & $3,916,728$ & $4,751,369$ & $6,557,901$ \\
\hline Ellis & 6,125 & 0 & 0 & $7,552,672$ & $7,552,672$ & $7,558,797$ \\
\hline Erath & 34,829 & 218,806 & 123,445 & $10,657,734$ & $10,781,179$ & $11,034,814$ \\
\hline Hill & 7,267 & 471 & 0 & $31,983,129$ & $31,983,129$ & $31,990,868$ \\
\hline Hood & 16,553 & $2,660,894$ & 156,109 & $72,781,121$ & $72,937,230$ & $75,614,677$ \\
\hline Jack & $3,999,135$ & 878,025 & $2,261,462$ & $16,294,739$ & $18,556,202$ & $23,433,361$ \\
\hline Johnson & 0 & 318,855 & 0 & $570,667,212$ & $570,667,212$ & $570,986,067$ \\
\hline Montague & $11,979,935$ & 34,090 & $9,682,791$ & 350,290 & $10,033,081$ & $22,047,106$ \\
\hline Palo Pinto & $3,232,091$ & 525,481 & $6,957,154$ & $16,076,018$ & $23,033,172$ & $26,790,743$ \\
\hline Parker & 73,886 & $1,672,455$ & 730,069 & $112,696,107$ & $113,426,176$ & $115,172,517$ \\
\hline Shackelford & $4,108,140$ & 66,203 & 849,166 & $2,234,492$ & $3,083,658$ & $7,258,000$ \\
\hline Somervell & 0 & 65,812 & 0 & $7,485,891$ & $7,485,891$ & $7,551,704$ \\
\hline Stephens & $12,811,777$ & 291,120 & $3,525,626$ & $11,751,922$ & $15,277,548$ & $28,380,445$ \\
\hline Tarrant & 0 & 241,264 & 0 & $563,514,077$ & $563,514,077$ & $563,755,341$ \\
\hline Wise & $2,400,875$ & $5,017,491$ & $6,426,006$ & $222,654,526$ & $229,080,532$ & $236,498,898$ \\
\hline Basin Total & $61,954,098$ & $14,912,113$ & $37,971,973$ & $1,899,092,788$ & $1,937,064,761$ & $2,013,930,972$ \\
\hline
\end{tabular}




\section{Co-Product Allocations}

In addition to natural gas, the sources reported in the TCEQ inventories are associated with the marketed products of condensate and, in some cases, oil. In fact, gas companies are focusing all of their new investment in areas with wet gas, which has a higher VOC content, for its higher value. The principle of co-product allocation is that when there are multiple valued products from a single system, the burdens of that system should be shared among all products. This study uses energy-based co-product allocation, which weights the burdens (i.e., emissions) of each process by the ratio of energy contained in all co-products that is embodied in the product of interest.

The factor that is applied depends on the relevant life cycle stage of a source. For production sources, we use the finest grain of spatial resolution available. Specifically, emissions for all production sources in the Special Inventory are allocated among condensate, oil, and natural gas products at the site level using site-level production statistics, as follows:

$$
\text { Allocation }_{\text {site }}=\frac{\left(Q_{G W \text { gas }, S}\right) * H H V_{\text {pipe gas }}}{\left(Q_{G W g a s, s}+Q_{C g a s, s}\right) * H H V_{\text {pipe gas }}+Q_{\text {oil }, s} * H H V_{\text {oil }}+Q_{\text {cond }, s} * H H V_{\text {cond }}}
$$

where:

$$
\begin{aligned}
& \text { Allocation }_{\text {site }}=\text { the site-level, energy-basis co-product factor for gas produced by gas } \\
& \text { wells (unitless) } \\
& Q_{G W g a s, s}=\text { the volume of gas-well gas produced at the site annually (Mcf) } \\
& Q_{C g a s, s}=\text { the volume of casinghead gas produced at the site annually }{ }^{150} \text { (Mcf) } \\
& Q_{o i l, s}=\text { the volume of oil produced at the site annually (bbl) } \\
& Q_{\text {cond,s }}=\text { the volume of condensate produced at the site annually (bbl) } \\
& H H V_{\text {pipe gas }}=\text { the energy content of natural gas product (i.e., pipeline gas) } \\
& \text { ○ } 1,027,000 \mathrm{Btu} / \mathrm{Mcf} \text { for pipeline-quality gas } \\
& H H V_{\text {oil }}=\text { the energy content of oil } \\
& \text { ○ } 5,800,000 \mathrm{Btu} / \mathrm{bbl} \text { for crude oil }{ }^{151} \\
& H H V_{\text {cond }}=\text { the energy content of condensate } \\
& \text { ○ } 5,418,000 \mathrm{Btu} / \mathrm{bbl} \text { for plant condensate. }{ }^{152}
\end{aligned}
$$

As Figure 59 depicts, the majority of these site-level co-product allocation factors are at or close to 1 -reflecting the fact that the majority of production within these counties is natural gas. However, Figure 59 also shows that $15 \%$ of the sites included within the Special Inventory produce no gas-well gas and, accordingly, the emissions from these sites do not contribute to the total emissions allocated to natural gas.

\footnotetext{
${ }^{150}$ Note that casinghead gas is a natural gas that is a co-product of oil production (produced by oil wells).

${ }^{151}$ API (2009), Table 3-8

${ }^{152}$ EIA (2011), Appendix A
} 


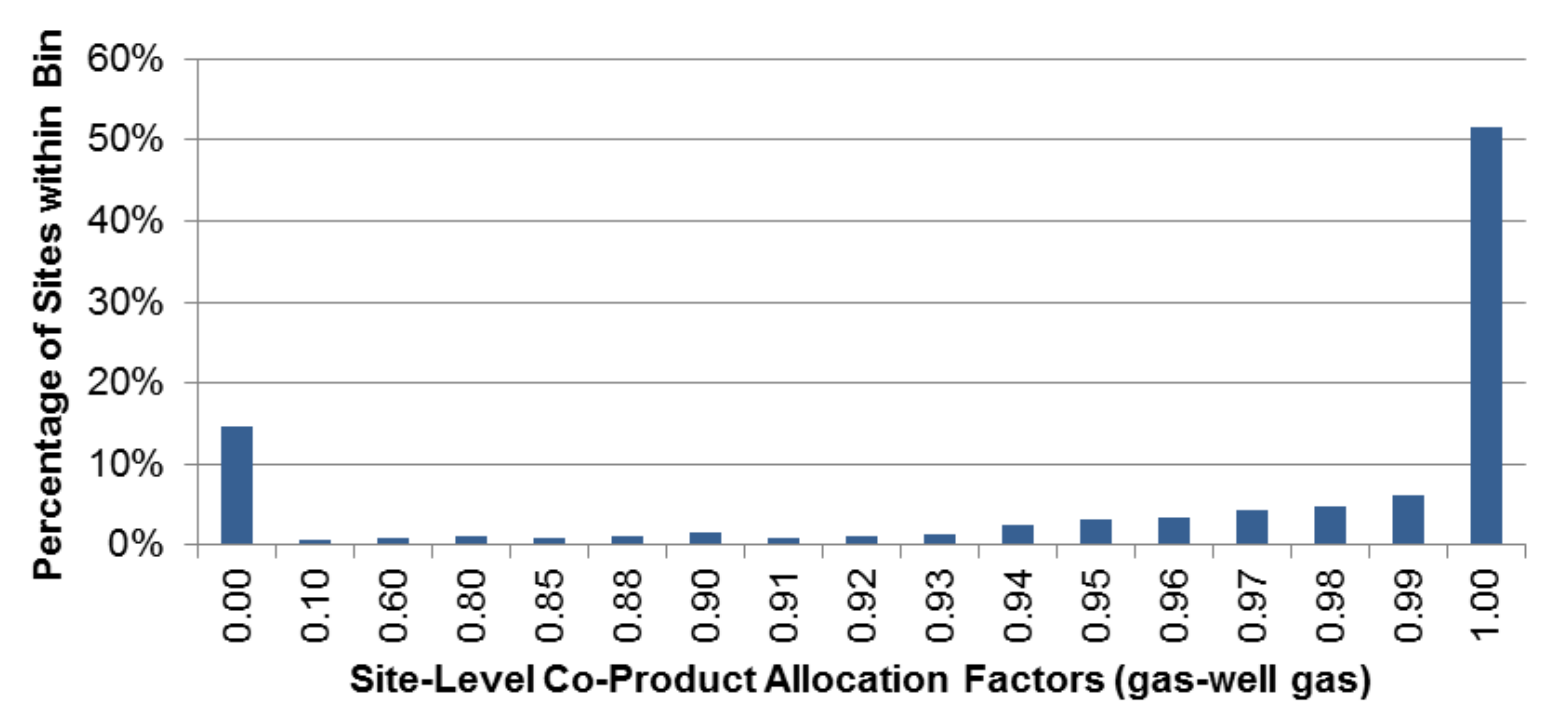

Figure 59. Distribution of site-level emissions allocated to gas

Site-level production statistics are not available for sites in the Point Source Inventory, and relevant counties have negligible oil production, lowering the chance that production-stage point sources emissions are associated with oil production. Therefore, emissions are allocated for all production sources in the Point Source Inventory among condensate and natural gas products at the county level using county-level production statistics (Figure 60). Similarly, Area Source Inventory data are available only at the county-level; so they are most appropriately allocated among co-products at this scale. This allocation is calculated as follows:

$$
\text { Allocation }_{\text {county }}=\frac{Q_{G W \text { gas }, \mathrm{t}} * H H V_{\text {pipe gas }}}{Q_{G W \text { gas }, c} * H H V_{\text {pipe gas }}+Q_{\text {cond }, c} * H H V_{\text {cond }}}
$$

where:

Allocation $_{\text {county }}=$ the county-level, energy-basis co-product factor for gas (unitless)

$Q_{G W g a s, c}=$ the volume of gas-well gas produced in the county annually (Mcf)

$Q_{c o n d, c}=$ the volume of condensate produced in the county annually (bbl)

$H H V_{\text {pipe gas }}=$ the energy content of natural gas product (i.e., pipeline gas) (Btu/Mcf)

$H H V_{\text {cond }}=$ the energy content of condensate $(\mathrm{Btu} / \mathrm{bbl})$. 


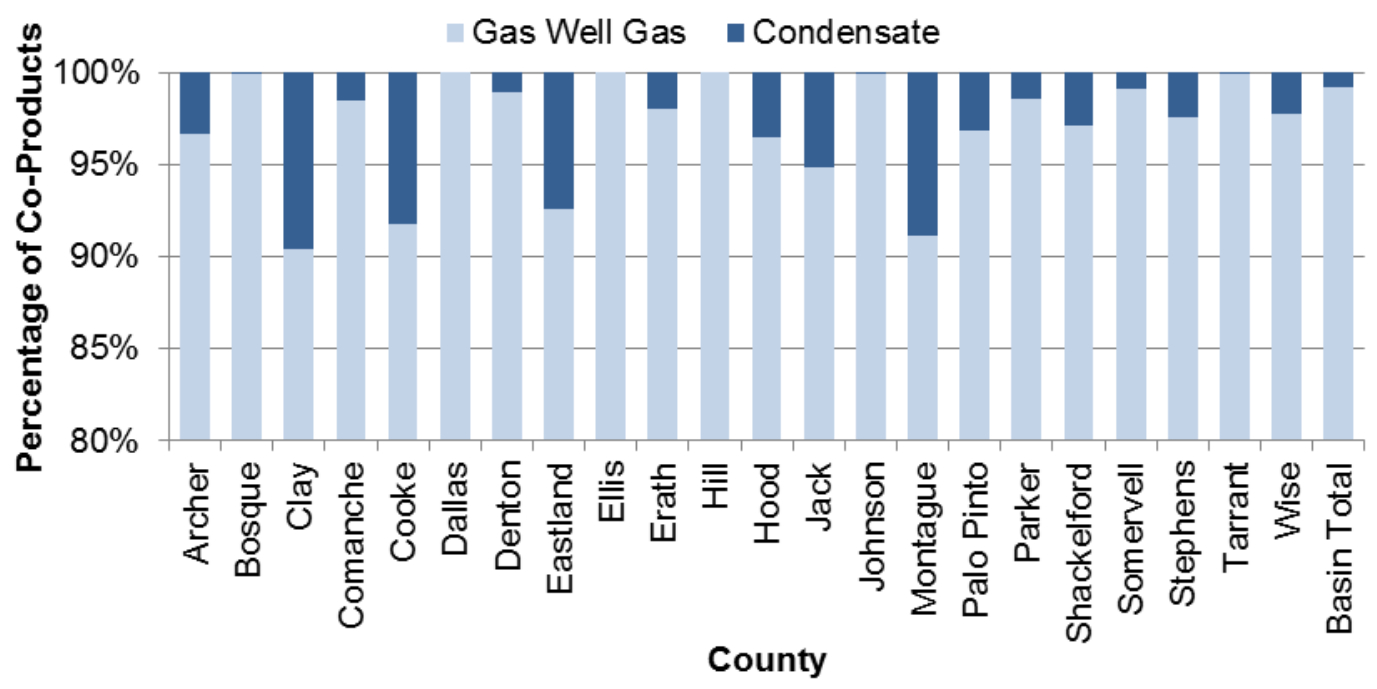

Figure 60. County-level gas production co-products by heat content

Regardless of the inventory in which the sources are described, emissions from processing sources are allocated at the basin level using basin-level production statistics, The relevant coproduct allocation includes casinghead gas volumes as well as gas-well gas volumes because all natural gas - regardless of whether the production source is a gas or oil well - is processed at these sites. Some of these processing steps might occur after the condensate is separated, but the order of processing steps varies by site and is not identifiable in the data of the TCEQ inventories. Therefore, co-products are allocated as follows:

$$
\text { Allocation }_{\text {basin }}=\frac{\left(Q_{G W \text { gas }, b}+Q_{\text {Cgas }, b}\right) * H H V_{\text {pipe gas }}}{\left(Q_{G W \text { gas }, b}+Q_{\text {Cgas }, b}\right) * H H V_{\text {pipe gas }}+Q_{\text {cond }, b} * H H V_{\text {cond }}}
$$

where:

$$
\begin{aligned}
& \text { Allocation }_{\text {basin }}=\text { the basin-level, energy-basis co-product factor for gas (unitless) } \\
& Q_{G W g a s, b}=\text { the volume of gas-well gas produced in the basin annually (Mcf) } \\
& Q_{\text {Cgas,s }}=\text { the volume of casinghead gas produced in the basin annually (Mcf) } \\
& Q_{\text {cond }}, \text { b = the volume of condensate produced in the basin annually (bbl) } \\
& H H V_{\text {pipe gas }}=\text { the energy content of natural gas product (i.e., pipeline gas) (Btu/Mcf) } \\
& H H V_{\text {cond }}=\text { the energy content of condensate (Btu/bbl). }
\end{aligned}
$$

Note that some processing profiles pertain to processes that might occur after the condensate is separated from the process stream and, therefore, should not be partially allocated to that coproduct. However, the specific order of processing steps is not readily identifiable in the data. In addition, the impact of neglecting this is small because condensate contributes less than $1 \%$ to the denominator of the allocation factor (Figure 61). 


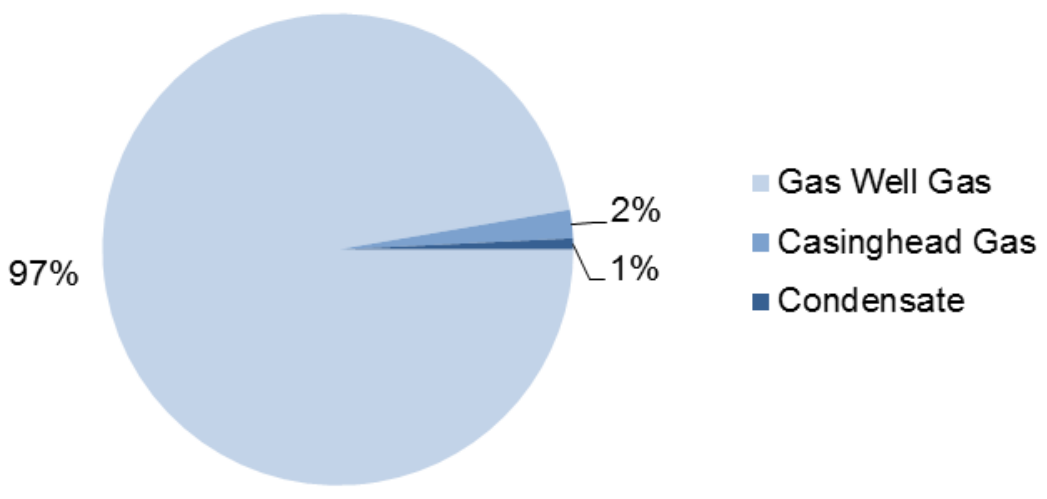

Figure 61. Basin-level gas processing co-products by heat content

In addition, because condensate and crude oil are separately marketable products, co-product allocation means that the substantial VOCs in the TCEQ Inventories corresponding to the storage and handling of these co-products - once separated from the natural gas stream - are outside the boundary of natural gas production and processing. Therefore, this study omits about $25 \%$ of the individual sources reported in the two inventories, which collectively represent $60 \%$ of the total reported VOC emissions, because they are associated only with the production and processing of the co-products of crude oil and condensate.

Regarding the co-production of oil within the counties of the basin, note that the 84 sites identified as production sites in the Point Source Inventory are all located within the 7 counties listed below-which include their respective percentage of the co-product energy associated with oil production:

- Denton: $0.2 \%$ from oil

- Hood: $0.0 \%$ from oil

- Johnson: $0.0 \%$ from oil

- Palo Pinto: $12.1 \%$ from oil

- Parker: $0.1 \%$ from oil

- Tarrant: $0.0 \%$ from oil

- Wise: $1.0 \%$ from oil.

With the exception of Palo Pinto County, these values suggest the co-production of oil represents a negligible amount, and the sole production site in Palo Pinto County identified in the Point Source Inventory is a gas well, associated with zero oil production, as verified through an online query of the Texas Railroad Commission's production statistics database. Therefore, this study does not attribute any production-related emissions from the Point Source Inventory to a coproduct of oil.

Overall, $1 \%$ of the estimated GHG emissions are allocated to condensate instead of natural gas. For comparison, note that Skone et al. (2011) base their co-product allocation on their reported 
$12 \%$ non-methane VOC whereas Stephenson et al. (2011) report 16.4\% allocation to condensate, ethane, and liquid petroleum gas. However, this proportion varies substantially across the 22 counties of the Barnett Shale play, as shown in Figure 62. Even among top-producing counties, which are shown by the larger bars in the lower panel of the figure, significant portions of GHGs are attributed to condensate instead of natural gas - ranging from $0.5 \%$ condensate for Johnson County and Tarrant County to $1.7 \%$ for Wise County. More strikingly, only $91.7 \%$ and $92.7 \%$ of emissions in Montague County and Cooke County, respectively, are associated with the natural gas product.

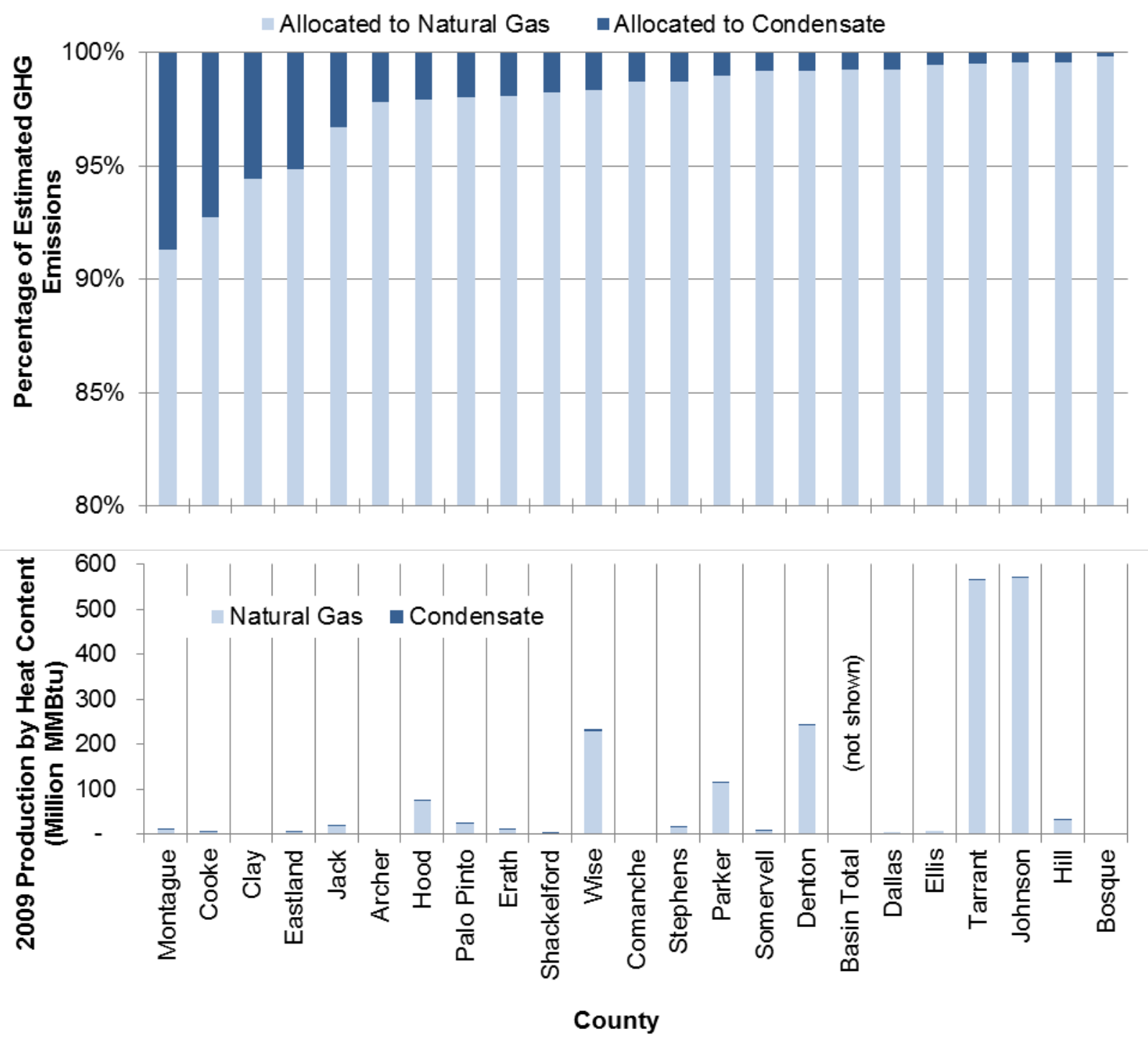

Figure 62. Proportion of GHG emissions associated with co-products 


\section{Estimation of Emissions by Source Profile}

Emissions estimations generally use a "black box" approach, where a profile is associated with a life cycle stage by the purpose it serves rather than by its physical location. However, for those profiles possibly related to multiple stages, such as compressor engines and fugitives, each source is associated with the life cycle stage by the categorization of the site at which the source is found.

In general, emission sources can be categorized into two broad types of profiles: combustion sources and gas-release sources, with certain unique characteristics of certain processing activities leading to a third category. A tiered approach is used to calculate emissions, in which secondary calculation methods are applied when the data requirements for preferred methods are not met for an individual source. If neither method is possible with the available data, median estimates from other sources of the same profile are used. Overall, preferred methods were used for $79 \%$ of sources, secondary for $18 \%$, and tertiary for the remaining $2 \%$. The following paragraphs introduce the main categories and methodologies, which are adapted from the methodologies presented by ENVIRON (2010), API (2009), and EPA (1995), as appropriate. These emissions estimates include both routine and non-routine emissions estimates for 2009.

Combustion sources include compressor engines, boilers, heaters, and turbines. In these profiles, $\mathrm{CO}_{2}$ emissions primarily come from chemical reactions during combustion, and methane emissions primarily come from the incomplete combustion of the combusted fuel. The composition of the fuel gas therefore influences the emissions, as do source characteristics and details of the level of usage of the source. This study's preferred methodology for calculating emissions from combustion sources is based on the quantity of fuel combusted and the composition of the fuel gas - as determined by a county-level estimation of production gas composition, assuming that the natural gas fuel used in all cases is the production gas at that site.

Gas leakage sources include both intentional and unintentional releases of gas. Within this category, there is a differentiation between potentially controllable leakage and fugitives, where the former typically involves gas released from an isolatable emission point and therefore is potentially controllable, and the latter comes from dispersed leaks and therefore is less feasible to control. This study's preferred methodology for calculating GHG emissions from gas-release sources therefore is based on the reported emissions of total VOCs and the ratio of $\mathrm{CO}_{2}$ and $\mathrm{CH}_{4}$ to VOCs in the released gas, which means it depends on the speciation of the released gas. Estimating these emissions assumes that production gas is the released gas in all cases, except when the profile is associated specifically with produced water handling; in this case, the released gas is assumed to be equivalent to the produced-water flash gas.

In addition, some processing sources require specialized estimation methods. For example, AGR units specifically remove $\mathrm{CO}_{2}$ from the production gas. Therefore, this study's method for estimating $\mathrm{CO}_{2}$ emissions from AGR differs substantially from that used for other profiles. Specifically, AGR units are associated with $\mathrm{CO}_{2}$ emissions equal to the difference in $\mathrm{CO}_{2}$ contained within the production gas and that in the final pipeline-quality gas.

The estimation of GHG emissions for different profiles consistently assumes that the speciation of production gas varies spatially based on the geology of the Barnett Shale. This variation can be reasonably represented by variation at the county level, as spatially interpolated from the 
sample of gas composition analyses collected from supplementary Special Inventory files provided by the TCEQ.

Similarly, all natural gas represented in the following methodologies is assumed to be the production gas, except where explicitly noted (as in the AGR profile calculations). The speciation of this production gas is spatially explicit to the county level for production sources and the basin average composition for processing sources.

In addition, many profiles rely on standardized emission factors, which represent industry-level averages across the specifics of individual equipment. The majority of these emission factors are obtained from the EPA's AP-42, Compilation of Air Pollutant Emission Factors (EPA 1995). Factors applied are shown in Table 19.

Table 19. EPA's AP-42 Compilation of Air Pollutant Emission Factors

\begin{tabular}{|c|c|c|c|}
\hline Profile & $\begin{array}{l}\mathrm{CO}_{2} \text { Emission } \\
\text { Factor }\end{array}$ & $\begin{array}{l}\mathrm{CH}_{4} \text { Emission } \\
\text { Factor }\end{array}$ & $\begin{array}{l}\text { VOC Emission } \\
\text { Factor }\end{array}$ \\
\hline External Combustion, Natural Gas ${ }^{a}$ & $\begin{array}{c}118 \\
\mathrm{lb} / \mathrm{MMBtu}\end{array}$ & $\begin{array}{c}2.25 \mathrm{e}-3 \\
\mathrm{lb} / \mathrm{MMBtu}\end{array}$ & $\begin{array}{c}5.39 e-3 \\
\text { lb/MMBtu }\end{array}$ \\
\hline$\overline{\text { External Combustion, Diesel }} \mathrm{l}^{\mathrm{b}, \mathrm{c}}$ & $\begin{array}{c}2710 \\
\mathrm{~kg} / 10^{3} \mathrm{~m}^{3}\end{array}$ & $\begin{array}{c}0.0062 \\
\mathrm{~kg} / 10^{3} \mathrm{~m}^{3}\end{array}$ & $\begin{array}{l}0.0240 \\
\mathrm{~kg} / 10^{3} \mathrm{~m}^{3}\end{array}$ \\
\hline $\begin{array}{l}\text { Internal Combustion, Natural Gas: } \\
\text { 2-Stroke Lean-Burn }\end{array}$ & $\begin{array}{c}110 \\
\mathrm{lb} / \mathrm{MMBtu}\end{array}$ & $\begin{array}{c}1.45 \\
\mathrm{Ib} / \mathrm{MMBtu}\end{array}$ & $\begin{array}{l}1.20 \mathrm{e}-01 \\
\mathrm{Ib} / \mathrm{MMBtu}\end{array}$ \\
\hline $\begin{array}{l}\text { Internal Combustion, Natural Gas: } \\
\text { 4-Stroke Lean-Burn }\end{array}$ & $\begin{array}{c}110 \\
\mathrm{lb} / \mathrm{MMBtu}\end{array}$ & $\begin{array}{c}1.25 \\
\mathrm{lb} / \mathrm{MMBtu}\end{array}$ & $\begin{array}{l}\text { 1.18e-01 } \\
\text { lb/MMBtu }\end{array}$ \\
\hline $\begin{array}{l}\text { Internal Combustion, Natural Gas: } \\
\text { 4-Stroke Rich-Burn }{ }^{f}\end{array}$ & $\begin{array}{c}110 \\
\mathrm{Ib} / \mathrm{MMBtu}\end{array}$ & $\begin{array}{l}2.30 \mathrm{e}-01 \\
\mathrm{Ib} / \mathrm{MMBtu}\end{array}$ & $\begin{array}{l}2.96 \mathrm{e}-02 \\
\mathrm{Ib} / \mathrm{MMBtu}\end{array}$ \\
\hline Internal Combustion, Diesel & $\begin{array}{c}164 \\
\mathrm{lb} / \mathrm{MMBtu}^{\mathrm{g}}\end{array}$ & $\begin{array}{l}\text { 3.15e-02 } \\
\text { lb/MMBtu }^{h}\end{array}$ & $\begin{array}{l}\text { 3.19e-01 } \\
\text { Ib/MMBtu }^{h}\end{array}$ \\
\hline Internal Combustion, Gasoline & $\begin{array}{c}154 \\
\mathrm{lb} / \mathrm{MMBtu}^{\mathrm{g}}\end{array}$ & $\begin{array}{l}1.89 \mathrm{e}-01 \\
\mathrm{lb} / \mathrm{MMBtu}^{\mathrm{h}}\end{array}$ & $\begin{array}{l}1.911 \mathrm{e} 00 \\
\mathrm{lb} / \mathrm{MMBtu}^{\mathrm{h}}\end{array}$ \\
\hline Natural Gas Turbine' & $\begin{array}{c}110 \\
\mathrm{lb} / \mathrm{MMBtu}\end{array}$ & $\begin{array}{l}8.60 \mathrm{e}-03 \\
\mathrm{Ib} / \mathrm{MMBtu}\end{array}$ & $\begin{array}{l}2.10 \mathrm{e}-03 \\
\mathrm{lb} / \mathrm{MMBtu}\end{array}$ \\
\hline $\begin{array}{l}\text { Stationary Large-Bore Diesel } \\
\text { Engines }\end{array}$ & $\begin{array}{c}2745 \\
\mathrm{~kg} / 10^{3} \mathrm{~m}^{3}\end{array}$ & $\begin{array}{c}0.1548 \\
\mathrm{~kg} / 10^{3} \mathrm{~m}^{3}\end{array}$ & $\begin{array}{c}1.7415 \\
\mathrm{~kg} / 10^{3} \mathrm{~m}^{3}\end{array}$ \\
\hline
\end{tabular}

${ }^{a}$ EPA (1995), Table 1.4-2

${ }^{\mathrm{b}}$ Diesel fuel is also used as a proxy for crude oil.

${ }^{\mathrm{c}} \mathrm{EPA}(1995)$

${ }^{\mathrm{d}}$ EPA (1995), Table 3.2-1

${ }^{e}$ EPA (1995), Table 3.2-2

${ }^{\mathrm{f}}$ EPA (1995), Table 3.2-3

${ }^{g}$ EPA (1995), Table 3.3-1

${ }^{\mathrm{h}}$ EPA (1995), Table 3.3-1, where total organic compounds from Exhaust $=2.1$ for gasoline and total organic compounds from Exhaust $=0.35$ for diesel, and Table 3.4-1, which states that total organic compounds by weight is $9 \% \mathrm{CH}_{4}$ and $91 \%$ non- $\mathrm{CH}_{4}$ for the one diesel engine measured

${ }^{\mathrm{I}}$ EPA (1995), Table 3.1-2a

${ }^{j} \mathrm{EPA}(1995)$ 


\section{Tiered Methods Counts}

This study applies a tiered approach to the estimation of GHG emissions, in which preferred methods are applied when available data allow, and secondary methods otherwise. For those sources unable to use either method, we apply a tertiary method of assigning the median estimate for that profile. Table 20 demonstrates the count of the usability of each method across the two main inventories.

Table 20. Count of Usability for each GHG Emissions Estimation Method for $\mathrm{CO}_{2}$ and Methane

\begin{tabular}{|c|c|c|c|c|c|c|}
\hline & \multicolumn{3}{|c|}{$\mathrm{CO}_{2}$} & \multicolumn{3}{|c|}{ Methane } \\
\hline & Method 1 & Method 2 & Method 3 & Method 1 & Method 2 & Method 3 \\
\hline Amine Units & $\mathrm{n} / \mathrm{a}$ & - & - & 4 & - & - \\
\hline Blowdowns and Vents & 1,366 & 68 & 10 & 1,366 & 68 & 10 \\
\hline Boilers and Heaters & 277 & - & 32 & 277 & - & 32 \\
\hline Engines & 1,467 & 364 & 35 & 708 & 1,133 & 25 \\
\hline Flares & 21 & - & 15 & $\mathrm{n} / \mathrm{a}$ & - & - \\
\hline Fugitives & 4,247 & - & 24 & 4,247 & - & 24 \\
\hline Glycol Dehydrator & 79 & 21 & 14 & 79 & 21 & 14 \\
\hline Produced-Water Loading & 1,948 & - & 11 & 1,948 & - & 11 \\
\hline Produced-Water Tanks & 4,429 & - & 106 & 4,429 & - & 106 \\
\hline Special Inventory Total & 13,834 & 453 & 247 & 13,058 & 1,222 & 222 \\
\hline Engines & - & 673 & - & - & 673 & - \\
\hline Flares & - & 17 & - & $\mathrm{n} / \mathrm{a}$ & - & - \\
\hline Other combustion & - & 264 & - & - & 264 & - \\
\hline Gas Leakage Sources & - & 735 & - & - & 735 & - \\
\hline Produced-Water Tanks & 90 & - & - & 90 & - & - \\
\hline Point-Source Inventory Total & 90 & 1,689 & 0 & 90 & 1,672 & 0 \\
\hline Combined Total & 13,924 & 2,142 & 247 & 13,148 & 2,894 & 222 \\
\hline
\end{tabular}

\section{General Leakage Profiles}

General leakage profiles include blowdowns, fugitives, pneumatics, and vents. Data on blowdowns, fugitives, and vents are obtained from both the Point Source Inventory and the Special Inventory, and data on pneumatics are obtained from the Area Source Inventory. Although these different sources have different causes, they are calculated by similar methods. Because these profiles occur at both production and processing sites, sources are assigned to the stage to which the site belongs.

The primary methods for estimating $\mathrm{CO}_{2}$ and methane emissions use the reported volume of gas released and this study's estimate of the composition of that gas. Where data are not available on volume of gas released, the secondary method uses the reported volume of VOC emissions and a ratio of the GHG to VOCs in the gas composition. These methods for calculating $\mathrm{CO}_{2}$ and methane emissions for leakage sources are adapted from ENVIRON's (2010) discussion of leakage sources, including well-completion venting, well blowdowns, permitted fugitives, and unpermitted fugitives. 
Note that unlike most profiles, inventory data on pneumatics come from the Area Source Inventory, which provides county-level data without individual source counts. Therefore, although emissions from pneumatics are calculated using methods analogous to other leakage profiles, such calculation occurs at the county level based on aggregated, county-level emissions reported in the inventory.

Carbon Dioxide Emissions: Primary Method

$$
E_{\mathrm{CO}_{2}}=Q_{\text {vented }} *\left(\frac{1.0 \mathrm{lb}-\text { mole }}{379.3 s c f}\right) * M W_{\text {gas }} * f_{\mathrm{CO}_{2}} * \frac{1 \text { tonne }}{2204.62 l b}
$$

where:

$E_{\mathrm{CO}_{2}}=$ the mass of $\mathrm{CO}_{2}$ emitted by the source annually (tonne/year)

$Q_{\text {vented }}=$ the total annual volume of gas emitted through the leakage source (scf/year)

$M W_{\text {vented }}=$ the molecular weight of the vented gas (lb/lb-mole)

$f_{\mathrm{CO}_{2}}=$ the fraction of $\mathrm{CO}_{2}$ in the leaked gas by mass (unitless).

\section{Carbon Dioxide Emissions: Secondary Method}

where:

$$
E_{\mathrm{CO}_{2}}=E_{V O C} * \frac{f_{\mathrm{CO}_{2}}}{f_{V O C}}
$$

$E_{\mathrm{CO}_{2}}=$ the mass of $\mathrm{CO}_{2}$ emitted by the source annually (tonne/year)

$E_{V O C}=$ the mass of VOCs emitted by the source annually (tonne/year)

$f_{\mathrm{CO}_{2}}=$ the fraction of $\mathrm{CO}_{2}$ in the production gas by mass (unitless)

$f_{V O C}=$ the fraction of VOCs in the production gas by mass (unitless).

\section{Methane Emissions: Primary Method}

$$
E_{C_{4}}=Q_{\text {vented }} *\left(\frac{1.0 l b-\text { mole }}{379.3 s c f}\right) * M W_{g a s} * f_{C_{4}} * \frac{1 \text { tonne }}{2204.62 l b}
$$

where:

$E_{\mathrm{CH}_{4}}=$ the mass of $\mathrm{CH}_{4}$ emitted by the source annually (tonne/year)

$Q_{\text {vented }}=$ the total annual volume of gas emitted through the leakage source (tonne/year)

$M W_{\text {vented }}=$ the molecular weight of the vented gas (lb/lb-mole)

$f_{\mathrm{CH}_{4}}=$ the fraction of $\mathrm{CH}_{4}$ in the leaked gas by mass (unitless).

\section{Methane Emissions: Secondary Method}

$$
E_{\mathrm{CH}_{4}}=E_{\mathrm{VOC}} * \frac{f_{C_{\mathrm{H}_{4}}}}{f_{\mathrm{VOC}}}
$$

where: 
$E_{\mathrm{CH}_{4}}=$ the mass of $\mathrm{CH}_{4}$ emitted by the source annually (tonne/year)

$E_{V O C}=$ the mass of VOCs emitted by the source annually (tonne/year)

$f_{\mathrm{CO}_{2}}=$ the fraction of $\mathrm{CO}_{2}$ in the production gas by mass (unitless)

$f_{V O C}=$ the fraction of VOCs in the production gas by mass (unitless).

\section{Compression Engines Profile}

Data on compressor engines are obtained from the Special Inventory and the Point Source Inventory. Because these profiles occur at both production and processing sites, the sources are assigned to the stage to which the site belongs.

The primary methods for estimating $\mathrm{CO}_{2}$ and methane emissions use the reported volume of fuel combusted and this study's estimate of the composition of that fuel, as well as the engine characteristics in the case of methane. Where the volume of fuel combusted is not available, the secondary method for $\mathrm{CO}_{2}$ emissions uses engine characteristics and operations data, some of which is based on standard assumptions; the secondary method for methane emissions uses the reported volume of VOC emissions and a ratio of the GHG-to-VOCs-related, profile-specific emission factors.

In addition to data availability, the secondary method is preferred for sources that failed a simple data-consistency screen, or "ratio test," based on the ratio of reported fuel consumption to an expected gas usage value, calculated as:

$$
\text { ratio }=\frac{Q_{\text {fuel }}}{E F U}=\frac{Q_{\text {fuel }}}{M D C * \frac{\text { annual }}{H H V}}
$$

where:

ratio $=$ the test value, where any ratio within a factor of 10 of matching (i.e., between $10 \%$ and $1000 \%$ ) is accepted (unitless)

$Q_{\text {fuel }}=$ the total annual amount of fuel combusted (MMscf/year)

$E F U=$ the expected fuel usage (MMscf/year)

$M D C=$ the reported maximum design capacity of the engine (MMBtu/hour)

$t_{\text {annual }}=$ the annual hours of usage of the engine (hour/year)

$H H V=$ a standardized higher heating value of the fuel, assumed to be 1,150 (Btu/scf).

A final criterion for using the primary method for methane emissions is the reported absence of emissions controls installed on the engine. Ideally, the primary method should be weighted by methane-control efficiency. However, the reported data on VOC control efficiency demonstrate substantial inconsistency, and standardized methane control ratings for engines are not readily available. So, this study assumes that any controls applied affect methane and VOCs equivalently and therefore applies our secondary method for all engines that report the presence of controls. Because the Point Source Inventory does not include information on controls, the 
secondary method is used, which accounts for the possibility of emissions controls, for all engines in that inventory.

\section{Carbon Dioxide Emissions: Primary Method}

$$
E_{\mathrm{CO}_{2}}=Q_{\text {fuel }} *\left(\frac{1.0 \mathrm{lb}-\text { mole }}{379.3 \mathrm{scf}}\right) * M W_{\text {gas }} * f_{C} * f_{O} *\left(\frac{44 g-\mathrm{CO}_{2}}{12 g-C}\right) * \frac{1 \text { tonne }}{2204.62 l b}
$$

where:

$E_{\mathrm{CO}_{2}}=$ the mass of $\mathrm{CO}_{2}$ emitted by the source annually (tonne/year)

$Q_{f u e l}=$ the total annual amount of fuel combusted (scf/year)

$M W_{\text {gas }}=$ the molecular weight of the combusted gas (lb/lb-mole)

$f_{C}=$ the fraction of carbon in the combusted fuel by mass (unitless)

$f_{O}=$ the fraction of fuel carbon oxidized to $\mathrm{CO}_{2}$ by mass, assumed to be 1.0 by convention (unitless).

\section{Carbon Dioxide Emissions: Secondary Method}

$$
E_{\mathrm{CO}_{2}}=\mathrm{HP} * L F * f_{e} * E F_{\mathrm{CO}_{2}} * t_{\text {annual }}
$$

where:

$E_{\mathrm{CO}_{2}}=$ the mass of $\mathrm{CO}_{2}$ emitted by the source annually (tonne/year)

$H P=$ the engine rating $(\mathrm{hp})$

$L F=$ the load factor of the engine (unitless)

$f_{e}=$ the energy-basis conversion factor for the engine (Btu/hp-hr)

$E F_{\mathrm{CO}_{2}}=$ the emissions factor of $\mathrm{CO}_{2}$ on an energy basis (tonne/Btu)

$t_{\text {annual }}=$ the annual hours of usage of the engine (hr/year).

\section{Methane Emissions: Primary Method}

$$
E_{\mathrm{CH}_{4}}=Q_{\text {fuel }} * \mathrm{HHV} * E F_{\mathrm{CH}_{4}}
$$

where:

$E_{\mathrm{CH}_{4}}=$ the mass of $\mathrm{CH}_{4}$ emitted by the source annually (tonne/year)

$Q_{f u e l}=$ the total annual amount of fuel combusted (scf/year)

$H H V=$ the higher heating value of the fuel (Btu/scf)

$E F_{\mathrm{CH}_{4}}=$ the emissions factor of $\mathrm{CH}_{4}$ on an energy basis (tonne/Btu). 
Methane Emissions: Secondary Method

$$
E_{C_{4}}=E_{V O C} * \frac{E F_{C H_{4}}}{E F_{V O C}}
$$

where:

$$
\begin{aligned}
& E_{C H_{4}}=\text { the mass of } \mathrm{CH}_{4} \text { emitted by the source annually (tonne/year) } \\
& E_{V O C}=\text { the mass of VOCs emitted by the source annually (tonne/year) } \\
& E F_{C H_{4}}=\text { the emissions factor of } \mathrm{CH}_{4} \text { on an energy basis (tonne/Btu) } \\
& E F_{V O C}=\text { the emissions factor of VOCs on an energy basis (tonne/Btu). }
\end{aligned}
$$

In addition to the standard assumptions described above, these methods depend on the following assumptions:

- The load factor $(L F)$ is assumed to be 0.8 for compressor engines with an engine rating greater than $500 \mathrm{hp}$ and 0.7 otherwise, based on the results of a 2005 study of compressor engines in Texas performed by the TCEQ. ${ }^{153}$

- The energy-basis conversion factor $\left(f_{e}\right)$ for all natural gas internal combustion engines is 7858 Btu/hp-hr. ${ }^{154}$

- The annual hours of usage of the engine $\left(t_{\text {annual }}\right)$ are $8,760 \mathrm{hr} / \mathrm{year}$ for engines without specific usage data, which includes all engines in the Point Source Inventory.

- Any reduction in $\mathrm{CO}_{2}$ released from the engine related to emissions controls is negligible.

\section{Boilers, Heaters, and Turbines}

Data on boilers and heaters are obtained from the Special Inventory, and data on boilers, heaters, and turbines are obtained from the Point Source Inventory. Although turbines substantially differ from boilers and heaters, estimation of emissions follows equivalent methods for all three profiles in the Point Source Inventory. Also, although boilers and heaters can occur at both production and processing sites, they are associated with natural gas processing; therefore, boilers and heaters are assigned to the processing stage.

The primary methods for estimating $\mathrm{CO}_{2}$ and methane emissions use the reported volume of fuel combusted and this study's estimate of the composition of that fuel. Where the volume of fuel combusted is not available, the secondary method for estimating emissions uses the reported volume of VOC emissions and a ratio of the GHG-to-VOCs-related, profile-specific emission factors.

\footnotetext{
${ }^{153}$ Personal communication with TCEQ (TCEQ 2012)
}

${ }^{154}$ ENVIRON (2010), p.84 
Carbon Dioxide Emissions: Primary Method

$$
E_{\mathrm{CO}_{2}}=Q_{\text {fuel }} *\left(\frac{1.0 \mathrm{lb}-\text { mole }}{379.3 s c f}\right) * M W_{\text {gas }} * f_{C} * f_{O} *\left(\frac{44 g-\mathrm{CO}_{2}}{12 g-C}\right) * \frac{1 \text { tonne }}{2204.62 l b}
$$

where:

$E_{\mathrm{CO}_{2}}=$ the mass of $\mathrm{CO}_{2}$ emitted by the source annually (tonne/year)

$Q_{f u e l}=$ the total annual amount of fuel combusted (scf/year)

$M W_{g a s}=$ the molecular weight of the combusted gas (lb/lb-mole)

$f_{C}=$ the fraction of carbon in the combusted fuel by mass (unitless)

$f_{O}=$ the fraction of fuel carbon oxidized to $\mathrm{CO}_{2}$ by mass, assumed to be 1.0 by convention (unitless).

Carbon Dioxide Emissions: Secondary Method

$$
E_{\mathrm{CO}_{2}}=E_{\mathrm{VOC}} * \frac{f_{\mathrm{CO}_{2}}}{f_{\mathrm{VOC}}}
$$

where:

$E_{\mathrm{CO}_{2}}=$ the mass of $\mathrm{CO}_{2}$ emitted by the source annually (tonne/year)

$E_{V O C}=$ the mass of VOCs emitted by the source annually (tonne/year)

$E F_{\mathrm{CO}_{2}}=$ the emissions factor of $\mathrm{CO}_{2}$ on an energy basis (tonne/Btu)

$E F_{V O C}=$ the emissions factor of VOCs on an energy basis (tonne/Btu).

Methane Emissions: Primary Method

$$
E_{\mathrm{CH}_{4}}=Q_{\text {fuel }} * \mathrm{HHV} * \mathrm{EF}_{\mathrm{CH}_{4}}
$$

where:

$E_{\mathrm{CH}_{4}}=$ the mass of $\mathrm{CH}_{4}$ emitted by the source annually (tonne/year)

$Q_{f u e l}=$ the total annual amount of fuel combusted (scf/year)

$H H V=$ the higher heating value of the fuel (Btu/scf)

$E F_{\mathrm{CH}_{4}}=$ the emissions factor of $\mathrm{CH}_{4}$ on an energy basis (tonne/Btu).

Methane Emissions: Secondary Method

$$
E_{C_{4}}=E_{V O C} * \frac{f_{C H_{4}}}{f_{V O C}}
$$

where:

$E_{\mathrm{CH}_{4}}=$ the mass of $\mathrm{CH}_{4}$ emitted by the source annually (tonne/yr)

$E_{V O C}=$ the mass of VOCs emitted by the source annually (tonne/year) 


$$
\begin{aligned}
& E F_{C H_{4}}=\text { the emissions factor of } \mathrm{CH}_{4} \text { on an energy basis (tonne/Btu) } \\
& E F_{V O C}=\text { the emissions factor of VOCs on an energy basis (tonne/Btu). }
\end{aligned}
$$

\section{Amine Units / Acid Gas Removal}

AGR, such as by amine units, removes $\mathrm{CO}_{2}$ from the production gas. Therefore, this study's method for estimating $\mathrm{CO}_{2}$ emissions from AGR differs substantially from that used for other profiles. AGR units are associated with $\mathrm{CO}_{2}$ emissions equal to the difference in $\mathrm{CO}_{2}$ contained within the production gas and that in the final pipeline-quality gas. Unlike other emissions sources, the $\mathrm{CO}_{2}$ emissions from amine units are calculated as a single, aggregated basin-wide estimate that does not depend on the number of sources in the inventories.

Specifically, the estimated emissions are estimated as follows:

$$
E_{\mathrm{CO}_{2}}=\left[M W_{\text {prod }} * f_{\mathrm{CO}_{2} \text { prod }}-M W_{\text {pipe }} * f_{\mathrm{CO}_{2} \text { pipe }}\right] * Q_{\text {prod }} * \frac{1 l b-\text { mole }}{379.3 \mathrm{scf}}
$$

where:

$$
\begin{aligned}
& E_{\mathrm{CO}_{2}}=\text { mass of } \mathrm{CO}_{2} \text { emitted by all AGR sources in the basin annually (tonne/year) } \\
& \mathrm{MW}_{\text {prod }}=\text { the average molecular weight of production gas within the basin (lb/lb-mole) } \\
& f_{\mathrm{CO}_{2} \text { prod }}=\text { the average percentage } \mathrm{CO}_{2} \text {, by mass, in the production gas (unitless) } \\
& \mathrm{MW}_{\text {pipe }}=\text { the molecular weight of pipeline-quality natural gas }{ }^{155} \text { (lb/lb-mole) } \\
& f_{\mathrm{CO}_{2} \text { prod }}=\text { the average percentage } \mathrm{CO}_{2} \text {, by mass, in pipeline gas }{ }^{156} \text { (unitless) } \\
& Q_{\text {prod }}=\text { the volume of natural gas produced within the basin annually (scf). }
\end{aligned}
$$

In contrast, methane emissions from AGR are estimated using calculation methods equivalent to those provided in that of General Leakage Sources, as previously discussed.

\section{Dehydrators}

GHG emissions from dehydrators are calculated using separate emissions factors depending on the life cycle stage of the site at which the source sites. In the Point Source Inventory, all dehydrators are all at processing sites; but in the Special Inventory, dehydrators exist at both production and processing sites. Therefore, following API (2009), this study uses an emission factor of $275.57 \mathrm{scf} / \mathrm{MMscf}$ gas processed for production sites, adjusting the $\mathrm{CH}_{4}$ content from the 78.8 molar percentage assumed in that reference. Alternatively, if a dehydrator is identified at a processing site, this study uses an emission factor of $121.55 \mathrm{scf} / \mathrm{MMscf}$ gas processed and adjusts the molar $\mathrm{CH}_{4}$ content from $86.8 \%$.

\footnotetext{
${ }^{155}$ Set to $17.4 \mathrm{lb} / \mathrm{lb}$-mole, as provided by EPA (1995) and used by ENVIRON (2010)

${ }^{156}$ Set to $0.47 \%$, as per EPA (2011). To the extent that this value overestimates the $\mathrm{CO}_{2}$ content in pipeline-quality gas, it underestimates $\mathrm{CO}_{2}$ emissions from acid gas removal, and vice versa.
} 
For those dehydrators identified as having a control present in the Special Inventory, and assuming that all dehydrators in the Point Source Inventory have emission controls, this study assumes a $98 \%$ control efficiency for methane and a $0 \%$ efficiency for $\mathrm{CO}_{2}$. Otherwise, this study assumes $0 \%$ efficiency of control for both emissions types. The $98 \%$ efficiency assumption is supported by standard efficiency assumptions for flares, as well as a reported $97 \%$ efficiency for separator-condensers (Schievelbein 1997), an alternative method of control for dehydrators.

\section{Primary Methods}

For dehydrators at production sites:

$$
\begin{aligned}
& E_{\mathrm{CH}_{4}}=P * 0.0052859 *\left[\frac{f_{\mathrm{CH}_{4, \text { county }}} * M W_{\text {gas, } \text { county }}}{16}\right] *\left[\frac{1}{0.788}\right] *(1-C E) \\
& E_{\mathrm{CO}_{2}}=P * 0.0052859 *\left[\frac{f_{\mathrm{CH}_{4}, \text { county }} * M W_{\text {gas, } \text { county }}}{16}\right] *\left[\frac{1}{0.788}\right] * \frac{f_{\mathrm{CO}_{2}, \text { county }}}{f_{\mathrm{CH}_{4}, \text { county }}}
\end{aligned}
$$

and for Dehydrators at Processing sites:

$$
\begin{aligned}
& E_{C_{4}}=P * 0.0023315 *\left[\frac{f_{C_{4}, \text { basin }} * M W_{\text {gas }, \text { basin }}}{16}\right] *\left[\frac{1}{0.868}\right] *(1-C E) \\
& E_{\mathrm{CO}_{2}}=P * 0.0023315 *\left[\frac{f_{\mathrm{CH}_{4}, \text { basin }^{*}}{ }^{M W_{\text {gas }, \text { basin }}}}{16}\right] *\left[\frac{1}{0.868}\right] * \frac{f_{\mathrm{CO}_{2}, \text { basin }}}{f_{\mathrm{CH}_{4}, \text { basin }}}
\end{aligned}
$$

where $\mathrm{CE}=0.98$ if controlled, 0 otherwise, and $\mathrm{P}$ is the volume of gas processed. Controls do not affect $\mathrm{CO}_{2}$ emissions, which are weighted by the ratio of $\mathrm{CO}_{2}$ to $\mathrm{CH}_{4}$ (by weight) in the production gas, by county.

\section{Secondary Methods}

For Dehydrators without $\mathrm{P}$ (which includes all Point Source Inventory dehydrators), the secondary method is based on VOC emissions:

$$
\begin{aligned}
& E_{C_{4}}=E_{V O C} * \frac{f_{C H_{4}}}{f_{V O C}} \\
& E_{C O_{2}}=E_{V O C} *\left(\frac{1}{1-C E}\right) * \frac{f_{C O_{2}}}{f_{V O C}}
\end{aligned}
$$

\section{Flares}

Due to a lack of sufficient information for identifying the specific source to which each flare is associated, this study identifies a flare's process stage by the type of site at which it is found and assumes that all flares combust production gas. This approach will likely overestimate natural gas process-chain emissions due to some of the flares controlling emissions from condensate and crude oil tanks, which should be omitted through co-product allocation; but the overestimation is expected to be small because total flare emissions are small. Only those that can be identified as emissions control for condensate tanks are removed; those that can be identified as combined emissions control for an included profile and condensate tanks are kept. Although this leads to a 
likely overestimation of emissions from flaring, flares only account for a small proportion of overall emissions, so this overestimation is expected to be small.

For $\mathrm{CO}_{2}$ emissions, the primary method, which depends on knowing the amount of gas combusted, treats flares equivalently to other combustion sources. The secondary method uses reported VOC emissions and an assumed 98\% efficiency to back-calculate the volume of gas combusted. Methane emissions are assumed to be attributed to the original source that is controlled by the flares and therefore are neither calculated nor assigned to this profile.

Carbon Dioxide Emissions: Primary Method

$$
E_{\mathrm{CO}_{2}}=\left(Q_{\text {waste }}+Q_{\text {pilot }}\right) *\left(\frac{1.0 l b-\text { mole }}{379.3 s c f}\right) * M W_{\text {gas }} * f_{C} * f_{O} *\left(\frac{44 g-\mathrm{CO}_{2}}{12 g-C}\right) * \frac{1 \text { tonne }}{2204.62 l b}
$$

where:

$E_{\mathrm{CO}_{2}}=$ the mass of $\mathrm{CO}_{2}$ emitted by the source annually (tonne/year)

$Q_{\text {waste }}=$ the total annual amount of waste gas combusted (scf/year)

$Q_{\text {pilot }}=$ the total annual amount of pilot gas combusted (scf/year)

$M W_{\text {gas }}=$ the molecular weight of the combusted gas (lb/lb-mole)

$f_{C}=$ the fraction of carbon in the combusted fuel by mass (unitless)

$f_{O}=$ the fraction of fuel carbon oxidized to $\mathrm{CO}_{2}$ by mass, assumed to be 1.0 by convention (unitless).

\section{Carbon Dioxide Emissions: Secondary Method}

$$
E_{\mathrm{CO}_{2}}=E_{V O C} *\left(\frac{1}{f_{V O C}}\right) *\left(\frac{1}{1-C E}\right) * f_{C} * f_{O} * C E
$$

where:

$E_{\mathrm{CO}_{2}}=$ the mass of $\mathrm{CO}_{2}$ emitted by the source annually (tonne/year)

$E_{V O C}=$ the mass of VOCs emitted by the source annually (tonne/year)

$f_{V O C}=$ the fraction of VOCs in the combusted gas by mass (unitless)

$C E=$ the assumed control efficiency of the flare, $98 \%$ (unitless)

$f_{C}=$ the fraction of carbon in the combusted gas by mass (unitless)

$f_{O}=$ the fraction of combusted gas carbon oxidized to $\mathrm{CO}_{2}$ by mass, assumed to be 1.0 by convention (unitless).

\section{Loading and Tanks}

For produced-water loading and produced-water tanks, GHG emissions are calculated from VOC emissions and the ratio of VOCs to GHGs in the water flash gas. 
Carbon Dioxide Emissions: Primary Method

$$
E_{\mathrm{CO}_{2}}=E_{\mathrm{VOC}} * \frac{f_{\mathrm{CO}_{2}}}{f_{\mathrm{VOC}}}
$$

where:

$E_{\mathrm{CO}_{2}}=$ the mass of $\mathrm{CO}_{2}$ emitted by the source annually (tonne/year)

$E_{V O C}=$ the mass of VOCs emitted by the source annually (tonne/year)

$f_{\mathrm{CO}_{2}}=$ the fraction of $\mathrm{CO}_{2}$ in the produced-water flash gas by mass (unitless)

$f_{V O C}=$ the fraction of VOCs in the produced-water flash gas by mass (unitless).

Methane Emissions: Primary Method

$$
E_{C_{4}}=E_{V O C} * \frac{f_{C H_{4}}}{f_{V O C}}
$$

where:

$E_{\mathrm{CH}_{4}}=$ the mass of $\mathrm{CH}_{4}$ emitted by the source annually (tonne/yr)

$E_{V O C}=$ the mass of VOCs emitted by the source annually (tonne/yr)

$f_{\mathrm{CO}_{2}}=$ the fraction of $\mathrm{CO}_{2}$ in the produced-water flash gas by mass (unitless)

$f_{V O C}=$ the fraction of VOCs in the produced-water flash gas by mass (unitless).

\section{Calculations of Gas Losses from Production and Processing}

\section{Gas Release Sources}

Profiles reporting gas release sources include amine units, blowdowns, fugitives, glycol dehydrators, and vents.

\section{Natural Gas Lost, Method 1: From Reported Vented Volume}

When the volume of gas vented is listed (only for some vents in the Special Inventory), the only calculation is a simple unit conversion, as follows:

$$
Q_{N G, \text { lost }}=Q_{\text {vented }} *\left(\frac{1 M M}{1 e 6}\right)
$$

where:

$$
\begin{aligned}
& Q_{N G, \text { lost }}=\text { the volume of natural gas lost or used by the source annually (MMscf/year) } \\
& Q_{\text {vented }}=\text { the total annual volume of gas emitted from the source (scf/year). }
\end{aligned}
$$




\section{Natural Gas Lost, Method 2: From Reported VOC Emissions}

For most gas leakage sources, the volume of gas released is not directly reported. For these, the volume of gas released can be calculated from the amount of VOC emissions, as follows:

$$
Q_{N G, l o s t}=E_{\mathrm{VOC}} * \frac{1}{f_{\text {VOC }}} *\left(\frac{2204.62 l b}{1 \text { tonne }}\right) *\left(\frac{1}{M W_{\text {gas }}}\right) *\left(\frac{379.3 s c f}{1.0 l b-\text { mole }}\right) *\left(\frac{1 M M}{1 e 6}\right)
$$

where:

$$
\begin{aligned}
& Q_{N G, l o s t}=\text { the volume of natural gas lost or used by the source annually (MMscf/year) } \\
& E_{V O C}=\text { the mass of VOCs emitted by the source annually (tonne/year) } \\
& f_{V O C}=\text { the fraction of VOCs in the production gas by mass (unitless) } \\
& M W_{g a s}=\text { the molecular weight of the production gas (lb/lb-mole). }
\end{aligned}
$$

\section{Engines}

Engines and other combustion sources (i.e., boilers and heaters) both sometimes include a direct report of the volume of fuel used. But only engines report the characteristics used for the ratio test, described in the section above on compressor engine emissions, and Method 2. Therefore, these combustion sources are calculated differently.

\section{Natural Gas Lost, Method 1: From Reported Volume of Fuel Used}

When the volume of gas combusted is listed (only relevant for some Special Inventory sources) and passes this study's Ratio Test for data entry issues, the value can be used directly, as follows:

$$
Q_{N G, \text { lost }}=Q_{\text {fuel }}
$$

where:

$$
\begin{aligned}
& Q_{N G, \text { lost }}=\text { the volume of natural gas lost or used by the source annually (MMscf/yr) } \\
& Q_{f u e l}=\text { the total annual volume of fuel combusted by the source (MMscf/year). }
\end{aligned}
$$

\section{Natural Gas Lost, Method 2: Using Engine Characteristics}

The secondary method uses engine characteristics to estimate the amount of fuel used, which is equivalent to the natural gas lost for these sources.

$$
Q_{N G, \text { lost }}=H P * L F * f_{e} * \frac{1}{H H V} * t_{\text {anuual }} *\left(\frac{1 M M}{1 e 6}\right)
$$

where:

$$
Q_{N G, \text { lost }}=\text { the volume of natural gas lost or used by the source annually (MMscf/year) }
$$


$H P=$ the engine rating $(\mathrm{hp})$

$L F=$ the load factor of the engine ( 0.8 or 0.7 , depending on horsepower)

$f_{e}=$ the energy-basis conversion factor for the engine (Btu/hp-hr)

$H H V=$ the higher heating value of the fuel (Btu/scf)

$t_{\text {annual }}=$ the annual hours of usage of the engine (hr/year).

\section{Non-Engine Combustion}

Engines and other combustion sources (i.e., boilers and heaters) both sometimes include direct report of the volume of fuel used. But only engines have the characteristics used both for the Ratio Test and Method 2. Therefore, these combustion sources are calculated differently.

\section{Natural Gas Lost, Method 1: From Reported Volume of Fuel Used}

When the volume of gas combusted is listed (which is only relevant for some Special Inventory sources), the value can be used directly, as follows:

$$
Q_{N G, \text { lost }}=Q_{\text {fuel }}
$$

where:

$$
\begin{aligned}
& Q_{N G, l o s t}=\text { the volume of natural gas lost or used by the source annually (MMscf/year) } \\
& Q_{f u e l}=\text { the total annual volume of fuel combusted by the source (MMscf/year) }
\end{aligned}
$$

\section{Natural Gas Lost, Method 2: From Reported VOC Emissions}

This alternative method only applies to Point Source Inventory non-engine combustion sources:

$$
Q_{N G, \text { lost }}=E_{V O C} * \frac{1}{E F_{V O C}} *\left(\frac{2204.62 l b}{1 \text { tonne }}\right) *\left(\frac{1}{H H V}\right) *\left(\frac{1 M M}{1 e 6}\right)
$$

where:

$Q_{N G, \text { lost }}=$ the volume of natural gas lost or used by the source annually (MMscf/year)

$E_{V O C}=$ the mass of VOCs emitted by the source annually (tonne/year)

$E F_{V O C}=$ the $\mathrm{VOC}$ emission factor for the source (lb/MMBtu)

$H H V=$ the higher heating value of the fuel (Btu/scf).

Methane Lost, for All Sources: Convert from Natural Gas Lost

For all sources, the conversion from estimated natural gas lost to estimated methane lost is completed as shown: 


$$
Q_{C H_{4}, \text { lost }}=Q_{N G, \text { lost }} * \frac{M W_{\text {gas }}}{M W_{C_{4}}} * f_{C H_{4}}
$$

where:

$$
\begin{aligned}
& Q_{N G, \text { lost }}=\text { the volume of natural gas lost or used by the source annually (MMscf/year) } \\
& Q_{C H_{4}, \text { lost }}=\text { the volume of } \mathrm{CH}_{4} \text { lost or used by the source annually (MMscf/year) } \\
& f_{C H_{4}}=\text { the fraction of } \mathrm{CH}_{4} \text { in the production gas by mass (unitless) } \\
& M W_{g a s}=\text { the molecular weight of the production gas (lb/lb-mole) } \\
& M W_{C H_{4}}=\text { the molecular weight of } \mathrm{CH}_{4}(16.0 \mathrm{lb} / \mathrm{lb}-\text { mole). }
\end{aligned}
$$

\section{Summary of Adjustments to Estimated Emissions}

Emissions from production sources in the Point Source Inventory are adjusted by allocation across co-products at the county-level, as follows:

$$
E_{\text {final }}=\left[E_{\text {raw }}\right] *\left[\text { Allocation }_{\text {county }}\right]
$$

where:

$$
\begin{aligned}
& E_{\text {raw }}=\text { the unadjusted emissions estimate, e.g., } \\
& E_{\mathrm{CO}_{2}}=Q_{f u e l} *\left(\frac{1.0 l b-\text { mole }}{379.3 s c f}\right) * M W_{\text {gas }} * f_{C} * f_{O} *\left(\frac{44 g-C O_{2}}{12 g-C}\right) * \frac{1 \text { tonne }}{2204.62 l b} \\
& \text { Allocation }_{\text {county }}=\text { the county-level allocation of emissions across co-products. }
\end{aligned}
$$

Emissions from production sources in the Area Source Inventory are adjusted by allocation across co-products at the county level and the adjustment for changes in production volumes, as follows:

$$
E_{\text {final }}=\left[E_{\text {raw }}\right] *\left[\text { Allocation }_{\text {county }}\right] *\left[\text { Adjustment }_{\text {county }}\right]
$$

where:

$$
\begin{aligned}
& E_{\text {raw }}=\text { the unadjusted emissions estimate } \\
& \text { Allocation }_{\text {county }}=\text { the county-level allocation of emissions across co-products } \\
& \text { Adjustment } \\
& \text { esounty }=\text { the county-level adjustment of emissions from } 2008 \text { to } 2009
\end{aligned}
$$

Adjustments to emissions from production sources in the Special Inventory differ from this by (1) allocation across co-products at the site-level, rather than at the county-level, (2) requiring site-level and inventory-level corrections, and (3) not requiring the production volume adjustment, as follows: 


$$
E_{\text {final }}=\left[E_{\text {raw }}\right] *\left[\text { Correction }_{\text {site }}\right] *\left[\text { Correction }_{\text {inventory }}\right] *\left[\text { Allocation }_{\text {site }}\right]
$$

where:

$E_{\text {raw }}=$ the unadjusted emissions estimate

Correction $_{\text {site }}=$ the site-level adjustment factor that accounts for the non-report of sources at the site that are below the reporting threshold for the Special Inventory

Correction $_{\text {inventory }}=$ the adjustment factor to all Special Inventory results that accounts for the " $98 \%$ completion rate" of the inventory reported by the TCEQ

Allocation $_{\text {site }}=$ the site-level allocation of emissions across co-products.

Emissions from processing sources in the Point Source Inventory are adjusted by allocation across co-products at the basin-level, as follows:

$$
E_{\text {final }}=\left[E_{\text {raw }}\right] *\left[\text { Allocation }_{\text {basin }}\right]
$$

where:

$E_{\text {raw }}=$ the unadjusted emissions estimate

Allocation $_{\text {basin }}=$ the basin-level allocation of emissions across co-products.

Finally, emissions from processing sources in the Special Inventory are adjusted by the inventory-level and site-level corrections and by allocation across co-products at the basin level, as follows:

$$
E_{\text {final }}=\left[E_{\text {raw }}\right] *\left[\text { Correction }_{\text {site }}\right] *\left[\text { Correction }_{\text {inventory }}\right] *\left[\text { Allocation }_{\text {basin }}\right]
$$

where:

$E_{\text {raw }}=$ the unadjusted emissions estimate

Correction $_{\text {site }}=$ the site-level adjustment factor that accounts for the non-report of sources at the site that are below the reporting threshold for the Special Inventory

Correction $_{\text {inventory }}=$ the adjustment factor to all Special Inventory results that accounts for the " $98 \%$ completion rate" of the inventory reported by the TCEQ

Allocation $_{\text {basin }}=$ the basin-level allocation of emissions across co-products.

\section{Greenhouse Gas Emission Factors}

To create emissions factors for process stages, the sum of estimated emissions for sources in each stage is divided by the production volume of gas associated with those emissions. The relevant statistics exist at the county level for production sources and at the basin level for processing sources.

For sources in the production stage, emissions and production can be associated at the county level. This emission factor focuses only on natural gas production from gas wells, omitting the 
casinghead gas produced as a co-product from oil wells. Specifically, for $\mathrm{CH}_{4}$ emissions associated with production (and where $\mathrm{CO}_{2}$ is calculated analogously):

$$
E F_{C_{4}, \text { prod }, i}=\frac{\sum_{n \in N_{\text {prod } i}} E_{C H_{4}, n}}{Q_{G W g a s, i}}
$$

where:

$$
\begin{aligned}
& E F_{C_{4}, \text { prod,i }}=\text { the } \mathrm{CH}_{4} \text { emission factor for production in county } i \text { (tonne/Mcf) } \\
& E_{\mathrm{CH}_{4}, n}=\text { the mass of } \mathrm{CH}_{4} \text { emitted from source } n \text { annually (tonne/year) } \\
& N_{\text {prod,i }}=\text { the set of production sources in county } i \\
& Q_{G \text { gas, } i}=\text { the volume of gas produced from gas wells in county } i \text { annually (Mcf/year). }
\end{aligned}
$$

For sources in the processing stage, however, emissions and production can only be associated at the basin level because centralized processing sites likely process Barnett Shale gas produced in neighboring counties. In addition, the gas processed by these facilities includes gas produced both from gas wells and oil wells (i.e., casinghead gas), and the denominator includes the sum of these two volumes, accordingly. Specifically, for $\mathrm{CH}_{4}$ emissions associated with processing (and where $\mathrm{CO}_{2}$ is calculated analogously):

$$
E F_{C H_{4}, \text { proc }}=\frac{\sum_{n \in N_{\text {proc }}} E_{C_{4}, n}}{Q_{G \text { Wgas }}+Q_{\text {cgas }}}
$$

where:

$$
\begin{aligned}
& E F_{C H_{4}, \text { proc }}=\text { the } \mathrm{CH}_{4} \text { emission factor for processing in the basin (tonne/Mcf) } \\
& E_{C_{4}, n}=\text { the mass of } \mathrm{CH}_{4} \text { emitted from source } n \text { annually (tonne/year) } \\
& N_{\text {proc }}=\text { the set of processing sources in the basin } \\
& Q_{G \text { Wgas }}=\text { the volume of gas-well gas produced in the basin annually (Mcf/year) } \\
& Q_{C \text { gas }}=\text { the volume of casinghead gas produced in the basin annually (Mcf/year). }
\end{aligned}
$$

The estimation strategy for the processing stage is exposed to a risk of leakage of production volumes both into and out of the basin, where the former corresponds to emissions caused by the processing of gas not accounted for in the basin's production statistics and the latter to gas included in the production statistics that is not accounted for in the processing emissions because such processing occurs outside the basin. The potential for bias from leakage is expected to be small because of the costs incurred in shipping unprocessed gas unnecessarily, as well as the relatively small amount of production in neighboring counties (the sum of which is only $8 \%$ the sum of gas production within the basin). Further, the potential for leakage in both directions increases the likelihood that any bias introduced by one direction of leakage will be cancelled by that in the other direction. But if not completely cancelling, the small scale of production outside the basin suggests that the sum of leakage would be out of the basin, meaning the estimates will underestimate emission factors. 


\section{From Inventory to LCA}

The final estimate of life cycle GHG emissions is calculated as:

$$
\begin{aligned}
E F_{\text {Lifecycle }}= & \left(\frac{1}{T E}\right) \\
& *\left[\frac{E F_{\text {PreProduction }}}{L_{1}}+\frac{E F_{\text {Production }}}{L_{2}}+\frac{E F_{\text {Processing }}}{L_{3}}+\frac{E F_{\text {Transmission }}}{L_{4}}+\frac{E F_{\text {Disposal }}}{L_{2}}\right] \\
& +E F_{\text {Combustion }}+E F_{\text {Construction }}+E F_{\text {Decommissioning }}
\end{aligned}
$$

where:

$E F_{\text {Lifecycle }}=$ the emission factor for the entire life cycle (g GHG/kWh generated)

$T E=$ the thermal efficiency of the power plant (kWh-equivalent input $/ \mathrm{kWh}$ generated)

$E F_{\text {PreProduction }}=$ the emission factor for all pre-production processes, including completions and workovers, amortized by the lifetime EUR (g GHG/kWh-equivalent extracted)

$E F_{\text {Production }}=$ the emission factor for all production processes $(\mathrm{g}$ GHG/kWh-equivalent produced)

$E F_{\text {Processing }}=$ the emission factor for all gas processing processes (g GHG/kWhequivalent processed)

$E F_{\text {Transmission }}=$ the emission factor for all processed gas transmission processes $(\mathrm{g}$ $\mathrm{GHG} / \mathrm{kWh}$-equivalent transmitted)

$E F_{\text {Disposal }}=$ the emission factor for all produced-water disposal processes ( $\mathrm{g} \mathrm{GHG} / \mathrm{kWh}$ equivalent produced)

$E F_{\text {Combustion }}=$ the emission factor for combustion at the power plant, based on the assumed TE (g GHG/kWh generated)

$E F_{\text {Construction }}=$ the emission factor for all power-plant construction processes, amortized over the lifetime production of the power plant ( $\mathrm{g} \mathrm{GHG} / \mathrm{kWh}$ generated)

$E F_{\text {Decommissioning }}=$ the emission factor for all power-plant decommissioning processes, amortized over the lifetime production of the power plant (g GHG/kWh generated)

$L_{1}=$ a loss factor representing the portion of gas extracted that remains in the product flow to be used as an input for combustion, reflecting process-chain losses inclusive of this life cycle stage onward (kWh-equivalent extracted/kWh-equivalent input)

$L_{2}=$ a loss factor representing the portion of gas produced that remains in the product flow to be used as an input for combustion, reflecting process-chain losses inclusive of this life cycle stage onward ( $\mathrm{kWh}$-equivalent produced/kWh-equivalent input)

$L_{3}=$ a loss factor representing the portion of gas processed that remains in the product flow to be used as an input for combustion, reflecting process-chain losses inclusive of this life cycle stage onward (kWh-equivalent processed/kWh-equivalent input) 
$L_{4}=$ a loss factor representing the portion of gas transmitted that remains in the product flow to be used as an input for combustion, reflecting process-chain losses inclusive of this life cycle stage onward ( $\mathrm{kWh}$-equivalent transmitted/kWh-equivalent input).

Using this formula, life cycle GHG emissions are estimated as shown in Table 21.

Table 21. Life Cycle GHG Emissions Values ( $\left.\mathrm{g} \mathrm{CO}_{2} \mathrm{e} / \mathrm{kWh}, 100-\mathrm{yr}\right)$

\begin{tabular}{|c|c|c|c|c|c|c|c|}
\hline & & $\begin{array}{c}\text { Not } \\
\text { Separated }\end{array}$ & $\begin{array}{c}\text { From } \\
\mathrm{CO}_{2}\end{array}$ & $\begin{array}{c}\text { From } \\
\text { Methane }\end{array}$ & $\begin{array}{c}\text { Sum Base- } \\
\text { EUR }\end{array}$ & $\begin{array}{l}\text { Sum High- } \\
\text { EUR }\end{array}$ & Sum Low-EUR \\
\hline & EUR (bcf) & & & & 1.42 & 4.26 & 0.45 \\
\hline \multirow[t]{6}{*}{$\begin{array}{l}\text { Fuel } \\
\text { Cycle }\end{array}$} & $\begin{array}{l}\text { Pre-Production (non- } \\
\text { completions) }\end{array}$ & & 13.9 & & 13.9 & 4.6 & 44.6 \\
\hline & $\begin{array}{l}\text { Completions and } \\
\text { Workovers }^{\mathrm{b}}\end{array}$ & & & 20.2 & 20.2 & 6.7 & 65.0 \\
\hline & Production & & 3.3 & 3.0 & 6.3 & 6.3 & 6.3 \\
\hline & Processing & & 15.6 & 2.4 & 18.0 & 18.0 & 18.0 \\
\hline & $\begin{array}{c}\text { Produced Water } \\
\text { Disposal }\end{array}$ & & 0.0 & 0.7 & 0.7 & 0.7 & 0.7 \\
\hline & Transmission $^{c}$ & & 3.2 & 16.2 & 19.4 & 19.4 & 19.4 \\
\hline \multirow[t]{2}{*}{$\begin{array}{l}\text { Power } \\
\text { Plant }\end{array}$} & $\begin{array}{l}\text { Construction and } \\
\text { Decommissioning }\end{array}$ & 1.2 & & & 1.2 & 1.2 & 1.2 \\
\hline & $\begin{array}{l}\text { Combustion at } \\
\text { Power Plant }^{\mathrm{e}}\end{array}$ & & 359.0 & & 359.0 & 359.0 & 359.0 \\
\hline Overall & Life Cycle & 1.2 & 395.0 & 42.4 & 438.6 & 415.8 & 514.1 \\
\hline
\end{tabular}

${ }^{a}$ Although lower estimates for this stage have been published, reported emissions increase as the comprehensiveness of processes considered increase. So we use the highest published estimate for this stage that provided results in a form that could be adjusted by EUR (Santoro et al., 2011).

${ }^{\mathrm{b}}$ Based on EPA (2011) estimate of 9,175 Mcf natural gas emission/completion, $1 \%$ of wells/year workover rate (EPA 2012b), 30-year assumed lifetime (Skone et al. 2011), and 22-county, Barnett Shale average natural gas molecular weight of $20.1 \mathrm{lb} / \mathrm{lb}-\mathrm{mol}$ and $66.2 \%$ methane by mass.

${ }^{\mathrm{c}}$ Based on Skone et al. (2011)

${ }^{\mathrm{d}}$ Based on Skone and James (2010)

${ }^{\mathrm{e}}$ Based on Skone et al. (2011) 


\section{Appendix C: Requirements, Standards, and Reporting}

Table 22. State Revisions to Oil and Gas Laws

\begin{tabular}{ll}
\hline PA & $\begin{array}{l}\text { Updated regulations in 2010. Particular emphasis on well construction, disclosure, handling and } \\
\text { disposal of recovered fluids. New } 2012 \text { legislation also created new setbacks, environmental } \\
\text { impact analysis requirements, new fees, floodplain drilling restrictions, restoration requirements, } \\
\text { general containment requirements, public disclosure requirements, restricted local control. }\end{array}$ \\
\hline NY & $\begin{array}{l}\text { Proposed major overhaul of regulations in } 2011 \text { specifically to address high-volume hydraulic } \\
\text { fracturing. Some of the most comprehensive rules in the nation. Added new subpart 560 } \\
\text { containing definitions specific to high-volume hydraulic fracturing, setback, reporting, well } \\
\text { construction, and reclamation standards. }\end{array}$ \\
\hline CO & $\begin{array}{l}\text { Major overhaul of regulations in 2009. In 2011, revised disclosure rule, added a requirement } \\
\text { that operators must notify Commission within } 48 \text { hours of intention to fracture and provide } \\
\text { landowners within 500 feet of proposed oil and gas location information regarding fracturing and } \\
\text { how to collect baseline monitoring. }\end{array}$ \\
\hline WY & $\begin{array}{l}\text { Updated regulations in 2010. Revised disclosure and pit requirements; strengthened } \\
\text { presumptive Best Available Control Technology requirements for air emissions (green } \\
\text { completions in Jonah Pinedale Anticline Area and Concentrated Development Areas). }\end{array}$ \\
\hline TX & Updated air rules and implemented disclosure rule in January 2012. \\
\hline LA & Finalized new disclosure rule in October 2011. \\
\hline
\end{tabular}


Table 23. Fracking Fluid Disclosure Requirements

\begin{tabular}{|c|c|c|c|c|c|c|}
\hline & Colorado & Louisiana & New York & Pennsylvania & Texas & Wyoming \\
\hline State Code & COGCC Rule 205A & $\begin{array}{l}\text { La. Admin Code. tit. 43, } \\
\text { pt. XIX, § } 118\end{array}$ & Draft SGEIS 8.2.1.1 & Act $13, \S 3222,3222.1$ & $\begin{array}{l}\text { 16 Tex. Admin Code } \S \\
3.29\end{array}$ & $\begin{array}{l}\text { WOGCC Rules, Ch. } \\
3 \S 45\end{array}$ \\
\hline Takes Effect & February 1, 2012 & October 20, 2011 & Proposed 2011 & April $16,2012^{157}$ & February 1, 2012 & October 17, 2011 \\
\hline Duty to Report? & $\begin{array}{l}\text { Yes. Names of } \\
\text { products in fracking } \\
\text { fluids, chemicals in } \\
\text { fracking fluids, } \\
\text { associated chemical } \\
\text { abstract numbers. }\end{array}$ & $\begin{array}{l}\text { Yes. Names of products } \\
\text { in fracking fluid, chemical } \\
\text { ingredients in fracking } \\
\text { fluid, chemical } \\
\text { concentrations of } \\
\text { hazardous chemicals. }\end{array}$ & $\begin{array}{l}\text { Yes. Fracking fluid } \\
\text { additive products and } \\
\text { material safety data } \\
\text { sheets }\end{array}$ & $\begin{array}{l}\text { Yes. Names of products } \\
\text { in fracking fluid, } \\
\text { chemicals in fracking } \\
\text { fluid, associated } \\
\text { chemical abstract } \\
\text { service numbers. }\end{array}$ & $\begin{array}{l}\text { Yes. Names of } \\
\text { products in fracking } \\
\text { fluid, chemicals in } \\
\text { fracking fluid, } \\
\text { associated chemical } \\
\text { abstract numbers, } \\
\text { volume of fracking fluid. }\end{array}$ & $\begin{array}{l}\text { Yes. Names of } \\
\text { products in fracking } \\
\text { fluid, chemicals } \\
\text { present in fluid, } \\
\text { associated chemical } \\
\text { abstract service } \\
\text { numbers, volume of } \\
\text { fracking fluid. }\end{array}$ \\
\hline To Whom? & $\begin{array}{l}\text { Yes, to Frac Focus } \\
\text { provided public can } \\
\text { search information by } \\
\text { company, chemical } \\
\text { ingredient, geographic } \\
\text { area, and other criteria } \\
\text { by Jan. } 1,2013 \text {. If not, } \\
\text { COGCC will build its } \\
\text { own searchable } \\
\text { database. } \\
\text { Must also provide } \\
\text { landowners within } 500 \\
\text { feet of the well with } \\
\text { information regarding } \\
\text { fracking and baseline } \\
\text { water sampling. }\end{array}$ & $\begin{array}{l}\text { Office of Conservation, } \\
\text { district manager or Frac } \\
\text { Focus }\end{array}$ & $\begin{array}{l}\text { NY Department of } \\
\text { Environmental } \\
\text { Conservation for public } \\
\text { disclosure }\end{array}$ & $\begin{array}{l}\text { PA Department of } \\
\text { Environmental } \\
\text { Protection or Frac } \\
\text { Focus. Similar } \\
\text { requirement to CO that } \\
\text { Frac Focus must be } \\
\text { searchable by Jan. 1, } \\
2013 \text {, or DEP may } \\
\text { require other form of } \\
\text { public disclosure. }\end{array}$ & Yes, to Frac Focus. & $\begin{array}{l}\text { Yes to WOGCC } \\
\text { website. }\end{array}$ \\
\hline
\end{tabular}

\footnotetext{
${ }^{157}$ Note, however, that Act is enjoined pending resolution of legal challenge to its constitutionality on other grounds.

${ }^{158} 2$ CCR 404-1, R. 305.e.(1).A. (2012).
} 


\begin{tabular}{|c|c|c|c|c|c|c|}
\hline & Colorado & Louisiana & New York & Pennsylvania & Texas & Wyoming \\
\hline When? & $\begin{array}{l}\text { No later than } 60 \text { days } \\
\text { after completion of } \\
\text { fracking operation or } \\
\text { no later than } 120 \text { days } \\
\text { after commencement } \\
\text { of fracking operation. }\end{array}$ & $\begin{array}{l}\text { Within } 20 \text { days after } \\
\text { operations are complete. }\end{array}$ & Prior to drilling. & $\begin{array}{l}\text { Within } 60 \text { days of } \\
\text { completion of well } \\
\text { completion }\end{array}$ & $\begin{array}{l}\text { On or before date } \\
\text { operator submits Well } \\
\text { Completion Report; } \\
\text { operator must also } \\
\text { upload required } \\
\text { information to } \\
\text { Disclosure Registry. }\end{array}$ & $\begin{array}{l}\text { Before fracking } \\
\text { begins (APD) and } \\
\text { after operation is } \\
\text { complete (Well } \\
\text { Completion Report } \\
\text { Form). }\end{array}$ \\
\hline $\begin{array}{l}\text { Trade Secret } \\
\text { Exemption? }\end{array}$ & $\begin{array}{l}\text { Yes, for chemicals but } \\
\text { not for chemical family } \\
\text { name. }\end{array}$ & $\begin{array}{l}\text { Yes, for chemicals but not } \\
\text { for chemical family. }\end{array}$ & $\begin{array}{l}\text { Yes, but must still } \\
\text { disclose information } \\
\text { regarding properties and } \\
\text { effects of hazardous } \\
\text { chemical. }\end{array}$ & $\begin{array}{l}\text { Yes, for chemicals but } \\
\text { not for chemical family. } \\
\text { Claims governed by } \\
\text { PA's "Right to Know" } \\
\text { law, which requires } \\
\text { companies submit trade } \\
\text { secret information to the } \\
\text { DEP. Citizens may } \\
\text { challenge information. }\end{array}$ & $\begin{array}{l}\text { Yes, for chemicals but } \\
\text { not for chemical } \\
\text { family. }{ }^{159}\end{array}$ & $\begin{array}{l}\text { Yes, operator can } \\
\text { make a request to } \\
\text { WOGCC to keep } \\
\text { proprietary } \\
\text { information } \\
\text { confidential. }\end{array}$ \\
\hline $\begin{array}{l}\text { Trade Secret } \\
\text { Disclosure? }\end{array}$ & $\begin{array}{l}\text { Yes, trade secrets } \\
\text { must be disclosed to } \\
\text { medical professional in } \\
\text { event of medical } \\
\text { emergency, to } \\
\text { Commission to } \\
\text { respond to a spill, } \\
\text { release or complaint or } \\
\text { if needed for diagnosis } \\
\text { or treatment of } \\
\text { exposed individual. } \\
\text { Disclosure must be } \\
\text { kept confidential. }\end{array}$ & $\begin{array}{l}\text { Yes, if required to be } \\
\text { provided to a health care } \\
\text { professional, } \\
\text { doctor, or nurse. }\end{array}$ & $\begin{array}{l}\text { Yes to health } \\
\text { professionals, } \\
\text { employees and } \\
\text { designated } \\
\text { representatives. }\end{array}$ & $\begin{array}{l}\text { Yes, if required to be } \\
\text { provided to a health care } \\
\text { professional in event of } \\
\text { an emergency. } \\
\text { Disclosure must be kept } \\
\text { confidential. }\end{array}$ & $\begin{array}{l}\text { Yes, to health } \\
\text { professionals and } \\
\text { emergency responders } \\
\text { to diagnose, treat, or } \\
\text { otherwise respond to } \\
\text { an emergency. } \\
\text { Disclosure must be } \\
\text { kept confidential. }\end{array}$ & No. \\
\hline
\end{tabular}

${ }^{159}$ The Texas law contains provisions that allow landowners on whose property operations are taking place, landowners with adjacent property to operations, or state departments and agencies with jurisdiction over matters relevant to trade secret information to challenge a claim of trade secret. 
Table 24. Water Acquisition Requirements

\begin{tabular}{|c|c|c|c|c|}
\hline Play/Basin & $\begin{array}{l}\text { Permit for } \\
\text { Withdrawal }\end{array}$ & Reporting & Other Requirements & Recycling \\
\hline $\begin{array}{l}\text { North San Juan } \\
\text { (Colorado) }\end{array}$ & $\begin{array}{l}\text { Permit for } \\
\text { groundwater } \\
\text { withdrawal } \\
\text { outside } \\
\text { designated } \\
\text { ground water } \\
\text { basin. } 160\end{array}$ & $\begin{array}{l}\text { Must report total volume } \\
\text { of water used in fracking } \\
\text { job to Frac Focus. }{ }^{161}\end{array}$ & $\begin{array}{l}\text { Local requirements } \\
\text { apply. }\end{array}$ & None. $^{163}$ \\
\hline $\begin{array}{l}\text { Upper Green } \\
\text { River } \\
\text { (Wyoming) }\end{array}$ & Yes $^{164}$ & $\begin{array}{l}\text { Yes, limited to amount, } \\
\text { not source. }\end{array}$ & None identified. & None. \\
\hline $\begin{array}{l}\text { Marcellus (New } \\
\text { York) }\end{array}$ & Yes $^{166}$ & $\begin{array}{l}\text { Operator must identify } \\
\text { source of water in permit } \\
\text { and report annually on } \\
\text { aggregate amounts } \\
\text { withdrawn or } \\
\text { purchased. }\end{array}$ & $\begin{array}{l}\text { Monitoring and other } \\
\text { requirements to ensure no } \\
\text { degradation to water } \\
\text { quality and quantity. }{ }^{168}\end{array}$ & $\begin{array}{l}\text { Must develop a } \\
\text { wastewater source } \\
\text { reduction strategy } \\
\text { identifying the methods } \\
\text { and procedures } \\
\text { operators will use to } \\
\text { maximize recycling and } \\
\text { reuse of flow back or } \\
\text { production fluid either } \\
\text { to fracture other wells } \\
\text { or for approved } \\
\text { beneficial uses. }\end{array}$ \\
\hline
\end{tabular}

${ }^{160}$ C.R.S. $\S \S 37-90-137$, 37-92-308 (2011). See also

http://cogcc.state.co.us/Library/Oil_and_Gas_Water_Sources_Fact_Sheet.pdf. The Colorado Ground Water Commission may define and alter designated groundwater basins within the state based on adequate factual information. See C.R.S. \$37-90-106 (2012).

${ }^{161}$ COGCC R. 205A(b)(2)(A)(viii) (2012).

${ }^{162}$ See, for example, Archuleta County Land Use Code Section 9.2: Archuleta County's Oil and Gas Development Permit Provisions (Amended Dec. 2010) http://www.archuletacounty.org/Planning/Section\%209\%20\%20Mining\%20December\%202010.pdf.

${ }^{163}$ See Response of the Colorado Oil and Gas Conservation Commission to the STRONGER Hydraulic Fracturing Questionnaire, 32, http://cogcc.state.co.us/Library/HydroFracStronger/COGCC Response To STRONGER 06132011.pdf (noting that R. 907(a)(3) encourages recycling by encouraging operators to submit waste management plans that may provide for reuse of waste water. Rules 903 and 907 encourage recycling by providing for multi-well pits. R. $902 . e$ and 903.a.(4) creates new pit classification for multi-well pits. "These pits are often centrally located in the oil or gas field, are used to store fluids from multiple wells, and may include treatment areas where fracturing flowback fluids and produced water can be brought up to specifications. COGCC is also working with several operators on waste sharing plans that will facilitate the reuse and recycling of fracturing fluids and produced water."

${ }^{164}$ National Conference of State Legislatures, "State Water Withdrawal Regulations," http://www.ncsl.org/issuesresearch/env-res/state-water-withdrawal-regulations.aspx.

${ }^{165}$ Conversation with Rick Marvel, engineer, WOGCC, May 29, 2012.

${ }^{166}$ NYSGEIS $\S 7.1 .1 .1$. Withdrawal permits will include conditions to monitor and enforce water quality and quantity standards and requirements. If withdrawing from within 500 feet of wetlands, must require monitoring during pump test. Lowering groundwater levels at or below wetlands is a significant impact triggering site-specific State Environmental Quality Review Act review. Withdrawals from groundwater within 500 feet of private wells also trigger site-specific State Environmental Quality Review Act reviews.

${ }^{167} \mathrm{Id}$.

${ }^{168}$ See Id (discussing various standards such as passby flow requirements, water conservation practices, and protections for aquatic life that may be included by permit).

${ }^{169}$ NYSGEIS $§ 5.12$. 


\begin{tabular}{|c|c|c|c|c|}
\hline Play/Basin & $\begin{array}{l}\text { Permit for } \\
\text { Withdrawal }\end{array}$ & Reporting & Other Requirements & Recycling \\
\hline $\begin{array}{l}\text { Marcellus } \\
\text { (Pennsylvania) }\end{array}$ & $\begin{array}{l}\text { Cannot } \\
\text { withdraw without } \\
\text { approved water } \\
\text { management } \\
\text { plan. }{ }^{170}\end{array}$ & $\begin{array}{l}\text { Report list of water } \\
\text { sources used under } \\
\text { approved water } \\
\text { management plan and } \\
\text { volume of water. }^{171}\end{array}$ & $\begin{array}{l}\text { Water management plan } \\
\text { that includes plan for } \\
\text { reuse of fluids. }{ }^{172}\end{array}$ & $\begin{array}{l}\text { Water management } \\
\text { plan must include plan } \\
\text { for reuse of fluids used } \\
\text { to fracture wells. }{ }^{173} \\
\text { Well completion report } \\
\text { must include total } \\
\text { volume of water } \\
\text { recycled. }^{174}\end{array}$ \\
\hline $\begin{array}{l}\text { Haynesville } \\
\text { (Louisiana) }\end{array}$ & None identified. & $\begin{array}{l}\text { Must report water source } \\
\text { and volumes after } \\
\text { completion or } \\
\text { recompletion. }\end{array}$ & None. & $\begin{array}{l}\text { Regulations recognize } \\
\text { processing of E\&P } \\
\text { waste into reusable } \\
\text { materials as alternative } \\
\text { to other means of } \\
\text { disposal and authorizes } \\
\text { commercial facilities for } \\
\text { the purpose of } \\
\text { generating reusable } \\
\text { material. }^{176}\end{array}$ \\
\hline $\begin{array}{l}\text { Eagle Ford } \\
\text { (Texas) }\end{array}$ & Yes. $^{1 / l}$ & $\begin{array}{l}\text { Report total volume of } \\
\text { water used in fracking to } \\
\text { Frac Focus. } 178\end{array}$ & None identified. & None. \\
\hline Barnett (Texas) & Yes. & $\begin{array}{l}\text { Report total volume of } \\
\text { water used in fracking to } \\
\text { Frac Focus. } 179\end{array}$ & None identified. & None. \\
\hline
\end{tabular}

17058 PA Con. Stat. ch. $32, \S 3211(\mathrm{~m})$. Condition of all permits to hydraulically fracture natural gas wells in unconventional formations.

${ }^{171} I d . \S 3222(\mathrm{~b} .1)(1)(\mathrm{vi})(2012)$.

${ }^{172} 58$ PA Con. Stat. ch. 32, § 3211(m). Operators must develop water management plan, which must be approved by DEP, governing withdrawals or use of water. Approval of plan is contingent on determination that withdrawal/use will not adversely affect quantity or quality of water, will protect and maintain designated and existing uses of water supply, will not cause adverse impact to water quality in watershed and will include a reuse plan for fluids for hydraulically fractured wells. If plan is operated in accord with conditions established by the Susquehanna River Basin Commission, the Delaware River Basin Commission or the Great Lakes Commission, it is presumed to meet above conditions.

17358 PA Con. Stat. ch. 32, §. 3211(m)(2)(iv).

${ }^{174}$ Id. $\S 3222$ (b.1)(1)(vi) (2012).

${ }^{175}$ Well History and Work Resume Report, Form WH-1, Louisiana Hydraulic Fracturing State Review, 5 (March 2011), http://www.strongerinc.org/documents/Final\%20Louisiana\%20HF\%20Review\%203-2011.pdf.

${ }^{176}$ La. Admin. Code tit. 43:XIX, § 565 (2010).

${ }^{177}$ Tex. Water Code, tit. 2, ch. 11. See also http://www.rrc.state.tx.us/barnettshale/wateruse.php Short-term permits issued by Texas Commission on Environmental Quality Regional Offices and permits for more than 10 acre-feet of water or for a term lasting more than 1 year are issued by the Commission's Water Rights Permitting Team.

${ }^{178} 16$ Tex. Admin. Code $\S 3.29(\mathrm{c})(2)(\mathrm{A})($ viii) (2011).

${ }^{179} \mathrm{Id}$ 
Table 25. Well Construction Standards

\begin{tabular}{|c|c|c|c|c|}
\hline $\begin{array}{l}\text { Play/Basin/ } \\
\text { Jurisdiction }\end{array}$ & Cement Bond Log & $\begin{array}{l}\text { Minimum } \\
\text { Surface Casing } \\
\text { Depth }\end{array}$ & $\begin{array}{c}\text { Pressure Tests for } \\
\text { Casing }\end{array}$ & $\begin{array}{l}\text { Monitor Bradenhead } \\
\text { Annulus Pressure }\end{array}$ \\
\hline Federal Lands $^{180}$ & Yes. & None. & $\begin{array}{l}\text { Yes. Mechanical integrity } \\
\text { test required before each } \\
\text { well stimulation operation. }\end{array}$ & $\begin{array}{l}\text { No. But must } \\
\text { continuously monitor } \\
\text { and record pressure } \\
\text { during well stimulation } \\
\text { and notify if annulus } \\
\text { pressure increases by } \\
\text { more than } 500 \text { lbs per } \\
\text { square inch. }\end{array}$ \\
\hline $\begin{array}{l}\text { North San Juan } \\
\text { (Colorado) }\end{array}$ & $\begin{array}{l}\text { Yes. Required on all } \\
\text { production casing, or } \\
\text { in the case of } \\
\text { production liner, the } \\
\text { intermediate } \\
\text { casing. }{ }^{181}\end{array}$ & $\begin{array}{l}\text { None specified in } \\
\text { rules, but OGCC } \\
\text { requires casing } \\
\text { be set at least } 50 \\
\text { feet below } \\
\text { aquifer to ground } \\
\text { surface. }\end{array}$ & $\begin{array}{l}\text { Yes. Must test production } \\
\text { casing during completion } \\
\text { and production. }\end{array}$ & $\begin{array}{l}\text { Must monitor and record } \\
\text { bradenhead annulus } \\
\text { pressure during fracking } \\
\text { and notify COGCC of } \\
\text { conditions indicating } \\
\text { fracking fluids have } \\
\text { escaped producing } \\
\text { reservoir. }{ }^{183}\end{array}$ \\
\hline $\begin{array}{l}\text { Upper Green } \\
\text { River (Wyoming) }\end{array}$ & $\begin{array}{l}\text { No specific } \\
\text { requirement. }\end{array}$ & $\begin{array}{l}\text { None specified } \\
\text { but casing must } \\
\text { be run below } \\
\text { known or } \\
\text { reasonably } \\
\text { estimated } \\
\text { utilizable fresh }^{185} \\
\text { water levels. }^{1}\end{array}$ & $\begin{array}{l}\text { No. Mechanical integrity } \\
\text { tests may be required but } \\
\text { not mandatory. }\end{array}$ & No \\
\hline $\begin{array}{l}\text { Barnett } \\
\text { (Texas) }\end{array}$ & No. & $\begin{array}{l}\text { None specified } \\
\text { but all usable- } \\
\text { quality water } \\
\text { zones be isolated } \\
\text { and sealed off to } \\
\text { effectively } \\
\text { prevent } \\
\text { contamination or } \\
\text { harm. }{ }^{187}\end{array}$ & $\begin{array}{l}\text { All casing must be steel } \\
\text { casing that has been } \\
\text { hydrostatically pressure } \\
\text { tested with an applied } \\
\text { pressure at least equal to } \\
\text { max. pressure to which } \\
\text { pipe will be subjected in } \\
\text { the well }\end{array}$ & $\begin{array}{l}\text { All wells must be } \\
\text { equipped with a } \\
\text { bradenhead. Must notify } \\
\text { district office when } \\
\text { pressure develops } \\
\text { between any two strings } \\
\text { of casing. Must perform } \\
\text { a pressure test with } \\
\text { bradenhead if well } \\
\text { shows pressure on the } \\
\text { bradenhead. }\end{array}$ \\
\hline
\end{tabular}

${ }^{180}$ BLM (2012). "Proposed Rule: Oil and Gas; Well Stimulation, Including Hydraulic Fracturing, on Federal and Indian Lands," Department of Interior, May 4, 2012, http://www.doi.gov/news/pressreleases/loader.cfm?csModule=security/getfile\&amp;pageid=293916. ${ }^{181}$ COGCC R. 317(o).

${ }^{182} \mathrm{Id}$. at $317(\mathrm{j})$.

${ }^{183} \mathrm{Id}$. at 341 .

${ }^{184}$ WOGCC Rules, ch. 3, $\S \S 12,21$, requires submission of well logs, which includes "electrical, radioactive, or other similar log runs," which may, but does not necessarily, include cement bond logs.

${ }^{185} I d . \S 22(\mathrm{a})(\mathrm{i})$.

${ }^{186} I d$. $\S 45$.

${ }^{187} 16$ Tex. Admin. Code $\S 3.13$.

${ }^{188} I d . \S 3.17$. 


\begin{tabular}{|c|c|c|c|c|}
\hline $\begin{array}{l}\text { Play/Basin/ } \\
\text { Jurisdiction }\end{array}$ & Cement Bond Log & $\begin{array}{l}\text { Minimum } \\
\text { Surface Casing } \\
\text { Depth }\end{array}$ & $\begin{array}{l}\text { Pressure Tests for } \\
\text { Casing }\end{array}$ & $\begin{array}{l}\text { Monitor Bradenhead } \\
\text { Annulus Pressure }\end{array}$ \\
\hline $\begin{array}{l}\text { Eagle Ford } \\
\text { (Texas) }\end{array}$ & No. & $\begin{array}{l}\text { None specified } \\
\text { but all usable- } \\
\text { quality water } \\
\text { zones must be } \\
\text { isolated and } \\
\text { sealed off to } \\
\text { effectively } \\
\text { prevent } \\
\text { contamination or } \\
\text { harm. }\end{array}$ & $\begin{array}{l}\text { All casing must be steel } \\
\text { casing that has been } \\
\text { hydrostatically pressure } \\
\text { tested with an applied } \\
\text { pressure at least equal to } \\
\text { the maximum pressure to } \\
\text { which pipe will be } \\
\text { subjected in the well. }\end{array}$ & $\begin{array}{l}\text { All wells must be } \\
\text { equipped with a } \\
\text { bradenhead. Must notify } \\
\text { district office when } \\
\text { pressure develops } \\
\text { between any two strings } \\
\text { of casing. Must perform } \\
\text { a pressure test with } \\
\text { bradenhead if well } \\
\text { shows pressure on the } \\
\text { bradenhead. }^{190}\end{array}$ \\
\hline $\begin{array}{l}\text { Haynesville } \\
\text { (Louisiana) }\end{array}$ & $\begin{array}{l}\text { Yes, operator must } \\
\text { run cement bond log, } \\
\text { temperature survey, } \\
\text { X-ray log, density log, } \\
\text { or other acceptable } \\
\text { test. }^{191}\end{array}$ & None. ${ }^{192}$ & $\begin{array}{l}\text { Surface, intermediate, and } \\
\text { producing casing must be } \\
\text { tested depending on their } \\
\text { depth. }\end{array}$ & No. \\
\hline $\begin{array}{l}\text { Marcellus } \\
\text { (New York) }\end{array}$ & $\begin{array}{l}\text { Department may } \\
\text { require a cement bond } \\
\text { long or other } \\
\text { measures to ensure } \\
\text { adequacy of the } \\
\text { bond. }{ }^{194}\end{array}$ & $\begin{array}{l}\text { Must be set to at } \\
\text { least } 75 \text { feet } \\
\text { beyond deepest } \\
\text { fresh water zone } \\
\text { or bedrock, } \\
\text { whichever is } \\
\text { deeper. }\end{array}$ & No. $^{195}$ & No. \\
\hline $\begin{array}{l}\text { Marcellus } \\
\text { (Pennsylvania) }\end{array}$ & $\begin{array}{l}\text { In response to a } \\
\text { potential natural gas } \\
\text { migration incident, the } \\
\text { department may } \\
\text { require operator to } \\
\text { evaluate adjacent oil } \\
\text { and gas wells with } \\
\text { different measures, } \\
\text { including cement bond } \\
\text { logs. }{ }^{196}\end{array}$ & $\begin{array}{l}\text { Must be set } 50 \\
\text { feet below } \\
\text { deepest fresh } \\
\text { groundwater or at } \\
\text { least } 50 \text { feet into } \\
\text { consolidated } \\
\text { rock, whichever } \\
\text { is deeper. }{ }^{197}\end{array}$ & $\begin{array}{l}\text { Yes. New casing must } \\
\text { have an internal pressure } \\
\text { rating that is at least } 20 \% \\
\text { greater than anticipated } \\
\text { maximum pressure to } \\
\text { which casing will be } \\
\text { exposed. Used casing } \\
\text { must be pressure tested } \\
\text { after cementing and } \\
\text { before continuation of } \\
\text { drilling. }\end{array}$ & No. \\
\hline
\end{tabular}

${ }^{189}$ Id. $\S 3.13$.

${ }^{190}$ Id. $\S 3.17$.

${ }^{191}$ La. Admin. Code, tit. 43, pt. XIX, §419(A)(3).

${ }^{192}$ Id. $\S 109$.

${ }^{193} \mathrm{Id}$.

${ }^{194}$ N.Y. Comp. Codes R. \& Regs. tit. 6, ch. V, §559.6(d)(2).

${ }^{195}$ Id. $\S 557.2$.

$19625 \mathrm{~Pa}$. Code $\S 78.89$.

${ }^{197}$ Id. $\$ 78.83$.

${ }^{198}$ Id. $\S 78.84$. 


\section{Table 26. Baseline Monitoring Requirements}

\begin{tabular}{|c|c|}
\hline Play/Basin & Requirement \\
\hline $\begin{array}{l}\text { North San Juan } \\
\text { (Colorado) }\end{array}$ & $\begin{array}{l}\text { Operators drilling within } 301-2,640 \text { feet of surface water intended to be used for drinking } \\
\text { water must collect baseline water samples from the surface water prior to drilling and } 3 \\
\text { months after the conclusion of drilling or completion. } \\
\text { Operators must collect water well samples from nearby wells prior to drilling, as well as } 1 \text {, } \\
3 \text {, and } 6 \text { years after completion. }{ }^{200} \\
\text { Operators must provide landowners within } 500 \text { feet of proposed oil and gas location with } \\
\text { instruction as to how to collect baseline water samples. }\end{array}$ \\
\hline $\begin{array}{l}\text { Marcellus } \\
\text { (New York) }\end{array}$ & $\begin{array}{l}\text { Operator must make reasonable attempt to sample and test all residential water wells } \\
\text { within } 1,000 \text { feet of a wellpad; must be sampled prior to commencing drilling. If no well is } \\
\text { located within } 1,000 \text { feet, or the surface owner denies permission, then the operator must } \\
\text { sample all wells within a } 2,000 \text {-foot radius. Monitoring continues at specified intervals as } \\
\text { determined by the DEC. } 202\end{array}$ \\
\hline $\begin{array}{l}\text { Marcellus } \\
\text { (Pennsylvania) }\end{array}$ & $\begin{array}{l}\text { PA law provides for a rebuttable presumption that a well operator is responsible for } \\
\text { pollution of a private or public water supply if the supply is within } 2,500 \text { feet of an } \\
\text { unconventional well and the pollution occurred within } 12 \text { months of the later of the } \\
\text { completion, drilling, stimulation or alteration of the well. Operators can overcome this } \\
\text { presumption by undertaking a pre-drilling or pre-alteration survey that demonstrates pre- } \\
\text { existing contamination or if landowner or water purveyor refuses to allow the operator to } \\
\text { test. }^{203}\end{array}$ \\
\hline
\end{tabular}

${ }^{199} 2$ Colo. Code Regs. $\S 404-1$; COGCC R. 317B(d)(e). Samples must be tested for BTEX, TDS, metals, and other specified parameters in the rules.

${ }^{200}$ Various Commission Orders. See COGCC Response to STRONGER, 4, available at http://cogcc.state.co.us/Library/HydroFracStronger/COGCC Response To STRONGER 06132011.pdf. R. 608 extends the requirements set forth in Commission Orders to other parts of the state with CBM wells and requires operators to identify all plugged and abandoned wells within $1 / 4$ mile of proposed CBM well, assess the risk of leaking gas or water, make a reasonable good-faith effort to conduct pre-production soil gas survey of all plugged and abandoned wells within $1 / 4$ mile of proposed CBM well and post-production survey 1 and every 3 years after production has commenced, and sample water wells located within $1 / 4$ or $1 / 2$ mile from proposed CBM well and within 1,3 , and 6 years thereafter.

2012 Colo. Code Regs. § 404-1; COGCC R. 305.e.(1).A. (2012).

${ }^{202}$ N .Y. Comp. Codes R. \& Regs. tit 6, § 560.5(d).

${ }^{203} 58 \mathrm{~Pa}$. Cons. Stat $\S 3218(\mathrm{c})$. 
Table 27. Closed-Loop or Pitless Drilling Requirements

\begin{tabular}{|c|c|c|}
\hline Play/Basin & Requirement & Date Adopted \\
\hline $\begin{array}{l}\text { North San Juan } \\
\text { (Colorado) }\end{array}$ & $\begin{array}{l}\text { Pitless drilling within } 301-500 \text { feet of surface water intended to be used } \\
\text { for drinking water. Pitless drilling or containment of all flowback and } \\
\text { stimulation fluids in liner pits within } 501-2,640 \text { feet of surface water } \\
\text { intended to be used for drinking water unless operator can } \\
\text { demonstrate pit will not adversely affect waters. }\end{array}$ & 2008 \\
\hline $\begin{array}{l}\text { Upper Green River } \\
\text { (Wyoming) }\end{array}$ & $\begin{array}{l}\text { Closed system required where groundwater is less than } 20 \text { feet below } \\
\text { surface. }\end{array}$ & 2010 \\
\hline $\begin{array}{l}\text { Marcellus } \\
\text { (New York) }\end{array}$ & $\begin{array}{l}\text { Closed-loop tank system for drilling fluids and cuttings produced from } \\
\text { horizontal drilling unless an acid rock drainage mitigation plan for on- } \\
\text { site burial of such cuttings is approved by department. } \\
\text { Cuttings contaminated with oil-based mud or polymer-based mud must } \\
\text { be contained and managed in a closed-loop tank system. }{ }^{207}\end{array}$ & Proposed 2011 \\
\hline $\begin{array}{l}\text { Marcellus } \\
\text { (Pennsylvania) }\end{array}$ & $\begin{array}{l}\text { Prohibits storage and disposal of production fluids and brine in pits } \\
\text { unless permitted under Clean Streams Law. }\end{array}$ & 2010 \\
\hline $\begin{array}{l}\text { Barnett } \\
\text { (Texas) }\end{array}$ & $\begin{array}{l}\text { Closed-loop mud system required for all drilling and reworking } \\
\text { operations unless operations located on open space of at least } 25 \\
\text { acres and not within } 1,000 \text { feet of residence or certain public places. }{ }^{209}\end{array}$ & 2009 \\
\hline
\end{tabular}

${ }^{204}$ COGCC R. 317B(d)(1), (e)(1); R. 904. Colorado does not define pitless drilling. The definition of pit is a "natural or man-made depression in the ground used for oil or gas exploration or production purposes. Pit does not include steel, fiberglass, concrete or other similar vessels which do not release their contents to surrounding soils." COGCC R. 100.

${ }^{205}$ WY ADC Oil Gen. ch. 4, $\S 1(\mathrm{u})$. Commission has authority to require closed system in other instances to protect surface and ground water, human beings, wildlife and livestock. Id. Closed system "includes, but is not limited to, the use of a combination of solids control equipment (e.g., unconventional shakers, flow line cleaners, desanders, desilters, mud cleaners, centrifuges, agitators, and necessary pumps and piping) incorporated in a series on the rig's steel mud tanks, or a self-contained unit that eliminates the need for a reserve pit for the purpose of dumping and dilution of drilling fluids for the removal of entrained drilling solids. A closed system for the purpose of the Commission's rules does not automatically include the use of a small pit, even to receive cuttings." WY ADC Oil Gen. ch. $1, \S 2(\mathrm{k})$.

${ }^{206}$ NY Dept. of Envtl Conservation Proposed Rules, 6 N.Y. Comp. Codes R. \& Regs. § 560.6. Closed-loop drilling system means a pitless drilling system where all drilling fluids and cuttings are contained at the surface within piping, separation equipment and tanks. 6 N.Y. Comp. Codes R. \& Regs. $§ 750-3.2$.

${ }^{207}$ New York Department of Environmental Conservation Proposed Rules, 6 N.Y. Comp. Codes R. \& Regs. $\S$ 560.7.

${ }^{208}$ PA Office of Oil and Gas Mgmt. Rules, ch. 78.57.

${ }^{209}$ Fort Worth, Tex. Ordinance, $\S 15-42(\mathrm{~A})(3),(\mathrm{A})(38)(\mathrm{b})$ (2009). 
Table 28. Produced Water Disposal

\begin{tabular}{|c|c|c|c|c|c|c|}
\hline State & Direct & Indirect & $\begin{array}{l}\text { Underground } \\
\text { Injection } \\
\text { Control }\end{array}$ & Ponds & Land & Reuse \\
\hline CO & $\begin{array}{l}\text { Yes, if water } \\
\text { meets criteria } \\
\text { for wildlife or } \\
\text { agricultural } \\
\text { propagation. } \\
\text { CBM } \\
\text { discharges via } \\
\text { permit. }{ }^{210}\end{array}$ & Yes & Yes & Yes & $\begin{array}{l}\text { Yes, water must meet } \\
\text { state water-quality } \\
\text { standard for } \\
\text { agricultural/livestock } \\
\text { use. }^{211}\end{array}$ & Encouraged $^{212}$ \\
\hline WY & $\begin{array}{l}\text { Yes, if water } \\
\text { meets criteria } \\
\text { for wildlife or } \\
\text { livestock } \\
\text { watering or } \\
\text { other } \\
\text { agricultural } \\
\text { uses. }{ }^{213}\end{array}$ & Yes & Yes & Yes & Yes, with permission. ${ }^{214}$ & Encouraged $^{215}$ \\
\hline TX & Yes $^{216}$ & $\mathrm{No}^{217}$ & Yes & $\begin{array}{l}\text { Yes, with } \\
\text { permit. }^{218}\end{array}$ & $\mathrm{No}^{219}$ & No provisions \\
\hline PA & No & $\begin{array}{l}\text { Yes, for new } \\
\text { and } \\
\text { expanded } \\
\text { discharges } \\
\text { meeting } \\
\text { standards. }\end{array}$ & Yes & Yes & $\mathrm{Yes}^{220}$ & Yes $^{221}$ \\
\hline NY & No & $\begin{array}{l}\text { Yes operator } \\
\text { must analyze } \\
\text { POTW } \\
\text { capacity and } \\
\text { create } \\
\text { contingency } \\
\text { plan if the } \\
\text { primary } \\
\text { wastewater } \\
\text { disposal is at } \\
\text { POTW. }\end{array}$ & Yes $^{222}$ & No & Only with permission. ${ }^{223}$ & Encouraged $^{224}$ \\
\hline
\end{tabular}

${ }^{210}$ Colorado follows national effluent limitations. 2 Colo. Code Regs. §404-1; COGCC R. 907.

2112 Colo. Code Regs. \$404-1, COGCC R. 907. Standard is 3,500 mg/l.

${ }^{212}$ No specific requirements but COGCC R. 907(a)(3) encourages recycling by encouraging operators to submit waste management plans which may provide for reuse of waste water, see

http://cogcc.state.co.us/Library/HydroFracStronger/COGCC Response_To_STRONGER 06132011.pdf

${ }^{213}$ WY Water Quality Rules \& Regs, ch. 2, appendix H. See also WOGCC Rules, ch. $4 \S 1$ (ee).

${ }^{214}$ WOGCC Rules, ch. $4 \S 1(\mathrm{~mm})$

${ }^{215} I d$. $\S 1(\mathrm{z})$. No specific requirements although "Commission encourages the recycling of drilling fluids and by administrative action approves the transfer of drilling fluids intended for recycling.

${ }^{216}$ Personal communication with John Becker, Texas Railroad Commission.

${ }^{217}$ Based on conversation with Phillip Urbany, engineer, TX Commission on Environmental Quality, May 29, 2012.

21816 Tex. Admin. Code $\$ 3.8(d)(2)$.

${ }^{219}$ Our research did not identify any prohibition on land application but also no clear authorization.

$22025 \mathrm{~Pa}$. Code $\$ 78.63$.

${ }^{221}$ AB 13, Sec. 3211(m). 


\begin{tabular}{|c|c|c|c|c|c|c|}
\hline State & Direct & Indirect & $\begin{array}{l}\text { Underground } \\
\text { Injection } \\
\text { Control }\end{array}$ & Ponds & Land & Reuse \\
\hline LA & $\mathrm{No}^{225}$ & $\begin{array}{l}\text { Discharge to } \\
\text { a POTW is } \\
\text { not a } \\
\text { permissible } \\
\text { disposal } \\
\text { method for } \\
\text { produced } \\
\text { water in } \\
\text { Louisiana. }\end{array}$ & Yes & Yes & $Y_{e s}^{221}$ & No provisions \\
\hline
\end{tabular}

${ }^{222}$ N.Y. Comp. Codes R. \& Regs. tit. 6, §750-1.24. See also 40 C.F.R. 144 \& 146.

${ }^{223}$ Revised SGEIS at 7-60: Those wanting to road spread production brine must petition for a beneficial use determination. NORM concentrations in Marcellus Shale likely won't allow road spreading of brine, but "[a]s more data becomes available, it is anticipated that petitions for such use will be evaluated by the Department."

${ }^{224}$ Proposed N.Y. Comp. Codes R. \& Regs., tit. 6, §560.7. Removed pit fluids must be disposed, recycled or reused as described in approved fluid disposal plan. Operator must submit fluid disposal plan (see regs at 750. 3.12).

${ }^{225}$ EPA National effluent limitation, see 40 CFR ch. I, subch. N; see also

http://www.deq.louisiana.gov/portal/Portals/0/planning/Permits\%20Docs/Timeline022912mcm-Version\%204.pdf (discharges prohibited onto vegetated areas, soil, intermittently exposed sediment surface, lakes, rivers, streams, bayous, canals, or other surface waters regionally characterized as upland, freshwater swamps, freshwater marshes, natural or manmade water bodies bounded by freshwater swamp/marsh).

${ }^{226}$ See La. Admin Code titl. 43, pt. XIX, §313.

${ }^{227}$ Id. $\$ 313(\mathrm{D})$. 
Table 29. Green Completion Requirements

\begin{tabular}{|c|c|c|c|}
\hline Play/Basin/Jurisdiction & Requirement & Flaring/Venting Allowed & Local \\
\hline Federal $^{228}$ & $\begin{array}{l}\text { Hydraulically } \\
\text { fractured gas } \\
\text { production wells } \\
\text { must capture and } \\
\text { route all saleable } \\
\text { gas to a sales line } \\
\text { during flowback } \\
\text { starting in } 2015 . \\
\text { Exception for low- } \\
\text { pressure wells. } \\
\text { Does not apply to } \\
\text { exploratory or } \\
\text { delineation wells. }\end{array}$ & $\begin{array}{l}\text { Pit flaring allowed until } 2015 \text { and } \\
\text { thereafter allowed for non- } \\
\text { recoverable gas. } \\
\text { Venting allowed where flaring } \\
\text { presents safety hazard or if flowback } \\
\text { is noncombustible. }\end{array}$ & N/A \\
\hline $\begin{array}{l}\text { North San Juan } \\
\text { (Colorado) }^{229}\end{array}$ & $\begin{array}{l}\text { Must use green } \\
\text { completion practices } \\
\text { to route saleable } \\
\text { gas to sales line as } \\
\text { soon as practicable. } \\
\text { Does not apply to } \\
\text { low-pressure or } \\
\text { wells with less than } \\
500 \text { MCFD of } \\
\text { naturally flowing } \\
\text { gas. } \\
\text { Exception for } \\
\text { exploratory wells } \\
\text { and wells not } \\
\text { sufficiently } \\
\text { proximate to sales } \\
\text { lines. }\end{array}$ & $\begin{array}{l}\text { Gaseous phase of non-flammable } \\
\text { effluent may be flared or vented until } \\
\text { flammable gas is encountered for } \\
\text { safety reasons. } \\
\text { During upset conditions. } \\
\text { If variance granted. }\end{array}$ & $\begin{array}{l}\text { Cannot vent or flare well } \\
\text { directly to atmosphere } \\
\text { without first going to } \\
\text { separation equipment or } \\
\text { portable tank. }\end{array}$ \\
\hline $\begin{array}{l}\text { Upper Green River } \\
\text { (Wyoming) }^{231}\end{array}$ & $\begin{array}{l}\text { Must eliminate } \\
\text { VOCs and } \\
\text { hazardous air } \\
\text { pollutants to the } \\
\text { extent practicable } \\
\text { by routing liquids to } \\
\text { tanks and gas to } \\
\text { sales line or } \\
\text { collection system. } \\
\text { Does not apply to } \\
\text { exploratory wells. }\end{array}$ & $\begin{array}{l}\text { Permitted when required by specific } \\
\text { operational events or circumstances. }\end{array}$ & None \\
\hline
\end{tabular}

${ }^{228}$ U.S. EPA, Final Rule, Oil and Natural Gas Sector: "New Source Performance Standards and National Emission Standards for Hazardous Air Pollutants Reviews," (2012).

${ }^{229}$ COGCC R. 805(b)(3).

${ }^{230}$ Archuleta County Land Use Code Sec. 9.2.6.3: Archuleta County's Oil and Gas Development Permit Provisions (Amended Dec. 2010) http://www.archuletacounty.org/DocumentView.aspx?DID=295.

${ }^{231}$ Wyoming Oil and Gas Production Facilities, ch. 6, § 2 Permitting Guidance (March 2010), http://deq.state.wy.us/aqd/Oil\%20and\%20Gas/March\%202010\%20FINAL\%20O\&G\%20GUIDANCE.pdf. 


\begin{tabular}{llcl}
\hline Play/Basin/Jurisdiction & Requirement & Flaring/Venting Allowed & \multicolumn{1}{c}{ Local } \\
\hline $\begin{array}{l}\text { Barnett } \\
\text { (Texas) }\end{array}$ & None & N/A & $\begin{array}{l}\text { All wells that have a sales } \\
\text { line must use techniques or } \\
\text { methods that minimize the } \\
\text { release of natural gas and } \\
\end{array}$ \\
& & & $\begin{array}{l}\text { vapors to the environment } \\
\text { during flowback except } \\
\text { wells permitted prior to July } \\
1,2009, \text { or the first well on }\end{array}$ \\
& & & a pad site. ${ }^{232}$ \\
\hline Marcellus & & & None identified \\
(New York) & REC whenever & Yes, if no sales line available. \\
- Proposed & sales line & & \\
\hline
\end{tabular}

${ }^{232}$ Fort Worth, Tex., Ordinance No. 18449-02-2009, § 15-42(A)(28).

${ }^{233}$ Proposed mitigation requirement via permit condition. New York Department of Environmental Compliance, Revised Draft SGEIS, §7.6.8. 
Table 30. Setback Requirements

\begin{tabular}{|c|c|c|c|c|c|}
\hline Play/Basin & $\begin{array}{l}\text { State-Distance } \\
\text { from home }\end{array}$ & $\begin{array}{l}\text { State-Distance } \\
\text { from Private } \\
\text { Water Well }\end{array}$ & $\begin{array}{l}\text { State-Distance } \\
\text { from source of } \\
\text { drinking water }\end{array}$ & Local & Vertical fragmentation? \\
\hline $\begin{array}{l}\text { Barnett } \\
\text { (Texas) }\end{array}$ & 200 feet $^{234}$ & None & None & $\begin{array}{l}600 \text { feet from } \\
\text { home, } \\
200 \text { feet to } \\
\text { fresh water } \\
\text { well }^{235}\end{array}$ & Yes \\
\hline $\begin{array}{l}\text { Eagle Ford } \\
\text { (Texas) }\end{array}$ & 200 feet & None & None & $\begin{array}{l}500 \text { feet from } \\
\text { home, } 236 \\
200 \text { feet from } \\
\text { home }^{237}\end{array}$ & Yes \\
\hline $\begin{array}{l}\text { Haynesville } \\
\text { (Louisiana) }\end{array}$ & 500 feet $^{238}$ & None & None & None & No \\
\hline $\begin{array}{l}\text { Marcellus } \\
\text { (Pennsylvania) }\end{array}$ & 500 feet $^{239}$ & 500 feet $^{240}$ & 1,000 feet $^{241}$ & $\begin{array}{l}200 \text { feet from } \\
\text { home or water } \\
\text { well }^{242}\end{array}$ & Yes, under current law ${ }^{243}$ \\
\hline $\begin{array}{l}\text { Marcellus } \\
\text { (New York) }\end{array}$ & None & 500 feet $^{244}$ & 500 feet $^{245}$ & $\mathrm{~N} / \mathrm{A}^{246}$ & $\begin{array}{l}\text { Yes, in that localities } \\
\text { have banned } \\
\text { development altogether, } \\
\text { and if the state } \\
\text { moratorium is lifted, it } \\
\text { seems likely localities } \\
\text { will attempt to regulate } \\
\text { this area }\end{array}$ \\
\hline
\end{tabular}

${ }^{234}$ Tex. Local Gov't Code 253.005(c).

${ }^{235}$ Fort Worth, Tex.; Ordinance No. 18449-02-2009.

${ }^{236}$ City of Burleson, Tex., Ordinance B-790-09.

${ }^{237}$ Fayette County, Tex., Ordinance. Local zoning ordinance provides for the same 200-foot setback limit from residential homes but ordinance notes "Zoning Hearing Board may attach additional conditions to protect the public's health, safety, and welfare, including increased setbacks."

${ }^{238}$ State of La. Office of Conservation, Order No. U-HS (Aug. 1, 2009),http://dnr.louisiana.gov/assets/docs/news/2009/U-HS.pdf. See also Louisiana Hydraulic Fracturing State Review, (Mar. 2011), 5.

239 Act 13, § 3215(a) (Unconventional wells cannot be drilled within $500 \mathrm{ft}$. of building or water well, without the consent of the owner of the building or well).

${ }^{240} I d$. DEP shall grant a variance from specified setback requirements if the restriction deprives the owner of the oil and gas rights of the right to produce or share in the oil or gas underlying the surface tract. Note, the statute also provides for a 300-foot setback from streams, springs, other bodies of water identified on a U.S. Geological Survey map, or wetlands, although these "shall" also be waived upon submission of a plan containing additional measures to protect waters. $I d$. $\S 3215(\mathrm{~b})$.

${ }^{241} I d$.

${ }^{242}$ South Franklin Township, Pa.; Ordinance No. 4-2008 (Wells may not be drilled within 200 feet from an existing habitable structure or existing water well without express written consent of the owner).

${ }^{243}$ Act 13 supersedes all local ordinances purporting to regulate oil and gas operations, other than those adopted pursuant to Pennsylvania municipalities and planning code and Flood Plain Management Act. However, implementation of this provision of the law has been enjoined pending resolution of a legal challenge brought by a number of local governments.

${ }^{244}$ Proposed 6 N.Y. Comp. Codes R. \& Regs. 560.4(a)(1) (Well pad must be at least 500 ft. from a private water well unless waived by water well owner).

${ }^{245}$ Id. at 560.4(a)(2) (Well pads may not be located within 500 feet of the boundary of a primary aquifer). In addition, NY prohibits well pads within a primary aquifer, 100-year floodplain, and within 2,000 ft. of any public 


\begin{tabular}{|c|c|c|c|c|c|}
\hline Play/Basin & $\begin{array}{l}\text { State-Distance } \\
\text { from home }\end{array}$ & $\begin{array}{l}\text { State-Distance } \\
\text { from Private } \\
\text { Water Well }\end{array}$ & $\begin{array}{l}\text { State-Distance } \\
\text { from source of } \\
\text { drinking water }\end{array}$ & Local & Vertical fragmentation? \\
\hline $\begin{array}{l}\text { North San Juan } \\
\text { (Colorado) }\end{array}$ & 150 feet $^{24 l}$ & None & $\begin{array}{l}\text { Buffer Zones to } \\
\text { protect surface } \\
\text { water intended } \\
\text { for drinking } \\
\text { water }\end{array}$ & $\begin{array}{l}450 \text { from home } \\
\text { without } \\
\text { consent }^{248}\end{array}$ & Yes \\
\hline $\begin{array}{l}\text { Upper Green River } \\
\text { (Wyoming) }\end{array}$ & 350 feet $^{249}$ & None & None & None & No \\
\hline
\end{tabular}

water supply well, reservoir, natural lake or man-made impoundment except those constructed for fresh water storage associated with hydraulic fracturing, and river or stream intakes. Id. at 560.4(a)(2)-(4).

${ }^{246}$ Our research did not identify any local laws directly regulating unconventional gas development in NY.

${ }^{247}$ COGCC R. 603(a). In high-density areas, wellheads must be at least $350 \mathrm{ft}$. from buildings. Id. at 603.e(2).

${ }^{248}$ Chapter 90 - La Plata County's Oil and Gas regulations, § 90-122:

http://co.laplata.co.us/sites/default/files/departments/planning/chapter_90_adopted_12_7_2010.pdf; Archuleta

County Land Use Code Section 9.2.6.2: Archuleta County's Oil and Gas Development Permit Provisions (Amended Dec. 2010) http://www.archuletacounty.org/DocumentCenter/Home/View/295.

${ }^{249}$ Pits, wellheads, pumping units, tanks and treaters shall be located no closer than $350 \mathrm{ft}$. from designated public places. Supervisor may extend setbacks or grant exceptions for good cause. WY ADC Oil Gen. ch. 3, § 22(b). 


\section{Appendix D: Risk Factor Data}

This appendix provides more detailed information on the six selected shale plays considered in this study. For each play, where data are available, we provide 1) an overview of the shale play geology and resource potential, 2) trend data on the number of wells being drilled, 3) information about water usage per well, 4) information on produced water volumes and wastewater management practices, 5) issues associated with freshwater acquisition, and 6) reported data on violations. In addition, this appendix provides more information about the severity index used for water violations (D.7).

\section{Marcellus Shale Play, Pennsylvania}

\section{Overview}

The Marcellus Shale formation extends across 600 miles within four states, covering an area of about 54,000 square miles. The thickness of the formation varies, but is typically thicker in the east (up to 250 feet) and thins toward the west (Sumi 2008). The Marcellus Shale is the middle Devonian layer between the upper Middle Devonian Mahantango and underlying Middle Devonian Onodaga Limestone formation (USGS 2011). Estimates of the total economically recoverable natural gas in the basin have changed significantly over the years - from an initial estimate of 1.9 trillion cubic feet (Tcf) in 2002 to 168-516 Tcf in 2008 (UM 2010). The U.S. Geological Survey recently estimated mean undiscovered resources for natural gas liquids of 3,379 million barrels and for natural gas of 84,198 billion cubic feet (USGS 2011).

Figure 63 shows the extent and approximate depth of the Macellus formation, which underlies New York, Pennsylvania, Maryland, West Virginia, and Ohio.

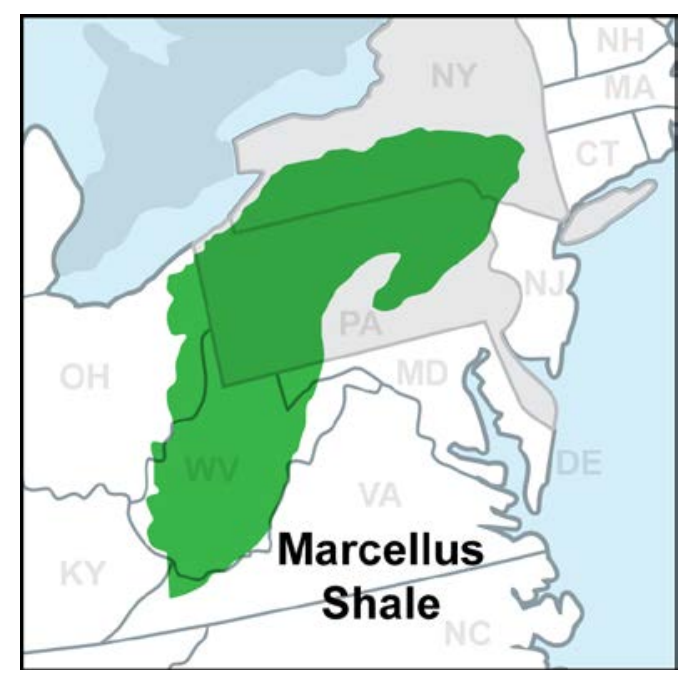

Figure 63. Extent of Marcellus Shale

\section{Number of Wells}

As of December 15, 2011, the Marcellus Shale Basin had 88 active operators. More than 9,600 permits have been submitted, with 9,328 issued. Only 36 permits have been denied since 2005 (PA DEP 2011a).The operators with the most permits in the Marcellus Shale include Chesapeake 
Appalachia LLC with 1,614 drilling permits, Range Resources Appalachia LLC with 917 permits, and Talisman Energy USA Inc., with 896 permits (PA DEP 2012e).

However, the number of permits does not necessarily reflect the number of wells drilled. Only $44 \%$ of the permits resulted in a drilled well (PA DEP 2011b). Figure 64 shows the total number of permits vs. wells drilled in 2010. Figure 65 shows the total number of wells drilled in 2011.

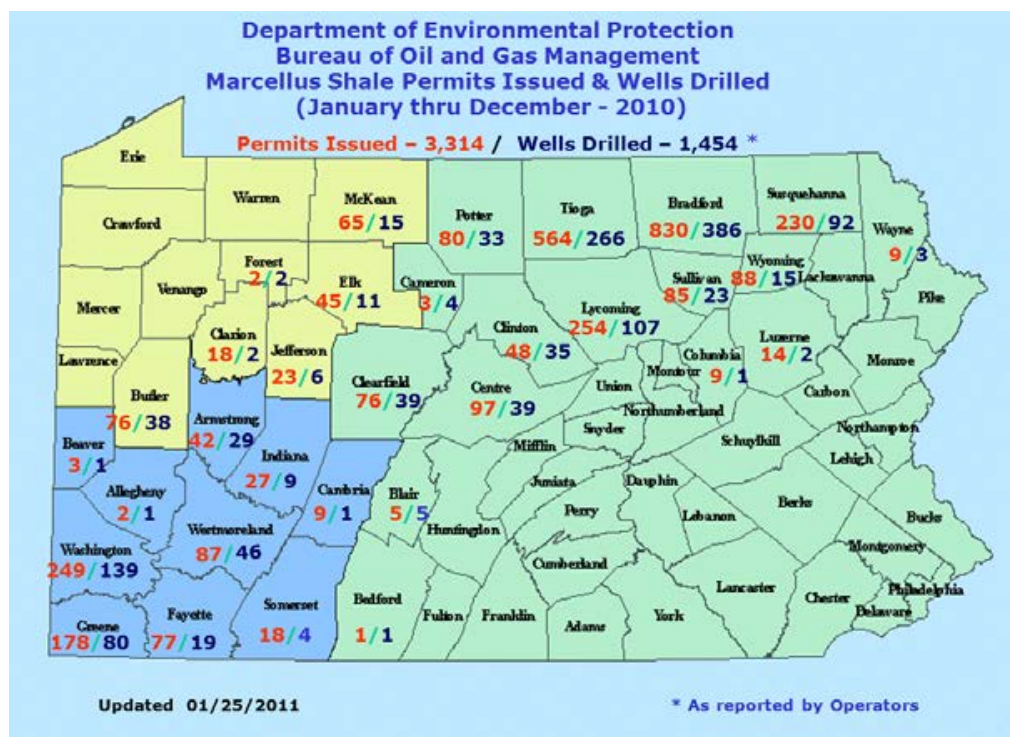

Figure 64. Marcellus Shale permits issued vs. number of wells drilled (PA DEP 2011b)

\section{Water Usage per Well}

Some 102 wells in the Marcellus Shale of Pennsylvania were randomly selected for an analysis of water usage per well. The total volume of water per well was acquired through fracfocus.org, and all other information (e.g., latitude, longitude, spud date) was gathered from the fractracker.com data set, "All Wells Marcellus," a compilation of data from the Pennsylvania Department of Environmental Protection (DEP). API numbers and well location files were cross checked between the fractracker and fracfocus data sets. Reporting to fracfocus is voluntary, causing some data to not match official API numbers and latitude/longitude found in regulated DEP data. If discrepancies occurred, then fracfocus data were discarded and a new well was chosen. Table 31 shows results for the 102 wells in Pennsylvania.

Table 31. Analysis of Water Usage per Well (gallons) for 102 Marcellus Wells (fracfocus.org)

\begin{tabular}{|c|c|c|c|c|}
\hline Mean & Max & Min & Range & Standard Deviation \\
\hline $4,842,070$ & $9,548,784$ & 430,584 & $9,118,200$ & $1,690,457$ \\
\hline Median & Upper Quartile & $\begin{array}{c}\text { Lower } \\
\text { Quartile }\end{array}$ & $\begin{array}{c}\text { Interquartile } \\
\text { Range }\end{array}$ & Skewness \\
\hline $4,567,320$ & $5,802,941$ & $3,912,996$ & $1,889,945$ & 0.4422 \\
\hline
\end{tabular}


As seen in Table 31, the average volume per well was about 4,842,000 gallons. It is important to note the large range of values - with a minimum of 430,584 gallons and a maximum of 9,548,784 gallons. A histogram (Figure 66) displaying the total volume of water was created by evenly distributing the range of values into twenty bins and then counting the total number of wells for each bin.

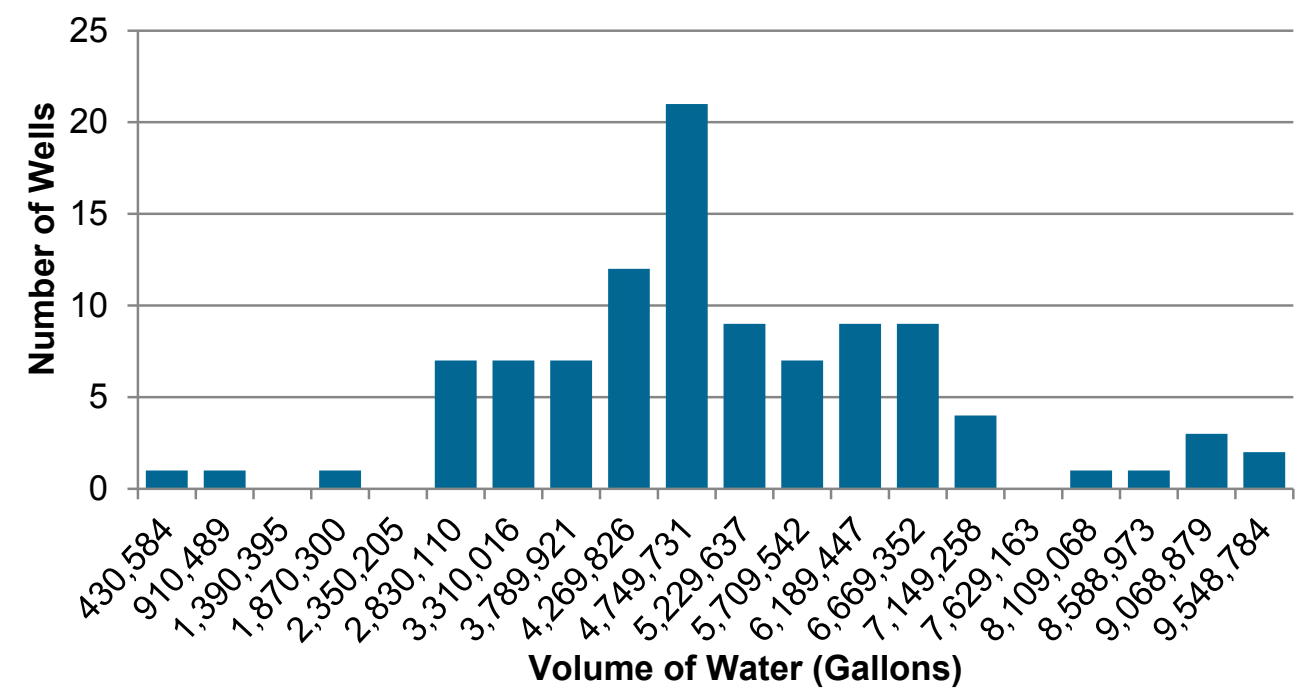

Figure 66. Histogram for 100 wells of total volumes (gallons) (fracfocus.org)

Table 32. Average Water Volume per Well by Well Type (gallons) (fracfocus.org)

\begin{tabular}{|c|c|c|}
\hline Well Type & Vertical & Horizontal \\
\hline Average & $5,431,035$ & $4,756,042$ \\
\hline Sample Size & 13 & 89 \\
\hline
\end{tabular}

The effect of a small sample size can be seen in the comparison of average water used by type in vertical and horizontal wells in Table 32. In general, horizontal wells use much more water than vertical wells - a vertical well typically uses 0.5 to 1 million gallons of water, whereas a horizontal well uses between 4 to 8 million gallons of water (Natural Gas 2010). Further data collection is needed to provide a better comparison of vertical and horizontal wells.

\section{Produced Water}

The DEP has official production and waste reporting data on its Oil and Gas Reporting website (PA DEP 2012b). The website contains statewide data that can be downloaded on production and waste on a yearly basis. Each waste data set contains the total waste for each well per year, with the waste described by quantity, waste type, and disposal method. Before 2010, waste reports were not well organized, and an online reporting system had not yet been created, causing many wells to be excluded from the data sets. Furthermore, a server malfunction caused the loss of any relevant 2007 data. Since 2010, all waste produced by all wells in Pennsylvania have been 
accurately reported. However, reporting period dates have changed to biannual, rather than annual.

Brine production and fracking fluid flowback were analyzed. Although the DEP does not have an official definition of flowback and brine, flowback can be considered the water produced before the well is put into production on a gas line.

For our analysis, natural gas wells in the Marcellus Basin were filtered out from DEP data. We observed that portions of a well's waste were reported multiple times if the waste was taken to more than one treatment facility. The duplicate data were removed from the analysis.

Brine and fracking fluid wastes were divided and analyzed separately. The results can be seen in Tables 33 and 34, along with Figures 67 and 68, with all units in gallons.

Table 33. Summary of Brine Produced (thousands of gallons) (PA DEP 2012b)

\begin{tabular}{|c|c|c|c|c|c|c|c|c|c|c|}
\hline & & & & & & Dispo & I Method & & & \\
\hline Year & $\begin{array}{l}\frac{00}{00} \\
\frac{10}{3} \\
\frac{\pi}{0}\end{array}$ & 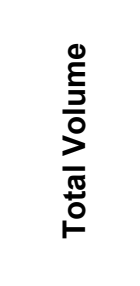 & 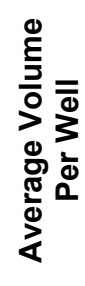 & 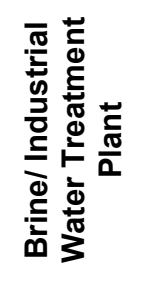 & 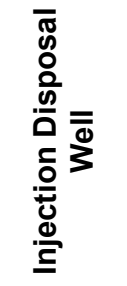 & 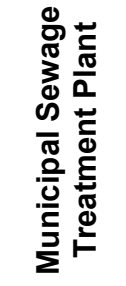 & ఫे & 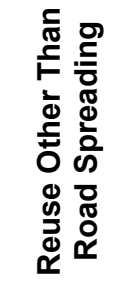 & 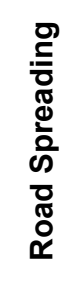 & 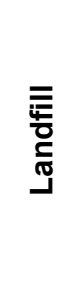 \\
\hline 2006 & 14 & 160.4 & 14.2 & 124.9 & 0 & 30.6 & 0 & 0 & 4.8 & 0 \\
\hline 2008 & 204 & $50,211.0$ & 246.1 & $1,345.1$ & 775.9 & $40,067.1$ & $3,457.8$ & $4,501.9$ & 63.0 & 0 \\
\hline 2009 & 445 & $231,316.3$ & 519.7 & $169,860.5$ & $4,707.5$ & $36,402.4$ & $16,466.8$ & $3,875.8$ & 3.1 & 0 \\
\hline $\begin{array}{l}\text { July 2010- } \\
\text { June } 2011\end{array}$ & 1,614 & $287,088.1$ & 177.8 & $123,623.9$ & $35,541.3$ & $2,711.6$ & $19,931.4$ & $105,248.4$ & 7.8 & 23.3 \\
\hline
\end{tabular}

Table 34. Summary of Fracking Fluid Produced (thousands of gallons) (PA DEP 2012b)

\begin{tabular}{|c|c|c|c|c|c|c|c|c|c|c|}
\hline \multirow[b]{2}{*}{$\begin{array}{l}\stackrel{\bar{J}}{ঠ} \\
\stackrel{2}{2}\end{array}$} & \multirow[b]{2}{*}{$\begin{array}{l}\frac{\infty}{0} \\
\frac{0}{0} \\
\frac{\pi}{0} \\
1\end{array}$} & \multirow[b]{2}{*}{$\begin{array}{l}\stackrel{0}{E} \\
\frac{0}{0} \\
\frac{0}{\pi} \\
\stackrel{\pi}{0}\end{array}$} & \multirow[b]{2}{*}{ 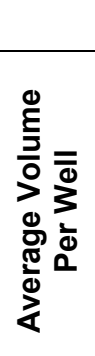 } & \multicolumn{7}{|c|}{ Disposal Method } \\
\hline & & & & 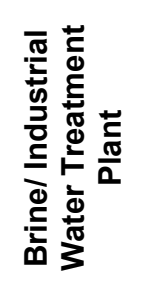 & 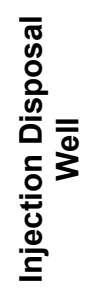 & 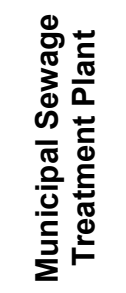 & 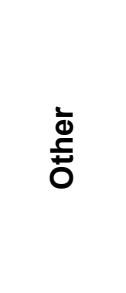 & 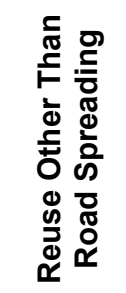 & 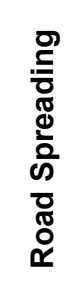 & 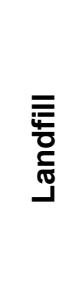 \\
\hline 2006 & 2 & 255.4 & 127.7 & 255.4 & 0 & 0 & 0 & 0 & 0 & 0 \\
\hline 2008 & 106 & $46,881.9$ & 442.3 & $8,792.4$ & 0 & $25,238.7$ & $11,717.3$ & $1,133.3$ & 0 & 0 \\
\hline 2009 & 225 & $105,869.6$ & 470.5 & $24,505.2$ & 610.2 & $46,570.4$ & $26,371.2$ & $7,812.4$ & 0 & 0 \\
\hline $\begin{array}{l}\text { July 2010- } \\
\text { June2011 }\end{array}$ & 1,128 & $249,336.3$ & 221.0 & $110,377.0$ & 945.1 & 284.9 & 646.1 & $137,009.5$ & 138.1 & 73.4 \\
\hline
\end{tabular}




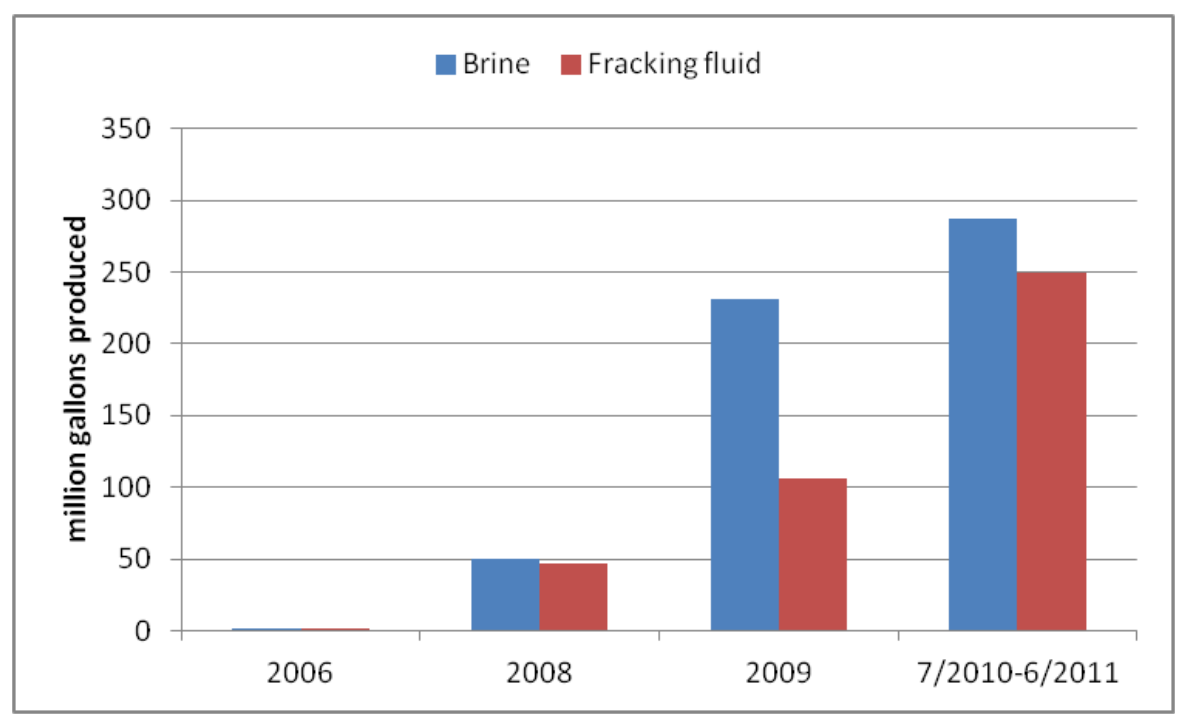

Figure 67. Total volume of produced water, 2006-2011 (PA DEP 2012b)

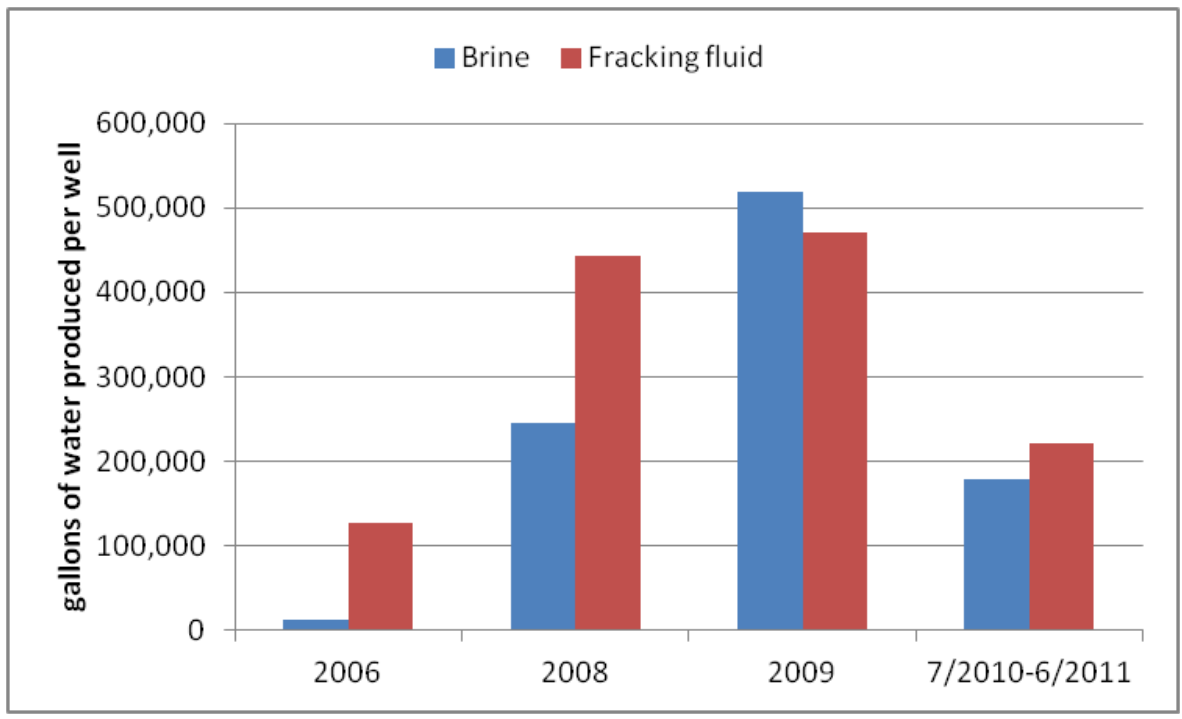

Figure 68. Average volume of produced water per well, 2006-2011 (PA DEP 2012b)

Based on Figure 67, the quantity of both produced brine and fracking fluid are clearly increasing each year-due to the increasing number of wells drilled each year. The final reporting period (July 2010-June 2011) had 1,614 wells producing brine, which is 1,169 more wells than the 2009 period (PA DEP 2012b). As seen in Figure 68, the increase in total brine and fracking fluid does not correlate with average produced brine and fracking fluid per well. There is no recognizable trend in produced water per well, as 2009 had a higher average than any other year.

\section{Water Acquisition}

Water withdrawal permit information for the Marcellus in this study focused on the Susquehanna River Basin (SRB). The Marcellus formation underlies $72 \%$ of the SRB, covering most of Pennsylvania and part of New York (Arthur 2010). The Susquehanna River Basin Commission 
(SRBC) has been the forerunner in determining water usage regulations, monitoring, and permits. The SRBC actively regulates water withdrawal by oil and gas operators; all water withdrawal outside of the SRB is regulated by the DEP.

SRBC issues a report on all approved water sources for natural gas development in the SRB (SRBC 2012a). These permits include the fresh-water source, as well as the maximum allowed uptake per day. These uptakes are rarely at capacity and, according to the SRBC, many sources are used for redundancy due to passby flow conditions when water levels are low (SRBC, 2012a). It is possible to source where operators obtain their water. For example, SWEPI, LP has three different public water suppliers in three different counties. Public water supply does not have a maximum allowed daily uptake, whereas all other supplies do. SWEPI only has one docket approval for a fresh-water source - the Allegheny River in Warren County. This permit allows up to 3 million gallons per day (mgd) of water to be used. SWEPI sources the rest of its water from other drilling companies who share their water permits. Overall, SWEPI has eight different water sources, ranging from 0.217 to $3 \mathrm{mgd}$. Additional information is available regarding percentage of ground-water to surface-water permits and amounts of water used (SRBC 2011a).

\section{Cost of Acquisition}

Fees are associated with fresh-water withdrawal permits. The schedule includes a breakdown of a tiered fee system based on withdrawal amount, as well as consumptive vs. non-consumptive use (SRBC 2011a). Consumptive use is defined in 18 CFR $\S 806.3$ as, "The loss of water transferred through a manmade conveyance system or any integral part thereof... injection of water or wastewater into a subsurface formation from which it would not reasonably be available for future use in the basin, diversion from the basin, or any other process by which the water is not returned to the waters of the basin undiminished in quantity (e-CFR 2012)."

On a per gallon basis, the SRBC fees range from $\$ 0.00685-0.1425 /$ gallon for consumptive use, and \$0.0030-0.07475/gallon for non-consumptive withdrawals (SRBC 2011a).

Considering SWEPI, LP, it can be seen that a typical docket of $0.250 \mathrm{mgd}$ of surface water would cost $\$ 9,975$ if the water was not used consumptively. If the use is consumptive, then $\$ 1,000$ is added as an annual compliance and monitoring fee. There will also be a consumptiveuse mitigation fee if the company wishes to use the fee as a method of compliance with 18 CFR $\S 806.22$ (b). This section states that during low flow periods, several steps may be taken to mitigate consumptive use. One option is to reduce water withdrawal from a source equal to the consumptive use of the operator. Another option is to take water from another approved source. If these or the other provided options are not chosen, the company may choose to pay a fee of $\$ 0.29$ per 1,000 gallons of water consumed. In the case of SWEPI, this may be an additional cost of $\$ 72.50$. Companies pay for metering systems and report to the SRBC on a daily basis for each well on its water use.

Another source of fresh water is public supply. The cost of this source varies from utility to utility, but most rates can be found on utility websites. Rates vary significantly from supplier to supplier, and oftentimes unique deals are made between supplier and operator. The deal between East Resources Management, LLC and Morningside Heights Water District approves up to 400,000 gallons per day at a rate of $\$ 0.0145$ per gallon (Pressconnects 2010 ). This is $60 \%$ greater 
than water supplier P.A. American Water, which charges $\$ 0.008979$ per gallon (American Water 2012).

The above costs refer to obtaining water and do not cover the price of transporting the water. Most water is transported by either pumping or trucking. PSU estimates average trucking costs of $\$ 0.2$ per gallon (Pressconnects 2010). Further analysis of water-supply distances to wells would need to be studied using GIS to assess the actual cost of water transportation.

\section{Violations}

The majority of the violations reported from 2009-2011 fall under the category of "minor - no effect" (Figure 69 and Table 35) (NEPA 2012). "Procedural" violations account for about 20\%, and "minor effect" and "substantial" account for about 10\%. Also, it should be noted that there are no "major" violations. This data set includes all of the violations from 2009-2011 (NEPA 2012). Further information on violations can be found in D.7 of this appendix.

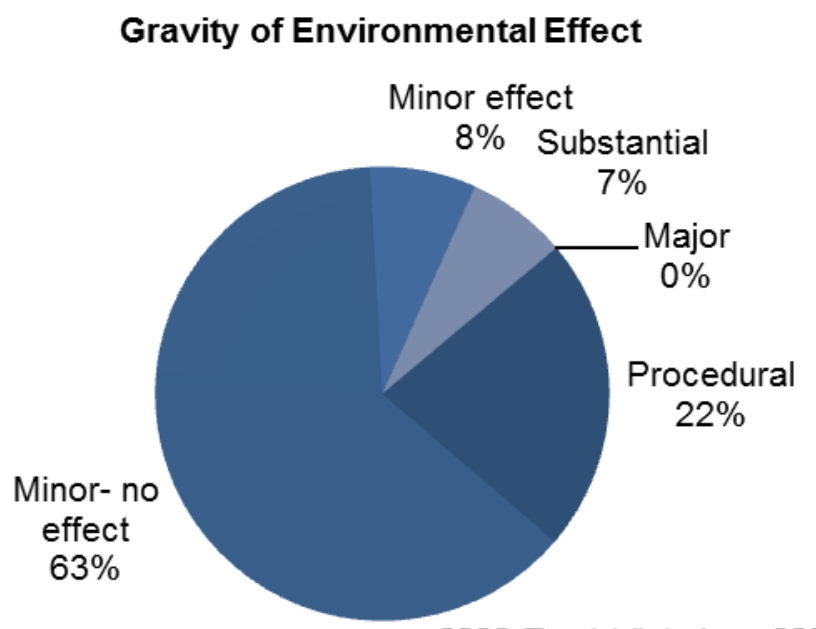

2280 Total Violations 2009-2011

Figure 69. Pennsylvania violations (NEPA 2012)

Table 35. Pennsylvania Violations (NEPA 2012)

\begin{tabular}{|l|r|r|}
\hline Procedural & 510 & $22.4 \%$ \\
\hline Minor - no effect & 1433 & $62.9 \%$ \\
\hline Minor effect & 173 & $7.6 \%$ \\
\hline Substantial & 164 & $7.2 \%$ \\
\hline Major & 0 & $0.0 \%$ \\
\hline Total & \multicolumn{2}{|c|}{2280} \\
\hline
\end{tabular}




\section{Barnett Shale Play, Texas}

\section{Overview}

In the early 1900s, geological mapping noted a thick, black, organic-rich shale in an outcrop near the Barnett stream (TRRC 2012e). The Barnett Shale formation exists under extensive areas in Texas and crops out on the flanks of the Llano Uplift, 150 miles to the south of the core area (Figure 70). Current boundaries of the formation are due primarily to erosion (TDWB 2007). The Fort Worth Basin is bounded by tectonic features to the east—notably, the Ouachita Overthrust, an eroded, buried mountain range - and to the north by the uplifted Muenster and Red River Arches. The Barnett Shale dips gently toward the core area and the Muenster Arch from the south where it crops out and thins considerably to the west; its base reaches a maximum depth of $\sim 8,500 \mathrm{ft}$ (subsea) in the northeast. The depth to the top of the Barnett ranges from $\sim 4,500 \mathrm{ft}$ in northwestern Jack County, to $\sim 2,500 \mathrm{ft}$ in southwest Palo Pinto County, to $\sim 3,500 \mathrm{ft}$ in northern Hamilton County, to $\sim 6,000 \mathrm{ft}$ in western McLennan County, to $\sim 7,000$ to $8,000 \mathrm{ft}$ in the DallasFort Worth area. Further west in Throckmorton, Shackelford, and Callahan Counties, the depth to the Barnett ranges between $\sim 4,000$ and 2,000 $\mathrm{ft}$ (TDWB 2007).

The U.S. Geological Survey (USGS) estimated the mean gas resources at 26.7 Tcf (USGS 2004).

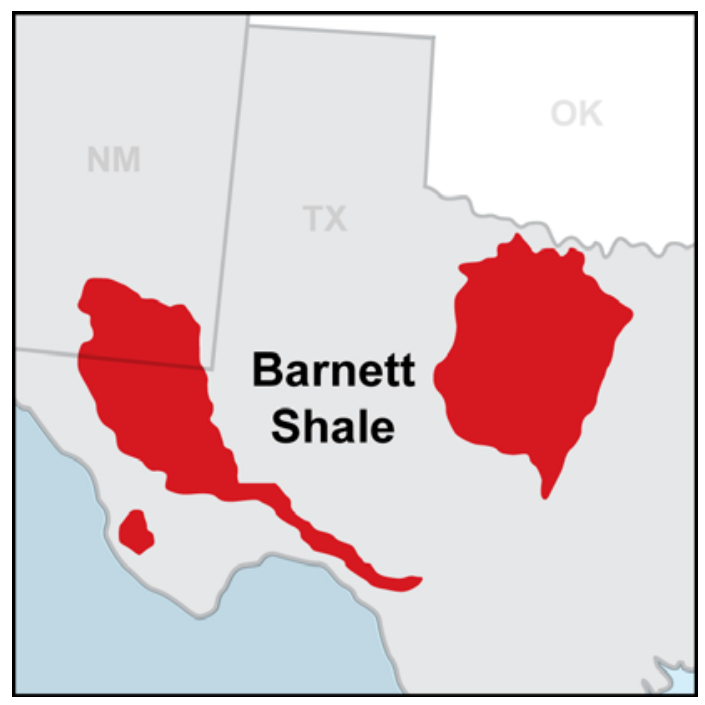

Figure 70. Extent of Barnett Shale

Figure 70 shows the extent of the Barnett Shale in Texas. The formation is actually considered to be a hydrocarbon source, reservoir, and trap, all at the same time. As a reservoir, it is known as a "tight" gas reservoir, indicating that the gas is not easily extracted. However, hydraulic fracturing technology has made it possible to extract the gas (TRRC, 2012d). For the Barnett Shale, permeability ranges from microdarcies to nanodarcies, porosity ranges from $0.5 \%$ to $6 \%$, and water saturation is below $50 \%$.

Future development will be hampered, in part, because major portions of the field are in urban areas, including the rapidly growing Dallas-Fort Worth Metroplex. Some local governments are researching means by which they can drill on existing public land (e.g., parks) without disrupting 
other activities so they may obtain royalties on any minerals found. Others are seeking compensation from drilling companies for roads damaged by overweight vehicles, because many of the roads are rural and not designed for use by heavy equipment. In addition, drilling and exploration have generated significant controversy (TRRC, 2012d).

\section{Number of Wells}

The Barnett Shale has experienced substantial development over the last decade, as evidenced by the number of wells (Figure 71) and estimates of total gas production (Figure 72).

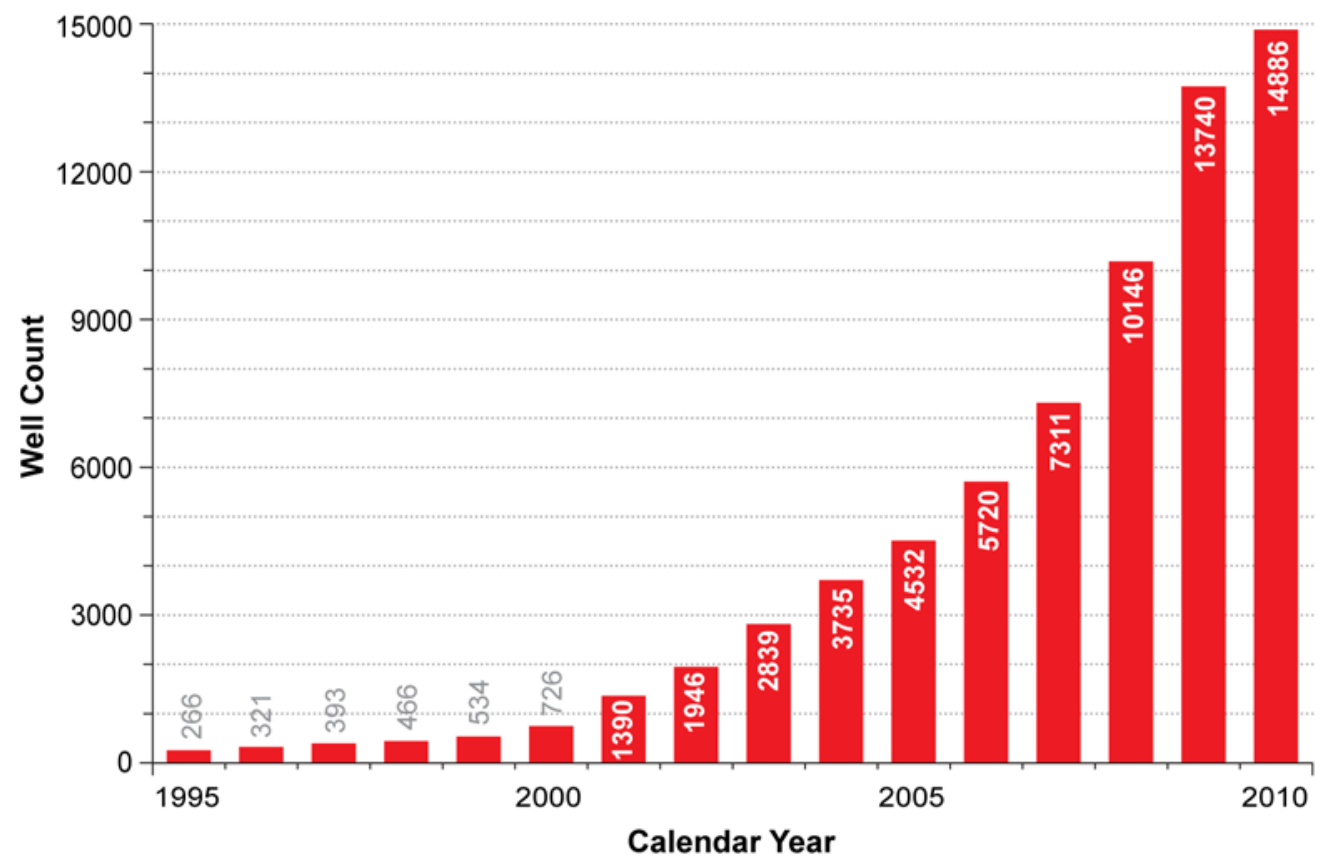

Figure 71. Wells in Barnett Shale, 1995-2010 (TRRC, 2012c) 


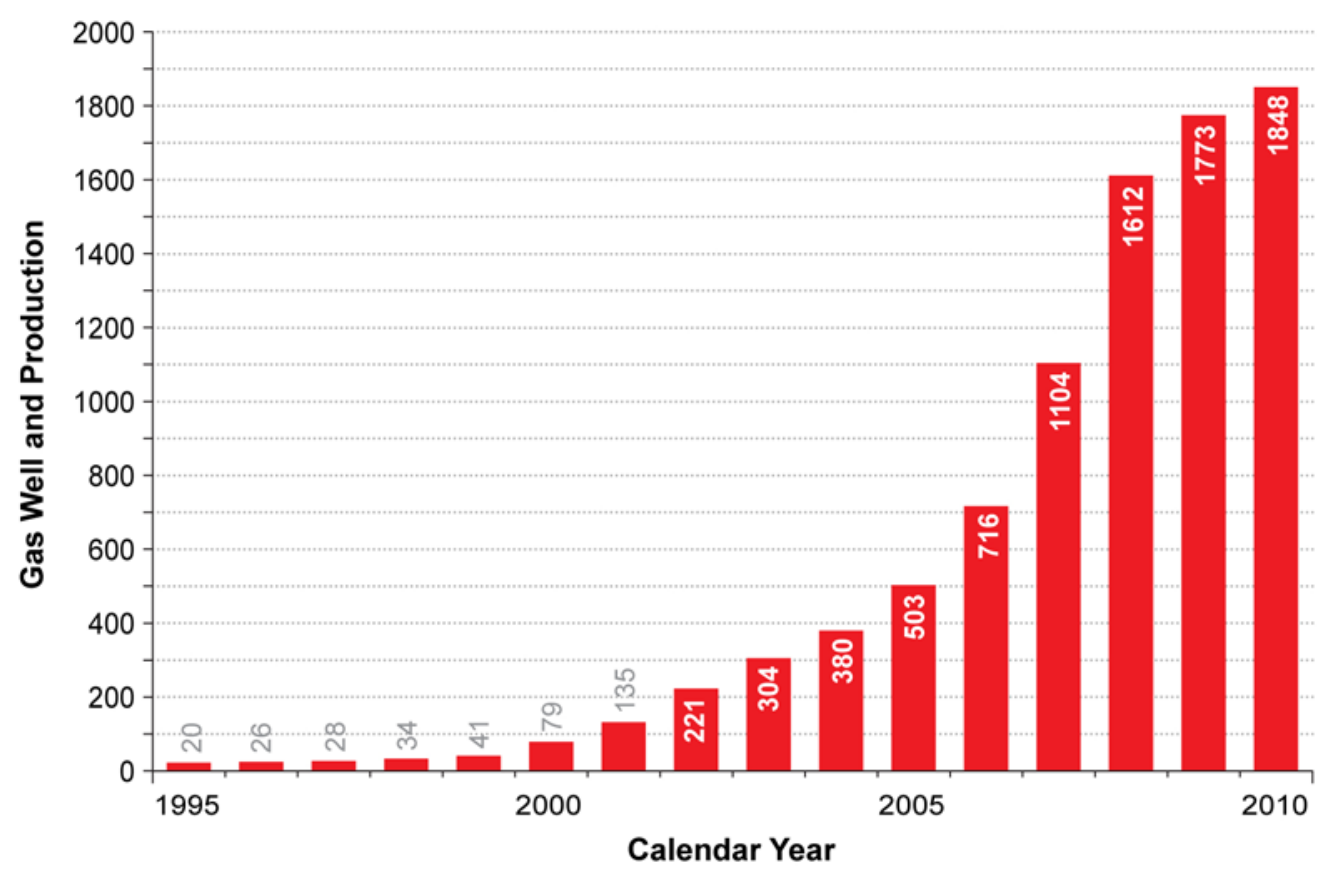

Figure 72. Gas production in the Barnett Shale (bcf), 1995-2010 (TRRC, 2012e)

\section{Water Usage per Well}

Table 36 shows the analysis results on 100 Barnett Shale wells selected randomly from fracfocus.org.

Table 36. Statistics of Water Use (Gallons) (fracfocus.org)

\begin{tabular}{|c|c|c|c|c|}
\hline Mean & Max & Min & Range & Standard Deviation \\
\hline $2,537,853.848$ & $26,315,125$ & 29,186 & $26,285,939$ & $3,512,472.559$ \\
\hline Median & Upper Quartile & $\begin{array}{c}\text { Lower } \\
\text { Quartile }\end{array}$ & $\begin{array}{c}\text { Interquartile } \\
\text { Range }\end{array}$ & Skewness \\
\hline $1,293,306$ & $4,298,286$ & 86,751 & $4,211,535$ & 3.500964058 \\
\hline
\end{tabular}




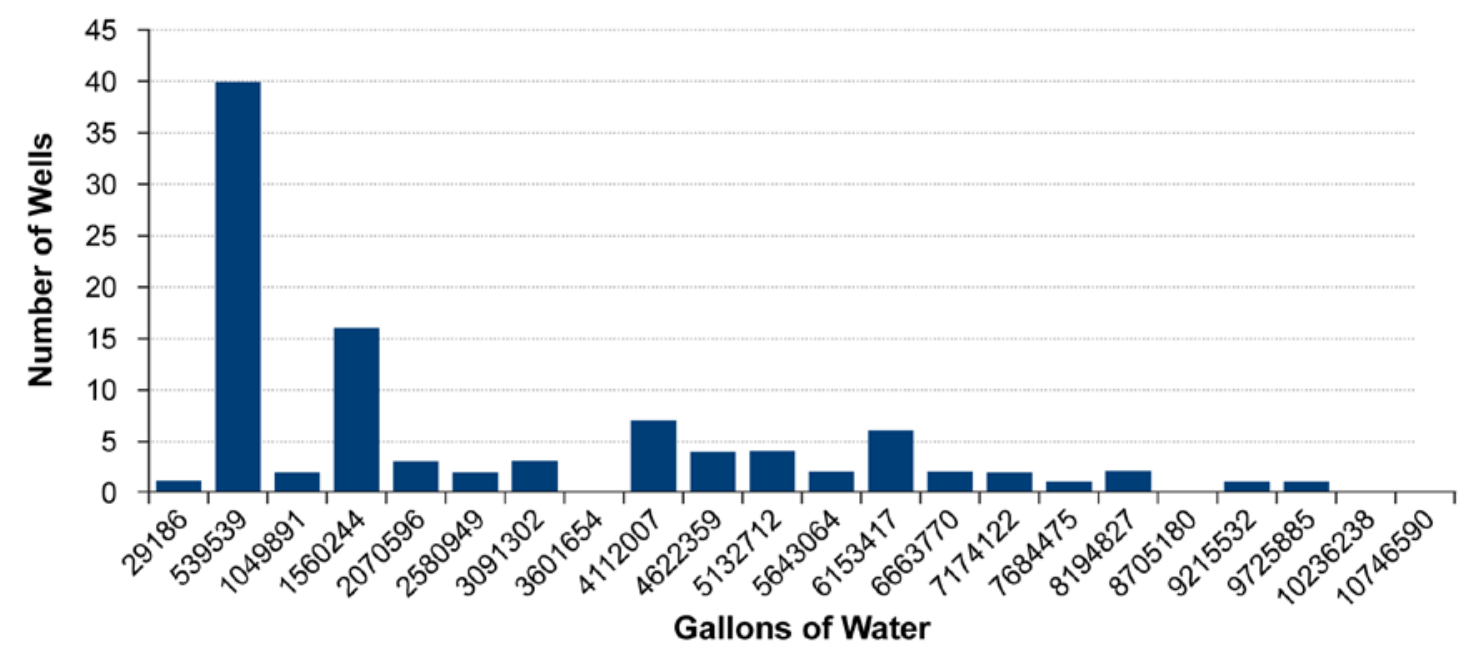

Figure 73. Histogram of $\mathbf{1 0 0}$ wells for total water volume (gallons) (fracfocus.org)

As seen in Table 36, the average volume per well was 2,537,853 gallons, with values ranging from 29,186 gallons to 26,315,125 gallons (fracfocus.org). Figure 73 is a histogram displaying the total volume of water, created by evenly distributing the range of values into twenty bins and then counting the total number of wells for each bin.

\section{Produced Water}

No produced water data are available for Barnett shale. However, the Railroad Commission (RRC) of Texas requires every operator to report - into a query system - how much water is disposed. The current method used for disposal in the Barnett Shale is deep-well injected. The Injection Volume Query from the RRC database was used and monthly county-wide or operatorwide injected volumes can be obtained (TRRC 2011).

\section{Violations}

Figure 74 expresses the violations from 2009-2011 in Texas according to the severity of environmental effect (Wiseman 2012). Of the 35 total violations (Table 37), 35\% of the violations are "minor - no effect" and "substantial." "Procedural" account for about $20 \%$, and "major" and "minor effect" account for $3 \%$. It should be noted that these violations only include wells for which formal compliance or administrative orders were issued. Therefore, these data are not comprehensive and do not represent the total number of violations. Further information on violations can be found in D.7 of this appendix. 


\section{Gravity of Environmental Effect}

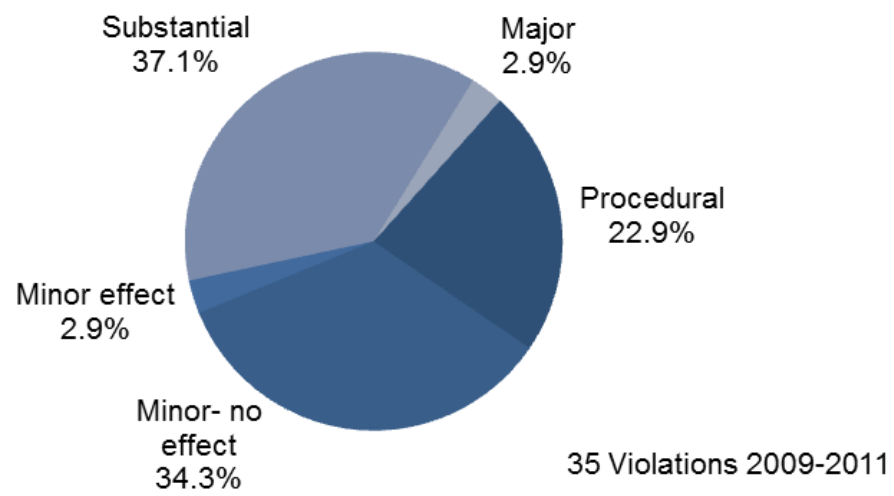

Figure 74. Texas violations (Wiseman 2012)

Table 37. Texas Violations (Wiseman 2012)

\begin{tabular}{|l|c|c|}
\hline \multicolumn{3}{|c|}{ Texas } \\
\hline Procedural & 8 & $22.9 \%$ \\
\hline Minor - no effect & 12 & $34.3 \%$ \\
\hline Minor effect & 1 & $2.9 \%$ \\
\hline Substantial & 13 & $37.1 \%$ \\
\hline Major & 1 & $2.9 \%$ \\
\hline Total & \multicolumn{3}{|c|}{35} \\
\hline
\end{tabular}

\section{Eagle Ford Shale Play, Texas}

\section{Overview}

The Eagle Ford Shale play extends across 23 counties, covering an area of 20,000 square miles (Figure 75). The Eagle Ford Shale has an average thickness of 250 feet and contains an estimated 21 Tcf of shale gas and 3 billion barrels of shale oil (EIA 2011). 


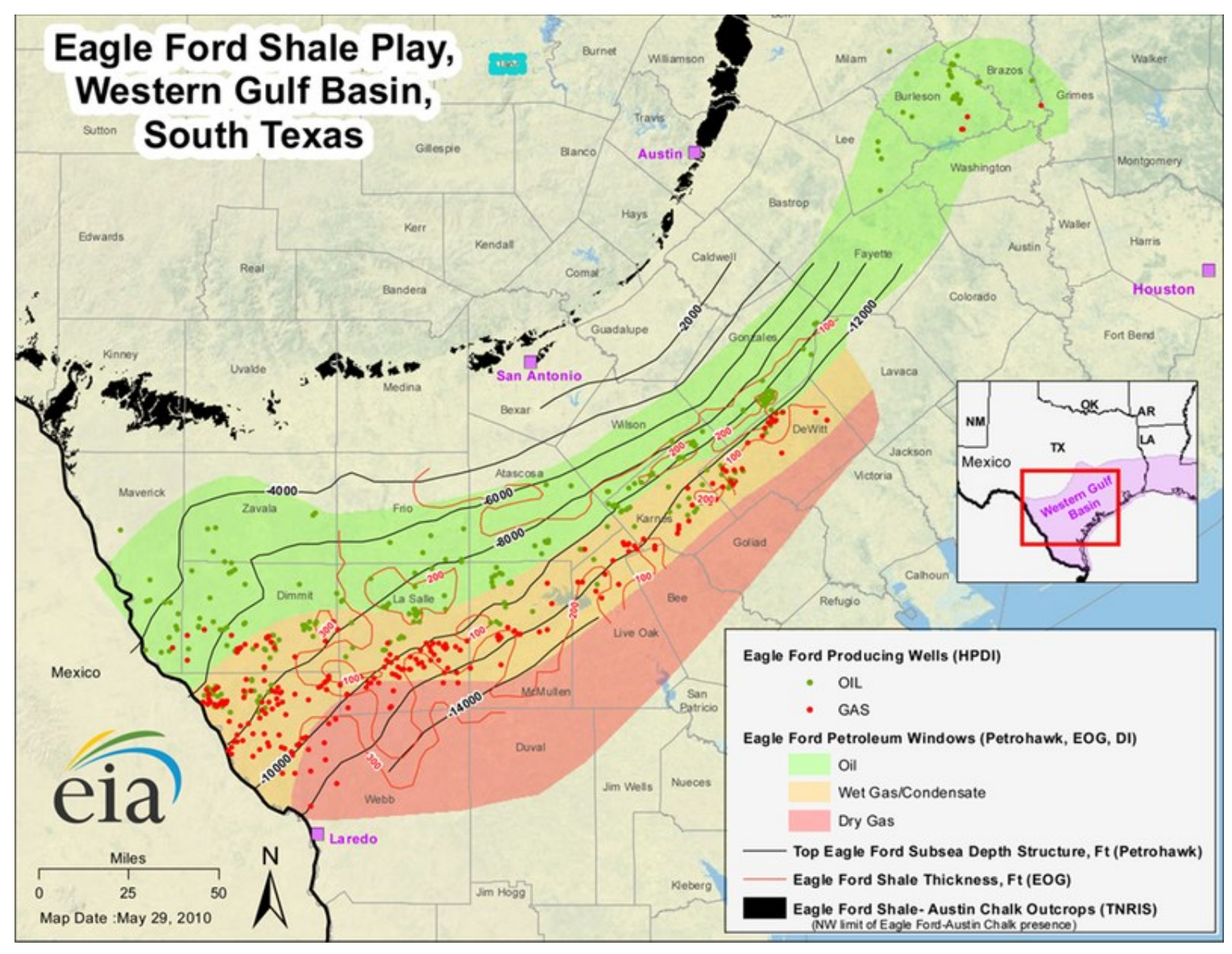

Figure 75. Extent of Eagle Ford Shale play (Eagle Ford Shale 2012)

\section{Number of Wells}

In 2008, Petrohawk drilled the first well in the Eagle Ford Shale, and since then, gas production has more than doubled - from $108 \mathrm{bcf}$ in 2010 to $287 \mathrm{bcf}$ in 2011. Oil production increased from more than 4 million barrels in 2010 to more than 36 million barrels in 2011 (TRRC 2012a). Increased production reflects the increases in drilling permits issued and in the number of oil and gas wells. Figure 76 shows the total number of producing oil and gas wells over the past three years. 


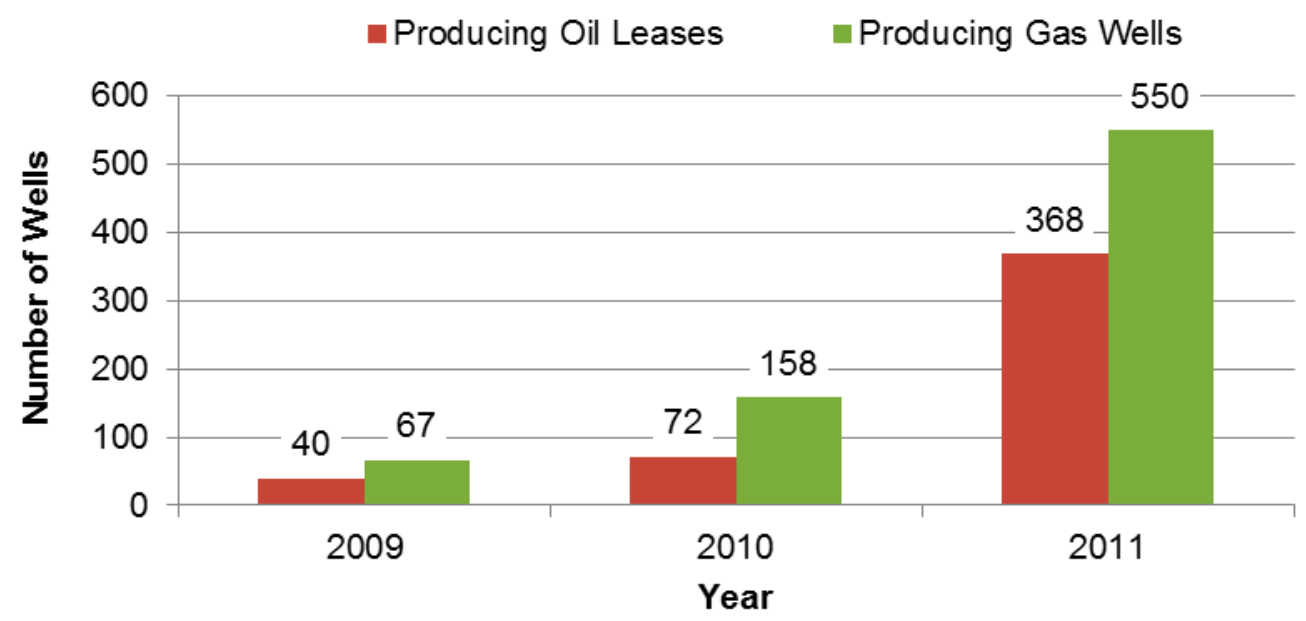

Figure 76. Number of producing oil and gas wells in Eagle Ford (Eagle Ford Shale 2012)

With 2,826 issued drilling permits in 2011 alone, the well count in Eagle Ford may steadily increase (Eagle Ford Shale 2012).

\section{Water Usage per Well}

Wells in the Eagle Ford Shale were randomly selected from fracfocus.org. Figure 77 shows a histogram of the water used per well, and Table 38 shows the average, maximum, and minimum water used per well.

Table 38. Fresh Water Use in Eagle Ford (in gallons) (fracfocus.org)

\begin{tabular}{|c|c|c|c|c|}
\hline Mean & Max & Min & Range & Standard Deviation \\
\hline $3,751,751$ & $7,084,098$ & 77,658 & $7,006,440$ & $1,276,506$ \\
\hline Median & Upper Quartile & Lower Quartile & Interquartile Range & Skewness \\
\hline $3,608,905$ & $4,386,965$ & $3,116,039$ & $1,270,927$ & -0.079 \\
\hline
\end{tabular}




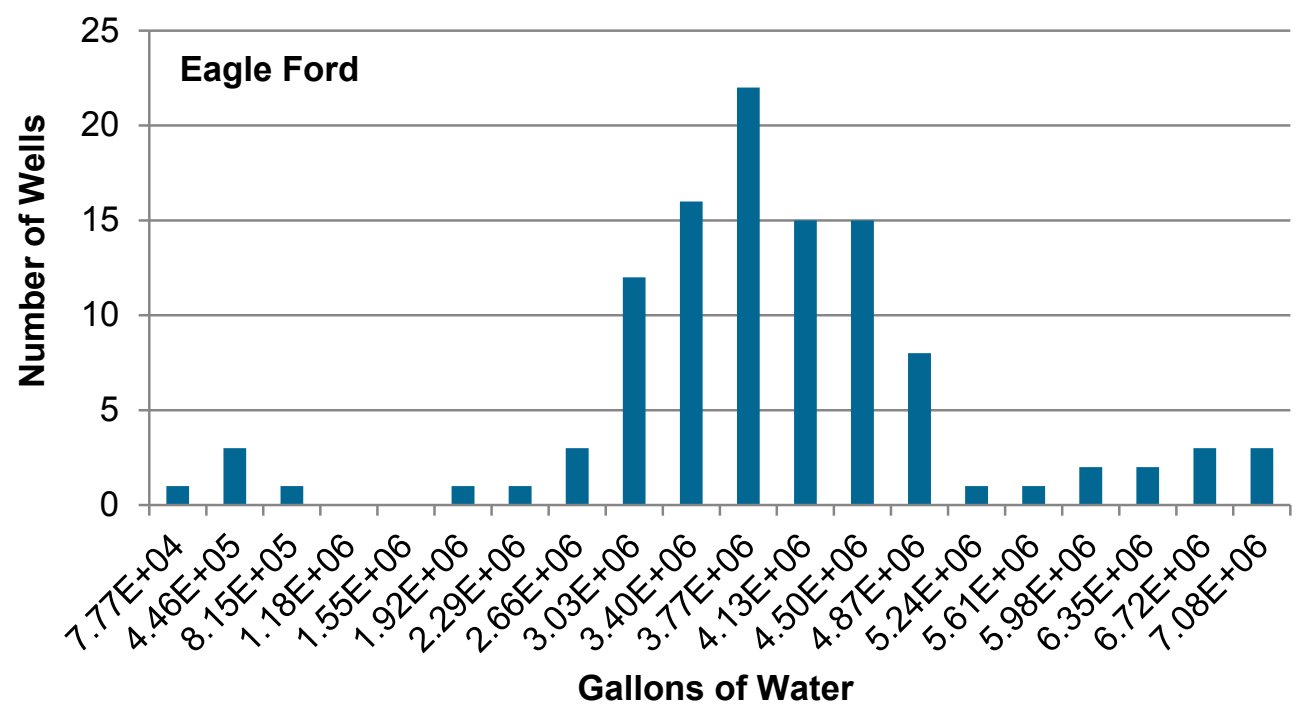

Figure 77. Fresh-water use in Eagle Ford per well (fracfocus.org)

The Texas Commission of Environmental Quality monitors surface water use in Texas. Surface water rights are issued to operators, and withdrawal amounts can be found on the TCEQ website (http://www.tceq.texas.gov/). However, withdrawal information is based on water-right number and is not shown on a well-to-well basis (TCEQ 2012).

\section{Haynesville Shale Play, Louisiana}

\section{Overview}

The Haynesville Shale extends over large sections of southwestern Arkansas, northwest Louisiana, and East Texas (Figure 19). It is up to 10,500 to 13,000 feet below the surface, with an average thickness of about 200-300 feet, and overs an area of about 9,000 square miles (TRRC 2012f).

Haynesville Shale is an important shale gas play in East Texas and Louisiana. Estimated recoverable reserves are as much as $60 \mathrm{Tcf}$, with each well producing $6.5 \mathrm{bcf}$ on average (Hammes 2009). The formation came into prominence in 2008 as a potentially major shale gas resource, and production has boomed since late March 2008 (TRRC 2011). Producing natural gas from the Haynesville Shale requires drilling wells from 10,000 to 13,000 feet deep, with the formation being deeper nearer the Gulf of Mexico. The Haynesville Shale has recently been estimated to be the largest natural gas field in the contiguous 48 states, with an estimated $250 \mathrm{Tcf}$ of recoverable gas (Nossiter 2008). 


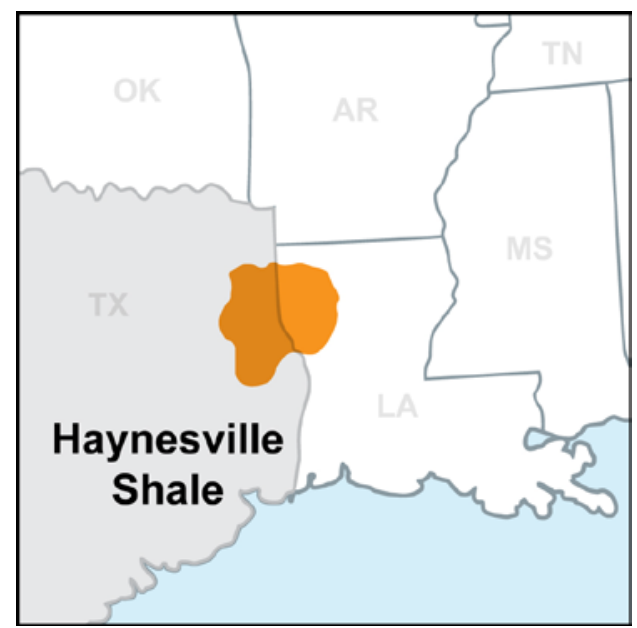

Figure 78. Extent of Haynesville Shale

The Haynesville Shale is lithologically heterogeneous, but is often an organic-rich mudstone. The composition varies greatly according to the geographic location and stratigraphic position of the mudstones - from calcareous mudstone near the ancient carbonate platforms and islands, to argillaceous mudstone in areas where submarine fans prograded into the basin and diluted organic matter. The Haynesville formation was deposited about 150 million years ago in a shallow offshore environment (Geology.com, 2012b).

\section{Number of Wells}

The State of Louisiana, Department of Natural Resources, provides information on monthly well counts. Well counts (Figure 79) have varied from 2009-2011 as old wells are abandoned and new wells are drilled and leased. However, total gas production (Figure 80) has increased from 2009-2011.

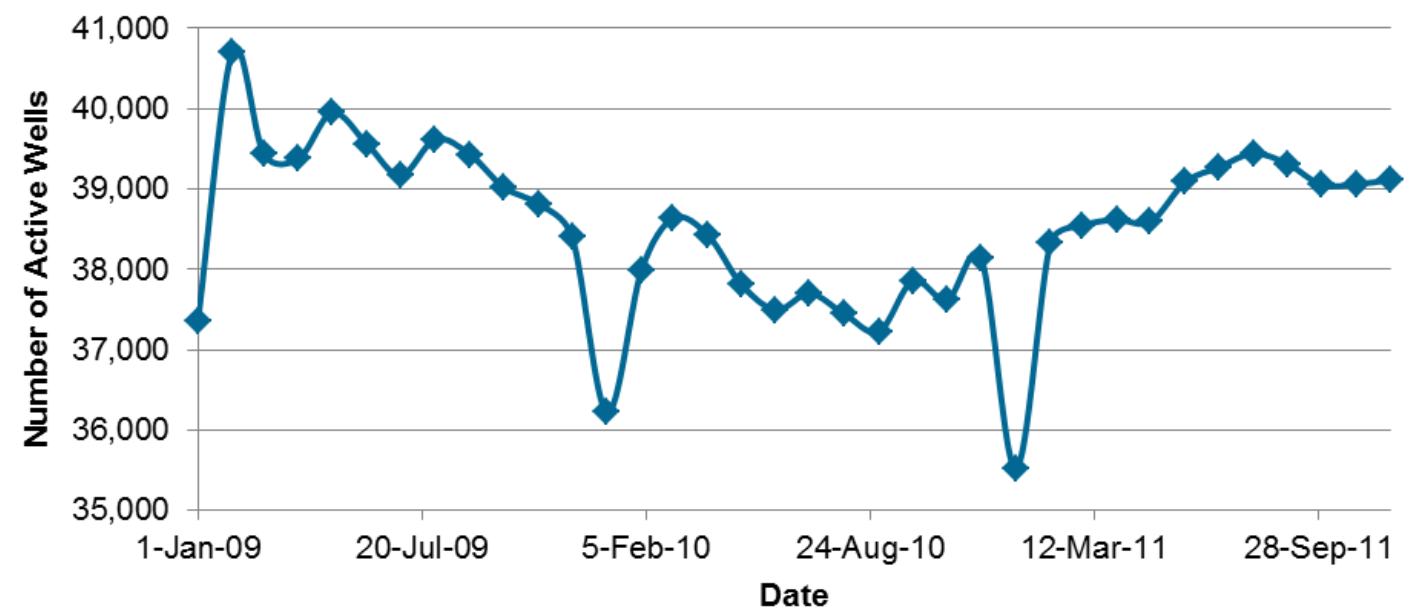

Figure 79. Monthly well count (2006-2011) (LADNR 2012b)

The total number of wells shows a significant drop at the end of 2010, after some natural fractures were seen in the formation cores extracted during test drilling. These fractures suggest 
the risk of anthropogenic faulting of the surrounding land; however, drilling continued after these problems were resolved.

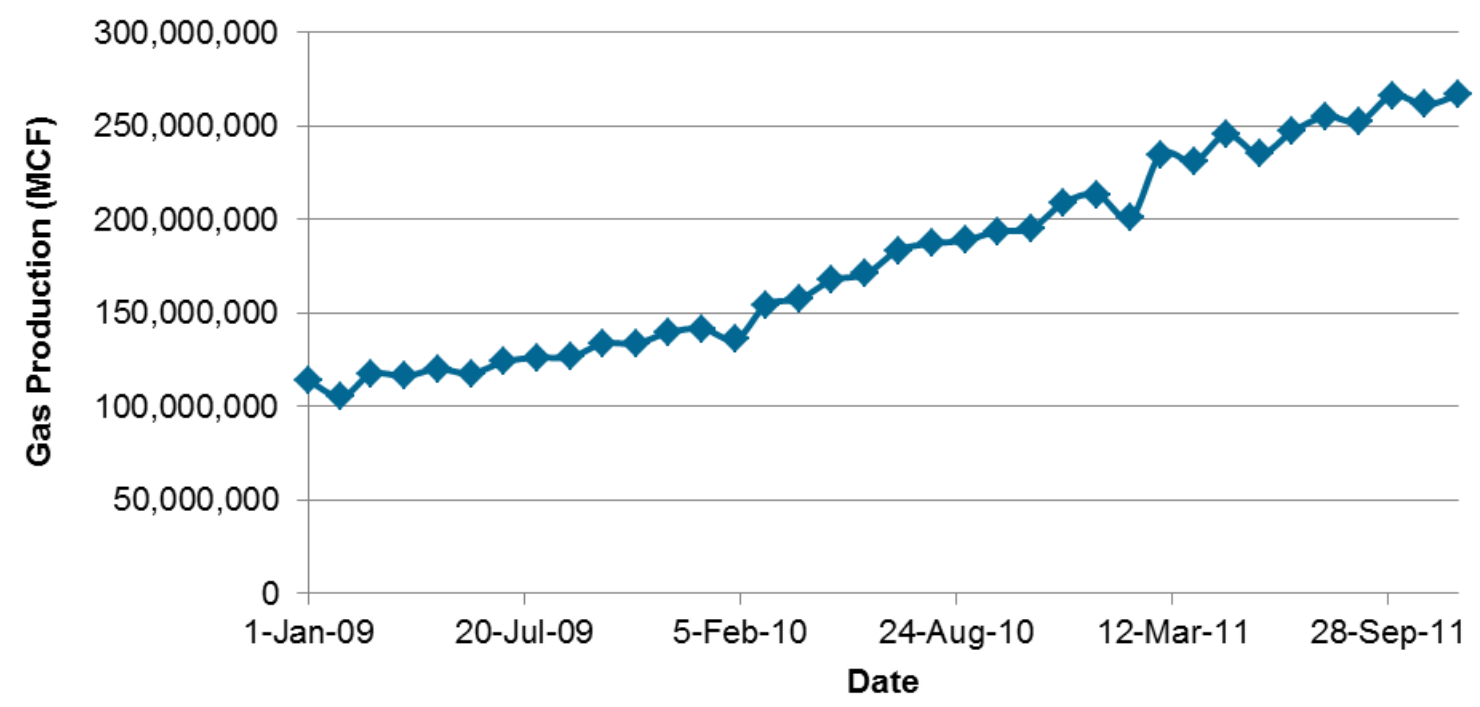

Figure 80. Monthly gas production (2009-2011) (EIA 2011)

Production is increasing almost linearly, despite a drop in well count. At the end of 2011, production was twice that in 2009.

\section{Water Usage per Well}

One hundred wells in the Haynesville Shale were randomly selected. Table 39 gives statistics on water usage, and Figure 81 is a histogram of the distribution of water usage distributed evenly into twenty bins.

Table 39. Analysis of Water Usage for 100 Haynesville Shale Wells (fracfocus.org)

\begin{tabular}{|c|c|c|c|c|}
\hline Mean & Max & Min & Range & Standard Deviation \\
\hline $4,568,683$ & $9,567,936$ & 8,736 & $9,559,200$ & $2,243,797$ \\
\hline Median & Upper Quartile & Lower Quartile & Interquartile Range & Skewness \\
\hline $4,925,256$ & $6,255,663$ & $3,875,203$ & $2,380,460$ & -0.578 \\
\hline
\end{tabular}




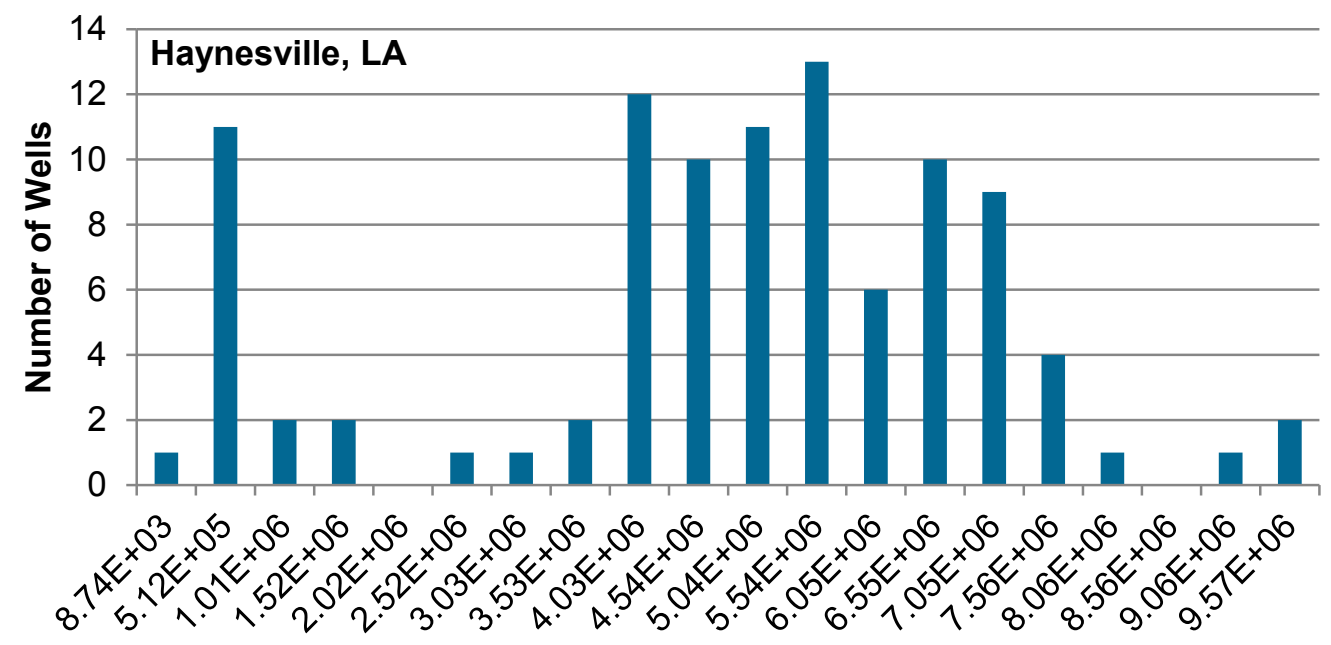

Gallons of Water

Figure 81. Fresh-water use for 100 -well sample (fracfocus.org)

\section{Violations}

Figure 82 expresses the violations from 2008-2011 in Louisiana according to the severity of environmental effect. A majority of the violations are in the "procedural" category (Table 40). "Minor - no effect" violations make up about 30\%, and "minor effect," "substantial," and "major" account for less than 10\% (Wiseman 2012). These data include mostly Haynesville wells with compliance orders from January 1, 2008 through July 14, 2011. About 83 additional well incidents had insufficient information to be categorized. Further information on violations can be found in D.7 of this appendix.

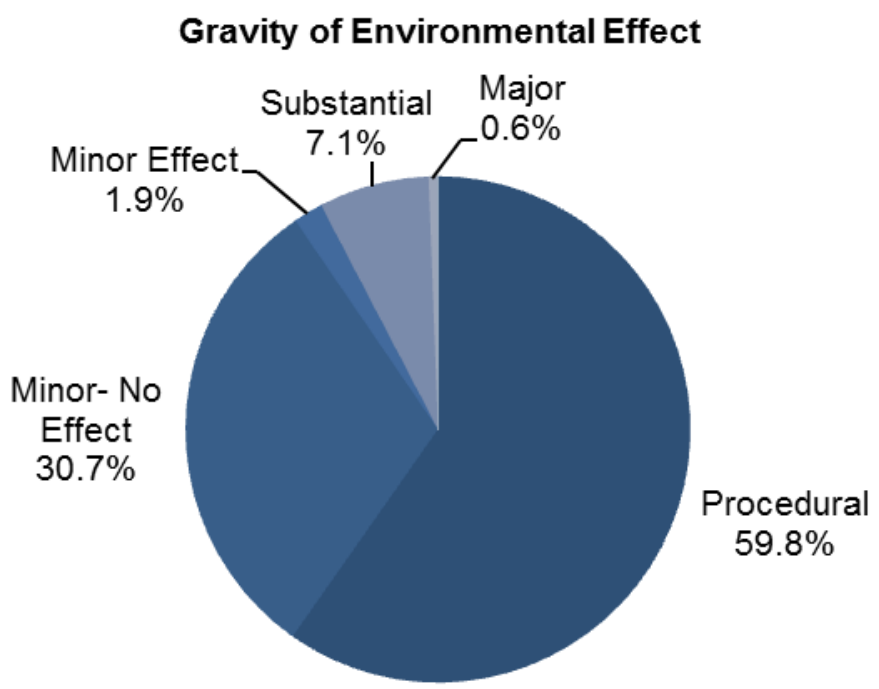

Figure 82. Louisiana violations (Wiseman 2012) 
Table 40. Louisiana Violations (Wiseman 2012)

\begin{tabular}{|l|r|r|}
\hline Procedural & 95 & $59.8 \%$ \\
\hline $\begin{array}{l}\text { Minor - no } \\
\text { effect }\end{array}$ & 49 & $30.7 \%$ \\
\hline Minor effect & 3 & $1.9 \%$ \\
\hline Substantial & 11 & $7.1 \%$ \\
\hline Major & 1 & $0.6 \%$ \\
\hline Total & \multicolumn{2}{|c|}{158} \\
\hline
\end{tabular}

\section{Upper San Juan Basin, Colorado, New Mexico}

\section{Overview}

The San Juan Basin covers an area of about 7,500 square miles across the Colorado and New Mexico border in the Four Corners region (Figure 83). It spans about 100 miles north-south in length and 90 miles east-west in width. In the San Juan Basin, the total thickness of all coalbeds ranges from 20 to more than 80 feet. Coalbed methane production occurs primarily in coals of the Fruitland Formation, but some coalbed methane is trapped within the underlying and adjacent Pictured Cliffs Sandstone; many wells are present in both zones (EPA 2004).

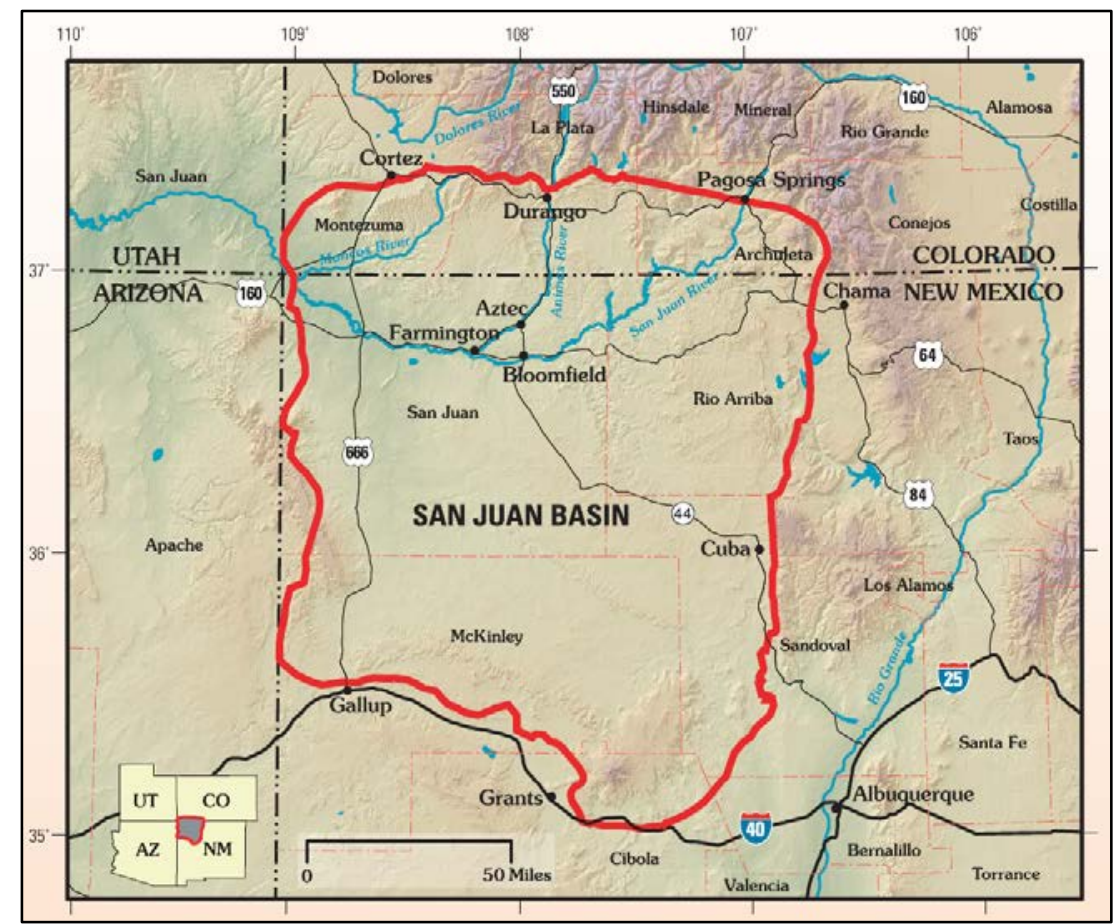

Figure 83. Extent of the San Juan Basin (USGS 2002a)

The Fruitland Formation is the primary coal-bearing unit of the San Juan Basin, as well as the target of most coalbed methane production. The Fruitland coals are thick and have individual beds up to 80 feet thick. The formation is composed of interbedded sandstone, siltstone, shale, 
and coal. Some of the most important natural-gas-producing formations include the Fruitland, Pictured Cliffs, Mesaverde, Dakota, and Paradox formations and are located in La Plata County. Early development of natural gas began here in the 1920s. In La Plata County, coalbed methane production began in the late 1970s. Traditional natural gas reserves have been-and continue to be-developed at a steady pace (USGS 2002a).

Two types of natural gas wells exist within La Plata County: conventional and coalbed. Conventional gas wells are usually deeper-3,500 to 10,000 feet-and extract gas and oil from sandstone formations such as the Mesaverde and Dakota (La Plata Energy Council 2012). The shallower coalbed gas wells generally range from 1,000 to 4,000 feet deep and extract gas from coal-bearing formations (EPA 2004). The Fruitland formation is La Plata County's methane-rich coalbed formation.

\section{Produced Water}

Conventional wells initially produce large volumes of gas and very little water. Over time, gas production declines and water increases. Coalbed wells are just the opposite, producing large quantities of water and low gas quantities at the beginning; later, water production declines and gas production increases. Table 41 shows oil, gas, and water production from 2007-2011.

Table 41. Oil, Gas, and Water Production in La Plata County (COGCC 2012a)

\begin{tabular}{|c|c|c|c|}
\hline Year & Oil Production (bbl) & Gas Production (Mcf) & Water Production (bbl) \\
\hline 2007 & 35,883 & $412,488,324$ & $24,032,308$ \\
\hline 2008 & 38,038 & $425,541,599$ & $20,154,062$ \\
\hline 2009 & 33,975 & $425,439,680$ & $24,177,214$ \\
\hline 2010 & 33,396 & $422,450,451$ & $31,942,703$ \\
\hline 2011 & 26,747 & $373,116,167$ & $21,231,213$ \\
\hline
\end{tabular}

Based on the database provided by the Colorado Oil and Gas Conservation Commission (COGCC), five methods are used to dispose of water in La Plata County: disposal in a central pit well, injection on lease, disposal at a commercial disposal facility, evaporation in an onsite pit, and through surface discharge (COGCC 2012a). Table 42 and Figure 84 show disposal methods in La Plata County from 2007 to 2011.

Table 42. Produced Water and Disposal Method in La Plata County (Million Gallons) (COGCC 2012a)

\begin{tabular}{|c|c|c|c|c|c|c|}
\hline Disposal Method & 2011 & 2010 & 2009 & 2008 & 2007 & Average \\
\hline $\begin{array}{c}\text { Central Disposal } \\
\text { Pit Well }\end{array}$ & 637 & 1,213 & 726 & 646 & 736 & 791 \\
\hline Injected on Lease & 350 & 362 & 175 & 201 & 179 & 253 \\
\hline $\begin{array}{c}\text { Commercial } \\
\text { Disposal Facility }\end{array}$ & 47 & 60 & 61 & 53 & 37 & 52 \\
\hline Onsite Pit & 2 & 2 & 1 & 2 & 1 & 1 \\
\hline Surface Discharge & NON & NON & NON & NON & NON & \\
\hline SUM & 1,036 & 1,638 & 963 & 901 & 953 & 1,098 \\
\hline Percentage & $60 \%$ & $61 \%$ & $51 \%$ & $48 \%$ & $57 \%$ & $55 \%$ \\
\hline Estimation & 1,725 & 2,697 & 1,876 & 1,872 & 1,674 & 1,969 \\
\hline
\end{tabular}




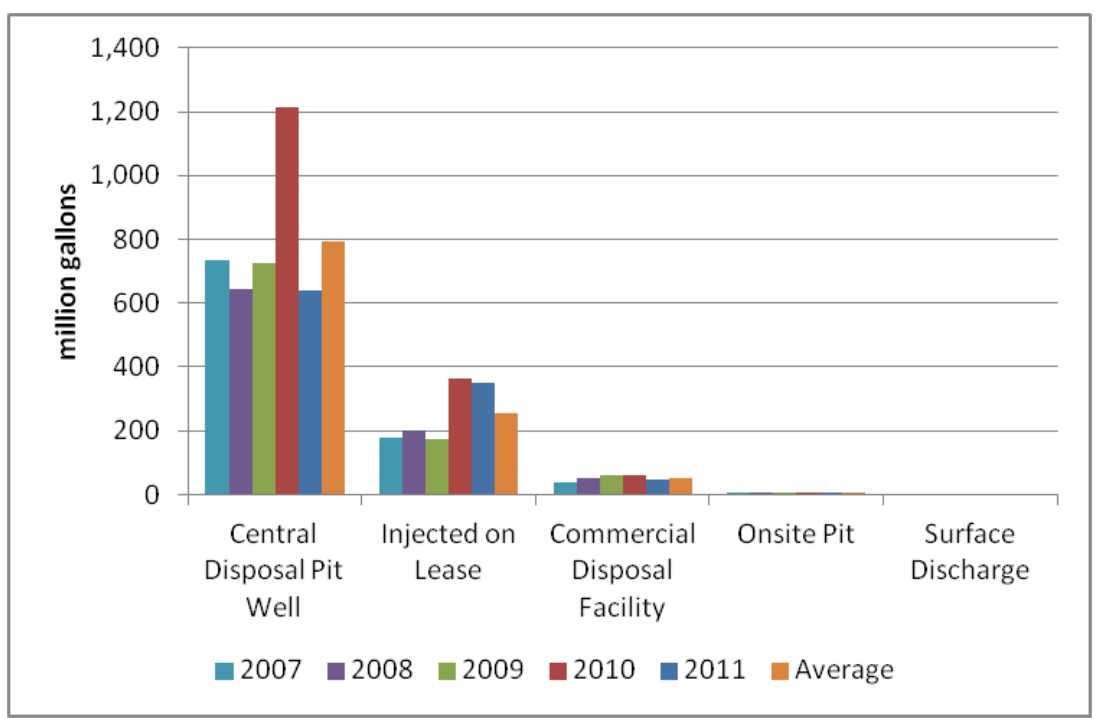

Figure 84. Water disposal volumes and methods in La Plata County (million gallons) (COGCC 2012a)

There is no surface discharge in La Plata County and minimal use of onsite pits. The most widely used method of disposal in La Plata County is a central disposal pit well. Some $70 \%$ of produced water is disposed in a central disposal pit well, $23 \%$ of produced water is injected on the lease, and $4.7 \%$ goes to a commercial disposal facility. Trends in the state of Colorado (Table 43) differ from those in La Plata County (Table 42).

Table 43. Produced Water and Disposal Method in the State of Colorado (Million Gallons) (COGCC 2012a)

\begin{tabular}{|c|c|c|c|c|c|c|}
\hline Disposal Method & $\mathbf{2 0 1 1}$ & $\mathbf{2 0 1 0}$ & $\mathbf{2 0 0 9}$ & $\mathbf{2 0 0 8}$ & $\mathbf{2 0 0 7}$ & Average \\
\hline $\begin{array}{c}\text { Central Disposal } \\
\text { Pit Well }\end{array}$ & 4,609 & 3,314 & 3,237 & 3,135 & 3,678 & 3,595 \\
\hline Injected on Lease & 8,095 & 11,243 & 6,715 & 7,194 & 11,666 & 8,983 \\
\hline $\begin{array}{c}\text { Commercial } \\
\text { Disposal Facility }\end{array}$ & 1,248 & 2,266 & 1,665 & 1,303 & 3,489 \\
\hline Onsite Pit & 3,001 & 2,962 & 3,213 & 5,128 & 3,588 & 3,579 \\
\hline Surface Discharge & 2,191 & 1,218 & 1,219 & 283 & 677 & 1,117 \\
\hline Sum & 19,144 & 21,003 & 16,049 & 17,042 & 20,572 & 18,762 \\
\hline
\end{tabular}

\section{Violations}

For the state of Colorado, the only publicly accessible statistics related to violations are Notices of Alleged Violations (NOAVs). The number of NOAVs does not represent the number of violations because violations do not necessarily lead to the issuance of NOAVs. Additionally, when NOAVs are issued, they may cite violations of more than one rule, order, or permit condition. Colorado violations could not be acquired. 


\section{Green River Basin, Wyoming}

\section{Overview}

The Green River Basin Oil Shale Field, as seen in Figure 85, is located in Wyoming, Utah, and Colorado, on the western flank of the Rocky Mountains. The main part of the Green River Basin Formation is located in the southwest portion of Wyoming. The Colorado oil shale is expected to hold the largest amount of oil from shale. Specifically, the Piceance Creek Basin is the large producer for oil shale in the Green River Formation (Oil Shale Gas 2012).

The estimates of the oil resource within the Green River Formation range from 1.3 to 2.0 trillion barrels. Because not all resources are recoverable, a moderate estimate of recoverable oil is about 800 billion barrels (Oil Shale Gas 2012).

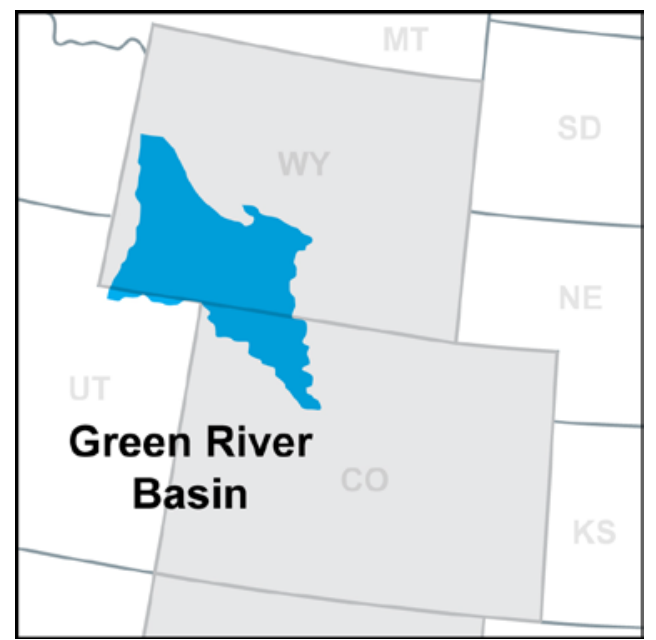

Figure 85. Extent of Green River Formation

The Jonah Field is located in the northern part of the Green River Basin and has produced more than 1.0 Tcf of gas since production commenced in 1992 (Oil Shale Gas 2012). Development of this field resulted from applying advanced fracture stimulation techniques. The field has undergone several iterations of development, with some sections of the field currently being developed on 10-acre well spacing; the current well spacing is around 20 acres. The field produces from a series of stacked reservoirs within the Cretaceous Mesaverde and Lance Formations. The field is bounded between two faults forming a wedge-shaped field.

\section{Water usage per well}

One hundred wells in the Green River Formation were randomly selected. Table 44 gives statistics about water usage, and Figure 86 is a histogram of water usage distributed evenly into twenty bins. 
Table 44. Analysis of Water Usage for 100 Green River Formation Wells (fracfocus.org)

\begin{tabular}{|c|c|c|c|c|}
\hline Mean & Max & Min & Range & Standard Deviation \\
\hline $1,076,417$ & $4,451,034$ & 14,467 & $4,436,567$ & $1,230,306$ \\
\hline Median & $\begin{array}{c}\text { Upper } \\
\text { Quartile }\end{array}$ & Lower Quartile & Interquartile Range & Skewness \\
\hline 367,522 & $1,665,741$ & 201,280 & $1,464,461$ & 1.40 \\
\hline
\end{tabular}

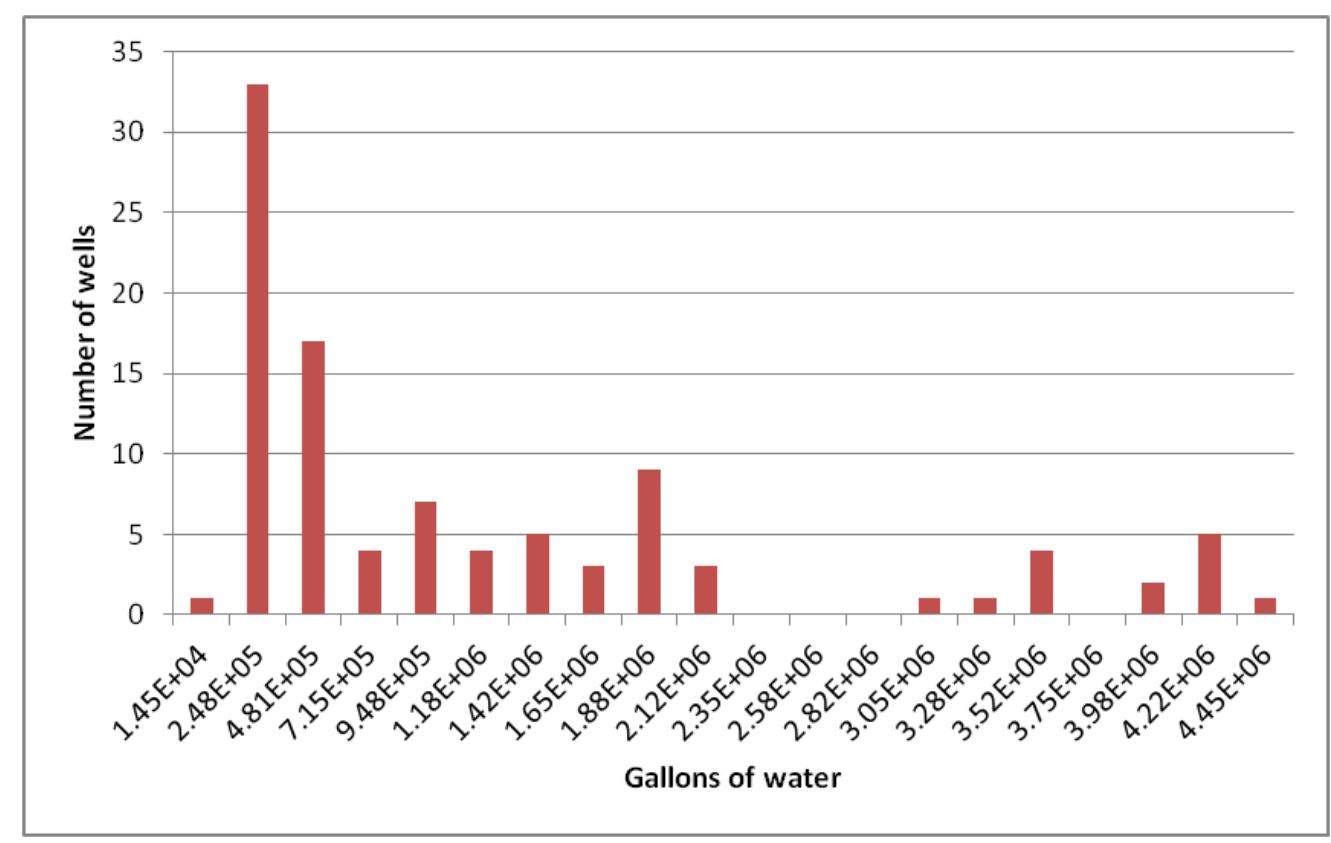

Figure 86. Fresh-water use for 100 -well sample (fracfocus.org)

Figure 87 shows the volumes of hydraulic fracturing fluids used in Wyoming by county. 


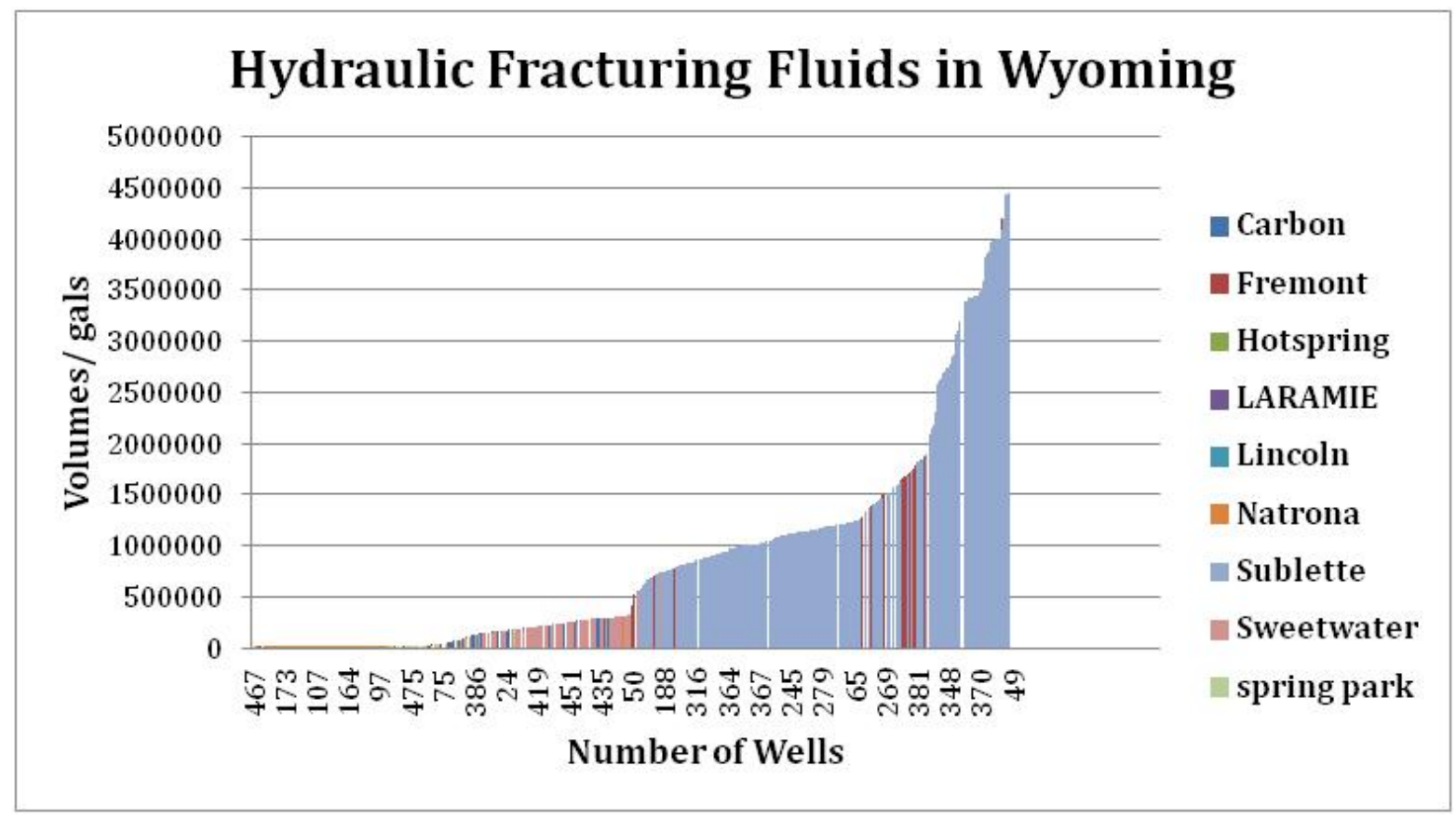

Figure 87. Volumes of hydraulic fracturing water (fracfocus.org)

\section{Produced Water}

Table 45 expresses the total oil, gas, and water produced within the Green River Basin from 2007-2011.

Table 45. Production of Oil, Gas, and Water in Green River Basin (WOGCC 2012)

\begin{tabular}{|c|c|c|c|}
\hline Year & $\begin{array}{c}\text { Oil Production } \\
\text { (barrels) }\end{array}$ & $\begin{array}{c}\text { Gas Production } \\
\text { (Mcf) }\end{array}$ & $\begin{array}{c}\text { Water Production } \\
\text { (Barrels) }\end{array}$ \\
\hline 2007 & $15,491,483$ & $1,218,888,397$ & $125,613,453$ \\
\hline 2008 & $15,824,924$ & $1,371,741,392$ & $150,830,391$ \\
\hline 2009 & $15,925,806$ & $1,428,200,434$ & $158,560,401$ \\
\hline 2010 & $20,544,588$ & $1,418,379,334$ & $169,901,204$ \\
\hline 2011 & $15,385,222$ & $1,347,348,632$ & $177,151,681$ \\
\hline
\end{tabular}

Table 46 provides injection volumes by field, although not all fields are represented.

Table 46. Injection Volumes (WOGCC 2012)

\begin{tabular}{|l|l|l|l|l|l|}
\hline Field & $\mathbf{2 0 0 7}(\mathbf{b b l})$ & $\mathbf{2 0 0 8}(\mathbf{b b l})$ & $\mathbf{2 0 0 9}(\mathbf{b b l})$ & $\mathbf{2 0 1 0}(\mathbf{b b l})$ & $\mathbf{2 0 1 1}(\mathbf{b b l})$ \\
\hline Big Piney & 577,239 & 167,646 & 189,178 & 70,354 & 40,247 \\
\hline Bison Basin & $1,989,960$ & $2,564,857$ & $2,223,756$ & $2,354,332$ & $2,296,464$ \\
\hline Brady & $4,419,146$ & $2,612,544$ & $1,943,879$ & $2,003,854$ & $4,688,163$ \\
\hline Cow Creek & $4,406,339$ & $8,174,082$ & $4,635,125$ & $5,517,186$ & $6,288,081$ \\
\hline Fontenelle & 111,267 & 117,390 & 115,376 & 110,948 & 102,167 \\
\hline Green River Bend & 592,890 & 381,857 & 549,775 & 616,873 & 432,311 \\
\hline Jonah & $1,367,707$ & $2,010,190$ & $1,588,080$ & $1,991,187$ & $2,703,926$ \\
\hline
\end{tabular}




\begin{tabular}{|l|l|l|l|l|l|}
\hline Field & $\mathbf{2 0 0 7} \mathbf{( b b l )}$ & $\mathbf{2 0 0 8} \mathbf{( b b l )}$ & $\mathbf{2 0 0 9}(\mathbf{b b l )}$ & $\mathbf{2 0 1 0} \mathbf{( b b l )}$ & $\mathbf{2 0 1 1}$ (bbl) \\
\hline LaBarge & 167,441 & $1,653,772$ & $1,752,291$ & $2,079,953$ & $1,344,187$ \\
\hline Lost Soldier & $23,577,864$ & $25,017,789$ & $32,557,565$ & $29,490,274$ & $37,367,198$ \\
\hline Mahoney Dome & 926,644 & 721,983 & $1,188,006$ & $1,085,123$ & $1,111,673$ \\
\hline McDonald Draw & 535,996 & 494,630 & 414,810 & 388,833 & 377,482 \\
\hline Patrick Draw & $1,551,255$ & $4,012,343$ & $1,196,017$ & $1,020,284$ & $1,179,744$ \\
\hline Pinedale & 954,458 & $6,749,055$ & $11,951,930$ & $12,027,080$ & $11,482,543$ \\
\hline Saddle Ridge & 221,413 & 206,610 & 227,843 & 231,330 & 208,498 \\
\hline Star Corral & 288,567 & 221,015 & 172,686 & 190,853 & 175,222 \\
\hline Tierney & $1,083,636$ & $1,813,532$ & $1,660,262$ & $1,831,283$ & $1,004,778$ \\
\hline Tip Top & 455,781 & 548,822 & 427,670 & 387,878 & 389,175 \\
\hline WC & $16,900,921$ & $33,853,193$ & $31,456,801$ & $24,984,327$ & $12,428,968$ \\
\hline Wertz & $20,610,169$ & $25,384,888$ & $1,953,919$ & $24,188,672$ & $30,240,574$ \\
\hline
\end{tabular}




\section{Severity of Environmental Impact Matrix}

Table 47 shows the categorization of environmental impacts for shale gas operations.

Table 47. Severity of Environmental Impact (Wiseman 2012)

\begin{tabular}{|c|c|c|c|}
\hline $\begin{array}{l}\text { Severity of } \\
\text { environmental } \\
\text { effect }\end{array}$ & $\begin{array}{l}\text { Activity for which violation } \\
\text { occurred }\end{array}$ & Enforcement action & Environmental factors \\
\hline Procedural & $\begin{array}{l}\text { - Permitting } \\
\text { - Reporting } \\
\text { - Testing } \\
\text { - Financial assurance }\end{array}$ & $\begin{array}{l}\text { "All ranges (violation } \\
\text { noted" through notice of } \\
\text { violation and/or } \\
\text { administrative order) }\end{array}$ & $\begin{array}{l}\text { No indication in violation/field } \\
\text { notes that failure to obtain } \\
\text { permit, report, conduct a test, or } \\
\text { provide financial guarantee } \\
\text { resulted in environmental } \\
\text { damage }\end{array}$ \\
\hline Minor - no effect & $\begin{array}{l}\text { - Equipment failures } \\
\text { - Pit construction, operation, and } \\
\text { maintenance } \\
\text { - Failure to prevent oil and gas } \\
\text { waste } \\
\text { - Commingling oil and gas } \\
\text { - Site maintenance, such as } \\
\text { moving weeds } \\
\text { - Sign posting and hazard labels }\end{array}$ & $\begin{array}{l}\text { "All ranges (violation } \\
\text { noted" through notice of } \\
\text { violation and/or } \\
\text { administrative order) }\end{array}$ & $\begin{array}{l}\text { No indication in field notes that } \\
\text { violation resulted in any } \\
\text { environmental damage }\end{array}$ \\
\hline Minor effect & $\begin{array}{l}\text { - Equipment failures that led to } \\
\text { release } \\
\text { - Pit construction, operation, and } \\
\text { maintenance that led to } \\
\text { release } \\
\text { - Air pollution } \\
\text { - Spills } \\
\text { - Disposal }\end{array}$ & $\begin{array}{l}\text { Violation noted, or } \\
\text { NOV/administrative order } \\
\text { paired with very small } \\
\text { environmental effect }\end{array}$ & $\begin{array}{l}\text { Small spills and improperly } \\
\text { disposed wastes (typically less } \\
\text { than } 5 \text { barrels of produced water } \\
\text { or oil) that did not move offsite or } \\
\text { otherwise suggest substantial } \\
\text { environmental damage. Small } \\
\text { quantities of air emissions (e.g., } \\
\text { slightly over the daily limit). }\end{array}$ \\
\hline Substantial & $\begin{array}{l}\text { - Equipment failures that led to } \\
\text { release } \\
\text { - Pit construction, operation, and } \\
\text { maintenance that led to } \\
\text { release } \\
\text { - Failure to plug well twelve } \\
\text { months after abandonment or } \\
\text { inactivity } \\
\text { - Air pollution } \\
\text { - Spills } \\
\text { - Disposal }\end{array}$ & $\begin{array}{l}\text { Violation noted, or } \\
\text { NOV/administrative order } \\
\text { + substantial } \\
\text { environmental effect; } \\
\text { remediation order }\end{array}$ & $\begin{array}{l}\text { Medium spills and improperly } \\
\text { disposed wastes (typically more } \\
\text { than } 5 \text { barrels and less than } 10 \\
\text { for produced water or oil that } \\
\text { stayed on site). For fracturing } \\
\text { fluid spills, any spill more than } 1 \\
\text { barrel was considered major. }\end{array}$ \\
\hline Major & $\begin{array}{l}\text { - Equipment failures that led to } \\
\text { release } \\
\text { - Pit construction, operation, and } \\
\text { maintenance that led to } \\
\text { release } \\
\text { - Air pollution } \\
\text { - Spills } \\
\text { - Disposal }\end{array}$ & $\begin{array}{l}\text { Violation noted, or } \\
\text { NOV/administrative order } \\
+>\text { substantial } \\
\text { environmental effect (or } \\
\text { high penalty + } \\
\text { substantial } \\
\text { environmental effect); } \\
\text { remediation order + } \\
\text { major environmental } \\
\text { effect }\end{array}$ & $\begin{array}{l}\text { Large spills or improperly } \\
\text { disposed of wastes (typically } 10 \\
\text { or more barrels, small to large } \\
\text { spills that moved off site and } \\
\text { impacted a resource (e.g., } \\
\text { drainage ditch, wetland). Any } \\
\text { spill of fracturing fluid }>1 \text { barrel. }\end{array}$ \\
\hline
\end{tabular}




\section{Appendix E: Assumptions Used in ReEDS}

\section{What is ReEDS? ${ }^{250}$}

The Regional Energy Deployment System is an optimization model used to assess the deployment of electric power generation technologies and transmission infrastructure throughout the contiguous United States into the future. The model, developed by NREL, is designed to analyze critical energy issues in the electric sector, especially with respect to the effect of potential energy policies such as clean energy and renewable energy standards or carbon restrictions.

ReEDS provides a detailed treatment of electricity-generating and electrical storage technologies, and specifically addresses a variety of issues related to renewable energy technologies - including accessibility and cost of transmission, regional quality of renewable resources, seasonal and diurnal generation profiles, variability of wind and solar power, and the influence of variability on the reliability of the electrical grid. ReEDS addresses these issues through a highly discretized regional structure, explicit statistical treatment of the variability in wind and solar output over time, and consideration of ancillary services requirements and costs.

\section{Qualitative Model Description}

To assess competition among the many electricity generation, storage, and transmission options throughout the contiguous United States, ReEDS chooses the cost-optimal mix of technologies that meet all regional electric power demand requirements, based on grid reliability (reserve) requirements, technology resource constraints, and policy constraints. This cost-minimization routine is performed for each of twenty 2-year periods from 2010 to 2050 . The major outputs of ReEDS include the amount of generator capacity and annual generation from each technology, storage capacity expansion, transmission capacity expansion, total electric sector costs, electricity price, fuel prices, and $\mathrm{CO}_{2}$ emissions. Time in ReEDS is subdivided within each 2-year period, with each year divided into four seasons with a representative day for each season, which is further divided into four diurnal time slices. Also, there is one additional summer-peak time slice. These 17 annual time slices enable ReEDS to capture the intricacies of meeting electric loads that vary throughout the day and year-with both conventional and renewable generators.

Although ReEDS includes all major generator types, it has been designed primarily to address the market issues that are of the greatest significance to renewable energy technologies. As a result, renewable and carbon-free energy technologies and barriers to their adoption are a focus. Diffuse resources such as wind and solar power come with concerns that conventional dispatchable power plants do not have, particularly regarding transmission and variability. The ReEDS model examines these issues primarily by using a much greater level of geographic disaggregation than do other long-term, large-scale, capacity expansion models. ReEDS uses 356 different resource regions in the continental United States. These 356 resource supply regions are grouped into four levels of larger regional groupings - balancing areas, reserve-sharing groups,

\footnotetext{
250 "What is ReEDS?" is taken from the 2011 detailed documentation for the ReEDS model.

Short, W., et al., Regional Energy Deployment System (ReEDS). NREL Technical report NREL/TP-6A20-46534, August 2011. http://www.nrel.gov/analysis/reeds/.
} 
North American Electric Reliability Council regions, ${ }^{251}$ and interconnects. States are also represented for the inclusion of state policies.

Many of the data inputs in ReEDS are tied to these regions and derived from a detailed GIS model/database of the wind and solar resource, transmission grid, and existing plant data. The geographic disaggregation of renewable resources enables ReEDS to calculate transmission distances, as well as the benefits of dispersed wind farms, PV arrays, or CSP plants supplying power to a demand region. Offshore wind is distinguished from onshore wind both in terms of technology cost/performance and resources. The wind and CSP supply curves are subdivided into five resource classes based on the quality of the resource-strength and dependability of wind or solar isolation.

Regarding resource variability and grid reliability, ReEDS also allows electric and thermal storage systems to be built and used for load shifting, resource firming, and ancillary services. Four varieties of storage are supported: pumped hydropower, batteries, compressed air energy storage, and thermal storage in buildings.

Along with wind and solar power data, ReEDS provides supply curves for hydropower, biomass, and geothermal resources in each of the 134 balancing areas. The geothermal and hydropower supply curves are in megawatts of recoverable capacity, and the biomass supply curve is in million British thermal units of annual feedstock production. In addition, other carbon-reducing options are considered. Nuclear power is an option, as is CCS on some coal and natural gas plants. CCS is treated simply, with only an additional capital cost for new coal and gas-fired power plants for the extra equipment and an efficiency penalty to account for the parasitic loads of the separation and sequestration process. Also, a limited set of existing coal plants can choose to retrofit to CCS for an associated cost, as well as a performance, penalty. The major conventional electricity-generating technologies considered in ReEDS include hydropower, simple- and combined-cycle natural gas, several varieties of coal, oil/gas steam, and nuclear. These technologies are characterized in ReEDS by the following:

- Capital cost $(\$ / \mathrm{MW})$

- Fixed and variable operating costs $(\$ / \mathrm{MWh})$

- Fuel costs (\$/MMBtu)

- Heat rate (MMBtu/MWh)

- Construction period (years)

- Equipment lifetime (years)

- Financing costs (such as nominal interest rate, loan period, debt fraction, debt-service-coverage ratio)

- Tax credits (investment or production)

\footnotetext{
${ }^{251}$ North American Electric Reliability Corporation, October 2010. “2010 Long-Term Reliability Assessment.” http://www.nerc.com/files/2010\%20LTRA.pdf. Accessed November 2, 2011.
} 
- Minimum turndown ratio (\%)

- Quick-start capability and cost $(\%, \$ / M W)$

- Spinning reserve capability

- Planned and unplanned outage rates (\%).

Renewable and storage technologies are governed by similar parameters - accounting for fundamental differences. For instance, heat rate is replaced with round-trip efficiency in pure storage technologies, and the dispatchability parameters - such as fuel cost, heat rate, turndown ratio, and operating reserve capability - are not used for non-dispatchable wind and solar technologies. These variable generation technologies are further characterized by changes in generation levels over the course of a year.

The model includes consideration of distinguishing characteristics of each conventional generating technology. There are several types of coal-fired power plants within ReEDS, including pulverized coal with and without sulfur dioxide scrubbers, advanced pulverized coal, integrated gasification combined cycle, biomass co-firing, and integrated gasification combined cycle with CCS options. Coal-plant generation is discouraged from daily cycling via a cost penalty, which represents a combination of additional fuel burned, heat rate drop-off, and mechanical wear-and-tear. Natural gas plants represented in ReEDS include simple-cycle combustion turbines, combined-cycle plants, and combined-cycle with CCS plants. Combinedcycle natural gas plants can provide some spinning reserve and quick-start capability, and simple-cycle gas plants can be used cheaply and easily for quick-start power. Nuclear power is represented as one technology in ReEDS and is considered to be baseload.

Retirement of conventional generation and hydropower can be modeled through exogenous specification of planned retirements or based on usage characteristics of the plants. All retiring non-hydro renewable plants are assumed to be refurbished or replaced immediately because the site is already developed and has transmission access and other infrastructure.

ReEDS tracks emissions of carbon and sulfur dioxide from both generators and storage technologies. Caps can be imposed at the national level for these emissions, and constraints can also be applied to impose caps at state or regional levels. There is another option of applying a carbon tax instead of a cap; the tax level and ramp-in pattern can be defined exogenously. In addition, ReEDS can impose clean energy or renewable energy standards at the regional or national level.

Annual electric loads and fuel price supply curves are exogenously specified to define the system boundaries for each period of the optimization. To allow for the evaluation of scenarios that might depart significantly from the Reference scenario, price elasticity of demand is integrated into the model: the exogenously defined demand projection can be adjusted up or down based on a comparison of an estimated business-as-usual electricity price path and a calculation of electricity price within the model for each of the twenty 2-year periods. For coal and natural gas 
pricing, supply curves based on the Annual Energy Outlook ${ }^{252}$ have been developed and used in ReEDS.

\section{Natural Gas Supply Curve Background and Development}

The EIA's Annual Energy Outlook 2011 has two specific scenarios that attempt to model the effects of high or low abundance of natural gas supply: High-EUR and Low-EUR. The HighEUR scenario increases the total unproved technically recoverable shale gas resource from $827 \mathrm{Tcf}$ in the Mid-EUR baseline scenario to $1,230 \mathrm{Tcf}$. In addition, the ultimate recovery per shale gas well is $50 \%$ higher than in the baseline scenario. Low-EUR reduces recoverable shale gas resource to $423 \mathrm{Tcf}$ and $50 \%$ lower ultimate recovery per shale gas well than in the MidEUR baseline scenario.

Deriving the coefficients for this study relied on assuming a linear regression model and employing an ordinary least-squares method. Linear regression is a statistical technique that examines the relationship between one dependent variable $(\mathrm{Y})$ and multiple explanatory variables, or regressors $(\mathrm{X})$, taking the linear form:

$$
Y_{i}=\beta_{0}+\beta_{1} * X_{1}+\beta_{2} * X_{2}+\cdots \beta_{n} * X_{n}+\varepsilon_{i}
$$

The estimated coefficients represent the marginal impact of a 1-unit change in each independent variable $\mathrm{X}_{\mathrm{i}}$ on $\mathrm{Y}$. Linear regression is often used for prediction or forecasting. ${ }^{253}$

In this case, because the objective was to develop a model to closely model the relationship between natural gas in the electric sector and consumption in the electric sector in different scenarios, the electric-sector price was modeled based on the following predictors: electricsector consumption, economy-wide consumption, year (2012-2035), and the natural gas scenario case. ${ }^{254}$ Each electric-sector price for each of the Annual Energy Outlook scenarios from 20122035 was treated as an independent observation used to estimate coefficients in the following model:

$$
\begin{aligned}
& \text { Electric Sector } \text { Price }_{i} \\
& \qquad \begin{aligned}
& \beta_{0}+\beta_{1} * \text { Electric Sector Consumption } n_{i}+\beta_{2} \\
& * \text { Economy }- \text { wide Consumption } n_{i} \\
& +\sum_{j=1}^{12} \beta_{j} * \text { Year }+\sum_{k=1}^{4} \beta_{k} * \text { Natural Gas Scenario }+\varepsilon_{i}
\end{aligned}
\end{aligned}
$$

Observations that occurred in High-EUR and Low-EUR were coded accordingly, creating two additional intercept shifter "dummy" variables. The year, rather than coded as continuous, was coded as a dummy variable to capture non-linear variation from year to year. To account for the

\footnotetext{
${ }^{252}$ Annual Energy Outlook 2011. DOE/EIA-0383. Washington, DC: U.S. Energy Information Administration.

${ }^{253}$ Damodar, Gujarati. Basic Econometrics (5 $5^{\text {th }}$ edition). McGraw Hill, 2007.

${ }^{254}$ Data for 2008-2011 as well as outlier scenarios (polmax0314a, polmaxlco20321a, polmaxlp0316a, lgbama050218a, lgbama200218a, aeo2010r1118a, oghtec110209a, ogltec110209a, hilng110209a, lolng110209a) were removed when running the model.
} 
predictor influence of economy-wide consumption, the average value for the year and the scenario for each data point were multiplied by $\beta_{2}$ (the derived electric-sector consumption coefficient). As a result, the intercept varied by year and by scenario, while the slope remained the same across year and scenario. The intercept and shifter for the years 2036-2050 was held constant with model results in 2035 .

The following tables summarize the assumptions used in ReEDS for: technology costs and performance (Table 48), wind performance (Table 49), CSP performance (Table 50), and utilityscale PV performance (Table 51).

Table 48. Technology Cost (\$2010) and Performance Assumptions Used in ReEDS

\begin{tabular}{|c|c|c|c|c|}
\hline & $\begin{array}{l}\text { Capital Cost } \\
(\$ / k W)\end{array}$ & $\begin{array}{c}\text { Variable O\&M } \\
\text { (\$/MWh) }\end{array}$ & $\begin{array}{c}\text { Fixed O\&M } \\
(\$ / k W-y r)\end{array}$ & $\begin{array}{c}\text { Heat Rate } \\
\text { (MMBtu/MWh) }\end{array}$ \\
\hline \multicolumn{5}{|c|}{ Coal Integrated Gasification Combined-Cycle CCS } \\
\hline 2010 & 4,075 & 7 & 32 & 9.0 \\
\hline 2020 & 4,075 & 7 & 32 & 9.0 \\
\hline 2030 & 4,075 & 7 & 32 & 7.9 \\
\hline 2040 & 4,075 & 7 & 32 & 7.9 \\
\hline 2050 & 4,075 & 7 & 32 & 7.9 \\
\hline \multicolumn{5}{|l|}{ CSP } \\
\hline 2010 & $7,179(8,217)^{a}$ & NA & $50(80)$ & NA \\
\hline 2020 & $6,639(4,077)$ & NA & $50(66)$ & NA \\
\hline 2030 & $5,398(2,983)$ & NA & $50(51)$ & NA \\
\hline 2040 & $4,778(2,983)$ & NA & $50(47)$ & NA \\
\hline 2050 & $4,778(2,983)$ & NA & $50(45)$ & NA \\
\hline \multicolumn{5}{|l|}{ Combined-Cycle Plants } \\
\hline 2010 & 1,250 & 4 & 6 & 7.5 \\
\hline 2020 & 1,250 & 4 & 6 & 6.7 \\
\hline 2030 & 1,250 & 4 & 6 & 6.7 \\
\hline 2040 & 1,250 & 4 & 6 & 6.7 \\
\hline 2050 & 1,250 & 4 & 6 & 6.7 \\
\hline \multicolumn{5}{|l|}{ Combined-Cycle Plants CCS } \\
\hline 2010 & 3,348 & 10 & 19 & 10.0 \\
\hline 2020 & 3,267 & 10 & 19 & 10.0 \\
\hline 2030 & 3,267 & 10 & 19 & 10.0 \\
\hline 2040 & 3,267 & 10 & 19 & 10.0 \\
\hline 2050 & 3,267 & 10 & 19 & 10.0 \\
\hline \multicolumn{5}{|c|}{ Simple-Cycle Combustion Turbines } \\
\hline 2010 & 661 & 30 & 5 & 12.5 \\
\hline 2020 & 661 & 30 & 5 & 10.3 \\
\hline 2030 & 661 & 30 & 5 & 10.3 \\
\hline 2040 & 661 & 30 & 5 & 10.3 \\
\hline 2050 & 661 & 30 & 5 & 10.3 \\
\hline
\end{tabular}




\begin{tabular}{|c|c|c|c|c|}
\hline & $\begin{array}{c}\text { Capital Cost } \\
(\$ / k W)\end{array}$ & $\begin{array}{c}\text { Variable O\&M } \\
\text { (\$/MWh) }\end{array}$ & $\begin{array}{c}\text { Fixed O\&M } \\
(\$ / \mathrm{kW}-\mathrm{yr})\end{array}$ & $\begin{array}{c}\text { Heat Rate } \\
\text { (MMBtu/MWh) }\end{array}$ \\
\hline \multicolumn{5}{|l|}{ New Coal } \\
\hline 2010 & 2,937 & 4 & 23 & 10.4 \\
\hline 2020 & 2,937 & 4 & 23 & 9.4 \\
\hline 2030 & 2,937 & 4 & 23 & 9.0 \\
\hline 2040 & 2,937 & 4 & 23 & 9.0 \\
\hline 2050 & 2,937 & 4 & 23 & 9.0 \\
\hline \multicolumn{5}{|l|}{ Nuclear } \\
\hline 2010 & $6,199(3,100)$ & NA & 129 & 9.7 \\
\hline 2020 & $6,199(3,100)$ & NA & 129 & 9.7 \\
\hline 2030 & $6,199(3,100)$ & NA & 129 & 9.7 \\
\hline 2040 & $6,199(3,100)$ & NA & 129 & 9.7 \\
\hline 2050 & $6,199(3,100)$ & NA & 129 & 9.7 \\
\hline \multicolumn{5}{|l|}{ Utility-Scale PV } \\
\hline 2010 & $4,067(4,067)$ & NA & $51(21)$ & NA \\
\hline 2020 & $2,560(2,013)$ & NA & $46(20)$ & NA \\
\hline 2030 & $2,351(1,912)$ & NA & $42(15)$ & NA \\
\hline 2040 & $2,191(1,797)$ & NA & $38(13)$ & NA \\
\hline 2050 & $2,058(1,720)$ & NA & $33(9)$ & NA \\
\hline \multicolumn{5}{|l|}{ Wind Offshore } \\
\hline 2010 & $3,702(3,702)$ & $0(23)$ & $101(16)$ & NA \\
\hline 2020 & $3,355(3,284)$ & $0(17)$ & $101(16)$ & NA \\
\hline 2030 & $3,042(2,912)$ & $0(14)$ & $101(16)$ & NA \\
\hline 2040 & $3,042(2,744)$ & $0(12)$ & $101(16)$ & NA \\
\hline 2050 & $3,042(2,744)$ & $0(12)$ & $101(16)$ & NA \\
\hline \multicolumn{5}{|l|}{ Wind Onshore } \\
\hline 2010 & $2,012(2,012)$ & $0(8)$ & $60(12)$ & NA \\
\hline 2020 & $2,012(1,964)$ & $0(5)$ & $60(12)$ & NA \\
\hline 2030 & $2,012(1,865)$ & $0(5)$ & $60(12)$ & NA \\
\hline 2040 & $2,012(1,805)$ & $0(5)$ & $60(12)$ & NA \\
\hline 2050 & $2,012(1,805)$ & $0(5)$ & $60(12)$ & NA \\
\hline
\end{tabular}

${ }^{a}$ Advanced RE Scenario assumptions displayed in parentheses

Table 49. Wind Performance Assumptions

\begin{tabular}{lccc}
\hline & Wind Power Class & On-Shore Wind & Off-Shore Wind \\
\hline $\mathbf{2 0 1 0}$ & & & \\
\hline Class 3 & $0.32(0.35)^{\mathrm{a}}$ & $0.36(0.37)$ \\
\hline Class 4 & $0.36(0.39)$ & $0.39(0.41)$ \\
\hline Class 5 & $0.42(0.43)$ & $0.45(0.44)$ \\
\hline Class 6 & $0.44(0.46)$ & $0.48(0.48)$ \\
\hline Class 7 & $0.46(0.50)$ & $0.50(0.52)$ \\
\hline
\end{tabular}

213 - Appendix E 


\begin{tabular}{|c|c|c|c|}
\hline & Wind Power Class & On-Shore Wind & Off-Shore Wind \\
\hline \multicolumn{4}{|l|}{2020} \\
\hline & Class 3 & $0.33(0.38)$ & $0.37(0.39)$ \\
\hline & Class 4 & $0.37(0.42)$ & $0.39(0.44)$ \\
\hline & Class 5 & $0.42(0.45)$ & $0.45(0.47)$ \\
\hline & Class 6 & $0.44(0.48)$ & $0.48(0.51)$ \\
\hline & Class 7 & $0.46(0.52)$ & $0.50(0.55)$ \\
\hline \multicolumn{4}{|l|}{2030} \\
\hline & Class 3 & $0.35(0.38)$ & $0.38(0.40)$ \\
\hline & Class 4 & $0.38(0.43)$ & $0.40(0.45)$ \\
\hline & Class 5 & $0.43(0.46)$ & $0.45(0.48)$ \\
\hline & Class 6 & $0.45(0.49)$ & $0.48(0.51)$ \\
\hline & Class 7 & $0.46(0.53)$ & $0.50(0.55)$ \\
\hline \multicolumn{4}{|l|}{2040} \\
\hline & Class 3 & $0.35(0.38)$ & $0.38(0.40)$ \\
\hline & Class 4 & $0.38(0.43)$ & $0.40(0.45)$ \\
\hline & Class 5 & $0.43(0.46)$ & $0.45(0.48)$ \\
\hline & Class 6 & $0.45(0.49)$ & $0.48(0.51)$ \\
\hline & Class 7 & $0.46(0.53)$ & $0.50(0.55)$ \\
\hline \multicolumn{4}{|l|}{2050} \\
\hline & Class 3 & $0.35(0.38)$ & $0.38(0.40)$ \\
\hline & Class 4 & $0.38(0.43)$ & $0.40(0.45)$ \\
\hline & Class 5 & $0.43(0.46)$ & $0.45(0.48)$ \\
\hline & Class 6 & $0.45(0.49)$ & $0.48(0.51)$ \\
\hline & Class 7 & $0.46(0.53)$ & $0.50(0.55)$ \\
\hline
\end{tabular}

${ }^{a}$ Advanced RE Scenario assumptions displayed in parentheses

Table 50. CSP Performance Assumptions

\begin{tabular}{lll}
\hline $\mathbf{2 0 1 0}$ & Wind Power Class & Capacity Factor \\
\hline & Class 1 & $0.28(0.28)^{\mathrm{a}}$ \\
\hline & Class 2 & $0.37(0.37)$ \\
\hline & Class 3 & $0.42(0.42)$ \\
\hline $\mathbf{2 0 2 0}$ & Class 4 & $0.44(0.44)$ \\
\hline & Class 5 & $0.46(0.46)$ \\
\hline & Class 1 & \\
\hline & Class 2 & $0.28(0.37)$ \\
\hline & Class 3 & $0.37(0.47)$ \\
\hline $\mathbf{2 0 3 0}$ & Class 4 & $0.42(0.52)$ \\
\hline & Class 5 & $0.44(0.54)$ \\
\hline
\end{tabular}

214 - Appendix E 


\begin{tabular}{|c|c|c|}
\hline & Wind Power Class & Capacity Factor \\
\hline & Class 2 & $0.47(0.47)$ \\
\hline & Class 3 & $0.52(0.52)$ \\
\hline & Class 4 & $0.54(0.54)$ \\
\hline & Class 5 & $0.56(0.56)$ \\
\hline \multicolumn{3}{|l|}{2040} \\
\hline & Class 1 & $0.37(0.37)$ \\
\hline & Class 2 & $0.47(0.47)$ \\
\hline & Class 3 & $0.52(0.52)$ \\
\hline & Class 4 & $0.54(0.54)$ \\
\hline & Class 5 & $0.56(0.56)$ \\
\hline \multicolumn{3}{|l|}{2050} \\
\hline & Class 1 & $0.37(0.37)$ \\
\hline & Class 2 & $0.47(0.47)$ \\
\hline & Class 3 & $0.52(0.52)$ \\
\hline & Class 4 & $0.54(0.54)$ \\
\hline & Class 5 & $0.56(0.56)$ \\
\hline
\end{tabular}

${ }^{\text {a }}$ Advanced RE Scenario assumptions displayed in parentheses

Table 51. Utility-Scale PV Performance Assumptions

\begin{tabular}{cc}
\hline Year & Capacity Factor \\
\hline 2010 & $0.16-0.27$ \\
\hline 2020 & $0.16-0.27$ \\
\hline 2030 & $0.16-0.27$ \\
\hline 2040 & $0.16-0.27$ \\
\hline 2050 & $0.16-0.27$ \\
\hline
\end{tabular}

\section{Treating Plant Retirement in ReEDS 255}

Assumptions about the retirement of conventional-generating units can have considerable cost implications. Considerations that go into the decision-making process on whether or not an individual plant should be retired involve a number of factors - specifically, the economics of plant operations and maintenance. Projecting these economic considerations into the future given the uncertainties involved is beyond the scope of ReEDS. Instead, ReEDS uses the following three retirement options that are not strictly economic:

- Scheduled lifetimes for existing coal, gas, and oil. These retirements are based on lifetime estimate data for power plants from Ventyx (2010). Near-term retirements are based on the officially reported retirement date as reported by EIA 860, EIA 411, or Ventyx unit research (Ventyx 2010). If there is no officially reported retirement date, a lifetime-based

\footnotetext{
${ }^{255}$ This section was taken from existing documentation of the ReEDS model.

Short, W. et al. (2011). "Regional Energy Deployment System (ReEDS)," NREL Technical report NREL/TP-6A2046534, August 2011. http://www.nrel.gov/analysis/reeds/.
} 
retirement is estimated based on the unit's commercial online date and the following lifetimes:

C Coal units $(<100 \mathrm{MW})=65$ years

○ Coal units $(>100 \mathrm{MW})=75$ years

$\bigcirc \quad$ Natural gas combined-cycle unit $=55$ years

○ Oil-gas-steam unit $=55$ years

- Usage-based retirements of coal. In addition to scheduled retirements, coal technologies, including co-fired coal with biomass, can retire based on proxies for economic considerations. Any capacity that remains unused for energy generation or operating reserves for 4 consecutive years is assumed to retire. Coal capacity is also retired by requiring a minimum annual capacity factor; after every 2-year investment period, if a coal unit has a capacity factor of less than this minimum capacity factor during the 2-year period, an amount of coal capacity is retired such that the capacity factor increases to this minimum threshold ( $10 \%$ in $2030,20 \%$ in 2040 , and $30 \%$ in 2050 ). Coal plants are not retired under this algorithm until after 2020.

- Scheduled nuclear license-based retirements. Nuclear power plants are retired based on the age of the plant. Under default assumptions, older nuclear plants that are on line before 1980 are assumed to retire after 60 years (one re-licensing renewal), whereas newer plants (on line during or after 1980) are assumed to retire after 80 years (two relicensing renewals). Other options can be implemented, such as assuming 60- or 80year lifetimes for all nuclear plants. 


\section{Glossary}

\begin{tabular}{|c|c|}
\hline annulus & $\begin{array}{l}\text { The space between two concentric lengths of pipe or between pipe and the hole in } \\
\text { which it is located. }\end{array}$ \\
\hline associated gas & $\begin{array}{l}\text { Natural gas that occurs with crude oil reservoirs, either as free gas or dissolved in } \\
\text { solution. It is usually produced with crude oil. }\end{array}$ \\
\hline basin & $\begin{array}{l}\text { A petroleum geology term that refers to a dip in the Earth's crust usually filled or being } \\
\text { filled with sediment. Basins are usually relatively large areas where oil and gas can be } \\
\text { found. }\end{array}$ \\
\hline $\begin{array}{l}\text { billion cubic feet } \\
\text { (bcf) }\end{array}$ & $\begin{array}{l}\text { Unit used to measure large quantities of gas, approximately equal to } 1 \text { trillion British } \\
\text { thermal units. }\end{array}$ \\
\hline $\begin{array}{l}\text { billion cubic feet } \\
\text { per day }(\mathrm{bcf} / \mathrm{d})\end{array}$ & $\begin{array}{l}\text { Unit used to measure the daily volume of gas produced, stored, transported, or } \\
\text { consumed. }\end{array}$ \\
\hline bradenhead & $\begin{array}{l}\text { A device that is used during inner-string grouting or pressure grouting operations. The } \\
\text { bradenhead is situated at the top of the well casing, where it allows a drill pipe to be } \\
\text { extended into the well while the well head is sealed and the annulus between the well } \\
\text { casing and drill pipe is pressurized. Also termed casing head, cement head, or largen } \\
\text { head. }\end{array}$ \\
\hline $\begin{array}{l}\text { British thermal unit } \\
\text { (Btu) }\end{array}$ & $\begin{array}{l}\text { An energy unit equivalent to the amount of energy needed to raise the temperature of } 1 \\
\text { pound of water } 1^{\circ} \mathrm{F} \text { from } 58.5^{\circ} \mathrm{F} \text { to } 59.5^{\circ} \mathrm{F} \text { under standard pressure of } 30 \text { inches of } \\
\text { mercury. Commonly used for measuring gas and other energy sales quantities. }\end{array}$ \\
\hline burner tip & The point of end-use consumption of a particular fuel. \\
\hline cement bond log & $\begin{array}{l}\text { A representation of the integrity of the cement job, especially whether the cement is } \\
\text { adhering solidly to the outside of the casing. The log is typically obtained from one of a } \\
\text { variety of sonic-type tools. }\end{array}$ \\
\hline $\begin{array}{l}\text { coal-bed methane } \\
\text { (CBM) }\end{array}$ & $\begin{array}{l}\text { Natural gas, primarily methane, generated during coal formation and recovered by } \\
\text { pumping water from coal seams, allowing gas to escape through shallow wells. It is } \\
\text { generally referred to as one type of unconventional gas. }\end{array}$ \\
\hline closed-loop drilling & $\begin{array}{l}\text { Drilling and fracturing operation that contains all fluids in tanks and other closed-to- } \\
\text { the-atmosphere equipment. Closed-loop drilling does not use open pits and therefore } \\
\text { can reduce the risks of leaks and spills. }\end{array}$ \\
\hline Combined-cycle & $\begin{array}{l}\text { An electric generating technology in which conventional gas combustion turbines are } \\
\text { combined with heat-recovery, steam-powered generation units, increasing the overall } \\
\text { efficiency of the generating facility. Electricity is produced from both the feed gas, as } \\
\text { well as from otherwise lost waste heat exiting gas turbines. In a conventional steam } \\
\text { power generating facility, electricity is generated only from the feed gas. }\end{array}$ \\
\hline completion & $\begin{array}{l}\text { Preparing a newly drilled well for production; usually involves setting casing (pipe that } \\
\text { lines the interior of a well to prevent caving and protect against ground-water } \\
\text { contamination) and perforating the casing to establish communication with the } \\
\text { producing formation. }\end{array}$ \\
\hline $\begin{array}{l}\text { compressed natural } \\
\text { gas }\end{array}$ & $\begin{array}{l}\text { Highly compressed natural gas stored and transported in high-pressure containers, } \\
\text { typically greater than } 3,000 \text { pounds per square inch ( } 200 \text { bar }) \text {; commonly used for } \\
\text { transport fuel. }\end{array}$ \\
\hline condensates & $\begin{array}{l}\text { Light hydrocarbon compounds that condense into liquid at surface temperatures and } \\
\text { pressures. They are generally produced with natural gas. }\end{array}$ \\
\hline cubic feet (cf) & $\begin{array}{l}\text { Common unit of measurement of gas volume equivalent to the amount of gas required } \\
\text { to fill a volume of } 1 \text { cubic foot under given temperature and pressure conditions. }\end{array}$ \\
\hline
\end{tabular}




\begin{tabular}{|c|c|}
\hline deep-well injection & $\begin{array}{l}\text { Technique for disposal of frac flowback or produced water in deep formations isolated } \\
\text { from producing zones and fresh-water aquifers. }\end{array}$ \\
\hline dry gas & $\begin{array}{l}\text { Natural gas, mainly methane, that remains after liquid hydrocarbon components have } \\
\text { been removed, making it suitable for pipeline shipping, liquefied natural gas } \\
\text { processing, or industrial usage. }\end{array}$ \\
\hline ethane $\left(\mathrm{C}_{2} \mathrm{H}_{6}\right)$ & $\begin{array}{l}\text { A normally gaseous natural gas liquid hydrocarbon extracted from natural gas or } \\
\text { refinery gas streams. }\end{array}$ \\
\hline flaring & $\begin{array}{l}\text { The process of disposing uncommercial or otherwise unwanted gas by burning. } \\
\text { Operators often flare associated gas in regions with limited gas markets. }\end{array}$ \\
\hline formation & $\begin{array}{l}\text { Refers to either a certain layer of the Earth's crust, or a certain area of a layer; often } \\
\text { refers to the area of rock where a petroleum or natural gas reservoir is located. }\end{array}$ \\
\hline $\begin{array}{l}\text { fracturing (or } \\
\text { fracking) }\end{array}$ & See hydraulic fracturing. \\
\hline frac flowback & $\begin{array}{l}\text { Fluids that are returned to the surface immediately following hydraulic fracturing that } \\
\text { include mostly the injected water, sand, and chemicals used for the fracturing. }\end{array}$ \\
\hline $\begin{array}{l}\text { geographic } \\
\text { information system } \\
\text { (GIS) }\end{array}$ & $\begin{array}{l}\text { Integrated hardware, software, and data used for capturing, managing, analyzing, and } \\
\text { displaying all forms of geographically referenced information. }\end{array}$ \\
\hline $\begin{array}{l}\text { gas-to-liquids } \\
\text { process }\end{array}$ & $\begin{array}{l}\text { A process that converts natural gas into synthetic liquid petroleum products, such as } \\
\text { diesel fuel and blending feedstock. }\end{array}$ \\
\hline glycol dehydrators & $\begin{array}{l}\text { Facilities in which a glycol-based process removes water from produced natural gas, } \\
\text { often in the field and before processing. The removal of water is needed to prevent } \\
\text { corrosion and water freezing in pipelines. }\end{array}$ \\
\hline green completion & $\begin{array}{l}\text { Using technology to recover gas that may otherwise be vented or flared during the } \\
\text { completion phase of a natural gas well. Also known as reduced emission completions. }\end{array}$ \\
\hline harmonization & $\begin{array}{l}\text { A meta-analytical procedure for adjusting published estimates from life } \\
\text { cycle assessment to develop a set of directly comparable estimates. } \\
\text { Harmonization clarifies a body of published estimates in ways useful to } \\
\text { decision-making and future analyses. See nrel.gov/harmonization for } \\
\text { further description and resources. }\end{array}$ \\
\hline $\begin{array}{l}\text { hydraulic fracturing } \\
\text { (or hydrofracking) }\end{array}$ & $\begin{array}{l}\text { The process of creating fractures in non-porous rock using specially formulated, water- } \\
\text { based solutions forced into wells at extremely high pressure; the cracks in the rock } \\
\text { allow for the release and collection of the natural gas. Fracking can be done in vertical } \\
\text { or horizontal wells. }\end{array}$ \\
\hline induced seismicity & $\begin{array}{l}\text { Seismic activity (e.g., earthquakes) that is caused by injection of fluids into deep } \\
\text { formations in proximity to natural faults. }\end{array}$ \\
\hline $\begin{array}{l}\text { life cycle } \\
\text { assessment (LCA) }\end{array}$ & $\begin{array}{l}\text { A technique to assess environmental impacts associated with all stages of a product's } \\
\text { life from "cradle to grave" (i.e., from raw material extraction through materials } \\
\text { processing, manufacture, distribution, use, repair and maintenance, and disposal or } \\
\text { decommissioning). LCAs can be applied to water, energy, greenhouse gas emissions, or } \\
\text { other metrics of interest. }\end{array}$ \\
\hline $\begin{array}{l}\text { liquefied natural gas } \\
\text { (LNG) }\end{array}$ & $\begin{array}{l}\text { Natural gas, mainly methane, that has been cooled to very low temperature }\left(-259^{\circ} \mathrm{F}\right) \text { so } \\
\text { that it will condense into a transportable colorless and odorless liquid. }\end{array}$ \\
\hline methane $\left(\mathrm{CH}_{4}\right)$ & $\begin{array}{l}\text { The lightest and most abundant of the hydrocarbon gases, it is the principal component } \\
\text { of natural gas and LNG. }\end{array}$ \\
\hline natural gas & $\begin{array}{l}\text { Naturally occurring mixture of hydrocarbon gases from underground sources composed } \\
\text { mainly of methane (more than } 85 \% \text { in some cases), ethane, propane, butane, pentane, } \\
\text { and impurities including carbon dioxide, helium, nitrogen, and hydrogen sulfide. }\end{array}$ \\
\hline
\end{tabular}




\begin{tabular}{|c|c|}
\hline natural gas liquids & $\begin{array}{l}\text { Natural gas components-including ethane, propane, butane, pentane, and } \\
\text { condensates - that are liquid at surface conditions. It does not include methane, which } \\
\text { remains in gaseous phase at surface conditions. }\end{array}$ \\
\hline $\begin{array}{l}\text { New York } \\
\text { Mercantile } \\
\text { Exchange }\end{array}$ & $\begin{array}{l}\text { The first U.S. exchange to trade natural gas futures contracts; the New York Mercantile } \\
\text { Exchange has contracts with major delivery points. }\end{array}$ \\
\hline $\begin{array}{l}\text { play (shale play, } \\
\text { shale gas play) }\end{array}$ & $\begin{array}{l}\text { A geographic area that has been targeted for exploration due to favorable geoseismic } \\
\text { survey results, well logs, or production results from a new well in the area. An area } \\
\text { comes into play when it is generally recognized that there is an economic quantity of oil } \\
\text { or gas to be found. }\end{array}$ \\
\hline $\begin{array}{l}\text { primacy (primary } \\
\text { enforcement } \\
\text { responsibility) }\end{array}$ & $\begin{array}{l}\text { The authority to implement the Underground Injection Control Program. To receive } \\
\text { primacy, a state, territory, or tribe must demonstrate to EPA that its Underground } \\
\text { Injection Control Program is at least as stringent as the federal standards; the state, } \\
\text { territory, or tribal Underground Injection Control requirements may be more stringent } \\
\text { than the federal requirements. EPA may grant primacy for all or part of the } \\
\text { Underground Injection Control Program (e.g., for certain classes of injection wells). }\end{array}$ \\
\hline produced water & $\begin{array}{l}\text { Water that is extracted with the oil and gas from the producing formation. Produced } \\
\text { water is usually highly saline and not usable without treatment. }\end{array}$ \\
\hline quad & A unit of energy equal to $10^{15} \mathrm{Btu}$, roughly equal to $1 \mathrm{Tcf}$. \\
\hline reserves & $\begin{array}{l}\text { Volumes of hydrocarbons that have a chance of being economically and technically } \\
\text { producible. }\end{array}$ \\
\hline reservoir & $\begin{array}{l}\text { A subsurface rock or formation having sufficient porosity and permeability to store and } \\
\text { transmit fluids such as gas, oil, and water. Reservoirs are typically composed of } \\
\text { sedimentary rocks with an overlying or adjoining impermeable seal or cap rock. }\end{array}$ \\
\hline shale gas & $\begin{array}{l}\text { Shale gas is defined as a natural gas produced from shale rock. Shale has low matrix } \\
\text { permeability; therefore, gas production in commercial quantities requires fracturing or } \\
\text { other stimulation to improve permeability. }\end{array}$ \\
\hline $\begin{array}{l}\text { social license to } \\
\text { operate }\end{array}$ & $\begin{array}{l}\text { A project that has the ongoing approval within the local community and other } \\
\text { stakeholders, ongoing approval or broad social acceptance, and, most frequently, as } \\
\text { ongoing acceptance. }\end{array}$ \\
\hline $\begin{array}{l}\text { trillion cubic feet } \\
\text { (Tcf) }\end{array}$ & $\begin{array}{l}\text { Unit used to measure large quantities of gas, typically reserve sizes. Approximately } \\
\text { equal to } 1 \text { quad of energy. }\end{array}$ \\
\hline unconventional gas & $\begin{array}{l}\text { Unconventional gas refers to gas produced from coal seams (coal-bed methane), shale } \\
\text { rocks (shale gas), and rocks with low permeability (tight gas). Once gas is produced } \\
\text { from these reservoirs, it has the same properties of gas produced from conventional } \\
\text { (i.e., sedimentary reservoirs with high porosity and permeability) sources. } \\
\text { Unconventional gas may have high levels of natural gas liquids (an exception is coal- } \\
\text { seam gas, which tends to be very dry with high proportion of methane versus natural } \\
\text { gas liquids) and may have low or high levels of carbon dioxide and high and low levels } \\
\text { of sulfur (sour or sweet). Because unconventional reservoirs have low permeability, } \\
\text { artificial methods to increase gas flows, such as mechanical or chemical fracking, is } \\
\text { often required before the wells are able to produce commercial quantities of gas. }\end{array}$ \\
\hline
\end{tabular}




\begin{tabular}{|l|l|}
\hline $\begin{array}{l}\text { Underground } \\
\text { Injection Control } \\
\text { Program }\end{array}$ & $\begin{array}{l}\text { The program that EPA, or an approved state, is authorized to implement under the Safe } \\
\text { Drinking Water Act that is responsible for regulating the underground injection of } \\
\text { fluids. This includes setting the minimum federal requirements for construction, } \\
\text { operation, permitting, and closure of underground injection wells. There are six } \\
\text { categories of wells regulated under the Underground Injection Control ranging from } \\
\text { Class I to Class VI. Class I wells are the most technologically sophisticated and are } \\
\text { used to inject wastes into deep, isolated rock formations below the lowermost } \\
\text { underground source of drinking water. Class I wells may inject hazardous waste, non- } \\
\text { hazardous industrial waste, or municipal wastewater. Class II wells are typically used } \\
\text { by the oil and gas industry to inject brines and other fluids associated with oil and gas } \\
\text { production, or storage of hydrocarbons. }\end{array}$ \\
\hline $\begin{array}{l}\text { volatile organic } \\
\text { compound (VOC) }\end{array}$ & $\begin{array}{l}\text { Gases and vapors, such as benzene, released by petroleum refineries, natural gas } \\
\text { drilling, petrochemical plants, plastics manufacturing, and the distribution and use of } \\
\text { gasoline. VOCs include carcinogens and chemicals that react with sunlight and nitrogen } \\
\text { oxides to form ground-level ozone, a component of smog. }\end{array}$ \\
\hline water recycling & $\begin{array}{l}\text { Collection of frac flowback or produced water and treating the fluid for beneficial use } \\
\text { that include hydraulic fracturing, agriculture, or release to streams. }\end{array}$ \\
\hline well completion & $\begin{array}{l}\text { Well completion incorporates the steps taken to transform a drilled well into a } \\
\text { producing one. These steps usually include casing, cementing, perforating, gravel } \\
\text { packing, and installing a production tree. }\end{array}$ \\
\hline well head & $\begin{array}{l}\text { The assembly of fittings and valve equipment used for producing a well and } \\
\text { maintaining surface control of a well. }\end{array}$ \\
\hline wet gas & $\begin{array}{l}\text { Natural gas with significant natural gas liquid components. Also sometimes called rich } \\
\text { gas. }\end{array}$ \\
\hline workover & $\begin{array}{l}\text { Work performed in a well after its completion in an effort to secure production where } \\
\text { there has been none, restore production that has ceased, or increase production. } \\
\text { Workovers for unconventional wells involve re-fracturing (re-stimulation). }\end{array}$ \\
\hline
\end{tabular}




\section{References}

\section{Introduction}

CERA (Cambridge Energy Research Associates). (2011). "Staying Power: Can U.S. Coal Plants Dodge Retirement for Another Decade?" CERA.

CRS (Congressional Research Service). (2011). "EPA's Regulation of Coal-Fired Power: Is a Train-Wreck Coming?" Library of Congress.

Credit Suisse. (2010). "Growth from Subtraction.”

Ebinger, C.; Massy, K.; Avasarala, G. (2012). "Liquid Markets: Assessing the Case for U.S. Exports of Liquefied Natural Gas.” Brookings Institute.

EIA, “Annual Energy Review,” October 2011

EIA. (2012a). “Annual Energy Outlook 2012 Early Release Overview.” Washington, D.C.: U.S. Department of Energy EIA.

EIA, "Monthly Energy Review,” April 27, 2012.

EIA “Electric Power Monthly,” May 29, 2012

EIA (Energy Information Administration). (2012b). "Short Term Energy Outlook." Washington, D.C.: U.S. Department of Energy EIA.

Howarth, R.; Santoro, R.; Ingraffea, A. (2011). "Methane and the Greenhouse Gas Footprint of Natural Gas from Shale Formations." Climatic Change Letters. DOI 10.1007/s10584-011-00615 .

Lustgarten, A. (2011). "Climate Benefits of Natural Gas May Be Overstated." ProPublica. http://www.propublica.org/article/natural-gas-and-coal-pollution-gap-in-doubt.

MIT (Massachusetts Institute of Technology). (2011). The Future of Natural Gas: An Interdisciplinary MIT Study. Cambridge, Mass.: MIT Energy Initiative.

Reuters (2012). “AEP Sees Coal-to-Gas Switching Reversing as Natgas Prices Rise,” 24 October 2012, New York..

SEAB (Secretary of Energy Advisory Board). (2011a). "Shale Gas Production Subcommittee 90Day Report.” Washington, D.C.: U.S. DOE.

SEAB. (2011b). "Shale Gas Production Subcommittee Second Ninety Day Report." Washington, D.C.: U.S. DOE.

Seto, C. (2011). "Technology in Unconventional Gas Resources." Supplemental Paper 2.3 in The Future of Natural Gas; An Interdisciplinary MIT Study.

http://web.mit.edu/mitei/research/studies/natural-gas-2011.shtml. 
Slone, D. (2012). "Future Outlook for Coal." Presentation to investors, ArchCoal.

UT (University of Texas). (2012). "Fact-Based Regulation for Environmental Protection in Shale Gas Development.” Austin: University of Texas Energy Institute.

Zoback, M.; Kitasei, S.; Copithorne, B. (2010). "Addressing the Risks from Shale Gas

Development." Washington, D.C.: WorldWatch Institute.

\section{Chapter 1}

API (American Petroleum Institute). (2009). Compendium of Greenhouse Gas Emissions Methodologies for the Oil and Natural Gas Industry. http://www.api.org/ehs/climate/new/upload/2009_GHG_COMPENDIUM.pdf.

Broderick, J.; Anderson, K.; Wood, R.; Gilbert, P.; Sharmina, M,; Footit, A.; Glynn, S.; Nicholls, F. (2011). "Shale Gas: An Updated Assessment of Environmental and Climate Change Impacts." Manchester, UK: University of Manchester Tyndall Centre.

Bruner K and Smosna R. 2011. A Comparative Study of the Mississippian Barnett Shale, Fort Worth Basin, and Devonian Marcellus Shale, Appalachian Basin. DOE/NETL-2011/1478. http://www.netl.doe.gov/technologies/oil-gas/publications/brochures/DOE-NETL-20111478\%20Marcellus-Barnett.pdf.

Bullin K and Krouskop P. 2008, Compositional Variety Complicates Processing Plans for US Shale Gas. http://www.bre.com/portals/0/technicalarticles/Keith\%20Bullin\%20\%20Composition\%20Variety \%20US\%20Shale\%20Gas.pdf. Based on a presentation to the Annual Forum, Gas Processors Association-Houston Chapter, Oct. 7, 2008, Houston, TX.

Burkhardt, J.; Heath, G.; Cohen, E. (2012). "Life Cycle Greenhouse Gas Emissions from Trough and Tower Concentrating Solar Power Electricity Generation: Systematic Review and Harmonization." Journal of Industrial Ecology. DOI: 10.1111/j.1530-9290.2012.00474.x.

Burnham, A.; Han, J.; Clark, C.; Wang, M.; Dunn, J.; Palou-Rivera, I. (2012). "Life cycle Greenhouse Gas Emissions of Shale Gas, Natural Gas, Coal and Petroleum." Environmental Science \& Technology (46); pp. 619-627.

CERA. (2011). "Mismeasuring Methane: Estimating Greenhouse Gas Emissions from Upstream Natural Gas Development.” www.ihs.com/images/MisMeasuringMethane082311.pdf.

EIA (Energy Information Administration). (2011). Annual Energy Review 2010. Washington, D.C.: U.S. DOE Energy Information Administration.

http://205.254.135.24/totalenergy/data/annual/pdf/aer.pdf.

EIA. (2012). Natural Gas Consumption by End Use. Washington, D.C.: U.S. DOE Energy Information Administration. http://205.254.135.7/dnav/ng/ng_cons_sum_dcu_nus_m.htm.

ENVIRON. (2010.) "Oil and Gas Exploration and Production Greenhouse Gas Protocol. Task 2 Report: Significant Source Categories and Technical Review of Estimation Methods." Prepared 
for Western States Regional Air Partnership (WRAP) Oil and Gas Greenhouse Gas Protocol Steering Committee.

EPA (U.S. Environmental Protection Agency). (1995). “Compilation of Air Pollutant Emission Factors. Vol. 1: Stationary Point and Area Sources." AP-42, 5th ed. http://www.epa.gov/ttnchie1/ap42/.

EPA. (2011). "Greenhouse Gas Emissions Reporting from the Petroleum and Natural Gas Industry." Washington, D.C.: U.S. EPA Climate Change Division.

http://www.epa.gov/climatechange/emissions/downloads10/Subpart-W_TSD.pdf.

EPA. (2012a). Inventory of Greenhouse Gas Emissions and Sinks: 1990-2010. Washington, D.C.: U.S. EPA. http://www.epa.gov/climatechange/emissions/usinventoryreport.html.

EPA. (2012b). "Oil and Natural Gas Sector: Standards of Performance for Crude Oil and Natural Gas Production, Transmission, and Distribution." Washington, D.C.: U.S. EPA Climate Change Division.

Forster, P.; Ramaswamy, V.; Artaxo, P.; Berntsen, T.; Betts, R.; Fahey, D. W.; Haywood, J.; Lean, J.; Lowe, D. C.; Myhre, G.; Nganga, J.; Prinn, R.; Raga, G.; Schulz, M.; Dorland, R.V. (2007). "Changes in Atmospheric Constituents and in Radiative Forcing." In Climate Change 2007: The Physical Science Basis. Eds. S. Solomon et al. Contribution of Working Group I to the Fourth Assessment Report of the Intergovernmental Panel on Climate Change. Cambridge, UK and New York: Cambridge University Press.

Heath, G.; Mann, M. (2012.) "Background and Reflections on the LCA Harmonization Project." Journal of Industrial Ecology. DOI: 10.1111/j.1530-9290.2012.00478.x.

Heath. G.; Arent, D.; O’Donoughue, P. (2012.) "Harmonization of Initial Estimates of Shale Gas Life Cycle GHG Emissions for Electric Power Generation.” NREL Technical Report.

Horne R, Grant T, Verghese K. 2009. Life Cycle Assessment: Principles, Practice and Prospects. CSIRO Publishing: Collingwood, Australia.

Howarth, R.W.; Santoro, R.; Ingraffea, A.; Phillips, N.; Townsend-Small, A. (2011). "Methane and the Greenhouse-Gas Footprint of Natural Gas from Shale Formations." Climatic Change (106); pp. 679-690.

Hultman, N.; Rebois, D.; Scholten, M.; Ramig, C. (2011.) “The Greenhouse Impact of Unconventional Gas for Electricity Generation." Environmental Research Letters (6); 044008. doi:10.1088/1748-9326/6/4/044008.

INTEK. (2011). "Review of Emerging Resources: U.S. Shale Gas and Shale Oil Plays." Prepared by INTEK for U.S. Energy Information Administration (EIA).

Jiang, M.; Griffin; Hendrickson; Jaramillo; VanBriesen; Venkatesh. (2011). "Life Cycle Greenhouse Gas Emissions of Marcellus Shale Gas.” Environmental Research Letters 6:034014 (doi:10.1088/1748-9326/6/3/034014). 
MIT (Massachusetts Institute of Technology). (2007.) The Future of Coal: An Interdisciplinary MIT Study. Cambridge, MA: MIT. http://web.mit.edu/coal/.

O’Donoughue, P.; Dolan, S.; Heath, G. (2012). "Life Cycle Greenhouse Gas Emissions from Natural Gas-Fired Electricity Generation: Systematic Review and Harmonization." Journal of Industrial Ecology (conditionally accepted).

Petron, G.; Frost, G.; Hirsch, A.; Montzka, S.; Karion, A.; Miller, B.; Trainer, M.; Sweeney, C.; Andrews, A.; Miller, L.; Kofler, J.; Dlugokencky, E.; Patrick, L.; Moore, T.; Ryerson, T.; Siso, C.; Kolodzey, W.; Lang, P.; Conway, T.; Novelli, P.; Masarie, K.; Hall, B.; Guenther, D.; Kitzis, D.; Miller, J.; Welsh, D.; Wolfe, D.; Neff, W.; Tans, P. (2012). "Hydrocarbon Emissions Characterization in the Colorado Front Range -A Pilot Study." Journal of Geophysical Research (117). D04304, doi:10.1029/2011JD016360.

Pring, M.; Hudson, D.; Renzaglia, J.; Smith, B.; Treimel, S. (2010). Characterization of Oil and Gas Production Equipment and Develop a Methodology to Estimate Statewide Emissions. Prepared for Texas Commission on Environmental Quality.

Santoro, R.L.; Howarth, R.H.; Ingraffea, A.R. (2011). "Indirect Emissions of Carbon Dioxide from Marcellus Shale Gas Development.” Ithaca, N.Y.: Cornell University Agriculture, Energy, \& Environment Program. http://www.eeb.cornell.edu/howarth/Marcellus.htm.

Schievelbein, V.H. (1997). "Reducing Methane Emissions from Glycol Dehydrators." Society of Petroleum Engineers/EPA Exploration and Production Environmental Conference, March 3-5, Dallas, Texas. http://www.onepetro.org/mslib/servlet/onepetropreview?id=00037929.

Seinfeld J and Pandis S. 2006. Atmospheric Chemistry and Physics: From Air Pollution to Climate Change. John Wiley \& Sons: Boston.

Shires, T. and Lev-On, M. (2012). Characterizing Pivotal Sources of Methane Emissions from Unconventional Natural Gas Production: Summary and Analysis of API and ANGA Survey Responses. Prepared for the American Petroleum Institute and the American Natural Gas Association.

Skone, T. and James, R. (2010). "Life Cycle Analysis: Natural Gas Combined Cycle (NGCC) Power Plant.” DOE/NETL-403-110509. Washington, D.C.: U.S. DOE National Energy Technology Laboratory. http://www.netl.doe.gov/energyanalyses/refshelf/PubDetails.aspx?Action=View\&PubId=353.

Skone, T.; Littlefield, J.; Marriott, J. (2011). "Life Cycle Greenhouse Gas Inventory of Natural Gas Extraction, Delivery and Electricity Production.” DOE/NETL-2011/1522. Washington, D.C.: U.S. DOE National Energy Technology Laboratory. http://www.netl.doe.gov/energyanalyses/pubs/NG-GHG-LCI.pdf.

Stephenson, T.; Valle, J.; Riera-Palou, X. 2011. "Modeling the Relative GHG Emissions of Conventional and Shale Gas Production." Environmental Science \& Technology (45); pp. 10757-10764. 
TCEQ (Texas Commission on Environmental Quality). (2010). "2009 Emissions Inventory Guidelines.” TCEQ Publication RG-360A/09.

http://www.tceq.texas.gov/assets/public/comm_exec/pubs/rg/rg360/rg36009/rg-360a.pdf.

TCEQ. (2011). "Barnett Shale Phase Two Special Inventory Data."

http://www.tceq.texas.gov/airquality/point-source-ei/psei.html.

TCEQ. (2012). Personal communication with Garvin Heath of TCEQ.

Townsend-Small, A.; Tyler, S.C.; Pataki, D.E.; Xu, X.; Christensen, L.E. (2012). "Isotopic Measurements of Atmospheric Methane in Los Angeles, California, USA: Influence of 'Fugitive' Fossil Fuel Emissions." Journal of Geophysical Research 117, D07308, doi:10.1029/2011JD016826.

TRRC (Texas Railroad Commission). (2012). "Production Data Query System (PDQ)." http://webapps2.rrc.state.tx.us/EWA/productionQueryAction.do.

Venkatesh; Jaramillo; Griffin; Matthews. (2011) "Uncertainty in Life Cycle Greenhouse Gas Emissions from United States Natural Gas End-Uses and Its Effects on Policy." Environmental Science \& Technology (45); pp. 8182-8189.

Vigon B, Tolle D, Cornaby B, Latham H, Harrison C, Boguski T, Hunt R, Sellers J. 1993. Life cycle Assessment: Inventory Guidelines and Principles. Prepared for the U.S. Environmental Protection Agency, Cincinnati Ohio. EPA/600/R-92/245.

http://infohouse.p2ric.org/ref/14/13578.pdf

Warner, E.; Heath, G. (2012). "Life Cycle Greenhouse Gas Emissions from Nuclear Electricity Generation: Systematic Review and Harmonization." Journal of Industrial Ecology. DOI:

10.1111/j.1530-9290.2012.00472.x.

Whitaker, M.; Heath, G.; O’Donoughue, P.; Vorum, M. (2012). "Life Cycle Greenhouse Gas Emissions from Coal-Fired Electricity Generation: Systematic Review and Harmonization." Journal of Industrial Ecology. DOI: 10.1111/j.1530-9290.2012.00465.x.

\section{Chapter 2}

Archuleta County Land Use Code Sec. 9.2.6.3: Archuleta County's Oil and Gas Development Permit Provisions (Amended Dec. 2010). http://www.archuletacounty.org/Planning/Section 9 Mining December 2010.pdf

Armendariz, A. (2009). "Emissions from Natural Gas Production in the Barnett Shale Area and Opportunities for Cost-Effective Improvements." http://www.edf.org/sites/default/files/9235_Barnett_Shale_Report.pdf.

BBC News. (2012). "Bulgaria Bans Shale Gas Drilling with 'Fracking' Method.”

BLM (Bureau of Land Management). (2012). "Proposed Rule: Oil and Gas; Well Stimulation, Including Hydraulic Fracturing, on Federal and Indian Lands." 
http://www.doi.gov/news/pressreleases/loader.cfm?csModule=security/getfile\&amp;pageid=293 $\underline{916 .}$

BPC (Bipartisan Policy Center). (2012). "Shale Gas: New Opportunities, New Challenges." http://www.scribd.com/doc/95194795/Shale-Gas-New-Opportunities-New-Challenges.

Cardi Reports. (2011). "The Economic Consequences of Marcellus Shale Gas Extraction: Key Issues." Prepared for Cornell University. http://www.greenchoices.cornell.edu/downloads/development/marcellus/Marcellus_CaRDI.pdf.

CCC (Colorado Conservation Voters). (2010). "Governor's Signature Brings Colorado a Step Closer to Cleaner Air." http://www.westernresourceadvocates.org/media/archive10/CleanAirCleanJobs.pdf.

CDWR (Colorado Division of Water Resources). (2012). "Water Sources and Demand for the Hydraulic Fracturing of Oil and Gas Wells in Colorado from 2010 through 2015." Colorado Division of Water Resources, Colorado Water Conservation Board, Colorado Oil and Gas Conservation Commission. http://cogcc.state.co.us/Library/Oil_and_Gas_Water_Sources_Fact_Sheet.pdf.

CDNR (Colorado Department of Natural Resources). (2012). "Recommendations from the Task Force Established by Executive Order 2012-002 Regarding Mechanisms to Work Collaboratively and Coordinate State and Local Oil and Gas Regulatory Structures." http://www.colorado.gov/cs/Satellite?blobcol=urldata\&blobheadername $1=$ ContentDisposition\&blobheadername $2=$ ContentType\&blobheadervalue $1=$ inline; +filename $\% 3 \mathrm{D} \% 22$ TaskForceLetter.pdf $\% 22 \&$ blobheadervalue 2 $=$ application/pdf\&blobkey $=$ id\&blobtable $=$ MungoBlobs\&blobwhere $=1251786375291 \&$ ssbinary $=$ true.

CDPHE (Colorado Department of Health and the Environment). (2008). "Statement of Purpose and Basis, Regulation XII, Section XIX.K." http://www.cdphe.state.co.us/regulations/airregs/5CCR1001-9.pdf.

CDPHE (Colorado Department of Health and the Environment). (2012). Regulation Number 7, XII, "Control of Ozone Via Ozone Precursors." http://www.cdphe.state.co.us/regulations/airregs/5CCR1001-9.pdf

COGCC (Colorado Oil and Gas Conservation Commission). (2008). "Statement of Basis, Specific Statutory Authority, and Purpose." 2 Colo. Code. Regs. 404-1. http://cogcc.state.co.us/rulemaking/StaffPreHearState/ProposedStatementBasisAuthorityPurpose. pdf.

COGCC. (2012). "Setback Stakeholder Group." http://cogcc.state.co.us/library/setbackstakeholdergroup/SetbackStakeholderGroup.asp.

CU (University of Colorado). (2012). "Study Shows Air Emissions Near Fracking Sites May Pose Health Risk." CU-Denver press release.

$$
226 \text { - References }
$$


http://www.ucdenver.edu/about/newsroom/newsreleases/Pages/health-impacts-of-frackingemissions.aspx.

Dryden. (2012). "Anschutz Exploration Corp. v. Town of Dryden.” 35 Misc.3d 450 (S. Ct. Tompkins County).

Earthworks. (2012). "Alternatives to Pits."

http://www.earthworksaction.org/issues/detail/alternatives_to pits.

Earthworks. (2012b). "Colorado Oil \& Gas Enforcement - Violations." http://www.earthworksaction.org/issues/detail/colorado_oil_gas_enforcement_violations.

Efstathiou Jr., J. (2012). “Drillers Say Costs Manageable from Pending Gas Emissions Rule.” http://www.bloomberg.com/news/2012-04-17/drillers-say-costs-manageable-from-pending-gasemissions-rule.html, April 17, 2012.

EPA (U.S. Environmental Protection Agency). (2000). "Profile of the Oil and Gas Extraction Industry."

http://www.epa.gov/compliance/resources/publications/assistance/sectors/notebooks/oilgas.pdf.

EPA. (2008). "EPA Form 7520-6: Underground Injection Control Permit Application." http://www.epa.gov/safewater/uic/pdfs/reportingforms/7520-6.pdf.

EPA. (2011a). "EPA Announces Schedule to Develop Natural Gas Wastewater Standards." http://yosemite.epa.gov/opa/admpress.nsf/0/91E7FADB4B114C4A8525792F00542001.

EPA. (2011b). "Letter from Jon M. Capacasa, EPA Region III, to Kelly Jean Heffner, Pennsylvania Department of Environmental Protection." http://www.epa.gov/region3/marcellus_shale/pdf/letter/heffner-letter5-12-11.pdf.

EPA. (2011c). "Letter from Shawn M. Garvin, EPA Region III, to Michael Krancer, Pennsylvania Department of Environmental Protection." http://www.uppermon.org/Marcellus_Shale/EPA-PADEP-Marcellus-7Mar11.html.

EPA. (2011d). "Letter from Stephen A. Owens, EPA, to Deborah Gold, Earthjustice, re: TSCA Section 21 Petition Concerning Chemical Substances and Mixtures Used in Oil and Gas Exploration or Production." http://www.epa.gov/oppt/chemtest/pubs/EPA_Letter_to_Earthjustice_on_TSCA_Petition.pdf.

EPA (2011e). "EPA's Study of Hydraulic Fracturing and Its Potential Impact on Drinking Water Resources," Environmental Protection Agency, http://www.epa.gov/hfstudy/.

EPA. (2012a). "Area Designations for 2008 Ground-level Ozone Standards.” http://www.epa.gov/ozonedesignations/2008standards/index.htm.

EPA. (2012b). "Hydraulic Fracturing Under the Safe Drinking Water Act," Environmental Protection Agency, http://water.epa.gov/type/groundwater/uic/class2/hydraulicfracturing/hydraulic-fracturing.cfm. 
EPA. (2012c). "Oil and Natural Gas Sector: New Source Performance Standards and National Emission Standards for Hazardous Air Pollutants Reviews." Final Rule.

http://www.epa.gov/airquality/oilandgas/pdfs/20120417finalrule.pdf.

Freudenthal. (2009). "Letter from Wyoming Governor Dave Freudenthal to Carol Rushin, EPA Region VIII, re: Wyoming 8-Hour Ozone Designation Recommendation, 12 March 2009, http://deq.state.wy.us/out/downloads/Rushin\%20Ozone.pdf.

Groat, C.; Grimshaw, T. (2012). "Fact-Based Regulation for Environmental Protection in Shale Gas." Austin: University of Texas Energy Institute.

http://energy.utexas.edu/images/ei_shale_gas_regulation120215.pdf.

GWPC (2009). "Modern Shale Gas Development in the United States: A Primer.” Ground Water Protection Council.

http://www.gwpc.org/sites/default/files/Shale\%20Gas\%20Primer\%202009.pdf

Hammer, R.; VanBriesen, J. (2012). “In Fracking's Wake: New Rules Are Needed to Protect Our Health and Environment from Contaminated Wastewater." Natural Resources Defense Council. http://www.nrdc.org/energy/files/Fracking-Wastewater-FullReport.pdf.

Holland, A. (2011). Oklahoma Geological Survey, Examination of Possibly Induced Seismicity from Hydraulic Fracturing in the Eola Field, Garvin County, Oklahoma 18, http://www.ogs.ou.edu/pubsscanned/openfile/OF1_2011.pdf.

IEA (2012). “Golden Rules for a Golden Age of Gas.” International Energy Agency. http://www.worldenergyoutlook.org/media/weowebsite/2012/goldenrules/WEO2012_GoldenRul esReport.pdf.

Jones, E.A. (2011). "Testimony for the US House Committee on Science, Space, and Technology: Review of Hydraulic Fracturing Technology."

http://science.house.gov/sites/republicans.science.house.gov/files/documents/hearings/Hydraulic \%20Fracturing\%20Written $\% 20$ Testimony-Final-5-9-2011\%20jones.pdf.

Kurth, T. (2010). “American Law and Jurisprudence on Fracing.” Haynes and Boone LLP. http://www.haynesboone.com/files/Publication/3477accb-8147-4dfc-b0b4380441178123/Presentation/PublicationAttachment/195a3398-5f02-4905-b76d3858a6959343/American_Law_Jurisprudence_Fracing.pdf.

Martin, J., Susan M. Mathiascheck \& Sarah Gleich. (2010). "Fractured Fairytales: The Context and Regulatory Constraints for Hydraulic Fracturing." Rocky Mountain Mineral Law Foundation Annual Institute Paper 3, December Issue.

McKenzie, L. et al. (2012). "Human Health Risk Assessment of Air Emissions from Development of Unconventional Natural Gas Resources." University of Colorado School of Public Health and Garfield County Board of County Commissioners. http://www.erierising.com/human-health-risk-assessment-of-air-emissions-from-developmentof-unconventional-natural-gas-resources/. (See upcoming issue of Journal of Geophysical Research). 
Middlefield. (2012). "Cooperstown Holstein Corp. v. Town of Middlefield." 943 N.Y.S.2d 722 (S. Ct. Otsego County).

Niquette, M. (2011). "Fracking Has Formerly Stable Ohio City Aquiver over Quakes," Bloomberg News. http://www.bloomberg.com/news/2011-12-14/fracking-has-formerly-stableohio-city-aquiver-over-earthquakes.html.

NPC (National Petroleum Council). (2011). “Prudent Development Realizing the Potential of North America's Abundant Natural Gas and Oil Resources.” http://www.npc.org/NARDExecSummVol.pdf.

New Mexico Oil Conservation Division. (2008). "Cases Where Pit Substances Contaminated New Mexico's Ground Water."

http:/Www.emnrd.state.nm.us/ocd/documents/GWImpactPublicRecordsSixColumns20081119.p df.

NRLC (Natural Resources Law Center). (2012). "Solid Waste." http://www.oilandgasbmps.org/resources/solidwaste.php.

Ohio Dep't of Natural Resources, (2012). Preliminary Report on the Northstar 1 Class II Injection Well and the Seismic Events in the Youngstown, Ohio, Area 17, http://ohiodnr.com/downloads/northstar/UICreport.pdf.

Railroad Commission of Texas. (RRC 2009. Self-Evaluation Report, available at http://www.sunset.state.tx.us/82ndreports/rct/ser.pdf.

Petron, G.; Frost, G.; Hirsch, A.; Montzka, S.; Karion, A.; Miller, B.; Trainer, M.; Sweeney, C.; Andrews, A.; Miller, L.; Kofler, J.; Dlugokencky, E.; Patrick, L.; Moore, T.; Ryerson, T.; Siso, C.; Kolodzey, W.; Lang, P.; Conway, T.; Novelli, P.; Masarie, K.; Hall, B.; Guenther, D.; Kitzis, D.; Miller, J.; Welsh, D.; Wolfe, D.; Neff, W.; Tans, P. (2012). "Hydrocarbon Emissions Characterization in the Colorado Front Range -A Pilot Study." Journal of Geophysical Research (117). D04304, doi:10.1029/2011JD016360.

PA DEP (Pennsylvania Department of Environmental Protection). (2010). "STRONGER Pennsylvania Hydraulic Fracturing State Review." http://www.strongerinc.org/documents/PA\%20HF\%20Review\%20Print $\% 20$ Version.pdf.

Robinson. (2012a). "Robinson Township, et al. v. Pennsylvania, Complaint for Declaratory Judgment and Injunctive Relief." http://c4409835.r35.cf2.rackcdn.com/03-29-10 part-1-of-thefinal-petition.pdf; $\underline{\text { http://c4409835.r35.cf2.rackcdn.com/03-29-13 part-2-of-the-final- }}$ petition.pdf.

Robinson. (2012b). "Robinson Township, et al. v. Pennsylvania, No. 284 M.D., Order (Commonwealth Court Pa.). http://canon-mcmillan.patch.com/articles/judge-grants-injunctionin-act-13-challenge\#pdf-9548282. 
SEAB (Secretary of Energy Advisory Board). (2011a). "Shale Gas Production Subcommittee 90Day Report," Washington, D.C. DOE.

http://www.shalegas.energy.gov/resources/081811_90_day report_final.pdf.

SEAB. (2011b). "Shale Gas Production Subcommittee Second Ninety Day Report." Washington, D.C.: DOE. http://www.shalegas.energy.gov/resources/111811_final_report.pdf.

Soraghan, M. (2011). "Oil and Gas: Puny Fines, Scant Enforcement Leave Drilling Violators with Little to Fear." http://www.eenews.net/public/Greenwire/2011/11/14/1.

Streater, S. (2010). “Air Quality Concerns May Dictate Uintah Basin's Natural Gas Drilling Future." New York Times, October 1. http://www.nytimes.com/gwire/2010/10/01/01greenwireair-quality-concerns-may-dictate-uintah-basins-30342.html?pagewanted=1.

State Review of Oil \& Natural Gas Environmental Regulations (STRONGER). (2010). Pennsylvania Hydraulic Fracturing State Review." http://www.strongerinc.org/documents/PA\%20HF\%20Review\%20Print\%20Version.pdf.

State Review of Oil \& Natural Gas Environmental Regulations (STRONGER). (2011a). "Colorado Hydraulic Fracturing State Review." http://www.strongerinc.org/documents/Colorado\%20HF\%20Review\%202011.pdf.

State Review of Oil \& Natural Gas Environmental Regulations (STRONGER). (2011b). "STRONGER Louisiana Hydraulic Fracturing State Review." http://www.shalegas.energy.gov/resources/071311_stronger_louisiana_hfreview.pdf.

TRCC (Texas Railroad Commission). "Waste Minimization in Drilling Operations." http://www.rrc.state.tx.us/forms/publications/wasteminmanual/wastemindrillingops.php.

Urbina, I. (2011). "Regulation Lax as Gas Wells' Tainted Water Hits Rivers." New York Times, Feb. 26. http://www.nytimes.com/2011/02/27/us/27gas.html? r=1\&pagewanted=all.

White House. (2011). "Blueprint for a Secure Energy Future." http://www.whitehouse.gov/sites/default/files/blueprint_secure_energy_future.pdf.

Wiseman, H. (2010). "Regulatory Adaptation in Fractured Appalachia," Villanova Environmental Law Journal (21:2).

Western Regional Air Partnership (2010-2012) Phase III Oil/Gas Emissions Inventories, http://www.wrapair.org/forums/ogwg/PhaseIII_Inventory.html.

WYDEQ (Wyoming Department of Environmental Quality). (2010). "Oil and Gas Production Facilities Chapter 6, Section 2 Permitting Guidance." http://deq.state.wy.us/aqd/Oil\%20and\%20Gas/March\%202010\%20FINAL\%20O\&G\%20GUID ANCE.pdf. 
Xcel Energy. (2012). "Colorado Clean Air-Clean Jobs Plan."

http://www.xcelenergy.com/Environment/Doing_Our_Part/Clean_Air_Projects/Colorado_Clean Air_-_Clean_Jobs_Plan.

\section{Chapter 3}

American Water. (2012). "Pennsylvania, Rates Information." http://www.amwater.com/paaw/customer-service/rates-information.html.

API (American Petroleum Institute). (2009a). "Environmental Protection For Onshore Oil and Gas Production Operations and Leases." API Recommended Practice 51R, first edition. Washington, DC: American Petroleum Institute. July. http://www.api.org/plicy/exploration/hydraulicfracturing/upload/API RP S1R.pdf

API (American Petroleum Institute). (2010b). "Freeing Up Energy—Hydraulic Fracturing: Unlocking America's Natural Gas Resources.” Washington, DC: American Petroleum Institute. July.

Andrew, A., Folger P., Humphries, M., Copland C., Tiemann, M., Meltz, R., and Brougher, C. (2009). "Unconventional Gas Shales: Development, Technology and Policy Issues." Congressional Research Service.

API (American Petroleum Institute). (2010). Water Management Associated with Hydraulic Fracturing, $1^{\text {st }}$ ed. API Publishing.

ASRPG (Appalachian Shale Recommended Practice Group). (2012). "Recommended Standards and Practices."

http://media.marketwire.com/attachments/201204/44703_ASRPGStandardsandPracticesDocume ntApril302012.pdf.

Arthur, J., Uretsky, M., and Wilson, P. (2010). "Water Resources and Use for Hydraulic Fracturing in the Marcellus Shale Region." ALL Consulting.

ASRPG (Appalachian Shale Recommended Practice Group). (2012). "Recommended Standards and Practices."

http://media.marketwire.com/attachments/201204/44703_ASRPGStandardsandPracticesDocume ntApril302012.pdf.

Bellabarba, M., Bulte-Loyer, H., Froelich, B., Le Roy-Delage, S., Kujik, R., Zerouy, S., Guillot, D., Meroni, N., Pastor, S., \& Zanchi, A. (2008). "Ensuring Zonal Isolation beyond the Life of the Well. Oil Field Review, 18-31.

Chief Oil and Gas, LLC. (2012). http://www.chiefog.com/marcellus_shale_best_practices

COGCC (Colorado Oil and Gas Conservation Commission). (2012a). "2011 Report To the Water Quality Control Commission and Water Quality Control Division of the Colorado Department of Public Health and Environment," February. 
COGCC. (2012b). "Fact Sheet: Water Sources and Demand for the Hydraulic Fracturing of Oil and Gas Wells in Colorado from 2010 through 2015."

http://cogcc.state.co.us/Library/Oil_and_Gas_Water_Sources_Fact_Sheet.pdf.

Colorado Oil \& Gas Enforcement Violations. (n.d.).

http://www.earthworksaction.org/issues/detail/colorado_oil_gas_enforcement_violations

Coyote Gulch. (2012). http://coyotegulch.wordpress.com/2012/02/10/cogcc-water-use-forhydraulic-fracturing-expected-to-increase-from-4-5-billion-gallons-now-to-6-billion-gallons-in$\underline{2015 / .}$

Davies, R.J., Mathias, S., Moss, J., Hustoft, S., Newport, L., (2012) “Hydraulic Fractures: How Far Can They Go?," Marine and Petroleum Geology, 4:2012, 22-27.

Eagle Ford Shale. (2012). “Drilling Rig Count.” http://www.eaglefordshale.com/.

e-CFR (Electronic Code of Federal Regulations). (2012).

http://ecfr.gpoaccess.gov/cgi/t/text/text-

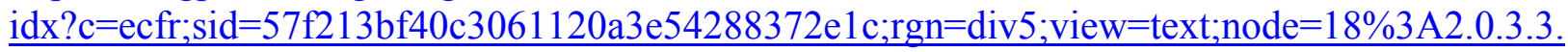
$\underline{3 ; \mathrm{idno}=18 ; \mathrm{cc}=\mathrm{ecfr} \# 18: 2.0 .3 .3 .3 \cdot 1.11 .5 \text {. }}$

EDF (Environmental Defense Fund). (2012). "Natural Gas: Challenge or Opportunity? Public Health and the Environment Must Come First." http://www.edf.org/sites/default/files/EDFNatural-Gas-Fact-Sheet-May2012.pdf.

EIA (U.S. Energy Information Administration). (2011). "Review of Emerging Resources: U.S. Shale Gas and Shale Oil Plays.” ftp://ftp.eia.doe.gov/natgas/usshaleplays.pdf.

Energy Collective. (2012). “Gas Industry's First Stabs at 'Standards' \& 'Practices': How Much Do They Reduce Accident Risk?"

http://theenergycollective.com/node/83870?utm_source=tec_newsletter\&utm_medium=email\&u tm campaign=newsletter.

Energy Institute. (2012). Fact-Based Regulation for Environmental Protection in Shale Gas Development. http://energy.utexas.edu/images/ei_shale_gas_regulation120215.pdf.

EPA (U.S. Environmental Protection Agency). (2004). "Evaluation of Impacts to Underground Sources of Drinking Water by Hydraulic Fracturing of Coalbed Methane Reservoirs. Attachment 1, The San Juan Basin."

EPA (U.S. Environmental Protection Agency). (2011). "Plan to Study the Potential Impacts of Hydraulic Fracturing on Drinking Water Resources." EPA/600/R-11/122. http://www.epa.gov/hfstudy/HF Study Plan 110211 FINAL 508.pdf

Falk, H., Lavergren, U., and Bergback, B. (2006). "Metal Mobility in Alum Shale from Öland, Sweden." Journal of Geochemical Exploration, 90(3), 157-165. 
Geology.com. (2012). "Haynesville Shale: News, Lease and Royalty Information." http://geology.com/articles/haynesville-shale.

GWPC (Ground Water Protection Council). (2009). "State Oil and Natural Gas Regulations Designed to Protect Water Resources." Washington, DC: U.S. Department of Energy, National Energy Technology Laboratory. http://data.memberclicks.com/site/coga/GWPC.pdf.

GWPC (Ground Water Protection Council) \& ALL Consulting. (2009). Modern Shale Gas Development in the US: A Primer. Contract DE-FG26-04NT15455. Washington, DC: U.S. Department of Energy, Office of Fossil Energy and National Energy Technology Laboratory. http://www.netl.doe.gov/technologies/oilgas/publications/EPreports/Shale Gas Primer 2009.pdf

Haerer, D. and McPherson, B. (2009). "Evaluating the Impacts and Capabilities of Long Term Subsurface Storage in the Context of Carbon Sequestration in the San Juan Basin, NM and CO." Energy Procedia. Vol 1. Pg. 2991-2998

Hoffman, J. (2011). "Water Use and the Shale Gas Industry.” Susquehanna River Basin Commission presentation.

http://www.stcplanning.org/usr/Program_Areas/Energy/Naturalgas_Resources/SRBC_Presentati on_Sept 2011.pdf.

Hopey, D. (2011). Radiation-fracking Link Sparks Swift Reactions. Pittsburgh Post-Gazette. March 5. http://www.post-gazette.com/pg/11064/1129908-113.stm.

IEA (International Energy Agency). (2012). Golden Rules for a Golden Age of Gas: World Energy Outlook.

JISEA (Joint Institute for Strategic Energy Analysis). (2011). "Prospectus: The Role of Natural Gas in the U.S. Energy Sector: Electric Sector Analysis.”

Kelso, M. (2011). “All MS Drilled Wells in PA (2011-12-16).” Fractracker.org. http://data.fractracker.org/cbi/dataset/datasetPreviewPage?uuid= 01a3a9acd627f511e1b64be84b d739fae9.

Kemp, J. (2012). http://blogs.reuters.com/john-kemp/.

Kenny, J.F.; Barber, N.L.; Hutson, S.S.; Linsey, K.S.; Lovelace, J.K.; Maupin, M.A. Estimated Use of Water in the United States in 2005. (2009). U.S. Geological Survey Circular 1344.

Reston, VA: USGS.

King, H. (2012). "Marcellus Shale - Appalachian Basin Natural Gas Play." http://geology.com/articles/marcellus-shale.shtml.

LADNR (Louisiana Department of Natural Resources). (2012). Haynesville Shale Wells Activity by Month. http://dnr.louisiana.gov/assets/OC/haynesville_shale/haynesville_monthly.pdf 
Lee, M. (2011). "Chesapeake Battles Out-Of-Control Marcellus Gas Well.” Bloomberg. April 20. http://www.bloomberg.com/news/2011-04-20/chesapeake-battles-out-of-control-gas-wellspill-in-pennsylvania.html

Levings, G.W., Kernodle, J.M., and Thorn, C.R. (1996). "Summary of the San Juan Structural Basin Regional Aquifer-System Analysis, New Mexico, Colorado, Arizona, and Utah.” U.S. Geological Survey. Water-Resources Investigations Report 95-4188.

LOGA (Louisiana Oil \& Gas Association). "Public Databases.” www.dnr.louisiana.gov

Lustgarten, A. (2009). Frack Fluid Spill in Dimock Contaminates Stream, Killing Fish. ProPublica. September 21. http://www.propublica.org/article/frack-fluid-spill-in-dimockcontaminates-stream-killing-fish-921

Mantell, M. (2011). Produced Water Reuse and Recycling Challenges and Opportunities across Major Shale Plays. EPA Hydraulic Fracturing Study Technical Workshop \#4. March 29-30, 2011. http://www.epa.gov/hfstudy/09 Mantell__ Reuse 508.pdf

McMahon, P. B., Thomas, J. C., and Hunt, A. G. (2011). "Use of Diverse Geochemical Data Sets to Determine Sources and Sinks of Nitrate and Methane in Groundwater, Garfield County, Colorado, 2009." U.S. Geological Survey Scientific Investigations Report 2010-5215. Reston, VA: US Department of the Interior, U.S. Geological Survey.

Natural Gas. (2010). "Water Withdrawals for Development of Marcellus Shale Gas in Pennsylvania." Marcellus Education Fact Sheet. Penn State College of Agricultural Sciences, Pennsylvania State University. http://pubs.cas.psu.edu/freepubs/pdfs/ua460.pdf.

NEPA (2012). "List of Violations." NEPA Gas Action: http://nepagasaction.org/index.php?option $=$ com_content\&view $=$ category \&id=54:lists-ofviolations\&Itemid $=75$.

Nicot, J. and Scanlon, B. 2012. "Water Use for Shale-Gas Production in Texas, U.S." Environmental Science and Technology. Vol. 46. Pg. 3580-3586.

NRC (Natural Resources Commission). 312 IAC 16-5-21; filed Feb 23, 1998, 11:30 a.m.: 21 IR 2346; readopted filed Nov 17, 2004, 11:00 a.m.: 28 IR 1315

NRC. (2004). “Article 16. Oil and Gas.” Indiana Administrative Code. www.in.gov/legislative/iac/T03120/A00160.PDF.

NEPA (2012). "List of Violations.” NEPA Gas Action: http://nepagasaction.org/index.php?option=com content\&view=category \&id=54:lists-ofviolations\&Itemid $=75$.

OilGasGlossary.com. (2010). Drilling fluid definition. Retrieved February 3, 2011, from http:// oilgasglossary.com/drilling-fluid.html 
PA DEP (Pennsylvania Department of Environmental Protection). (2010). "STRONGER Pennsylvania Hydraulic Fracturing State Review."

http://www.strongerinc.org/documents/PA\%20HF\%20Review\%20Print\%20Version.pdf.

PA DEP (Pennsylvania Department of Environmental Protection). (2010b). "Consent Order and Settlement Agreement (Commonwealth of Pennsylvania Department of Environmental Protection and Cabot Oil \& Gas Corporation). PA: Pennsylvania Department of Environmental Protection. December.

PA DEP (Pennsylvania Department of Environmental Protection). (2011a). "Permits Issued Wells Drilled Map."

http://files.dep.state.pa.us/OilGas/BOGM/BOGMPortalFiles/OilGasReports/2012/2011Wellsper mitte-drilled.pdf.

PA DEP. (2011b).

http://www.dep.state.pa.us/dep/deputate/minres/oilgas/Marcellus\%20Wells\%20permitteddrilled\%20NOVEMBER\%202011.gif.

PA DEP. (2011c).

http://www.dep.state.pa.us/dep/deputate/minres/oilgas/2011\%20wells\%20drilled.gif.

PA DEP (2012a).

http://files.dep.state.pa.us/OilGas/BOGM/BOGMPortalFiles/OilGasReports/2012/

PA DEP (2012b). PA DEP Oil \& Gas Reporting Website.

https://www.paoilandgasreporting.state.pa.us/publicreports/Modules/Welcome/Welcome.aspx

Pashin, J. C. (2007). "Hydrodynamics of Coalbed Methane Reservoirs in the Black Warrior Basin: Key to Understanding Reservoir Performance and Environmental Issues.” Applied Geochemistry, 22, 2257-2272.

Phillips, S. (2011). "Burning Question: Where are PA's Deep Injection Wells?" http://stateimpact.npr.org/pennsylvania/2011/09/22/burning-question-where-are-pas-deepinjection-wells/.

Pressconnects. (2010). "A Reply Letter about Agreement to Sell Water to East Resources Management, LLC to Mr. Scott Blauvelt of East Resources Management, LLC from Rita Y. McCarthy, Town Manager of Painted Post, NY." http://www.pressconnects.com/assets/pdf/CB164390922.PDF.

Puko, T. (2010). "Drinking Water From Mon Deemed Safe. The Pittsburgh Tribune-Review. August 7. http://www.pittsburghlive.com/x/pittsburghtrib/news/s 693882.html.

Rassenfoss, S. (2011). "From Flowback to Fracturing: Water Recycling Grows in the Marcellus Shale." Journal of Petroleum Technology. http://www.spe.org/jpt/print/archives/2011/07/12Marcellus.pdf. 
Rights, and Local Community Needs. (2010). http://www.elaiet.com/EMD/MARCELLUS_SHALE_GAS_DEVELOPMENT.pdf.

Robinson, J. (2012). "Reducing Environmental Risk Associated with Marcellus Shale Gas Fracturing." Oil and Gas Journal. http:/www.ogj.com/articles/print/vol-110/issue-4/explorationdevelopment/reducing-environmental.html.

SEAB. (2011). "Shale Gas Production Subcommittee Second Ninety Day Report," November 18. Washington, D.C.: DOE.

http://www.shalegas.energy.gov/resources/111811 final_report.pdf.

SEAB. (2011). "Shale Gas Production Subcommittee Second Ninety Day Report," November 18. Washington, D.C.: DOE.

http://www.shalegas.energy.gov/resources/111811 final report.pdf.

SRBC (Susquehanna River Basin Commission). (2010). "Natural Gas Well Development in the Susquehanna River Basin.”

http://www.srbc.net/programs/docs/ProjectReviewMarcellusShale(NEW)(1 2010).pdf.

SRBC. (2011a). "Regulatory Program Fee Schedule."

http://www.srbc.net/programs/docs/Regulatory $\% 20$ Program $\% 20 \mathrm{Fee} \% 20$ Schedule $\% 20 \mathrm{FY} \% 2020$ 12\%206_23 2011.pdf.

SRBC. (2011b). “Water Resource Portal, GIS Map.” http://gis.srbc.net/.

SRBC. (2012a). "Approved Water Sources for Natural Gas Development." http:/www.srbc.net/downloads/ApprovedSourceList.pdf

SRBC. (2012b). "Frequently Asked Questions (FAQs): SRBC's Role in Regulating Natural Gas Development." http://www.srbc.net/programs/natural gas development faq.htm.

State Review of Oil \& Natural Gas Environmental Regulations (STRONGER). (2010).

"Pennsylvania Hydraulic Fracturing State Review."

http://www.strongerinc.org/documents/PA\%20HF\%20Review\%20Print $\% 20$ Version.pdf

Sumi, L. (2008). "Shale Gas: Focus on the Marcellus Shale.” For the Oil \& Gas Accountability Project/Earthworks.

http://www.earthworksaction.org/files/publications/OGAPMarcellusShaleReport-6-1208.pdf?pubs/OGAPMarcellusShaleReport-6-12-08.pdf.

TCEQ (Texas Commission on Environmental Quality). (2012). "Water Rights Database and Related Files." http://www.tceq.texas.gov/permitting/water supply/water rights/wr databases.html, accessed May 2012.

TRRC. (Texas Railroad Commission) (2011). "H10 Filing System, Injection Volume Query." http://webapps.rrc.state.tx.us/H10/searchVolume.do;jsessionid=PFLTyx8rpmyb3h2hvvkTvwvD

$$
236 \text { - References }
$$


06v32MrVQpfj7YNmp4hLLGjhypTc!-

2019483779? fromMain=yes\&sessionId=133831371055223.

TRRC. (2012a). “Eagle Ford Information.” http://www.rrc.state.tx.us/eagleford/index.php.

TRRC. (2012b). "Eagle Ford Task Force Finds South Texas Water Supply Sufficient." Press

release. http://www.rrc.state.tx.us/commissioners/porter/press/012612.php.

TRRC. (2012c). "Newark, East (Barnett Shale) Well Count.” 1993 through July 19, 2012. http://www.rrc.state.tx.us/barnettshale/barnettshalewellcount 1993-2012.pdf

TRRC (2012d). "Water use in the Barnett Shale."

http://www.rrc.state.tx.us/barnettshale/wateruse barnettshale.php

TRRC. (Texas Railroad Commission). (2012e). "Barnett Shale Information."

http://www.rrc.state.tx.us/barnettshale/index.php

TRRC. (2012f). "Haynesville/Bossier Shale Information."

http://www.rrc.state.tx.us/bossierplay/index.php

TWDB (Texas Water Development Board). (2012). "State Water Plan."

http://www.twdb.state.tx.us/publications/state_water_plan/2012/2012_SWP.pdf.

UM (University of Maryland). (2010). "Marcellus Shale Gas Development: Reconciling Shale

Gas Development with Environmental Protection, Landowner." UM School of Public Policy.

USGS (U.S. Geological Survey). (2002a). "Assessment of Undiscovered Oil and Gas Resources of the San Juan Basin of New Mexico and Colorado." http://pubs.usgs.gov/fs/fs-147-02/FS-14702.pdf.

USGS. (2002b). "TDS in Selected Petroleum Provinces."

http://energy.cr.usgs.gov/prov/prodwat/provcomp.htm

USGS. (2003). "Assessment of Undiscovered Oil and Gas Resources of the Bend Arch-Fort Worth Basin Province of North-Central Texas and Southwestern Oklahoma." http://pubs.usgs.gov/fs/2004/3022/fs-2004-3022.html.

USGS. (2011). "National Assessment of Oil and Gas: Assessment of Undiscovered Oil and Gas Resources of Devonian Marcellus Shale of the Appalachian Basin Province." http://pubs.usgs.gov/fs/2011/3092/pdf/fs2011-3092.pdf.

Veil, J. 2010. "Oil and Natural Gas Technology Final Report Water Management Technologies Used by Marcellus Shale Gas Producers.” Argonne National Laboratory.

Ward Jr., K. (2010). “Environmentalists Urge Tougher Water Standards. The Charleston Gazette. July 19. http://sundaygazettemail.com/News/201007190845. 
Williams, D.O. (2011). "Fines for Garden Gulch Drilling Spills Finally to be Imposed after More than Three Years." The Colorado Independent. June 21.

http://coloradoindependent.com/91659/fines-for-garden-gulch-drilling-spills-finally-to-beimposed-after-more-than-three-years.

Wiseman, H. (2012). "Regulation of Shale Gas Development: Fact-based Regulation for Environmental Protection in Shale Gas Resource Development," Energy Institute, University of Texas, Austin.

WRA (Western Resource Advocates). (2012). "Fracking Our Future, Measuring Water and Community Impacts from Hydraulic Fracturing."

http://www.westernresourceadvocates.org/frackwater/WRA FrackingOurFuture 2012.pdf.

WWDC (Wyoming Water Development Commission). (2010). "Green River Basin Plan.” WY Water Development Commission Basing Planning Program.

Yoxtheimer, D. (2011). "Water Resource Management for Marcellus Natural Gas." Penn State Cooperative Extension Water Resources Webinar Series.

https://meeting.psu.edu/p88048189/?launcher=false \&fcsContent=true\&pbMode=normal.

Zoback, M.; Kitasei, S.; Copithorne, B. (2010). "Addressing the Environmental Risks from Shale Gas Development."

http://www.worldwatch.org/files/pdf/Hydraulic\%20Fracturing\%20Paper.pdf.

\section{Chapter 4}

Book, K. (2012). "Assessing the Case for U.S. Exports of Liquefied Natural Gas.” Brookings Institution speech.

BPC (Bipartisan Policy Center). (2011). "Environmental Regulation and Electric System Reliability.”

CERA (Cambridge Energy Research Associates). (2011). "Staying Power: Can U.S. Coal Plants Dodge Retirement for Another Decade?"

C2ES. (2011). (Formerly Pew Center on Global Climate Change). "Responses to the Senate Energy and Natural Resources Committee CES White Paper." Center for Climate and Energy Solutions.

C2ES. (2012). (Formerly Pew Center on Global Climate Change). "Renewable and Alternative Energy Portfolio Standards." Center for Climate and Energy Solutions.

Deloitte (2011). "Made in America: The Economic Impact of LNG Exports from the United States," Deloitte Center for Energy Solutions and Deloitte Marketplace.

Denholm, P.; Drury, E.; Margolis, R. (2009). "Solar Deployment System (Solar DS) Model: Documentation and Base Case Results." National Renewable Energy Lab, Golden, CO: NREL.

DOE (U.S. Department of Energy). (2012). "SunShot Vision Study."

$$
238 \text { - References }
$$


Ebinger, C.; Massy, K.; Avasarala, G. (2012). "Liquid Markets: Assessing the Case for U.S. Exports of Liquefied Natural Gas.” Brookings Institute.

EEI (Edison Electric Institute). (2011). "Potential Impacts of Environmental Regulation on the U.S. Generation Fleet.” Prepared for EEI by ICF International.

EIA (U.S. Energy Information Administration). (2010). Annual Energy Outlook 2010. Washington, D.C.: U.S. Department of Energy EIA.

EIA. (2011). Annual Energy Outlook 2011. Washington, D.C.: U.S. Department of Energy EIA. EIA. (2012a). “Analysis of the Clean Energy Standard Act of 2012.” Washington, D.C.: U.S. Department of Energy EIA.

EIA. (2012b). "Effect of Increased Natural Gas Exports on Domestic Energy Markets." Washington, D.C.: U.S. Department of Energy EIA.

EIA. (2012c). "Electric Power Monthly.” Washington, D.C.: U.S. Department of Energy EIA.

IEA (International Energy Agency). (2012). “Golden Rules for the Golden Age of Natural Gas.”

IHS. (2009). "Measuring the Economic and Energy Impacts of Proposals to Regulate Hydraulic Fracturing.” IHS Global Insight.

IPCC (Intergovernmental Panel on Climate Change). (2007). "Summary for Policymakers." In Climate Change 2007: Mitigation. Contribution of Working Group III to the Fourth Assessment Report of the IPCC, ed. B. Metz, O.R. Davidson, P.R. Bosch, R. Dave, L.A. Meyer. Cambridge, UK and New York: Cambridge University Press.

Macedonia, J.; Kruger, J.; Long, L.; McGuiness, M. (2011). "Environmental Regulation and Electricity System Reliability.” Bipartisan Policy Center.

Martin, R. (2012). Superfuel: Thorium, the Green Energy Source for the Future. New York: Palgrave Macmillan.

NERA (2011). "Proposed CATR + MACT.” Prepared by NERA Economic Consulting for American Coalition for Clean Coal Electricity.

NREL (National Renewable Energy Laboratory). (2012). "Renewable Energy Futures.”

OECD (Organization of Economic Cooperation and Development). (2011). "Current Status, Technical Feasibility and Economics of Small Nuclear Reactors.” OECD Nuclear Energy Agency.

Pickering, G. (2010. "Market Analysis for Sabine Pass LNG Export Terminal.” Navigant Consulting.

SNL. (2011). Figure derived by NREL using SNL Financial Database query, 2011.

$$
239 \text { - References }
$$


Wellkamp, N.; Weiss, D. (2010). “American Fuel: Developing Natural Gas for Heavy Vehicles.” Center for American Progress. 